- Digitalisierte Fassung im Format PDF -

\title{
Die höheren Pilze
}

\author{
Gustav Lindau
}

Die Digitalisierung dieses Werkes erfolgte im Rahmen des Projektes BioLib (www.BioLib.de).

Die Bilddateien wurden im Rahmen des Projektes Virtuelle Fachbibliothek Biologie (ViFaBio) durch die Universitätsbibliothek Johann Christian Senckenberg (Frankfurt am Main) in das Format PDF überführt, archiviert und zugänglich gemacht. 
KRYPTOGAMENFLORA

· FÜR ANFÄNGER. Bd.1

DIE HÖHEREN PILZE VoN

PROF. DR. G. LINDAU

ZWEITE AUFLAGE 


\section{für Anfänger.}

Eine Einführung

in das Studium der blütenlosen Gewächse

für Studierende und Liebhaber.

Herausgegeben von

\section{Prof. Dr. Gustav Lindau,}

Privatdozent der Botanik an der Universität Berlin.

Kustos am Kgl. Botan. Museum zu Dahlem.

Erster Band.

Die höheren Pilze.

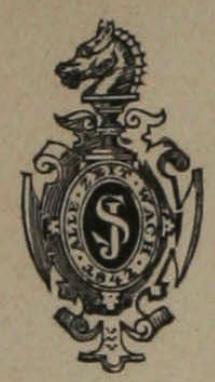

Berlin.

Verlag von Julius Springer.

1917.

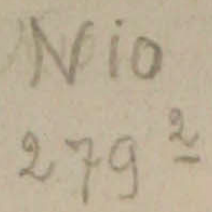




\section{¿ \\ Die höheren Pilze. \\ (Basidiomycetes.)}

Von

Prof. Dr. Gustav Lindau,

Privatdozent der Botanik an der Universität Berlin.

Kustos am Kgl. Botan. Museum zu Dahlem.

Zweite, durchgesehene Auflage.

Mit 607 Figuren im Text.

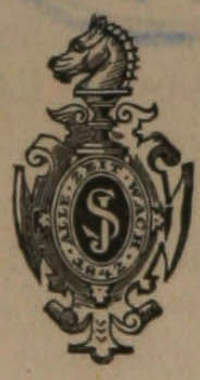

Berlin.

Verlag von Julius Springer.

1917. 


\section{Vorwort.}

Für den Anfänger, der sich mit den blütenlosen Pflanzen beschäftigen will, macht sich seit langen Jahren das Fehlen eines billigen, praktischen und auf dem neuesten Standpunkt stehenden Werkes fühlbar, das in erster Linie dem Selbststudium dienen kann, aber zugleich auch dem Fortgeschritteneren noch etwas zu bieten vermag. Die kleinen Bücher von Kummer und Wünsche, aus denen die ältere Generation hauptsächlich ihre Belehrung schöpfen konnte, sind vollständig veraltet, ohne daß dafür ein vollwertiger Ersatz in Deutschland geschaffen worden wäre. In diese Lücke, die gerade jetzt, wo die Kryptogamenkunde in unaufhaltsamem Fortschritte begriffen ist, sehr fühlbar zutage tritt, soll die ,Kryptogamenflora für Anfänger" einspringen.

Als Ziel dieser Bändchenserie, welche die gesamten blütenlosen Gewächse behandeln soll, schwebt mir ganz besonders die Rücksicht auf den Anfänger vor. Es gilt hier, wertvolles Terrain zu erobern und der Botanik neue Jünger und Liebhaber zuzuführen, die bisher durch den Mangel an brauchbarer Literatur abgeschreckt wurden, sich mit der niederen Pflanzenwelt zu beschäftigen. Vor allem sollen die Schüler und Lehrer für das reizvolle Studium der Kryptogamen wieder mehr interessiert werden, aber das Werk wendet sich nicht minder an Pharmazeuten, Mediziner, Landwirte, Forstleute, Gärtner, kurz an alle diejenigen, welche von Beruf aus gezwungen sind, sich mit diesen Gewächsen zu befassen. Nicht zu vergessen die große Zahl der Liebhaber, denen der Zugang zu den Kryptogamen verschlossen war, weil ihnen die Anregung und die Anleitung fehlte, um sich einzuarbeiten. Für alle diese soll das Werk ein Führer sein, den sie getrost verwerfen mögen, wenn ihre Kenntnisse über ihn hinausgewachsen sind.

Das zweite Ziel, das ich zu verwirklichen suchte, betrifft die strenge Wissenschaftlichkeit der Anlage und Ausführung. Bei allem Entgegenkommen gegen den Anfänger, das sich im Vermeiden unnötiger Kunstausdrücke und in der Beschränkung auf das kritisch geprüfte Material erstrecken mußte, durfte keinesfalls der neueste Standpunkt der Kryptogamenkunde au ßer acht gelassen werden. Die neueren Einteilungsprinzipien mußten als Grundlage dienen, selbst auf die Gefahr 
hin, daß das Werk zu gelehrt erscheinen könnte. Wie weit es mir gelungen ist, dem Bedürfnis des Anfängers Rechnung zu tragen, wird der Gebrauch des Buches bald ergeben. Jedenfalls würde ich für jeden Hinweis dankbar sein, der praktische Gesichtspunkte enthält, die noch nicht zur Anwendung, gekommen sind.

Da das ganze Werk darauf zugeschnitten ist, erst die Arten kennen zu lernen, ehe das eigentliche mikroskopische Studium einzusetzen hat, so mußte auf die Ausarbeitung der Bestimmungsschlüssel die meiste Sorgfalt verwendet werden. Hierbei mußte ich mich auf die Literatur stützen, von der nicht bloß die großen Werke, sondern auch viele Spezialbehandlungen herangezogen wurden. Originaldiagnosen sind deshalb vermieden, eigene Beobachtungen werden nur herangezogen werden, wenn sie dem Hauptzweck sich unterordnen. Bei den Bestimmungstabellen gab es nur die Wahl zwischen der Schlüsselform und der dichotomischen Anordnung. Letztere läßt sich aber nicht anwenden, wenn auch die Diagnosen gleichzeitig hinein verflochten werden sollen. Mag auch die Schlüsselform etwas unübersichtlich sein, ich glaube es doch erreicht zu haben, daß die verwandten Arten möglichst nahe zusammenstehen, so daß auch die natürliche Einteilung einer Gattung, soweit davon heute überhaupt die Rede sein kann, zur Geltung zu kommen vermag.

Ich unterbreite der Kritik zuerst das Bänd chen über Basidio myceten, ein zweites wird die übrigen Pilze behandeln. Es sollen dann die Flechten, Algen, Moose und Gefäßkryptogamen folgen, so daß in etwa 3-4 Jahren die Serie vollendet vorliegen soll.

Das Gebiet der Flora umfaßt etwa Mitteleuropa, so daß von der Nordküste Deutschlands bis zu den Alpen die häufigsten Arten wohl alle, die seltenen zum größten Teil darin zu finden sind.

So möge denn die Anfängerflora den Bedürfnissen und Anforderungen des Interessenten entgegenkommen und sich Freunde in allen Kreisen erwerben, welche der reizvollen Beschäftigung mit den niederen Gewächsen Verständnis und Liebe entgegenbringen. Den schönsten Lohn aber würde ich darin finden, wenn der Kryptogamenkunde dadurch neue Schüler und Anhäger zugeführt würden.

Für die vortreffliche Ausstattung möchte ich auch an dieser Stelle der Verlagsbuchhandlung, die mit Bereitwilligkeit auch auf meine übrigen Wünsche eingegangen ist, meinen ganz besonderen Dank aussprechen, denn das Schicksal eines Buches hängt nicht bloß von seinem Inhalt, sondern auch von seinem äußeren Gewande ab.

Groß-Lichterfelde, im Mai 1911.

G. Lindau. 


\section{Vorwort zur zweiten Áuflage.}

Die erste Auflage der Flora ist von den Sammlern und Freunden der höheren Pilzwelt freundlich aufgenommen worden, so daß schon nach verhältnismäßig kurzer Zeit sich eine neue Auflage nötig machte.

Geändert im Text habe ich fast nichts, nur die langen Schlüssel habe ich durch das Einsetzen der Untergattungen und Wiederholen der Zahlen so erleichtert, daß meiner Ansicht nach die Benutzung der Tabellen dadurch vereinfacht wird. Wesentliche Veränderungen in der Benennung der Arten haben sich nicht ergeben. Nur bei den ersten Familien (den Corticiaceen und Thelephoraceen) hätte ich gern tiefer eingegriffen, wenn die Arbeit von Brinkmann über die westphälischen Thelephoraceen früher erschienen wäre. Ich bekam sie erst, als die Bogen bereits das Imprimatur überschritten hatten. Die dadurch verbleibende Lücke will ich später ausfüllen.

Wie in den späteren Bänden, so habe ich auch hierim Gattungsverzeichnis die gebräuchlichsten Synonyme gegeben und glaube, dadurch die Benutzung noch erleichtert zu haben.

Möge dem Buche beschieden sein, auch in der neuen Auflage die Kenntnis der höheren Pilze zu verbreiten und dem Sammler und Anfänger in allen Fragen beizustehen.

Der Verlagsbuchhandlung gebührt für ihre Arbeit und Mühe mein ergebenster Dank.

Berlin-Lichterfelde, im Mai 1917.

G. Lindau. 


\section{Inhaltsverzeichnis.}
A. Allgemeiner Teil.

I. Die mikroskopische Technik

II. Das Sammeln .

III. Das Beobachten und Bestimmen

IV. Die Präparation für das Herbar

V. Das wissenschaftliche System der Pilze . . . . . . . (12)

Bestimmungstabelle der Familien . . . . . . . . . . (14)

B. Spezieller Teil.

I. Auriculariaceae, II. Pilacraceae, III. Tremellaceae . . . 1

IV. Dacryomycetaceae . . . . . . . . . . . . 4

V. Exobasidiaceae . . . . . . . . . . . . . 6

VI. Tulasnellaceae, VII. Corticiaceae . . . . . . . 7

VIII. Thelephoraceae . . . . . . . . . . . . 20

IX. Clavariaceae . . . . . . . . . . . . . . . . . . . . . 26

X. Hydnaceae . . . . . . . . . . . . . . . . . . . . . . . 36

XI. Polyporaceae . . . . . . . . . . . . . . . . 46

XII. Agaricaceae . . . . . . . . . . . . . . . . . . . . . . 84

XIII. Phallaceae . . . . . . . . . . . . . . . 207

XIV. Hysterangiaceae, XV. Hymenogastraceae . . . . . . 208

XVI. Lycoperdaceae. . . . . . . . . . . . . . . . 210

XVII. Nidulariaceae . . . . . . . . . . . . . . . . . 215

XVIII. Sclerodermataceae . . . . . . . . . . . . 217

XIX. Tulostomataceae, XX. Sphaerobolaceae . . . . . . 219

Verzeichnis der Gattungen, Arten und Abbildungen . . . . 220 


\section{Die mikroskopische Technik.}

Bei der Bestimmung der höheren Pflanzen wird man fast stets mit der makroskopischen Betrachtung und der Musterung durch die Lupe zum Ziele kommen. Je tiefer man aber auf der Stufenreihe des Gawächsreiches hinabsteigt, um so kleiner werden die Formen und um so kleiner vor allem die Organe, welche für die sichere Unterscheidung und Definierung herangezogen werden müssen. Nur in Ausnahmefällen wird man mit der Lupe allein auskommen, Sicherheit in der Beobachtung gewährt nur das Mikroskop.

Für den Anfänger, namentlich wenn er nicht gelehrten Berufen angehört, sondern aus Liebhaberei sich dem Studium irgendeiner Gruppe der niederen Gewächse widmen will, bildet die Aussicht, mit dem Mikroskop arbeiten zu müssen, ein gewisses Abschreckungsmittel teils des Anschaffungspreises wegen, teils wegen der Unkenntnis mit der mikroskopischen Technik. Und doch brauchte beides nicht als Hinderungsgrund zu gelten, denn die Schwierigkeiten, die früher einmal vorhanden waren, sind heutzutage fast ganz beseitigt.

Die Preise der Mikroskope können nicht mehr für unerschwinglich gelten, denn für 120-150 M. erhält man schon ein völlig ausreichendes Instrument, das man später jederzeit noch mit stärkeren Linsen ausstatten kann. Selbst von kleineren Firmen werden jetzt gute Mikroskope für systematische Zwecke geliefert. Da es hier nicht meine Absicht sein kann, Empfehlungen für bestimmte Firmen oder Systeme auszusprechen, so möchte ich nur betonen, daß der Anfänger sich bei der Beschaffung eines Mikroskops stets an jemanden wenden möge, der Erfahrung besitzt. Dem Anfänger wird gern jeder mit seinem Rate zur Verfügung stehen.

Schwieriger ist die Erlernung der mikroskopischen Technik, aber guter Wille und die Übung hilft über alles hinweg. Man muß mit dem Mikroskope nicht bloß sehen lernen, sondern man muß in erster Linie die Objekte so vorzubereiten verstehen, daß man überhaupt etwas sehen kann. Das mikroskopische Sehen ist Sache der Übung. Während man bei sonstigen Beobachtungen meist mehrere Sinne, vor allem den Tastsinn, noch zur Verfügung hat, muß beim Mikroskopieren der Gesichtssinn allein in die Schranken treten. Wenn deshalb im Anfange viele Verwechselungen und Irrtümer vorkommen, so darf man sich nicht abschrecken lassen; schließlich überwindet die Kritik des Auges und vor allem der Versuch, das Beobachtete auf das Papier zu übertragen, alle vorhandenen Schwierigkeiten. Man beobachte deshalb vom ersten Tage an nicht bloß, sondern zeichne die gesehenen

Lindau, Kryptogamenflora. I. 2. Aufl. 
Gegenstände nach, indem man mit den einfachsten Objekten beginnt. Ein Zeichenapparat ist dazu nicht erforderlich, erst wenn man Zeichnungen mit genauer Kontrolle der Vergrößerung anfertigen will, muß man sich einen solchen anschaffen. Dann wird man aber längst über das Anfängerstadium hinaus sein. Wenn man einige Stunden unter Leitung eines geübten Mikroskopikers arbeiten kann, so werden sich die ersten Schwierigkeiten in der Handhabung deş Instrumentes und im Sehenlernen bald überwinden lassen.

Nicht so einfach erscheint das Präparieren. In vielen Fällen wird es ja genügen, die Objekte mit den Präpariernadeln auf dem Objektträger in Wasser zu zerteilen und auszubreiten, oft aber hindert die Natur des Gegenstandes daran. In solchen Fällen müssen Schnitte gemacht werden, die entweder quer oder längs das Objekt in feine Scheibchen zerlegen. Man bedarf dazu eines guten und scharfen Rasiermessers, das stets scharf gehalten werden muß. Die richtige Handhabung läßt sich am besten zeigen, man wird dann bald allein die nötige Übung gewinnen.

Für das Studium der Pilze kommen in erster Linie Querschnitte in Betracht, die durch den Fruchtkörper und unter Umständen auch durch das Substrat geführt werden müssen. Wie man ein Objekt zu behandeln hat, läßt sich allgemein nicht sagen, da fast jedes einzelne individuell anzugreifen ist. Bei den Basidiomyceten (abgesehen von den parasitischen Brand- und Rostpilzen) macht man stets Querschnitte, welche das Hymenium treffen. Dadurch erhält man die Basidien, Cystiden und Sporen, die für die Beurteilung der Art oder Gattung häufig allein maßgebend sind. Der Schnitt muß das Hymenium stets senkrecht treffen. Bei den Lamellen erfordern Querschnitte große Übung, hier kommt man in den meisten Fällen dadurch zum Ziel, daß man einen möglichst feinen Flächenschnitt über die Lamelle führt und den Schnitt dann unter dem Deckglase etwas drückt. Meist finden sich dann am Rande des Schnittes Stellen, welche wie Querschnitte aussehen und alle Einzelheiten zeigen. Im allgemeinen wird man mit etwa 400 facher Vergrößerung auskommen.

Das Färben der Objekte und die Anfertigung der Präparate läßt sich aus jeder Anleitung zum Mikroskopieren leicht ersehen. Das Messen gehört zu den wichtigsten Arbeiten, und man versäume daher nicht, beim Ankauf eines Mikroskops auch ein Okularmikrometer anzuschaffen. Die einfache Handhabung läßt sich leicht erlernen.

\section{Das Sammeln.}

Der Anfänger solltə seine Studienobjekte stets im frischen $\mathrm{Zu}$ stande untersuchen, erst wenn er größere Erfahrung erlangthat, braucht er vor getrockneten Herbarexemplaren nicht zurückzuschrecken. Im allgemeinen wird er also darauf angewiesen sein, sich die Exemplare selbst einzusammeln. Im Anfang gibtes natürlich viele Schwierigkeiten 
zu überwinden, denn nicht an allen Orten und zu allen Zeiten kann man Basidiomyceten finden; zudem sehen viele Hutpilze von oben gleich aus und zeigen erst auf der Unterseite die charakteristischen Merkmale. Es erscheint deshalb nicht überflüssig, eine kurze Anleitung für das Sammeln zu geben.

Man versehe sich, um höhere Pilze zu sammeln, mit einer Botanisiertrommel oder sonst einem geeigneten Behälter, mit viel Papier, am besten unbedrucktem Zeitungspapier - es können dabei auch einige stärkəre Packpapierstücke sein - sowie mit einigen Glaszylindern für sehr zarte Formen. Zum Einsammeln von harten Baumschwämmen ist ein starkes Messer oder eine Säge erforderlich: Spezielle Zwecke, etwa Ausgraben von Myzelien oder Hypogäen, erfordern natürlich besondere Instrumente, die der Anfänger nicht notwendig hat.

Jedes Exemplar wird einzeln oder zu mehreren in Papier gewickelt. Ich habe es immer für praktisch gehalten, einen ZetteI in das Papier hineinzulegen, auf dem der Standort, Datum, unter Umständen auch die Farbe, Klebrigkeit usw. bemerkt werden. Diese an Ort und Stelle gemachten Notizen sind oft für die Bestimmung sehr wichtig und können gar nicht ausführlich genug gemacht werden. Die einzelnen Paketchen verstaut man dann in der Kapsel oder Trommel. Man kann die Paketchen ziemlich fest aneinander legen, ohne befürchten zu müssen, daß die Hüte zerbrechen. Zu Haus bearbeitet man dann die Exemplare weiter für die Sammlung. Darüber im folgenden Abschnitt.

Wo soll man sammeln und wann? Diese beiden Fragen lassen sich allgemein nicht beantworten. Die meisten Arten lieben feuchte Luft und Nachttemperaturen nicht unter $8-10^{\circ} \mathrm{C}$. Man findet deshalb die meisten Basidiomyceten der Zahl und Art nach im Spätsommer und Herbst, also im September und Oktober ${ }^{\mathbf{1}}$ ). Doch treten viele auch in Regenperioden vom Juni bis August auf. Eigentliche Winterpilze gibt es nur wenige, manche allerdings mit holzigem Fruchtkörper halten das ganze Jahr über aus. Der Anfänger tut gut, sich über das Erscheinen der einzelnen Arten Auszüge aus dem Text zu machen. Sie vermögen ihm manchen Hinweis auf die Bestimmung zu geben.

Mit wenigen Ausnahmen (Exobasidiaceen, Nyctalis, Baumschwämme) sind die Basidiomyceten saprophytische Pilze, welche also auf totem Pflanzengewebe oder auf der Erde wohnen. In den Familien $8-10,12-16,18-19$ finden sich besonders zahlreiche Erdbewohner, während die übrigen hauptsächlich holzbewohnende Arten umfassen. Dazwischen finden sich viele Formen, deren Myzel im Laube, Moose oder auf toten Ästen nistet, bisweilen ist der Wohnort nicht deutlich erkennbar, sondern der Fruchtkörper kommt aus der bloßen Erde hervor. Solche Formen sitzen häufig auf unterirdischen

$\left.{ }^{1}\right)$ Im systematischen Teile sind Januar bis März mit W. (Winter), April bis Juni mit F. (Frühling), und entsprechend die weiteren Monate mit S. und H. bezeichnet. Die meisten Arten der Agaricaceen, welche mit S. H. bezeichnet sind, beschränken sich auf September und Oktober. 
Ästen, Zapfen usw. Beim Einsammeln achte man auf diese Verhältnisse genauer. Die waldbewohnenden Formen zeigen sich meist auf Lauboder Nadelwald beschränkt, manche allerdings machen keinen Unterschied und kommen in allen Waldarten vor.

Die holzbewohnenden Arten der Corticiaceen finden sich meist an Ästen, welche auf dem Boden zwischen Laub liegen, manche aber bewohnen auch aufrechte Stämme oder noch hängende Äste oder überziehen Baumstümpfe. Stümpfe und Stämme bevorzugen die Polyporaceen, die oft riesige Konsolen hoch oben am lebenden Baum bilden. Die Holzbewohner unter den A g ari c a c e en sitzen an Stümpfen und am Grunde vỏn Stämmen, soweit sie nicht Zweige bevorzugen, die im Laube verborgen liegen. Im Walde beachte man besonders die aufgeschichteten Holzklafter; hier wird man nur selten Stereum und andere Corticiaceen vergeblich suchen. Auch Tremellaceen und Dacryomycetaceen finden sich an solchen Holzstapeln, allerdings häufiger an alten Zäunen aus Nadelholz. Namentlich nach Regenwetter wird man dort stets erfolgreich nach derartigen Formen suchen können.

In den Wäldern selbst achte man besonders auf Lokalitäten, die sich durch irgendeine Besonderheit auszeichnen, also Lichtungen, Sumpfstellen, Hügel, Gebüsche, eingesprengte Laubholzpartien im Nadelwald und umgekehrt; immer wird man einige Arten finden, die von denen der normalen Umgebung verschieden sind.

Die offenen Gelände sind besonders reich an Agaricaceen, doch finden sich auch $\mathrm{Hydnaceen}$, Clavariaceen u. a. Am ergiebigsten sind die Sandheiden, die licht bewachsenen Kiefernheiden, Wiesen, Dämme, Wegränder usw. Hier wird man im Herbst bei feuchtwarmem Wetter viele Arten antreffen. Besondere Aufmerksamkeit erfordern diejenigen Lokalitäten, welche gedüngt werden, und die Dungplätze selbst. Es kommen hier nicht bloß Wiesen, Felder, Gärten in Betracht, sondern auch Parks, Mistbeete, Komposthaufen, Gewächshäuser, Pflanzenkübel u. a. Überall wird man eine reiche Ausbeute finden, wenn man gerade die günstige Zeit trifft.

Vor allen Dingen lasse sich der Anfänger nicht entmutigen, wenn er an einer ihm günstig erscheinenden Lokalität nicht gleich reiche Ausbeute macht oder das Vermutete nicht sofort findet. Man besuche solche Orte häufiger, und die Geduld wird schließlich doch belohnt werden. Es ist nämlich eine eigenartige Erscheinung, daß viele höhere Pilze nicht in jedem Jahre an dem beobachteten Standort auftreten, sondern sich nur mit Unterbrechungen, oft von vielen Jahren, zeigen. $\mathrm{Ob}$ in solchen Fällen das Myzel des Pilzes im Boden abgestorben ist oder erst wieder Kraft zur Fruchtkörperbildung schöpfen muß, darüber kann man nur Vermutungen aufstellen. In vielen Fällen wird ja ein Neuanfliegen der Sporen und daraus die Neubildung eines Myzels notwendig sein, oft ist wohl aber, wie z. B. bei den Phallaceen, eine wirkliche Ruhepause erforderlich.

Indessen liegt wohl ein Hauptgrund für das unregelmäßige. Erscheinen der Fruchtkörper auch in der nicht in jedem Jahre gleich- 
bleibenden Verteilung von Feuchtigkeit und Wärme. In Westfalen, Ostpreußen, Schlesien und in den Distrikten der Mittelgebirge findet gewöhnlich eine etwa gleiche Verteilung der Regenmengen (oder Nebel) auf die Monate August bis Oktober statt, aber in der Region der norddeutschen Kiefernwälder bleiben die Niederschläge häufig im Septəmber mehr oder weniger aus. Während daher in jenen Gagenden die Individuenzahl der Hutpilze weniger schwankt, findet man im Kiefernwalde häufig die ganze Vegetation auf wenige Tage beschränkt. Dann freilich erscheint der Boden wie bedeckt mit den vergänglichen Gebilden der Pilzwelt, aber wenige Tage Trockenheit oder ein Nachtfrost vernichtet alle Hüte. Der Sammler muß daher im Herbst immer gerüstet stehen, um sofort Exkursionen zu machen, wenn feuchtwarmes Wetter geherrscht hat. Ein Herabgehen der Nachttemperatur unter $8^{\circ} \mathrm{C}$ läßt schon viele Hüte nicht mehr zur Entwicklung kommen, ein starker Nachtfrost gegen Ende September zerstört gewöhnlich schon alle Hoffnungen auf den Oktober.

Die Individuenzahl ist aber nicht bloßvon der Gunst der Witterung abhängig. Während viele Blätterpilze stets in großenTrupps erscheinen und oft Hunderte von Hüten auf begrenzter Fläche wahrscheinlich aus einem Myzel entwickeln, erscheinen andere wieder, z.B. Cortinarien, nur in einzelnen Exemplaren und häufig weit entfernt voneinander. Man hat mehr Aussicht, die Hüte der ersteren Arten regelmäßig zur bestimmten Jahreszeit zu finden, da ihr Myzel im Boden perenniert. Vielfach beobachtet man auch bei ihnen die Bildung von Hexenringen. Hier beginnt das Myzel sich von einem Punkte aus zentrifugal zu entwickeln und bringt in jedem Jahre an der Peripherie des Myzels die Fruchtkörper hervor. Von Jahr zu Jahr werden damit die Ringe größer, bis sie sich durch die Beschaffenheit des Bodens oder andere Zufälligkeiten in einzelne Gruppen auflösen. Unter günstigen Verhältnissen beobachtec man Hexenringe von $10 \mathrm{~m}$ und mehr im Durchmesser.

Alle diese Dinge möge der Anfänger gleich vom Beginn seiner Tätigkeit an notieren und beachten, denn erst dadurch gewinnt das Studium der Hutpilze seinen eigenartigen Reiz. Zu Anfang allerdings sollte stets auf die eigentliche Systematik, das Namengeben und Bestimmen, das Schwergewicht gelegt werden, später kommt, wenn erst die Schwierigkeiten überwunden sind, dann ganz von selbst die angenehme und anziehende Nutzanwendung.

Das erste Auffinden von Hypogäen ist meist Sache des Zufalls. Wer sich speziell auf das Einsammeln dieser Formen legt, wird im Lauf der Zeit eine solche Übung gewinnen, daß er dem Standort von vornherein ansieht, ob solche Formen vermutet werden können.

\section{Das Beobachten und Bestimmen.}

Aller Anfang ist schwer. Dieses Sprichwort gilt wie keines für das Studium der Basidiomyceten. Die ungeheure Formenfülle, die minimalen Unterschiede der Gattungen und Arten, das z. T. schwierige 
Auffinden und Präparieren für die Sammlung werden jeden Anfänger zuerst in seinem Eifer erlahmen lassen. Abør sobald erst einige Erfolge da sind, wird das Einarbeiten leichter, die gewonnene Sicherheit wird bald auch den Eifer wieder erhöhen, so daß der tote Punkt, der sich bei jeder Arbeit einzustellen pflegt, sich dann leicht überwinden läßt.

Am best $n$ bleibt es, wenn der Anfänger mit einem Kenner einige Exkursionen macht und sich von ihm eine Anzahl von gemeinen Arten sicher bestimmen läßt. Vor allem sollte dabei Rücksicht genommen werden auf Arten aus möglichst verschiedenen Gattungen, damit sich der Anfänger zuerst die Charaktere der Gattungen aneignen kann. Ist er imstande, eine möglichst große Zahl davon sicher zu erkennen und voneinander zu unterscheiden, wobei es zuerst gar nicht auf dic Namen der Arten anzukommen braucht, so kann er getrost sich mit den Unterschieden der Arten vertraut machen. Man vermeide vor allem die Jagd nach seltenen Arten. Diese findet man von selbst, sobald man erst einen Überblick über die gemeinen Spezies gewonnen hat.

Wenn man von den systematisch sehr schwierigen Corticieon und Gallertpilzen absieht, so würde für die Familien 8-12 in erster Linie die Bestimmung der Sporenfarbe notwendig sein. Die Sporen werden meist innerhalb weniger Stunden in solcher Zahl abgeworfen, da $\beta$ hre Farb e leicht bestimmt werden kann. Sollte sich auf dem Papier, in dem die frischen Pilze transportiert werden, nicht schon ein deutliches Sporenbild ergeben, so legt man zu Haus die Hüte oder Fruchtkörper mit der Sporenseite nach unten auf weißes und blaues Papier. Auf letzterem heben sich weiße Sporen ab, auf ersterem die schwarz, braun oder rosa gefärbten. Oft zeigen die Lamellen selbst schon bei der Reife die Farbe der Sporen an. Ist der Hut schon zu alt zum Sporenwerfen, so muß die mikroskopische Untersuchung stattfinden, wobei aber zu beachten ist, daß die dunkel gefärbten Sporen im durchfallenden Lichte viel heller gefärbt erscheinen als die auf dem Papier in Haufen liegenden Sporenmassen.

Über die äußere Form des Hutes oder der verzweigten Fruchtkörper von Clavariaceen, Hydnaceen, Polyporaceen usw. entscheidet der makroskopische oder Lupenbefund.

Anders ist es mit dem Schleier oder Velum. Um dabei zu sicheren Beobachtungen zu gelangen, ist die Mitnahme einer Entwicklungsserie von Fruchtkörpern notwendig. Hat man erst Übung, so sieht man dem fertigen Hut schon häufig an, wie die Hüllenverhältnisse beschaffen waren. Für die Beobachtung mögen einige Angaben über die Entwicklung des Hutes bei den Agaricaceen als Anhalt dienen.

Der Hut entsteht am Myzel als kleines Knöpfehen. Nach der Differenzierung des Stiles vom Hute beginnt die Streckung des Stieles und später des Hutes. Bei vielen Gattungen sind beide Teile des Fruchtkörpers nicht weiter durch Fäden oder Hüllen verbunden. Beim fertigen Hute zeigen sich deshalb weder am Stiel noch auf der Hutoberfläche irgendwelche Andeutungen von Hautfetzen, Fasern, Schuppen oder Fäden. 
Bei anderen Gattungen wird der Hut mit dem Stiel vor der Aufspannung durch eine Hülle verbunden, welche entweder aus feinen Fasern besteht oder aus festem Gewebe gebildet wird. Man nennt diese Hülle Velum partiale, weil nicht der ganze Hut, sondern nur die Lamellen dadurch eingehüllt und geschützt werden. Die Reste dieser Hülle findet man am Rande des Hutes und am Stiel in Gestalt von feinen Fäden, Hautfetzen, Schuppen oder einem Hautringe am Stiel. Auf der Hutoberfläche dagegen sind nur in seltenen Fällen Reste zu sehen, weil die Hülle meist die Hutoberfläche nicht umfaßt.

Bei den höchst entwickelten Gattungen wird eine allgemeine Hülle ausgebildet (Velum universale), welche in der Jugend über die Hutoberfläche sich spannt und am Grunde des Stiels angesetzt erscheint. Beim Zerreißen findet man auf dem Hute Fetzen, Fasern oder Schuppen am Grunde des Stiels dagegen Fasern, ringförmige Schuppen oder eine lappige, mehr oder weniger hohe kragenartige, häutige Hülle (Volva). Bei wenigen Gattungen kommen dann beide Hüllen gemeinsam vor. Dann finden sich also auf der Hutoberfläche Fetzen, Schuppen oder Fasern, am Hutrande Fetzen oder Fäden, in der Stielmitte ein Ring oder ringförmige Schuppen und Fasern und am Grunde endlich nur eine Andeutung einer Scheide oder eine wohlausgebildete kragenartige Hülle.

Auf diese Verhältnisse, die äußerst mannigfaltig ausgebildet sind, möge der Anfänger sorgfältig achten. Das klare Erkennen dieser Hüllenbildung wird ihm viele Mühe beim Bestimmen ersparen.

Äußerst wichtig sind die Lamellen und ihre Ausgestaltung. Zur sicheren Erkenntnis davon mache man einen Längsschnitt durch den Hut und die Stielmitte. Zu beachten ist, ob die Lamellen alle vom Ansatz am Stiel bis zum Hutrande durchlaufen, oder ob sich einzelne kürzere vom Rande her einschieben. Je nachdem der Hut bis zum Rande fleischig ist oder sich stark verdünnt, wird die Form der Lamelle in der Breite variieren. Sie kann fast gleich breit durchlaufen oder nach dem Rande zu sich stark verschmälern. Sie kann am freien Rande, der Schneide, gerade oder mannigfach gebogen sein, an der Schneide auch Zähnelung oder feine Körnelung durch große Cystiden aufweisen. Wichtig ist der Ansatz der Lamellen am Stiel. Der einfachste Fall ist, $\mathrm{da} ß$ sie breit angewachsen erscheinen, sich aber oft im Alter loslösen. Sie können gerade abgeschnitten sein am unteren Ende oder lang herablaufen, häufig sind sie kurz vor dem Ansatz ausgebuchtet und sitzen dann mit einem Zahn am Stiel an oder laufen zahnförmig herab. Endlich können sie mehr oder weniger weit von dem Stiele endigen oder nur mit einer Spitze bis gerade zum Stiellaufen. Diese Verhältnisse wechseln je nach der Art außerordentlich. Es hängt dies ebenfalls davon ab, ob der Hut in der Mitte dick- oder dünnfleischig ist, ob er emporgewölbt oder eingedrückt erscheint usw. Angaben darüber konnten bei den Beschreibungen nicht immer gemacht werden, da sonst der Umfang des Buches allzusehr angeschwollen wäre. Am besten ist, wenn sich der Beobachter, sobald er die Art sicher bestimmt 
hat, durch eine einfache Bleistiftskizze bei der Diagnose am Rande diese Verhältnisse für späteres schnelles Bestimmen einzeichnet.

In den älteren Pilzwerken gar nicht, in den neueren wenigstens teilweise berücksichtigt ist der Bau des Hymeniums. Unter einem Hymenium versteht man bei den Pilzen ganz allgemein ein Lager, das aus Fruktifikationsorganen gebildet wird, zwischen denen gewöhnlich noch sterile Hyphenenden stehen. Ein solches Hymenium findet sich bei den Basidiomyceten in allen Stadien der Ausbildung. Bei den niederen Corticiaceen kommt ein geschlossenes Hymenium noch nicht zustande, weil die Basidien regellos als Endigungen der Myzeläste gebildet werden. Die Differenzierung setzt aber bereits in dieser Familie ein, indem die basidienbildenden Äste enger und ungefähr in gleicher Höhe zusammentreten. Bei den Thelephoraceen und Clavariaceen bilden die Hymenien ausgedehnte, glatte Flächen, welche die Fruchtkörper überziehen. Der ganze Fruchtkörper ist also hier noch gleichsam der Träger der Fruchschicht. Bei den übrigen gymnokarpen Familien tritt nun das Bestreben auf, die Fläche des Hymeniums zu vergrößern, ohne daß die Dimensionen des ganzen Fruchtkörpers wachsen. Dies wird auf verschiedene Arten erreicht, aber stets so, daß das Hymenium nur bestimmte Anhangsgebilde des Fruchtkörpers überzieht.

Bei den Hydnaceen werden Stacheln, die in großer Zahl auf der Unterseite des Hutes stehen, von dem Hymenium überzogen. Das Gegenteil davon, eine Auskleidung von röhrenartigen Einsenkungen, findet bei den Polyporaceen statt. Die Agaricinen zeigen die höchste Differenzierung und die beste Raumausnutzung, indem bei ihnen das Hymenium die Flächen von blätterartigen Organen, Lamellen genannt, überzieht. Durch die radiale Anordnung dieser Blätter wird eine wunderbare Ausnutzung des Raumes erreicht, wie sie besser nicht erdacht werden kann.

In den einfachsten Fällen besteht das Hymenium aus den dicht aneinander stehenden Basidien. Man bezeichnet mit diesem Namen ungeteilte keulenartige Enden von Hyphen, an deren Scheitel gewöhnlich 4 feine Fädchen (Sterigmen) stehen, die je eine Spore tragen. Bei den Protobasidiomyceten sind die Basidien anders gestaltet, weil sie durch Teilwände in 4 Zellen zerlegt werden, von denen jede ein Sterigma mit einer Spore entstehen läßt. Entweder ist die quergeteilte Basidie fädig und durch 3 Querwände in 4 übereinander stehende Zellen geteilt oder die über Kreuz geteilte Basidie ist kugelig und durch 2 sich rechtwinklig schneidende Wände in 4 Zellen geteilt.

Meistens nun mischen sich unter die Basidien sterile Hyphenendigungen, die in ihrer Form sehr abweichen und viel größer sind als die Basidien. Man bezeichnet diese Zellen mit dem Namen Cystiden. Bei den Corticiaceen kommen sie in mannigfaltigster Ausbildung vor und charakterisieren die einzelnen Gattungen. Bei den übrigen Familien kommen sie fast regelmäßig vor und zeigen sich hier meist in Form von spitzen, langkeuligen Zellen, die oft mit dickerer Membran, Inkrustierung oder stark lichtbrechendem Inhalt versehen sind. 
Bei den angiokarpen Familien werden bei der einen Gruppe in den Kammern die Basidien in Hymenien gebildet, welche die Kammerwände auskleiden. Nach der Sporenreife zerfließen gewöhnlich die Basidien, und man findet dann nur lockere Sporenmassen vor, zwischen denen einzelne Fäden liegen können, die von den Resten der Kammerwände herrühren. Bei der zweiten Gruppe (Plectobasidieen) dagegen werden die Basidien regellos an dem Myzel gebildet, das das ganze Innere des Fruchtkörpers durchzieht. Nach der Reife liegen die Sporen frei zwischen besonders ausgebildeten Fäden, welche als Reste des Myzels aufzufassen sind und als Capillitium bezeichnet werden.

Die Sporen besitzen meist eine glatte, farblose oder gefärbtề Membran. Bisweilen finden sich Stacheln, Warzen, Körnchen auf der Oberfläche. Der Inhalt ist meist farblos, seltener mit gefärbten öltropfen versehen.

Um die geschilderten Verhältnisse sehen zu können, bedarf es natürlich der mikroskopischen Beobachtung. Man fertigt mit dem Rasiermesser feine Schnitte senkrecht zum Hymenium an, nur bei den Lamellen kommt man häufig mit Flächenschnitten schneller zum Ziel, die man bei der Beobachtung etwas drückt. Wichtig ist es, die Maße der Sporen, Basidien und Cystiden festzustellen; auch diese trage man sofort in das Buch ein. Ich habe aus Gründen der Raumersparnis die Sporenmaße nur da eingetragen, wo es im Interesse der Unterscheidung verwandter Arten notwendig schien, sonst sind die Maße fortgelassen; von vielen Arten findet man überhaupt keine Angaben in der Literatur.

Wenn man nun alle Beobachtungen über Farbe, Gestalt, Hüllenbildung, Lamellen, Hymeniúm, Sporen usw. gemacht und notiert hat, gilt es, die Bestimmung vorzunehmen. Wer mit dem Glauben an einen Bestimmungsschlüssel herangeht, daß er in ihr ein unfehlbares Mittel zur Bestimmung besäße, der wird in den meisten Fällen daneben treffen. Solche Schlüssel sind natürlich nur äußerliche Hilfsmittel, die der Formenfülle und der Variabilität der einzelnen Art gegenüber z. T. versagen. Man gewöhne sich deshalb von Anfang an, den Schlüssel kritisch zu benutzen. In allen irgendwie zweifelhaften Fällen verfolge man beide im Schlüssel angegebene Bahnen, eine führt dann zum Ziel. Ich habe von vornherein versucht, möglichst auffällige Merkmale an die Spitze zu stellen, die jederzeit leicht festzustellen sind. Bisweilen ist es sehr schwer, solche Merkmale zu finden, besonders bei polymorphen Gruppen. Dann empfiehlt es sich, möglichst alle Bahnen bei der Bestimmung einzuschlagen. Für den Anfänger wird die Benutzung der Schlüssel schwierig sein, deshalb soll sein Streben darauf gerichtet sein, möglichst viele gemeine Arten aus allen Gattungen kennen zu lernen. Kennt er erst einige Dutzend Arten sicher, so kann er sich leichter das Bild des Pilzes aus der Beschreibung vorstellen. Es mag auch gleich darauf hingewiesen werden, daß es für den Geübteren angenehm ist, neben dem Buche noch eine größere Flora oder ein koloriertes Abbildungswerk vergleichen zu können. Für den Anfänger ist es allerdings keineswegs notwendig. 
Viele Anfänger begehen den Fehler, daß sie ein Exemplar unter allen Umständen bestimmen wollen. Wenn es dann nicht gelingt, so verlieren sie die Lust oder klagen das Bestimmungsbuch an. Gewöhnlich aber liegt der Fall so, daß selbst ein Kenner die Art nicht sofort herausfinden könnte, weil das Material nicht ausreicht, oder die Art zu einer kritischen Gruppe gehört. Deshalb lege man solche Exemplare, wenn alle Bemühungen, sie zu bestimmen, scheitern, ruhig beiseite oder mache sich Notizen. Ein günstiger Zufall bringt häufig den Namen ans Licht und damit den Grund, weshalb das Bestimmen durchaus nicht gelingen wollte.

Wer Übung im Zeichnen und Kolorieren besitzt, der möge nicht versäumen, sich Skizzen nach den frischen Exemplaren zu machen. Mit dem Ausführen der Bilder kann er dann so manche langweilige Stunde angenehm ausfüllen.

\section{Die Präparation für das Herbar.}

Die eingesammelten Schätze werden zu Haus sofort ausgepackt, gesondert, und vorläufig etikettiert. Wer bereits in die einzelnen $\mathrm{Pa}$ ketchen Zettel hineinlegt, spart das letztere. Kann die Präparation nicht sofort vorgenommen werden, so legt man das ganze Sammelbehältnis nachts in den Keller.

Man trenne zuerst alle krustigen Pilze, die Holz, Laub oder Erde überziehen, ab, ebenso die gallertigen Fruchtkörper. Beide läßt man eintrocknen, allzu dicke Äste spalte man' oder schneide flache Oberflächenstücke davon ab. Die Bestimmung nehme man aber möglichst in frischem Zustande vor.

Ganz abweichend davon ist nun die Behandlung der fleischigen Hutpilze und der Gasteromyceten. Man mag über den Wert eines Herbars von solchen Formen denken, wie man will, man wird, selbst wenn die Präparation nicht vorzüglich ausgefallen ist, doch ein gutes Hilfsmittel für die Bestimmung daran haben. Eine Zeichnung und gute Notizen können die Exemplare ersetzen, aber die wenigsten besitzen die Übung, die Fruchtkörper in der richtigen Weise zu kolorieren.

Am besten lassen sich die Hutpilze nach der Methode von Herpell präparieren, obwohl Zeit und Übung dazu gehören, um tadellose Präparate zu bekommen. Ich gebe eine etwas vereinfachte Form der Präparation, wie sie Hennings meist angewendet hat. Es kommthauptsächlich dabei darauf an, die Farben möglichst zu erhalten, was aber trotz aller Sorgfalt nicht immer möglich ist.

Man nimmt mehrere frische etwa gleichgroße Exemplare zur Herstellung eines Präparates. Von einem schneidet man den Hut am Stielansatz $a b$ und legt ihn flach mit den Lamellen (Poren, Stacheln) nach unten auf weißes oder blaues Papier, wie das schon oben angegeben ist (S. 6). Da sich der Sporenstaub in trockenem Zustande leicht verwischt, so bereitet man sich das Papier für die Sporen dadurch vor, 
daß man es mit einer alkoholischen Lösung von Kolophonium oder Schellack tränkt. Wenn die Sporen abgeworfen sind, erhitzt man das Papier leicht von der Unterseite; dann schmilzt das Harz und fixiert die Sporen. Nach dem Erkalten sind die Sporen unverwischbar. Man macht dann durch Hut und Stiel einen-nicht zu dünnen Längsschnitt, einen Flächenschnitt am Stiel, der die Beringung, Beschuppung usw. zeigt. Ferner zieht man die Oberfläche des Hutes ab; läßt sie sich nicht gut abtrennen, so schneidet man Fleisch und Lamellen möglichst vollständig heraus. Ferner kann man noch eine Huthälfte in derselben Weise behandeln. Unter Umständen kann man noch andere Schnitte ausführen, um den Fruchtkörper in den verschiedenste Stellungen zu bekommen. Alle diese Stücke legt man zwischen gutes Fließpapier mit gut saugenden Zwischenlagen und preßt bei gelindem Druck. Je schneller nun die Austrocknung vor sich geht, um so eher konservieren sich die Farben. Man presse nicht zu stark, nicht in einem geheizten Raum und wechsle am ersten Tage möglichst alle halben Stunden, dann nach 2-3, endlich nach 6-7 Stunden die Zwischenlagen. Sind die Schnitte dann ganz trocken, so stelle man sie so zusammen, daß Längsschnitte von ganzen Pilzen oder Pilzgruppen entstehen, wie man sie in der Natur findet. Diese klebt man mit Stärkekleister auf glattes weißes Papier auf. Man preßt diese Präparate dann leicht, bis sie völlig trocken sind. Man wird im Zusammenstellen solcher Pilztafeln bald eine gewisse Übung erwerben und kann meist recht geschmackvolle Gruppen arrangieren, die man durch Beigabe von Moos, Grashalmen usw. noch natürlicher gestalten kann.

Die kleinen, fast lederigen Formen kann man meist unmittelbar pressen, höchstens sind Längsschnitte erforderlich. Von Gasteromyceten macht man ebenfalls Längsschnitte, dagegen braucht man die kleineren Formen nur leicht zu pressen oder zu trocknen, um gute Herbarexemplare zu erhalten.

Durch die holzigen Fruchtkörper der Polyporaceen muß man Querschnitte anfertigen, um das Innere auf Jahrringbildung, Konsistenz und Farbe untersuchen zu können. Zerlegt man nun eine ganze Konsole in mehrere flache Scheiben, so kann man diese ins Herbar legen und durch Aufeinanderlegen der Scheiben jederzeit den Fruchtkörper wieder aufbauen. Im allgemeinen vermeide der Anfänger, sich etwa eine vom Herbar getrennte Sammlung von großen Fruchtkörpern anzulegen. Sie erfordert viel Platz und wird doch niemals so übersichtlich wie eineHerbarium.

Die Phallaceen kann man auf Papier auflegen und eintrocknen lassen.

Daß die Basidiomyceten unter den Insekten viele Feinde haben, kennt jeder, der einen Hut im Herbste einmal durchgebrochen hat, Es wimmelt darin von Maden, in den harten Konsolen von kleinen Käfern; würde man diese Eindringlinge nicht abtöten, so würde das Herbar bald zerfressen sein. Es muß deshalb die Hauptaufgabe sein, die Exemplare steril dem Herbar einzuverleiben. Wenn man die so- 
eben geschilderte Präpatarionstechnik befolgt, so werdenim allgemeinen die Tiere nach Beendigung der Präparation verschwunden sein. Um aber alle etwa noch vorhandenen abzutöten, ist es am besten, sie den Dämpfen von Schwefelkohlenstoff oder noch besser von Carboneum tetrachloratum auszusetzen. Man nimmt eine Kiste mit gut schließendem Deckel und legt die zu vergiftenden Präparate hinein. In einem kleinen flachen Gefäß stellt man dann einen von den genannten Stoffen hinein und schließt den Deckel. Die Kiste muß auf dem Boden oder in einem unbewohnten Raum stehen. Die Menge der Flüssigkeit läßt sich leicht ausprobieren, allgemeine Vorschriften sind darüber schwer zu geben. Die Präparate müssen in Carboneumdämpfen 48 Stunden, in Schwefelkohlenstoffdämpfen 4-6 Tage bleiben. Dann werden sie herausgenommen und etwas ausgelüftet. Man bestreut sie darauf mit Naphthalin und kann sie in Papierkapseln einschließen und ins Herbar legen. Werden die Mappen in Schränken aufbewahrt, und wird das verdunstete Naphthalin von Zeit zu Zeit ersetzt, so ist jede Gefahr ausgeschlossen, daß nachträglich Fraß ins Herbar kommt.

Wer sich einzelne Hüte (oder etwa Phallaceen) in natura konservieren will, der möge dazu ausschließlich Alkohol nehmen. Zwar zieht Alkohol die Farben aus und läßt die Gewebe schrumpfen, so daß die Exemplare viel kleiner werden, aber diese Nachteile werden dadurch wieder aufgewogen, daß die Pilze fest und hart bleiben. Formol härtet das Gewebe nicht genügend und ist deshalb wenig geeignet, als Konservierungsflüssigkeit zu dienen, zumal die Farben ebenfalls dảrin ausbleichen. Man setze die Pilze zuerst in 50 proz. Spiritus und steigere innerhalb von 8 Tagen die Konzentration bis auf $90 \%$. In dieser Flüssigkeit bleiben die Exemplare dann unveränderlich. Da eine solche Alkoholsammlung aber teuer ist und viel Platz beansprucht, wird man im allgemeinen dem Herbar den Vorzug geben.

Wer sich seine mikroskopischen Präparate aufhebt, der stecke sie zu den Exemplaren im Herbar. Es gibt in den Handlungen für mikroskopische Bedarfsartikel kleine Kartons, in die gerade ein Präparat hineingeht. Diese klebt man auf dem Herbarbogen fest. Man hat dann den Vorteil, daß Exemplar, Zeichnung und Präparat stets beisammen bleiben und immer zu finden sind.

Über das Format des Herbars, die Stärke der Herbarbogen, die Feinheit der Umschlagbögen, Zettel usw. entscheiden der Geschmack und der Geldbeutel des Besitzers. Vorschriften können darüber nicht gegeben werden, ebensowenig über die allgemeine Anlage eines Herbars, die den meisten Pilzsammlern ja bekannt sein wird.

\section{Das wissenschaftliche System der Pilze.}

Der vorliegende 1. Band wird nur einen Teil des Pilzreiches behandeln, und zwar die Basidiomyceten in ihren höheren Formen, während alles übrige sowie die Brand- und Rostpilze dem zweiten Bande vorbehalten werden sollen. 
Wir unterscheiden zwei Hauptklassen der Pilze, Phycom ye eten und Mycomyceten. Die ersteren sind ausschließlich mikroskopische Arten und können deshalb nur mit dem Mikroskop studiert werden. Ihr Myzelium ist häufig sehr reduziert und nur auf eine Zelle oder wenige Fäden beschränkt; dazu finden sich im Myzel keine Teilungswände. Viele von ihnen leben im Wasser oder in höheren Pflanzen, in Algen, oder sie kommen in totem organischen Substrat vor. Ihre Fortpflanzung ist fast stets geschlechtlich oder läßt sich jedenfalls aus geschlechtlichen Fortpflanzungsarten ableiten. Besondere Fruchtkörper werden fast gar nicht gebildet, höchstens kommt es zu Hüllenbildungen.

Im Gegensatz dazu besitzen die Mycomyceten stets ein gut entwickeltes Myzel, das mit Querwänden versehen ist. Fast immer kommt es zur Bildung von komplizierten Fruchtkörpern. Die geschlechtliche Fortpflanzung im landläufigen Sinne fehlt. Wir können nach der Art der Sporenbildung zwei Klassen unterscheiden: die Ascomyceten mit Sporen in geschlossenen Behältern (Schläuche, Asken) und die B asidiom yceten mit Sporen, welche auf besonderen Zellen gebildet werden (Basidien). Bei den ersteren also endogene, bei den letzteren exogene Sporenbildung.

Es würde also folgendes Schema entstehen:

I. Phycomyceten,

II. Mycomyceten.

1. Ascomyceten mit Schläuchen,

2. Basidiomyceten mit Basidien.

Die Basidiomyceten, die uns hier ausschließlich angehen, umfassen sehr heterogene Elemente. An der Spitze stehen die parasitischen Formen der Brand- und Rostpilze, es folgen dann solche mit gallertigen Fruchtkörpern, darauf beginnt sich bei den höheren Familien der Fruchtkörper in verschiedener Weise auszubilden, wodurch eine höchst mannigfaltige Ausgestaltung zustande kommt, die für die Haupteinteilung in Familien sehr wichtig ist.

Um die Familie bestimmen zu wollen, muß man die Form der Basidien kennen. Bei den Brand- und Rostpilzen macht die Basidie gleichsam erst eine Ruhepause durch, ehe sie aus der Chlamydospore hervorkeimt. Man wird aber diese beiden Familien jederzeit leicht an diesen Chlamydosporen erkennen können. Im zweiten Bande soll darüber das Nähere mitgeteilt werden. Von den drei Familien mit geteilten Basidien sind 1 und 3 leicht $\mathrm{zu}$ erkennen an dem gallertigen Fruchtkörper, die Pilacraceen dagegen sehen wie ein gestieltes Köpfchen aus und unterscheiden sich dadurch scharf von allen anderen Basidiomyceten.

Die Eubasidii haben ausschließlich ungeteilte Basidien, die mit Ausnahme von Familie 4 keulig oder kuglig sind und die Sporen fast mmer scheitelständig auf \pm langen Sterigmen tragen. Man muß dann wieder unterscheiden zwischen Fruchtkörpern mit offenen und geschlossenen Hymenien. Man betrachte für die Abgrenzung und Unterscheidung der angiokarpen Familien die Abbildungen. Die wissen- 
schaftlichen Unterschiede, welche sich aus der Entwicklungsgeschichte ergeben, können hier in einem Anfängerbuch nicht näher auseinandergesetzt werden.

Die Unterschiede der Familien 6-12, die in einer besonderen Tabelle zusammengestellt worden sind, beruhen auf der Differenzierung des Hymeniums, das in der verschiedensten Weise eine möglichst große Fläche apf kleinstem Raum zu erlangen sucht. Darauf brauche ich hier nicht weiter einzugehen, nachdem auf S. 8 bereits darüber das Notwendigste gesagt worden ist.

Bestimmungsschlüssel der Familien der Basidiomyceten.

A. Konidienträger nur basidienähnlich, aus Chlamydosporen hervorwachsend. Hemibasidii (Ustilagineen). (Siehe Bd. II.)

B. Konidienträger regelmäßig als Basidien ausgebildet (nur bei den Uredinaceae aus Chlamydosporen entstehend). Eubasidii.

a) Basidien mehrzellig (Protobasidiomycetes).

I. Basidien fädig, in 4 Zellen quer geteilt (A uriculariineae). 1. Basidien aus Chlamydosporen hervorwachsend.

Uredinaceae. (Siehe Bd. II.)

2. Basidien im offenen Hymenium stehend, aus Hyphen hervorgehend. Fk. gallertig.

1. Auriculariaceae (S. 1).

3. Basidien in einem geschlossenen Fk. entstehend. Fk. kopfig, gestielt.

2. Pilacraceae (S. 1).

II. Basidien fast kuglig, über Kreuz in 4 nebeneinander liegende Zellen geteilt (Tremellineae).

3. Tremellaceae (S. 1).

b) Basidien \pm keulig, seltener kuglig, ungeteilt, Sporen meist auf Sterigmen an der Spitze der B. sitzend (A u t o b a si di om y cetes).

I. Basidien langkeulig, an der Spitze sich in 2 lange Sterigmen gabelnd. Sporen vor der Keimung sich teilend. Fk. gallertig (Dacryomycetineae). 4. Dacryomycetaceae (S. 4).

II. Basidien kürzer keulig od. kuglig, Sterigmen fädig.

1. Basidien in einem offenen (gymnokarpen) Hymeniumstehend.

a) Hymenium ganz frei, ohne Fk. Parasiten auf Blättern u. Stengeln (Exobasidiineae).

\section{Exobasidiaceae (S. 6).}

$\beta$ ) Hymenium auf einem Fk., überhaupt auf einer Unterlage stehend, nicht parasitisch auf Blättern (H y meno mycetineae).

(Familie 6-12 siehe die folgende Tabelle.)

2. Basidienlager die Wände von Kammern auskleidend (angiokarp).

a) Hymenium in einer Gleba gebildet, die durch den sich streckenden Fk. emporgehoben wird u. zerfließt (Phal . lineae).

13. Phallaceae (S. 207). 
Das wissenschaftliche System der Pilze.

$\beta$ ) Hymenium im Innern der Fk., nicht emporgehoben (od. wenn, dann nicht abfließend).

$\dagger$ Basidien in Hymenien stehend, welche die Wände von Kammern auskleiden (Gasteromycetes).

* Hymenialkammern im Zusammenhang bleibend u. einen einheitlichen Fk. bildend.

§ Fk. bei der Reife fleischig bleibend, nicht staubig zerfallend. Unterirdisch.

$\triangle \mathrm{Fk}$. mit steriler Columella, von der die sterilen Gewebestränge strahlig abgehen.

14. Hysterangiaceae (S. 208).

$\Delta \Delta \mathrm{Fk}$, ohne Columella, sterile Gewebestränge von der Peridie entspringend, nicht strahlig.

15. Hymenogastraceae (S. 208).

$\S \S$ Fk. bei der Reife mit pulveriger Sporenmasse u. Capillitium erfüllt (Lycoperdineae).

16. Lycoperdaceae (S. 210).

** Fk. mit mehreren, voneinander ganz getrennten Hymenialkammern(Sporangiolen)(Nidulariineae).

17. Nidulariaceae (S. 215).

†† Basidien an den Hyphen in knäuelf. Gruppen entstehend u. im Innern gleichmäßig verteilt (Plectobasidiineae).

* Gleba bei der Reife trocken, staubig od. zerfließend. $\S$ Capillitium rudimentär, Gleba mit sterilen Gewebsadern. Fk. nicht od. kurz gestielt.

18. Selerodermataceae (S. 217).

$\S \S$ Capillitium netzf., mit der inneren Peridie verbunden. Fk. lg. gestielt.

19. Tulostomataceae (S. 219).

** Gleba kuglig, schleimig, abgeschleudert.

20. Sphaerobolaceae (S. 219).

Bestimmungsschlüssel der Hymen omycetineae (Fam. 6-12). A. Basidien kuglig, Sterigmen fehlend. Hymenium flach ausgebreitet.

6. Tulasnellaceae (S. 7).

B. Basidien \pm keulig, Sterigmen stets vorhanden.

a) Hymenium glatt, höchstens schwach warzig, runzlig od. sonst verunebnet.

I. Fk. locker fädig od. fester verflochten u. dann häutig, lederig, holzig, flach ausgebreitet, muschelf., seltener aufrecht trichterf. od. ästig.

1. Fk. flockig, fädig od. häutig, meist flach ausgebreitet, seltener am Rande abstehend, dann aber die Sporen nie stachlig, braun.

7. Corticiaceae (S. 7). 
2. Fk. lederig, angewachsen, meist \pm frei abstehend, becher-, schüssel- od. trichterf., selten hutf., bisweilen in Äste geteilt usw. Sporen stachlig od. glatt.

\section{Thelephoraceae (S. 20).}

II. Fk. meist fleischig, seltener knorpelig od. lederig, keulig, ästig, Äste stielrund od. flach.

$$
\text { 9. Clavariaceae (S. 26). }
$$

b) Hymenium aui Stacheln od. zahnartigen Vorsprüngen.

$$
\text { 10. Hydnaceae (S. } 36 \text { ). }
$$

c) Hymenium das Innere von Röhren od. Waben auskleidend. 11. Polyporaceae (S. 46).

d) Hymenium flache, blattartige Lamellen überziehend. 12. Agaricaceae (S. 84).

I. Hymenium auf Adern, Leisten od. Falten stehend. 12a. Cantharelleae (S. 84).

II. Hymenium auf deutlich ausgebildeten L. stehend.

1. L. hinten St.-Ansatz od. an der Hutanheftungsstelle anastomosierend $u$. oft wabenf. Zellen bildend.

12 b. Paxilleae (S. 87).

2. L. hinten nicht anastomosierend, sondern durchgehend. a) L., meist auch der Hut bei der Reife zerfließend.

12c. Coprineae (S. 89).

$\beta)$ L. nicht zerfließend, nur vertrocknend od. verfaulend. $\dagger$ L. dick u. fleischig, wachsartig, weitläufig.

12d. Hygrophoreae (S. 93).

$\dagger \dagger$ L. fleischig-häutig od. lederig-häutig.

* Hyphen der Fk. zweierlei, oft mit Milchsaftröhren, L. meist leicht zerbrechlich, nicht zähe.

12e. Lactarieae (S. 100).

** Hyphen gleichartig. § Fk. bei der Reife leder-od. korkartig, vertrocknend.

$12 \mathrm{f}$. Marasmieae (S. 115).

$\S \S \mathrm{Fk}$. bei der Reife fleischig od. häutig, verfaulend. 12 g. Agariceae (S. 123).

Ich will zum Schluß noch einige Ausdrücke erklären, damit dem Anfänger ihre Bedeutung möglichst klar wird. Im allgemeinen halte ich von einem solchen Glossar nicht viel, da die Ausdrücke so lange toter Ballast bleiben, wie sie nicht von lebendiger Anschauung getragen werden. Der Anfänger wird immer einige Mühe haben, um sich einzuarbeiten, und lernt durch Nachbestimmen von Arten mehr als etwa durch Auswendiglernen der Kunstausdrücke.

Myzelium. Vegetativer Teil des Pilzes, bestehend aus \pm dicht verflochtenen Fäden. Bei noch dichterem Gefüge können Stränge (Rhizomorphen) oder Platten entstehen. 
Sklerotien Sehr dichte Myzelverflechtungen, welche zelliges Gefüge und eine besondere Rinde zeigen. Sie bezeichnen einen Dauerzustand des Myzels.

Fruchtkörper. Damit bezeichnet man ganz allgemein den \pm differenzierten Teil des Pilzes, der das Hymenium trägt.

Hymenium (Fruchtschicht) entsteht durch das lagerartige $\mathrm{Zu}$ sammentreten der Basidien. Bei den Angiokarpen Gleba genannt.

Cystiden sind die sterilen \pm langkeuligen Hyphenenden, welche zwischen den Basidien stehen. Man unterscheidet bei den Corticieen mehrere Arten von Cystiden, über deren Form man durch einen Querschnitt leicht ins klare kommt.

Trama ist die Schicht von Hyphen, aus der das Hymenium unmittelbar hervorgeht, z. B. die Schicht zwischen den Poren der Polyporeen, die mittlere Schicht der Lamellen usw.

Velum partiale ist die Hülle, welche den Hut mit dem Stiel zum Schutze des hymenialen Teiles des Fruchtkörpers verbindet (auch Cortina genannt). Der Überrest am Stiel kann einen Ring (annulus superus) bilden.

Velum universaleist die Hülle, welche den ganzen Hut umgibt. Sie kann am Grunde des Stieles als Scheide (Volva) zurückbleiben und auf dem Hut als Schuppen oder Hautfetzen.

Peridium ist die Hülle bei der angiokarpen Familien.

Spore heißt jede Fortpflanzungszelle der Pilze.

Chlam yd os p or e ist eine Zelle, welche einen Dauerzustand durchmacht und dann in der Regel unmittelbar fruktifikativ auskeimt.

Konidienträger ist ein besonders gestalteter Faden, an dem rgendwie exogene Sporen entstehen (Konidien).

Basidie ist ein regelmäßig gestalteter Konidienträger, der bei jeder Art in allen Punkten fast konstant ist.

Die Beifügung des Autornamens zu einer Spezies ersetzt gleichsam ein Zitat. Ich habe nur denjenigen Autor zitiert, der die Spezies aufgestellt hat. Ist die Art noch heute in derselben Gattung geblieben, so wird keine Klammer beigefügt, während die Klammer bezeichnet, daß die Art ursprünglich in einer anderen Gattung untergebracht worden ist. Zur Vereinfachung habe ich den Autor, der die Art in die jetzt geltende Gattung gestellt hat, fortgelassen. Man wird aus größere systematischen Werken leicht diesen Autor ergänzen können. Synonyme habe ich im Verzeichnis der Arten gegeben, ich folge der Nomenklatur, wie sie in den größeren Werken von Winter, Schroeter und Hennings niedergelegt ist. Diese z. T. schwierigen Nomenklaturfragen gehören nicht in ein Anfängerbuch.

Endlich seien noch einige größere Bestimmungsbücher neben Fries' klassischen Arbeiten angeführt. 
Fries, Elias, Hymenomycetes europaei. 2 ed. Upsala 1874.

- Icones selectae Hymenomycetum. 2 vol. 1877-84.

Krombholz, J. V., Naturgetreue Abbildungen und Beschreibungen der eßbaren, schädlichen und verdächtigen Schwämme. 10 Hefte. Prag 1831-47.

Cooke, M. C., Illustrations of British Fungi (Hymenomycetes) London $1881-91$.

Len z, H. O., Die nützlichen und schädlichen Schwämme. 7.Aufl.1890. Bresadola, G., I funghi mangerecci e velenosi dell'Europa media, con speciale riguardo a quelli che crescono nel Trentino. 2 ed. Trento 1906.

Michael, E., Führer für Pilzfreunde. 3 Bde. Zwickau 1901-05. Ricken, A., Die Blätterpilze Deutschlands und der angrenzenden Länder, besonders Österreichs und der Schweiz. Leipzig 1910-15. Wünsche, O., Die verbreitetsten Pilze Deutschlands. Leipzig 1896. Kummer, P., Führer in die Pilzkunde. 2. Aufl. Zerbst 1881. Winter, G., Pilze in Rabenhorsts Kryptogamenflora Deutschlands. Bd. I. $1881-83$.

Schroeter, J., Pilze in Cohns Kryptogamenflora von Schlesien I. $1885-89$.

Rolland, L., Atlas des Champignous de France, Suisse et Belgique. Paris 1910.

Herter, W., Autobasidiomycetes in Kryptogamenflora der Mark Brandenburg VI. 1. Heft 1910.

Brinkmann, W., Die Thelephoreen Westfalens. Münstnr 1916 (nicht mehr benutzt). 


\section{Abkürzungen im Text.}

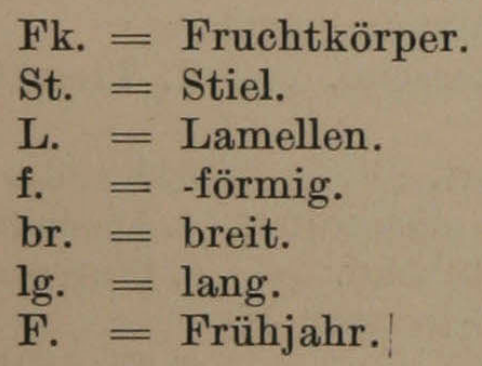

S. = Sommer.

H. = Herbst.

W. = Winter.

Lb. = Laubholz, Laub.

Nd. = Nadelholz, Nadel.

u. $=$ und.

od. $=$ oder.

\section{Familie: Auriculariaceae.}

Fk. ziemlich groß, gallertig, in der äußeren Gallertschicht die langen, aus vier übereinander stehenden Zellen gebildeten Basidien. Sporen je eine an jeder Basidienzelle, mit Sterigma.

Gattung: Auricularia Bull. (Ohrenpilz).

Die häufigste Art bildet trocken unscheinbare, schwärzliche Krusten auf Lbzweigen, die feucht dick gallertig aufschwellen und dann ohrenförmige, mit Ruuzeln, Gruben und Adern versehene schwärzliche, oft auch ungestaltete Klumpen darstellen. Besonders auf Sambucus nigra, häufig. S. H. (Fig. 1.) (Judasohr.)

\section{A. auricula judae (L.).}

\section{Familie: Pilacraceae.}

Fk. gestielt mit Köpfchen, klein. Basidien wie bei vor. Fam., in einer festen Hülle eingeschlossen.

\section{Gattung: Pilacre Fries (Hütchenträger).}

Einzige Art höchstens $1 \mathrm{~cm}$ hohe Fk. von graubräunlicher Farbe bildend, gesellig zusammenstehend. Hülle des Köpfchens fest, dann vergehend u. der staubige Inhalt frei werdend. Auf Rinde von alten Eichen und Buchen, selten. S. H. (Fig. 2.) (Peters H.) P. Petersii Berk. et Curt.

\section{Familie: Tremellaceae.}

Fk. gallertig, in der äußeren Gallertschicht die kugligen oder eif., von oben über Kreuz vierteiligen Basidien stehend. Sporen je eine an jeder Basidienzelle, mit sehr langem Sterigma.

Lindau, Kryptogamenflora. I. 2. Aufl. 
Bestimmungsschlüssel der Gattungen.

A. Fk. glatte od. höckrige Überzüge über Gras, Moos usw. bildend.

B. Fk. abstehend an Zweigen od. Holz, dick, gallertig, nicht weithin krustig.

a) Oberfläche des gallertigen Fk. faltig, vom Hymenium überzogen ${ }^{1}$ ).

I. Konidien der Nebenfruchtformen nicht zu Lagern zusammentretend, sondern stets einzeln.
1. Sporen in Hefekonidien aussprossend.
2. Tremella.

2. Nicht Hefekonidien bildend.

a) Konidien häkchenf. gekrümmt.

3. Exidia.

$\beta$ ) Konidien gerade, in Köpfchen angeordnet.

II. Konidien zu Lagern zusammenstehend.

1. Sebacina.

b) Fk. hutf., unterseits stachlig, Stacheln vom Hymenium überzogen.

6. Tremellodon.

\section{Gattung: Sebacina Tul. (Wachskruste).}

Fk. krustig, Moos, Halme, Erde überziehend, zuerst wergartig, später fest, wachsartig, brüchig.

Einzige Art mit milchweißer, im Alter gelblicher Kruste und flockiger Umrandung. In Wäldern zerstreut. S. H. (Fig. 3.) (Überziehende W.)

S. incrustans (Pers.).

\section{Gattung: Tremella Dill. (Zitterpilz).}

Fk. trocken hart, ${ }^{\circ}$ hornartig, feucht gallertig oder knorpelig, kuglig bis eif., mit schmalem Grunde aufsitzend, auf der Ober. fläche mit gehirnartigen, z. T. tiefen Windungen und Falten.

1. Fk. frisch rötlich, weißlich od. \pm gelblich od. rotgelb.

Fk. frisch \pm olivengrün.

2. Fk. hell fleischfarben, trocken schmutzig rötlich bis braun, etwa $1 \mathrm{~cm}$ im Durchm., innen weiß, hart. An Kiefernholz und -zweigen. H. W. F. (Fig. 4.) (Gehirn-Z.)

Fk. gold- oder hellgelb. T. encephala Willd.

3. Fk. lebhaft goldgelb oder orangefarben, $2-4 \mathrm{~cm}$ im Durchm., mit gehirnartigen Falten, an der Basis zusammengezogen und weißlich. Auf Lbzweigen. H. W. F. (Fig. 5.) (Eingeweide-Z.)

T. mesenterica Schaeff.

Fk. hell gelb, etwas kuglig, 1-4 cm im Durchm., wellig. Auf Lbzweigen. H. W. F. (Gelblicher Z.) T. lutescens Pers.

1) Die Unterscheidung dieser vier Gattungen wird dem Anfänger unmöglich sein. Er kann nur durch mikroskopische Untersuchung einigermaßen zur Klarheit kommen. Man sehe deshalb bei den hierher gehörigen Gattungen die angeführten Arten durch, wodurch bei Berücksichtigung der makroskopischen Merkmale meistens doch eine Entscheidung möglich sein wird. 
4. Fk. knorpelig, schwärzlich olivengrün, trocken schwarz, mit tiefen Windungen, fast kuglig, $3-5 \mathrm{~mm}$ im Durchm. Gesellig aus der Rinde der Äste von Prunus spinosa hervorbrechend. H. (Grünlicher Z.)

T. virescens Bref.

Fk. zäh gallertig, olivengrün, trocken schwärzlich, schwach faltig, kuglig, 3-4 mm im Durchm., mehrere zusammenfließend und flache Krusten bildend. An Stämmen und Zweigen von Sarothamnus scoparius. H. W. F. (Ginster-Z.) T. genistae Lib.

3. Gattung: Exidia Fries (Gallertpilz).

Fk. wie bei Tremella, nur durch die häkchenförmigen Konidien sicher zu unterscheiden.

1. Fk. weißlich bis milchweiß, durchscheinend glasig, oberflächlich glatt, später mit seichten gewundenen Furchen, $2-3 \mathrm{~cm} \mathrm{im}$ Durchm., oft auf weite Strecken zusammenfließend. Auf Zweigen von Lbbäumen, besonders Rotbuche. H. W. F. (Weißlicher G.)

\section{E. albida (Huds.).}

Fk. feucht, stets dunkel gefärbt, braun, grau, schwärzlich. 2 .

2. Fk. mit braunem Ton.

Fk. mit grauem od. schwärzlichem Ton.

3. Fk. bernsteinbraun, dann dunkler, trocken glänzend schwarz, fast kreiself., gestielt, oben scheibig abgeflacht oder etwas schüsselartig vertieft, $0,5-2 \mathrm{~cm}$ br. Hymenium die scheibige Oberfläche überziehend. Auf abgefallenen Zweigen von Lbbäumen häufig, besonders von Weiden, Pappeln, Kirschen usw. H. W. F. (Zäher G.)

E. gelatinosa (Bull.).

Fk. dunkel zimmet- od. rotbraun, durchscheinend, am Rande gekerbt, kraus, kuglig abgeflacht, $3-5 \mathrm{~cm}$ breit, häufig zusammenfließend. Auf Stümpfen und Zweigen von Erlen u. Birken. H. W. (Ausgebreiteter G.)

E. repanda Fries.

4. Fk. zuerst grau, dann schwärzlich, trocken zu papierartiger, glänzend schwarzer Haut zusammenschrumpfend, knollig, mit schmalem Grunde aufsitzend, $3-6 \mathrm{~cm}$ br., oben flach und vom Hymenium überzogen, zuerst glatt, dann mit kegelförmigen Warzen bedeckt, unten unregelmäßig faltig. Auf abgefallenen Zweigen von Lbbäumen häufig, besonders auf Eiche u. Rotbuche. H. W. F. (Fig. 6.) (Drüsiger G.) E. glandulosa (Bull.).

Fk. schwärzlich, trocken glänzend schwarz, kreiself. gestielt, $1-2 \mathrm{~cm}$ br. unterseits mit Höckern und Runzeln, oberseits vom Hymenium bekleidet und mit einzelnen drüsigen Warzen bedeckt. Einzeln od. gesellig aus der Rinde von Lindenzweigen hervorbrechend. W. (Fig.7.) (Abgestutzter G.)

E. truncata Fries.

4. Gattung: Ulocolla Bref. (Kräuselgallerte).

Fk. wie bei Exidia, von der sie nur durch die stäbchenförmigen, in Köpfchen zusammenstehenden Konidien sich unterscheidet. Diese sind mit Sicherheit nur in der Kultur zu erzielen. 
Fk. gelbbraun wie gebrannter Zucker, vielfach gewunden und gefaltet, ausgebreitet, abgeflacht. $3-5 \mathrm{~cm}$ br., meist weit zusammenfließend. An Holz und Stümpfen, besonders an Nd. H. W. F. (Fig. 8.) (Zucker-K.)

U. saccharina (Fries).

Fk. zimmetbraun, durchscheinend, oberflächlich mit gekröseartigen Lappen und Windungen, an der Basis faltig, $2-5 \mathrm{~cm}$ br. und hoch, oft zusammenfließend, im ganzen üppiger als vor. Art. An Holz u. Stümpfen, Nd. bevorzugend. H. W. F. (Blättrige K.) U. foliacea (Pers.).

\section{Gattung: Craterocolla Bref. (Kruggallerte).}

Fk. von zweierlei Art, gallertig. Basidienfk. kuglig, oben faltig, stark aufquellend. Konidienfk. klein krugf., innen von den Konidienträgern ausgekleidet.

Basidienfk. der einzigen Art blaß fleischfarben, $1-4 \mathrm{~cm} \mathrm{br}$. Konidienfk. rot, zuerst geschlossen, dann krugf. geöffnet, viel kleiner. An Stämmen u. Zweigen von Prunus avium. H. (Fig. 9.) (Kirsch-K.)

C. cerasi (Schum.).

\section{Gattung: Tremellodon Pers. (Zitterzahn).}

Fk. gallertig, trocken knorpelig, abstehend, halbkreisf. od. seitlich gestielt, unterseits mit Stacheln besetzt, die das Hymenium tragen.

Fk. der einzigen Art milchweiß oder fast farblos, $2-6 \mathrm{~cm}$ br., mit 2-4 cm langen Stacheln. An Stümpfen von Nd., nicht häufig. S. H. (Fig. 10.) (Gallertartiger Z.) T. gelatinosus (Scop.).

\section{Familie: Dacryomycetaceae.}

Fk. gallertig od. knorpelig, trocken meist ganz unscheinbar zusammenschrumpfend. Basidienlager den Fk. ganz od. nur teilweise bedeckend. Basidien lang, keulig, nach oben in zwei lange Sterigmen auswachsend, an deren Spitze je eine ei- oder etwas nierenf. Spore entsteht. Sporen meist sofort auskeimend, sich teilend $\mathrm{u}$. Sproßkonidien bildend.

\section{Bestimmungsschlüssel der Gattungen.}

A. Fk. tremellaartig, ungestaltet, mit Windungen auf der Oberfläche sitzend.

1. Dacryomyces.

B. Fk. gestielt, stift- od. fadenf., oft verzweigt.

a) Fk. köpfchenf., dick, St. im Holz verborgen.

2. Ditiola.

b) Fk. pfriemlich zungenf., flach, oft verzweigt.

I. Fk. auf einer Seite flach, becher- oder spatelf. u. nur hier vom Basidienlager überzogen.

3. Guepinia. 
II. Fk. nicht flach, allseitig vom Basidienlager bedeckt.

1. Fk. keulig, gefurcht, wie eine kleine Morchel aussehend.

2. Fk. stielrund, pfriemlich oder verzweigt, wie Clavaria aussehend.

4. Dacryomitra.

5. Calocera.

\section{Gattung: Dacryomyces Nees (Tränenpilz).}

Fk. zu gelben oder roten Flecken eintrocknend, feucht gallertig aufquellend, ohne bestimmte Gestalt, mit Windungen, wie Tremella aussehend, aber kleiner. Basidien die der Familie.

1. Fk. gelbrot, rot oder orangefarben.

Fk. gelb, gallertig, zuerst fast kuglig oder flachgedrückt, später unregelmäßig rundlich, auf der Oberfläche gefaltet, $2-10 \mathrm{~cm}$ br. Sporen länglich zylindrisch, beidendig gerundet, kaum gekrümmt, $15-22 \mu$ lg., $4-7 \mu$ dick. Auf bearbeitetem Holz, besonders von Nd. Besonders im H. W. gemein. (Zerfließen. der T.)

D. deliquescens (Bull.).

2. Fk. gelbrot bis etwas orange, knorpelig-gallertig, zuerst kuglig, dann mehr unregelmäßig, etwas faltig, $4-6 \mathrm{~mm}$ br. Sporen wie bei vor., etwas stärker gekrümmt, $20-30 \mu \mathrm{lg}$., $9-12 \mu$ dick. An Ästen u. bearbeitetem Holz der Nd. Das ganze Jahr. (Fig. 11.) (Nd.-T.)

D. abietinus (Pers.).

Fk. lebhaft orangefarben, weich gallertig, zuerst fast kuglig, dann mit Falten, zuletzt schleimig zerfließend. Sporen lg. eif., innen etwas gebuchtet, $35 \mu \mathrm{lg}$., $15 \mu$ dick. An Stümpfen u. Zweigen von Nd. Fast das ganze Jahr. (Goldhaariger T.)

D. chrysocomus (Bull.).

\section{Gattung: Ditiola Fries (Kopfträne).}

Fk. knorpelig gallertig, keulig-kopfig, etwas flach, vom Basidienlager überzogen, im Substrat mit mehreren starken stielartigen Wurzeln, im ganzen wie ein Backenzahn aussehend. Einzige Art, höchstens bis $9 \mathrm{~mm}$ hoch, goldgelb, anfangs wie von einem weißen Schleier umhüllt, Sporen an der Basis schief zugespitzt, 8-10 $\mu$ lg., $4 \mu$ dick. Auf feuchten, faulenden Kieferbrettern, nicht häufig. W. F. (Fig. 12.) (Bewurzelte K.) D. radicata (Alb. et Schw.).

3. Gattung: Guepinia Fries (Guepinie).

Fk. gallertig, trocken knorpelig, spatel-, becher- od. kreiself., nur auf der flachen Seite vom Basidienlager überzogen.

Fk. weißgelblich, schildf. hervorbrechend, mit dickem Rande u. kurzem, dickem, nach unten hin behaartem St., 8-10 $\mathrm{mm}$ br. Sporen mondf., $40-45 \mu \mathrm{lg}$., $15 \mu$ dick. Auf Eichenholz selten. H. (Fig. 13.) (Femsjons G.)

G. Femsjoniana Olsen.

Fk. hellgelblich, becherf., $0,5-1,5 \mathrm{~cm}$ hoch u. $3-8 \mathrm{~mm}$ br., Sporen zylindrisch, beidendig abgerundet, innen abgeflacht, 10 bis 
$13 \mu \lg ., 4-6 \mu$ dick. Auf alten Eichenstümpfen, selten. H. (SchüsselG.) G. peziza Tul.

4. Gattung: Dacryomitra Tul. (Tränenmütze).

Fk. gallertig-knorpelig, mit Stiel u. einem keulen- od. zungenf., etwas gefurchten Kopfteil. Einzige Art mit gelbem Stiel u. orange- farbener Keule, fast wie eine kleine Morchel aussehend, 6-10 mm hoch. An Stümpfen u. Brettern von Eichen, selten. S. H. (Fig. 14.) (Zungenf. T.)

D. glossoides (Pers.).

5. Gattung: Calocera Fries (Schönhorn).

Fk. knorpelig zähe, keulenf. od. pfriemlich, einfach od. verzweigt, wie Clavaria aussehend, aber trocken hornartig durchsichtig. 1. Fk. verzweigt.

Fk. unverzweigt, pfriemlich, orangegelb, trocken rot u. hornartig, feucht knorpelig, bis $1 \mathrm{~cm}$ hoch, $1 \mathrm{~mm}$ dick. An Holz u. Stümpfen von Lb., besonders Eichen häufig. S. H. (Fig. 15.) (Hornartiges S.)

C. cornea (Batsch).

2. Äste des Fk. nicht br. an der Spitze, sondern spitz, stielrund. 3.

Fk. am Ende od, von der Mitte ab mit einigen kurzen, abstehenden Ästchen, Hauptstamm keulig, nach oben verbreitert u. etwas flach gedrückt, $1-1,5 \mathrm{~cm}$ hoch, dunkel orangefarben. An altem Holz. Fast das ganze Jahr. (Fig. 16.) (Handf. S.)

C. palmata (Schum.).

3. Fk. feucht knorpelig zähe, klebrig, glatt, goldgelb bis or angefarben, von unten od. der Mitte ab mehrfach bis reichlich gabelteilig, $6 \mathrm{~cm} \mathrm{u.} \mathrm{höher,} \mathrm{Äste} \mathrm{spitz,} \mathrm{drehrund.} \mathrm{Wurzelartige} \mathrm{Basis} \mathrm{weit}$ in das Holz reichend, weiß, zottig. An Stümpfen u. Holz von Nd. Häufig, namentlich im Gebirge. S. H. (Fig. 17.) (Klebriges S.)

C. viscosa (Pers.).

Fk. weich, stark schrumpfend beim Trocknen, gelb, $1-2 \mathrm{~cm}$ hoch, mit weitläufig stehenden, gabeligen, spitzen, drehrunden Ästen, am Grunde weißfilzig. An Ndstümpfen, viel seltener als vor. H. (Gabelteiliges S.)

C. furcata Fries.

\section{Familie: Exobasidiaceae.}

Ausschließlich Parasiten. Fk. fehlend. Basidienlager nackt, aus der Oberhaut der Wirtspflanzen hervorbrechend.

Bestimmungsschlüssel der Gattungen.

A. Basidien ausgebreitete, zusammenhängende Lager auf der Wirtspflanze bildend. Basidien viersporig.

1. Exobasidium.

B. Basidien in kleiner Zahl aus den Spaltöffnungen hervorbrechend, meist sechssporig.

2. Microstroma. ${ }^{1} \bar{T}$

1) Nach neueren cytologischen Versuchen gehört die Gattung nicht zu den Basidiomyceten. Da man sie aber hier gewöhnlich sucht, habe ich sie stehen gelassen. 
1. Gattung: Exobasidium Woron. (Nacktbasidie).

Myzel im Wirt, oft gallenartige Anschwellungen der Stengel u. Blätter verursachend. Basidien aus der Oberhaut in großen, weit ausgebreiteten, weißlichen Lagern hervorbrechend.

1. Auf Vaccinium-Arten weißlich-rötliche Überzüge an den meist geschwollenen Stengeln u. Blättern bildend, häufig. S. (Fig. 18.) (Preißelbeer-N.).

E. vaccinii (Fuck.)

2. Auf Rhododendron-Arten in den Alpen \pm große, weiße od. fleischrote Gallen erzeugend, seltener in Gärten. S. (Rhododendron-N.)

E. rhododendri Cram.

3. Auf Andromeda polifolia, nicht selten. S. (Andromeda-N.)

E. andromedae Peck.

2. Gattung: Microstroma Niessl (Kleinstroma).

Basidien büschelförmig zu den Spaltöffnungen der Blätter (neist nur unterseits) hervorwachsend, punktf. Räschen bildend, die zu einem weißen, kreidigen U̇berzug verschmelzen.

Auf Juglans regia über $1 \mathrm{~cm}$ große, eckige Überzüge auf den Blättern bildend, im Gebirge häufiger. S. (Fig. 19.) (Nußbaum-K.)

M. juglandis (Bér.).

Auf Quercus-Arten 2-4 mm große, eckige Überzüge auf den Blättern bildend. Seltner als vor. S. (Eichen-K.)

\section{M. album (Desm.).}

\section{Familie: Tulasnellaceae.}

Fk. aus dem flach ausgebreiteten, wachsartig-gallertigen Basidienlager bestehend. Basidien kuglig, ungeteilt, 4 ungestielte, sofort keimende Sporen tragend.

\section{Gattung: Tulasnella Schroet. (Tulasnelle).}

Lager rötlich, ohne bestimmten Umriß. Auf Rinde von Koniferen u. Eichen, selten. H. W. (Fig. 20.) (Rötliche T.)

\section{T. incarnata (Olsen).}

\section{Familie: Corticiaceae.}

Fk. schimmel- od. spinnewebartig od. fleischig-häutig, der Unterlage anliegend, weit ausgebreitete Filze od. derbe Häute bildend, höchstens muschelartig am Rande abstuhend, auf der Oberfläche glatt od. mit unregelmäßigen flachen Warzen od. flachen Runzeln bedeckt. Basidien mit 2-6, an Sterigmen sitzenden Sporen.

$$
\text { Bestimmungsschlüssel der Gattungen }{ }^{\mathbf{1}} \text { ). }
$$

A. Gewebe des Fk. entweder locker wergartig od. etwas fester, aber noch ohne festgefügte Mittelschicht. Meist nur flach auf-

1) Die Gattungen dieser Familie sind ohne Mikroskop nicht zu unterscheiden. 
liegende, selten sich am Rande etwas abhebende Lager, oft am Rande strahlig-faserig.

a) Membran der Sporen gefärbt.

I. Sporen rauh od. stachlig.

II. Sporen ganz glatt.

1. Tomentella.

2. Coniophora.

b) Membran der Sporen farblos.

I. Fk. im frischen Zustande stets flach anliegend, sich nicht muschelartig abhebend $u$. nicht mit Randsaum, höchstens faserig.

1. Im Basidienlager keine Cystiden.

a) Fk. unterrindig. Basidien nicht in palisadenartig geschlossener Schicht stehend.

$\beta$ ) Fk. oberrindig. Basidien in palisadenartig geschlossener Schicht stehend.

2. Im Basidienlager Cystiden stets vorhanden.

a) Zweierlei Cystiden vorhanden, die einen dünn- u. glatt-, die anderen dick- u. rauhwandig.

B) Nur einerlei Cystiden vorhanden, mit meist dicker Membran. 6. Kneiffia.

II. Fk. in frischem Zustande od. in der

\section{Vuilleminia.}

4. Corticium. Jugend fast an allen Seiten abstehend, daher becher- od. schüsself.

1. Im Basidienlager nur Basidien vorhanden.

2. Im Basidienlager noch sterile $\mathrm{Fä-}$ den vorhanden.

\section{Cytidia.}

8. Aleurodiscus.

B. Gewebe des Fk. fest häutig od, lederartig, mit fester Hyphenschicht unter dem Basidienlager. Häufig vom Substrat hutartig abstehend.

a) Basidienlager ohne spitze, hervorragende

Borsten.

b) Basidienlager mit spitzen, hervorragenden Borsten.

9. Stereum.

10. Hymenochaete.

1. Gattung: Tomentella Pers. (Filzschwamm).

Fk. aus einem lockern, verwebten Filz bestehend. Basidien an den Myzelfäden büschelig entstehend, noch kein eigentliches Lager bildend.

1. Filz weiß od. irgendwie braun. 2. Filz rot, blaugrün od. stahlblau.

2. Filz weiß od. gelbbraun.

Filz dunkelbraun. 
3. Filz isabellfarben, weit ausgebreitet. Sporen ellipsoidisch, farblos, $10 \mu \mathrm{lg}$., $8 \mu$ dick, stachlig.. An Holz u. Rinde von Nd. in feuchten Wäldern. H. (Isabellfarbener F.) T. isabellina (Fries).

Filz weiß bis gelblichbraun. Sporen strohgelb, kuglig, stachlig, ca. $6 \mu \mathrm{im}$ Durchm. An Holz u. Rinde, auch über Lb. von Buchen, Birken, selten über Kiefernadeln in feuchten Wäldern. H. (Häutiger F.)

T. pellicula (Fries).

4. Filz kastanien- od. rostbraun. Sporen gelbbraun, stachlig, kuglig, 8-10 $\mu$ im Durchm. Auf morschen Lbstümpfen, Rinde, Lb. usw. häufig in feuchten Wäldern. S. H. (Fig. 21.) (Rostfarbener F.)

T. ferruginea Pers.

Filz fester, fast häutig, schokoladenbraun, am Umfang heller, faserig. Sporen ellipsoidisch, eckig, warzig, braun, $6-11 \mu \mathrm{lg}$., 5-8 $\mu$ dick. Auf alten Lb.- u. Ndstümpfen, auch Lb., Holz, Moos usw. überziehend, in feuchten Wäldern häufig. S. H. (Schokoladenfarbiger F.)

T. fusea (Pers.).

5. Filz fast häutig, mit kleinen Wärzchen besetzt, lebhaft rot, im Alter erst braun werdend. Sporen kuglig, stachlig, braun, $10 \mu$ im Durchm. An morschem Holz u. Rinde von Buche u. Tanne, seltener. F. (Roter F.) T. punicea (Alb. et Schwein.).

Filz sehr zart, blaugrün bis stahlblau, erst im Alter olivenbraun werdend. Sporen kuglig, fast glatt, farblos, $2-3 \mu$ im Durchm. An Stümpfen, Holz, Rinde von Lb., oft über Moosen u. auf dem. Boden, nicht selten. Fast das ganze Jahr. (Stahlblauer F.)

T. chalybaea Pers.

2. Gattung: Coniophora DC. (Staubträger).

Fk. häutig, flach ansitzend, glatt od. unregelmäßig warzig.

Fk. sehr weit verbreitet, handgroß u. darüber, dick, weich fleischig-häutig, später zerbrechlich, leicht ablösbar, zuerst weiß, dann gelblichbraun mit weißem, flockigem Rande. Oberfläche glatt od. warzig u. wellig, von den Sporen zuletzt braun bestäubt. Sporen gelbbraun, glatt, kurz ellipsoidisch, $11-14 \mu \mathrm{lg}$., $7-9 \mu$ dick. Auf alten Stümpfen u. Pfählen von Nd. u. Lb., an Pflanzenkübeln, häufig an Holz in Häusern, Kellern u. dort oft große weiße Watten von sterilem Myzel bildend, das Holz langsam zerstörend. Das ganze Jahr. (Fig. 22.) (Gehirnartiger S.) C. cerebella (Pers.).

Fk. zart häutig, groß, frisch gelbbraun, in der Mitte flockigwarzig, am Rande mit gelben, strahligen Hyphen. Sporen eif., gelbbraun, $9-12 \mu$ lg., $6-7 \mu$ dick. An Stümpfen, Holz u. Rinde, besonders von Nd., an Kübeln, Pfählen, nicht selten. H. (Trockenhäutiger S.)

C. arida (Fries.).

3. Gattung: Vuilleminia Maire (Vuilleminie).

Fk. unter der Rinde wachsend. Sporen farblos, glatt.

Fk. der einzigen Art weithin unter der Rinde wachsend u. sie abhebend, frisch weich fleischig bis wachsartig, dick, schmutzig 
weiß od. grau bis rötlich od. gelblich grau, glatt, trocken dünnkrustig, rissig, schmutzigbraun. Sporen ellipsoidisch, etwas gekrümmt, $17-21 \mu$ lg., $6-9 \mu$ dick. An feuchtliegenden Lbzweigen, besonders von Eiche, überall in Wäldern häufig. Das ganze Jahr. (Fig. 23.) (Fressende V.)

V. comedens (Nees).

\section{Gattung: Corticium Pers. (Rindenpilz).}

Fk. frisch, stets ganz angeheftet, später sich höchstens am Rande lösend, aber nicht muschelartig abstehend, flockig, häutig, lederig, fleischig, meist ganz glatt. Sporen glatt od. punktiert, nicht stachlig, farblos.

1. Fk. weiß, höchstens im Alter am Rande od. im Innern gelblich oder bräunlich werdend.

Fk. von Anfang an gelb od. braun.

Fk. grau, rötlich, bläulich.

2. Fk. weiß bleibend.

Fk. im Alter am Rande od. fast ganz gelblich od. bräunlich werdend.

3. Fk. im Umfange mit strahlig auslaufenden Hyphen.

Fk. fädig, häutig, jedenfalls am Umfang nicht auffällig mit ausstrahlenden Hyphen.

4. Stets ein wachsartiges, festes Hymenium vorhanden, ohne Sklerotien.

Spinnwebartige od. dünnhäutige, weit verbreitete Überzüge bildend, im Zentrum noch kein festes, wachsartiges Hymenium vorhanden, im H. am Myzel 1-3 mm lge., weiße, dann bräunliche Sklerotien entstehend. Sporen ellipsoidisch, $5-7 \mu \mathrm{lg}$., $4 \mu$ dick od. kuglig. Auf Rinde älterer Lb. u. Ndstämme, besonders über Blattflechten u. hier die Sklerotien bildend, häufig. S. H. W. (Zentrifugaler R.) C. centrifugum (Lév.).

5. Fk. häutig, wachsartig, trocken rissig, am Rande locker faserig. Sporen ellipsoidisch, $5-7 \mu \mathrm{lg}$., $3-4 \mu$ dick, einseitig etwas flach. Auf Lb.- u. Ndrinde häufig. Das ganze Jahr. (Fig. 24.) (Milchweißer R.)

C. lacteum (Fries).

Fk. etwa $2-3 \mathrm{~cm}$ breit, Hymenium wasserhell, trocken weiß. Sporen umgekehrt eif., $8-12 \mu$ lg., $5-8 \mu$ dick. Auf Holz, Rinde, Zweigen, Brettern usw. von Lb. u. Sträuchern, seltener von Nd., häufig. Das ganze Jahr. (Fig. 25.) (Zusammenfließender R.) C. confluens (Fries).

6. Überzüge viel zusammenhängender, häutig, Hymenium zusammenhängend.

7.

Überzüge sehr zart, krümelig bis dünnhäutig, aber nur ein sehr lockeres Hymenium bildend. Sporen breit eif., einseitig zugespitzt, $5-7 \mu$ lg., $3-4 \mu$ dick. Über faulendem Lb., Ästen, besonders über Pteridium aquilinum, nicht selten. S. (Schleimiger R.)

C. mucidum (Schroet.).

7. Kreideweiße, schimmelartige od. dünnhäutige, weit verbreitete 
Überzüge bildend. Sporen fast kuglig, $4-5 \mu$ lg., $3,5-4,5 \mu$ dick. Auf Stümpfen, Stämmen, Holz, über Moosen u. Erde, nicht selten. H. S. (Hollunder-R.) C. sambuei (Pers.).

Überzüge weiß, dünnhäutig, zusammenhängend, oberseits mit flockigen, feinen Warzen, trocken glatt, rissig. Sporen ellipsoidisch, 9-11 $\mu$ lg., $7-8 \mu$ dick. Auf Stümpfen, morscher Rinde, besonders von Lb., auch auf der Erde, seltner. H. W. (Wolliger R.)

c. bombycinum (Somf.).

8. Fk. weiß od. schmutzig weiß, später meist \pm gelb.

Fk. fest aufliegend, wachsartig, glatt, trocken rissig, braun, am Rande weißlich, später ockerfarben. Sporen ellipsoidisch, $6-7 \mu$ lg., $4-5 \mu$ dick. An alten Stümpfen, Holz u. Rinde, besonders von Lb., nicht zu häufig. S. H. (Ockerfarbener R.)

C. ochraceum (Fries).

9. Fk. weißlich locker, mit weit ausgebreitetem, spinnwebartigem, sehr lockerem, schwefelgelbem Myzel. Sporen kuglig, $2-3 \mu$ im Durchm. An Holz u. Rinde von Nd., nicht häufig. H. W. F. (Safrangelber R.)

C. croceum (Kunze).

Überzüge schimmelartig, krümelig, flockig, nur selten mehr filzig-häutig, zuerst schmutzig weiß od. graugrün, später \pm crêmegelb, am Rande meist allmählich verlaufend. Sporen mandel- od. zitronenf., $5-9 \mu$ lg., $2-4 \mu$ dick. An Holz, Rinde, Brettern, Pfählen von Lb. u. Nd., nicht selten. H. (Gekrönter R.)

i0. Rand stets \pm faserig od. strahlig.

C. coronatum (Schroet.).

Rand nicht mit strahligen Hyphen, sondern der ganze Überzug zart körnig, ockergelb, zuerst schmutzig weiß, Hymenium keine geschlossene Decke bildend. Sporen kuglig, mandelf. od. etwas spindelf., gelblich, $10-12 \mu$ lg., $5-7 \mu$ dick. An morschem $\mathrm{Holz}$ u. Rinde von Eichen, Rotbuchen u. andern Lb., ničcht häufig. H. (Gelblicher R.)

C. flavescens (Bonord.).

11. Hymenium auch im Alter glatt bleibend,höchstens etwas rissig. 12.

Hymenium im Alter schwammig löcherig, ockergelb mit rötlichem Stich, im: ganzen krümelig od. häutig, aderig, fest anhaftend. Sporen \pm kuglig, mit Spitzchen, 3-4 $\mu$ im Durchm., sehr fein punktiert. An Lbzweigen, nicht häufig. S. H. (Schweizerischer R.)

C. helveticum (Pers.).

12. Überzüge weit ausgedehnt, fast kreisf., unterseits mit Fasern, glatt, lederbraun. Sporen kuglig, $5-7 \mu$ im Durchm., farblos. An Holz u. Rinde von Lb. u. Nd., nicht selten. S. H. (Lederbrauner R.)

C. alutaceum (Schrad.).

Überzüge ausgebreitet, dünnhäutig, ockergelb bis hellbraun, Hymenium frisch fast wachsartig, trocken leicht zerbrechlich, glatt. Sporen zylindrisch, mit seitlichem Spitzchen am Grunde, $5-7 \mu$ lg., $3-4 \mu$ dick, schwach gelblich. An faulenden Brettern u. Rinde von Kiefern, nicht häufig. H. (Weicher R.)

C. molle (Fries). 
13. Fk. graublau, blau (vgl. auch C. laeve). 16. Fk. rötlich, rosa. 14.

14. Rand faserig strahlig. 15 .

Rand filzig, nicht faserig. Fk. ausgebreitet, häutig, ablösbar, unten zottig, oben kahl, glatt, blaß fleischfarbig, seltener etwas bläulich. Sporen zylindrisch, abgerundet, $9-11 \mu$ lg., $4-5 \mu$ dick. An Brettern, Zweigen von Lb. u. Nd. nicht selten. H. W. (Glatter R.) C. laeve (Pers.).

15. Fk. ausgebreitet, angeheftet, krustig, blaß rosa bis rosenrot. Hymenium bereift, später rissig-runzelig, glatt. Sporen ellipsoidisch, $10-15 \mu$ lg., $4-10 \mu$ dick, rosa. An Zweigen u. Rinde von Lb., auch an größeren Kräuterstengeln, nicht allzu häufig. H. W. (Rosafarbener R.) C. roseum (Pers.).

Fk. dünn, weich fleischig, hell rosen- od. fleischrot, trocken zusammenfallend, papierartig, glänzend. Sporen eif. bis birnf., 9-13 $\mu$ lg., 6-9 $\mu$ dick. An Stümpfen, Ästen, über Nd., Blättern, Moosen, nicht häufig. H. (Blütenfarbener R.)

\section{C. anthochroum (Pers.).}

16. Fk. filzig, ausgebreitet, am Rande wimprig od. filzig, Hymenium glatt, bleigrau bis bläulichgrau. Sporen fast kuglig, stachelig, $10-14 \mu$ lg., $9-10 \mu$ dick. Über Moosen, Lb., Ästen, Humus im Lbwald, selten. H. (Stahlblauer R.)

C. chalybaeum (Pers.).

Fk. zuerst fast rundlich, dann ausgebreitet, filzig, schön blau, am Rande filzig, etwas weißlich, Hymenium wachsartig, warzig. schwach borstig, dann kahl. Sporen unbekannt. Auf faulem Lbholz u. Rinde, auch auf Lb. u. Gras, nicht häufig. F. S. (Meerblauer R.)

C. coeruleum (Schrad.).

5. Gattung: Gloeopeniophora von Höhn. u. Litsch. (Spindelträger).

Fk. ausgebreitet, wachsartig. Im Hymenium zweierlei Cystiden vorhanden, dünnwandige mit öligem Inhalt u. größere, dickwandige, mit rauher Membran. Sporen farblos, glatt.

Fk. aus den Lentizellen hervorbrechend, anfangs klein, dann zusammenfließend, \pm rundlich, \pm fleischrot, blaugrau bereift, gegen den Rand heller u. faserig-mehlig. Sporen zylindrisch, kaum gekrümmt, an einer Seite abgeflacht, mit basalem seitlichen Spitzchen, 8-10 $\mu$ lg., 3-4 $\mu$ dick. An dürren Lbästen, z. B. Erlen, selten. S. H. (Fleckenförmiger S.) G. maculiformis (Fries).

Fk. unregelmäßig ausgebreitet, häutig bis dünn lederig, frisch fast wachsartig, lebhaft fleisch- od. orangerot, nicht bereift, trocken nicht rissig, Rand etwas mehlig od. ganz kurz faserig. Sporen länglich ellipsoidisch, auf einer Seite abgeflacht, $8-10 \mu$ lg., $3-5 \mu$ dick. An Stümpfen, Wurzeln, Zweigen, Rinde u. Holz von Lb., seltener Kiefern, nicht selten. Fast das ganze Jahr. (Fleischroter S.)

G. incarnata (Pers.). 
6. Gattung: Kneiffia Fries (Kneiffie).

Fk. ausgebreitet, wachsartig, locker fädig od. krümelig. Hymenium nur mit eingesenkten, dickwandigen, rauhen Cystiden versehen. Sporen farblos, glatt.!

1. Fk. weiß od. gelblich, seltner trocken od. im Alter sich leicht bräunend.

Fk. von Anfang an bräunlich, ockerfarben, grau od. graubräunlich.

10.

Fk, rötlich bis blutrot.

11.

2. Fk. schimmelartig od. krümelig, Hymenium zwar geschlossen, aber locker.

Fk. fest, häutig bis lederig, wachsartig.

4.

3. Fk. schimmelartig, die Unterlage überziehend, weißlich. Basidientragende Äste büschelig verzweigt, am Ende in eine lange, rauhwarzige Borste auslaufend. Sporen ungefähr kuglig, $2-3 \mu \mathrm{br}$. Über Moosen, Blättern, Ästen, Stümpfen von Lb. u. Nd., besonders in feuchten Wäldern, nicht häufig. H. W. F. (Wollige K.)

K. byssoidea (Pers.).

Fk. sehr zart, krümelig, dem Substrat anhaftend u. allmählich verlaufend, weiß oder schwach gelblich. Sporen breit ellipsoidisch, fast kuglig, $5-7 \mu \mathrm{lg}$., $4-6 \mu$ dick. Das Hymenium ist selten ausgebildet, dafür aber werden lockere Hyphenknäuel

* gebildet, die wie Mehl aussehen u. umgebildete sterile Hymenium. teile darstellen (Hymenialbulbillen, als Aegerita candida bakannt). An faulenden entrindeten Ästen u. Rinde von Lb. u. Nd., die Aegeritaform nicht selten. Fast das ganze Jahr. (Mehlige K.)

\section{K. aegerita (Hoffm.).}

4. Fk. nicht mit radial strahligen Fasern am Rande, höchstens etwas filzig od. fädig-kleiig.

Fk. ausgebreitet, frisch dicht anliegend, fast wachsartig, milchweiß, im Umfang mit weißen, strahligen Fasern, trocken zäh lederartig, glatt, weiß od. etwas gelblich. Sporen zylindrisch abgerundet, $5-6 \mu$ lg., $3 \mu$ dick. Auf alten Stümpfen, Brettern, Pfählen von Kiefern, auch in Gebäuden, häufig. Das ganze Jahr. (Fig. 26.) (Riesen-K.) K. gigantea (Fries).

5. Fk. im Umfang anfangs etwas filzig, niemals radialfasrig, im Alter glatt u. gleichartig.

\begin{tabular}{ll} 
Fk. von Anfang an am Rande glatt u. gleichartig. & 8. \\
\hline
\end{tabular}

6. Hymenium trocken nicht rissig.

Fk. weit ausgebreitet, anfangs filzig, dann weichhäutig, im Umfang fädig-kleiig, später gleichartig, weiß, dann crêmegelb. Hymenium sammetartig, glatt od. schwach unregelmäßig warzig, trocken rissig. Sporen länglich, auf einer Seite etwas eingedrückt, $6-8 \mu$ lg., $3-4 \mu$ dick. Auf morschem Holz u. Rinde von Sträuchern, Lb. u. Nd., nicht selten. S. H. (Crêmefarbene K.) K. cremea (Bres.). 
7. Fk. ausgebreitet, angewachsen, unterseits fasrig, am Rande filzig, später glatt, Hymenium wachsartig, glatt, weißlich bis gelb. Sporen umgekehrt eif., $5-6 \mu$ lg., $2-3 \mu$ dick. Auf morschem $\mathrm{Holz}$ von Lb. u. Nd., ziemlich selten. S. H. (Glatte K.)

K. laevis (Pers.).

Fk. ausgebreitet, häutig, am Rande bereift od. fast fasərig, frisch gelblich, trocken fleischfarben, Hymenium glatt. Sporen zylindrisch, gekrümmt, $6-8 \mu \mathrm{lg} ., 2-3 \mu$ dick. An Holz u. Rinde von Lb. u. Nd., nicht allzu häufig. S. H. (Sammet-K.)

\section{K. velutina (DC.)}

8. Fk. nicht reihenweise übereinander entstehend, einzeln.

Fk. reihenweise übereinander stehend, wachsartig, weich, gelblich, Hymenium kahl, unregelmäßig warzig, weiß bereift, trocken rissig. An Lb. u. Nd., selten. S. H. (Reihen-K.)

\section{K. serialis (Fries).}

9. Fk. ausgebreitet, fest angewachsen, wachsartig, unregelmäßig gestaltet, weiß od. tonfarben, Hymenium glatt, von kurzen Borsten sammethaarig, trocken rissig. Sporen länglich, $6-8 \mu \mathrm{lg}$,, 3-4 $\mu$ dick. An faulem Holz u. Rinde von Lb. u. Nd., nicht allzu häufig. S. H. (Behaarte K.) K. pubera (Fries).

Fk. ausgebreitet, wachsartig häutig, im Umkreis bereift, weiß, später gelbbräunlich, Hymenium meist glatt, seltener etwas warzig, zuletzt gefureht, durch die Cystiden etwas rauh. Sporen zylirdrisch, etwas zusammengedrückt, $10-15 \mu$ lg., $4-5 \mu$ dick. An Holz u. Rinde von Lb. u. Nd., nicht selten. H. (Borstige K.)

K. setigera Fries.

10. Fk. anliegend, frisch fleischig, hellgraubraun, glatt, am Rande schwach zottig, trocken zimmetbraun, lederartig, rissig. Sporen zylindrisch eif., $7-10 \mu$ lg., $3-5 \mu$ dick. An alten Stämmen von Wacholder, nicht häufig. S. (Geglättete K.)

\section{K. laevigata (Fries).}

Fk. anliegend, frisch wachsartig, fleischig, grau od. graubräunlich, mit etwas strahligem Rande, trocken krustig, rissig, graubraun. Sporen ellipsoidisch od. mehr länglich, $3-5 \mu \mathrm{lg}$., $1-2 \mu$ dick. An Holz u. Rinde von Lb. u. Nd., häufig. Das ganze Jahr. (Graue K.)

K. cinerea (Pers.).

11. Rand strahlig faserig.

Rand ganz glatt. Fk. ausgebreitet, angewachsen, starr, fleischfarben, später verblassend, kahl, Hymenium weißlich bereift, glatt, trocken rissig. Sporen zylindrisch, gekrümmt, $8-10 \mu \mathrm{lg}$., $3-4 \mu$ dick. An berindeten Lbästen, nicht selten. H. W. F. (Nackte K.)

K. nuda (Fries).

12. Fk. frisch aufliegend, knorpelig-wachsartig, rundlich, dann aber zusammenfließend, weitverbreitet, fleischfarben bis rötlich-violett, grob höckerig-warzig, trocken am Rande sich ablösend u. umgeschlagen, oben hell fleischrot, unten schwärzlich, glatt. Sporen zylindrisch, abgerundet, meist schwach gebogen, $11-14 \mu \mathrm{lg}$., 
Corticiaceae.

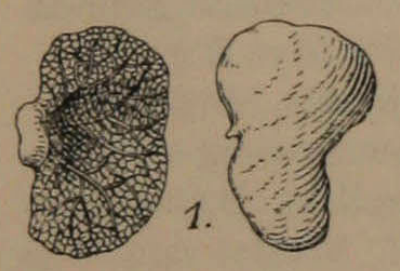

6.

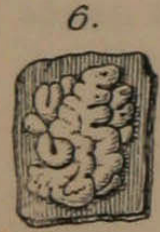

12.
128

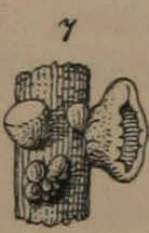

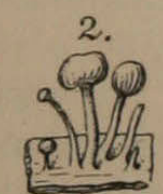

$e^{3}$

(1)

all

8.40

9.

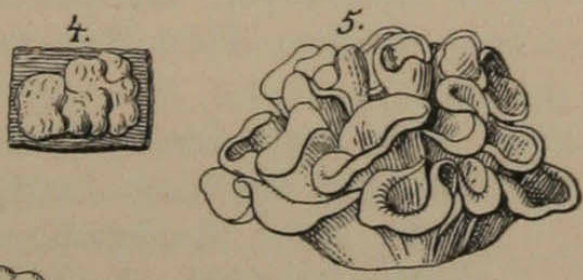

\section{दोंजक है।}

. 350.53

13.

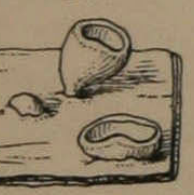

14.
MLa
15.

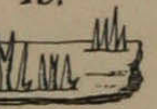

16.

II) $\sin ^{10}$

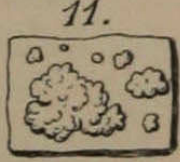<smiles>c1cncc2cccc-2c1</smiles>

(n)

हा हो

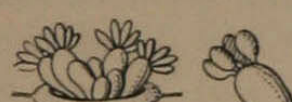
19.

23.

-

24.

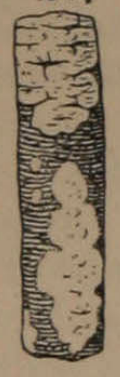

30.

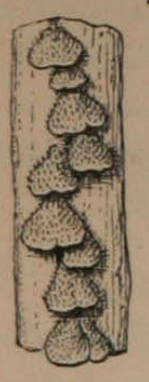

30.

39.
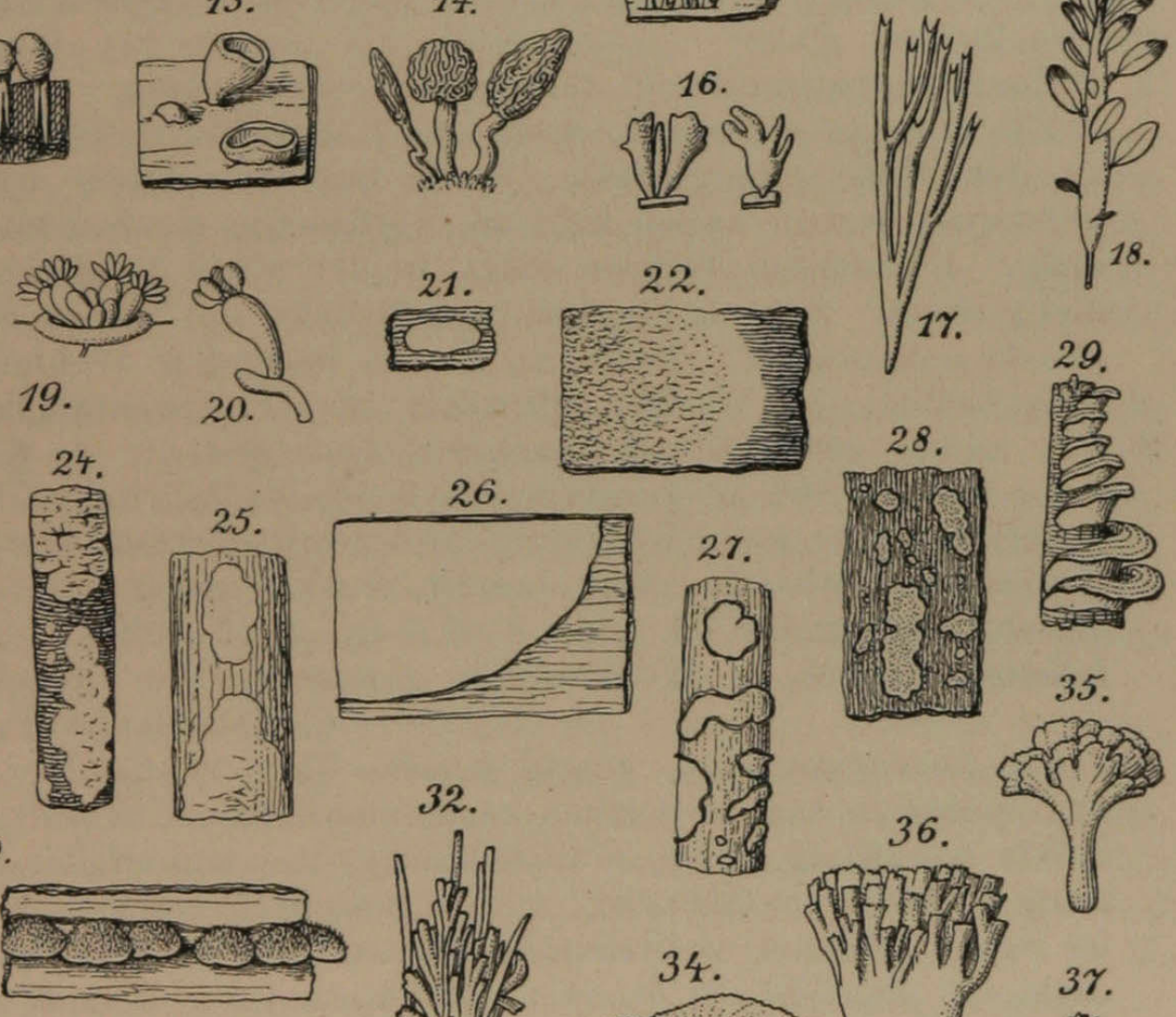

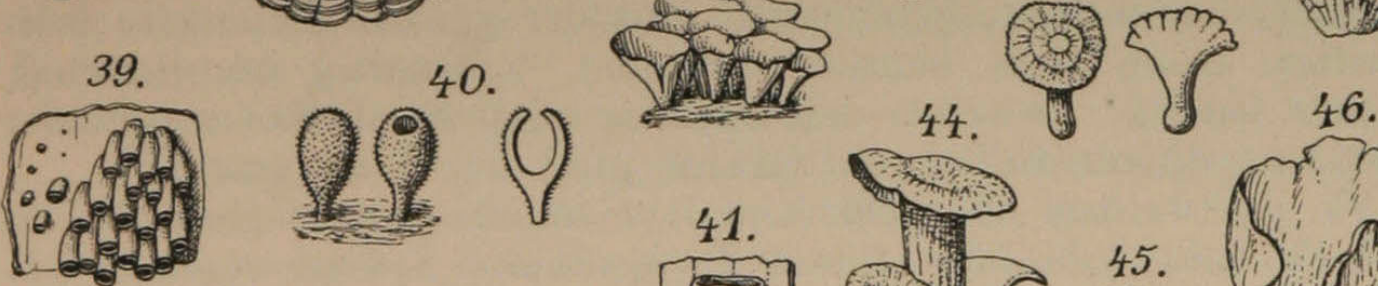

43
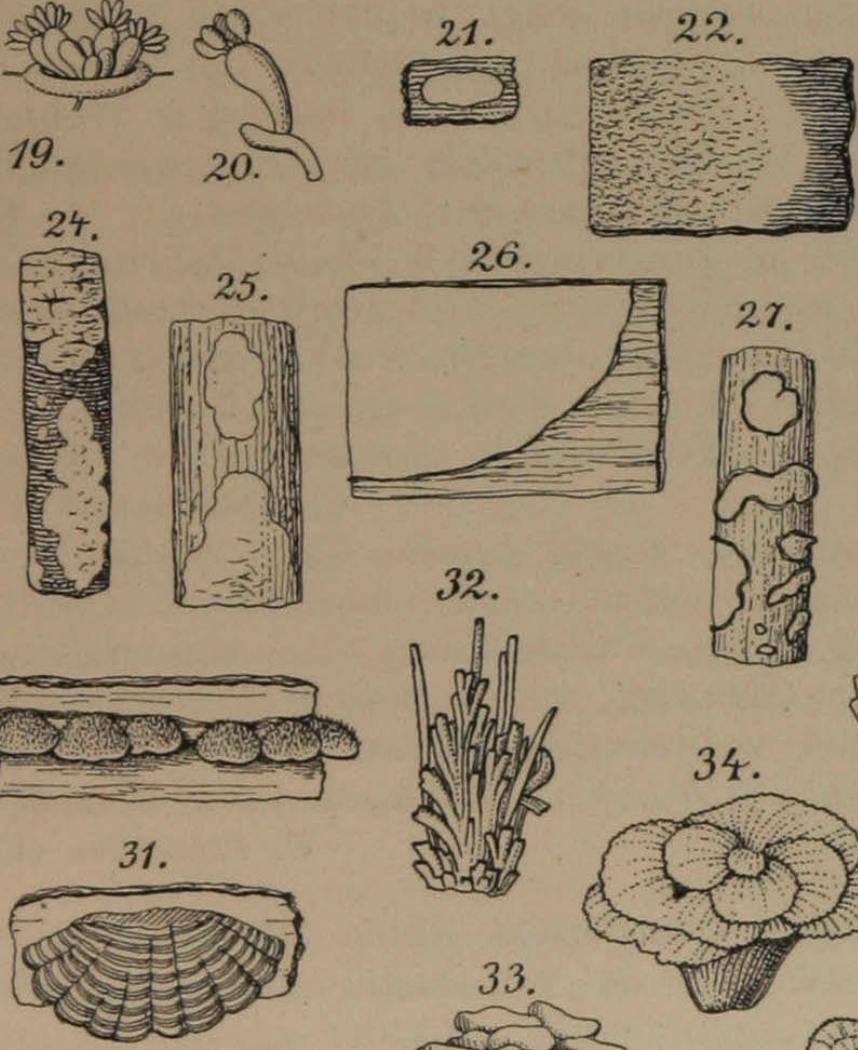

29.

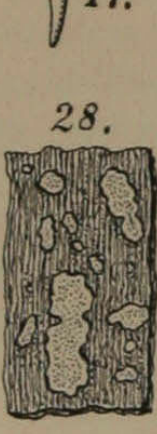

26.

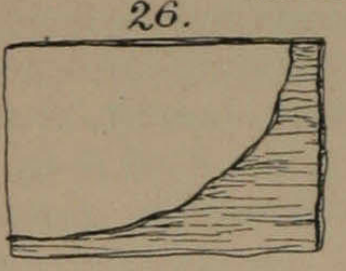

32.

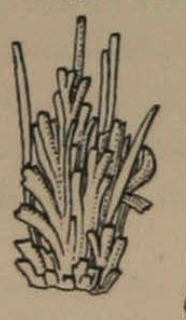

33.
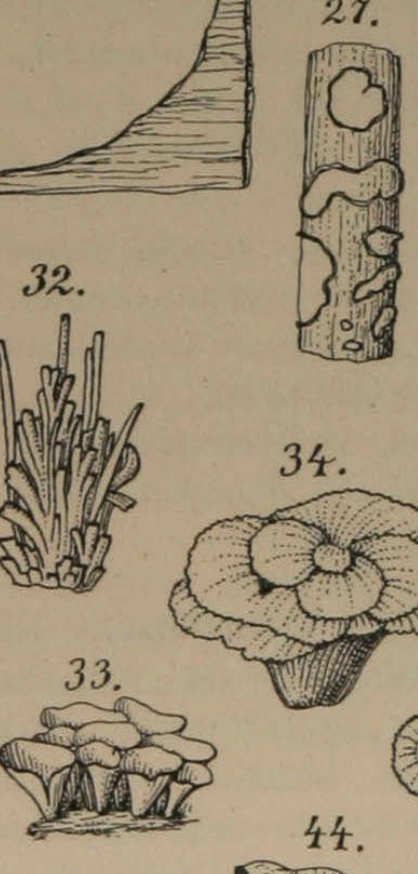

36.

34. Hyong

瑟

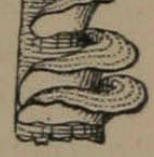

35.

35.

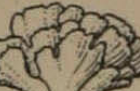


3-4 $\mu$ dick. An berindeten Lbästen, häufig, besonders gemein an Eiche. Fast das ganze Jahr. (Fig. 27.) (Rinden-K.)

K. corticalis (Bull.).

Fk. frisch locker anhängend, unterseits spinnwebeartig u. blutrot, im Umfang fasrig, fleischrot, trocken heller, Hymenium glatt, kahl, fleischrot. Sporen umgekehrt eif., 5-6 $\mu$ lg., $3 \mu$ dick. An faulenden Lb.- u. Ndzweigen, nicht selten. Das ganze Jahr. (Blutrote K.)

K. sanguinea (Fries).

7. Gattung: Cytidia Quél. (Becherrindenschwamm).

Fk. anfangs schüssel- od. scheibenf., später meist flach ausgebreitet, fleischig-wachsartig, etwas gallertig. Hymenium glatt. Sporen farblos, glatt.

1. Hymenium rotbraun od. fleischrot, trocken rissig.

Fk. anfangs anliegend, dann am Rande frei u. schüsself., nur in der Mitte angewachsen, $5-12 \mathrm{~mm}$ br., frisch wachsartig, purpurrot, weich, außen kahl od. weißzottig, trocken hart, lederartig. Hymenium blutrot, glatt, in der Mitte höckerig, trocken nicht rissig. Sporen länglich, am Grunde mit einem Spitzchen, $15-18 \mu$ lg., $4-6{ }^{7} \mu$ dick. An feucht liegenden Weidenzweigen, nicht selten. H. W. F. (Blutroter B.) C. cruenta (Pers.).

2. Fk. zuerst schüssel- od. becherf., fast gestielt, $4-8 \mathrm{~mm}$ br., dann ausgebreitet u. zusammenfließend, wachsartig weich, etwas gallertig, später mehr lederartig, außen mit dichtem, weißem Filz, Hymenium rotbraun, glatt, bereift, trocken rissig. Sporen zylindrisch, abgerundet od. eif., $8-9 \mu$ lg., $2-3 \mu$ dick. An abgefallenen Pappel- u. Weidenästen, zerstreut. | F. (Flockiger B.) C. floceulenta (Fries).

Fk. hervorbrechend, zuerst kreisf., dann schüsself., $2-5 \mathrm{~mm}$ br., später in langen Reihen zusammenfließend, frisch, fleischig, außen weißfilzig, trocken dünnhäutig, zusammenfallend, Hymenium in der Mitte höckerig, dunkel fleischrot, trocken verblassend u. rissig. Sporen zylindrisch, abgerundet, $9-11 \mu$ lg., $2-3 \mu$ dick. An abgefallenen Zweigen von Salicaceen u. Birken, zerstreut. H. W. (Fleischiger B.)

C. sareoides (Fries).

8. Gattung: Aleurodiseus Rabh. (Mehlscheibe).

Fk. becher-, schüssel- od. scheibenf., nur in der Mitte angewachsen, od. weit ausgebreitet $u$. mit der ganzen Unterseite festgeheftet, frisch stets deutlich berandet, wachsartig od. fleischig, trocken lederig. Zwischen den Basidien auch sterile Fäden, seltener Cystiden. Sporen rötlich od. farblos, glatt od. etwas stachlig.

1. Fk. mit weißem od. gelblichem Hymenium. Sporen glatt. 2 .

Fk. mit irgendwie rotem Hymenium. Sporen stachlig od. punktiert.

2. Rand des Fk. dem Substrat fest anhaftend, nicht abgelöst. 3.

Fk. zuerst schüssel- od. scheibenf., später rundlich od. länglich 
ausgebreitet, am Rande dünn. frei u. nackt, nur außen angedrückt weißhaarig, $1-3 \mathrm{~cm} \mathrm{lg.} \mathrm{u.} \mathrm{br.,} \mathrm{lederig.} \mathrm{Hymenium} \mathrm{weiß,}$ blaßgrau od. weißlich lila, oft etwas filzig od. mehlig, glatt, im Alter wenig rissig. Sporen oval od. kuglig, $12-18 \mu$ groß, mit deutlichem basalen Spitzchen, glatt. Auf morscher Eichenrinde, nicht selten. Fast das ganz Jahr. (Schüsself. M.)

A. disciformis (DC.).

3. Fk. unregelmäßig ausgebreitet, dünn, Rand meist allmählich verlaufend, angeheftet. Hymenium rein od. schmutzig weiß, bisweilen etwas gelblich, glatt, im Alter zerrissen, oft fast pulverig. Sporen meist br. eif., $10-13 \mu$ lg., $6-7 \mu$ dick, mit basalem, seitlichem Spitzchen, glatt. Auf Rinde, seltner von Aborn-Arten, aber auch auf anderen Lb., nicht selten. H. W. F. (Ahorn-M.)

A. acerinus (Pers.).

Fk. rund, in der Mitte höckerig, später zusammenfließend, weit ausgebreitet, Rand strahlig, fest aufliegend. Hymenium wachsfarben, später weiß bereift, warzig. Sporen länglich eif., $9-10 \mu$ lg., $3 \mu$ dick, glatt. An berindeten Ästen von Pappeln, seltner Eichen od. Linden, fast das ganze Jahr. (Höckerige M.)

A. polygonius (Pers.).

4. Fk. aus der Rinde hervorbrechend, becherf., später scheibig, dick, lederig zähe u. meist zusammenfließend, außen u. am Rande weiß, filzig. Hymenium scharlachrot, später verblassend ockerfarben bis bräunlichgelb, beim Anfeuchten wieder rot werdend. Sporen br. ellipsoidisch, $20-26 \mu \mathrm{lg}$., $16-20 \mu$ dick, rötlich, fein stachlig. An Zweigen u. Stämmen von Nd., häufig. Das ganze Jahr. (Fig. 28.) (Formlose M.)

A. amorphus (Pers.).

Fk. weit ausgebreitet, wachsartig fleischig, trocken krustig, mit scharfem, schwach weiß gefranstem, wenig abstehendem Rande. Hymenium hell rosen- od. fleischrot, später rötlich gelb, fast glatt, trocken rissig u. verblassend. Sporen ellipsoidisch, $14-18 \mu \mathrm{lg}$., $10-12 \mu$ dick, mit basalem Spitzchen, hellrot, punktiert. Auf Zweigen von Rosen u. Brombeeren, nicht häufig. F. S. H. (Rote M.)

A. aurantius (Pers.).

9. Gattung: Stereum Pers. (Lederschwamm).

Fk. dick, lederartig, oft fast holzig, nur z. T. aufgewachsen, der freie Teil des Randes abstehend, oft dachziegelf, übereinander stehend. Hymenium verschieden gefärbt, bei Druck sich oft verfärbend. Sporen glatt, farblos.

1. Hymenium violett, lila od, rötlich.

Hymenium weiß, gelblich, bräunlich bis dunkelbraun.

2. Hymenium bläulich rot od, orangerot, nicht rein violett. 3 .

Fk. meist mit dem oberen Teil halbkreisf. abstehend, $2-3 \mathrm{~cm}$ br., am Rande wellig, meist in dachziegeligen Rasen, oberseitig filzig-zottig, weiß od. grau, undeutlich gezont. Hymenium meist nach unten gelegen, lebhaft violett, im Alter bräunlich, glatt.

Lindau, Kryptogamenflora. I. 2. Aufl. 
(Bei der var. lilacinum Schroet. die Fk. kleiner u. das Hymenium lebhaft lila.) Sporen zylindrisch, abgerundet, $6-7 \mu \mathrm{lg} ., 2,5 \mu$ dick. Auf Stümpfen u. Stämmen von Lb., häufig. H. W. F. (Fig. 29.) (Purpurfarbener L.)

S. purpureum Pers.

3. Fk. lederig, zähe, weit verbreitet, anfangs becherf., dann mit dem oberen Teil abstehend, wellig verbogen, bis $4 \mathrm{~cm}$ br., häufig zu langen horizontalen Reihen zusammenfließend, außen behaart, weißlich od. bräunlich weiß, Rand gelblich scharf. Hymenium frisch lebhaft orangerot, trocken abblassend bis ockerfarben, glatt. Sporen zylindrisch, abgerundet, $6-8 \mu$ lg., ca. $3 \mu$ dick. An alten Stümpfen, Ästen, Pfählen, Brettern, Kübeln von Lb., gemein. Das ganze Jahr. (Fig. 30.) (Behaarter L.)

\section{S. hirsutum (Willd.).}

Fk. knorpelig lederig, trocken holzig, zuerst schildf., klein, rundlich, mit etwas abstehendem Rande, später meist zu größeren, gefelderten Krusten zusammenfließend, hell purpurrot, trocken rötlichgrau, weiß bereift. Hymenium warzig, violettrötlich od. fleischfarben, trocken grau. Sporen zylindrisch, abgerundet, 6-7 $\mu$ lg., $2-4 \mu$ dick. An abgefallenen Ästen von Nd., besonders Kiefern, zerstreut. Das ganze Jahr. (Kiefern-L.)

4. Hymenium bei Druck blutrot werdend.

$$
\text { S. pini (Fries). }
$$

\section{Hymenium bei Druck sich nicht verfärbend.}

5. Fk. außen zottig behaart.

Fk. angedrückt seidenhaarig, kahl, höchstens in der Jugend schwach behaart.

6. Fk. dünn, lederig, z. T. horizontal abstehend, $2-3 \mathrm{~cm} \mathrm{br.,} \mathrm{oft}$ dachziegelig übereinander stehend, ockerfarben od. gelbbraun, konzentrisch gezont, Rand weiß, scharf, wellig. Hymenium grau, später bräunlich, trocken ockerfarben. Sporen zylindrisch, abgerundet, $6-7 \mu$ lg., $3 \mu$ dick. An Stümpfen u. Stämmen von Nd., besonders an Brettern, häufig, Das ganze Jahr. (Krauser L.)

S. crispum (Pers.).

Fk. lederig, halbiert abstehend, 2-3 cm br., dachziegelig, rostfarben, Rand stumpf, weiß. Hymenium glatt, bräunlich. An alten Lbstümpfen, gern an Buchen u. Eichen, nicht häufig. Das ganze Jahr. (Brauner L.)

S. spadiceum (Pers.).

7. Fk. dünn lederig, ausgebreitet, mit weißem, scharfem, zurückgekrümmtem Rande, außen angedrückt seidenhaarig, etwas streifig. Hymenium graubraun, glatt, schwach bereift. Sporen zylindrisch, 8-10 $\mu$ lg., $3 \mu$ dick. An Stämmen, Ästen, Brettern von Nd., häufig. Fast das ganze Jahr. (Blutiger L.)

S. sanguinolentum (Alb. et. Schw.).

Fk. korkig-holzig, weit ausgebreitet, angewachsen, geschichtet, innen hellbräunlich, außen bräunlich od. fast schwärzlich, in der Jugend schwach behaart, später kahl, runzelig, Rand dick, wulstig, abstehend, meist umgeschlagen, weiß, später braun. 
Hymenium zuerst graubraun, bereift, selten mehr gelblich od. bläulich, glatt, trocken rötlich od. hellbräunlich, rissig. Sporen zylindrisch, abgerundet, $9-12 \mu$ lg., $3-4 \mu$ dick. Auf alten Stümpfen von Lb., häufig. Das ganze Jahr. (Rauher L.)

S. rugosum Pers.

8. Hymenium hellbraun bis dunkelbraun.

Fk. häutig-lederig, fast nierenf., angedrückt, gefranst, weiß, trocken gelbbraun, fein filzig. Hymenium crême- od, strohgelb, streifig, am Rande wei $\beta$, Sporen wurstf., $7-8 \mu \mathrm{lg}$. An trockenen Lbzweigen in Wäldern, selten. S. H. (Fast eckiger L.)

S. subcostatum (Karst.).

9. Hymenium nicht radiärfaserig.

10.

Fk. dick, weich, muschelig, faserig, rasig verwachsen, dunkelbraun, verbleichend, am Rande dunkelbraun, nicht zerrissen. Hymenium radiärfaserig, glatt od. rauh, etwas dunkler braun. An Stämmen von Lb. (Eichen, Ahorn, Pappeln usw.), selten an Kiefern, nicht häufig. H. (Filziger L.)

\section{S. gausa patum (Fries).}

10. Fk. ausgebreitet, korkig, starr, fest angeheftet, ohne bestimmte Gestalt, zusammenhängend, weißlich, trocken gelbbraun. Hymenium blaß gelbbräunlich, jung sammetartig, dann kahl. Sporen länglich od. umgekehrt eif., $4-6 \mu$ lg., $2-3 \mu$ dick. An morschem Lb. u. Nd., selten. S. H. (Riechender L.)

S. odoratum (Fries).

Fk. holzig, höckerig, gedrängt u. zusammenfließend, felderigrissig, undeutlich gerandet, schwarzbraun, unterseits u. am Rande kahl. Hymenium zimmetfarben, verblassend, bereift, gewölbt. Sporen verkehrt eif., $4-5 \mu$ lg., $3-4 \mu$ dick. Auf alten Lbstümpfen (z. B. Eichen), nicht häufig. S. H. (Krustiger L.)

\section{S. frustulosum Fries.}

\section{Gattung: Hymenochaete Lév. (Borstenscheibe).}

Fk. mit fester Mittelgewebsschicht, filzig, lederig, ausgebreitet. Hymenium mit spitzen, dickwandigen Borsten besetzt. Sporen farblos, glatt.

1. Auf Lb.

Fk. dick korkig-lederartig, fast ganz angewachsen, oberseits umbrabraun, schwach filzig, meist dachziegelig übereinander, Rand oben bis $1 \mathrm{~cm}$ abstehend, dickwulstig, stumpf. Mittelgewebe braun. Hymenium dunkel rostbraun, später blasser, ziemlich dicht mit bis $50 \mu$ langen, braunen, dickwandigen Borsten besetzt. An alten Stümpfen von Tanne, Fichte, Knieholz, im Gebirge. Das ganze Jahr. (Tannen-B.) H. abietina (Pers.).

2. Fk. lederig bis korkig.

Fk. filzig verwebte, weit verbreitete, lebhaft zimmetbraune Überzüge bildend, am Rande strahlig. Basidientragende Hyphen büschelig verzweigt, Endauszweigungen lange, spitze, braune 
Borsten bildend. Sporen ellipsoidisch. An abgefallenen Lbzweigen in Wäldern, zerstreut. H. (Zimmetbraune B.)

H. cinnamomea (Pers.).

3. Fk. lederig, dünn, schlaff, ausgebreitet, jung gelbbraun, später kastanienbraun, außen seidenhaarig, später kahl, Rand 0,5-1 cm abstehend u. zurückgeschlagen, goldgelb od. braun. Mittelgewebe gelb. Hymenium rost- bis kastanienbraun, trocken blaß, mit braunen, steifen Borsten besetzt. Sporen zylindrisch, etwas gekrümmt, 3-5 $\mu$ lg., $1 \mu$ dick. An abgefallenen Lbzweigen, nicht selten. Das ganze Jahr. (Tabakbrauner B.)

H. tabacina (Sowerby).

Fk. lederartig korkig, starr, flach, weit verbreitet, meist dachziegelig gehäuft, im oberen Teil $3-4 \mathrm{~cm}$ abstehend, Unterseite umbrabraun, erst filzig, dann kahl, gezont. Rand scharf, zuerst gelb. Mittelgewebe braun. Hymenium rostbraun, gezont, mit scharf zugespitzten, $60-80 \mu$ langen, braunen Borsten besetzt. Auf alten Lbstämmen, Pfählen (z. B. Eiche, Rotbuche), nicht selten. Fast das ganze Jahr. (Fig. 31.) (Rubinroter B.)

H. rubiginosa (Dicks.).

\section{Familie: Thelephoraceae.}

Fk. lederig zähe u. ohne Mittelgewebe od. häutig od. fleischig zähe. Hymenium die Ober- od. Unterseite überziehend. Sporen farblos od. braun, glatt od. stachlig. (In Fällen, wo man zweifelhaft sein könnte, ob ein Pilz hierher od. zu den Corticiaceen zu ziehen ist, entscheidet die Untersuchung der Sporen. Letztere Familie besitzt nie braune, stachlige Sporen.)

\section{Bestimmungsschlüssel der Gattungen.}

A. Fk. lederig-zähe, ausgebreitet od. hutf. halbiert od. lappig zerteilt od. fast hutpilzartig, gestielt od. nicht. Sporen braun, stachlig.

1. Thelephora.

B. Fk. dünn häutig od. fleischig, trichterf., becherf. Sporen glatt.

a) Fk. dünn häutig, winzig klein, becher- od. schüsself. od. fast zylindrisch, Hymenium die Innenseite der Becher überziehend.
I. Fk. dicht gedrängt stehend.
II. Fk. einzeln stehend.
2. Solenia.
3. Cyphella.

b) Fk. fleischig-zähe, trichterf., seltener kreiself., stets gestielt, Hymenium die Außenseite der Trichter überziehend.

4. Craterellus.

1. Gattung: Thelephora Fries (Warzenpilz).

Fk. lederig-zähe, von gleichmäßig durchgehendem Aufbau, ohne besonderes Mittelgewebe, krustig, halbkreisf., hutf., lappig zerteilt, 
gestielt od. ungestielt. Hymenium unterseits od.allseitig, meist mit unregelmäßigen, stumpfen Warzen besetzt, bräunlich od. graubräunlich. Sporen ellipsoidisch, oft eckig, braun, stachlig.

1. Fk. ganz ungestielt.

Fk. irgendwie, wenn auch nur kurz gestielt.

2. Fk. sich irgendwie von der Unterlage abhebend, aber ohne Stiel (Sect. Euthelephora).

Fk. flach, der Unterlage anliegend, fleischig-lederig, oft über $50 \mathrm{~cm}$ weit verbreitet, umbrabraun, im Umfange weißflockig. Hymenium schwach warzig. Sporen rundlich eckig, 8-10 $\mu$ lg., $6-8 \mu$ dick. (Sect. Hypochniopsis.) Auf der Erde in Wäldern, auch Moos, Ästchen, Lb. u. Nd. überziehend, nicht selten, namentlich im Vorgebirgswald. S. H. (Pinsel-W.)

T. penieillata (Pers.).

3. Fk. am Rande nicht weißlich gefranst, höchstens wollig zottig. 4 .

Fk. weit verbreitet, kriechend, im Umfange, oft auch von der Mitte aus in lappenartige, nach oben verbreiterte, niederliegende od. etwas aufsteigende Zweige gespalten, deren Enden am Rande kammartig weißlich gefranst sind. Hymenium unterseitig, graubraun, unregelmäßig stumpf-warzig. Geruch dumpfig, unangenehm. Auf dem Boden in Wäldern, zerstreut. H. (Fig. 32.) (Kammartiger W.)

T. eristata (Pers.).

4. Ausschließlich in trockenen Ndwäldern, Heiden (sehr selten auch einmal im trockenen Lbwald am Rande) vorkommend. 5.

Fk. rasig-dachziegelig übereinander stehend, fest stielartig zusammengezogen am Grunde u. zusammenfließend, oberseits gelblichweiß, dann rotbraun, wollig-zottig, am Rande erweitert. Hymenium unterseits, warzig,! bräunlich. In Lbwäldern am Boden, über Ästen u. Lb., besonders in Buchenwäldern, nicht häufig. H. (Fig. 33.) (Endivien-W.) T. intybacea Pers.

5. Fk. schief aufrecht, muschelf., am Grunde stielartig zusammengezogen, bis $5 \mathrm{~cm}$ hoch, in rundlichen, fast trichterf. Rasen zusammenstehend, erst weich, dann hart, fast holzig, oberseits dunkelbraun, rauh striegelhaarig u. zottig, am Rande ebenso. Hymenium unterseitig, graubraun, unregelmäßig warzig u. faltig. Sporen rundlich eckig, stachlig, $7-10 \mu$ lg., $6-8 \mu$ dick. Auf der Erde, über Ästen, Nd., Moosen in Ndwäldern u. Heiden, häufig. S. H. (Fig. 34.) (Erd-W.) T. terrestris Ehrh.

Fk. weit ausgebreitet, meist ganz od. im oberen Teil lappenartig, oft halbkreisf. horizontal abstehend u. dachziegelig-rasig, oberseits dunkelbraun, grob faserig-schuppig, am Rande scharf, weißlich, dann dunkelbraun, faserig. Hymenium unterseitig, graubraun, stumpf warzig. Sporen rundlich eckig, stachlig, $7-9 \mu$ lg., $6-7 \mu$ dick. Auf der Erde, über Zweigen, oft an jungen Kiefernstämmchen hinaufwachsend u. sie erstickend, häufig. S. H. (Lappiger W.)

T. laciniata Pers.

6. Stamm der Fk. vielfach verzweigt, sich in zahlreiche Lappen 
auflösend, die allseitig vom Hymenium bedeckt sind (Sect. Merisma).

Fk. zentral gestielt, hutartig, Hymenium nur außen (Sect. Scyphopilus).

7. Fk. stets mit aufrechtem Stamm, nicht krustig ergossen. 8.

Fk. weit ergossen, weich, weiß, trocken gelblich, in zahlreiche, flach niederliegende od. halb abstehende, schmale, flache, bandod. keulenf. Lappen mit breiten, abgestutzten Enden geteilt. Hymenium unterseitig, hell rötlich braun. Geruch widerlich. In schattigen Lbwäldern, nicht häufig. S. H. (Ekelerregender W.) T. fastidiosa (Pers.).

8. Letzte Auszweichungen der Fk. stets flach.

Fk. mit knolligem Stiel, unregelmäßig verzweigt, lederartigweich, rotbraun, Zweige stielrund, nach oben dünner, weißlich bereift, mit scharfer weißlicher Spitze. Kleiner als die Arten unter 9. Geruchlos. Auf der Erde in Ndwäldern, selten. H. (Stielrunder W.)

T. clavularis Fries.

9. St. dick, stammartig od. vor den Verzweigungen fast ganz verschwindend.

10.

St. gleichdick, zottig, braun, scharf abgesetzt, oben in gefranste, hell rostbraune, später dunkler werdende Lappen geteilt, die an den Enden weißlich gezähnt od. in unregelmäßige, aufrechte, verästelte, glatte Zweige geteilt sind. In Lbwäldern, meist am Grunde der Stämme, nicht häufig. S. (Fig. 35). (Blütenkopf-W.)

T. anthocephala (Bull.).

10. St. verhältnismäßig dick, stammartig, oben nicht abgesetzt, sondern sofort in die bandf., $2-4 \mathrm{~cm}$ br., dicht stehenden, braunen, aufrechten Äste übergehend, die an der Spitze weiß gefranst sind. Im ganzen $4-7 \mathrm{~cm}$ hoch, weich lederig, zähe. Geruch widerlich. Hauptsächlich in Kiefernwäldern auf der Erde, häufig. S. H. (Fig. 36.) (Handf.W.) T. palmata (Scop.).

St. fast verschwindend, dann der Fk. von der Basis an korallenartig verzweigt, weich lederig, graubraun bis braunschwarz, Äste aufrecht, gedrängt, viel schmaler als bei vor., die äußeren stufenweise kleiner, an der Spitze fransig-zähnig, nach oben etwas verdickt, zusammengedrückt. Geruchlos. Auf der Erde in feuchten Wäldern, zerstreut. H. (Fig. 37.) (KorallenW.) T. coralloides Fries.

11. Rand des Hutes ganz.

St. aufrecht, bis $1,5 \mathrm{~cm}$ dick, Hut $2-4 \mathrm{~cm}$ br., trichterf., lederig, am Rande oft in mehrere Lappen geteilt, jedenfalls nie ganzrandig, braun, etwas gezont, zottig-schuppig, im Alter glatt, am Rande dünn u. blasser. Hymenium graubraun, schwach runzelig. Sporen unregelmäßig eckig, $8-10 \mu$ lg., $6-7 \mu$ dick. In Kieferuwäldern u. auf Heiden, auf dem Sandboden od. zwischen Gras, häufig. S. H. (Fig. 38.) (Muskatbrauner W.)

T. caryophyllea (Schaeff.). 
12. Hut nicht strahlig streifig.

13.

St. kurz, Hut trichterf., weich lederig, rostfarbig, kleinhöckerig, etwas schuppig, stets deutlich strahlig streifig. Hymenium rostbraun, schwach bereift, streifig. Auf der Erde in trockenen Ndwäldern, häufig. H. (Strahliger W.) T. radiata (Holmsk.).

13. St. sehr kurz, am Grunde zottig, rasig gehäuft. Hut korkig lederig, trichterf., schuppig, blaß rötlichbraun. Hymenium gerippt, borstig, blaß. Sporen unregelmäßig kuglig, $8 \mu \mathrm{im}$ Durchm. Auf der Erde in Buchenwäldern, nicht häufig. S. H. (Blasser W.)

T. pallida Pers.

St. kurz, zottig, Hut niedergedrückt, häutig lederig, kahl, blaß bräunlich, Rand wellig. Hymenium gerippt, borstig, blaß. Sporen ellipsoidisch, $4-5 \mu \mathrm{lg} ., 2-3 \mu$ dick. Auf Sandboden in Heiden, zerstreut. H. (Welliger W.) T. undulata (Pers.).

\section{Gattung: Solenia Hoffm. (Zwergröhre).}

Fk. sehr klein, becher- od. röhrenf., halbkuglig, trocken geschlossen u. dann kuglig od. zylindrisch, sehr dicht gedrängt stehend, außen meist haarig, Hymenium innen, glatt. Sporen farblos, glatt. Die Fk. stehen so dicht zusammen, daß sie eine Kruste, die trocken rissig aussieht, $\mathrm{zu}$ bilden scheinen.

1. Fk. weiß.

Fk. braun od. bräunlichgrau.

2. Fk. zylindrisch, röhrenf., $2-6 \mathrm{~mm}$ lg., in dicht gedrängten, mehrere cm langen Überzügen zusammenstehend, weiß, trocken etwas bräunlich werdend, filzig-seidenhaarig. In Wäldern auf feucht liegendem Holz von Betula, Abies usw., nicht häufig. Das ganze Jahr. (Fig. 39.) (Büschlige Z.)

S. fasciculata Pers.

Fk. zylindrisch, röhrenf., nicht so dicht stehend, zart, weiß, kahl. Auf faulem Holz in Wäldern, selten. Fast das ganze Jahr. (Weiße Z.)

3. Fk. zylindrisch od. röhrenf.

S. candida Hoffm.

Fk. halbkuglig, trocken kuglig.

4. Fk. dicht stehend, eine weit verbreitete Kruste bildend, zylindrisch, ca. $1 \mathrm{~mm}$ hoch, am Grunde von filzigen Haaren umgeben, außen mit ockerfarbenen, krausen Haaren besetzt. Sporen zylindrisch, abgerundet, $11-13 \mu$ lg., $3-4 \mu$ dick. An abgefallenen Zweigen von Lb., besonders Weide, Pappel, Erle, nicht selten. Fast das ganze Jahr. (Löcherige Z.)

S. poriiformis (Yers.).

Fk. röhrig, 1-2 mm lg., weitläufiger stehend, trocken geschlossen, außen mit zottigen, ockerfarbigen Haaren, an der Mündung heller. Sporen ellipsoidisch, $6-7 \mu$ lg., $4-5 \mu$ dick. An abgefallenen Lbästen, seltener als vor. H. W. (Ockerbraune Z.)

$$
\text { S. ochracea Hoffm. }
$$

5. Fk. fast ungestielt, feucht halbkugelig mit eingebogenem Rande, trocken kuglig, geschlossen, $1 / 2 \mathrm{~mm}$ br., sehr dicht krustig stehend, außen mit hellbraunen zottigen Haaren bedeckt. Sporen ellipso- 
idisch, $6 \mu$ lg., $4 \mu$ dick. Auf abgefallenen Lbästen, auf dem Hirnschnitt von Stämmen, besonders Birke, Buche usw., häufig. Fast das ganze Jahr. (Fig. 40.) (Unregelmäßige Z.)

\section{S. anomala (Pers.).}

Fk. gestielt, oben halbkugelig, trocken kuglig, in rundlichen gewölbten Rasen od, ausgebreiteten Krusten dicht zusammenstehend, am Grunde braunfilzig, $0,8-1 \mathrm{~mm}$ hoch, außen mit krausen, filzigen, braunen Haaren bedeckt. Sporen zylindrisch, abgerundet, $8-10 \mu$ lg., $2-3 \mu$ dick. Auf abgefallenen Lbästen, seltener als vor. S. H. (Gestielte Z.) S. stipitata Fuck.

\section{Gattung: Cyphella Fries (Zwergbecher).}

Fk. sehr klein, sitzend od, gestielt, becher-, schüssel-, glockenod. trichterf., einzeln stehend, außen glatt od. behaart, Hymenium innen, in der Jugend glatt. Sporen farblos, glatt.

1. Fk. außen deutlich behaart od. seltener flockig.

Fk. ganz kahl, gestielt, becher-, trichter- od. füllhornf., $2-6 \mathrm{~mm}$ lg., $2 \mathrm{~mm}$ br., weißlich, trocken gelblich bis schwefelgelb. Sporen eif., $8-11 \mu$ lg., $5-6 \mu$ dick. Auf faulenden Kräuterstengeln, besonders von Brennesseln, nicht selten. S. H. (Fig. 41.) (Schalenf. Z.) C. capula (Holmsk.).

2. Fk. gesellig, weiß, od. trocken grau, niemals dunkler.

Fk. braun bis schwärzlich, häutig, papierartig, fingerhutf., St. $2-4 \mathrm{~mm} \mathrm{lg}$., Hut hängend, $10-12 \mathrm{~mm}$ lg., $5-8 \mathrm{~mm}$ br., außen mit angedrückten Längsfasern. Hymenium weiß, später grau. Sporen kuglig, $12 \mu \mathrm{im}$ Durchm. Auf Kiefernrinde in Wäldern der Vorberge, selten. H. (Fig. 42.) (Fingerhutf. Z.)

C. digitalis (Alb. et Schw.).

3. Fk. sitzend od. sehr kurz gestielt.

Fk. mit $6 \mathrm{~mm}$ lg. St., häutig, trichterf., $1 \mathrm{~mm}$ im Durchm., in der Mitte mit erhabenem stumpfen Höcker, reinweiß, außen flaumig behaart, trocken gelblich. Auf faulenden Kiefernzapfen feuchter Wälder, selten. S. (Höckeriger Z.)

$$
\text { C. gibba (Alb. et. Schw.) }
$$

4. An Zweigen, Stämmen, Holz.

An Moosen, Stengeln, Grashalmen, Blättern.

5. Fk. kuglig, dann glockenf. od. etwas gewunden, oft schief, sitzend, häutig, blaßgrau, außen zart weißflockig. Sporen eif.-keulig, 10-12 $\mu$ lg., 4-6 $\mu$ dick. An Stämmen von Lonicera, Symphoricarpus, auch an Kiefernholz, selten. H. (Blaßgrauer Z.)

C. griseopallida Weinm.

Fk. knorpelig, zähe, halbkuglig mit eingebogenem Rand, trocken kuglig, sitzend, 1-2 mm br., außen weißzottig. Hymenium graubraun od. violettbraun. Sporen eif., am Grunde spitzig, 13-16 $\mu$ lg., 10-12 $\mu$ dick. An Lbzweigen, nicht häufig. Das ganze Jahr. (Fig. 43.) (Weißvioletter Z.) C. alboviolescens (Alb. et Schw.). 
6. Über Moosen.

An Stengeln, Halmen, Blättern.

7. Fk. weich u. dünnhäutig, flach schüssel- od. becherf., später tellerf. flach, 2-10 mm im Durchm., an einem Punkte angewachsen, sitzend, schneeweiß, trocken grau, außen fein seidenhaarig. Hymenium zuletzt flach runzelig, trocken glatt. Sporen eif., am Grunde zugespitzt, $9 \mu$ lg., $5 \mu$ dick. Über' größeren Moosen in Wäldern, auf Wiesen u. Sümpfen, seltner auf dem Boden, nicht selten. H. W. F. (Moosliebender Z.)

C. muscigena (Pers.).

Fk. häutig, becherf., meist abwärts hängend, sitzend od. sehr kurz gestielt, $1-5 \mathrm{~mm}$ im Durchm., außen weißlich od. grau, trocken weiß, fädig streifig, am Rande feinhaarig. Hymenium glatt, weiß, dann bräunlich bestäubt. Sporen fast kuglig, $6-7 \mu$ lg., 5-6 $\mu$ dick, leicht bräunlich. Auf Moosen in Wäldern, nicht häufig. H. (Moosbewohnender Z.) $\quad$ C. muscicola Fries.

8. Fk. krug-, becher- od. glockenf.

Fk. herdig, schüsself. mit eingebogenem Rand, trocken kuglig, ca. $5 \mathrm{~mm}$ br., sitzend, rein weiß, mit langen Haaren besetzt. Hymenium glatt, weiß. Sporen ellipsoidisch, innen abgeflacht, $10-12 \mu \mathrm{lg}$., $8-9 \mu$ dick. Auf abgestorbenen Kräuterstengeln, nicht selten. H. W. F. (Zottiger Z.) C. villosa Karst.

9. Fk. häutig, sehr zart, weiß, kuglig, sitzend, später glockig, 0,5 bis $1 \mathrm{~mm}$ br., dicht behaart. Auf Rotbuchenblättern, selten. S. H. (Buchen-Z.) C. faginea Desm.

Fk. häutig, sehr klein, krug- od. becherf., sitzend, gebuchtet, weiß, zottig. Sporen kuglig bis eif. An Grashalmen, bisweilen auch an Kräuterstengeln, nicht häufig. S. (Goldbachs Z.)

\section{Goldbachii Weinm.}

\section{Gattung: Craterellus Pers. (Trompetenpilz).}

Fk. fleischig bis fleischig lederig, trichterf., seltener kreiself., gestielt. Hymenium außenseitig, kahl, glatt od. mit Längsrunzeln. Sporen farblos, glatt.

1. Hymenium runzelig. Sporenpulver hellgelblich (Sect. Cantha rellopsis).

Hymenium glatt od. schwach runzelig. Sporenpulver weiß (Sect. Eucraterellus).

Fk. dünnfleischig, zähe, röhrenf., bis zum Grunde hohl, dann oben erweitert, trompeten- od. füllhornartig, $5-10 \mathrm{~cm}$ hoch (bisweilen bis $25 \mathrm{~cm}$ ), mit dünnem, später welligem Rand, innen rauchgrau bis schwarz, trocken graubräunlich. Hymenium außenseitig, zuerst glatt, dann mit Runzeln. Sporen eif., innen abgeflacht, $11-13 \mu$ lg., $6-7 \mu$ dick. Auf der Erde, meist herdenweise, in Lb.-, besonders Rotbuchenwäldern, häufig. S. H. (Fig. 44.) (Totentrompete.)

c. cornucopioides (L.).

2. Fk. kreiself., d. h. der Fk. fast bis zum Scheitel voll, nicht bis zum Grunde hohl. 
Fk. bis zum Grunde röhrig hohl, 5-7 em hoch, oben trichterf. erweitert, fleischig-häutig, mit dünnem, welligem Rande, oben rauchgrau. St. glatt, lebhaft gelb. Hymenium gelb, glatt, später mit stumpfen, gewundenen u. verzweigten Längsfalten. Sporen eif., $8-9 \mu$ lg., $6-7 \mu$ dick. Geruch fast erdbeerartig. Zwischen Moos auf Erde, in Lbwäldern, häufig. S. (Gelblicher T.)

c. lutescens (Pers.).

3. Fk. gestielt, häutig lederig, $2-4 \mathrm{~cm}$ hoch, St. voll od. höchstens im oberen Teil röhrig, glatt, graubraun. Hut anfangs kreisf., wenig eingesunken in der Mitte, später trichterf., mit scharfem, oft stark welligem Rande, graubräunlich, glatt, später schwach runzelig. Sporen eif., $9-11 \mu \mathrm{lg} ., 6-7 \mu$ dick. In Lbwäldern auf der Erde zwischen Moos u. Lb., nicht selten. S. (Fig. 45.) (Krauser T.)

C. crispus (Sowerby).

Fk. fleischig, kreiself., voll, im Alter in der Mitte trichterf. eingedrückt, bis $9 \mathrm{~cm}$ hoch, mit scharfem Rand u. vollem, unten verdünntem St., anfangs violett, später ockerfarben, filzig-rauh. Hymenium anfangs violett od. purpurfarben, später braun, aderigrunzelig. Sporen eif., $9-12 \mu$ lg., $4-5 \mu$ dick, hellgelblich. Auf der Erde zwischen Moos in feuchten Ndwäldern, besonders im Vorgebirge, nicht selten. S. (Fig. 46.) (Keuliger T.)

$$
\text { c. clavatus (Pers.). }
$$

\section{Familie: Clavariaceae.}

Fk. fleischig od. zähe, zylindrisch, keulenf., unverzweigt od. \pm reich korallenartig verzweigt, mit stielrunden od. wenig zusammengedrückten Ästen od. seltener Fk. blattartig flach $u$. vielfacheWindungen bildend. Hymenium die Fk. od. deren Äste allseitig umkleidend. Basidien mit 2 od. 4 Sterigmen. Sporen farblos od. gelbbraun, glatt.

Bestimmungsschlüssel der Gattungen.

A. Fk. keulig od. zylindrisch, verzweigt od. nicht, stielrund, ebenso die Äste.

a) Hymeniumtragender Teil des Fk. stets keulig ungeteilt, klein, St. fädig.

I. Fk. mit fädigem Stielchen u. dickem Keulchen, meist nicht sich aus Sklerotien entwickelnd. Basidien mit 2 Sterigmen.

1. Pistillaria.

II. Fk. mit langem fädigem St. u. fast fadenf. Keule, sich meist aus Sklerotien entwickelnd. Basidien mit 4 Sterigmen.

\section{Typhula.}

b) Hymeniumtragender Teil des Fk. keulig, aber dann dick, fleischig u. groß, häufiger verzweigt, korallenartig verästelt, stets immer groß. 
I. Sporenpulver weiß.

1. Basidien mit 2 Sterigmen. Sporen mit dicker fester Membran.

2. Basidien mit 4 Sterigmen. Sporen mit dünner Membran.

II. Sporenpulver ockerbraun.

3. Clavulina.

4. Clavaria.

5. Clavariella.

B. Fk. dick gestielt, mit flachen, blattartigen, krausen, durcheinander gewundenen Zweigen.

6. Sparassis.

\section{Gattung: Pistillaria Fries (Mörserkeule).}

Fk. mit niedrigem, fädigem St. u. dicker kleiner Keule, die vom Hymenium bekleidet wird. Basidien mit 2 Sterigmen. Sklerotien nur gelegentlich vorhanden.

1. Fk. weiß od. gelblich.

Fk. gesellig, mit fadenförmigem St. u. scharf abgesetzter, ellipsoidischer, rosenroter Keule, im ganzen $2-3 \mathrm{~mm}$ hoch, trocken hornartig, erst dunkler, dann blasser werdend. Sporen länglich, $9-10 \mu$ lg., $5-6 \mu$ dick. Bisweilen entspringt der Fk. einem Sklerotium. An trockenen Kräuterstengeln u. Blättern, nicht selten. S. H. (Fig. 47.) (Schimmernde M.) P. micans (Pers.).

2. Fk. weiß, bereift, verkehrt eif., länglich oder rundlich, mit leicht flockigem, an der Basis schwach verdicktem Stielchen. Auf Stengeln, Zweigen, Blättern, selten. S. H. (Ungleiche M.)

P. inaequalis Lasch.

Fk. weiß, trocken gelblich, sehr zart, $2-4 \mathrm{~mm}$ hoch, Keule vom St. nicht scharf abgesetzt, aber verdickt, am Scheitel abgerundet. An faulenden Blättern u. Stengeln, selten. F. S. H. (Zwerg-M.)

P. pusilla Fries.

\section{Gattung: Typhula Fries (Fadenkeulchen).}

Fk. fädig, bisweilen etwas verzweigt, Keule walzig, wenig abgesetzt. Basidien mit 4 Strrigmen. Sklerotien fast immer vorhanden.

1. Keule gelblich, bräunlich od. grünlich, niemals weiß bleibend. 2.

Keule weiß u. so bleibend.

2. Nicht aus einem Skerotium entspringend.

Aus einem Sklerotium entspringend.

3. Fk. 1-2 cm hoch, St. fädig, weiß, glatt, Keule länglich, fast lineal, gelblich, trocken hellrötlich. An faulenden Farnwedeln in Gebirgswäldern, selten. H. (Todes F.)

T. Todei Fries.

Fk. honiggelb, unverzweigt, kahl, mit länglicher Keule u. blasserem St. Zwischen Moosen in Wäldern, selten. H. (Gelbliches F.)

T. gilva Lasch.

3. Keule gelblich od. bräunlich.

4.

Fk. 5-6 mm hoch, anfangs grünlichweiß, dann mit dunkelolivgrauer Keule u. braunem, schwach behaartem St. Aus einem braunen, linsenf., in der Mitte eingedrückten Sklerotium 
hervorgehend. Auf Stengeln, Blattstielen, Blättern von Walnuß, Wolfsmilch, Umbelliferen, selten. S. (Grünliches F.)

\section{T. virescens (Niessl).}

4. Keule von Anfang an bräunlich.

Keule erst weißlich, dann gelblich od. bräunlich werdend. 6 .

5. Fk. fädig, 4-6 cm lg., ockerfarben, später dunkler, Keule undeutlich abgesetzt, ca. $1 \mathrm{~cm} \mathrm{lg.,} \mathrm{nach} \mathrm{oben} \mathrm{verjüngt.} \mathrm{Sklerotium}$ rund, etwa $2 \mathrm{~mm}$ im Durchm., flach gewölbt, später in der Mitte niedergedrückt, außen zuerst weiß, dann braun u. endlich schwarz, innen weiß. Gesellig zwischen faulenden Blättern, nicht selten. Fk. im H., Sklerotien schon im F. (Linsenwurzeliges F.)

T. phacorrhiza (Reichard).

Fk. ebenso. Sklerotium länglich keulig, später seitlich zusammengedrückt, dreieckig, herzf., außen weiß, später braun, innen weiß. Gesellig zwischen faulenden Blättern, nicht selten. Fk. im H., Sklerotien schon im F. (Flachgedrücktes F.)

T. complanata (de Bary).

6. Fk. mit fädigem, bereiftem,-dann kahlem St., Keule zylindrisch, wenig abgesetzt, weißlich, bereift, dann bräunlich. Sklerotium schwärzlich, schwach zusammengedrückt, runzelig. An dürren Brombeerranken, selten. H. (Laschs F.)

T. Laschii Rabenh.

Fk. 1-2 cm hoch, Keule wenig vom St. abgesetzt, länglich, zuerst weißlich, dann gelblich, nach unten bräunlich. Sklerotium kuglig od. etwas unregelmäßig, \pm flach, außen gelbbraun, dann schwärzlich. An faulenden Stengeln von Mulgedium alpinum u. Adenostyles albifrons, im Gebirge. S. (Sklerotienartiges F.)

T. sclerotioides (Pers.).

7. St. weiß.

Fk. $1-4 \mathrm{~cm}$ hoch, häufig verzweigt, St. bis $3 \mathrm{~cm} \mathrm{lg.,} \mathrm{fast}$ hornartig, ganz od. im unteren Teil rotbraun, Keule deutlich abgesetzt, weiß, länglich, doppelt so dick wie der St. Sklerotium länglich, zuerst eingewachsen, dann frei, rotbraun, dann schwärzlich, runzelig. Auf faulenden Blattstielen u. Kräuterstengeln, zerstreut. S. H. (Fig. 48.) (Rotfüßiges F.)

T. erythropus (Pers.).

8. St. irgendwie behaart.

St. von Anfang an kahl.

9. St. in der ganzen Länge fein flaumhaarig.

10.

Fk. 1-2 cm hoch, St. weiß od. gelblichweiß, nur am Grunde zottig behaart, Keule 1-2 mm lg., zylindrisch, nach oben verjüngt. Sklerotium kuglig, anfangs weiß, zuletzt dunkelbraun. An faulenden Blättern u. Stengeln, häufig. Fk. im H., Sklerotien H. W. F. (Fig. 49.) (Variierendes F.) T. variabilis Riess.

10. Fk. $1-2 \mathrm{~cm}$ hoch, St. schlaff, weiß, fein flaumhaarig, Keule scharf abgesetzt, eif., $1-2 \mathrm{~mm}$ lg., meist etwas zusammengedrückt. Sklerotium eingewachsen, länglich od. rundlich, 
dunkelbraun. Auf faulenden Blättern u. Stengeln, zerstreut. H. (Fig. 50.) (Rundliches F.) T. gyrans (Batsch).

Fk. 5-6 mm hoch, St. schwach behaart, Keule abgesetzt, länglich. Sklerotium linsenf., gelb, durchscheinend. An Stengeln von Wolfsmilch-Arten, selten. H. (Wolfsmilch-F.)

\section{T. euphorbiae (Fuck.).}

11. Aus einem Sklerotium entspringend.

Nicht aus einem Sklerotium entspringend.

12. Fk. 3-6 $\mathrm{mm}$ hoch, St. $2-5 \mathrm{~mm}$ lg., Keule bauchig, schwach zusammengedrückt, scharf abgesetzt, hohl, $1 \mathrm{~mm}$ lg. Sklerotien zuerst ganz eingewachsen, flach, $1 \mathrm{~mm}$ groß, zuletzt dunkelbraun. Auf faulenden Blättern, seltner Stengeln, zerstreut. Fk. im H., Sklerotien im W. F. S. (Eif. F.)

T. ovata (Pers.).

Fk. $2-9 \mathrm{~mm}$ hoch, St. fädig, Keule zylindrisch, stumpf. Sklerotium rundlich, blaß, glatt. Zwischen Moosen, seltener auch an Blättern auf feuchten Wiesen. H. (Moosbewohnendes F.)

T. muscicola (Pers.).

13. Fk. $5-7 \mathrm{~mm}$ hoch, St. sehr kurz, Keule verdickt, schwach zusammengedrückt. Auf trockenen Farnwedeln, selten. H. (Unbedeutendes F.) T. quisquiliaris (Fries).

Fk. $2-3 \mathrm{~mm}$ hoch, frisch durchscheinend, trocken hornartig, gelblich, Keule schmal eif. Auf faulenden Grasblättern, selten. F. S. (Halmbewohnendes F.)

T. culmigena (Fries).

3. Gattung: Clavulina Schroet. (Keulchenpilz).

Fk. fleischig, zerbrechlich, unverzweigt od. it korallenartig verästelt. Hymeniumtragender Teil nicht scharf vom Stteil abgegrenzt. Basidien mit 2 Sterigmen. Sporen farblos, groß, fast kuglig, mit derber Membran, daher auch bei trockenen Exemplaren sehr auffällig. Sämtlich eßbar, aber wegen der Kleinheit wenig lohnend. 1. Fk. frisch weiß.

Fk. frisch grau, zerbrechlich, fleischig, bis $5 \mathrm{~cm}$ hoch, aus kurzem, $5-10 \mathrm{~mm}$ dickem Stamm reichlich verzweigt. Äste rundlich od. zusammengedrückt, am Ende stumpf. Hymenium grau, trocken graubraun. Sporen $8-10 \mu$ lg., $7-9 \mu$ dick. Herdig in Lb-u. Ndwäldern an der Erde häufig. H. (Fig. 51.) (Grauer K.)

$$
\text { C. cinerea (Bull.). }
$$

2. Fk. von einem kurzen Stamm aus \pm reichlich verästelt.

Fk. unverzweigt od. nur im obern Teil spärlich verzweigt, $5-8 \mathrm{~cm}$ hoch, sehr zerbrechlich, oben zusaminengedrückt od. in ein oder mehrere Spitzchen auslaufend. Hymenium runzelig. Sporen 9-11 $\mu$ lg., 8-9 $\mu$ dick. Herdig auf dem Boden zwischen Moos in schattigen Ndwäldern, besonders im Vorgebirge. S. H. (Fig. 52.) (Rauher K.)

C. rugosa (Bull.).

3. Zweige am Ende mit scharfen Spitzen od. kammartig eingeschnitten.

Fk. trocken-fleischig, sehr leicht zerbrechlich, bis $6 \mathrm{~cm}$ hoch, 
aus kurzem, dünnem Stamm reich, mehrfach gabelig verzweigt. Zweige dicht stehend, stielrund, an den Enden abgerundet, oft keulig verdickt. Sporen kuglig, $7-8 \mu \mathrm{im}$ Durchm. od. fast kuglig, 5-6 $\mu$ lg., 4-6 $\mu$ dick. An der Erde besonders in Lbwäldern, nicht häufig. S. (Fig. 53.) (Kunzes K.) C. Kunzei (Fries).

4. Fk. weiß, trocken hellbraun, $2-5 \mathrm{~cm}$ hoch, zähfleischig, Stamm vom Grunde od. von der Mitte aus reichlich verzweigt. Äste etwas abstehend, an den Enden mit scharfen Spitzen od. kammartig eingeschnitten. Sporen fast kuglig, $8-10 \mu$ lg., $6-9 \mu$ dick. Auf der Erde am Grunde der Bäume, unter Gebüsch usw. in Lbwäldern, aber auch unter Nd. häufig. S. H. (Fig. 54.) (Kammförmiger K.)

c. cristata (Holmsk.).

Fk. weiß, etwas zerbrechlich, bis $11 \mathrm{~cm}$ hoch, mit hohlem, ziemlich dickem, wiederholt u. regelmäßig verästeltem Stamm. Äste zylindrisch, nach oben verbreitert, mit zahlreichen spitzen Zweigen. Sporen etwa kuglig, 7-8 $\mu$ im Durchm. Zwischen Rasen im Nd- u. Lbwald, nicht selten. S. H. (Fig. 55.) (KorallenK.)

c. coralloides (L.).

\section{Gattung: Clavaria Vaill. (Keulenpilz).}

Fk. fleischig, zähe od. zerbrechlich, einfach od. \pm verzweigt. Hymeniumtragender Teil vom St. nicht scharf abgesetzt. Basidien mit 4 Sterigmen. Sporen farblos, mit dünner, zarter Membran. Sämtlich eßbar, die kleineren Formen aber zu zähe.

1. Fk. einfach keulig, selten mit einer dichotomen Verzweigung. (Sect. Holocoryne.)

Fk. einfach od. wenig geteilt, aber dann stets mehrere Fk. rasig od. büschelf. verbunden (Sect. Syncoryne).

Fk. mit Stamm, aus ihm mehrfach korallenartig od. kammartig verzweigt (Sect. Ramaria).

2. Fk. weiß, höchstens gelblich werdend.

Fk. gelb, gelbbräunlich bis dunkelbraun.

3. Fk. bis $1,5 \mathrm{~cm}$ hoch, fleischig, am Grunde mit strahlig verbreitetem Myzel, St. halb so lg., Keule glatt, zylindrisch, ungetgilt od. an der Spitze eingeschnitten od. in 2-3 Äste geteilt, stumpf od. wenig zugespitzt. Sporen eif., $6-7 \mu$ lg., $3-4 \mu$ dick. Auf faulenden Stümpfen im Walde, oft zwischen Moosen u. auf grüner Algenkruste, zerstreut. H. (Schleimiger K.)

\section{C. mucida Pers.}

Fk. 2,5-4 cm hoch, aufrecht, einzeln, Keule in den St. übergehend, verdickt, oft etwas sichelf. gebogen, stumpf. Zwischen Gras in feuchten Lbwäldern, selten. H. (Fig. 56.) (Sichelförmiger $K$.) C. falcata Pers.

4. St. u. Keule dünn, höchstens bis $8 \mathrm{~mm}$ dick.

Fk. $8-25 \mathrm{~cm}$ hoch, fleischig, trocken zähe, gelblich od. hellbräunlich, später grau, rötlichbraun od. lederbraun, innen weiß. St. voll, allmählich in die oben $2-5 \mathrm{~cm}$ dicke, oben abgerundete 
Clavariaceae.

(48.

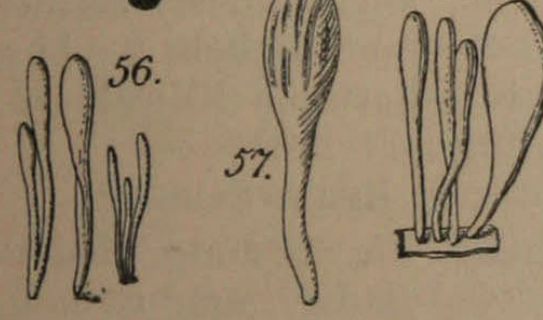

(2) 64.

11

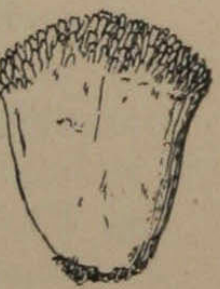

69.

66.

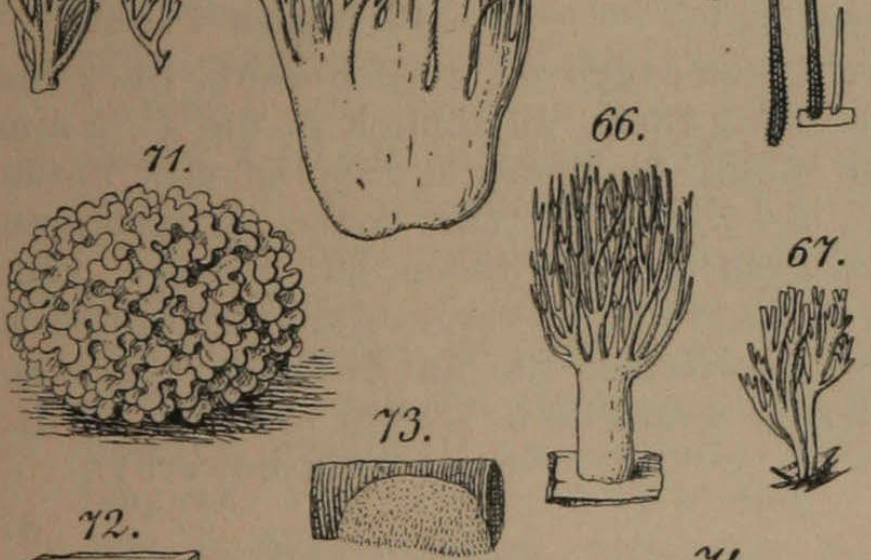

(4)

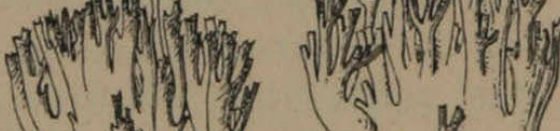

Y.

wy

(8).

तथ

vi

(1)

vit

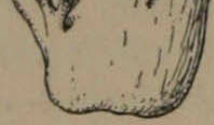

46.

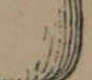

and

15.

$\frac{72 .}{\operatorname{sinan}}$

74.

12Impm 80 .

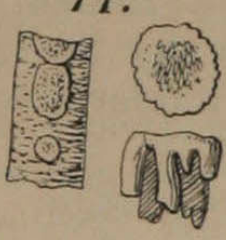

(i)

ही?
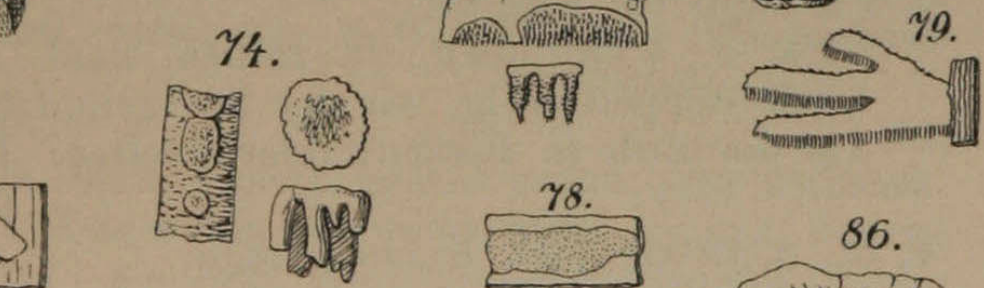
od. abgestutzte, runzelige Keule übergehend. Sporen länglich, 7-12 $\mu$ lg., 5-6 $\mu$ dick. Auf der Erde zwischen Lb. in feuchten Lb-, besonders Buchenwäldern, nicht selten. S. H. (Fig. 57.) (Herkuleskeule.)

C. pistillaris L.

5. Nur in Lbwäldern.

Fk. $6-8 \mathrm{~cm}$ hoch, voll, leicht zerbrechlich, gelblichweiß, später blaß rötlichgelb od. hellbräunlich, St. 3-4 mm dick, am Grund zottig, allmählich in die bis $8 \mathrm{~mm}$ dicke, abgerundete, seltner mehrspitzig stumpfe Keule verlaufend. Sporen länglich, 9-11 $\mu$ lg., 4-5 $\mu$ dick. Herdig zwischen Nd. in schattigen Ndwäldern, nicht selten. S. H. (Fig. 58.) (Zungenförmiger K.)

c. ligula Schaeff.

6. Fk. 6-10 cm lg., aufrecht, dann schlaff, am Grunde niederliegend, ockerfarben, später dunkler, St. fädig, am Grunde strahlig-faserig, allmählich in die $2-3 \mathrm{~mm}$ dicke, oben meist verjüngte Keule sich verbreiternd. Sporen eif., $7-9 \mu$ lg., $4-5 \mu$ dick. Gesellig in schattigen Wäldern im Lb., zerstreut. $H$. (Fig. 59.) (Binsenförmiger K.)

c. juncea Fries.

Fk. $10-20 \mathrm{~cm} \mathrm{lg.,} \mathrm{hohl,} \mathrm{gelbbraun} \mathrm{od,} \mathrm{rötlichbraun,} \mathrm{St.} 2$ bis $3 \mathrm{~mm}$ dick, am Grunde zottig-filzig, allmählich in die $4-5 \mathrm{~mm}$ dicke, meist zugespitzte Keule übergehend. Sporen eif., unten zugespitzt, 14-18 $\mu$ lg., 5-7 $\mu$ dick. (An Ästen zu mehreren hervorbrechend, nur $2-3 \mathrm{~cm}$ lg., gewunden od. gedreht, voll, weiß bestäubt u. Sporen etwas größer ist var. cont or ta (Holmsk.). H. Salten.) Auf der Erde zwischen Lb. an Zweigen in lichten Wäldern, gern unter Birken, zerstreut u. schwer sichtbar. S. H. (Fig. 60.) (Hoher K.)

C. ardenia Sowerby.

7. Fk. weiß od. gelblich.

Fk. 5-8 $\mathrm{cm}$ hoch, St. rötlich, kahl, an der Basis verdickt, Keule doppelt so lg. wie der St., zylindrisch, orangerot, stumpf. Auf der Erde in Birkenwäldern, selten. H. (Knolliger K.)

C. bulbosa Schum.

8. St. u. meist auch Keule \pm gelb.

Fk. fleischig, sehr zerbrechlich, $3-8 \mathrm{~cm}$ hoch, $3-5 \mathrm{~mm}$ dick, ungeteilt zylindrisch-keulig, weiß od. nach oben gelblich braun, am Grunde mehrere rasig vereinigt. Sporen ellipsoidisch, $6-8 \mu$ lg., $3-5 \mu$ dick. Zwischen Gras in Wäldern, auch Ndwäldern, an Wegen, lichten Stellen usw. H. (Fig. 61.) (Zerbrechlicher K.) c. fragilis Holmsk.

9. Fk. leicht zerbrechlich, unverzweigt, $2-7 \mathrm{~cm}$ hoch, $2-4 \mathrm{~mm}$ dick, leicht keulig, oben abgerundet, schmutzig gelblichweiß od. hellbräunlich, St. weißlich od. \pm gelb, am Grunde zu 4-8 büschelig-rasig. Sporen länglich, $6-10 \mu$ lg., $4-5 \mu$ dick. An lichten Stellen von Kiefernwäldern, Heiden, zwischen Moosen, an Wegen usw., häufig. H. (Tonfarbiger K.)

C. argillacea Pers. 
Fk. zerbrechlich, 3-6 cm hoch, aufrecht, oben keulig, 2 bis $3 \mathrm{~mm}$ dick, oben abgerundet od. spitzig, goldgelb bis orangegelb, meistens zu mehreren am Grunde locker büschelig. Sporen eif., $5-7 \mu$ lg., $4 \mu$ dick. Zwischen Moos $u$. Gras an lichten Stellen von Lb.- u. Ndwäldern, zerstreut. H. (Fig. 62.) (Ungleicher K.)

C. inaequalis Müller.

10. Fk. weiß od. weißlich, höchstens die Astspitzen gelblich od. rötlich.

Fk. gelb od. violett.

11. Fk. 4-12 cm hoch u. ebenso br.

12.

Fk. zähfleischig, $1-4 \mathrm{~cm}$ hoch, Stamm dünn, rundlich, Äste nicht zahlreich, gabelteilig, dicht stehend, kraus, fast kammf., weiß, an den Spitzen höchstens gelblich. Sporen eif., $4-5 \mu \mathrm{lg}$., 3-4 $\mu$ dick. Auf Lohe, feuchter Erde, zwischen Moos, besonders in Gärten, zerstreut. H. (Zarter K.) C. subtilis Pers.

12. Fk. fleischig, $8-12 \mathrm{~cm}$ hoch, bis $8 \mathrm{~cm}$ breit, aus dünnem Stamm, sehr stark verzweigt, zuerst weiß, dann ledergelb. Verzweigungen kandelaberartig, quirlf., an dem Verzweigungspunkt fast becherartig erweitert, Äste dünn, zylindrisch, am Ende becherartig erweitert $u$. am Rande in feine Spitzchen ausgezogen. Sporen fast kuglig, 4-5 $\mu$ lg., $3 \mu$ dick. Auf alten Kiefern- od. Pappelstümpfen, selten. S. H. (Becherförmiger K.) C. pyxidata Pers.

Fk. knollige rundliche Massen bildend, fleischig, $4-12 \mathrm{~cm}$ hoch u. ebenso br. Stamm 2-5 cm dick, kurz, weiß. Äste sehr zahlreich, dicht stehend, kurz u. dick, gefurcht od. gestreift, schmutzig weiß od. etwas gelblich, Endauszweigungen kurz abgestutzt, gezähnelt, an der Spitze rötlich, dann bräunlich. Sporen länglich, $12-15 \mu$ lg., $5-6 \mu$ dick. Zwischen Moos, Lb., Nd., gern in Mischwäldern, zerstreut. S. H. (Fig. 63.) (Ziegenbart, Korallenschwamm.)

13. Fk. gelb od. rotgelb.

C. botrytes Pers.

Fk. bis $5 \mathrm{~cm}$ hoch, blau, violett, später braun, sehr zerbrech. lich, stark verzweigt, Äste wenig verzweigt, glatt, stumpf. Sporen länglich, 9-11 $\mu$ lg., 7-8 $\mu$ dick. An feuchten Stellen der Wälder zwischen Moosen u. Gras, selten. H. (Fig. 64.) (Amethystfarbener K.)

C. amethystina (Holmsk.).

14. Fk. stark verzweigt.

Fk. schlank, 2-3 mal gabelig geteilt, gelb, $2 \mathrm{~cm}$ hoch, mit dünnem Stamm u. gekrümmten, spitzen Ästen. Auf schattigen Wiesen zwischen Moos, selten. H. (Moosliebender K.)

C. muscoides L.

15. Fk. 6-15 cm hoch, fleischig, zerbrechlich, gelb od. rötlichgelb, Stamm ca. 2,5 cm hoch u. br., Zweige aufrecht, stielrund, sehr dicht stehend, stumpf. Sporen schief ellipsoidisch, 8-11 $\mu$ lg., 4-5 $\mu$ dick. An der Erde in Lb.- u. Ndwäldern, zwischen Moos usw., nicht selten. S. H. (Fig. 65.) (Gelber K.)

C. flava Schaeffer.

Lind a u, Kryptogamenflora. I. 2. Aufl. 
Fk. $2-5 \mathrm{~cm}$ hoch, lebhaft gelb od. rotgelb, frisch etwas klebrig, Stamm 1-2 cm hoch, stielrund, wiederholt gabelig verzweigt, Äste weitläufig stehend, fast rechtwinklig umgebogen, stielrund, Endästchen fast gleich hoch stehend, meist abgerundet, im Alter gelblich braun. Sporen fast kuglig, 4-5 $\mu$ im Durchm. Zwischen Gras u. Moos auf Heiden, Kiefernwäldern, nicht selten. S. H. (Abgeflachter K.)

C. fastigiata $\mathrm{L}$.

5. Gattung: Clavariella Karsten (Braunkeule).

Fk. wie bei Clavaria. Sporenpulver ockerfarben, Sporen ockerfarben od. gelbbräunlich. Eßbar, aber nur die größeren Arten lohnend.

1. Auf Stümpfen u. Stämmen wachsend.

Auf der Erde wachsend.

2. Fk. 2-6 cm hoch, rötlich ockergelb, Stamm dick, Äste fast wirbelig, wiederholt $2-3$ gablig, gedrängt, mit grünlichen, sehr spitzen, steifen Ästchen. Sporen ellipsoidisch, $7-9 \mu \lg ., 3-5 \mu$ dick. An morschen Ndstämmen, selten. S. H. (Spitzige B.) C. a piculata (Fries).

Fk. bis $8 \mathrm{~cm}$ hoch u. br., blaßgelb, später bräunlich, Stamm dünn, kurz, am Grunde weißfilzig, sehr reichlich verzweigt, Äste bogig, dünn, stielrund, dicht, steif aufrecht, am Ende in mehrere gablig verzweigte bräunliche Spitzen auslaufend. Sporenpulver dunkel zimmetbraun. Sporen ellipsoidisch, $6 \mu$ lg., $3 \mu$ dick. An alten Stümpfen von Lb., seltener an Nd., nicht selten. H. (Fig. 66.) (Aufrechte B.) C. stricta (Pers.).

3. Fk. gelb, rot, ockerfarben, hellbraun, niemals weiß bleibend od. grau.

Fk. 8-12 $\mathrm{cm}$ hoch, fleischig, Stamm bis $3 \mathrm{~cm}$ dick, weißlich, stark verzweigt, Äste ungleich lg., schwach runzlig, rauchgrau, verschmälert, an den Enden stumpf. Sporenpulver braun. Sporen länglich, schief zugespitzt, $9-11 \mu \mathrm{lg}$., $4-5 \mu$ dick. In Lb.- u. Ndwäldern zwischen Lb., zerstreut. S. H. (Graue B.) C. grisea (Pers.).

4. Fk. hellbräunlich, weder irgendwie gelb noch rot.

Fk. irgendwie od. ganz gelb od. rot.

5. 7.

5. Bei Verletzung sich nicht verfärbend.

6.

Fk. gelbbräunlich, trocken etwas dunkler, $3-8 \mathrm{~cm}$ hoch, Stamm bis $1 \mathrm{~cm}$ hoch, unten weiß filzig, frisch bei Verletzung grünlich werdend. Äste reichlich, eng stehend, trocken der Länge nach gefurcht-runzelig, Enden dünn, lg. u. scharf zugespitzt. Sporen länglich, $6-8 \mu \mathrm{lg}$., $3-5 \mu$ dick. Geschmack bitter. In Lb.- u. Ndwäldern am Boden zwischen Moos, häufig. S. H. (Fig. 67.) (Tannen-B.) • C. abietina (Pers.).

6. Fk. 4-6 cm hoch, hell ockerfarben od. sehr hell rötlichbraun. Stamm $1 \mathrm{~cm}$ hoch, sehr stark verzweigt, Äste dicht stehend, etwas zusammengedrückt, nach oben heller u. am Ende meist 
in 2-3 fast weiße, scharfe Spitzen endigend. Sporen länglicheif., schwach gebogen, $8-9 \mu$ lg., $3-4 \mu$ dick. Am Boden in Lb.- u. Ndwäldern, selten. S. (Handförmige B.)

C. palmata (Pers.).

Fk. 1-6 cm hoch, dünn, schlaff, ockerfarben, Stamm kurz, ziemlich dick, Äste dicht stehend, konvergierend, ungleïch lg. Sporen ellipsoidisch, 6-8 $\mu \mathrm{lg}$., 3-5 $\mu$ dick. Zwischen Moos u. Heidekraut in Ndwäldern, seltener auch unter Lbbäumen, selten. H. (Schlaffe B.)

7. Fk. nicht vollständig safrangelb.

c. flaccida (Fries).

Fk. 1-2 cm hoch, vollständig safrangelb, Äste u. Ästchen schwach gabelig. Sporen $6-7 \mu$ lg., $2-3 \mu$ dick. An der Erde im Gebüsch der Lbwälder, selten. S. H. (Safrangelbe B.)

8. Stamm kahl.

c. crocea (Pers.).

Fk. 8-11 cm hoch, fleischfarben, dann blasser, ledergelb, zähe. Stamm niederliegend od. aufrecht, weißfilzig, Äste aufrecht, locker, biegsam, kantig, nach oben verdickt, mit fast wirtelig stehenden,! spitzen Ästchen. Sporen 8-10 $\mu$ lg., 4-5 $\mu$ dick. Geschmack bitterlich. An der Erde in Ndwäldern, selten. H. (Schwedische B.)

'9. Zweige gelb.

c. suecica (Fries).

Fk. $8-15 \mathrm{~cm}$ hoch, fleischig, weißlich bis hell ockerfarben, nach oben hell gelblich rot od. fleischrot, Stamm $3-5 \mathrm{~cm}$ hoch, Äste dicht aufrecht, stumpf. 'Sporen zylindrisch, abgerundet, 8-12 $\mu$ lg., $2-4 \mu$ dick. An der Erde in Lb.- u. Ndwäldern, häufig. S. H. (Fig. 68.) (Ziegenbart, Judenbart.)

c. formosa (Pers.).

10. Fk. fleischrot-bräunlich, $8-11 \mathrm{~cm}$ hoch, trocken, rötlich-lederfarbig, von Grund an stark verzweigt, Zweige straff, parallel, an der Spitze 2-3 zähnig, gelb. Sporen eif., 7-11 $\mu$ lg., $4-5 \mu$ dick. Am Boden in Lbwäldern zwischen Holz, Erde, Zweigen, selten in Kieferwäldern, zerstreut. S. H. (Fig. 69.) (Dichte B.) C. condensata (Fries).

Fk. 8-15 cm hoch, blaß, Stamm dick fleischig, Äste dick, aufrecht, zylindrisch, sehr dicht, gabelig verzweigt, gelb, mit gezähnelten, stumpfen Enden. Sporen ellipsoidisch, 8-11 $\mu \mathrm{lg}$., 4-5 $\mu$ dick. Auf der Erde zwischen Lb., an Wegen im Lb.- u. Ndwald, nicht selten. H. (Fig. 70.) (Goldgelbe B.)

\section{C. aurea (Schaeffer).}

6. Gattung: Sparassis Fries (Glucke).

Fk. sehr groß. Stamm dick, fleischig, reich verzweigt. Zweige flack blattartig, kraus, auf beiden Seiten vom Hymenium bedeckt. Sporen weiß, glatt. Feinster Speisepilz.

Einzige Art mit weißlichen, später bräunlichen, rundlichen Fk., bis $20 \mathrm{~cm} \mathrm{u.} \mathrm{mehr} \mathrm{br.} \mathrm{u.} \mathrm{hoch.} \mathrm{Stamm} \mathrm{bis} 3 \mathrm{~cm}$ dick, bis $6 \mathrm{~cm}$ 
hoch. Sporen fast kuglig, $4-6 \mu$ lg., $3-4 \mu$ dick. In Ndwäldern am Grunde von Stämmen u. Stümpfen der Bäume, zerstreut, im Vorgebirge häufiger. S. H. (Fig. 71.) (Glucke, Judenbart, Ziegenbart.)

S. ramosa (Schaeffer).

\section{Familie: Hydnaceae.}

Fk. von verschiedener Gestalt, häutig, Clavaria-artig, hutartig halbiert od. hutpilzartig, bisweilen nur aus den Stacheln bestehend. Hymenium allseitig Stacheln od. Warzen bekleidend, die verschiedenartig auf der Unterlage verteilt stehen können. Basidien mit 4 Sterigmen. Sporen farblos od. gefärbt, glatt od. rauh.

\section{Bestimmungsschlüssel der Gattungen.}

A. Der ganze Pilz nur aus Stacheln bestehend. 1. Mucronella. B. Stacheln auf einer Unterlage befestigt.

a) Hymenium aufWarzen od. stielrunden Stacheln.

I. Hymenium auf Warzen od. Körnchen.

1. Warzen am Scheitel glatt, gerundet, nicht getielt.

2. Grandinia ${ }^{1}$ ).

2. Warzen am Scheitel wimprig, vielteilig. 3. Odontia ${ }^{\mathbf{1}}$ ).

II. Hymenium auf deutlichen stielrunden Stacheln.

1. Stacheln dick, büschelig od. zerstreut stehend, häufig unregelmäßig.

4. Radulum.

2. Stacheln regelmäßig, pfriemlich, spitz, dicht stehend.

a) Sporen farblos.

5. Hydnum.

$\beta$ ) Sporen violett.

6. Amaurodon.

$\gamma)$ Sporen braun.

* Fk. flach ausgebreitet.

** Fk. gestielt, holzig od. korkig.

*** Fk. gestielt, fleischig.

7. Caldesiella.

8. Calodon.

9. Sarcodon.

b) Hymenium auf flachgedrückten, schmalen od. breiteren, oben kammartig zackigen Blättern stehend.

I. Blätter sehr niedrige lge. Streifen bildend, die kammartig runzelig sind.

10. Phlebia.

II. Blätter zahnf., schmal, meist zugespitzt, eingeschnitten od. nicht.

1. Fk. flach ausgebreitet.

11. Xylodon.

2. Fk. von der Unterlage abstehend, lederig.12. Irpex.

3. Fk. von der Unterlage abstehend, fleischig od. häutig.

13. Sistotrema.

1) Die Unterschiede zwischen diesen beiden Gattungen sind nicht scharf, man vergleiche deshalb die Arten. 
1. Gattung: Mucronella Fries (Stachelspitzchen).

Der ganze Pilz nur aus spitzen, glatten Stacheln bestehend. Sporen farblos, glatt.

Stacheln zu 4-12 am Grunde verwachsen, hängend, 6-9 mm lg., weiß, später gelblich. An faulenden Lb.- u. Ndstämmen, selten. H. (Fig. 72.) (Bündeliges S.) M. fascicularis (Alb. et Schwein.).

Stacheln einzeln, gerade aufrecht, unregelmäßig zerstreut, 2 bis $5 \mathrm{~mm}$ lg., spitz, weiß, später gelblich. Auf faulem Kiefernholz, selten. H. (Kahles S.)

M. calva (Alb. et Schwein.).

\section{Gattung: Grandinia Fries (Körnchenpilz).}

Fk. häutig, flach, weit ausgebreitet, auf der obern Seite mit halbkugligen, körnigen Warzen besetzt, gleichmäßig vom Hymenium bezogen. Sporen farblos, glatt.

Fk. weit ausgebreitet, frisch wachsartig fleischig, trocken krustig, rissig, ockerfarben bis ledergelb, im Umfang kahl, oberseits mit halbkugligen Wärzchen dicht besetzt. Sporen länglich, $6-7 \mu$ lg., $3 \mu$ dick. Auf Holz, Brettern, Bohlen von Kiefernholz, nicht selten. F. S. H. (Ledergelber K.)

G. alutacea (Pers.).

Fk. rundlich, zusammenhängend sich ablösend, milchweiß, unterseits kahl, gelblich, im Umfang kleiig, oberseits stark rissig mit kleinen, gedrängten Körnchen bedeckt. An morschem Holz von Kiefern, nicht häufig. S. (Warziger K.) G. papillosa Fries.

\section{Gattung: Odontia Pers. (Zähnchenpilz).}

Fk. häutig od. fleischig, flach, anliegend, oberseits mit zerstreuten, halbkugligen od. kegelförmigen, am Scheitel meist faserig oder pinselig zerteilten Warzen besetzt, allseitig vom Hymenium bezogen. Sporen farblos glatt.

1. Warzen des Hymeniums nicht an der Spitze wimperig.

Warzen des Hymeniums stets an der Spitze wimperig od. zerschlitzt.

2. Fk. unregelmäßig, der Unterlage fest anliegend, dünnfleischig, trocken krustig, weiß, im Umfang kahl, oberseits mit dichtstehenden, halbkugligen od. am Scheitel leicht vertieften Warzen. Sporen länglich, 5-6 $\mu$ lg., $2-5 \mu$ dick. An Kiefern- u. Lbholz, besonders Weiden, zerstreut. Das ganze Jahr. (Krustiger Z.)

o. erustosa (Pers.).

Fk. zuerst sehr dünn, fast reifartig, dann dicker, crêmegelb, sehr stark zerrissen, am Rand gleichartig od. allmählich verlaufend. Hymenium glatt od. fein papillös, seltener kleinwarzig od. etwas stachlig. Sporen br. ellipsoidisch, einseitig etwas abgeflacht, unten zugespitzt, $3-5 \mu \mathrm{lg}$., $2 \mu$ dick. Auf morschen Lbästen, zerstreut. H. (Zerstreuter Z.) o. conspersa Bresadola.

3. Fk. weit ausgebreitet, häutig, wergartig, fest anliegend, weiß, am Rande strahlig. Warzen fast kegelf. stachlig, an der Spitze 
wimperig zerschlitzt u. gelbbraun. An Nd.- u. Lbästen, zerstreut. H. (Fig. 73.) (Bärtiger Z.) O. barba jovis (Bull.).

Fk. häutig, lederig, kreisf., dann verbreitet, dicht anliegend, ablösbar, hell schokoladenbraun, von wurzelartigen Fasern durchzogen, am Rande weißstrahlig. Warzen körnig, an der Spitze faserig zerschlitzt, rotbraun. Sporen länglich eif., etwas gekrümmt, $4 \mu$ lg., $2 \mu$ dick. An feucht liegendem Lbholz im Gebüsch. u. in Wäldern, nicht selten. S. H. (Fassriger Z.)

0. fimbriata (Pers.).

\section{Gattung: Radulum Fries (Reibeisenpilz).}

Fk. ausgebreitet, fest aufliegend od. mit dem obern Rand abstehend, oberseitig mit unregelmäßigen, papillenförmigen, grobstachligen, zerstreut od. büschelig stehenden Hervorragungen besetzt, die vom Hymenium überzogen werden. Sporen farblos, glatt.

1. Fk. hellfarbig.

Fk. zuerst unterrindig, dann entblößt, schwarz. Höcker verlängert, ziemlich groß, verschieden gestaltet, schwach zusammengedrückt. An Stämmen u. Ästen von Birken, selten. H. (Schwarzer R.)

R. aterrimum Fries.

2. Fk. weißlich bis gelblich.

Fk. bräunlich, rostfarben od. rot.

3. Fk. kreisf., weißlich, später blaßgelb, am Rande strahlig faserig. Wärzchen zuerst weich, klein, dann dick, stumpf, zerstreut od. büschelig gestellt. Auf morschen Lbzweigen, seltener an Kiefern, in Wäldern, zerstreut. S. H. (Fig. 74.) (Kreisförmiger R.)

\section{R. orbiculare Fries.}

Fk. weit ausgebreitet, krustig, kahl, gelblich. Höcker verkürzt, kegelig, zerstreut od. gehäuft. An Lbstämmen, zerstreut. Fast das ganze Jahr. (Backenzahnartiger R.)

4. Fk. braungelb, ockerbraun, rostbraun.

$$
\text { R. molariforme (Pers.). }
$$

Fk. rot bis orange.

5. Fk. dünnhäutig, ausgebreitet, wachsartig, braungelb-rostfarbig. Stacheln gerade, spitz, gedrängt, gleich lg., rostfarben od. gelblich. Auf faulem Lb., selten. S. H. (Fig. 75.) (Häutiger R.)

R. membranaceum (Bull.).

Fk. kreisf., dann verbreitet, fleischig-lederig, trocken fast holzig, flach aufsitzend, ablösbar, ockerfarben, später mehr braun. Stacheln dick, ungleich (bis $5 \mathrm{~mm}$ ) lg., stumpf, meist büschelig. An Lbzweigen, besonders Eiche, in Wäldern, nicht selten. S. H. (Fig. 76.) (Eichen-R.)

R. quercinum (Pers.).

6. Fk. flach ausgebreitet, aus der Rinde hervorbrechend u. von ihr umgeben, fleischig, trocken krustig, rissig, fleischrot bis orangefarben. Höcker warzig od. grobstachelig, ungleich dick, stumpf, oft verbogen. An abgefallenen Lbästen, zerstreut. H. W. (Hydnumartiger R.)

R. hydnoideum (Pers.). 
Fk. weit ausgedehnt, weich lederartig, abziehbar, am oberen Rande etwas zurückgebogen, überhängend, lebhaft rot, am Rande weiß. Höcker spät erst ausgebildet, warzenartig od. an der Spitze kammartig geteilt, unregelmäßig, rot, an der Spitze weißlich. An Rinde von Lb., selten. F. S. H. (Kmets R.)

\section{R. Kmetii Bresadola.}

\section{Gattung: Hydnum L. (Stachelpilz).}

Fk. von verschiedenartigster Konsistenz u. von Gestalt flach ausgebreiteter Krusten bis zu hutförmigen Gebilden. Hymenium die Außenseite von drehrunden, pfriemlichen, langen Stacheln bedeckend. Sporen farblos, glatt. Einige größэre Arten eßbar.

1. Fk. \pm der Unterlage anliegend, nicht ein unterscheidbarer Stamm vorhanden.

Fk. mit deutlich unterschiedenem Stammteil, daher meist gestielt.

2 Fk. flach ausgebreitet, anliegend, Stacheln von der Oberfläche meist senkrecht abstehend (Sect. Microdon).

Fk. im ganzen anliegend, aber sich teilweise von der Unterlage abhebend, daher die Stacheln liegend (Sect. Hypodon). 14.

3. Stamm reich verästelt. Stacheln an den Zweigenden hängend (Sect. Dryodon).

Stamm nicht verästelt.

4. St. seitlich am Hut ansitzend, Hut halbiert kreisf. (Sect. Pleurodon).

St. zentral unter dem Hut.

5. St. allmählich in den kegel- od. trichterf. Hut übergehend (Sect. Phellodon).

St. vom Hut scharf abgesetzt (Sect. Tyrodon). 22.

6. Stacheln weiß.

Stacheln gefärbt.

7. Stacheln drehrund, ungezähnelt.

8:

Fk. weit ausgebreitet, filzig, wei $\beta$, am Rande gleichartig. Stacheln pfriemlich ziemlich lg., unter der Lupe seitlich fein gezähnelt. An faulem Holz, Zweigen von Lbbäumen, gern in hohlen Weiden u. Pappeln, nicht selten. Fast das ganze Jahr. (Ausgeprägter S.)

H. argutum Fries.

8. Rand des Fk. kahl, meist scharf abgesetzt.

Rand des Fk. flockig, faserig od. filzig.

9. Fk. sehr dünn u. zart, eingewachsen, trocken fast versehwindend, rundlich od. länglich, später ausgebreitet, mit scharf begrenztem Rand, weiß, trocken hellgrau. Stacheln sehr entfernt stehend, kaum $1 \mathrm{~mm}$ lg., leicht abwischbar, spitz. An faulen Stümpfen u. Holz von Kiefern, zerstreut. S. H. (Zarter S.)

H. subtile Fries.

Fk. dünn häutig, durchscheinend, weiß, weit verbreitet, am Rand kahl. Stacheln ca. $2 \mathrm{~mm}$ lg., pfriemlich, gleich lg., trocken 
gelblich. An Stämmen u. Holz von Lb., seltener an Kiefern, zerstreut. S. H. (Durehscheinender S.)

10. Fk. häutig.

Fk. mehlig, weit ausgebreitet, weiß, dann krustig, am Rande schwach flockig. Stacheln sehr fein, kurz, etwas entfernt stehend. An faulem Holz u. Zweigen von Lb. u. Kiefern, zerstreut. F. H. (Mehliger S.)

H. farinaceum Pers.

11. Fk. häutig, sehr zart, weit ausgebreitet, weiß, am Rande schimmelartig flockig. Stacheln dicht stehend, kurz, gleich lg. Auf Holz, Stümpfen, Balken von Kiefern, zerstreut. H. W. F. (Schneeweißer S.)

H. niveum (Pers.).

Fk. häutig, weit ausgebreitet, ablösbar, weiß, unterseitig u. am Rande faserig od. filzig. Stacheln dicht stehend, $2-3 \mathrm{~mm}$ lg., trocken gelblich. An faulenden Stümpfen u. Ästen von Lb., häufig. Fast das ganze Jahr. (Schleimiger S.)

H. mucidum Pers.

12. Stacheln gelblich od. ockerfarben.

Fk. dünn, krustig, zuerst graugrün, flockig bereift, dann kahl u. rostbraun, am Rand bläulich faserig, später die kleinen rundlichen Fk. zusammenfließend. Stacheln kurz, kegelig pfriemlich, hirschbraun, später schwärzlich. An faulem Lb., seltner an Kiefern, selten. H. (Braunschwarzer S.)

H. fuscoatrum Fries.

13. Fk. hautartig, ausgebreitet, leicht ablösbar, gelblich, unterseitig u. am Rande in der Jugend zottig. Stacheln spitz, etwas schief stehend, am Grunde zusammenfließend u. dadurch gabelig od. eingeschnitten erscheinend. An $\mathrm{Holz} u$. Rinde von Kiefern, zerstreut. S. H. (Fig. 77.) (Kiefern-S.) H. pinastri Fries.

Fk. längs ausgebreitet, krustig angewachsen, blaß ockergelb, am Rande kahl. Stacheln klein, gedrängt, spitz. An Kiefernstümpfen, selten. H. (Fig. 78.) (Lederfarbener S.)

\section{H. alutaceum Fries.}

14. Fk. lederig, dünn.

15.

Fk. fleischig od. weichkorkig, dick.

16.

15. Fk. zum größeren Teil angewachsen, meist sich lappenartig von der Unterlage abhebend, seltener nur am Rande frei, ockerfarben, oberseits konzentrisch gezont. Stacheln sehr klein, ockerfarben. An Stämmen u. Zweigen, besonders von Nd., selten. F. S. H. (Ockerfarbiger S.)

H. ochraceum Pers.

Fk. nur mit dem oberen Rande abstehend, sonst angewachsen, oberseits weißfilzig, ungezont. Stacheln dichtstehend, kurz, rötlich gelb. An abgefallenen Lbzweigen, besonders von Eichen, zerstreut. H. (Verschämter S.) H. pudorinum Fries.

16. Fk. fleischig, flach, $50 \mathrm{~cm} \mathrm{u}$. mehr ausgebreitet od. häufiger dick unf. knollig, höckrig u. fast ästig, schwefelgelb, später oft bräunlich, oben höckerig. Stacheln hängend, dichtstehend, pfriemlich, 
$1-2 \mathrm{~cm} \mathrm{lg}$. Geruch frisch apfelartig, dann widerlich. An lebenden Äpfelbäumen, sie sehr schädigend, nicht selten. Fast das ganze Jahr. (Schiedermayrs S.)

H. Schiederma yri Heufler.

Fk. fleischig, weit verbreitet, dick, fast halbkreisf., $3-7 \mathrm{~cm}$ lg., 2-4 cm br. abstehend, meist in dachziegeligen Rasen, ockerfarben, oberseits faserig-zottig, am Rande gewimpert. Stacheln hängend, spitz, ca. $1 \mathrm{~cm} \mathrm{lg.} \mathrm{An} \mathrm{Lbstämmen,} \mathrm{besonders} \mathrm{Rot-}$ buchen, nicht häufig. H. (Fig. 79.) (Gewimperter S.)

H. cirrhatum Pers.

17. Fk. herzf., am Grunde in einen bis $8 \mathrm{~cm} \mathrm{lg.} \mathrm{St.} \mathrm{zusammenge-}$ zogen, $10-20 \mathrm{~cm}$ br. u. lg., oberhalb faserig zerschlitzt, zuerst weiß, dann gelblich, flaischig, am Grunde zähe. Stacheln sehr dicht stehend, $3-6 \mathrm{~cm} \mathrm{lg.,} \mathrm{gerade,} \mathrm{weiß,} \mathrm{trocken} \mathrm{gelblich.} \mathrm{Auf}$ faulenden Lbstämmen, besonders von Eichen, zerstreut. S. H. (Fig. 80.) (Igel-S.)

H. erinaceus Bull.

Fk. aus kurzem, rundlichem Stamme bald in zahlreiche dünne, dicht stehende Äste aufgelöst, fleischig, weiß, später gelblich, $6-40 \mathrm{~cm} \mathrm{lg.} \mathrm{u.} \mathrm{br.} \mathrm{Stacheln} \mathrm{hängend,} \mathrm{1-1,5} \mathrm{cm} \mathrm{lg.,} \mathrm{spitz.} \mathrm{An}$ Ästen, in hohlen Stämmen von Lb. u. Nd., besonders von Rotbuche, Eiche, Tanne usw., nicht selten. H. Guter Speisepilz. (Fig. 81.) (Korallenschwamm.)

H. coralloides Scop.

18. Fk. klein, rasig gehäuft, gelblich, Hut fleischig, spatel- od. nierenf., St. kurz, dick, seitlich ansitzend. Stacheln blaß. An dürren Ästen von Prunus padus, selten. H. (Gelblicher S.)

H. luteolum Fries.

Hut halbkreisf., am St.-Ansatz ausgebuchtet, flach, dünn lederartig, behaart, anfangs braun, dann schwärzlich, $1-1,5 \mathrm{~cm}$ br., Rand scharf. St. 4-6 cm lg., ca. 1,5 mm dick, braun, dicht abstehend behaart, innen schwärzlich. Stacheln dichtstehend, ca. $2 \mathrm{~mm}$ lg., grau, später braun. Auf alten, faulen Kiefernzapfen, nicht selten. Fast das ganze Jahr. (Fig. 82.) (Ohrlöffel-S.)

H. auriscalpium L.

19. Hut ungezont.

Hut konzentrisch gezont, lederig, keulenf., später flach trichterig, $3-5 \mathrm{~cm}$ br., hell graubraun, oben schwach filzig. St. $2-3 \mathrm{~cm}$ hoch, 3-5 mm dick, graubraun, zähe. Stacheln weiß, bis $4 \mathrm{~mm}$ lg., spitz. Geruch schwach zimmetartig. Rasig auf dem Boden in Ndwäldern, oft miteinander verwachsend, nicht selten. S. H. (Becherförmiger S.)

H. eyathiforme Schaeffer.

20. Ganz kahl.

Hut filzig, korkig-lederig, starr, niedergedrückt, etwas höckerig, blauschwarz, am Rande weiß, dann schwarz. St. schwarz, dick. Stacheln weiß, dann grau. Am Boden gesellig in Ndwäldern, zerstreut. S. H. (Schwarzer S.) H. nigrum Fries.

21. Hut dünn, lederig, starr, trichterf., später flach u. unregelmäßig, streifig, nicht gezont, $3-5 \mathrm{~cm}$ br., schwarz, Rand weiß. St. dünn, schwarz, $2-3 \mathrm{~cm}$ hoch. Stacheln weiß, kurz. Geruchlos. 
Auf dem Boden dürrer u. sandiger Kiefernwälder \pm rasig, zerstreut. H. (Schwarzweißer S.)

H. melaleucum Fries.

Hut dünn, lederig, trichterf., schwarzbraun, trocken grau werdend, $2-4 \mathrm{~cm}$ br., Rand weiß. St. schwarz, dünn, Stacheln dichtstehend, ca. $1,5 \mathrm{~cm}$ lg., weiß, später grau. Stark nach Steinklee riechend. Rasig auf der Erde von Ndwäldern, oft zusammengewachsen, zerstreut. H. (Fig. 83.) (Riechender S.)

H. graveolens (Pers.).

22. Hut grau od. gelbbräunlich bis dunkler bräunlich.

Hut zuerst grau od. rotbräunlich, später aber schmutzig violett, feinfilzig, in der Mitte grubig; am Rande gebogen u. gelappt, $3-11 \mathrm{~cm}$ br., innen wei ; seltener violett. St. $3-11 \mathrm{~cm} \mathrm{lg.,} 1,5$ bis $2 \mathrm{~cm}$ dick, bisweilen verzweigt. Stacheln dünn, wei $\beta$, spitz. In moosigen, feuchten Ndwäldern, besonders in den Vorbergen, zerstreut. S. H. (Violetter S.)

H. violascens Alb. u. Schwein.

23. Hut oben ganz glatt u. kahl.

Hut oben mit Schüppchen, Fasern od. Filz bedeckt, wenigstens in der Jugend.

24. Hut fleischig, ausgebreitet, bisweilen am Rande gelappt, braun, $10-16 \mathrm{~cm}$ br., in der Mitte uneben, grubig. St. $3-5 \mathrm{~cm} \mathrm{lg.,}$ bis $2 \mathrm{~cm}$ dick, bräunlich. Stacheln weiß, später grau, ea. $6 \mathrm{~mm}$ lg., pfriemlich. Auf dem Boden in Ndwäldern, selten. H. Eßbar. (Glatter S.)

H. laevi gatum Swartz.

Hut fleischig, zerbrechlich, $4-14 \mathrm{~cm}$ br., flach, gebuckelt, seltener etwas eingedrückt, am Rande verbogen und oft gelappt, weißlich, gelblich bis ockerfarben. St. dick, kurz. Stacheln dicht stehend, sehr zerbrechlich, selten zusam mengedrückt, meist stielrund, gewöhnlich heller als der Hut. Guter Speisepilz. Auf feuchteren Stellen in Lb.- u. Ndwäldern, auch im Vorgebirge, häufig. S. H. (Fig. 84.) (Stoppelschwamm, Steinschwamm.)

H. repandum $\mathrm{L}$.

25. Hut in der Jugend filzig od. rötlich zottig, später kahl.

Hüte rasig verwachsen, fleischig, rötlich rostfarben, oberseits mit kleinen, faserigen, angedrückten Schuppen bedeckt. St. blasser, kahl, bisweilen verzweigt. Stacheln sich verfärbend, rostbraun. In Lbwäldern am Boden, selten. S. H. (Veränderlicher S.)

H. versipelle Fries.

26. Hut fleischig, zerbrechlich, $10-15 \mathrm{~cm}$ br., zuerst fein filzig, später glatt, grau od. schmutzig ockerbraun, am Rande heller u. dick, wellig verbogen, trocken eingerollt. St. $5 \mathrm{~cm} \mathrm{lg.,} \mathrm{bis}$ $2 \mathrm{~cm}$ br., grau, glatt. Stacheln weiß, später gelblich, spitz. Eßbar. Am Boden in Ndwäldern, selten. S. H. (Fig. 85.) (Zerbrechlicher S.)

H. fragile Fries.

Hut in der Mitte niedergedrückt, fleischig, dünn, weiß, nach dem Rande hin rötlich od. bräunlich, $11-14 \mathrm{~cm}$ br., in der Jugend oben mit dünnen, anliegenden, rötlichen Zotten. St. 
5-8 $\mathrm{cm}$ hoch, unten verdickt, rußfarben, rauh. Stacheln kurz, weiß, bei Berührung rötlich werdend. Auf sterilem Sandboden in Kiefernwäldern gesellig, oft, in Hexenringen, nicht häufig. S. H. (Grauweißer S.) H. fuligineoalbum Schmidt.

\section{Gattung: Amaurodon Schroet. (Schwarzzahn).}

Fk. flach ausgebreitet, sonst wie Hydnum Sect. Microdon. Sporenpulver schwarz. Sporen dunkel violett, trocken verblassend, gelbbräunlich, durch Alkalien wieder dunkel werdend.

Einzige Art dunkel blauviolett, trocken bis gelbgrün abblassend, Fk. flach ausgebreitet, locker, filzig. Stacheln dicht stehend, bis $3 \mathrm{~mm}$ lg., drehrund, spitz, an der Spitze oft zerfasert, meist büschelig zusammenstehend. Sporen kuglig, $4-5 \mu \mathrm{im}$ Durchm. Auf faulem Lb. in Wäldern, besonders Erle u. Weißbuche, selten. H. (Grüner S.)

\section{A. viridis (Alb. et Schwein.).}

\section{Gattung: Caldesiella Sacc. (Caldesielle).}

Fk. flach ausgebreitet, sonst wie Calodon. Sporen braun, höckerig. stachlig.

Einzige Art, eine weit verbreitete, filzige Unterlage bildend, die lebhaft rostbraun, am Rande flockig od. strahlig-filzig ist. Stacheln dicht stehend, $5-8 \mathrm{~cm}$ lg., angedrückt, spitz, rostbraun, im Alter umbrabraun. Sporen fast kuglig, $8-10 \mu$ lg., $7-8 \mu$ dick. Auf faulem Holz von Kiefern od. anderen Bäumen, selten. H. (Braune C.)

C. ferruginea (Pers.).

\section{Gattung: Calodon Quélet (Schönzahn).}

Fk. von lederiger, korkiger od. \pm holziger Konsistenz, gestielt, St. in den kegel- od. trichterf. Hut übergehend. Stacheln am Hut unterseitig. Sporen braun, punktiert od. höckerig.

1. St. braun od. orange.

St. violett, kurz, filzig. Fk. weich, korkig-schwammig, bis $10 \mathrm{~cm}$ hoch, innen ganz violett u. später weißlich u. nur violett gezont. Hut $8-15 \mathrm{~cm}$ br., kreiself., später mit ausgebreitetem, stumpfem Rande, weißlich bis ockerfarben, bei Druck braun werdend, in der Mitte höckerig, eingewachsen-filzig. Stacheln dicht stehend, 4-8 mm lg., zuerst rötlich, dann violett, endlich braun. Geruch stark anis- od. fenchelartig. Gesellig auf dem Boden in Nd.- u. trockenen Lbwäldern, nicht selten. S. H. (Fig. 86.) (Duftender S.)

C. suaveolens (Scopoli).

2. St. braun.

Hut korkig filzig, 3-10 cm br., kreiself., in der Mitte grubighöckerig, orangefarben, ungezont, am Rande dünn, abgerundet, anfangs weißfilzig. St. orangefarben, bis $4 \mathrm{~cm}$ hoch, $2 \mathrm{~cm}$ dick. Stacheln dicht stehend, 4-6 mm lg., anfangs weißlich, dann braun mit helleren Spitzen. Am Boden in trockenen Ndwäldern, zerstreut. S. (Orangefarbener S.) C. aurantiacus (Batsch). 
3. Hut u. St. in der Jugend von weißem Filz überzogen.

Hut 3-5 cm br., filzig lederig, flach trichterf., rostbraun od. dunkel ockerfarben, glatt, konzentrisch gezont, strahlig runzelig, Rand dünn, unten steril. St. bis $2,5 \mathrm{~cm}$ hoch, rostbraun, angedrückt filzig, am Grunde knollig. Stacheln am St. herablaufend, dicht stehend, $3-5 \mathrm{~mm}$ lg., dünn, hell-, später rostbraun. Gesellig, oft zusammengewachsen, auf der Erde u. über Zweigen in Lb.u. Ndwäldern, zerstreut. S. H. (Gezonter S.)

C. zonatus (Batsch).

4. Hut kreiself., oben flach od. eingedrückt, mit stumpfem Rande, $5-11 \mathrm{~cm}$ br., schwammig-korkig, anfangs mit weißem, blutrote Tropfen ausschwitzendem Filz bedeckt, dann glatt, rostbraun. St. bis $2 \mathrm{~cm}$ hoch, rostbraun. Stacheln bis $5 \mathrm{~mm} \mathrm{lg.,} \mathrm{spitz,} \mathrm{rost-}$ braun. Frisch nach Mehl riechend. Gesellig am Boden in Lb.u. Ndwäldern, nicht selten. S. (Bastard-S.)

C. hybridus (Bull.).

Hut kreiself., dann am Rande ausgebreitet u. verflachend, braun, selten gezont, korkig-filzig, bis $15 \mathrm{~cm}$ br., $10 \mathrm{~cm}$ hoch, anfangs mit weißem Filz überzogen. St. kurz, oft fehlend, braun. Stacheln spitz, $8 \mathrm{~mm}$ lg., nach dem Rande kürzer, grau, später braun, an der Spitze heller. Geruch frisch zimmetartig. Auf der Erde in dürren, sandigen Kiefernwäldern, nicht selten. S. H. (Fester S.)

C. compactus (Pers.).

\section{Gattung: Sarcodon Quélet (Fleischzahn).}

Fk. fleischig, mit zentralem St. Hut scharf abgesetzt, gewölbt. Stacheln pfriemlich, braun werdend. Sporen braun, stachlig od. höckerig.

Hut kreisf., 4-15 cm u. breiter, flach gewölbt, später in der Mitte niedergedrückt, am Rand anfangs eingerollt, ungezont, umbrabraun, mit großen, dicken, konzentrischen, sparrigen Schuppen. St. $2-8 \mathrm{~cm}$ lg., unten braun, nach oben weißlich. Stacheln pfriemlich. dicht stehend, etwas am St. herablaufend, 5-6 mm lg., weiß, dann braun. Eßbar. Am Boden in dürren Kiefernwäldern, nicht selten. S. H. (Fig. 87.) (Rehpilz, Hirschschwamm, Habichtspilz.)

S. imbricatus (L.).

Hut kreisf., 8-11 cm br., flach gewölbt, in der Mitte etwas eingedrückt, ocker- bis rotbraun od. rostbraun, \pm dicht mit dunkel braunen, anliegenden, später abfallenden Schuppen besetzt. St. weißlich, ungleich dick. Stacheln weißlich, dann braun mit weißlicher Spitze. Am Boden in Ndwäldern, selten. S. H. (Fig. 88.) (Schuppiger F.)

S. subsquamosus (Batsch).

10. Gattung: Phlebia Fries (Aderschwamm).

Fk. knorpelig, wachsartig, flach ausgebreitet, oben vom Hymenium überzogen u. mit Falten u. Adern bedeckt, die eine scharfe, kammartige Schneide besitzen. Sporen farblos, glatt. 
Einzige Art mit strahlig ausgebreitetem, fleischfarbigem od. orangerotem Fk., der am Rand blaß, strahlig-faserig ist. Falten strahlig, etwas gewunden, kammartig, innen schwach höckerig. An alten Baumstümpfen, dicken Ästen von Lbbäumen, seltener Kiefern in feuchten Waldteilen, nicht selten. S. H. (Orangefarbener A.)

P. aurantiaca (Sowerby).

\section{Gattung: Xylodon Karsten (Holzzahn).}

Fk. zähe, filzig od. lederig, flach ausgebreitet. Platten zahnartig, dicht stehend, flach, vom Hymenium überzogen. Sporen farblos, glatt.

1. An Lb.

Fk. dünn, häutig, fest angewachsen, weiß, zart flockig, dann kahl. Zähne spatelig, ganzrandig od. an der Spitze etwas eingeschnitten, klein, zart, am Grunde undeutlich verbunden. An berindeten Ästen von Fichten, Kiefern u. Tannen, nicht häufig, in den Vorbergen häufiger. S. H. W. (Spatelförmiger H.)

\section{X. spatulatus (Schrad.).}

2. Fk. lederig, kreisf., dann zusammenfließend, weiß, später gelblich-weiß, am Rande striegelhaarig. Oberfläche buchtig gefaltet, mit fingerf. eingeschnittenen u. gefransten, aufrechten Zähnen. Auf abgefallenen Lbästen, besonders Kirsche, zerstreut. S. H. W. (Seltsamer H.)

X. paradoxus (Schrad.).

Fk. oft weit ausgebreitet, weiß od. gelblich weiß, am Rande häufig flockig-fädig. Zähne am Grunde wabenartig verbunden, oft labyrinthartige Poren bildend, $2-4 \mathrm{~mm}$ lg., am Rande meist eingeschnitten, gesägt, ungleichartig. An Lbästen, besonders Rotbuche nicht selten. S. H. W. (Fig. 89.) (Schiefer H.)

X. obliquus (Schrad.).

\section{Gattung: Irpex Fries (Eggenschwamm).}

Fk. zähe, filzig-lederig, ganz od. teilweise sich von der Unterlage abhebend, sitzend, fast kurzgestielt, hängend. Platten zahnartig, dichtstehend. Sporen farblos glatt.

1. Fk. aufliegend, von der Unterlage abstehend, ganz ohne St.Bildung.

Fk. sehr dünn, häutig-lederig, fast halbkreisf., am Grunde zu einem kurzen St. zusammengezogen, hängend, $1-2 \mathrm{~cm}$ br., oft rasig, gelblich od. ockerfarben, trocken hellbräunlich, oberseits gefaltet $u$. runzelig, mit angedrückten, haarigen Schuppen. Zähne reihenweise gestellt, zerschlitzt, weißlich. An Holz u. Stümpfen von Kiefern, selten. S. H. (Hängender E.)

I. pendulus (Alb. et Schwein.).

2. Zähne fleischrot, violett od. bräunlich.

Fk. ausgebreitet, etwas zurückgebogen, lederig, zottig, konzentrisch gefurcht, weiß. Zähne milchweiß, dicht, reihenweise, 
spitz, etwas eingeschnitten. An Stämmen u. Holz von Lb.- u. Ndbäumen, nicht häufig. H. (Milchweißer E.)

I. lacteus (Fries).

3. Fk. ausgebreitet, zurückgebogen, weich lederig, behaart, nicht gezont, milchweiß. Zähne dick, weißlich fleischrot, zugespitzt, am Grunde in Reihen verbunden. Reihenweise u. rasig an Brettern u. Stümpfen von Kiefern, zerstreut. H. (Weißrötlicher E.)

I. carneoalbus (Fries).

Fk. lederig, zum größten Teil anhaftend, im obern Teil frei abstehend, oft dachziegelig übereinander, oben weiß od. grau, silberhaarig-zottig, gezont, $1-2 \mathrm{~cm}$ abstehend. Zähne bis $4 \mathrm{~mm}$ lg., fleischrot, violett, zuletzt bräunlich, reihenweise am Grunde verbunden. (Alles weißlich grau gefärbt. var. Hollii [Kunże et Schmidt].) An Zäunen, Brettern, gefälltem Holz von Kiefern, gemein. Das ganze Jahr. (Fig. 90.) (Braunvioletter E.)

I. fuscoviolaceus (Schrader).

13. Gattung: Sistotrema Pers. (Schütterzahn).

Fk. gestielt, hutf., unterseits die Zähne tragend, fleischig od. häutig. Platten zahnf., schmal lamellenartig, meist ordnungslos od. strahlig, vom Hymenium überzogen. Sporen farblos, glatt.

Einzige Art mit 2-3 cm langem, gestieltem Fk. Hut \pm regelmäßig, oben flach, zottig filzig, zuerst weiß, dann gelblich, rötlichgelb bis ockerfarben. St. aufrecht, dünn, oft seitenständig. Zähne zugespitzt od. br. abgestutzt, weiß od. gelblich. An Erde, zwischen Moos, oft an Wegrändern im Kiefernwald, zerstreut. S. H. (Fig. 91.) (Zusammenfließender S.)

S. confluens Pers.

\section{Familie: Polyporaceae.}

Fk. von verschiedenэr Gastalt u. Substanz, flach krustig, sich abhebend, seitlich od. zentral gestielt, lederig, korkig, wergartig, fleischig usw. Hymenium die Innenseite von Höhlungen überziehend, die aus aderig verbundenen Falten, gewundenen Gängen, Röhren od. selten aus radiär verlaufenden L. gebildet werden. Basidien keulig, fast stets viersporig. Sporen hyalin od. gefärbt.

Bestimmungsschlüssel der Gattungen.

A. Höhlungen durch niedrige, anfangs faltenf., später sich zu engeren Gruben od. Gängen zusammenschließende Erhabenheiten gebildet.

\section{Merulius.}

B. Wirkliche Röhren od. tiefe unregelmäßig gewundene Gänge od. ungefähr radiär verlaufende L. gebildet.

a) Substanz der Fk. zwischen die Röhren, Gänge usw. hineingehend $u$. diese deshalb nicht von jenem ablösbar. 
I. Röhren fest aneinander liegend (Gänge usw. dicht zusammenschließend).

1. Hymenium in engen, etwa zylindrischen Röhren.

a) Substanz des Hutes von der zwischen den Röhren verschieden.

* Fk. umgewendet, flach aufgewachsen.

** Fk. halbiert, hutf., gestielt od.

\section{Poria.} nicht.

§ Fk. von Anfang an \pm holzig.

$\S \S$ Fk. anders beschaffen.

$\dagger$ Fk. anfangs fleischig, dann hart werdend.

†† Fk. häutig, lederartig od. wergartig.

3. Fomes ${ }^{1}$ ).

B) Substanz des Hutes von der zwischen den Röhren nicht verschieden, daher die Röhren gleichsam in den Hut eingesenkt.

\section{Polyporus.}

\section{Polystictus.}

\section{Trametes.}

2. Hymenium nicht in Röhren, sondern in Gängen od. auf L.

a) Labyrinthartige, \pm lggestreckte Gänge vorhanden. Fk. lederig.

* Gänge labyrinthartig.

** Gänge lggestreckt, mehr lamellenartig.

7. Daedalea.

8. Lenzites.

$\beta$ ) Wirkliche, radiäre, unten wabenartig verbundene $\mathrm{L}$. vorhanden. Fk. fast fleischig.

\section{Favolus.}

II. Röhren isoliert stehend (Gänge usw. nie vorhanden).

1. Fk. umgewendet, häutig.

2. Fk. seitlich angeheftet, \pm fleischig. 11. Fistulina.

\section{Porothelium.}

b) Substanz des Fk. nicht zwischen die Röhren gehend, daher die Röhrenschicht leicht abhebbar.

1. Sporenpulver weiß, Sporenmembran farblos.

2. Sporenpulver blaßrot, Sporenmembran blaß gefärbt.

\section{Suillus.}

\section{Tylopilus.}

1) Die Beurteilung der inneren Struktur erfordert einige Übung, die man sich aber bald durch zahlreiche Untersuchungen erwirbt. 
3. Sporenpulver braun, Sporenmembran gefärbt.

4. Sporenpulver schwarz.

14. Boletus.

$\mathrm{Zweifelhafte}$ Gattung.

Nur Chlamydosporen, keine Poren.
15. Strobilom yees.

16. Ceriom yces.

\section{Gattung: Merulius Haller (Faltenschwamm).}

Fk. weich, fast gallertartig, lederig od. weich watteartig, krustenf. aufgewachsen od. halbiert hutf. u. teilweise abstehend, auf der Oberseite mit aderigen, stumpfen, in der Mitte $\pm \mathrm{zu}$ Poren zusammenschließanden Falten, die vom Hymenium überzogen werden. Sporen hyalin od. braun.

1. Sporen hyalin.

Sporen braun. In der Jugend weiche, weiße, watteartige Myzelmassen bildend, die zu seidenglänzenden grauweißen Überzügen eintrocknen. Fk. groß, flach aufgewachsen, oft am Rande lappig abstehend, oft fast dachziegelig übereinander, am Rande weiß, filzig. Hymenium ockerbraun bestäubt, mit stumpfen, gewundenen, oft maschig verbundenen Falten, die auch zahnartig od. stachelig an einer Wabenecke vorgezogen sein können. Sporen fast eif., $10-11 \mu \mathrm{lg} ., 5-6 \mu$ dick, gelbbraun. In Häusern auf Holz, Balken, Steinen usw., das Holz zerstörend u. großen Schaden anrichtend, nur in schlecht ventilierten Räumen, bei Zugluft absterbend. Selten im Walde an Wurzeln u. Stämmen von Kiefern. Das ganze Jahr. (Fig. 92.) (Hausschwamm.)

\section{M. lacrimans (Wulfen) $)^{\mathbf{1}}$ ).}

2. Fk. flach krustig aufliegend, am Rande allmählich verlaufend, nicht scharf.

Fk. nicht vollständig aufliegend, sondern teilweise lappig abgebogen, Rand scharf.

3. Hymenium nicht rein weiß.

Fk. wollig, ausgebreitet, später hautartig dünn, milchweiß, Falten netzf. verbunden, später flache, unregelmäßige Runzeln bildend. An Rinde u. Holz von Lb.- u. Ndbäumen, selten. H. (Flüchtiger F.)

M. fugax Fries.

4. Hymenium fleischrot od. blaßrot.

Hymenium gelb, olivengrün, grauviolett usw.

5. Falten u. daraus entstehende porenartige Höhlungen stets glatt. 6 . Fk. weich wachsartig, krustig aufgewachsen, am Rand fast kahl,

1) Nach neueren Untersuchungen von Falck zerfällt die Art in zwei nahe verwandte: M. domesticus in den Häusern und M. silvester im Walde. Jener hat das Optimum seiner Entwicklung bei 22, dieser bei 26 C. Die Unterschiede sind rein physiologisch; äußere Unterschiede lassen sich nicht feststellen. Näher kann hier nicht darauf eingegangen werden. 
fleischrot od. rotbraun. Falten sich zu länglichen, zerschlitzten, auf einer Seite höheren Poren vereinigend. An abgefallenen Lbbästen u. -stämmen, nicht häufig. H. (Roter F.)

\section{M. rufus Pers.}

6. Fk. weichhäutig, dünn, ausgebreitet, locker angeheftet, unterseits u. am Rande flockig-zottig u. weiß. Falten dicht, schwach hervorragend, zu gewundenen Poren vereinigt, fleischrot, trocken fast orangerot. Auf faulem Holz u. Ästen von Kiefern, selten. H. (Weicher F.)

M. molluseus Fries.

Fk. dünnhäutig, flach aufgewachsen, krustig, anfangs glatt weißlich, später rötlich, Falten niedrig, runzelig, sich zu eckigen, niedrigen Poren vereinigend, am Rande u. unterseits weißfädig. An faulendem Nd., seltner Lb., zerstreut. H. W. F. (Kriechender F.)

M. serpens Tode.

7. Fk. wollig, sehr weich, ausgebreitet, locker angeheftet, unterseits seidig faserig, am Rande wollig, lila. Falten kraus höckerig, zu gewundenen Poren verbunden, olivengrün, grauviolett, schmutzig gelb. Auf faulem Kiefernholz, selten. H. (Fig. 93.) (Strangförmiger $\mathrm{F}$.)

M. himantioides Fries.

Fk. dünn, häutig, weich fleischig, ausgebreitet, im Umfange spinnwebartig zottig, goldgelb. Falten kraus, zu flachen, gewundenen Poren verbunden. Auf abgefallenen Zweigen, Holz, über Blättern u. Moos, zerstreut. H. (Goldgelber F.)

\section{M. aureus Fries.}

8. Fk. sehr dünn, weich fleischig, am Rande frei u. zurückgeschlagen, auf der freien Fläche kurz zottig, weiß, oft gezont. Hymenium milchweiß od. gelblich, später fleischfarbig mit flachen, netzf. od. gewundenen Poren. Sporen länglich zylindrisch, 9-10 $\mu \mathrm{lg}$., $3 \mu$ dick. An Ästen u. Stümpfen von Lb., nicht selten. H. W. F. (Lederiger F.)

M. corium (Pers.).

Fk. gallertig-fleischig, trocken knorpelig, zuletzt mit den Rändern napff. bis wagerecht abstehend, meist dachziegelig übereinander, oberer Teil grob zottig, weißlich od. grau. Hymenium weiß, gelblich od. rötlich schimmernd, mit krausen, \pm dichten, später flach netzf. verbundenen Falten. Sporen länglich zylindrisch, $4 \mu \lg$., $1-1,5 \mu$ dick. An Stümpfen u. Stämmen, besonders von Weiden u. Pappeln, nicht selten. S. A. (Fig. 94.) (Gallertiger F.)

M. tremellosus Schrader.

\section{Gattung: Poria Pers. (Porenschwamm).}

Fk. flach ausgebreitet, der Unterlage ganz anliegend, häufig nur aus Myzel u. Röhren bestehend, gewöhnlich aber dicker von lederiger, häutiger, fleischiger bis holziger Konsistenz. Röhren meist eng zusammen, bisweilen aber zerstreut stehend, verschieden gefärbt.

1. Poren weiß, entweder nur in der Jugend od. so bleibend. 7.

Poren gelb, violett.

Poren rot od. braun.

2.

Lindau, Kryptogamenflora. I. 2. Aufl. 
2. Fk. meist rundlich od. aber von unbestimmtem Umriß, dünn, glatt, kahl, ohne deutliche Unterlage, violett. Röhren kurz, zellen- od. aderf. Auf faulendem Nd., selten. H. (Violetter P.)

$$
\text { P. violacea (Fries). }
$$

Fk. weit ausgebreitet, dünn lederartig, mit zottigem Rande, gelb. Röhren kurz, glänzend, gelb. Auf faulenden Stämmen u. Holz von Nd. in feuchten Wäldern, selten. H. (Fig. 95.) (Glänzender P.)

P. nitida Pers.

3. Fk. u. Poren rot.

Fk. u. Poren braun.

4. Fk. am Rande glatt.

Fk. ausgebreitet, weich, hellrot od. rosenrot, am Rande weißfaserig. Röhren kurz, Mündungen eckig, etwas eingeschnitten, schimmernd. Auf faulem Holz von Lb., zerstreut. H. F. (Schimmernder P.)

P. micans (Ehrenberg).

5. Fk. ausgebreitet, korkig lederig, glatt, fleischfarben, später schmutzig rot, am Rand etwas abstehend. Röhren meist schief, zusammengedrückt, verlängert, Mündungen ungleich. An Stämmen von Nd., zerstreut. H. F. (Fig. 96.) (Hellroter P.)

\section{P. incarnata (Alb. et Schw.).}

Fk. ausgebreitet, dünn lederig, angewachsen, glatt, kahl, am Rande scharf begrenzt, blutrot. Poren klein, zart. Auf faulenden, feuchten Ästen u. Stämmen, zerstreut. H. (Roter P.)

\section{P. rufa (Schrader).}

6. Fk. krustenf. anliegend, ausgebreitet, filzig-holzig, fast zimmetbraun, dann rostbraun, am Rande zuerst zottig, dann kahl. Röhren 0,5-1 cm lg., Mündungen ziemlich weit, rund, ganzrandig. An Stämmen, behauenem Holz, nicht selten. Das ganze Jahr. (Zusammenhängender P.)

P. contigua (Pers.).

Fk. fest, filzig-korkartig, aufgewachsen, polsterartig, rostbraun, später dunkler, fast ganz aus Röhren bestehend. Röhren 1 bis $2 \mathrm{~cm}$ lg., Mündungen ziemlich groß, ungleich, zerschlitzt. An Stämmen u. faulenden Lbästen, zerstreut. S. H. (Fig. 97.) (Rostfarbiger P.)

P. ferruginosa (Schrader).

7. Poren u. Fk. in der Jugend weiß, sich dann von selbst od. durch Druck verfärbend.

Poren u. Fk. weiß bleibend.

8. Poren u. Fleisch auf Druck sich nicht verfärbend.

Fk. rundlich, später zu großen Flächen zusammenfließend, weich, weißlich, bei Druck u. Verletzung blutrot, dann bräunlich werdend, am Rande dickfilzig, dann kahl. Röhrenmündungen zuerst fein, dann sehr verschieden weit, rundlich, später zerschlitzt. Auf feuchten Stämmen u. Ästen von Lb. u. Nd., seltener auch auf der Erde, zerstreut. S. H. (Blutiger P.)

P. sanguinolenta (Alb. et Schw.). 
9. Poren gelblich od. hellbräunlich werdend.

Fk. spinnwebartig-faserig, zart, weit ausgebreitet, weiß, in der Mitte die kleinen, zuerst weißen, dann rötlichen Poren. Auf der Erde, selten. H. (Erdbewohnender P.)

P. terrestris (DC.).

10. Rand nicht zottig.

Fk. unregelmäßig ausgebreitet, schwach wellig, weißlich, fast durchscheinend, von der Unterlage abtrennbar, mit dünnem, zottigem Rande. Röhren sehr lg., fast fleischig, weich, später gelb, mit rundlichen, stumpfen u. ganzrandigen Mündungen. An Lbstämmen, namentlich Rotbuchen, zerstreut. H. (Glasheller P.)

P. vitrea Pers.

11. Fk. weit ausgebreitet, dünn, lederartig zäh, unversehrt ablösbar, weiß, glatt, am Rand gleichartig. Röhren gelblich werdend. Mündungen rundlich, gleichgroß, stumpf. An Holz, Balken von Kiefern, nicht selten. H. (Schwieliger P.)

\section{P. callosa (Fries).}

Fk. ausgebreitet, eingewachsen, nicht ablösbar, krustig, fest, ganz aus Poren bestehend, die bei älteren Exemplaren in mehreren, je $2-3 \mathrm{~mm}$ dicken Schichten übereinander stahen. Röhren dicht gedrängt, ledergelb werdend, sehr dicht, Mündungen klein, gleichgroß. An faulen Lbstämmen, zerstreut. Ausdauernd.

P. obducens (Pers.).

12. Fk. zäh, lederig korkig, niemals fleischig u. weich bleibend.

Fk. wollig, faserig, weich fleischig u. so bleibend.

13. Poren stets eng, punktf.

Poren weit, stets auffällig.

14. Fk. weit ausgebreitet, scharf begrenzt, fast holzig, $1-1,5 \mathrm{~cm}$ dick, am Rand kahl, glatt, etwas' wulstig, weiß. Röhren 0,5 bis $1 \mathrm{~cm}$ lg., dicht, Mündungen fein, gleichdick, rundlich. An Stämmen u. bearbeitetem Holz von Lb. u. Nd., nicht selten. Fast das ganze Jahr. (Fig. 98.) (Brotkrumen-P.)

P. medulla panis (Pers.).

Fk. weit ausgebreitet, weiß. Poren oberflächlich, sehr klein punktf., nackt. Auf Rinde von Lb., zerstreut. S. H. (Rindenbewohnender P.)

P. corticola (Pers.).

15. Fk. im Umfang faserig, weit ausgebreitet, weiß, später blaß gelblich. Röhren 1,5 cm lg., dicht stehend, Mündungen von mittlerer Größe, ungleich, rundlich od. kantig, oft zerschlitzt. An Zweigen, Lb. u. Nd. in Wäldern, zerstreut. Fast das ganze Jahr. (Schleimiger P.)

P. mucida Pers.

Fk. ausgebreitet, teilweise vom Substrat ablösbar, weiß, dann gelblich werdend, am Rande in der Jugend schwach flaumig. Röhren verlängert, gebogen, Mündungen weit, verschieden ge-

1) Vgl. auch 15 P. sinuosa und mucida. 
formt, oft zerschlitzt. An Stämmen von Nd., zerstreut. Fast das ganze Jahr. (Eckiger P.)

P. sinuosa (Fries).

16. Poren dicht stehend, klein od. groß.

Fk. kreisrund, sehr dünn u. weich, vergänglich, weiß, mit flockig-strahligem Rande. Poren entfernt voneinander stehend, flach napff. An faulem Holz von Nd., seltener an Lb., nicht selten. S. H. W. (Fig. 99.) (Netzf. P.) P. reticulata (Pers.).

17. Poren fein, rundlich, gleichmäßig. 18.

Poren viel größer, ungleich, eckig.

18. Fk. weit ausgebreitet, trocken zäh, weiß, am Rand kahl. Röhren 1-2 mm lg. Auf faulem Holz, Zweigen, Stämmen von Lb. u. Nd., häufig. S. H. (Fig. 100.) (Gemeiner P.)

P. vulgaris (Fries).

Fk. weit ausgebreitet, weich, sehr dünn, weiß, am Rande strahlig faserig. Röhren sehr kurz. Mündungen später bisweilen zerschlitzt. Auf faulem Lb. u. über Lb., nicht selten. S. H. (Weicher P.)

P. mollusea (Pers.).

19. Fk. häutig filzig, weich, unten zottig, leicht ablösbar, meist weit ausgebreitet. Röhren 2-3 mm lg., in der Jugend fein behaart. Poren weit, eckig, oft zähnig. Auf faulem Holz u. Ästen von Lb., zerstreut. S. H. (Fig. 101.) (Zähneliger P.)

P. radula Pers.

Fk. weit ausgebreitet, mit einem flockigen, weiten, sich weithin verbreitenden Myzel. Röhren 5-8 mm lg., weich. Poren groß, eckig, oft zerschlitzt. Geruch scharf. Auf Lb. u. Nd., oft in Häusern die Balken zerstörend, häufig. Das ganze Jahr. (Fig. 102.) (Loh-P.)

P. vaporaria Pers.

(Als Varietät gilt var. Vaillantii (DC.), unterschieden dadurch, daß der ganze Fk. sich in strangartige Myzelüberzüge auflöst, auf denen nur hier u. da gruppenweise Röhren auftreten.)

\section{Gattung: Fomes Fries (Holzschwamm).}

Fk. im Innern zähflockig, zunderartig, selten weich, stets saftlos, gleichmäßig, mit harter, holzartiger Rinde umkleidet, ausdauernd, oft mit konzentrischen Zonen, abstehend, halbiert od. gestielt. Röhren oft schichtweise übereinander.

1. Fk. stets ungestielt, höchstens seitlich etwas stielartig zusammengezogen.

Fk. innen rostbraun, korkig-holzig. St. bis $8 \mathrm{~cm} \mathrm{lg.,} \mathrm{bisweilen}$ sehr kurz, seitlich. Hut nieren- od. fast kreisf., bis $8 \mathrm{~cm}$ im Durchm., 1-3 cm dick, oberseits erst braun bestäubt, dann wie der St. glänzend lackiert, zuerst kirschrot, dann dunkelschokoladenbraun. Röhren bis $1 \mathrm{~cm} \mathrm{lg.,} \mathrm{rostbraun.} \mathrm{Am} \mathrm{Grunde}$ von alten Lb. nicht selten. Fast das ganze Jahr. (Fig. 103.) (Lackierter H.)

F. lucidus (Leysser).

2. Substanz des Fk. im Innern weiß, hell- bis holzfarben. 3. Substanz des Fk. im Innern braun, rot od. rostbraun. 11. 
3. Fk. im Innern holzig, nicht flockig-zunderartig, Röhren nicht oder nur selten schichtweise übereinander stehend.

Fk. im Innern flockig-zunderartig, hart, Röhren nach den Vegetationsperioden übereinander geschichtet.

4. Hut oben weiß.

8.

Hut oben irgendwie braun.

5.

6.

5. Hut muschelf., leicht ablösbar, meist mehrere verwachsen, holzig, weiß, ungezont, zuerst zottig, dann kahl, mit scharfem Rand, innen weiß. Poren rundlich, ungleich, stumpf. An abgefallenen Buchenzweigen, zerstreut. S. H. (Nees' H.) F. Neesii (Fries).

Hüte dachziegelig übereinander, mit herablaufender Basis verwachsen, oben etwa $1-1,5 \mathrm{~cm}$ breit, flockig-holzig, ungezont, zuerst flockig od. zottig, mit stumpfem Rand, ganz weiß. Poren kurz, klein, rund. An Pappeln, nicht selten. S. H. (Pappel-H.) F. populinus (Fries).

6. Hüte meist wagerecht abstehend, regelmäßig, flach, nicht glänzend u. schwärzlich.

Fk. sehr verschieden gestaltet, schalenf., inkrustierend, halbkreisf. abstehend, oft verschmelzend $u$. verwachsen, holzig, innen holzfarben, oberseits kastanien- bis umbrabraun, am Rande heller u. mit vielen schmalen konzentrischen Zonen, runzelig, höckerig, in der Jugend seidenartig glänzend, im Alter mit einer kahlen, glatten, schwärzlichen Kruste überzogen. Röhren bisweilen, nicht immer geschichtet, weiß, dann hell ockerbraun, schimmernd, fein. Sporen eif., $5 \mu$ lg., $4 \mu$ dick. Auf Nd. sehr schädlich, ganze Bestände vernichtend, häufig. Das ganze Jahr. (Fig. 104.) (Kiefernwurzelschwamm.) F. annosus (Fries).

7. Hut nierenf., flach, höchstens $5 \mathrm{~mm}$ dick, glatt u. kahl, ungezont, kastanienbraun, innen weiß. Poren sehr klein, rundlich, gelblich, nach dem Rande hin braun. An Pappeln, zerstreut. H. (Kastanienbrauner H.)

F. castaneus (Fries).

Hut verschieden geformt, etwas herablaufend, flach, ungezont, kahl, zuerst glatt, später konzentrisch gefurcht-gefaltet, weiß, dann rotbraun od. braun, innen blaß. Poren klein, kurz, rötlichrostbraun, in der Jugend weißzottig. An Eschenstämmen, zerstreut. H. (Eschen-H.)

F. fraxineus (Bull.).

8. Hüte nicht dachziegelig übereinander stehend, kahl. 9 .

Hüte dachziegelig übereinander stehend, ausgebreitet, umgebogen, korkig-holzig, zottig, weiß od. grau. Poren geschichtet, weiß, rundlich, klein. An Baumstämmen, zerstreut. S. H. (Fig. 105.) (Verwachsener H.) F. connatus (Fries).

9. Hut oben gleichfarbig, höchstens der Rand verschieden gefärbt.

10.

Hut flach, kahl, grau bereift, gezont, jedes Jahr eine anders farbene Zone bildend (weißgrau, gelbbraun, blutrot), innen lederfarbig. Poren rundlich, strohfarben, an der Mündung weiß 
gerieben rötlich. An Lb. (Eiche, Rotbuche), zerstreut. S. H. (Berandeter H.)

F. marginatus (Fries).

10. Hut ausgebreitet, dick, höckerig, $8-11 \mathrm{~cm}$ groß, sehr hart, weiß, später schwärzlich mit gelbbraunem Rande, innen weiß. Poren geschichtet, klein, gleichgroß, gelblich. An Ulmenstämmen, nicht selten. Fast das ganze Jahr. (Ulmen-H.)

F. ulmarius (Sowerby).

Hut anfangs polster-, später huf- $u$. konsolenf., $10-15 \mathrm{~cm}$ lg., $3-5 \mathrm{~cm}$ dick, innen holzfarben, oberseits kahl, mit einer festen Kruste überzogen, runzelig, dunkelbraun, zuletzt schwärzlich, am Rande stumpf, beim Wachstum fast orange- od. zinnoberrot. Poren geschichtet, fein rundlich, weißlich, später hell ockerfarben, etwas unregelmäßig. Sporen länglich, $4-5 \mu$ lg., $3 \mu$. dick. An alten Ndstümpfen, verbreitet. Das ganze Jahr hindurch. (Koniferen-H.)

11. Sporenpulver braun, Sporenmembran braun.

Sporenpulver weiß, Sporenmembran hyalin.

12. Hut abstehend, ungestielt, stets deutlich vorhanden.

Fk. korkig, fast nur aus Röhren bestehend, weit verbreitet, aus der Rinde hervorbrechend, am Rand oft kammartig, gezähnt aufrecht, dunkelbraun. Röhren $1-2 \mathrm{~cm}$ lg., Mündungen klein, eckig, zuletzt gezähnelt, kastanienbraun, später schwärzlich. An alten Stämmen u. Ästen von Lb., besonders Rotbuche häufig. S. H. W. (Fig. 106.) (Schiefer H.) F. obliquus (Pers.).

13. Hut perennierend, halbkreis- od. nierenf., oben abgeflacht, unten meist nur schwach gewölbt, $8-10 \mathrm{~cm}$ br., $2-5 \mathrm{~cm}$ dick (oft viel größer), hinten oft gebuckelt u. stielf. verschmälert, innen rostbraun, weich filzig, oberseits zuerst feinhaarig, braun bestäubt, später kahl, mit gebrechlicher, graubrauner Rinde, gezont, Rand dick, abgerundet. Röhren geschichtet, $1-3 \mathrm{~cm}$ lg., nach dem Rand zu scharf abgesetzt, rostbraun, Mündungen weiß, bei Druck braun, später rostbraun. An alten Lbstümpfen, besonders Pappeln, Buchen, häufig. Das ganze Jahr. (Fig. 107.) (Abgeflachter H.)

F. applanatus (Pers.).

Hut perennierend, dick polster-od. konsolenartig, $6-15 \mathrm{~cm}$ br., bis $8 \mathrm{~cm}$ dick (u. größer), innen weich filzig, dunkelkastanienbraun, oberseits fein filzig, später glatt, mit bräunlicher, gebrechlicher Rinde, konzentrisch gefurcht. Röhren bis $4 \mathrm{~cm}$ lg., geschichtet, dunkelbraun, Mündungen sehr fein, weißlich, später braun. An alten Lindenstämmen, selten. Das ganze Jahr. (Fig. 108.) (Lebhafter H.)

F. vegetus (Fries).

14. Mündungen rost- od. zimmetbraun, nicht rosenrot.

Hut korkig-holzig, dick, fast keilf., bis $8 \mathrm{~cm} \mathrm{lg.,} 1-3 \mathrm{~cm}$ dick, innen rosenrot, oberseits mit filzigem, schwärzlichgrauem Flaum. Röhren geschichtet, kurz, Mündungen fein, rosenrot. An Ndstämmen, selten. Das ganze Jahr. (Rosenroter H.)

F. roseus (Alb. et Schwein.). 
15. Hut oberseits nicht od. nur sehr undeutlich konzentrisch gezont u. dann Röhren ungeschichtet.

16.

Hut oberseits deutlich konzentrisch gezont, Röhren stets deutlich geschichtet.

17.

16. Hut holzig, zum größten Teil aus sich weit hinabziehenden Röhren bestehend, nur mit dem oberen, 1-2 em br. Rand abstehend, oberseits braun, später schwarz, glatt, Rand stumpf, wellig. Röhren 2-3 mm lg., Mündungen sehr klein, rundlich, zimmetbraun. An alten Weidenstämmen, auch Weißbuchen, nicht selten. Das ganze Jahr. (Weiden-H.)

F. salicinus (Pers.).

Hut holzig, sehr hart, halbkuglig od. knollig, sehr dick (bis $15 \mathrm{~cm}$ ), innen gelbbraun, oberseits zuerst kurz rauhhaarig, gelbbraun, später grau, glatt od. höckerig, selten undeutlich gezont. Röhren 1-3 cm lg., ungeschichtet, Mündungen rundlich, sehr klein, grau bereift, zuletzt zimmetbraun. Auf alten Stämmen, besonders von Nd., zerstreut. Das ganze Jahr. (Gelbbrauner H.) F. fulvus (Scopoli).

17. Mündungen zuerst grau bereift, dann rost- bzw. zimmetbraun. 18. Mündungen nicht bereift, zimmet- bzw. gelbbraun. 19.

18. Hut huff.-polsterartig, im Umfang kreisf., $10-30 \mathrm{~cm} \mathrm{lg.,} 5$ bis $15 \mathrm{~cm}$ dick, innen wergartig-korkig, rostbraun, oberseits gewölbt, in der Jugend fein filzig, gelbbraun, dann glatt, mit dünner fester Haut überzogen, bräunlich, zuletzt grau mit undeutlichen Zonen, Rand stumpf. Röhren vielschichtig, rostfarben. Mündungen klein, rundlich, anfangs grau bereift, später rostbraun. (F. nigricans, durch glänzend schwarze, harte,! glatte Oberfläche verschieden, ist vielleicht nur eine Altersform.) An alten Lbstämmen, nicht selten. Dăs ganze Jahr. (Fig. 109.) (Zunderschwamm.)

F. fomentarius (L.).

Hut holzig, sehr hart, kuglig-knollig, später mehr huf- od. polsterf., $6-20 \mathrm{~cm}$ br., bis $10 \mathrm{~cm}$ dick, innen rostbraun, oberseits in der Jugend fein flockig, gelbbraun, später kahl mit harter, grauer od. schwärzlicher, glanzloser Rinde, gezont, Rand stumpf, rundlich. Röhren mehrschichtig, Mündungen fein, rundlich, anfangs grau bereift, später zimmetbraun. An Lbstämmen, häufig. Das ganze Jahr. (Fig. 110.) (Feuerschwamm.)

F. igniarius (L.).

19. Hut korkig-holzig, im obern Teil abstehend, muschelf. od. halbkreisf., 4-6 cm lg., hinten $0,5 \mathrm{~cm}$ dick, oberseits filzig-striegelhaarig, kastanienbraun, gezont, Rand dünn, gelbbraun. Röhren mehrschichtig, $2-3 \mathrm{~cm}$ lg., Mündungen fein, rundlich, zimmetbraun, frisch gelbbraun. An alten Weidenstämmen, nicht selten. S. H. W. (Muschelf. H.) F. conchatus (Pers.).

Hut korkig-lederig, halbkreisf., abgeflacht, $6 \mathrm{~cm}$ br., $1 \mathrm{~cm}$ dick, oft dachziegelig übereinander, oberseits filzig, rostbraun, tief weitläufig gezont, im Alter kahl, dunkelbraun, Rand dünn, in 
der Jugend gelbbraun. Röhren mehrschichtig, $2 \mathrm{~cm}$ lg., Mündungen sehr fein, gelbbraun. Am Grunde von alten Stachel- u. Johannisbeerstämmen, häufig. S. H. W. (Fig. 111.) (Stachelbeer-H.)

F. ribis (Schum.).

\section{Gattung: Polyporus Micheli (Porenschwamm).}

Hut zähfleischig, dann erhärtend, seltener käsig flockig, zerbrechlich, auf der Oberfläche meist ohne Zonen, aber das Gewebe im Innern oft faserig radiärstrahlig u. oft gezont. Röhren stets ungeschichtet. Substanz zwischen den Röhren von der des Hutes verschieden, oft anders gefärbt. Sporenpulver weiß.

A. Hüte stiellos, breit ansitzend, auch umgewendet, nicht zerschlitzt, oft dachziegelig übereinander, seltener (vgl. von $19 \mathrm{ab}$ ) am Grunde etwas stielartig zusammengezogen.

1. Hüte stets dachziegelig übereinander, sehr selten einmal einzeln. 2.

Hüte stets einzeln (dachziegelig nur bisweilen bei resinosus, benzoinus, trabeus, amorphus, mollis, die auch durch 3 erreicht werden).

2. Gewebe des Hutes von Anfang an braun.

Gewebe des Hutes weiß, gelblich, gelblichbraun, nur bei imberbis nachträglich braun werdend.

3. An Lb. (Beschreibung siehe S. 61). P. resinosus (Schrad.).

An Nd. (Beschreibung siehe S. 61).

P. benzoinus (Wahlenberg).

4. Hut von Anfang an kahl, nicht zottig, flockig od. haarig.

Hut irgendwie zottig od. haarig.

5. Hut weißlich, gelblich od. rötlich u. so bleibend.

Hüte dicht dachziegelig, in-großen Rasen, auf einer grundständigen Anschwellung sitzend, am Rand gelappt, mit konzentrischen Furchen, anfangs bla $\beta$ weißlich, dann braun werdend. Poren zart, dicht, lineal u. labyrinthf., gelblich. Am Grunde alter Stämme, selten. S. H. (Fig. 112.) (Bartloser P.)

\section{P. imberbis (Bull.).}

6. Auf Nd.

Hüte dachziegelig, 5-6 cm groß, korkig-fleischig, glatt, kahl, ungezont, gelblich, mit scharfem Rand. Poren kurz, klein, rundlich, weiß, später gelblich. An Ästen u. Stämmen von Lb., selten. H. (Blasser P.)

P. pallescens Fries.

7. Poren sich bei Berührung nicht verfärbend.

Poren weiß, durch Druck rot werdend (Beschreibung siehe S. 60 ).

P. mollis (Pers.).

8. Hutoberfläche rauh (Beschreibung siehe S. 61).

P. trabeus Rostkovius.

Hüte dachziegelig, polsterf., bis $12 \mathrm{~cm}$ groß, ca. $2,5 \mathrm{~cm}$ dick, mit höckeriger Basis, fleischig-korkig, zerbrechlich, glatt, kahl, weißlich, mit stumpfen, rötlichem Rand. Poren lg., rundlich, 
Polyporaceae.

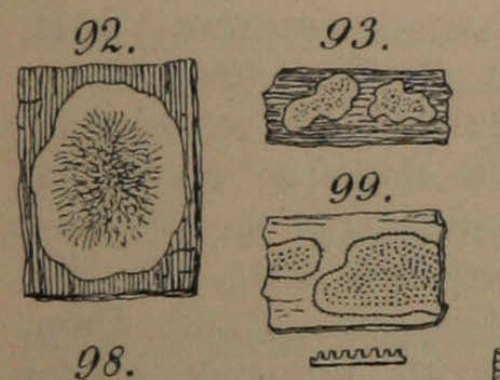

94

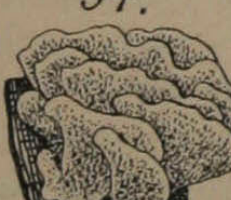

95.

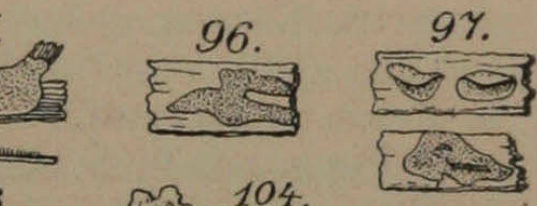

103. $1063^{104}$

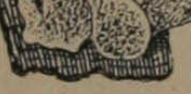

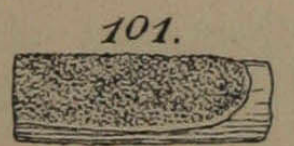

$\left.\int\right)$

20 3

n
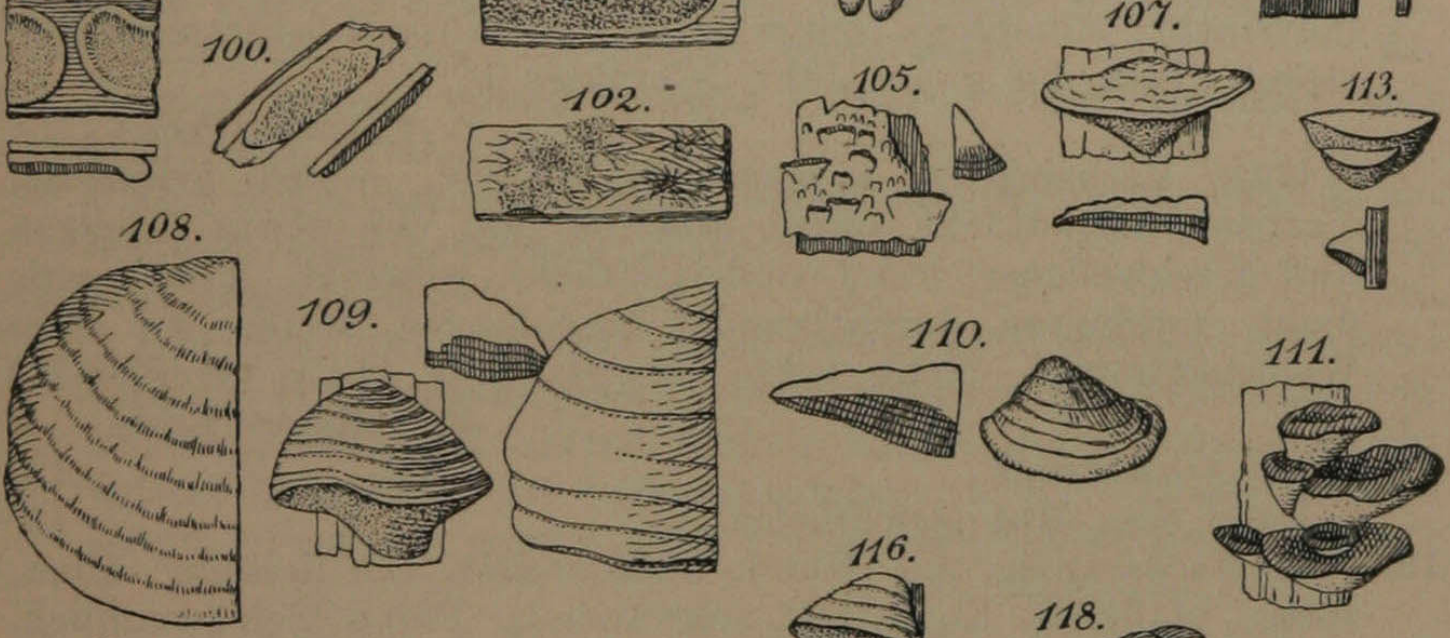

111.

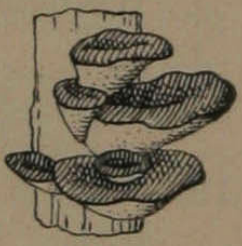

112.
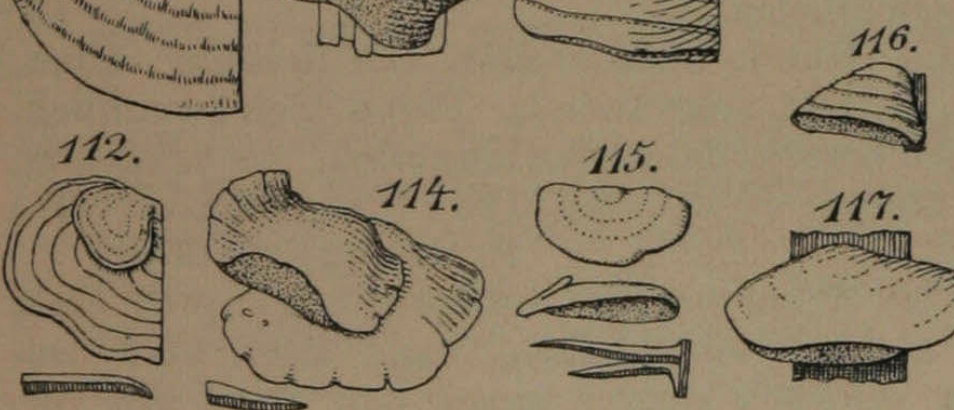

118.
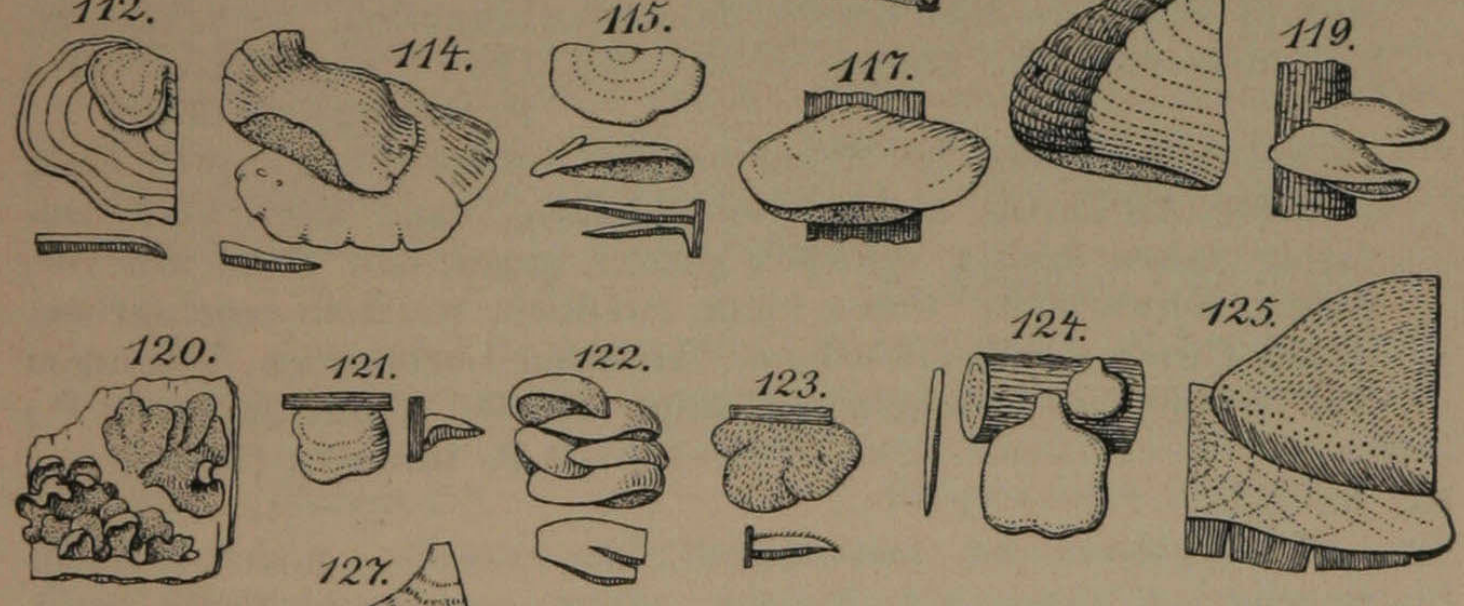

$$
126 .
$$



$\Delta$

130.

$\sqrt{130 .}$
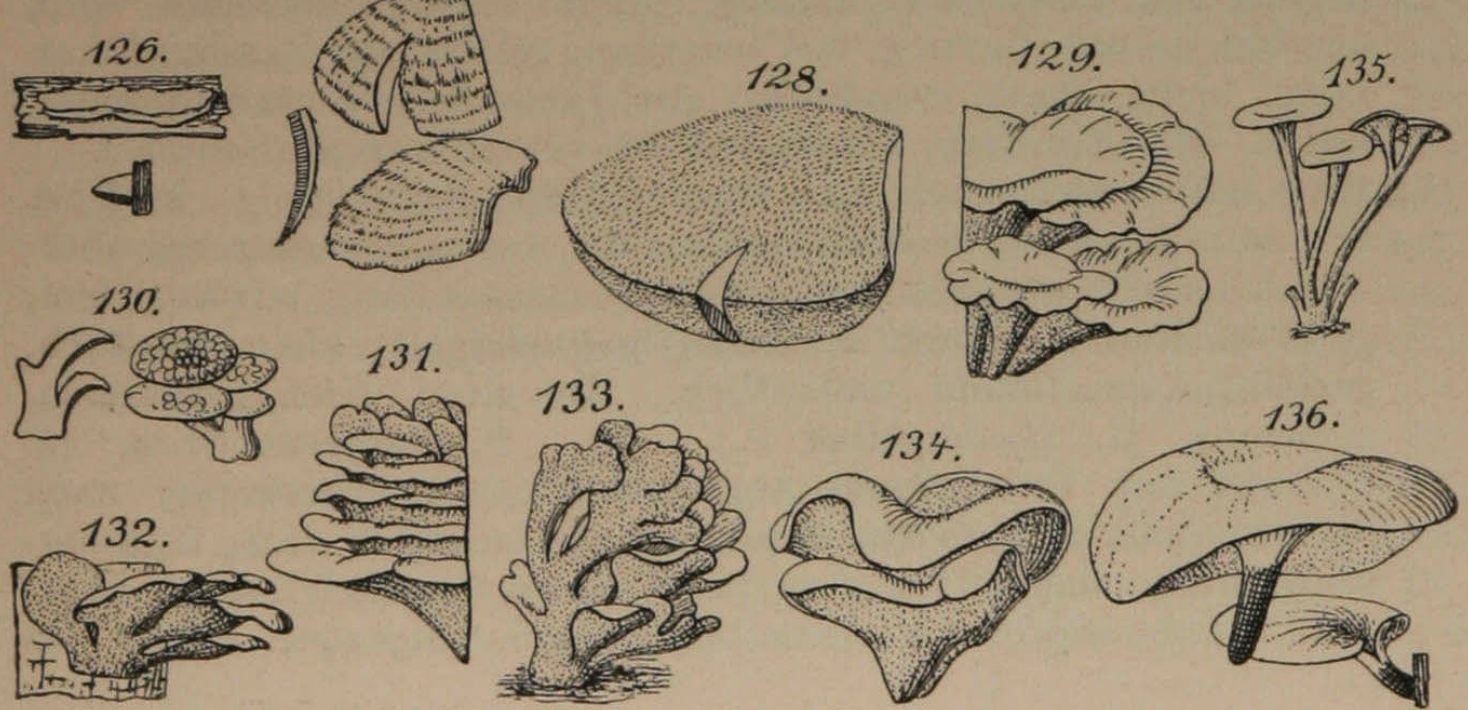

136.

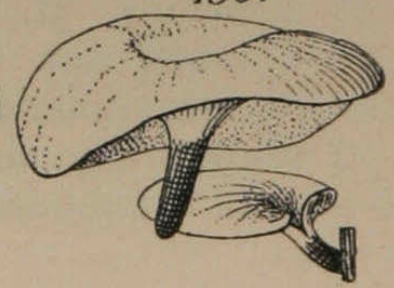


weiß. Grruch ekelerregend. An Kieferstämmen, zerstreut. S. H. (Fig. 113.) (Herber P.) P. stipticus (Pers.).

9. Poren zuerst rundlich, später verbreitert u. labyrinthf., gebogen.10.

Poren rundlich bleibend, nur bei borealis etwas gebogen. 11.

10. Hüte dachziegelig, hinten ausgebreitet, umgebogen -u. bisweilen ganz umgewendet, zuerst zäh fleischig, dann lederartig, runzelig, grau bis schwärzlich, seidenhaarig, $1-2 \mathrm{~cm}$ br., Rand dünn, kraus, zuletzt schwarz. Poren ziemlich groß, ungleich, später labyrinthf., silbergrau, schimmernd. An alten Lbstämmen, zerstreut. Fast das ganze Jahr. (Krauser P.)

P. crispus (Pers.).

Hüte dachziegelig, ausgebreitet nierenf., weich lederartig, elastisch, angedrückt zottig, weißlich um den etwas lappigen und geschwollenen Rand niedergedrückt, gefurcht. Poren zart, dicht, verlängert, durcheinander geschlungen, weiß. An alten Weidenstämmen, nicht selten. S. H. (Fig. 114.) (Weiden-P.) P. salignus Fries.

11. Rand schwärzlich.

Rand dem Hut gleichfarbig.

13.

12. Hüte dachziegelig, am Grunde ausgebreitet, zäh fleischig, dünn, zottig, blaßgrau, Rand steif, schwärzlich. Poren klein, rundlich, stumpf, zuerst weißlich bereift, dann graubräunlich. An Stämmen, bəsonders von Lb., häufig. S. H. (Fig. 115.) (Angebrannter P.) P. adustus (Willd.).

Hüts dachziegelig, 5-12 cm br., br. aufsitzend, ziemlich dick, fleischig, korkartig, anfangs seidenhaarig, dann kahl, blaß rußfarbig, innen faserig, schwach gezont, gegen den Rand hin verdünnt, schwärzlich. Poren klein, rundlich, weißlich-rauchfarben, durch Druck dunkler werdend. An alten Lbstämmen, besonders von Weiden u. Rotbuchen, häufig. S. H. (Rauchfarbener P.) P. fumosus (Pers.).

13. An Nd.

Hüte polster- od. fast nierenf., $2-6 \mathrm{~cm}$ br., mehrere dachziegelig od. rasig, zäh fleischig, dann korkig, oberseits weiß, schwach gezont, flaumig, mit scharfem, gelblichem Rande. Poren kurz, klein, flach, rundlich. An faulenden Birkenstämmen, selten. H. (Fig. 116.) (Behaarter P.) P. pubescens (Schum.).

14. Hüte hinten dick, nach vorn verschmälert, bis $10 \mathrm{~cm} \mathrm{lg.,} 3-5 \mathrm{~cm}$ br., anfangs weich fleischig, dann zähe, meist dachziegelig, oberseits ledergelb, ungezont, runzelig od. schwach filzig, mit scharfem, glattem Rande. Poren 4-6 mm lg., ledergelb, klein, ungleich, gezähnt, am Rande undeutlich. An alten Kiefernstämmen, zerstreut. H. (Ledergelber P.)

P. alutaceus Fries.

Hüte mit br. Grunde angewachsen, dick, bisweilen nach hinten stielartig verschmälert, bis $7 \mathrm{~cm} \mathrm{lg.,} 2 \mathrm{~cm}$ dick, fleischigschwammig, dann korkig, innen weißlich, parallel faserig, oberseits rauhhaarig, weiß, dann blaßgelblich, ungezont. Poren bis 
$1 \mathrm{~cm}$ lg., weißlich, ungleich, verbogen, mit zerschlitztem Rand An alten Ndstämmen, namentlich in Gebirgswaldungen, nicht selten. H. (Fig. 117.) (Nördlicher P.)

P. borealis (Wahlenberg).

Poren gelblich od. rötlich (Beschreibung siehe S. 60).

P. amorphus Fries.

15. Hut innen weiß od. holzfarben, niemals dunkel gefärbt, wenn mehr gelblich, dann von weicher käseartiger Konsistenz. 16.

Hut innen irgendwie gefärbt, nicht weiß.

31 .

16. Hut zu Anfang etwas fleischig u. saftig, dann erhärtend, mit besonderer Rindenschicht.

17.

Hut innen faserig od. käsig, weich, zähe werdend, nicht so erhärtend, ohne besondere Rinde.

19.

17. Hut ungezont.

18.

Hut dick, höckerig, hutf., innen frisch weich, trocken schwammartig-korkig, oberseits gelb u. braun gezont u. mit konzentrischen Furchen, kahl, mit harter, rissiger Rinde. Poren kurz, gelblich, zuletzt bräunlich. An Lärchenstämmen in den Südalpen, nicht selten. Fast das ganze Jahr. (Fig. 118.) (Lärchenschwamm.) P. officinalis (Vill.).

18. Hut halbkreis-, huf- od. nierenf., hinten kurz stielartig verschmälert, fleischig, dann korkartig, ungezont, kahl, mit dünner, abziehbarer, bräunlicher Rinde. Rand eingerollt, stumpf, dick. Poren ca. $4 \mathrm{~mm} \mathrm{lg.,} \mathrm{weiß,} \mathrm{im} \mathrm{Alter} \mathrm{vom} \mathrm{Hut} \mathrm{trennbar.} \mathrm{An}$ Birkenstämmen, sie abtötend, oft in großer Zahl, häufig. Das ganze Jahr. (Fig. 119.) (Birken-P.)

\section{P. betulinus (Bulliard).}

Hut zungenf., flach gewölbt, weich, dann erhärtend, glatt, bla $\beta$ lederfarbig, nach hinten etwas zusammengezogen. Poren kurz, klein, weißlich. An alten Eichen, nicht häufig. Fast das ganze Jahr. (Eichen-P.)

P. quercinus (Schrad.).

19. Hut innen I faserig, nicht käsig-weich, innen stets gezont. 20.

Hut innen von käsiger, wässerig-weicher Konsistenz, nicht faserig, innen selten gezont.

20. Poren bei Druck sich nicht verfärbend.

Hut hinten dick, nach dem Rande verdünnt, $10-15 \mathrm{~cm}$ br., innen wässerig-fleischig, dann grobfaserig, oberseits weißlich, später rotbraun, mit striegeligen rotbraunen Haaren u. weißem Rande. Mündungen labyrinthf. gewunden, weiß, bei Druck rotbraun. An alten Ndstümpfen, nicht häufig. H. (Weinmanns P.) P. Weinmanni Fries.

21. An Lb. 22.

Hut fast ganz der Unterlage angewachsen, mit dem oberen Teil etwa $1-2 \mathrm{~cm}$ br. abstehend, oft dachziegelig, zähe, oberseits u. am Rande seidenhaarig, weiß. Röhren kurz, goldgelb od. rötlich, mit feinen, zuerst weiß bereiften Mündungen. An alten 
Kiefernstümpfen, nicht selten. Fast das ganze Jahr. (Fig. 120.) (Formloser P.) P. amorphus Fries.

22. Poren weiß, dann bräunlich od. rötlich. 23.

Hut ausgebreitet-zurückgebogen, oft große krustige Überzüge bildend, dünn, zähfleischig, oberseits seidenhaarig, weiß, Rand steif, weiß. Poren dunkelzimmetbraun, klein, kurz, rundlich, stumpf. An Lbstämmen (Buche, Birke usw.), nicht häufig. H. (Fig. 121.) (Zweifarbiger P.)

P. dichrous Fries.

23. Hut polsterf., buckelig, runzelig, am Grunde verschmälert, bis $15 \mathrm{~cm} \mathrm{lg} ., 4 \mathrm{~cm}$ dick, innen fleischig schwammig, geschichtet, oberseits höckerig, zottig, Rand stumpf. Poren $1 \mathrm{~cm} \mathrm{lg.,} \mathrm{weiß,}$ später bräunlich, vom Hute trennbar, rund, fein. An hohlen Lbstämmen, zerstreut. S. H. (Schaumiger P.)

\section{P. spumeus (Sowerby).}

Hut mit etwas verschmälerter Basis, zäh fleischig, ungezont, oberseits glatt, kahl, weiß. Poren klein, kurz, rundlich, weiß, dann rötlich. An Weiden u. Buchen, nicht häufig. H. (Weißer P.)

P. albus (Hudson).

24. Poren bei Druck sich in der Farbe nicht ändernd.

Hut ausgebreitet-krustig od. umgebogen, bisweilen dreieckig mit stielf. vorgezogener Basis, od. sogar etwas schirmf. mit mehr zentralem St., seltener mehrere Hüte übereinander, innen fleischig, weich, oberseits runzelig, fleischfarben, mit scharfem Rande. Röhren verlängert, Mündungen ungleich, gewunden, weiß, bei Druck rot werdend. Auf faulenden Ndstämmen, zerstreut. H. (Weicher P.)

P. mollis (Pers.).

25. Hut innen gezont, nicht außen.

Hut innen nicht gezont.

26. Fk. weit ausgebreitet, umgebogen, wässerig-fleischig, zerbrechlich, fast ganz aus Röhren bestehend, hellbräunlich od. schmutzig weißlich, runzelig, wellig, innen gezont. Röhren verlängert, Mündungen rundlich, weißlich, gezähnt od. zerschlitzt. An Kiefernstämmen im Walde, ferner an Brettern u. Balken der Häuser, schädlich u. nicht selten. Das ganze Jahr. (Zerstörender P.)

P. destructor (Schrader).

Hut fleischig, dann korkig, schwach flaumig, oberseits ungezont, schmutzig scherbengelb, innen gezont, mit welligem Rande. Poren klein, kurz, rund, gleichgroß, weiß. An Schwarzpappelstämmen, selten. H. (Scherbengelber P.)

P. testaceus Fries.

27. Hutoberfläche weißlich, auf Druck sich verfärbend.

Hutoberfläche sich auf Druck nicht verfärbend.

28. Hut nierenf., flach, hinten meist sehr dick u. etwas stielartig ausgezogen, innen fleischig, zerbrechlich, zuletzt etwas faserig, oberseits striegelhaarig, runzelig, weißlich, bei Berührung braun. Röhren lg., weißlich, Mündungen gewunden, verlängert. An faulenden Ndstämmen, zerstreut. H. (Zerbrechlicher P.)

P. fragilis Fries. 
Hut ausgebreitet-umgebogen od. dreieckig, bisweilen etwas trichterf. u. fast gestielt, selten mehrere übereinander, $3-6 \mathrm{~cm}$ lg., $2 \mathrm{~cm}$ dick, frisch weiß, bei Berührung od. Verletzung blau, dann schmutzig grün werdend, oberseits uneben, mit kurzzottigen od. anliegenden Fasern. Röhren bis $1 \mathrm{~cm}$ lg., Mündungen fein, ungleich, gebogen u. gezähnelt. An Baumstämmen, auch Bauholz, zerstreut. H. W. F. (Blauer P.)

\section{P. caesius (Schrader).}

29. An Lb.

Hut halbkreisf., oft etwas umgewendet, bisweilen dachziegelig, fleischig, später fest, oberseits rauh, ungezont, gelblichweiß, mit stumpfem Rande. Poren kurz, klein, rundlich, od. etwas verlängert, gezähnt, weiß. An faulendem Fichtenholz, selten. H. (Fig. 122.) (Balken-P.)

P. trabeus Rostkovius.

30. Hut keilf., dünner werdend, hinten dick, fleischig, zerbrechlich, schneeweiß, am Rande scharf, oberseits anfangs flaumig, dann kahl, ungezont. Röhren lg., Mündungen zuletzt labyrinthf., weiß. An alten Lbstämmen (Weide, Rotbuche), zerstreut. S. H. (Fig. 123.) (Milchweißer P.)

P. lacteus Fries.

Hut fast nierenf., oft etwas gestielt, $3-8 \mathrm{~cm}$ br., weich fleischig, zerbrechlich, feucht durchscheinend weiß, oberseits kahl, glatt, ungezont, von scharfem Geruch. Poren kurz, klein, rund, gleichgroß. An Lbstämmen (Birke), zerstreut. (Fig. 124.) (Chionischer P.)

P. chioneus Fries.

31. Hut oberseitig von Anfang an kahl.

Hut oberseitig irgendwie behaart, mindestens in der Jugend. 35.

32. Hutoberfläche in der Jugend einen harzartigen Saft ausschwitzend, dann mit starrer Rinde.

Hut keinen Saft ausschwitzend, Rinde weicher.

33. Hut fächerf. ausgebreitet, bis $20 \mathrm{~cm}$ br., bis $2 \mathrm{~cm}$ dick, innen fleischig, dann lederartig-zähe, blaßbräunlich, am Rande verschmälert, oberseits in der Jugend einen harzigen Saft ausschwitzend, später mit rot- od. dunkelbrauner, starrer, runzeliger od. körniger, rissiger Rinde überzogen. Röhren 0,5 cm lg., braun, Mündungen fein, gleich, anfangs weißlich, später zimmetbraun. An alten Ndstämmen, besonders im Gebirge, nicht selten. S. H. (Harziger P.)

P. resinosus (Schrader).

Hut ebenso, holzig, härter, dunkelbraun mit blaßbläulichem Rande. Mündungen rostfarben-umbrabraun. Geruch wie Trametes odorata. Wie vor. (Benzoe-P.)

\section{P. benzoinus (Wahlenb.).}

34. Hut 10-14 cm groß, fleischig, runzelig, rostbraun, ungezont, mit scharfem, schmutziggelbem Rande. Poren klein, rund, fast gleichgroß, stumpf, gelblich. An alten Buchenstämmen, selten. H. (Gelblicher P.)

P. helveolus Rostkovius. 
Hut polsterf., knollig, bis $40 \mathrm{~cm}$ groß, innen kastanienbraun, zuerst saftig, weich, dann korkig-faserig u. am Rande gelbliche wässerige Tropfen abscheidend, oberseits höckerig-grubig, mit dünner glatter, dunkelbrauner Rinde. Röhren $1-2 \mathrm{~cm} l g .$, dunkelbraun, Mündungen rundlich. An alten Eichen, sie abtötend, zerstreut. S. H. W. (Fig. 125.) (Falscher Feuerschwamm.)

P. pseudoigniarius (Bulliard).

35. An Lb. 36.

Hut polsterf., bis $8 \mathrm{~cm}$ br., dreieckig, bisweilen hinten etwas ausgezogen, innen lederfarbig, fleischig-korkig, oberseits zottig, dann kahl, ungezont, fleischfarben, mit weicher, rauher Rinde. Poren kurz, klein, rundlich, regelmäßig, stumpf, weißlichrötlich. An Ndstämmen, selten. H. (Rötlicher P.)

\section{P. erubescens Fries.}

36. Hutoberfläche nur in der Jugend haarig, dann kahl werdend. 37.

Hutoberfläche dauernd haarig.

37. Hut beiderseits gewölbt, am Grunde etwas ausgebreitet, dünn, innen zäh fleischig, zimmetbraun, oberseitig anfangs zottig, dann kahl, ungezont, zimmetbraun, später gelbbraun, Rand stumpf, ungleich. Poren kurz, klein, zart, gleichgroß, scharf, schwach glänzend, zimmetbraun. An Ästen u. Stämmen von Lb. (Eiche, Eberesche usw.), zerstreut. S. H. (Zimmetbrauner P.)

P. rutilans (Pers.).

Hut polsterf., verlängert, seltener auch umgewendet, $1-2,5 \mathrm{~cm}$ dick, innen korkig-fleischig, elastisch, weich, oberseits zottig, dann kahl, ungezont, blaßgelblich od. rötlich, mit stumpflichem, abstehendem Rande. Poren verlängert, ungleich, eckig, gelbbräunlich. An Eichen u. Buchen, nicht häufig. H. (Nest-P.) P. nidulans Fries.

38. Sporenpulver braun, Mündungen rostbraun.

Hut $4-6 \mathrm{~cm}$ lg., $1,5 \mathrm{~cm}$ dick, in der Jugend umgewendet, dann umgebogen, innen fleischig, weich, später zähe, faserig, gelbbraun, oberseits gelb, filzig, ungezont. Röhren kurz, Mündungen ungleich groß, safrangelb. Sporenpulver weiß. An alten Eichen, selten. S. H. (Fig. 126.) (Safrangelber P.)

\section{P. croceus (Pers.).}

39. Hut halbkreisf., $10-20 \mathrm{~cm} \mathrm{lg.,} 0,5-1 \mathrm{~cm}$ dick, innen weich, gelbbraun, oberseits rauhaarig-filzig, rostbraun, am Rand heller, später fast schwärzlich, undeutlich gezont, Rand scharf, oft abwärts gebogen. Röhren bis $0,5 \mathrm{~cm}$ lg., gelbbraun, dann rostbraun, Mündungen klein, rundlich, gleichfarbig. An alten Eichen u. Buchen zerstreut. S. H. (Fig. 127.) (Korkiger P.)

P. cuticularis (Bulliard).

Hut halbkreisf., polsterf., hinten sehr dick, nach vorn verdünnt, ca. $20 \mathrm{~cm} \mathrm{lg.,} \mathrm{bis} 8 \mathrm{~cm}$ dick, innen saftig, weich, grobfaserig, gelbbraun, später kastanienbraun, oberseits mit striegelig-filzigen, dunkelbraunen, fast schwärzlichen Haarbüscheln besetzt. Röhren 
1-3 cm lg., fast goldgelb, später rostfarben, Mündungen klein, rundlich, rostbraun. An Lb., besonders Apfelbäumen, häufig. S. H. W. (Fig. 128.) (Rauhaariger P.)

P. hispidus (Bulliard).

B. Hüte deutlich seitlich od. zentral gestielt, oft zerschlitzt $u$. einem gemeinsamen Stiel entspringend, oft dachziegelig.

1. Hüte dachziegelig od. gehäuft, \pm gestielt, gewöhnlich aus einem gemeinsamen Knollen entspringend od. am Grunde verwachsen. 2.

Hüte einzeln, seitlich od. zentral gestielt.

2. Poren vom Hutfleisch nicht trennbar.

Poren vom Hutfleisch leicht trennbar.

3. Hüte rost- od. kastanienbraun, Mündungen weiß, sich verfärbend.

Hüte rasig, vielteilig, zäh lederartig, fast halbiert, dachziegelig verwachsend, kahl, gelb, am Grunde zu einem zylindrischen, bräunlichen St. verschmälert. Poren blaß. Am Grunde alter Stämme, zerstreut. S. H. (Lappiger P.)

P. lobatus (Schrader).

4. Hüte dachziegelig, trichterf., eingeschnitten halbiert, etwas gezont, längsrunzelig, zäh lederartig, rostfarben, St. aus gemeinsamer Basis verästelt. Poren buchtig, gezähnelt, weiß, dann rot werdend. An Stämmen u. auf der Erde, zerstreut. S. H. (Fig. 129.) (Acanthusartiger P.)

\section{P. acanthoides (Bulliard).}

Hüte halbkreisf., bis $30 \mathrm{~cm}$ br., dachziegelig, wellig, zäh fleischig, dann fast lederartig, oberseits körnig od. feinschuppig, kastanienbraun, undeutlich gezont, St. in großer Zahl einem dicken Knollen entspringend. Röhren kurz, Mündungen fein, anfangs rundlich, weiß, bei Berührung schwärzlich werdend, später zerschlitzt, schmutzig bräunlich. Geruch säuerlich. Am Grunde alter Lbstämme, zerstreut. S. H. (Riesen-P.)

\section{P. giganteus (Pers.).}

5. Hüte oberseits zottig, mindestens in der Jugend.

Hüte von Anfang an kahl.

6. Hüte oft kreisrund, erweitert, wellig u. uneben, dan€ben ganz unregelmäßig, dachziegelig od. ganz verschieden zusammengesetzt, fleischig-faserig, starr u. zerbrechlich, oberseits zottig, ledergelb bis isabellfarbig, ungezont. Röhren klein, weiß, weich, Mündungen flockig. An alten Walnußstämmen u. von da benachbarte Gräser, Stengel usw. umfließend, im Gebirge häufiger. S. H. (Angehefteter P.)

P. alligatus Fries.

Hüte halbiert, ca. $10 \mathrm{~cm} \mathrm{lg.,} 1 \mathrm{~cm}$ dick, hinten eingedrückt, gestielt, mehrere am Grunde mit den St. verwachsen, weich fleischig, später fast korkig, zerbrechlich innen gelblichweiß, dann gelb od. grünlich, oberseits feinzottig, später rissig u. schuppig, grünlichgelb mit rötlichem Anflug, St. weiß. Röhren 
bis $5 \mathrm{~mm} \mathrm{lg.,} \mathrm{herablaufend,} \mathrm{Mündungen} \mathrm{wei} \beta$, später gelblich, eckig u. zerschlitzt. Am Grunde der Stämme in Lbwäldern im Boden wurzelnd, zerstreut. S. H. (Fig. 130.) (Kammf. P.)

P. cristatus (Pers.).

7. Mündungen gelb.

Mündungen weiß od. hellbräunlich.

8.

9.

8. Hüte sehr br., lappig, sitzend od. gestielt, dachziegelig aus gemeinsamem Grunde. faserig-käseartig, ziemlich fest, dann zerfallend, oberseits kahl, gelbbraun, am Rande schwach gezont u. blasser. Poren klein, rund, blaß, schmutzig gelb. An Baumstämmen, auch in Höhlen (dann keulig), zerstreut. S. H. (Fig. 131.) (Dachziegeliger P.)

P. imbricatus (Bulliard).

Hüte halbkreisf., sitzend od. gestielt, meist viele am Grunde zu großen Massen vereinigt, bis $30 \mathrm{~cm}$ lang, $4 \mathrm{~cm}$ dick, weich fleischig mit gelbem Saft, dann erhärtend u. weiß, trocken, oberseits hellgelb od. orange, verblassend bis weißlich. Röhren ea. $4 \mathrm{~mm}$ lg., Mündungen sehr fein, ungleich, schwefelgelb. An Lb. bäumen nicht selten. S. H., Myzel perennierend. (Fig. 132.) (Stammbewohnender P.)

P. caudicinus (Schaeffer).

9. Hutoberseite weiß, bräunlich od. gelblich.

Hüte halbiert, $3-6 \mathrm{~cm}$ groß, ca. 0,5 cm dick, am Rande dünn, ausgeschweift, seltener lappig, fleischig, trocken leicht zerbrechlich, innen weiß, sehr viele am Grunde zu einem mehrfach verzweigten weißen Stamm vereinigt, oberseits grau od. rußfarben, kahl. Röhren 2-3 mm lg., herablaufend, Mündungen weißlich. Guter Speisepilz. In Lbwäldern am Boden bei alten Stämmen, nicht selten. S. H. (Fig. 133.) (Eichhase, Klapperschwamm, Schipperling.)

P. frondosus (Flora danica).

10. Hüte kleiner, bis $5 \mathrm{~cm}$ groß.

11.

Hüte halbiert, auch exzentrisch gestielt, gelappt, $12-15 \mathrm{~cm}$ br., fest fleischig, trocken zerbrechlich, zu mehreren mit den weißen St. bis zu $50 \mathrm{~cm}$ großen Rasen verbunden, oberseits zuerst glatt, fleischfarben od. gelblich, später rissig-schuppig, rotbraun. Röhren 2-3 $\mathrm{mm}$ lg., herablaufend, weißlich gelblich, Mündung fein, rundlich. Auf dem Boden in Ndwäldern, zerstreut. S. H. (Fig. 134.) (Semmelpilz.) P. confluens (Alb. et Schwein.).

11. Hüte halbiert, buchtig, später spatelf., fleischig, St. zu einem kurzen Stamm verschmolzen, oberseits gelbbraun. Poren weißbräunlich. Am Grunde alter Stämme, selten. S. H. (Endivien-P.) P. intybaceus Fries.

Hüte kreisrund, $1-5 \mathrm{~cm}$ br., gewölbt, dann in der Mitte eingedrückt, fleischig, innen weiß, sehr viele zu großen kopff. Rasen zusammentretend, St. mehrfach verzweigt, weiß, aus gemeinsamem Stamm. Hutoberseite hell- bis dunkelbraun, seltener wei $\beta$. Röhren sehr kurz, herablaufend, Mündungen weiß, rundlich. 
Guter Speisepilz. Am Grunde alter Stämme in Lbwäldern, zerstreut. S. H. (Fig. 135.) (Brödling, Habichtssehwamm.)

P. umbellatus (Pers.).

12. St. sэitenständig od. exzэntrisch, an der Basis schwarz.

St. zentral od. exzentrisch, an der Basis gleichfarbig mit dem Hut.

13. Hutoberfläche kahl, glatt.

19.

Hutobərfläche schuppig od. anfangs flockig. 17.

14. Hutoberfläche nicht rauchgrau.

Hut trichtərf., solt эn $э$ mehrere zusammen, exzæntrisch gestielt, bis $25 \mathrm{~cm} \mathrm{lg.,} 14 \mathrm{~cm}$ br., obərhalb der Stanheftungsstelle kegelf. vertieft, zähfleischig, obərseits glatt, rauchgrau, mit bauchigem, eingerolltım Rande. St. schwarz, netzig gezeichnet, bis $15 \mathrm{~cm}$ lg. Röhren weit herablaufend, Mündungen ungleich groß, eckig, gezähnt, schmutzig weißgelb, im Alter bräunlich. An alten Lbstämmen (Esche, Ahorn usw.), selten. S. H. (Rostkovius' P.)

P. Rostkovii Fries.

15. St. von Anfang an kahl.

Hut trichtorf., oft fast aufgerollt, bis $85 \mathrm{~cm}$ br., zähfleischig. zuletzt lederartig, hart, oberseits glatt u. kahl, blaß ockerfarben, später kastanienbraun, wie lackiert glänzend, St. fast seitenständig, bis $7 \mathrm{~cm}$ hoch, zuerst filzig, dann kahl, schwarz. Röhren $1-1,5 \mathrm{~m}$ lg., herablaufend, Mündungen sehr fein, rundlich, weißlich, später ockerfarben. An alten Lbstämmen (Weiden, Pappeln), zerstreut. F. S. H. (Fig. 136.) (Pechschwarzer P.) P. picipes Fries.

16. Hut dünn, oft tutenf., zähfleischig, später lederig hart, oberseits ocker- oder graubraun, dann braun, St. seitenständig od. exzentrisch, glatt u. kahl, nach unten hin schwarz. Röhren kurz, herablaufend, Mündungen klein, ungleich, anfangs weiß, dann gelbbräunlich. An alten Lbstämmen, zerstreut. Fast das ganze Jahr. (Mannigfacher P.)

P. varius (Pers.).

Hut halbkreis- od. nierenf., gewölbt, $2-10 \mathrm{~cm}$ br., fleischig. dann hart, fast holzig, oberseits ocker- od. gelbbraun, glänzend, St. seitenständig, exzentrisch (selten zentral = var. nummularius [Bull.]), bis $3 \mathrm{~cm}$ lg., glatt, oben blaß, unten schwarz. Röhren kurz, Mündungen rundlich, blaß, dann hellbräunlich. An Lbästen, nicht selten. S. H. (Eleganter P.)

17. St. filzig od. sammethaarig.

18.

Hut halbkreis - od. nierenf., $10-30 \mathrm{~cm}$ lg., zähfleischig, später fast holzig, oberseits weißlichgelb od. ockerfarben, mit breiten, braunen, konzentrischen, angedrückten Schuppen, am Rand scharf, eingebogen. St. seitenständig, gekrümmt, bis $8 \mathrm{~cm} \mathrm{lg.,}$ glatt, oben weißlich, unten schwarz. Röhren $2 \mathrm{~cm} \mathrm{lg.,} \mathrm{Mündungen}$ fein, weiß, später sehr weit, eckig, gelblich, als Netzzeichnung am St. herablaufend. Geruch schwach fenchelartig. An Lb. schädlich, nicht selten. F. S. H. (Fig. 137.) (Schuppiger P.) P. squamosus (Hudson).

Lindau, Kryptogamenflora. I. 2. Aufl. 
18. Hut halbiert od. nierenf., $5-6 \mathrm{~cm}$ br., dick, fleischig, dann fast holzig, oberseits bla $\beta$ ockerfarben, erst glatt, dann mit dichtstehenden, dicken, schwärzlichen Schuppen. St. seitlich, kurz, filzig, oben weiß, unten braun. Poren wabenartig, sechseckig, gezähnt, zitronengelb. An Lb. (Birke), selten. S. H. (Bouchés P.)

P. Boucheanus Klotzsch.

Hut flach, dann trichterf., dünn, $5-8 \mathrm{~cm}$ br., zähfleischig, später lederartig, oberseits weißlich od. ockerbraun, zuerst fein braunflockig, später schuppig. St. seitlich od. exzentrisch, kurz, nach oben verdünnt, sammetartig behaart, unten dick, schwarz. Röhren ca. $1 \mathrm{~mm}$ lg., weit herablaufend, Mündungen fein, ungleich, weißlich, Gruch schwach gewürzartig. An Stümpfen, mit Erde bedecktem $\mid \mathrm{Holz}$ in Lbwäldern, zerstreut. S. H. (Fig. 138.) (Schwarzfüßiger P.) P. melanopus (Pers.).

19. Hut kahl, ohne Zotten u. Schuppen.

Hut irgendwie filzig, zottig, schuppig.

20. Hutoberseite braungelblich, rehbraun.

20.

22.

21.

Hut kreisrund, niedergedrückt-genabelt, dünn, fleischig-zähe, kahl, blaß rauchgrau, Rand umgebogen. St. zentral, blaß, dünn, kahl, beidendig verdickt, am Grunde oft bräunlich. Poren klein, rundlich, gleichgroß, zuerst weiß, dann grau. Auf der Erde im Lbwald selten. S. H. (Grauer P.)

\section{P. fuligineus (Pers.).}

21. Hut flach, ca. $2,5 \mathrm{~cm}$ br., zäh, dann lederartig, kahl, glatt, ungezont, blaß, später rehbraun, Rand etwas geschweift. St. zentral, $2 \mathrm{~cm}$ lg., kahl, blaß. Poren klein, rundlich, weißlich. An Stämmen, solten. H. (Fig. 139.) (Zarthutiger P.)

\section{P. leptocephalus (Jacquin).}

Hut flach gewölbt, $2-5 \mathrm{~cm}$ br., zäh-fleischig, fast lederartig, ungezont, kahl, braungelblich. St. zentral, $2-5 \mathrm{~cm}$ hoch, 4 bis $5 \mathrm{~mm}$ dick, kahl, blaß, bisweilen beidendig angeschwollen. Poren rundlich-eckig, ganz, gelblich. Zwischen Holzsplittern auf der Erde, selten. H. (Bräunlicher P.) P. fuscidulus (Schrader).

22. St. dünn im Verhältnis zur Länge, höchstens $1 \mathrm{~cm}$ dick.

23.

St. verkürzt, knollig, unförmlich, jedenfalls nie schlank im Verhältnis zur Länge.

23. Mündugenn weiß od. gelblich.

26.

Hut zuerst gewölbt, dann flach, dünn, $1-1,5 \mathrm{~cm}$ br., gelbbraun, am Rande striegelhaarig. St. $1-2 \mathrm{~cm}$ hoch, $1-2 \mathrm{~mm}$ dick, gelbbraun, untøn zottig. Mündungen klein, rundlich, ockerfarben, später etwas dunkler. Auf Ästen von Lb., zerstreut. F. S. (Wimperiger P.)

P. ciliatus Fries.

24. Mündungen eckig, länglich.

Hut zuerst gewölbt, dann niedergedrückt, $2,5 \mathrm{~cm}$ br., zähfleischig, oberseits schwach flockig, im Alter rissig-schuppig, gelblich rauchgrau. St. fast zentral, $3-4 \mathrm{~cm} \mathrm{lg.,} \mathrm{ca.} 1 \mathrm{~cm}$ dick, 
netzartig-schuppig. Poren klein, rund, schneeweiß, später verblassend. An Lbstämmen, selten. S. H. (Schuppen-P.)

P. lepideus Fries.

25. Hut gewölbt, später etwas eingedrückt, ca. $2-3 \mathrm{~cm}$ br., fleischig, dann zäh-lederartig, oberseits zuerst braunschuppig, dann fast glatt, ockerfarben, am Rande striegelhaarig. St. $1-3 \mathrm{~cm} \mathrm{lg.,}$ schuppig, graubraun. Mündungen weiß, eckig, länglich, langgestreckt, weit. An Lb., selten, in den Südalpen häufiger. H. W. F. (Fig. 140.) (Geschmückter P.) P. arcularius (Batsch).

Hut gewölbt, dann flach, dünn, fleischig, dann zäh-lederartig, oberseits graubraun, od. ockerfarben, zuerst filzig, dann angedrückt schuppig. St. $4-5 \mathrm{~cm}$ lg., $0,5 \mathrm{~cm}$ dick, weichhaarigschuppig, grau, Mündungen sehr fein, weiß, später ziemlich weit, gelblich. An Stämmen von Lb. in Wäldern, nicht selten. Fast das ganze Jahr. (Fig. 141.) (Winterlicher P.)

P. brumalis (Pers.).

26. Mündungen irgendwie gelb (zitronengelb, schwefelgelb, grüngelb, weißgelb).

Mündungen weißlich od. grau, fleischrötlich, bräunlich. 29.

27. Fleisch weißlich u. so bleibend.

Hut kreisel- od. fast trichterf., bisweilen halbiert, $6-30 \mathrm{~cm}$ br., dick, bisweilen mehrere zusammenfließend, weich schwammig, dann filzig-korkartig, innen gelb-, dann rostbraun, oberseits zuerst striegelig filzig, später höckerig, grubig, gelb-, dann rostbraun. St. kurz u. knollig, dick, bis $6 \mathrm{~cm}$ hoch, oft fast fehlend. Röhren 5-7 mm lg., herablaufend, Mündungen zuerst schwefelgelb, dann braun, zerschlitzt, in zahnartige, spitze Platten getrennt. In Ndwäldern auf der Erde u. an Stümpfen, nicht selton. S. H. (Sistotremaartiger S.)

P. sistotremoides (Alb. et Schwein.).

28. Hut rundlich od. halbiert, rissig-schuppig, braun, dann schwarzbraun, viele dicht nebeneinander wachsend $u$. die braunen, auf gedunsenen St. an der Basis oft verbunden. Mündungen weit, weißgelb. Auf der Erde in Ndwäldern im Gebirge, nicht selten. S. H. (Fig. 142.) (Ziegenfuß-P.) P. pes caprae Pers.

Hut verschieden gestaltet, oft unregelmäßig, $6-8 \mathrm{~cm}$ br., $1-1,5 \mathrm{~cm}$ dick, gewölbt, am Rande meist verbogen, fleischig, trocken zerbrechlich, oberseits weißlich, oft rötlich angehaucht, glatt, später rissig od. felderig. St. zentral, $2-4 \mathrm{~cm}$ hoch, $1-2 \mathrm{~cm}$ dick, weiß, glatt, voll. Röhren kurz, herablaufend, Mündungen fein, rundlich, weiß, dann zitronengelb. Eßbar. Auf der Erde in Ndwäldern, nicht selten. S. (Fig. 143.) (Schafeuter.)

P. ovinus (Schaeffer).

29. Hutfleisch weiß, höchstens bei Verletzungen sich rötend. 30 .

Hutfleisch entweder von Jugend an od. später rötlich od. bräunlich werdend. 
30. Fk. in der Jugend gestaltlos, überall Poren tragend, später sehr verschieden gestaltet, inkrustierend, meist noch ein dicker, unförmlicher, rostbrauner, wolliger St. wahrnehmbar, schwammig, dann korkig-lederig, oberseits mit schülfrig sich ablösendem Filz bedeckt, im Alter kahl, weißgrau, später rostfarben. Poren ungleich, labyrinthf., weißgrau, dann braun, zerschlitzt, gezähnt. Am Boden in Wäldern, selten. S. H. (Fig. 144.) (Zweijähriger P.)

\section{P. biennis (Bulliard).}

Hut kreiself., schwammig, weich, dann zähfaserig, korkig, $3-8 \mathrm{~cm}$ br., innen hellrötlich, oberseits höckerig, hellrötlich od. rotbraun, St. $2-3 \mathrm{~cm} \mathrm{lg}$. u. dick, rotbraun. Röhren $4-5 \mathrm{~mm}$ lg., weiß, dann fleischrot bis bräunlich, Mündungen groß, oft gewunden, zuletzt zerschlitzt. An der Erde zwischen Gras bei alten Lbstämmen, zerstreut. S. H. (Rötlicher P.)

\section{P. rufescens (Pers.).}

31. Hut kreisrund, bis $6 \mathrm{~cm}$ br., gewölbt, am Rand eingerollt, innen fleischig, weiß, bei Verletzungen rot werdend, oberseits rauchgrau, schwärzlich werdend, in der Mitte oft rotbraun, seidenhaarig-feinschuppig. St. $1-4 \mathrm{~cm} \mathrm{lg.,} 1 \mathrm{~cm}$ dick, grau, schwach filzig. Mündungen fein, weiß, dann grau. Auf der Erde in Ndwäldern, zerstreut. S. H. (Fig. 145.) (Schwarzweißer P.)

\section{P. leucomelas (Pers.).}

Hut meist kreisrund, 5-12 cm br., gewölbt, zähfleischig, weiß, oberseits weißlich, später gefeldert-schuppig. St. $1-3 \mathrm{~cm}$ hoch, $1 \mathrm{~cm}$ dick, knollig, hart, weißlich-grau. Mündungen fein, ungleich, etwas gebogen, weiß. Am Boden in Gebirgsndwäldern, nicht selten. S. H. (Fig. 146.) (Wenigschuppiger P.)

\section{P. subsquamosus (L.).}

\section{Gattung: Polystictus Fries (Punktschwamm).}

Hut lederartig od. häutig od. wergartig, nicht holzig werdend, mit dünner, faseriger Rinde bedeckt, mit einer mittleren, faserigen Schicht, die zwischen die Röhren geht. Röhren ungeschichtet, gewöhnlich von der Mitte sich zum Rande entwickelnd, zuerst flach, punktf., dann wie bei Polyporus.

1. Hüte ausgebreitet, teilweise sich abhebend u. umgebogen. 2.

Hüte halbiert, sitzend.

Hüte zentral gestielt.

2. Hüte ausgebreitet, krustenf. verwachsend, der obere Teil horizontal umgebogen $\mathrm{u}$. dachziegelf. übereinander, korkig-wergartig, dünn, rötlich-rostbraun, innen blasser, ungezont, angedrückt seidenhaarig. Poren punktf., rund, blasser. An faulem Holz, besonders in Bergwerken, nicht selten. Fast das ganze Jahr. (Welliger P.) P. undatus (Pers.).

Hüte ausgebreitet, oben polster- od. halbkreisf. abstehend, $2-4 \mathrm{~cm}$ lg., weichfilzig, innen $\mathrm{u}$. außen gelblich-rostbraun, oberseits filzig, ungezont. Röhren $1-2 \mathrm{~cm}$ lg., Mündungen eckig, 
rostbraun. Auf Zweigen von Rotbuchen u. Birken, selten. S. H. (Vielgestaltiger P.)

P. polymorphus (Rostkovius).

3. Hüte im Innern weiß.

Hüte im Innern gefärbt.

10.

4. Hüte gezont.

5.

Hut knollig, spatelf., keilf., kuglig, halbkreisf., $2-5 \mathrm{~cm} \lg$., $1-2 \mathrm{~cm}$ dick, weiß, wergartig, korkig, oberseits ungezont, runzelig-grubig, Rand abgerundet. Mündungen fein, weißlich. An alten Ndstämmen, namentlich im Gabirge, zerstreut. S. H. (Weißlicher P.)

P. albidus (Trog).

5. Mündungen weiß od. gelblich.

6.

Hüte ausgebreitet, zurückgebogen, meist dachziegelig, lederartig, dünn, oberseits grauweiß, zottig, undeutlich gezont, Rand oft wellig. Mündungen purpurn, dann violett, eckig, ganzrandig, dann zerschlitzt. An Nd., zerstreut. Fast das ganze Jahr. (Fig. 147.) (Tannen-P.) P. abietinus (Dicks.).

6. Hutoberseite irgendwie behaart bleibend, Zonen meist mehrfarbig.

Hüte nierenf., dachziegelig, lederartig, dünn, steif, zuerst flaumig, dann kahl, graubraun u. ebenso gezont, $1-1,5 \mathrm{~cm} \mathrm{lg}$. Poren stumpf, verschieden gestaltet, weiß. An Nd., zerstreut. S. H. (Fig. 148.) (Fester P.) $\quad$ P. stereoides (Fries).

7. Hutoberfläche nicht seidenartig glänzend, nicht so bunt gezont. 8 .

Hüte halbkreisf., bis $12 \mathrm{~cm} \mathrm{lg}$., $6 \mathrm{~cm}$ br. u. $3 \mathrm{~mm}$ dick, meist dicht dachziegelig, lederartig, oberseits fein sammet- od. seidenhaarig, seidenglänzend, mit vielen schmalen (weißlich, grau, braun, schwärzlich, bläulich, grünlich) konzentrischen Zonen, Rand wellig, weißlich. Mündungen rundlich od. zerschlitzt, weißlich, später hell ockerfarben. An Stümpfen von Lb., gemein. Das ganze Jahr. (Fig. 149.) (Bunter P.) P. versicolor (L.).

8. Behaarung des Hutes weich, fast anliegend, sammetartig. 9.

Hüte halbkreis- bis nierenf., $5-8 \mathrm{~cm} \mathrm{lg}$., bis $1 \mathrm{~cm}$ dick, korkiglederartig, oberseits mit aufrechten, zottigen, sammetartigen Haaren, mit mehreren Zonen (weißlich, grau, bräunlich), Rand stumpf, meist braun. Mündungen gelblich, oft grau werdend. An Lbstämmen, nicht selten. H. W. F. (Rauhaariger P.)

\section{P. hirsutus (Wulfen).}

9. Hüte ganz flach, bis $6 \mathrm{~cm}$ lg., korkig-lederartig, an Rand verdünnt, scharf, oberseits weich-sammetartig, weiß, dann gelblich, schwach gezont. Mündungen rundlich, weiß bis gelblich. An alten Lbstümpfen, auch in Gruben an Zimmerholz, zerstreut.

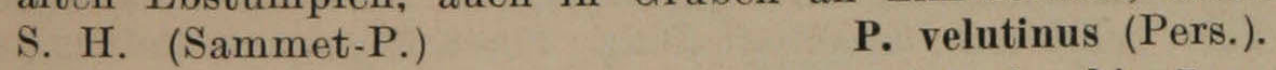

Hüte am Grunde zusammengezogen, höckerig, bis $7 \mathrm{~cm}$ lg., $5-6 \mathrm{~mm}$ dick, lederartig, meist dachziegelig, oberseits fein sammetartig, nicht glänzend, schmutzig weiß, graubräunlich, schwach gezont, Rand stumpf, dick. Mündungen anfangs weiß, 
dann hellbräunlich. An alten Lbstümpfen, häufig. H. W. F. (Gezonter P.)

P. zonatus (Nees).

10. Hutfleisch braun.

Hüte halbkreisf., bis $8 \mathrm{~cm} \mathrm{lg}$., $1-2 \mathrm{~cm}$ dick, außen u. innen zinnoberrot, oberseits anfangs feinhaarig, dann kahl, schwach gezont. Mündungen rundlich, rot. An Lbstämmen, sehr zerstreut, im Süden häufiger. H. W. F. (Fig. 150.) (Zinnoberroter P.)

P. cinnabarinus (Jacquin).

11. Hutfleisch korkig-holzig werdend, Oberseite des Hutes später kahl.

Hüte halbkreisf., meist dachziegelig, $3-9 \mathrm{~cm} \lg$., bis $3 \mathrm{~cm}$ dick, nach dem Rande verdünnt, grob-faserig-korkig, oberseits zottig-striegelhaarig, gelbbraun, später dunkelbraun, undeutlich gezont. Röhren bis $1 \mathrm{~cm}$ lg., rostbraun, Mündungen gelblichweiß schimmernd, später rostbraun, ungleich. Auf alten Stämmen von Lb. u. Nd., zerstreut. S. H. (Fig. 151.) (Fuchsroter P.)

P. vulpinus (Fries).

12. Hüte halbkreis- od. keilf., $4-6 \mathrm{~cm} \lg$., $2-3 \mathrm{~cm}$ dick, dachziegelig, innen korkig-holzig u. rostbraun, oberseits seidenglänzend, schwach gezont, mit gelbbraunen, strahligen, sammetartigen Haaren besetzt, dann glatt, Rand scharf. Röhren $2 \mathrm{~mm}$ lg., gelbbraun, Mündungen zuerst silberartig schimmernd, dann rostbraun. An alten Lbstämmen, nicht selten. S. H. (Fig. 152.) (Strahliger P.) P. radiatus (Sowerby).

Hüts nach vorn keilf. verschmälert, hinten br., weit herablaufend, $3-4 \mathrm{~cm} \mathrm{lg.,} \mathrm{bis} 2 \mathrm{~cm}$ dick, oft in lg. Reihen zusammenfließend, innen korkig-holzig u. dunkel-rostbraun, oberseits rauhhaarig, filzig, dunkelbraun, später kahl, runzelig, gezont, Rand scharf. Röhren 2-5 mm lg., Mündungen unregelmäßig, grauschimmernd, dann weiß, bisweilen länglich, mattbräunlich. An Kiefernstämmen, zerstreut. H. W. F. (Fig. 153.) (Dreikantiger P.) P. triqueter (Alb. u. Schwein.).

13. Hutfleisch einheitlich.

Hut kreisf., flach, 8-12 em br., ungezont, sammethaarig gelbbraun, aus zwei Schichten bestehend: obere flockig-filzig, weich, untere holzig-korkig, mit dem St. zusammenhängend. St. gelbbraun, filzig, aufgedunsen, ea. $2^{1 / 2} \mathrm{~cm}$ hoch u. dick. Poren herablaufend, graubraun, ganz. Zwischen Nd. in Wäldern, selten. S. H. (Runder P.) P. cireinatus (Fries).

14. St. schlank, kahl od. sammethaarig.

Hut unförmlich, bis $12 \mathrm{~cm}$ br., mehrere rasig od. dachziegelig verwachsen, korkig-hart, ungezont. St. zentral od. exzentrisch, kurz, gelbbraun, dauerhaft filzig. Poren fein, ganz, anfangs wei $\beta$ bereift. Auf der Erde in Ndwäldern, zerstreut. S. H. (Fig. 154.) (Filziger P.)

P. tomentosus (Fries).

15. Hüte trichterf. bis scheibig, mit vertiefter Mitte, kreisrund, $3-8 \mathrm{~cm}$ br., oft mehrere zusammenfließend, innen lederartig u. 
Polyporaceae.

$\sum_{139 .}^{13 \%}$

L6 $\prod_{145}$.

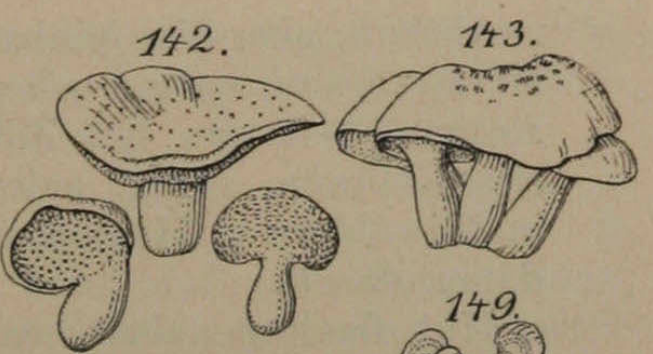

(144. 146. 14\% 14. 14. 14. 14.

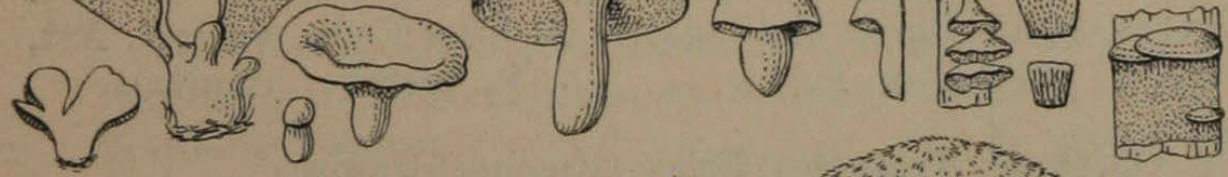

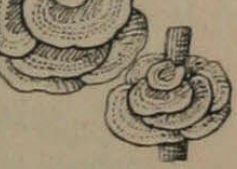
${ }_{1150}^{150}$
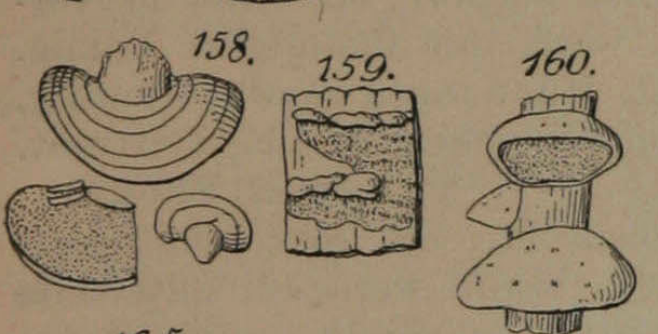

161.
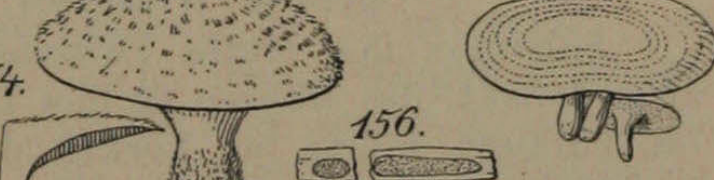

155.
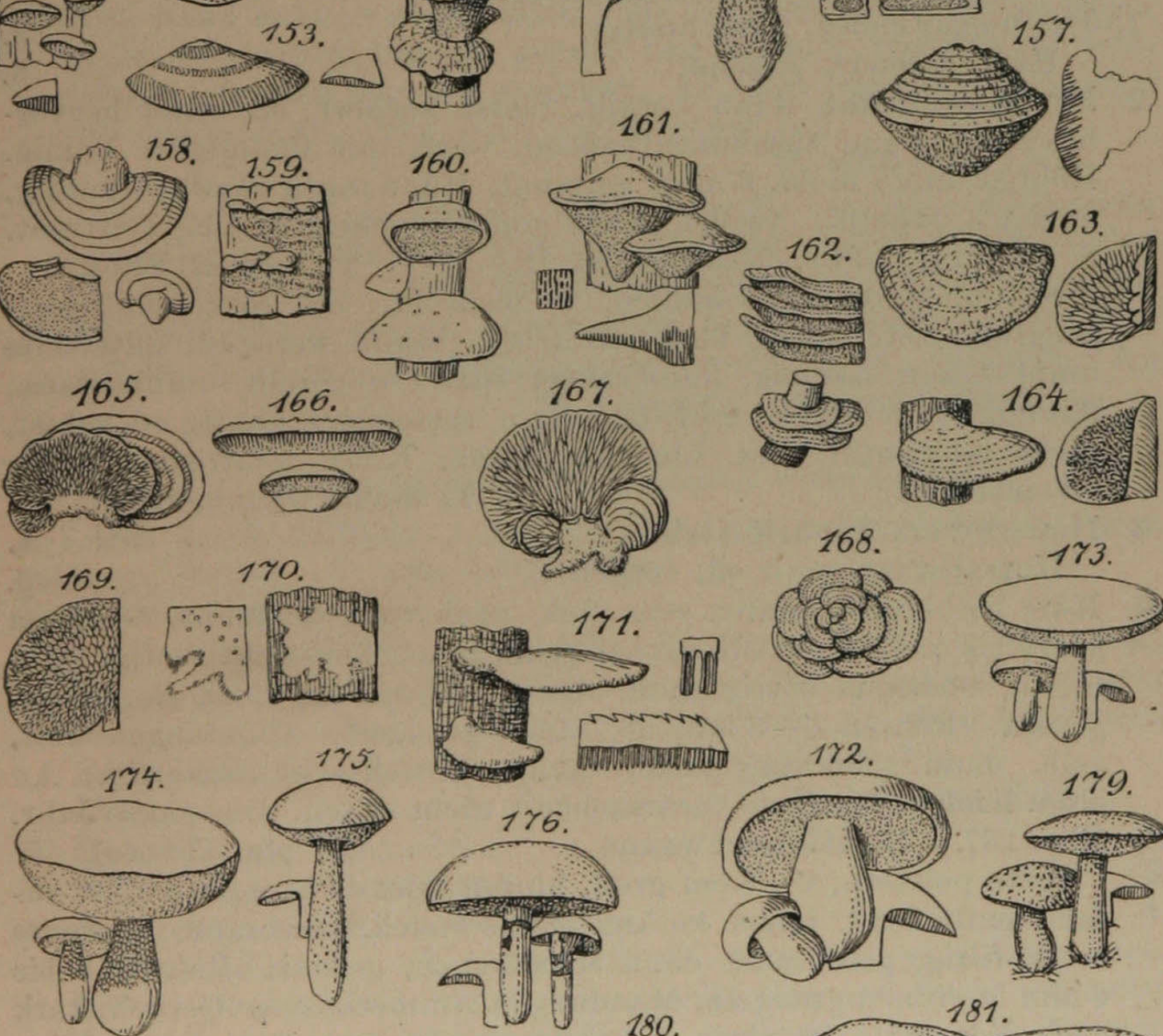

163.

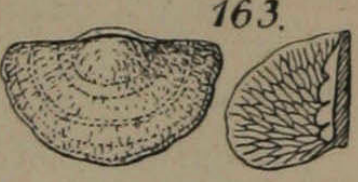

168.
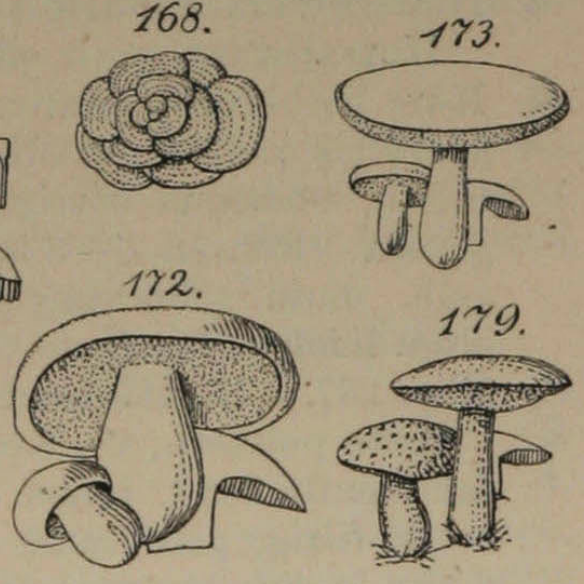

inim
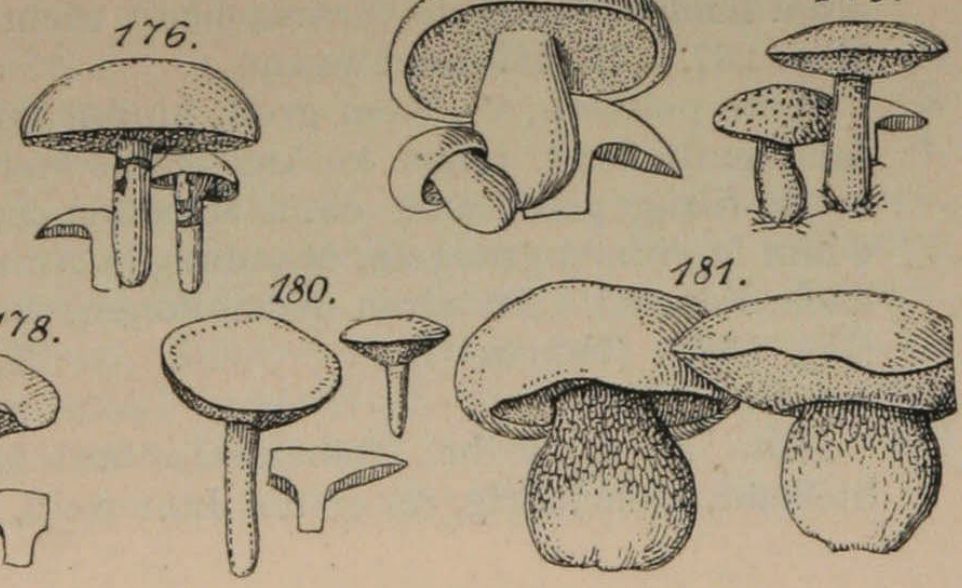
rostbraun, oberseits feinhaarig, später striegelig od. glatt, gezont, zimmetbraun, später ocker- oder graubraun, Rand scharf, dünn. Röhren 2-3 mm lg., Mündungen anfangs weiß bereift, dann zimmetbraun, eckig, zuletzt zerschlitzt. Auf sandigem Boden in Ndwäldern u. Heiden, überall häufig. S. H. (Fig. 155.) (Ausdauernder P.)

P. perennis (L.).

Hut flach genabelt, ca. $2,5 \mathrm{~cm}$ br., dünn, oberseits anfangs flaumig, dann kahl, rostfarbig, gezont, Rand sehr dünn, wimperigeingeschnitten, von etwas weniger fester Konsistenz als vor. Art. St. schlanker, kahl. Poren klein, ganz. Auf der Erde, wie vor. Art, aber seltner. (Bemalter P.)'

P. pietus (Schultz).

\section{Gattung: Trametes Fries (Riechschwamm).}

Substanz des Hutes zwischen die Röhren gehend od. anders ausgedrückt, die Röhren in den Hut eingesenkt. Hüte umgewendet od. halbiert, holzig od. korkig, dauerhaft.

1. Fk. umgewendet, ausgebreitet.

Hüte halbiert, sitzend.

2. Fk. ausgebreitet, dünn korkig, zuerst höckerf. od. rund hervorbrechend, dann zusammenfließend, weiß, mit flaumigem Rande. Röhren durch dicke Wände getrennt, Mündungen rundlich-kantig, ungleich, stumpf. An der Rinde von Sträuchern u. Lb., zerstreut. S. H. (Fig. 156.) (Kriechender R.) T. serpens Fries.

Fk. umgewendet, rundlich, $2-5 \mathrm{~cm}$ br., od. sehr verlängert, fußgroß, fast häutig, blaß-holzfarben, braun werdend, unterseits umbrabraun, flaumig, Rand scharf, später umgerollt, umbrabraun, flaumig. Mündungen weit, buchtig u. zerschlitzt, kantig od. schief, nicht labyrintif. An Lbästen (Birke, Erle), zerstreut. S. H. (Weicher R.)

T. mollis (Sommerfeld).

3. Hutsubstanz dunkelgefärbt.

Hutsubstanz weiß od. rötlich.

4. Hüte halbkreisf., hinten sehr dick, nach vorn verdünnt, $6-12 \mathrm{~cm}$ groß, bis $8 \mathrm{~cm}$ dick, oft dachziegelig, innen korkig-holzartig, gelbbraun, oberseits zottig rauh, dann schwärzlich, höckerig, rissig, gezont. Röhren 5-8 mm lg., innen graugelb. Mündungen weit, gelb, dann schmutzig ockerbraun. Geruch schwammartig. An alten Kiefern Rotfäule verursachend, nicht selten. Das ganze Jahr. (Fig. 157:) (Rotfäuleschwamm.) T. pini (Thore).

Hüte polsterf., $5-8 \mathrm{~cm}$ groß, hinten sehr dick, mehrere oft zusammenfließend, innen korkig, etwas weich, rostbraun, oberseits zottig-filzig, gelbbraun, dann schwärzlich, gezont. Röhren 5 bis $6 \mathrm{~mm}$ lg., innen graugelb, Mündungen zimmetbraun. Geruch stark nach Fenchel. An alten Ndstämmen, häufig. Das ganze Jahr. (Fig. 158.) (Fenchel-R.) T. odorata (Wulfen).

5. An Lb.

Hüte bis $2 \mathrm{~cm}$ br., reihenweise auf $\mathrm{lg}$. Strecken zusammenfließend, mehrjährig, im ersten Jahr weiß, wergartig, dann korkig- 
weich, hellbräunlich, oberseits grubig-runzelig, angedrückt zottig. gelbbräunlich. Röhren kurz, weiß. An Kiefern, auch an Balken, nicht selten. H. (Fig. 159.) (Reihenf. R.) T. serialis Fries.

6. Auffällig stark nach Anis riechend.

Nicht stark riechend, niemals nach Anis.

7. Hut unregelmäßig, korkig, elastisch, kahl, blaß. Mündungen klein, rund, gleichgroß, weißlich bis ockergelb. An alten Weidenstämmen, nicht selten. Fast das ganze Jahr. (Fig. 160.) (Anis-R.)

T. odora (L.).

Hut dick polsterf., 5-12 em br., fleischig-korkig, zottig, weiß. Mündungen groß, rundlich, weiß, dann braun. Wie vor. (Veilchen-, Weidenschwamm.)

T. suaveolens (L.).

8. Hut fast halbkreisf., am Grunde höckerig, $8-15 \mathrm{~cm}$ groß, 1 bis $2 \mathrm{~cm}$ dick, beiderseits ziemlich flach, innen wergartig-faserig, ziemlich fest, weiß, oberseits zottig behaart, weißlich, grau, gezont, Rand anfangs abgerundet, dann ziemlich scharf. Mündungen lggestreckt, zuerst linienf., gerade, fast strahlig, weißlich od. hellgelblich. Gəruch schwach säuerlich. An alten Lbstümpfen, häufig. Das ganze Jahr. (Fig. 161.) (Höckeriger R.)

T. gibbosa (Pers.).

Hut halbkreis- od. nierenf., $5-8 \mathrm{~cm}$ groß, $1-1,5 \mathrm{~cm}$ dick, innen korkig-holzig, schmutzig-rötlich, oberseits zuerst feinfilzig, bei Druck rot werdend, dann kahl, hellbräunlich, rot, schwach gezont. Mündungen lggestreckt, zuerst weiß bereift, dann wie der Hut gefärbt. An alten Weidenstämmen, zerstreut. H. (Rötlicher R.)

T. rubescens (Alb. et Schwein.).

7. Gattung: Daedalea Pers. (Labyrinthschwamm).

Hut meist halbiert, selten umgewendet, korkig-lederig. Poren gebogen, linienf. od. weit labyrinthf.

1. Hut halbiert, sitzend.

Fk. umgewendet, ausgebreitet, bis $70 \mathrm{~cm}$ groß, korkig, dick, wellig, blaß, holzfarben, innen gezont. Poren schmal, entfernt stehend, rundlich od. verlängert $u$. gebogen. An alten bemoosten Buchenstämmen, selten. S. H. (Ausgebreiteter L.)

D. latissima Fries.

2. Hut grau od. holzfarben.

Hut irgendwie ziegelrot.

3. Hut holzig-korkig, nicht biegsam.

Hut halbkreis- od. muschelf., $5-8 \mathrm{~cm} \lg$., ea. $0,5 \mathrm{~cm}$ dick, hinten herablaufend, meist dachziegelig, biegsam, innen lederartig u. weiß, oberseits zottig u. striegelig behaart, grau od. hellbräunlich, gezont, Rand scharf. Löcher $2-3 \mathrm{~mm}$ tief, labyrinthf. gewunden, später fast zahnf. zerschlitzt, gleichfarbig. An alten Stämmen u. Stümpfen von Lb., nicht selten. S. H. (Fig. 162.) (Einfarbiger L.)

D. unicolor (Bulliard). 
4. Hut halbkreisf., hinten sehr dick, deshalb oft polsterf. od. knollig, $5-20 \mathrm{~cm} \mathrm{lg.,} \mathrm{bis} 8 \mathrm{~cm}$ dick, innen korkig-holzartig, oberseits höckerig, kahl, hellbräunlich, fast ungezont, Rand scharf. Löcher länglich, sehr stark labyrinthartig gewunden. An alten Eichen, selten auch anderen Lb., häufig. Das ganze Jahr. (Fig. 163.) (Eichen-L.)

D. quercina (L.).

Hut $3-8 \mathrm{~cm}$ br., ziemlich dick, schwach wellig, meist dachziegelig, korkig-holzig, oberseits filzig, grau, mit wenigen br. Zonen. Löcher sehr eng, klein, stark gewunden u. verschlungen, grau od. weißlich. An alten Lbstämmen, selten. S. H. (Grauer L.)

D. cinerea Fries.

5. Hüte mit herablaufender Basis, dachziegelf., verwachsend, korkig, innen weiß, oberseits sammethaarig, mit verschiedenfarbigen, bräunlichen, ziegelrot gesäumten Zonen, am Rand flockig, weiß. Löcher dicht, labyrinthf., weiß bereift, später rötlich, schwarz gefleckt. An Walnußbäumen, in den Alpen. S. H. (Zinnober-L.)

D. cinnabarina Secretan.

Hut dick, halbkreis- od. knollenf., fast kugelig, 4-6 cm lg., $2-5 \mathrm{~cm}$ dick, innen korkig-holzig u. kastanienbraun, oberseits uneben, rotbraun, später dunkelbraun, schwach gezont. Löcher eng, labyrinthf., grau, später rotbraun. An alten Lbstämmen, zerstreut. S. H. (Fig. 164.) (Unebener L.)

\section{D. confragosa (Bolton).}

\section{Gattung: Lenzites Fries (Balkenschwamm).}

Hut halbiert, hinten oft stielartig zusammengezogen, lederartig, filzig, bis korkig-holzig. Gänge fast lamellenartig, aber durch Querbalken miteinander verbunden, nach dem Rande hin meist porenartig.

1. Hutsubstanz braun gefärbt.

Hutsubstanz weiß.

2. L. nicht fleischrot.

3.

Hut sitzend, flach, bis $10 \mathrm{~cm}$ br., runzelig, lederartig, sehr dünnfilzig, später kahl, braun. L. steif, einfach od. gegabelt, bisweilen anastomisierend, fleischrot, ganzrandig. An eichenen Balken u. Stämmen, nicht selten. S. H. (Eichen-B.) L. trabea (Pers.).

3. Hut halbkreisf. od. lggestreckt, $4-10 \mathrm{~cm}$ lg., 1,5 cm dick, außen zottig-striegelhaarig, dunkelkastanienbraun, gezont, höckerig-filzig, am Rande gelbbraun. L. verzweigt, anastomosierend, gelblichweiß, später rostbraun, am Rände Poren od. labyrinthartige Gänge. Auf Ndstümpfen, Balken, Zäunen, häufig. Das ganze Jahr. (Fig. 165.) (Zaunbewohnender B.) L. sepiaria (Wulfen).

Hut halbkreisf. od. länglich, meist über $4 \mathrm{~cm} \mathrm{lg}$., $0,5 \mathrm{~cm}$ dick, lederartig, oberseits filzig, umbrabraun, später fast glatt, undeutlich gezont, am Rand fast weißlich. L. ungleich, oft zu Poren ver- 
bunden, braun, bläulich-grau bereift, am Rande oft gezähnelt. An Stümpfen u. Balken von Nd., häufig. H. (Fig. 166.) (Tannen-B.) L. abietina (Bulliard).

4. L. weiß od. schmutzig weiß.

Hut flach, mit höckeriger Basis, korkig-lederig, oberseits rauh, schwach filzig, gezont u. strahlig-runzlig, zuerst blaß zitronengelb, später dunkler. L. entfernt voneinander, dünn, nach hinten anastomosierend, zitronengelb, dann umbrabraun. An Kirsch- u. Eichbäumen, zerstreut. S. H. (Dreifarbiger B.)

L. tricolor (Bulliard).

5. An Lb.; L. nicht über den Rand hinausragend.

Hut ausgebreitet-umgebogen, höckerig, faserig-runzlig, dünn, lederartig, blaß-weißlich. L. hoch, dicht, wenig verästelt, weiß, über den Rand des Hutes hinausgreifend. An Stümpfen von Nd., seltən. H. (Verschiedəngestaltiger B.)

L. heteromorpha Fries.

6. Hutobers sits gezont.

Hut ausgebreitst-umgebogen, dachziegelig, flach, korkig-lederartig, weich, ungezont, milchweiß, ssidenartig von dünnem, angedrücktəm Filz. L. dünn, dichotom verzweigt, weiß. An Lb., besonders Eschen, saltın. S. H. (Weißlicher B.)

\section{L. albida Fries.}

7. Hut halbkreis- od. nierenf., hint эn stielf. zusammengezogen, 4-10 em lg., 1-1,5 cm dick, oft dachziegelig, filzig-korkig, obersits striegelhaarig-filzig, bla $\beta$, grau bis bräunlich, gezont, Rand ziemlich scharf. $\mathrm{L}$. nach vorn verschmälert, weißlich bis leicht bräunlich. An Lb., besonders Birken, nicht selten. H. W. F. (Fig. 167.) (Birken-B.) L. betulina (L.).

Hut halbkreis- od. nierenf., $2-3 \mathrm{~cm}$ groß, ca. 1,5 cm dick, oberseits sammetartig filzig, bunt gezont (weiß, grau, bräunlich). L. dick, häufig anastomosierend, weiß. An Lb., zerstreut. S. H. (Fig. 168.) (Bunter B.)

L. variegata Fries.

9. Gattung: Favolus Fries (Wabenschwamm).

Hüte halbkreisf., seitlich gestielt, lederartig. L. wabenf. anastomosierend, strahlig verlaufend.

Einzige Art nur im südlichsten Gabiet. Hut weißlich, fast kreisrund, kahl u. glatt. An Lbstämmen. S. H. (Fig. 169.) (Europäischer W.)

F, europaeus Fries.

10. Gattung: Porothelium Fries (Warzenröhre).

Fk. flach ausgebreitet, häutig od. krustig, zuerst mit warzenf., gesondert stehenden Hervorragungen besetzt, die sich später zu Röhren verlängern.

Fk. unregelmäßig, ausgebreitet, häutig, weiß, am Rand nackt. 
Warzen entfernt stehend, zylindrisch, weiß, beim Trocknen rotbräunlich, zerbrechlich. Auf Zweigen, Balken. S. (Zarte W.)

P. subtile (Schrader).

Fk. weit ausgebreitet, häutig, weiß, am Rande lg. weißfransig. Röhren später in der Mitte meist dicht beisammen stehend, am Rande aber einzeln stehend. Auf Holz u. Zweigen, namentlich Eiche, Weide usw., nicht häufig. S. H. (Fig. 170.) (Gefranste W.)

\section{P. fimbriatum (Pers.).}

\section{Gattung: Fistulina Bull. (Leberschwamm).}

Hut zungen- od." polsterf., hinten meist stielf., grobfaserig, Röhren anfangs oben geschlossen, dann sich öffnend, trennbar. Sporen braun.

Einzige Art, $10-20 \mathrm{~cm}$ lg., bis $6 \mathrm{~cm}$ dick, innen fleischig, mit rötlichem Saft, später grobfaserig, zähe, blutrot, weiß gestreift, strahlig, oberseits blut- bis braunrot, büschelig behaart. Röhren blaß, dann rotbraun. Jung eßbar. An alten Eichen, nicht selten. S. H. (Fig. 171.) (Leber-, Zungenpilz.) F. hepatica (Schaeffer).

\section{Gattung: Suillus Karsten (Röhrenpilz).}

Hut zentral gestielt, Röhren nach abwärts gerichtet, dicht nebeneinander stehend, trennbar voneinander u. vom Hutfleisch. Sporenpulver weiß. Sporen hyalin.

1. Fleisch sich bei Verletzungen nicht blau färbend.

Hut 5-15 cm br., innen weiß, bei Verletzung schnell dunkelblau werdend, oberseits weißlich od. gelblich, filzig. St. dick, knollig, $5-8 \mathrm{~cm}$ hoch, bis $3 \mathrm{~cm}$ dick, gleichfarbig, unten filzig, oberhalb der Mitte glatt, an der Grenze mit einem schwachen, filzigen Ring. Röhren weiß, später leicht hellgelb. Auf Sandboden lichter Wälder zerstreut. S. H. (Fig. 172.) (Bläulichwerdender R.)

S. cyanescens (Bulliard).

2. Hut 5-6 cm br., halbkugelig, dann abgeflacht od. eingedrückt, innen weiß, oberseits rotbraun, etwas glänzend, eingewachsenfilzig. St. 5-6 cm hoch, bis $1,5 \mathrm{~cm}$ dick, rotbraun, zuletzt hohl. Röhren weiß, dann hellgelb. Eßbar. In lichten Mischwäldern, stellenweise häufig. S. H. (Fig. 173.) (Hasenpilz, Hasensteinpilz.)

S. castaneus (Bulliard).

Hut flach gewölbt, $5-8 \mathrm{~cm}$ br., innen weiß, höchstens gelblich oberseits kahl, glatt, glänzend gelbbraun. St. $3-6 \mathrm{~cm}$ hoch, $1 \mathrm{~cm}$ u. mehr dick, später hohl, Röhren sehr weich, weiß, dann zitroengelb. Auf Wiesen u. Heiden zerstreut., S. H. (Gelbbrauner R.)

S. fulvidus (Fries).

13. Gattung: Tylopilus Karsten (Röhrenpilz).

Wie vor. Gattung, aber das Sporenpulver rost- od. fleischrot. Sporen farblos mit rostroten öltropfen.

Hut zuletzt ausgebreitet, $8-11 \mathrm{~cm}$ br., weich, sammethaarig, 
später kahl, bräunlich-lederfarbig. St. 10-14 cm lg., knollig, voll, fast glatt, nach oben verjüngt u. rauh. Röhren um den St. niedergedrückt, weiß, auf Druck bräunlich. Auf Waldwiesen, selten. S. H. (Lederfarbener R.)

T. alutarius (Fries).

Hut gewölbt, dann ausgebreitet, bis $7 \mathrm{~cm}$ br., selten größer, innen weiß, bei Verletzung rötlich werdend, oberseits mattbraun, glatt. St. $6-8 \mathrm{~cm} \mathrm{lg.,} 1-1,5 \mathrm{~cm}$ dick, voll, bräunlich, oben mit regelmäßiger, brauner, erhöhter Netzzeichnung. Röhren vom St. scharf getrennt, weiß, später rosenrot. Giftig. An alten Stümpfen u. Stämmen in Ndwäldern, nicht selten. S. H. (Fig. 174.) (Gallenpilz.)

T. felleus (Bulliard).

\section{Gattung: Boletus Dillenius (Röhrenpilz).}

Wie vor. Gattung, aber Sporenpulver braun. Sporen gelb od. bräunlich. Bisweilen ein Ring vorhanden.

1. Röhren weiß, höchstens grau werdend.

Röhren lebhaft gefärbt, meist gelb, auch rot, braun usw.

2. Röhren vom St. getrennt, Mündungen klein, rund.

Röhren herablaufend, Mündungen weit, eckig, ungleich groß. 4.

3. Hut gewölbt, dann llach, ca. 6-12 cm br., innen weiß, weich, bisweilen schmutziggrau werdend, oberseits glatt, feucht schmierig, trübbraun, selten weiß od. heller braun. St. $8-15 \mathrm{~cm}$ hoch, $2-2,5 \mathrm{~cm}$ dick, voll, weiß, mit faserigen, schwarzen Schuppen. Röhren weiß, dann mehr grau, vom St. scharf getrennt, Mündungen klein, rund. Eßbar. In Wäldern u. Heiden, häufig. S. H. (Fig. 175.) (Graukappe, Kapuzinerpilz, Birkenpilz.)

\section{B. seaber Bulliard.}

Hut kuglig, dann gewölbt, 5-20 $\mathrm{cm}$ br., rotbraun od. orangefarben, glatt, später schuppig, Fleisch weiß, meist bläulich od. rötlich werdend, am Rande mit den hängenden, häutigen Resten des Schleiers, der St. u. Hut verband, versehen. St. $6-20 \mathrm{~cm}$, selten etwas bauchig, mit schwarzen Runzeln od. Schuppen. Röhren vom St. scharf geschieden, weiß, später grau, Mündungen klein, rundlich. Eßbar. In Heiden, lichten Mischwäldern usw., häufig. S. H. (Rotkuppe.)

B. rufus (Schaeffer).

4. Hut trocken.

Hut halbkuglig, dann ausgebreitet, 5-12 cm br., weiß, später schmutzig gelblich, schleimig, dann glatt, Fleisch weiß, bläulich bis gelbbraun werdend, Rand mit den Resten des flockigen Schleiers. St. $6-8 \mathrm{~cm}$ hoch, zylindrisch, im obern Drittel mit weißem, flockigem, vergänglichem Ringe, oberhalb desselben weißlich mit Netzzeichnung, unterhalb weißlich, dann gelbbräunlich, schleimig. Röhren angewachsen, weiß, dann schmutzig graubräunlich, Mündungen groß, eckig. Eßbar. In Ndwäldern zwischen Moos, zerstreut. S. (Fig. 176.) (Klebriger R.)

B. viscidus $\mathrm{L}$. 
5. Hut polsterf., seidig-zottig, trocken, olivenbraun. St. kegelf., $8 \mathrm{~cm} \mathrm{lg.,} \mathrm{am} \mathrm{Grunde} \mathrm{bis} 4 \mathrm{~cm}$ dick, fest, glatt u. kahl, weißlich, nach oben umbrabraun. Röhren frei, verlängert, weißlich, Mündungen unregelmäßig, gelblich-olivenfarben. An grasigen Stellen in Ndwäldern, selten. S. H. (Rauchfarbener R.)

B. fuligineus Fries.

Hut flach gewölbt, $5-8 \mathrm{~cm}$ br., trocken, flockig, rissig-schuppig, fast bleifarben. St. kurz, selten bis $8 \mathrm{~cm}$ lg., keulig-knollig, kleinschuppig, weißlich od. z. T. braun. Röhren rings um den St. kürzer, weißlich, mit ziemlich großen, weißlichen Poren. In Lbwäldern, selten. S. H. (Rauher R.)

B. asprellus Fries.

6. Röhren sehr kurz, Mündungen buchtig od. gewunden-gefaltet. 7 .

Röhren \pm lg., Mündungen rund od. punktf. 10.

7. Mündungen wie die Röhren gelb, gelbgrün od. gelbbraun. 8.

Hut gewölbt, dann ausgebreitet u. flach, $8-12 \mathrm{~cm}$ br., kahl, klebrig, gelbweiß, Fleisch weiß, Rand anfangs eingerollt, dann scharf. St. fast knollig, weiß, rotgefleckt u. -gestreift. Röhren herablaufend, gelb, Mündungen rötlich-rostfarben, buchtig. In Ndwäldern, selten. S. H. (Sanfter R.)

B. placidus Bonorden.

8. Hut gelb, grau od. rötlich.

Hut flach, $5-8 \mathrm{~cm}$ br., trocken, kahl, braunrot. St. dünn, 5- $12 \mathrm{~cm}$ hoch, gleich dick, glatt, blaßrötlich od. gelblich. Röhren angeheftet, gelb od. gelbbraun, Mündungen gewunden u. gefaltet. In trockenen Ndwäldern, nicht häufig. S. H. (Fig. 177.) (Zerschlitzter R.) B. sistotrema Fries.

9. Hut gewölbt, dann verflacht, zuerst seidenhaarig, dann kahl, getigert, erst grat, dann gelblich. St. gleichdick, glatt, gelbbraun. Röhren weit herablaufend, gelbgrünlich, Mündungen gewunden. In Erlenbrüchen, selten. S. H. (Fig. 178.) (Grauer R.)

B. lividus Bulliard.

Hut flach ausgebreitet, $3-5 \mathrm{~cm}$ br., feucht klebrig, hell rotbraun, trocken glänzend. Fleisch weiß, bei Verletzung rötlich werdend. St. zylindrisch, bis $6 \mathrm{~cm} \mathrm{lg.,} \mathrm{hell} \mathrm{rotbraun.} \mathrm{Röhren}$ angewachsen, etwas herablaufend, Mündungen gewunden, zuletzt zerschlitzt. In feuchten Wäldern, selten. S. H. (Rötlicher R.) B. rubescens Trog.

10. Mündungen braun, rot.

Mündungen gelb od. gelbgrün.

11. St. zylindrisch.

St. knollig, bauchig, später keulenf.

13.

12. Hut halbkuglig gewölbt, mit eingerolltem Rande, später ausgebreitet, $5-8 \mathrm{~cm}$ br., gelb, mit büschelig-haarigen, sich später ablösenden Schüppchen besetzt, Fleisch gelblich, schwach blau werdend. Rand scharf, zuerst etwas über die Röhrenschicht hervorragend. St. $5-8 \mathrm{~cm} \mathrm{lg.,} 1-1,5 \mathrm{~cm}$ dick, glatt, gelb, 
seltener rötlich. Röhren angewachsen. Mündungen sehr fein, bräunlich, zimmetbraun od. schmutzig gelblich in der Jugend. Eßbar. In sandigen Ndwäldern, häufig. S. H. (Fig. 179.) (Sandpilz, Hirsepilz.)

B. variegatus Swartz.

Hut halbkuglig, dann ausgebreitet, $3-8 \mathrm{~cm}$ br., rötlichgelb od. blaßbräunlich, feucht klebrig, trocken glänzend, Fleisch gelblich. St. 3-8 cm lg., 0,5-1 cm dick, dem Hut gleichfarbig, innen am Grunde gelb u. gelbmilchend. Röhren angewachsen u. herablaufend, rostbraun, Mündungen groß, eckig, rostbraun. Geschmack brennend. In Ndwäldern, nicht selten. S. H. (Fig. 180). (Pfeffer-R.)

B. piperatus Bulliard.

13. Fleisch gelb, sich an der Luft bläuend.

Hut halbkuglig, dann flach, 10-20 cm br., ledergelb, später weißlich, feucht etwaș klebrig, Fleisch weiß, bei Verletzung rötlich, dann blau werdend. St. eif.-bauchig, 5-8 cm lg., gelb od. rot, oben mit feiner roter Netzzeichnung. Röhren gelb, vom St. scharf gesondert, Mündungen blutrot od. orangerot. Mild schmeckend. Giftig. In Lbwäldern, zerstreut. S. (Fig. 181.) (Satanspilz.)

B. satanas Lenz.

14. Hut zuletzt polsterf., $5-20 \mathrm{~cm}$ br., umbrabraun, anfangs filzig, feucht etwas klebrig, Fleisch gelb, schnell dunkelblau werdend. St. knollig-keulig, 6-10 cm lg., gelb, nach oben orange- od. mennigrot, mit purpurroten, filzigen, meist netzf. geordneten Schuppen. Röhren grünlichgelb, vom St. getrennt, Mündungen lebhaft gelbrot. Geschmack mild. Gilt als giftig. In Wäldern zerstreut. S. (Fig. 182.) (Schusterpilz, Hexenschwamm, Judenschwamm.)

B. luridus Schaeffer.

Hut polsterf., gelblichgrün, später gelb, glatt, trocken, Fleisch gelb, bald blau werdend. St. knollig-eif., 5-8 cm lg., rosen- od. blutrot, mit undeutlicher Netzzeichnung. Röhren gelb, vom St. geschieden, Mündungen fein orangerot. Verdächtig. In Wäldern, auf Wiesen, zerstreut. S. (Wolfspilz.)

B. lupinus Fries.

15. St. mit netzartiger Zeichnung.

St. ohne jede Andeutung einer netzartigen Zeichnung. 24.

16. Fleisch beim Bruch sich nicht bläuend.

Fleisch beim Bruch leicht blau anlaufend.

17. Fleisch unveränderlich bleibend.

Hut halbkuglig mit scharfem, eingebogenem Rand, ca. $5-10 \mathrm{~cm}$ br., kastanien- od. olivenbraun, trocken, Fleisch weiß, schnell gelb werdend. St. knollig-keulenf., bis $8 \mathrm{~cm} \mathrm{lg.,} \mathrm{gelb,} \mathrm{unten}$ bräunlich, oben mit erhabener Netzzeichnung. Röhren gelb, vom St. geschieden, Mündungen sehr fein, goldgelb. Eßbar. In lichten Wäldern, zerstreut. S. H. (Fig. 183.) (Bronzefarbener R.)

B. aereus Bulliard.

18. Fleisch gelb od. gelblich.

Hut zuerst fast kuglig, dann ausgebreitet, meist $10-20 \mathrm{~cm}$ br., \pm braun, oft weißlich, feucht €twas klebrig, glatt, Fleisch 
weiß, fest. St. dickknollig, dann keulenf., bis $16 \mathrm{~cm}$ hoch, 4 bis $6 \mathrm{~cm}$ dick, hellbräunlich, oben fast weiß u. mit erhabener, weißer Netzzeichnung. Röhren weiß, zuletzt grünlichgelb, vom St. scharf getrennt, Mündungen rundlich, weiß, dann grünlichgelb. Guter Speisepilz. In lichten Wäldern, Gebüschen, auf Lichtungen usw., häufig. S. H. (Fig. 184.) (Steinpilz, Herrenpilz, Eichpilz.)

B. edulis Bulliard.

19. Hutoberfläche trocken.

20.

Hut kuglig, dann ausgebreitet, $5-15 \mathrm{~cm}$ br., anfangs mit braunem Schleim überzogen, dann lebhaft rot od. rotgelb, glatt, glänzend, Fleisch gelb, weich. St. $5-8 \mathrm{~cm}$ lg., zylindrisch, rotgelb, in der Mitte mit einem häutigen Ring, oberhalb desselben mit rotbrauner Netzzeichnung. Röhren angewachsen, gelb, Mündungen ungleich, eckig. Eßbar. In Ndwäldern, häufig. S. H. (Fig. 185.) (Goldpilz.) $\quad$ B. flavus Withering.

20. Hut halbkuglig, dann polsterf., $10-22 \mathrm{~cm}$ br., blutrot, glatt, trocken, Fleisch gelb. St. $5-8 \mathrm{~cm}$ hoch, gelb, am Grund rötlich, nach oben mit netzartiger Zeichnung. Röhren halbfrei, kurz goldgelb. Speisepilz. In Wäldern, Heiden, besonders im Süden nicht selten. S. H. (Königspilz.) B. regius Krombholz.

Hut gewölbt, dann ziemlich flach, $5-8 \mathrm{~cm}$ br., in der Mitte mit stumpfem Buckel, gelbbraun, trocken, mit groben, eingewachsenen, schuppigen Fasern, Fleisch gelblich. St. $4-8 \mathrm{~cm}$ hoch, hohl, gelblich od. ockerfarben, oberhalb der Mitte mit einem filzig-flockigen, schmutzig weißlichen Ringe, unterhalb flockig, oberhalb netzartig gezeichnet. Röhren angewachsen, herablaufend, nach dem Rande zu strahlig. Mündungen grünlichgelb, in der Tiefe geteilt. In lichten Ndwäldern zwischen Moos, selten, im Süden häufiger. S. (Fig. 186.) (Hohlstieliger R.)

B. cavipes Opatowski.

21. Hutoberfläche ledergelb od. olivenbraun.

Hut polsterf., dann ausgebreitet, meist über $5 \mathrm{~cm}$ br., schwach filzig, zuerst braun, dann ziegelrot, Fleisch blaß. St. aufgedunsen, bauchig, $8 \mathrm{~cm} \mathrm{lg.,} \mathrm{ca.} 2 \mathrm{~cm}$ dick, wurzelnd, an der Spitze schwach netzig. Röhren angeheftet, kurz, Mündungen klein, eckig, gelb. In Wäldern, selten. S. H. (Fig. 187.) (Bewurzelter R.)

\section{B. appendiculatus Schaeffer.}

22. St. nicht vollständig scharlachrot, höchstens unten rot. 23.

Hut kuglig, dann polsterf., bis $19 \mathrm{~cm}$ br., olivenbraun, filzig, Fleisch blaßgelb. St. zuerst keulig, später mehr zylindrisch, $6-10 \mathrm{~cm} \mathrm{lg.,} \mathrm{vollständig} \mathrm{od.} \mathrm{wenigstens} \mathrm{oben} \mathrm{scharlachrot} \mathrm{mit}$ Netzzeichnung. Röhren gelb, Mündungen eckig, gelb, fein. In Wäldern, Gabüschen, nicht selten. Giftig. S. (Fig. 188.) (Schönfuß-R.)

B. calopus Fries.

23. Hut kuglig, dann polsterf., $10-20 \mathrm{~cm}$ br., schwach filzig, zuerst bräunlich, dann ledergelb, seltner rötlich, Fleisch weißlich. St. 
stark knollig, $2-5 \mathrm{~cm}$ dick, dann fast zylindrisch, bis $8 \mathrm{~cm} \mathrm{lg}$., gelb, oben mit gelber od. roter erhabener Netzzeichnung, unten dichter rotfilzig. Röhren am St. verkürzt, gelb bis grünlich. Mündungen rundlich, gelbgrün. Gruch wanzenartig, Gaschmack bitter. Giftig. In Lbwäldern, zerstreut. S. H. (Fig. 189.) (Dickfuß-R.)

B. pachypus Fries.

Hut gewölbt, mit eingebogenem Rand, $4-6 \mathrm{~cm}$ br., glatt, olivenbraun, Fleisch weiß. St. keulig-knollig, $5-7 \mathrm{~cm}$ hoch, oben gelb, unten rot, mit roten Punkten u. Netzzeichnung. Röhren kurz, am St. angewachsen, gelb bis grünlich, Mündungen klein, ungleich, grünlich. Verdächtig. In Mischwäldern, selten. S. (Olivenbrauner R.)

B. olivaceus Schaeffer.

24. Röhren rings um den St. niedergedrückt, abgerundet, deshalb fast frei.

Röhren am St. angeheftet.

25. Hut polsterf., dann erweitert, $15 \mathrm{~cm}$ u. mehr br., flockig, dann körnig od. felderig rissig, nicht glänzend, gelbbraun, Fleisch unter der Oberhaut gelblich. St. fast knollig, dick, gelb, bisweilen unter der Spitze rötlich gezont. Röhren frei, gelb. In Eichenwäldern, selten. S. (Fig. 190.) (Rissiger R.)

B. impolitus Fries.

Hut polsterf., geschweift, schwach filzig, umbrabraun, mit eingebogenem, oft purpurrotem Rande. St. dick, eif.-knollig, am Grunde oft spindelf., gelblich u. rötlich-bunt. Röhren halbfrei, Mündungen klein, rund. Eßbar. In Lbwäldern, selten. S. H. (Duftender R.)

B. fragrans Vittadini.

26. Hutoberseite nicht klebrig.

27.

Hutoberseite klebrig.

27. Nicht parasitisch.

Hut gewölbt, dann flach, ea. $6 \mathrm{~cm}$ br., seidenartig glatt, schmutzig gelb, dann würfelig-rissig. St. dünn, starr, $5-10 \mathrm{~cm} \mathrm{lg}$. gekrümmt, innen u. außen gelb. Röhren herablaufend, goldgelb. Auf Scleroderma-Arten in Wäldern, selten. S. (Fig. 191.) (Schmarotzer-R.)

B. parasiticus Bulliard.

28. Fleisch gelblich, sich (wenn auch schwach) bläuend, wenn nicht, dann unter der Oberhaut purpurrot.

Hut halbkuglig, dann polsterf. ausgebreitet, $4-6 \mathrm{~cm}$ br., weichfilzig, braun, später rissig, Fleisch weiß, unveränderlich. St. unten verdickt, 6-8 cm lg., kleiig-flockig, gelbbräunlich. Röhren gelb, dem St. angewachsen, Mündungen fein, rundlich, gelb. Eßbar. Zwischen Moos am Grunde alter Stämme, zerstreut. S. H. (Fig. 192.) (Kastanienbrauner R.)

\section{B. spadiceus Schaeffer.}

29. St. faserig-streifig od. mit rötlichem flockigem Filz, nicht der ganzen Länge nach gekörnelt.

30 .

Hut gewölbt, später ausgebreitet, bis $10 \mathrm{~cm}$ br., weichfilzig, oliven- od. rotbraun, oft rissig-gefeldert, Fleisch gelblich, schwach Lind au, Kryptogamenflora. I. 2. Aufl. 
blau werdend. St. dünn, meist nach unten verjüngt, gelblich, selten rötlich, körnig-rauh (event. unter der Lupe), durch flache Rippen weitläufig netzig od. streifig. Röhren dem St. angewachsen, grünlichgelb, Mündungen weit, eckig. Eßbar. In Wäldern u. Gebüschen, häufig. S. H. (Fig. 193.) (Ziegenlippe.)

B. subtomentosus $\mathrm{L}$.

30. Hut halbkuglig, dann ausgebreitet, $6-8 \mathrm{~cm}$ br., olivenbraun, später gelbbräunlich, flockig-filzig, Fleisch gelb, blau werdend. St. unten wurzelartig verdünnt, $5-6 \mathrm{~cm} \mathrm{lg.,} \mathrm{glatt,} \mathrm{gelb,} \mathrm{unten}$ mit rötlichem, flockigem Filz. Röhren angewachsen, zitronengelb, Mündungen ziemlich weit, rundlich. Verdächtig. In Lbwäldern, zerstreut. S. H. (Wurzelnder R.)

B. radicans Pers.

Hut flach, 5-7 cm br., braun, \pm purpurrot, feinfilzig, dann kahl, glatt, rissig-felderig, Fleisch-gelblich, unter der Oberhaut purpurrot, bisweilen etwas sich bläuend. St. $5-6 \mathrm{~cm}$ lg., zylindrisch, $1-1,5 \mathrm{~cm}$ dick, fest, faserig gestreift, gelb od. \pm scharlachrot. Röhren angewachsen, chrom- bis grüngelb, Mündungen ziemlich groß, eckig. Eßbar. In Wäldern u. Gebüschen, nicht selten. S. H. (Fig. 194.) (Kosarke, Butterpilz.)

\section{B. chrysenteron Bulliard.}

31. Fleisch weiß, sich schwach verfärbend.

Fleisch weiß, gelblich, blaß, sich nicht verfärbend.

32. Hut halbkuglig, dann polsterf., $6-10 \mathrm{~cm}$ br., kastanienbraun, glatt, feucht klebrig, trocken glänzend, Rand etwas eingerollt, Fleisch weiß od. blaßgelblich, schwach blau werdend. St. $8 \mathrm{~cm}$ lg., zylindrisch, blasser, braun bereift. Röhren angeheftet, bei Berührung schnell grünlich werdend, Mündungen eckig, ziemlich weit. Eßbar. In Ndwäldern, Heiden, häufig. S. H. (Fig. 195.) (Maronenpilz.)

B. badius Fries.

Hut flach gewölbt, $3-8 \mathrm{~cm}$ br., blaß lederbraun od. rotbraun, feucht klebrig-schleimig, trocken glänzend, glatt, Fleisch weiß, rötlich werdend. St. zylindrisch od. nach oben verdickt, $3-6 \mathrm{~cm}$ lg., hell rotbraun od. gelblich, glatt. Röhren herablaufend, gelblichgrün, Mündungen sehr weit, eckig, fast strahlig, in der Tiefe durch niedrigere Wände mehrteilig. Eßbar. In Kiefernwäldern, besonders an lichten Stellen, häufig. S. H. (Fig. 196.) (Ochsenreische, Kuhpilz.)

33. St. mit Ring.

B. bovinus $\mathrm{L}$.

Hut halbkuglig, flach, $5-8 \mathrm{~cm}$ br., gelb od. rötlichgelb, zuerst mit rostfarbenem Schleim bedeckt, dann nackt, glänzend, Fleisch hellgelb. St. zylindrisch, $5-8 \mathrm{~cm}$ hoch, $1-1,5 \mathrm{~cm}$ dick, innen hellgelb, oben mit zuerst weißen, dænn bräunlichen od. schwärzlichen körnigen Schüppchen. Röhren angewachsen, Mündungen sehr fein, hellgelb, rundlich, einen weißen Saft absondernd, bisweilen in der Tiefe 2-4 teilig. Eßbar. Auf Waldwiesen, an Waldrändern, häufig. S. H. (Fig. 197.) (Schälpilz, Schmeerpilz.)

B. granulatus $\mathrm{L}$. 
34. Mündungen in der Tiefe nicht durch Wände geteilt.

Hut gebuckelt, dann flach, 5-8 cm br., klebrig, graugelblich, Fleisch blaß. St. $5-8 \mathrm{~cm}$ hoch, zylindrisch, blaß, mit klebrigem Ring u. oberhalb desselben mit vergänglichen Drüsen bedeckt. Röhren herablaufend, Mündungen schmutzig gelb,! in der Tiefe durch Wände geteilt. Eßbar. In Sümpfen, moorigen Kiefernwäldern, besonders im Gebirge, nicht häufig. S. H. (Fig. 198.)
(Gelblicher R.)
B. flavidus Fries.

35. Hut fast kuglig, dann flach ausgebreitet, $5-11 \mathrm{~cm} \mathrm{br.,} \mathrm{gelb,}$ zuerst mit dickem braunem Schleim überzogen, dann trocken u. glänzend, am Rande mit den Resten des dünnhäutigen Schleiers, Fleisch weiß, bald zerfließend. St. $5-10 \mathrm{~cm}$ hoch, zylindrisch, weißlich, in der Mitte mit häutigem Ring, oberhalb desselben gelblich, mit feinen, weißen, später bräunlichen, flockigen Punkten besetzt. Röhren angewachsen, hellgelb, Mündungen fein, rundlich. Eßbar. An Rändern u. Lichtungen von Ndwäldern, häufig. S. H. (Fig. 199.) (Butterpilz, Schälpilz.) B. luteus L.

Hut flach gewölbt, bis $12 \mathrm{~cm}$ br., goldgelb od. rostfarben, klebrig, Fleisch gelb. St. $5-11 \mathrm{~cm}$ hoch, goldgelb, später rot werdend, mit vergänglichem Ringe, oberhalb desselben weißgelblich punktiert. Röhren herablaufend, Mündungen klein, goldod. schwefelgelb. Eßbar. In Wäldern, selten. S. H. (Schöner R.)

B. elegans Schumacher.

\section{Gattung: Strobilomyces Berkeley (Schuppenröhrling).}

Hut mit dem St. zuerst durch einen filzigen Schleier verbunden. Sporenpulver schwarz, sonst wie vor. Gatt.

Hut kuglig, dann abgeflacht, 5-10 cm br., mit dicker, filzigflockiger Rinde überzogen; die anfangs schmutziggrau ist u. dann in dicke, br., gefelderte Schuppen zerreißt. Fleisch weiß, dann rötlich, zuletzt schwarz werdend, Rand mit den Resten des flockigen Schleiers. St. zylindrisch, bis $15 \mathrm{~cm}$ hoch, grau, später schwarz. Röhren angewachsen, weißlich, dann grau, Mündungen weit, eckig. In Ndwäldern der Gebirge, zerstreut. S. H. (Fig. 200.) (Schwarzer S.)

$$
\text { S. strobilaceus (Scopoli). }
$$

\section{Gattung: Ceriomyces Corda.}

Fk. meist kissenf. od. kuglig, fleischig od. korkig. Hyphen im Innern in Chlamydosporen zerfallend, deshalb bei der Reife im Innern staubig. Röhren nur selten beobachtet, daher nicht feststellbar, zu welcher anderen Gattung gehörig.

Fk. kuglig bis polsterf., bis $15 \mathrm{~cm}$ im Durchm., weiß, weich, filzig, später braun werdend, im Innern geschichtet. Am Grunde von Kiefernstümpfen u. -pfählen, selten. S. H. W.

$$
\text { C. albus (Corda). }
$$


Fk. kissenf., oft zusammenfließend, $3-4 \mathrm{~cm}$ br., flockig, weiß, durch Berührung sich rötend, innen pulverig-faserig, rötlich. An kiefernen Brettern, Kübeln in Kellern u, Gewächshäusern, selten. S. H. W.

C. rubescens (Boudier).

\section{Familie: Agaricaceae.}

Fk. hutf., verschieden ausgestaltet, ohne od. mit seitlichem od. zentalem St., meist fleischig, selten häutig od. lederig. Hymenium auf senkrecht stehenden, meist unter sich freien, selten am Grunde od. am St. anastomosierenden L. od. selten auf strahlig verlaufenden Adern od. Falten stehend. Basidien meist viersporig. Sporen hyalin od. gefärbt.

\section{Unterfamilie: Cantharelleae.}

Hut unterseits mit gewöhnlich strahlig verlaufenden Leisten od. Adern besetzt, auf denen das Hymenium steht.

\section{Bestimmungsschlüssel der Gattungen.}

A. Hut auf der Unterseite mit dünnen einfachen Adern.

1. Arrhenia.

B. Hut auf der Unterseite mit derben Leisten od. Falten.

a) Substanz des Fk. häutig-lederig, zähe. 2. Trogia.

b) Substanz des Fk. weichhäutig, dünn.

I. Hut ungestielt, zuerst schüsself. $\quad 3$. Leptotus.

II. Hut seitlich gestielt, fächerf.

c) Substanz des zentral gest. Hutes fleischig, derb.

4. Leptoglossum.

5. Cantharellus.

1. Gattung: Arrhenia Fries (Arrhenie).

Hut nicht od. wenig gest., häutig, sehr zart. Adern dünn, einfach, in geringer Zahl.

Hut umgewendet, kreisf., hanfkorngroß, außen glatt, zottig, grau, nach dem Rande hin faltig. Auf faulem Holz, selten. (Fig. 201.) (Schüsself. A.)

A. cupularis (Wahlenberg).

Hut braun, häutig, rundlich, gewölbt, kahl, mit seitlichem, fädigem, braunem, ca. $1 \mathrm{~cm}$ lg., steifem, zottigem St. Adern entfernt stehend, einfach. Auf nackter Erde in Buchenwäldern, selten. (Ohrf. A.)

A. aurisealpium Fries.

\section{Gattung: Trogia Fries (Trogie).}

Hut ungestielt, häutig-lederartig, dünn, zähe, dauerhaft, lappig, Falten dichotom verzweigt.

Einzige Art mit sitzendem, an einem Punkt befestigtem, becherf. od. lappig abstehendem Hut, meist dachziegelig, außen gelblich bis 
Cantharelleae.
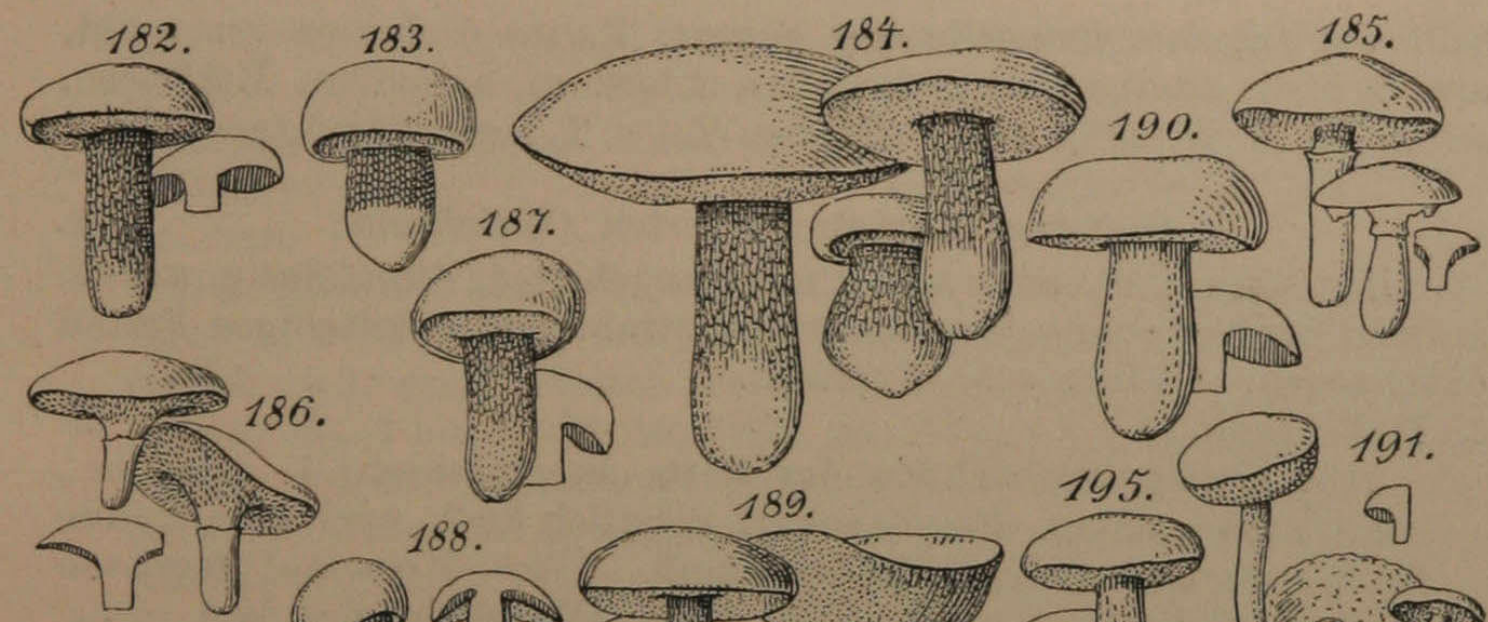

192
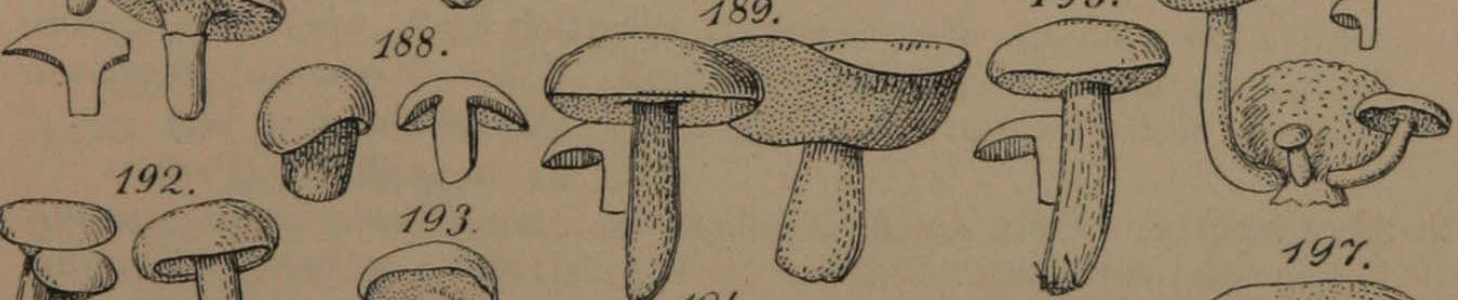

(1) 193

4

202.

202. $U$ (

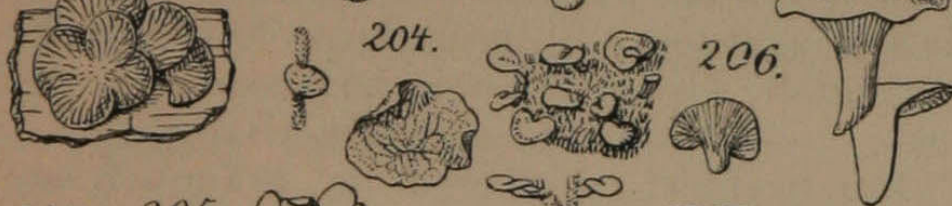

203. 205.2103

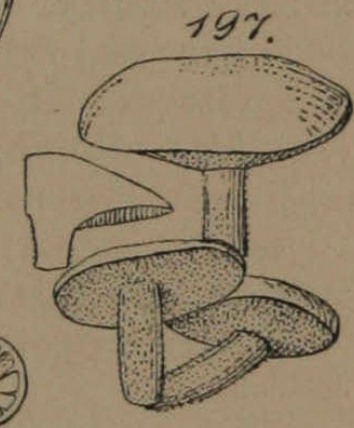

S10.211.

2010

W

194.

196.

$20 \%$.

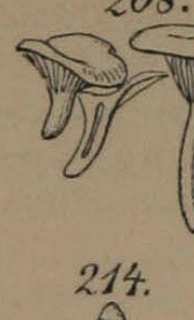

$\iint_{\pi}^{209}$ 215.216.

13. $>$ की

r

A p

225. की $22 \%$ की 226 (0) 224.

(III) 218.221 (n) 230 . (2) U11i) (3) an (ind 
hellbräunlich, fein striegelhaarig, gezont. Falten dichotom verzweigt, am Grunde aderig verbunden. An Lbästen, besonders Rotbuche, selten. S. H. W. (Fig. 202.) (Buchen-T.) T. faginea (Schrader).

3. Gattung: Leptotus Karsten (Weichrohr).

Hut ungestielt, an einem Punkt angeheftet, dünnhäutig, weich, anfangs becherf., innen von niedrigen, strahligen, gabelteiligen Falten durchzogen. Gleicht sehr Cyphella.

1. Hut braun.

2.

Hut häutig, becherf., in der Mitte angewachsen, $4-8 \mathrm{~cm}$ br., weiß, außen zottig. Falten scharf, ziemlich hoch, nach dem Rande $2-3-$, auch 5 mal gabelteilig, weiß. Über Moos auf feuchten Wiesen, nicht häufig. H. (Fig. 203.) (Moosliebendes W.) L. bryophilus (Pers.).

2. Hut häutig, weich, flach, $2-3 \mathrm{~cm}$ br., am Rande lappig, kraus, braun od. rotbraun. Falten niedrig, strahlig, gabelig. Ebenda, zerstreut. H. (Lappiges W.) L. lobatus (Pers.).

Hut dünnhäutig, weich, sitzend, am untern Rand mit weißlichen Fasern angeheftet, $1-3 \mathrm{~cm}$ br., lappig abstehend, graubraun, gegen den Grund heller, außen glatt. Falten weitläufig, dichotom, netzaderig verbunden. Ebenda, zerstreut. H. (Fig. 204.) (Netzaderiges W.) L. retirugus (Bulliard).

4. Gattung: Leptoglossum Karst (Weichzunge).

Hut seitlich gestielt, häutig, weich. Falten gabelteilig.

Hut sehr weich u. zart, zuletzt zungenartig vorgestreckt, ca. $1,5 \mathrm{~cm}$ br., grau, seidenhaarig, ungezont. St. grau, kurz, weiß bereift. Falten weitläufig, niedrig, grau. Über Moosen, zerstreut. S. H. (Fig. 205.) (Graugrüne W.) L. glaucum (Batsch).

Hut häutig, fächerf., fast trichterf., $1-2,5 \mathrm{~cm}$ br., bräunlich od. graubraun, gezont, glatt, am Rande gelappt u. kraus. St. höchstens $1 \mathrm{~cm}$ lg., am Grunde weißzottig. Über Moosen, zerstreut. H. F. (Fig. 206.) (Moosliebende W.)

L. muscigenum (Bulliard).

\section{Gattung: Cantharellus Adanson (Faltenpilz).}

Hut zentral gestielt, fleischig. Falten od. Leisten \pm hoch, gabelteilig, oft durch Querfalten verbunden.

1. Hut u. St. orange- od. dottergelb.

Hut u. St. andersfarbig.

2. Hut bis $8 \mathrm{~cm}$ br., gewölbt, eingedrückt, kreiself., flach, kahl, dottergelb bis orangerot, St. nach unten verjüngt, voll u. fest. Falten dick aderf., vielfach gabelteilig. Geschmack pfeffrig. Guter Speisepilz. In Lb- u. Ndwäldern, besonders Heiden, Grasplätzen, gemein. S. H. (Fig. 207.) (Pfifferling, Pfefferling, Gähling, Rehling, Eierschwamm, Galluschel.)

C. eibarius Fries.

Hut orangerot, etwas filzig, namentlich am Rande, $4-8 \mathrm{~cm}$ br., meist in der Mitte eingedrückt u. am Rande gerollt. St. zylindrisch, 
voll, später hohl, orangefarben. Falten lamellenartig, bis $3 \mathrm{~mm}$ hoch, mehrmals gabelteilig, herablaufend. Verdächtig. In Wäldern, besonders Ndwald, im Moos, häufig. S. H. (Fig. 208.) (Falscher Eierschwamm.)

c. aurantiacus (Wulfen).

3. St. hohl.

Hut gewölbt, dann eingedrückt, in der Mitte mit einem spitzen Höcker, 2-4 cm br., am Rand eingerollt, dann wellig, grau od. schwärzlich, glatt, Fleisch weiß, bei Verletzung blutrot werdend. St. voll 5-7 cm hoch, weißlich od. hellgrau, am Grunde weißzottig. Adern dichtstehend, gabelig, weiß. In Wäldern u. Heiden, zwischen Moos u. Heidekraut, nicht selten. S. H. (Fig. 209.) (Genabelter F.)

c. umbonatus (Gmelin).

4. St. hellgrau bis schwärzlich.

5.

St. gelb od. gelbbraun.

6.

5. Meist büschelig zu 10-20 zusammenstehend. Hut in der Mitte eingedrückt, ohne Höcker, $1-2 \mathrm{~cm}$ br., graubraun, später schwärzlich, graubraun, Fleisch weißbleibend. St. bis $2 \mathrm{~cm}$ lg., spindelig, nach oben verdickt, hellgrau. Adern dichtstehend, weiß, herab. laufend. Auf Brandstellen in Wäldern, nicht selten. H. (Fig. 210.) (Kohlen-F.) C. carbonarius (Alb. et Schwein.).

Hut trichterf., vom Scheitel bis zur Stbasis röhrig hohl, dünnfleischig, 2-3 $\mathrm{cm}$ br., schwärzlich grau, zottig schuppig, Rand scharf. St. bis $6 \mathrm{~cm}$ hoch, schwärzlich. Hymenium blaugrau, Falten dick, entfernt stehend, mehrfach gabelteilig. In Lbwäldern nicht selten. S. H. (Hohlstieliger F.) C. hydrolips (Bulliard).

6. Hut fast häutig, trichterf., in der Mitte vertieft, später durchbohrt, $3-6 \mathrm{~cm}$ br., graubraun bis graugelb, flockig-runzlig. St. $5-6 \mathrm{~cm}$ hoch, gelb, glatt. Falten dick, entfernt stehend, gelb od. grau, gabelig. In Wäldern zwischen Moos, besonders im Gebirge, nicht selten. S. H. (Fig. 211.) (Trichterf. F,)

\section{C. infundibuliformis (Scopoli).}

Hut trichterf., dünnfleischig, $3-6 \mathrm{~cm}$ br., bräunlich, flockig, am Rande oft gelappt u. kraus. St. gelb od. gelbbraun, meist zusammengedrückt, hohl. Hymenium gelb od. graugelb. Falten leistenf., entfernt voneinander, gabelig. In Wäldern zwischen Moos, zerstreut. S. H. (Fig. 212.) (Trompetenf. F.)

C. tubiformis (Bulliard).

\section{Unterfamilie: Paxilleae.}

Fk. derbfleischig. L. häutig, sich leicht vom Hute lösend u. meist leicht in zwei Platton spaltbar, am St. anastomosierend u. oft röhrenf. Höhlungen bildend.

Einzige Gattung: Paxillus Fries (Pfahlpilz).

L. herablaufend. Sporenpulver braun.

1. Hut weißlich, gelblich, selten hellbräunlich.

Hut kräftig braun, niemals weißlich. 
2. L. \pm herablaufend, Hut zentral gestielt.

Hut dünnfleischig, fächerf. od. kreisf., umgewendet, $2-6 \mathrm{~cm}$ br., weißlich, später gelblich bis hellbräunlich, anfangs fein filzig, dann glatt, Rand scharf u. dünn, eingebogen, dann gerade, oft wellig. St: fehlend, aber oft ein seitlicher od. zentraler St.-Ansatz vorhanden. L. von einem Punkte ausstrahlend, oft exzentrisch strahlend, vielfach gabelig, gekräuselt, am Mittelpunkt oft durch Querleisten verbunden, weiß, dann dottergelb bis bräunlich. (Unterirdischer P.)

P. acheruntius (Humboldt).

(Kommt in zwei Unterarten vor: Hut seitlich gestielt, fächerf., mehrere in dichten Gruppen. An alten Kiefernstümpfen, nicht selten. S. H. P. panuoides [Fries]. - Hut meist einzeln, umgewendet, im Mittelpunkt angeheftet od. mit einem \pm lg. St. glockig herabhängend. An Holz in Kellern, Ställen, Bergwerken usw. Das ganze Jahr. P. acheruntius [Humb.].)

3. Hut dünnfleischig, flach gewölbt, dann etwas niedergedrückt, kahl, feucht, weißlich, Rand umgerollt. St. $2-3 \mathrm{~cm}$ hoch, rötlich, nach unten verdickt. L. schwach herablaufend, schmal, später wässerig-rostfarben. In Ndwäldern, selten. S. H. (Bunter P.) P. panaeolus Fries.

Hut fleischig, flach, 2,5-11 cm br., trocken, seidenhaarig od. geglättet, schmutzig weißlich, nach dem Rand hin kleinschuppigrissig. Rand eingerollt, nackt. St. voll, $5-8 \mathrm{~cm}$ lg., blaß, selten rötlich. L. weit herablaufend, schmutzig weiß, dann dunkler, gabelig. An feuchten Stellen in Wäldern, selten. S. H. (Schuppiger P.)

P. lepista Fries.

4. St. zentral.

Hut fleischig, spatelf., einseitig vorgestreckt, flach, dann trichterf. 5-12 cm br., rostbraun, sammethaarig, dann kahl, körnig-rissig, Fleisch gelblich weiß, Rand eingerollt, filzig. St. bis $5 \mathrm{~cm} \mathrm{lg.,}$ unten wurzelartig verlängert, schwarzbraun filzig. L. kurz herablaufend, am Grunde anastomosierend, gelblich. An alten Kiefern stämmen, nicht selten. S. H. (Schwarzfilziger P.)

\section{P. atrotomentosus (Batsch).}

5. Hut dickfleischig, flach gewölbt, $4-7 \mathrm{~cm}$ br., kastanienbraun, weichfilzig, rissig, Fleisch weiß, später gelblich, Rand eingebogen. St. $3-5 \mathrm{~cm}$ lg., spindelf., gelb, rotbraun punktiert u. gefasert. L. herablaufend, entfernt stehend, wellig-kraus, am Grunde anastomosierend u. zellig, chromgelb. Zwischen Moos in Wäldern, selten. S. (Pelletiers P.)

P. Pelletieri Lév.

Hut fleischig, flach, dann in der Mitte niedergedrückt u. fast trichterf., 6-12 cm br., ockerbraun, glänzend, Fleisch gelblich bis bräunlich, Rand eingerollt, filzig-zottig. L. herablaufend, hellbraun, dann rostbraun. Eßbar. Auf der Erde in Wäldern, Gebüschen usw., häufig. S. H. (Fig. 213.) (Krämpling.)

P. involutus (Batsch). 


\section{Unterfamilie: Coprineae.}

Fk. weichfleischig, zentral gestielt, L. verschieden lg., sehr regelmäßig. L. u. meist auch der Hut bei der Reife zerfließend. Zwischen den Basidien große Cystiden.

\section{Bestimmungsschlüssel der Gattungen.}

A. Sporenpulver braun od. gelbbraun.

B. Sporenpulver schwarz.
1. Bolbitius.

2. Coprinus.

1. Gattung: Bolbitius Fries (Goldmistpilz).

Hut dünnhäutig, schnell vergänglich, meist ohne Schleier. L. dünn, wässerig. Sporen braun.

1. Hut irgendwie gelblich.

Hut kegelf., lehmbraun, trocken weißlich, in der Mitte schwach klebrig, glatt, Rand gestreift. St. bis $12 \mathrm{~cm}$ lg., röhrig, weiß, glatt, glänzend, zähe. L. blaß-, dann rostbraun. Auf gedüngten Grasplätzen, Waldrändern usw., nicht selten. S. (Fig. 214.) (Kegelf. G.)

B. conocephalus (Bulliard).

2. St. anfangs od. bleibend mit Flöckchen od. Schuppen besetzt. 3 .

Hut glockig-kegelf., dann ausgebreitet, $2-3 \mathrm{~cm}$ br., Mitte gelb, klebrig, Rand weißlich, später bräunlich, gestreift u. zerschlitzt. St. glatt, glänzend, hohl, 6-14 cm lg., gelblich. L. blaß, dann purpur- od. rötlichbraun. Auf Kuhmist, gedüngten Wiesen usw., zerstreut. S. (Fig. 215.) (Schwankender G.)

B. titubans (Bulliard).

3. Hut kegelf., in der Mitte flach gebuckelt, dann ausgebreitet, bis $6 \mathrm{~cm}$ br., gelblich mit dunklerer Mitte, dann ausbleichend, Rand glatt, dann gestreift. St. hellgelblich, anfangs mit weißen Flocken besetzt, dann kahI, 6-8 cm hoch, hohl. L. gelb, dann rostbraun. Auf Pferdemist an Waldwegen, Wiesen usw., zerstreut. S. (Gelblicher G.)

B. flavidus (Bolton).

Hut eif., dann ausgebreitet, geschweift, $5-6 \mathrm{~cm}$ br., klebrig, dottergelb, am Rand später gespalten u. gefurcht. St. hohl, $5-8 \mathrm{~cm}$ lg., weißschuppig. L. lehmgelb. Auf Pferdemist ebenda, selten. (Dottergelber G.)

B. vitellinus (Pers.).

2. Gattung: Coprinus Pers. (Mistpilz).

Hut meist dünnhäutig, meist mit flockigem od. kleiigem Velum universale. L. häutig, oft glänzend durch die Cystiden, zerfließend (meist mit dem Hut) zu einer tintenartigen Masse.

1. Hut mit dem St. durch einen Schleier vereinigt, deshalb nachher der St. mit Ring.

Hut mit dem Rande dem St. anliegend, höchstens durch feine Hyphen mit ihnen verbunden. Ohne Ring.

2. Hüte über $4 \mathrm{~cm}$ br.

Hut zylindrisch, dann glockenf., höchstens bis $2 \mathrm{~cm}$ br., weiß- 
lich od. in der Mitte gelblich, später grau, anfangs mit kleiigen Schüppchen besetzt, Rand zuletzt umgerollt. St. $3-5 \mathrm{~cm} \mathrm{lg.,}$ zart, hohl, kahl, weißlich, am Grunde mit zottig behaarter Verdickung, in der Mitte mit zartem, beweglichem, weißem Ring. Auf Mist, auch in Kulturen, nicht selten. F. S. H. (Fig. 216.) (Vergänglicher M.)

C. ephemeroides (Bulliard).

3. Hutoberfläche mit kleinen Schüppchen, niemals die Haut selbst in grobe Schuppen zerschlitzt.

Hutoberfläche in grobe, sparrige, dicke Schuppen aufgelöst. 5 .

4. Hut eif., dann ausgebreitet, in der Jugend mehlig-bereift, graubräunlich, glatt od. rissig-schuppig, $5-8 \mathrm{~cm}$ br. St. hohl, zerbrechlich, etwas faserig, $8 \mathrm{~cm}$ lg., mit vergänglichem Ring. L. angeheftet, umbrabraun bis schwarz. Am Grunde alter Stämme dicht büschelig, zerstreut. S. H. (Brauner M.)

\section{C. fuscescens (Schaeffer)}

Hut eif., dann glocken- bis kegelf., 5-11 cm br., graubraun, feinhaarig, in der Mitte mit eingewachsenen kleiigen Schuppen, Rand, wellig, anfangs scharf, dann zerschlitzt. St. $10-18 \mathrm{~cm} \mathrm{lg.,}$ wei $\beta$, faserig, glatt, unter der Mitte mit faserigem, vergänglichem Ring. L. sehr dicht, weiß, dann von der Schneide aus braun u. zuletzt schwarz werdend. Am Grunde von Stämmen dichtgedrängt, häufig. S. H. (Fig. 217.) (Tinten-M.)

\section{C. atramentarius (Bulliard).}

5. St. bei Berührung nicht schwarz werdend.

Hut kegelf., dann ausgebreitet, gefurcht, in der Jugend zottig, in der Mitte sparrig-schuppig schmutzig grau, $8 \mathrm{~cm}$ br., St. $14 \mathrm{~cm}$ lg., faserig, weiß, bei Berührung schwarz werdend, mit Ring. L. purpurumbrabraun, bauchig. Auf Kuhmist, zerstreut. S. H. (Fig. 218.) (Schwarzwerdender M.) C. sterquilinus Fries.

6. Hut eif., dann ausgebreitet, bis $8 \mathrm{~cm}$ br., reinweiß, mit dicken, dachziegelf., konzentrischen Schuppen. St. 8-11 cm lg., am Grunde knollig, kleinflockig, nach oben kahl, in der Mitte mit vergänglichem Ring. L. weiß, dann von der Schneide aus braun u. schwarz werdend, bis $1 \mathrm{~cm}$ br. Aaf gedüngtem Boden in Höfen, Grasplätzen usw., zerstreut. F. S. H. (Eif. M.)

C. ovatus (Schaeffer).

Hut fleischig, zylindrisch, bis $10 \mathrm{~cm}$ hoch, dann kegelf. ausgebreitet, weiß mit dicken, sparrigen, haarigen Schuppen, Rand später zerschlitzt. St. bis $16 \mathrm{~cm} \mathrm{lg.,} \mathrm{fest,} \mathrm{hohl} \mathrm{u.} \mathrm{mit} \mathrm{flockigen}$ Fasern gefüllt, faserig, am Grunde knollig, weiß, in der Mitte mit beweglichem, dauerhaftem Ringe. L. dicht, $1 \mathrm{~cm}$ br., weiß, dann von der Schneide rosenrot bis schwarz werdend. Eßbar, wenn die Hüte noch unentwickelt sind. Auf gedüngten Stellen in Wiesen, an Wegen, in Gärten usw., häufig. S. H. (Fig. 219.) (Porzellan-M.)

C. porcellanus (Schaeffer).

7. Hut von Anfang an kahl.

Hut kleiig bestäubt, filzig, schuppig, zottig. 
8. L. an den St. heranreichend, Hut größer als $1,5 \mathrm{~cm}$. 9. Hut eif., dann flach ausgebreitet $u$. mit eingeschlagenem Rande, meist 2-4, selten bis $15 \mathrm{~mm}$ br., jung hellrötlich-braun, in der Mitte dunkler, später hellbräunlich. St. $2-6 \mathrm{~cm} \mathrm{lg.,} \mathrm{hohl,}$ glatt, kahl, weißlich od. hellbräunlich. L. in geringer Zahl, frei, schmal. Auf Mist in Kulturen, nicht selten. Das ganze Jahr. (Schroeters M.)

C. Schroeteri Karsten.

9. Hut zylindrisch, dann glockenf., über $2 \mathrm{~cm}$ br., kahl, klebrig, ockergelb, mit feingestreiftem, spätere ingeschnittenem Rande. St. hohl, kurz, kahl. L. weiß, dann schwärzlich. Auf der Erde an Wegen, in Gärten, selten. S. H. (Fig. 220.) (Gehäufter M.)

C. congregatus (Bulliard).

Hut ei-, dann glockenf., kahl, weißlich strohgelb, in der Mitte etwas dunkler, $2,5 \mathrm{~cm}$ br. St. hohl, 2-14 cm lg., kahl, weiß. L. weiß, dann braunschwärzlich. Gesellig auf dem Boden in Wäldern, Gebüschen, zerstreut. S. H. (Fig. 221.) (Fingerf. M.)

\section{C. digitalis (Batsch).}

10. Hutoberfläche kleiig ođ. feinschülferig, später meist kahl. 11.

Hutoberfläche zuerst mit filzigem Überzug, der sich in Schuppen auflöst, besetzt, später oft kahl.

11. Hüte über $1 \mathrm{~cm}$, meist sogar über $2 \mathrm{~cm} \mathrm{br}$.

Hut ei-, dann glockenf., $6-8 \mathrm{~mm}$ br., grau-kleiig, gestreift, später zerschlitzt, in der Mitte mit kleinen punktf. Wärzchen bedeckt, bläulich-graubraun. St. hohl, $2,5 \mathrm{~cm}$ hoch, hyalin durchscheinend. L. frei, den St. berührend, schwarz. Auf Mist u. feuchtem Boden, zerstreut. S. H. (Warziger M.)

\section{C. papillatus (Batsch).}

12. L. am St. angeheftet bzw. angewachsen.

13.

L. frei od, einem Ring angewachsen.

15.

13. St. am Grunde nicht auf einem braunfilzigen Geflecht aufsitzend.

Hut ei-, dann glockenf. u. ausgebreitet, $3-4 \mathrm{~cm}$ br., graubraun, zuerst kleiig bestäubt, in der Mitte mit stumpfem, gelbbraunem, fleischigem Nabel, Rand gestreift. St. hohl, 5-8 cm lg., glänzend. L. angewachsen, zuerst weißlich, dann braunviolctt bis schwarz. Der ganze Pilz auf einem dichten, zottigen, gelbbraunen bis rotgelben Filz stehend. An alten Stämmen, in Kellern, Gruben usw., nicht selten. S. (Fig. 222.) (Strahliger M.)

$$
\text { C. radians (Desm.). }
$$

14. Hut ei- bis glockenf., dann flach ausgebreitet, $3-5 \mathrm{~cm}$ br., gefurcht, kleiig-schuppig, graubraun, am Scheitel kastanienbraun, Rand umgeschlagen, nicht zerschlitzt. St. $5-8 \mathrm{~cm}$ hoch, verjüngt, weiß, angedrückt seidig. L. angeheftet, weiß, dann hellrötlich bis braunschwarz. In Gärten, auf Viehweiden, in Häusern, nicht selten. F. S. H. (Fig. 223.) (Hausbewohnender M.) 
Hut ei-, dann glockenf., ausgebreitet, 1,5-2 cm br., gefurcht, weißlich mit ockerfarbener, gebuckelter Mitte, kleiig bestäubt, später ockerfarben mit dunklerer Mitte, Rand meist zerschlitzt. St. bis zu $7 \mathrm{~cm} \mathrm{lg.,} \mathrm{hohl,} \mathrm{glatt,} \mathrm{weißlich,} \mathrm{seidenglänzend,} \mathrm{am}$ Grunde schwach wulstig. L. angeheftet, weiß, dann braun bis schwarz. Auf Mist, gedüngtem Boden, Laub usw., häufig. F. S. H. (Eintags-M.)

15. L. nicht einem Ring angewachsen.

C. ephemerus (Bulliard).

Hut länglich eif., dann halbkuglig, zuletzt flach, $1-2,5 \mathrm{~cm}$ br., gefurcht-gefaltet, am Scheitel schwach bereift, dann kahl, ockerfarben, später grau mit brauner Mitte, Rand umgeschlagen. St. hohl, 2-8 cm lg., kahl, weißlich, seidenglänzend. L. an einen vom St. entfernten Ring angewachsen, wei $\beta$, dann schwärzlich mit weißer Schneide. Auf Wiesen, an Wegen, häufig. F. S. H._(Fig. 224.) (Gefalteter M.) C. plicatilis (Curtis).

16. Hut fast kuglig, dann glockenf. u. ausgebreitet, $2-4 \mathrm{~cm}$ br., ockerfarben mit rostbrauner, etwas fleischiger Mitte, zuerst dick kleiig bestäubt, Rand gestreift, zerschlitzt. St. hohl, weiß, glatt, $8-12 \mathrm{~cm} \mathrm{lg}$. L. frei, an den St. heranreichend, rosenrot dann schwarz. Rasenweise an alten Stämmen, häufig. F. S. (Stammbewohnender M.) C. truncorum (Schaeffer).

Hut länglich eif., dann glocken- bis kegelf., $3-5 \mathrm{~cm}$ br., oekerfarben, mit rostbraner, fleischiger Mitte, mit glänzenden, weißlichen, kleiigen, sich leicht ablösenden Körnchen bestreut, Rand gefurcht, zerschlitzt. St. hohl, 5-15 cm lg., glatt, weiß, glänzend. L. frei, weißlich, dann braun bis schwarz mit weißer Schneide. Rasenweise am Grunde alter Stämme, auf feuchtem Boden usw., häufig. F. S. H. (Fig. 225.) (Schimmernder M.)

\section{C. micaceus (Bulliard).}

17. Hüte über $1 \mathrm{~cm}$ br., wenn bei C. stercorarius schmaler, dann Sklerotien vorhanden.

18.

Hut sehr zart, zuletzt glockig, 2-7 mm br., gelblich, in der Mitte rötlich, aschgraufilzig, bald zerschlitzt u. gefaltet. St. fädig, hyalin, kahl. L. wenige, frei, blaß schwärzlich. Aıf Mist, besonders in Kulturen, häufig. Das ganze Jahr. (Fig. 226.) (Strahlenstreifiger M.)

C. radiatus (Bolton).

18. Geruch fehlend, jedenfalls nicht scharf laugenartig.

Hut sehr zart, keulig, dann ausgebreitet, $2,5 \mathrm{~cm}$ br., gestreift, von flockigen, zurückgekrümmten Schuppen weiß-zottig, später kahl. St. $5 \mathrm{~cm} \mathrm{lg.,} \mathrm{weiß} \mathrm{wollig,} \mathrm{später} \mathrm{kahl.} \mathrm{L.} \mathrm{frei,} \mathrm{weiß,} \mathrm{dann}$ schwärzlich. Geruch scharf laugenartig. Auf Mist an feuchten Orten, zerstreut. S. H. (Starkriechender M.)

C. nareoticus (Batsch).

19. Mit Sklerotien.

20.

Ohne Sklerotien.

21.

20. Hut ei-, dann glockenf., ausgebreitet, $2-3 \mathrm{~cm}$ br., dicht mit einem weißen, pulverig- od. zottig-schuppigen Überzug besetzt. 
St. meist einem Sklerotium entspringend, hohl, 7-10 $\mathrm{cm} \mathrm{lg.,}$ weiß, oben kahl, unten weißflaumig u. schuppig. L. fast frei, grau, dann schwarz. Sklerotien unregelmäßig höckerig, 3-15 mm lg., grau, schwarz gefleckt, innen weiß. Auf Mist in Wäldern, häufig in Kulturen. Das ganze Jahr. (Fig. 227.) (Schneeweißer M.)

C. niveus (Pers.).

Hut ei-, dann glockenf., ausgebreitet, $0,3-3 \mathrm{~cm}$ br., mit dichtem anfangs weißem, mehlig-kleiigem, später grauem, mehr zottigem Überzug bedeckt, Rand gestreift, eingerollt. St. $3-8 \mathrm{~cm} \mathrm{lg.,} \mathrm{zart,}$ weiß, fast hyalin, feinhaarig. L. frei, grau, dann schwarz. Sklerotien fast kuglig, $1-3 \mathrm{~mm}$ br., schwarz, innen weiß. Auf Mist, überall häufig. Das ganze Jahr. (Fig. 228.) (Gemeiner M.)

C. stercorarius (Bulliard).

21. Hut länglich eif., dann flach ausgebreitet, $2-3 \mathrm{~cm}$ br., weißlich, weißzottig, mit graubrauner Mitte, Rand strahlig gestreift, zuletzt umgebogen. St. 6-10 cm lg., hohl, sehr zerbrechlich, weiß, wolligschuppig. L. frei, schwarz. Auf Mist, zwischen Lb. in Wäldern, zerstreut. F. S. H. (Fig. 229.) (Hasenpfoten-M.)

\section{C. lagopus Fries.}

Hut keulig, dann kegelf., 2,5-5 cm br., in der Jugend nit flockigen, sparrig abstehenden Schuppen bedeckt, dann nackt, grau, in der Mitte bräunlich, Rand gefurcht, dann zerschlitzt. St. hohl, 5-8 cm lg., weiß, kleinschuppig. L. frei, schwarz. Auf Mist u. gedüngtem Boden in Wäldern, Gärten usw., häufig. F.S. H. (Fig. 230.) (Grauer M.) $\quad$ C. fimetarius (L.).

\section{Unterfamilie: Hygrophoreae.}

L. sehr dickfleischig, fast wachsartig, entfernt stehend, verschieden lg. u. kürzere u. längere regelmäßig abwechselnd.

\section{Bestimmungsschlüssel der Gattungen.}

A. Sporenpulver schwarz.

1. Gomphidius.

B. Sporenpulver nicht schwarz, meist weiß.

a) Parasitiseh auf anderen Hutpilzen, mit Chla-

mydosporen im Hut.

2. Nyetalis.

b) Nicht parasitisch, ohne Chlamydosporen.

I. Schleier zwischen Hut u. Stiel vorhanden, schleimig.

3. Limacium.

II. Schleier fehlend.

4. Hygrophorus.

\section{Gattung: Gomphidius Fries (Keilpilz).}

Hut fleischig, durch einen schleimigen Schleier mit dem St. verbunden, an dem ein vergänglicher Ring zurückbleibt. L. dick, herablaufend, weitläufig, weich, spaltbar. Sporenpulver schwarz. Sporen spindelf. 
1. L. anfangs grau od. weißlich, erst später dunkler.

Hut fast kegelf., mit stumpfem Buckel, dann flach, 5-11 mm br., braunrot, klebrig, Fleisch rötlich-bräunlich. St. bis $10 \mathrm{~cm}$ hoch, gelbbraun, oben mit flockigem, verschwindendem Ring. L. purpurbraun, dann dunkelbraun. Zwischen Moos in Wäldern, nicht selten. S. H. (Fig. 231.) (Klebriger K.) G. viscidus (L.).

2. St. innen u. außon gefärbt.

3.

Hut halbkuglig, dann flach, ea. 2,5 cm br., weißlich, grau od. rötlich-bräunlich. St. 3-5 cm hoch, innen u. außen weiß, nach unten etwas verdünnt. L. weiß, später gran. In Wäldern, selten.
S. H. (Zierlicher K.)
G. gracilis Berkeley.

3. Hut bis $6 \mathrm{~cm}$ br., rosenrot, schleimig. St. bis $6 \mathrm{~cm}$ hoch, weiß, am Grunde außэn u. innэn rot, oben mit einem weißen, spinnwabigen, vergänglichen Ring. L. waißlich, grau bis schwarz. Zwischen Moos in Wäldern, häufig. S. H. (Fig. 232.) (Rosenroter $\mathrm{K}$.)

G. roseus Fries.

Hut flach gewölbt, dann ausgebraitet, $5-14 \mathrm{~cm}$ br., schmutzig grau bis schwach violett, schleimig, Fleisch weißlich. St. $5-9 \mathrm{~cm}$ hoch, unten außэn u. innen gelb, oben weißlich, mit einem anliegenden, schleimig-s sidenhaarigen Ringe. L. weißlich, grau, dann schwarz. Auf Grasplätzen, in Wäldern, Gabüsch usw., häufig. S. H. (Fig. 233.) (Schleimiger K.)

G. glutinosus (Schaeffer).

\section{Gattung: Nyctalis Fries (Nachtpilz).}

Hut fleischig, im Innern an den Hyphen oft Chlamydosporen entwickelt u. dann die Basidienfruktifikation \pm unterdrückt. L. entfernt, dick u. fleischig. Parasiten auf anderen Hutpilzen (soweit die Arten hier in Betracht kommen).

Hut kegelf., später flach, 1,5-2,5 cm br., grau, zuerst bereift, Rand schwach eingebogen. St. $1-3 \mathrm{~cm}$ lg., hohl, grau od. weißlich, flockig seidenhaarig. L. dick, weiß, später bräunlich, gewunden. Chlamydosporen braun, auf den L. hervorbrechend. Parasitisch auf Russula adusta, zerstreut. S. H. (Fig. 234.) (Parasitischer N.)

\section{N. parasitica (Bulliard).}

Hut meist nicht gut entwickeit, sondern durch die den Hut mit braunem Pulver füllenden Chlamydosporen varbildet, halbkuglig od. kuglig, $1-2 \mathrm{~cm}$ br., weißlich, flockig. St. voll, bereift, zuletzt bräunlich, 1-2,5 cm lg. L. dick, schmutzig grau. Parasitisch auf Russula adusta, nigricans, größэren Lactaria.Arten usw., zerstreut. S. H. (Fig. 235.) (Lycoperdonähnlicher N.)

N. Iycoperdoides (Bulliard).

3. Gattung: Limacium Fries (Schleimkopf).

Hut fleischig, mit dem St. durch einen schleimigen Schleier verbunden, der am St. a's vergänglicher Ring auftritt. L. herablaufend. Sonst wie folg. Gattung. 
1. Hutoberfläche weiß od. gelb.

Hutoberfläche irgendwie rot od, rötlich.

Hutoberfläche gelb od. gelbbraun.

Hutoberfläche oliven-, umbrabraun, überhaupt dunkelbraun. 11

2. Nicht riechend.

Hut gewölbt, dann flach, $3-4 \mathrm{~cm}$ br., klebrig, weißlich, später gelblich werdend, in der Mitte meist blaß ockergelb. St. voll, 6-7 cm hoch, zylindrisch, nach oben kleiig u. punktiert. I. etwas herablaufend, derb. Charakteristisch wie der Weidenbohrer riechend. In Wäldern, zerstreut. S. H. (Stinkender S.)

\section{L. cossum (Sowerby).}

3. St. u. Hutrand nicht gelbflockig.

Hut gewölbt, dann ausgebreitet, $3-8 \mathrm{~cm}$ br., weiß, schleimig, Rand zuerst eingerollt, gelbflockig. St. bis $10 \mathrm{~cm} \mathrm{lg.,} \mathrm{voll,} \mathrm{weiß,}$ nur unten schleimig, oben gelbflockig. L. dick, weiß. Zwischen Lb. in Lbwäldern, zerstreut. S. H. (Fig. 236.) (Goldflockiger S.)

L. chrysodon (Batsch).

4. Hut halbkuglig, dann ausgebreitet, gelblichweiß, glatt. St. 4 bis $5 \mathrm{~cm}$ lg., voll, am Grunde spindelig, punktiert, rauh. L. blaß, gelblich. Geschmack mild, eßbar. In Lbwäldern, zerstreut. S. H. (Fig. 237.) (Eßbarer S.) - L. penarium (Fries).

Hut halbkuglig, dann ausgebreitet, $3-8 \mathrm{~cm}$ br., weiß, schleimig, trocken glänzend, Rand zuerst eingerollt, dann gerade. St. zylindrisch, 5-12 cm lg., selten später hohl, bis zur Mitte schleimig, darüber trocken u. mit erhabenen, weißen Punkten u. Schuppen besetzt. L. elfenbeinweiß, dick. Eßbar. In Lb- u. Ndwäldern, häufig. S. H. (Fig. 238.) (Elfenbein-S.)

\section{L. eburneum (Bulliard).}

5. L. weiß u. dann irgendwie rot werdend.

Hut gewölbt, dann niedergedrückt, glatt, klebrig, $5-12 \mathrm{~cm}$ br., fleischfarbig, selten gelb-gefleckt. St. voll, $5-12 \mathrm{~cm} \mathrm{lg.,}$ weiß, an der Spitze verjüngt, von weißen Punkten rauh. L. rein wei $\beta$, dick. In Ndwäldern im Gabirge, zerstreut. S. (Schamroter S.)

L. pudorinum (Fries).

6. Hut halbkuglig, dann flach gewölbt, $3-8 \mathrm{~cm}$ br., zuerst weiß, dann purpurrot werdend, schleimig, später trocken u. schuppig, Rand zuerst eingerollt, klebrig, später schwach filzig, Fleisch weiß, rot werdend. St. voll, $3-8 \mathrm{~cm} \lg$., wei $\beta$, dann rot punktiert u. fleckig. L. etwas herablaufend, dick, weiß, später purpurrot. In schattigen Ndwäldern, selten, S. H. (Rötlicher S.)

L. rubescens (Pers.).

Hut gewölbt, dann flach, 3-6 cm br., weiß, in der Mitte mit roten Schuppen, ziemlich trocken, Rand eingerollt, filzig, dann gerade. St. $4 \mathrm{~cm} \mathrm{lg.,} \mathrm{voll,} \mathrm{weiß,} \mathrm{mit} \mathrm{kleinen} \mathrm{roten} \mathrm{Schuppen,}$ 
oben mit einem flockigen Ring. L. etwas herablaufend, weiß, später purpurrot. Wie vor. Art. (Purpurfarbener S.)

L. purpurascens (Alb. et Schwein.).

7. Hut gewölbt u. gebuckelt, später flach u. in der Mitte niedergedrückt, 2,5-3 cm br., klebrig, blaß, gelbbraun, in der Mitte fast rostbraun. St. voll, $5-6 \mathrm{~cm} \mathrm{lg.,} \mathrm{flockig,} \mathrm{unten} \mathrm{klebrig,}$ oben weiß punktiert. L. etwas herablaufend, weiß, dann blaßgelblich. Zwischen Moos in Ndwäldern, selten. S. (Fig. 239.) (Scheibenf. S.)

L. discoideum (Pers.).

Hut halbkuglig, dann flach, meist stumpf gebuckelt, 8-10 cm br., klebrig, gelb. St. 4-10 $\mathrm{cm}$ hoch, voll, oben trocken, kahl, unten klebrig. L. weit herablaufend, weiß, dann gelblich. Zwischen Moos u. Gras in Wäldern, zerstreut. S. H. (Fig. 240.) (Glänzender S.)

L. nitidum Fries.

8. St. mit körnigen schwarzen Püńktchen od. Fasern.

Hut flachgewölbt, stumpf gebuckelt, dannleicht niedergedrückt, $3-6 \mathrm{~cm}$ br., schleimig, braun, später grau, Rand eingerollt, weißflockig. St. 5-8 cm lg., weiß, flockig-schuppig, mit schwachen flockigen Ringen oberhalb der Mitte. L. dick, weiß. Zwischen Moos in Ndwäldern, besonders der Vorgebirge, zerstreut. S. H. (Braunweißer S.)

9. Geruchlos.

L. fuscoalbum (Lasch).

Hut gewölbt, dann flāch, $3-7 \mathrm{~cm}$ br., schleimig, graubraun, in der Mitte mit dichtstehenden, weißen, durchscheinenden Wärzchen besetzt, Rand eingerollt, filzig, dann kahl. St. $6-9 \mathrm{~cm}$ lg., voll, weiß, faserig gestreift, oben von körnigen Schüppchen rauh. L. weiß. Groruch stark anisartig. Zwischen Moos in Ndwäldern, besonders der Vorgebirge, zerstreut. S. H. (Fig. 241.) (Wohlriechender S.)

L. agathosmum (Fries).

10. Hut gewölbt, später flach, gebuckelt, $3-6 \mathrm{~cm}$ br., klebrig, graubraun, flockig od. fädig-streifig, mit brauner, rissiger, braunwarziger Mitte. St. $3-8 \mathrm{~cm}$ lg., voll, wei $\beta$, von schwarzen Punkten rauh. L. weiß od. hellgrau. In Ndwäldern, Heiden usw., zerstreut. S. H. (Fig. 242.) (Pockiger S.) L. pustulatum (Pers.).

Hut gewölbt, dann ausgebreitet, gebuckelt, $2-3 \mathrm{~cm}$ br., schleimig, ang edrückt-fädig, schuppig, grau, in der Mitte braun. St. voll, 5-8 cm lg., weiß, unten mit schwarzen Fasern. L. weiß. In Ndwäldern, besonders der Vorberge, zerstreut. S. H. (Fig. 243.) (Grauwəißэr S.)

L. tephroleucum (Pers.).

11. L. weiß od. grau.

Hut flachgewölbt, dann ausgebreitet, oft trichterf., $3-6 \mathrm{~cm}$ br., mit dickem olivenfarbenen Schleim überzogen, nach dessen Verschwinden gelblich od. rötlichgelblich. St. 5-10 $\mathrm{cm}$ hoch, dottergelb, über der Mitte mit schleimig-fädigem, vergänglichem Ring, oft braunschuppig. L. dottergelb od. rötlich. Zwischen Moos u. Gras in Ndwäldern, Heiden usw., häufig. H. (Dottergelber S.)

L. vitellum (Alb. et Schwein.). 
12. Hut halbkuglig, dann flach, spitz- od. stumpfhöckerig, $2,5-5 \mathrm{~cm}$ br., dunkel olivenbraun, \pm schwärzlich gestreift, zuerst mit dickem, braunem Schleim überzogen, später heller. St. voll, $3-10 \mathrm{~cm} \mathrm{lg}$., weiß, oberhalb der Mitte mit schleimig-faserigem, vergänglichem Ringe, trocken braunfleckig. L. weiß. In Ndwäldern, zerstreut. S. H. (Olivweißer S.)

\section{L. olivaceoalbum (Fries).}

Hut gewölbt, dann flach, 2,5-5 cm br., umbrabraun, später grau- bis olivenbraun, mit blasserem Rande, kahl. St. voll, $5-8 \mathrm{~cm}$ hoch, klebrig, faserig-gestreift, an der Spitze schuppig. L. ziemlich dünn, weißlich-aschgrau. In Lbwäldern, zerstreut. S. H. (Fig. 244.) (Klebriger S.) I. limacinum (Scopoli).

\section{Gattung: Hygrophorus Fries (Wasserkopf).}

Hut fleischig, ohne Schleier. St. in den Hut übergehend. L. fleischig, dick, entfernt stehend, nicht spaltbar.

1. Hut bei feuchtem Wetter klebrig, trocken glänzend, selten flockigschuppig, weich, saftig, zerbrechlich. St. weich. L. wachsartig, weich, zerbrechlich (Unterg. Hygrocybe Fries).

2.

Hut nicht klebrig, nicht glänzend, fleischig, trocken, ziemlich zähe, fest. St. zäh. L. derb, zähe, bogig (Unterg. Camarophyllus Fries).

14.

2. L. an den St. lose angeheftet od. mit schmalem Grunde angewachsen, nicht herablaufend.

L. herablaufend.

3. Hutoberfläche braun, graubraun, olivenbraun

Hutoberfläche rot od. gelb, selten weißlich.

4. L. nicht gelb.

10.

4.

6.

Hut kegelf., spitz, geschweift, faserig-streifig, mit klebrigem, olivenbraunem Schleim überzogen, trocken schwarz, glänzend. St. hohl, zylindrisch, trocken, braun-faserig. L. abgerundet u. frei, ,zitronengelb. An grasigen Stellen in Gebirge, zerstreut. S. (Fig. 245.) (Kastanienbrauner W.) H. spadiceus (Scopoli).

5. Hut stumpf kegelig, dann glockenf., ausgebreitet, gebuckelt, klebrig, braun od. graubraun, später orangefarben u. kahl. St. hohl, ungleich dick, ziemlich lg., heller. L. angewachsen, bräunlich mit orangefarbener Schneide. Auf Grasplätzen, selten. H. (Schmutziger W.)

H. squalidus (Lasch).

Hut glockig, dann ausgebreitet, $2-6 \mathrm{~cm}$ br., graubraun, klebrig, dann trocken, rissig-schuppig. St.5-9 cm lg., hohl, zusammengedrückt, weißlich, glatt. L. angewachsen, weiß, dann bläulich grau. Stark nach salpetriger Säure riechend. Auf Waldwiesen, zerstreut. S. H. (Fig. 246.) (Salpeter-W.)

\section{H. nitratus (Pers.).}

6. Fleisch bei Verletzung nicht schwarz werdend.

Hut kegelf., 2-4 cm hoch u. br., schwach klebrig, trocken seidenglänzend, dunkel goldgelb, Rand zuletzt geschweift $u$. Lind au, Kryptogamenflora. I. 2. Aufl. 
eingeschnitten, Fleisch goldgelb, bei Verletzung schwarz werdend. St. bis $9 \mathrm{~cm}$ hoch, zylindrisch, hohl, oft gedreht, grobfaserig, gelb, schwarz werdend. L. hinten sehr verschmälert, angeheftet, weißlich od. gelblich, schwarz werdend. Auf Wiesen, Grasplätzen usw., häufig. S. H. (Fig. 247.) (Kegelf. W.)

7. Hut höchstens bis $3 \mathrm{~cm}$ br.

H. conicus (Scopoli).

Hut über $5 \mathrm{~cm}$ br.

8. Hut glocken-, bis halbkugelf., dann ausgebreitet, etwas gebuckelt, $1-2,5 \mathrm{~cm}$ br., weißlich od. gelblich, mit grünlichem, schlüpfrigem Schleim überzogen, trocken wachsgelb, glänzend, Rand gestreift. St.4-5 cm lg., schleimig, gleichfarbig, hohl. L. zahnf. angeheftet, dottergelb, bisweilen grünlich. Zwischen Gras u. Moos auf offenen Stellen, zerstreut. S. H. (Fig. 248.) (Papageigrüner W.)

H. psittacinus (Schaeffer).

Hut gewölbt, dann flach, gelb od. scharlachrot, $2-3 \mathrm{~cm}$ br., schleimig, Rand gestreift. St. hohl, 6-9 cm lg., glatt, klebrig, glänzend. L. angeheftet, bauchig, weißlichgelb. Auf Grasplätzen, selten. H. (Fig. 249.) (Grüngelber W.)

H. chlorophanus Fries.

9. Hut flach kegelf.-gewölbt, 5-10 cm br., schwach klebrig, goldgelb, glänzend, Rand geschweift, eingebogen. St. $6-15 \mathrm{~cm} \mathrm{lg.,}$ zylindrisch, hohl, gelb. L. lebhaft gelb mit hellerer Schneide. Auf Wiesen, Heiden zwischen Gras u. Moos, besonders im Vorgebirge, nicht häufig. S. H. (Fig. 250.) (Rötlicher W.)

H. obrusseus Fries.

Hut glockig, dann ausgebreitet, 5-12 cm br., schwach klebrig, scharlach- od. blutrot, verblassend, glatt, Rand eingebogen, oft lappig. St. zylindrisch, voll, dann hohl, bis $6 \mathrm{~cm}$ hoch, gelblich od. rotgelb, am Grunde weiß. L. angeheftet, bauchig, gelb, später rötlich, am Grunde aderig verbunden. Auf Wiesen, Heiden, an Waldrändern, häufig. S. H. (Fig. 251.) (Roter W.)

H. puniceus Fries.

10. Hutoberfläche gelb od. gelbbraun.

11.

Hutoberfläche rot.

12.

11. Hut flach gewölbt, $1-2,5 \mathrm{~cm}$ br., klebrig, gelbbraun, schwach glänzend. St. $5-8 \mathrm{~cm}$ hoch, zylindrisch, gelbbraun, an der Spitze oft dunkler. L. herablaufend, weißlich, rötlich od. graubräunlich. Auf moosigen Wiesen, selten. S. (Fig. 252.) (Freudiger W.)

H. laetus (Pers.).

Hut flach gewölbt, $3 \mathrm{~cm}$ br., fast klebrig, wachsgelb, glänzend, Rand feinstreifig. St. $2-4 \mathrm{~cm}$ hoch, zylindrisch, hohl, gelb, am Grunde heller. L. br. angewachsen, herablaufend, fast dreieckig, gelblich. Im Grase in Wäldern, Gebüschen, nicht selten. H. (Fig. 253.) (Wachsgelber W.) H. ceraceus (Wulfen).

12. L. gleichmäßig gefärbt.

13.

Hut halbkuglig, dann flach, $2-7 \mathrm{~cm}$ br., klebrig, scharlachrot, 
trocken glatt, verblassend. St. hohl, zusammengedrückt, ca. $5 \mathrm{~cm}$ lg., oben scharlachrot, unten gelb. L. br., angewachsen, mit einem Zahn herablaufend, am Grunde aderig verbunden, zuerst gleichmäßig gelbrot, dann oben purpurrot, in der Mitte gelb, an der Schneide grau. Auf feuchten Wiesen, in Sümpfen, nicht selten. H. (Fig. 254.) (Scharlachroter W.)

\section{H. miniatus (Scopoli).}

13. Hut kegel-, dann glockenf., spitz gebuckelt, 6-9 cm br., scharlachrot, glatt, verblassend. St. $2-4 \mathrm{~cm}$ lg., hohl, seidenglänzend, scharlachrot, am Grunde weiß. L. herablaufend, dreieckig, gelb. Auf Grasplätzen, an Waldrändern, selten. S. (Spitziger W.)

H. mucronellus Fries.

Hut halbkuglig, dann ausgebreitet $u$. in der Mitte niedergedrückt, $1-2 \mathrm{~cm}$ br., trocken glatt od. feinschuppig, fast zinnoberrot, verblassend. St. $3-5 \mathrm{~cm}$ hoch, zylindrisch, zinnoberrot. L. br. angewachsen, mit einem Zahn herablaufend, gelb od. gelbrot. Auf feuchten Wiesen, in Sümpfen usw., häufig. S. H. (Flammender W.)

H. flammans (Scopoli).

14. Hutoberfläche weiß, ebenso alle übrigen Teile des Pilzes. 15.

Hutoberfläche gelb, orangefarben, bläulich, selten hell ockerfarben.

Hutoberfläche rauchgrau, graubraun bis schwärzlich.

15. Hut glockenf., dann flach, in der Mitte niedergedrückt, $2-3 \mathrm{~cm}$ br., feucht, bald trocken, matt, Rand gestreift. St. bis $6 \mathrm{~cm}$ hoch, 2-4 mm dick, hohl, kegelf. in den Hut erweitert. L. bogig herablaufend, sehr weit entfernt stehend. Auf Wiesen, Weiden usw., nicht selten. S. H. (Fig. 255.) (Schneeweißer W.)

H. niveus (Scopoli).

Hut gewölbt u. gebuckelt, dann niedergedrückt, $2-6 \mathrm{~cm}$ br., feucht, dann trocken, rissig u. etwas flockig. St. bis $6 \mathrm{~cm}$ hoch, bis $1 \mathrm{~cm}$ dick, voll, in den Hut erweitert. L. bogenf. herablaufend. Auf Wiesen, Triften usw., häufig bis ins Hochgebirge. S. H. (Heide-W.)

H. ericeus (Bulliard).

16. L. weißlich od. gelbbräunlich.

Hut gewölbt, dann flach ausgebreitet, in der Mitte gebuckelt, $5-8 \mathrm{~cm}$ br., trocken, angedrückt-faserig, \pm lebhaft orangefarben, St. voll, $5-8 \mathrm{~cm}$ lg., kleinschuppig-fasrig, orangefarben. L. herablaufend, etwas heller als der Hut. In schattigen Lbwäldern, selten. S. H. (Fig. 256.) (Hain-W.)

\section{H. nemoreus (Lasch).}

17. Hut glockenf., dann ausgebreitet, etwas gebuckelt, $2-3 \mathrm{~cm}$ br., klebrig, bläulich. St. hohl, $5 \mathrm{~cm} \mathrm{lg}$., L. mit einem Zähnchen herablaufend, weißlich. Zwischen Moosen auf Wiesen u. in Wäldern, selten. (Fig. 257.) (Bewässerter W.)

H. irrigatus (Pers.)

Hut gewölbt u. gebuckelt, dann abgeflacht, kreiself., 3-11 cm br., trocken, hell gelblich od. ockerfarben, zuletzt faltig-rissig, 
Rand dünn, gerade. St. voll, 2-12 cm lg., gleichfarbig, nach oben verdickt. L. weit herablaufend, gleichfarbig od. weißlich. Im Grase auf Wesen usw., nicht selten. S. H. (Feigenähnlicher W.)

H. ficoides (Bulliard).

18. Hut kegelf., dann ausgebreitet, gebuckelt, $2-3 \mathrm{~cm}$ br., rauchgrau, oft etwas olivbraun, mit dicken, angedrückten Schuppen besetzt. St. voll, $2-4 \mathrm{~cm}$ lg., grau. L. bogenf. angeheftet, mit einem Zahn herablaufend, am Grunde aderig verbunden, grau, dann bräunlich. Nach frischem Mehl riechend. Zwischen Moos u. Gras in Ndwäldern, nicht selten. S. H. (Fig. 258.) (Schaf-W.).

H. ovinus (Bulliard).

Hut flachgewölbt u. gebuckelt, später ausgebreitet $u$. in der Mitte eingedrückt, $8-15 \mathrm{~cm}$ br., zuerst feucht, faserig streifig, graubraun od. schwärzlich, bisweilen schwarz, Rand oft heller, dünn, zuerst eingebogen. St. $8-10 \mathrm{~cm} \mathrm{lg.,} \mathrm{kreiself.} \mathrm{in} \mathrm{den} \mathrm{Hut}$ erweitert, glatt, grau. L. bogenf., weit herablaufend, weiß. In Ndwäldern, besonders im Gebirge, zerstreut. S. H. (Fig. 259.) (Ziegen-W.)

H. caprinus (Scopoli).

\section{Unterfamilie: Lactarieae.}

Fk. fast stets regelmäßig schirmf. mit zentralem St. ${ }^{1}$. Fleisch starr, leicht brüchig, außer den gewöhnlichen Myzelhyphen noch Milchsaftröhren vorhanden, die aber nicht immer mit Flüssigkeit erfüllt sind. L. dichtstehend, nicht wachsartig, sondern fleischig, brüchig, Sporen kuglig od. eif., stachlig od. punktiert.

Bestimmungsschlüssel der Gattungen.

A. Bei Verletzungen Milch absondernd.

1. Lactaria.

B. Bei Verletzungen keine Milch absondernd.

a) Sporenpulver weiß od. leicht gelblich.

b) Sporenpulver ockerbraun.

2. Russula.

3. Russulina.

1. Gattung: Lactaria Pers. (Milchling).

Dickfleischig, im jugendlichen Zustande stets Milch absondernd bei Verletzungen, im Alter oft saftlos. L. fleischig, brüchig, lange u. kurze regelmäßig abwechselnd. Sporenpulver weiß od. gelblich.

1. Milch weiß, so bleibend od. erst später sich verfärbend.

2.

Hut gewölbt, dann flach, zuletzt in der Mitte eingedrückt, $3-15 \mathrm{~cm}$ br., ziegel- od. orangerot, gezont, später grünlich werdend, verblassend, Fleisch gelbrot, Rand zuerst scharf eingerollt, kahl. St. bis $8 \mathrm{~cm} \mathrm{lg.,} \mathrm{später} \mathrm{hohl,} \mathrm{gleichfarbig.} \mathrm{L.} \mathrm{gelbrot,}$ bei Verletzungen grünlich. Milch lebhaft gelbrot, dann grünlich

1) Bei einiger UUbung kennt man die Lactarieae sofort am Habitus. Beschreiben läßt sich das aber nicht, sondern man muß viel beobachten, um L. sofort von Agariceen unterscheiden zu können. 
Lactarieae.
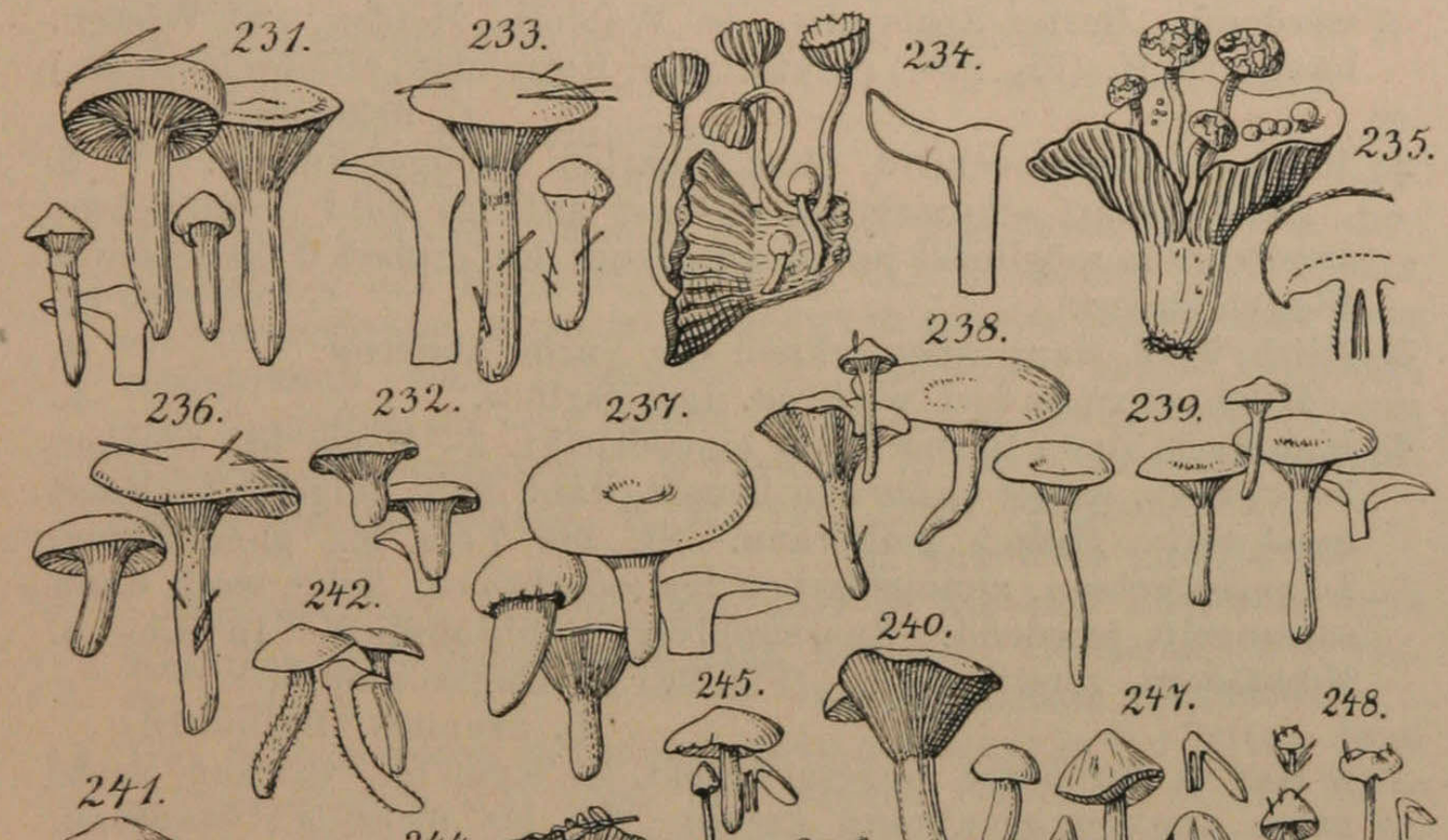

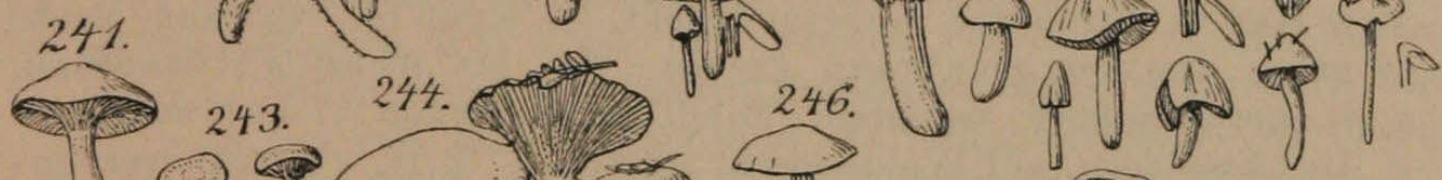
${ }_{250 .}{ }_{15}^{252}$ - (251.

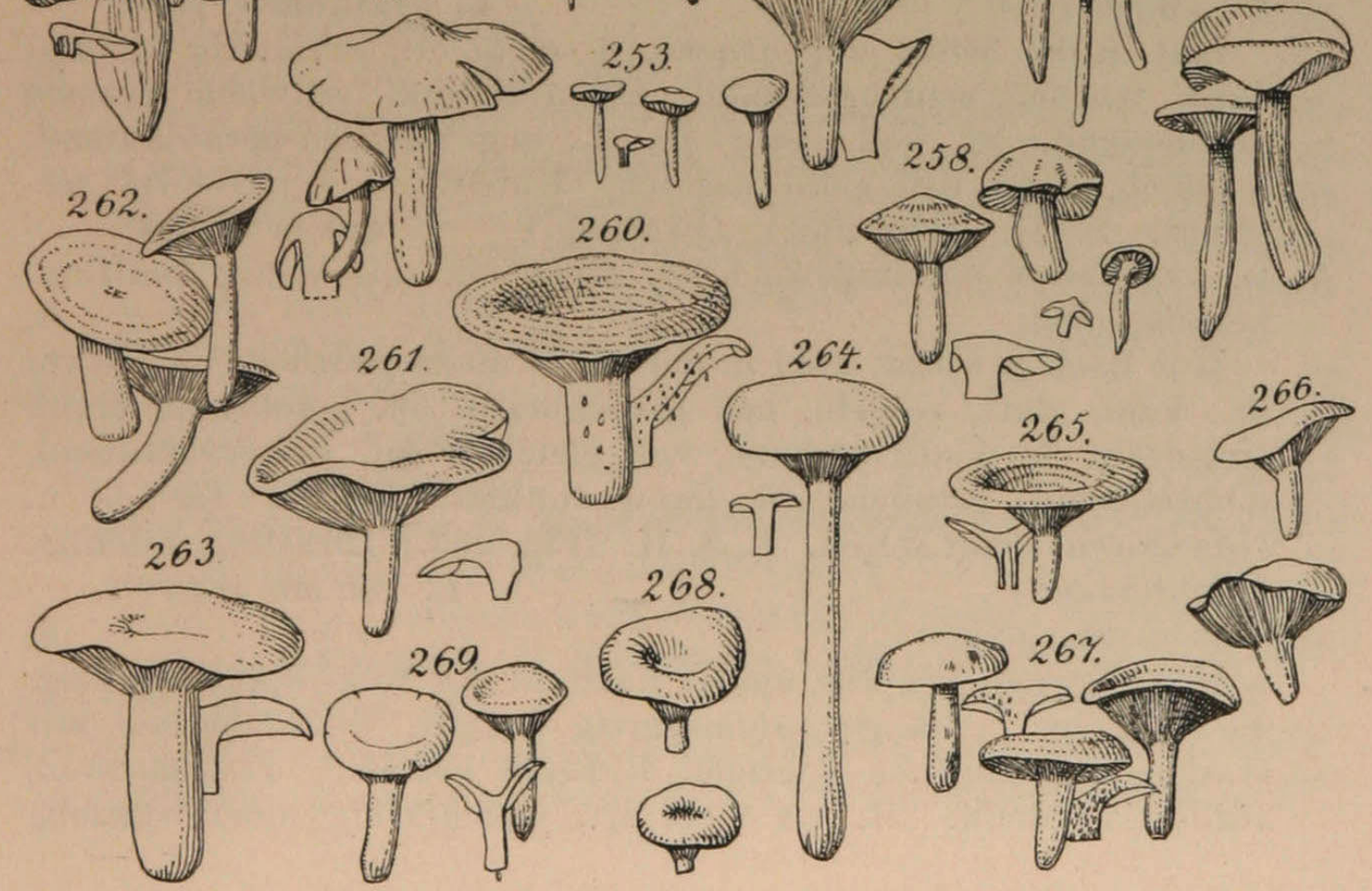


werdend. Bester Speisepilz. In Wäldern, Heiden, auf Wiesen, häufig. S. H. (Fig. 260.) (Blutreizker, Rotreizker, Milchschwamm.) L. deliciosa (L.).

2. Milch mild schmeckend, ohne scharfen Nachgeschmack.

Milch scharf schmeckend, seltener anfangs mild (man nehme zur Prüfung möglichst junge, milchende Exemplare u. kaue etwas Fleisch davon).

3. Milch weiß, dann aber schnell die Farbe ändernd.

Milch unverändert weiß od. fast farblos.

4. Hut flach, dann in der Mitte eingedrückt, 3-10 cm br., trocken lederbraun, zuerst rußbraun bereift, dann kahl, ungezont. Rand geschweift, Fleisch gelbbraun. St. bis $7 \mathrm{~cm} \mathrm{lg.,} \mathrm{gleichfarbig.}$ L. angewachsen, zimmetfarben bis lederbraun. Milch wei $\beta$, dann safrangelb werdend. Sporenpulver gelbbräunlich. In Lb- u. Ndwäldern, zerstreut. S. (Fig. 261.) (Ungezonter M.)

\section{L. azonites (Bulliard).}

Hut in der Mitte niedergedrückt, $6-8 \mathrm{~cm}$ br., trocken, aschgrau, dunkler graubraun gezont. St. bis $6 \mathrm{~cm}$ lg., blaßgrau. L. herablaufend, weißlich. Milch weiß, schnell violett werdend. In Lbwäldern, auf Waldwiesen, zerstreut. S. H. (Violett werdender M.)

L. violascens (Otto).

5. Hut anfangs klebrig, schmierig, später glatt u. trocken.

Hut von Anfang an trocken.

6. Hut flach gewölbt, gebuckelt, später niedergedrückt, $3-6 \mathrm{~cm}$ im Durchm., schwach gezont, klebrig, dann trocken, rissig, fleischrot od. rötlich-scherbenfarbig, trocken grauledergelb, matt. St. 3-6 em hoch, voll, blaß. L. herablaufend, zuerst weißrötlich, dann gelblich. In lichten Lbwäldern, Erlenbrüchen usw., selten. S. (Becherf. M.)

L. eyathula (Fries).

Hut in der Mitte eingedrückt, $6-8 \mathrm{~cm}$ br., schmierig klebrig, dann trocken seidenglänzend, zimmetbraun, schwach gezont, verblassend. St. voll, rotbraun. L. angewachsen-herablaufend, weißlich, dann hell gelbbräunlich. Eßbar. In Lbwäldern, zerstreut. S. H. (Fig. 262.) (Brätling.) L. quieta (Fries).

7. L. angeheftet od. angewachsen, nicht od. nur wenig (seriflua) herablaufend.

Hut flach gewölbt, bald in der Mitte niedergedrückt, $5-10 \mathrm{~cm}$ br., kahl, glatt, rotgelb, hell rötlichbraun od. gelbbraun, Rand eingerollt. St. 5-12 cm hoch, voll, gleichfarben. L. herablaufend, dichtstehend, gelblichweiß, dann dunkler. Eßbar. In Lb- u. Ndwäldern, nicht selten. F. S. H. (Fig. 263.) (Brätling, Süßling, Milchreizker.)

L. volema (Fries).

8. Hut u. St. glatt.

Hut schwach gewölbt, später flach, in der Mitte spitz höckerig, $4-6 \mathrm{~cm}$ br., anfangs sammetartig bereift, dunkelbraun, mit starken, gewundenen aderigen Runzeln bedeckt. Fleisch weiß, rötlich werdend. St. bis $6 \mathrm{~cm}$ lg., gleichfarbig, oben runzelig 
gefaltet. L. weiß, dann ockerfarben. Sporenpulver hellbräunlich. An alten Stämmen zwischen Moos, im Gebirge, zerstreut. S. H. (Fig. 264.) (Holzbewohnender M.)

L. lignyota (Fries).

9. L. erst heller, dann rotbraun.

L. heller bleibend, rötlichgelb.

11.

10. Hut flach gewölbt, meist in der Mitte gebuckelt, später niedergedrückt u. oft trichterf., $3-6 \mathrm{~cm}$ br., schmutzig rötlichbraun od. zimmetbraun, ungezont od. schwach gezont, Fleisch schmutzig rötlichbraun, Rand eingerollt. L. blaßrötlich, später rotbraun, vom Sporenpulver weiß bereift. Milch häufig einen etwas bitteren Geschmack hinterlassend. Geruchlos. In Lb-u. auch Ndwäldern, häufig bis ins Gebirge. S. H. (Fig. 265.) (Süßlicher M.)

\section{L. subduleis (Bulliard).}

Hut usw. wie bei vor. Art, aber in frischem Zustande nach Kampfer, in getrocknetem nach Bocksklee riechend. Wie vor. (Kampfer-M.)

L. camphorata (Bulliard).

11. Hut flach gewölbt, mit einem spitzen Höcker in der Mitte, dann niedergedrückt, $2,5-6 \mathrm{~cm}$ br., gelblich rotbraun, in der Mitte dunkler, glatt, ungezont, Fleisch bräunlich, Rand eingerollt. St. 3-6 cm lg., voll, gelblich-rotbraun. L. wenig herablaufend, blaß, gelbrötlich. Milch trüb, fast farblos, spärlich. In Wäldern u. in Gebüschen, häufig. S. (Serum-M.) L. seriflua (DC.).

Hut flach gewölbt, dann niedergedrückt $u$. oft mit einem spitzen Höcker, 2,5-6 cm br., glatt, orangegelb, hellrotbraun od. gelbbraun, ungezont, Fleisch bla $\beta$, Rand schwach gerollt. St. $6-8 \mathrm{~cm}$ lg., voll, gleichfarben. L. angeheftet, blaß, später rötlichgelb. Eßbar. In Lbwäldern, nicht selten. S. H. (Fig. 266.) (Milder M.) L. mitissima (Fries).

12. Milch weiß, sich dann schnell verfärbend.

13.

Milch weiß bleibend.

20.

13. Milch weiß, dann grau, gelb od. rot. 14.

Hut gewölbt, dann in der Mitte niedergedrückt, $4-8 \mathrm{~cm}$ br., stark schleimig, dann trockener, schmutzig-gelblich, bräunlich od. schmutzig fleischrot, gezont od. nicht, Rand anfangs eingerollt. St. $3-5 \mathrm{~cm}$ lg., zuerst stark schleimig, zuletzt hohl, gleichfarbig. L. weiß. Milch langsam violett werdend. In Lbwäldern, zerstreut. H. (Fig. 267.) (Feuchter M.)

L. uvida (Fries).

14. Milch grau werdend.

Mileh rot werdend.

Milch gelb werdend.

15.

16.

17.

15. Hut flach gewölbt, in der Mitte eingedrückt, glatt, trocken, später rissig, umbrabraun mit olivenbraunem Schein, ungezont. St. $2-2,5 \mathrm{~cm}$ lg., hellgrau, nach oben meist verjüngt. L. etwas herablaufend, hellgelblich. In Ndwäldern, nicht häufig. S. H. (Fig. 268.) (Umbrabrauner M.)

L. umbrina (Pers.).

Hut schwach gebuckelt, dann verflacht $u$. in der Mitte nieder. gedrückt, $5-8 \mathrm{~cm}$ br., schleimig, klebrig, trocken seidenglänzend, 
fleischrötlich od. graubraun, ungezont, Rand glatt. St. bis $10 \mathrm{~cm}$ lg., hohl, weißlich od. bläulich. L. etwas herablaufend, weißlich, später ockergelb. In schattigen Wäldern im Moose, nicht häufig.
S. H. (Fig. 269.) (Welker M.)
L. vieta (Fries).

16. Hut unregelmäßig gewölbt, dann niedergedrückt u. trichterf., $5-8 \mathrm{~cm}$ br., trocken, matt, hell ockerfarben od. graubraun, seltner fast weiß, ungezont. St. kurz, nach unten verjüngt, bisweilen exzentrisch, später hohl. L. blaßgelb, später hell ockergelb. Sporenpulver hell gelblich. In Lbwäldern, zerstreut. S. H. (Schamhafter M.)

L. pudibunda (Scopoli).

Hut flach, 6-8 cm br., schleimig, klebrig, graubraun, schwach gezont. St. hohl, zylindrisch, $6-7 \mathrm{~cm} \mathrm{lg}$., blaß. L. herablaufend, weiß, später sich rötend. In Wäldern u. auf Waldwiesen im Moose, selten. S. H. (Bleicher M.) L. lurida (Pers.).

17. Hut in der Jugend schleimig-klebrig, später erst trocken. 18.

Hut flach, in der Mitte eingedrückt, dann trichterf., $5-8 \mathrm{~cm}$ br., trocken, kahl, hell fleischrot od. gelblich, mit dunklen rötlichen Zonen, Rand anfangs eingerollt. St. $6-8 \mathrm{~cm}$ lg., weiß. L. herablaufend, blaßgelblich od. -rötlich. In Lb-, seltener Ndwäldern, zerstreut. S. H. (Gold-M.)

L. ehrysorrhea (Fries).

18. Rand des Hutes filzig od. zottig.

19.

Hut gewölbt, mit schwachem Höcker, dann niedergedrückt, $3-6 \mathrm{~cm}$ br., rot- od. gelbbraun, ungezont, Rand anfangs eingerollt, glatt. St. $4-5 \mathrm{~cm}$ lg., hohl, gleichfarbig. L. angewachsen u. herablaufend, hellrötlich od. lebhaft gelb. In Lbwäldern, nicht häufig. S. H. (Fig. 270.) (Schwefel-M.)

L. thiogala (Bulliard).

19. Hut in der Mitte niedergedrückt,' $8-15 \mathrm{~cm}$ br. od. breiter, in der Mitte stark schleimig, gelb, ungezont, Rand anfangs eingerollt, zottig striegelhaarig. St. hohl, 5-6 cm lg., gelblich, mit eingedrückten, grubigen Flecken. L. weißlich. Besonders in Ndwäldern in kleinen Gruppen, nicht selten. S. H. (Fig. 271.) (Grubiger M.)

\section{L. scrobiculata (Scopoli).}

Hut in der Mitte niedergedrückt, 6-12 cm br., kahl, zuerst klebrig, weiß od. in der Mitte hell ockerfarben, Rand zuerst eingerollt, weißzottig. St. bis $6 \mathrm{~cm} \mathrm{lg}$., hohl, glatt, weiß. L. herablaufend, weiß. In Lbwäldern, selten. S. H. (Umgebogener M.)

$$
\text { L. resima (Fries). }
$$

20. Hutoberfläche von Anfang an trocken.

Hut in der Jugend schleimig-klebrig, erst später trocken werdend.

21. Hut am Rande kahl.

Hut am Rande filzig od. zottig.

22. Hut, Fleisch, L. weiß.

Hut fahlgelb, aschgrau, braunrötlich bis braunschwarz, L. gelblich. 
23. Hut in der Mitte niedergedrückt, dann trichterf., $8-16 \mathrm{~cm}$ br., glatt, weiß, ungezont, Rand anfangs eingerollt. St. voll, weiß, bis $6 \mathrm{~cm} \mathrm{lg.} \mathrm{Milch} \mathrm{zuerst} \mathrm{reichlich,} \mathrm{dann} \mathrm{spärlich.} \mathrm{L.} \mathrm{herablaufend,}$ gabelig. Soll eßbar sein. In Wäldern, häufig. S. H. (Fig. 272.) (Bitterling, Pfefferpilz.) L. piperata (Scopoli).

Hut wie bei vor., 6-12 cm br. St. voll, 6-10 $\mathrm{cm}$ hoch, weiß, oben meist bläulich, später bräunlich werdend. L. nicht herablaufend, angewachsen, sonst wie vor. In Wäldern, besonders den Vorbergen, nicht selten. S. H. (Pergament-M.)

\section{L. pargamena (Swartz).}

24. Hutoberfläche von Anfang an trocken, ganz ungezont.

Hut flach gewölbt od. niedergedrückt, $6-8 \mathrm{~cm}$ br.; glatt, frisch feucht, aber nicht klebrig, aschgrau od. braun, schwach gezont. St. $4-6 \mathrm{~cm}$ hoch, nach unten verdünnt, blaßbräunlich. In Wäldern, nicht selten. S. H. (Fig. 273.) (Feuer-M.)

\section{L. pyrogala (Bulliard).}

25. Hut gewölbt, dann eingedrückt, trichterf., 6-12 cm br., glanzlos, anfangs graubraun, dann schwarzbraun, Rand anfangs eingerollt. St. $4-6 \mathrm{~cm}$ hoch, voll, gleichfarbig od. heller. Besonders in Ndwäldern, nicht selten. S. H. (Fig. 274.) (Bleigrauer M.)

L. plumbea (Bulliard).

Hut flach gewölbt, dann niedergedrückt, $5-15 \mathrm{~cm}$ br., kahl, später rissig-schuppig, fahlgelb od. blaß braunrötlich, Rand herabgebogen, später eingeschnitten od. geschweift. St. 3 bis $8 \mathrm{~cm}$ hoch, ungleich dick. Zwischen Moos u. Gras auf lichten Waldstellen, zerstreut. S. H. (Verbogener M.)

\section{L. flexuosa (Fries).}

26. Hut irgendwie braun, L. nicht rein weiß.

Hut hartfleischig, flach gewölbt, bald eingedrückt u. trichterf., $8-20 \mathrm{~cm}$ br., feinfilzig, weiß, ungezont, Rand eingebogen, filzig. St. 4-10 cm hoch, voll, weiß, flaumhaarig. Milch reichlich, dann aber spärlich. L. herablaufend, bisweilen verzweigt. Angeblich giftig. In Lb- u. Ndwäldern, häufig. S. H. (Fig. 275.) (Wollschwamm, Kotschieber, Schieberling.) L.vellerea (Fries).

27. Hut grau, graubraun, ockerbraun.

Hut flach gewölbt, anfangs in der Mitte stumpf gebuckelt, dann eingedrückt, fast trichterf., 5-11 $\mathrm{cm}$ br., anfangs kleinflockig, rotbraun, schimmernd, ungezont, Rand eingerollt, filzig, dann flach, scharf. St. voll, 5-8 cm hoch, hell-rotbraun, am Grunde flaumhaarig. L. etwas herablaufend, hellgelblich bis rötlich, später rotbraun. Geschmack sehr scharf u. brennend. Giftig. In Ndwäldern bis ins Gebirge, häufig. S. H. (Fig. 276.) (Rotbrauner M.)

L. rufa (Scopoli).

28. Hut gewölbt, dann in der Mitte niedergedrückt, $8-12 \mathrm{~cm}$ br., seidenhaarig, dann flockig-schuppig od. rissig, ockerbraun, verblassend, Rand eingerollt. St. $5-8 \mathrm{~cm}$ hoch, später hohl, blaß, 
feinhaarig. L. herablaufend, blaß weißlich, später ockerfarben. Geschmack scharf, bisweilen milde. In Ndwäldern, zerstreut. S. H. (Fig. 277.) (Isabellfarbiger M.) L. helva (Fries).

Hut halbkuglig, oft gebuckelt, dann verflacht, $4-8 \mathrm{~cm}$ br., kleinschuppig, grau od. graubraun, meist mit violettem Schimmer, Rand stark eingerollt. St. voll, $4-8 \mathrm{~cm}$ lg., bla $\beta$, außen rauhfaserig. L. herablaufend, blaß, dann ockerfarben. Geruch nach Perubalsam. In Ndwäldern, an Wegen, häufig. S. H. (Fig. 278.) (Wohlriechender M.)

L. glyciosma (Fries).

29. Hutrand filzig.

Hutrand von Anfang an kahl.

30. Hutoberfläche nicht mit blutroten Flecken od. Zonen. 31.

Hut in der Mitte eingedrückt, später trichterf., $8-12 \mathrm{~cm}$ br., zuerst flockig, dann weißlich, klebrig, meist mit blutroten Flecken od. Zonen, Fleisch weiß, Rand anfangs eingerollt, zottig. St. voll, $3-5 \mathrm{~cm}$ hoch, weiß. L. anfangs weißlich, dann fleischrot. Auf Wiesen, Weideplätzen, lichten Wäldern usw., zerstreut. S. H. (Blutiger M.)

L. sanguinalis (Batsch).

31. Hut gewölbt, dann eingedrückt, $3-10 \mathrm{~cm}$ br., schwach klebrig, hell ifleischrot, gelblich od. weiß, oft mit sehr regelmäßigen rötlichen Zonen od. schwach gezont, Rand eingerollt, weiß striegeligzottig. St. $3-6 \mathrm{~cm} \mathrm{lg.,} \mathrm{bald} \mathrm{hohl,} \mathrm{gleichfarbig.} \mathrm{L.} \mathrm{weißlich.}$ Giftig (?). In Wäldern, auf Grasplätzen, an Wegen, häufig. S. H. (Fig. 279.) (Birkenreizker, Birkenrietsche.)

\section{L. torminosa (Schaeffer).}

Hut flach, dann eingedrückt, $6-20 \mathrm{~cm}$ br., zuerst klebrigschleimig, schmutzig oliven- bis umbrabraun, ungezont, Fleisch schmutzig bräunlich, Rand eingerollt, filzig, anfangs gelbzottig. St. voll, bis $5 \mathrm{~cm}$ lg., klebrig, gleichfarbig dem Hute. L. blaß, schmutzig werdend. Verdächtig. In Wäldern, Gebüschen, Gärten, zerstreut. S. H. (Tödlicher M.)

L. necator (Pers.).

32. Hut orangefarben od. lederbraun.

33.

Hut gelblich, rötlich, gelbbräunlich, grünlich.

34.

33. Hut gewölbt, in der Mitte gebuckelt, dann eingedrückt, bis $6 \mathrm{~cm}$ br., später glatt, glänzend, orangefarben. St. 6 cm lg., später hohl, gleichfarbig. L. angewachsen, herablaufend, weißlich, später ockerfarben. In Lbwäldern, zerstreut. S. (Fig. 280.) (Orangefarbener M.)

L. aurantiaca (Flora danica).

Hut flach gewölbt, dann niedergedrückt, $4-6 \mathrm{~cm}$ br., später glatt, mit erhabenen Runzeln, ungezont, lederbraun, Rand abwärts gebogen, scharf, oft gestreift. St. hohl, $4-6 \mathrm{~cm}$ lg., gleichfarben. L. etwas herablaufend, gelb, dann etwas dunkler. In Wäldern, auf Heiden, selten. S. H. (Fig. 281.) (Lederbrauner M.) L. jecorina (Fries).

34. Hutoberfläche graugrün od. fleischrot. 
35. Hut genabelt, $6-8 \mathrm{~cm}$ br., glatt, fleischfarbig bis rot, verblassend, oft glänzend, mit umgebogenem, dünnem Rande. St. verschieden lg., später hohl, an der Spitze grubig, etwas gefleckt. L. weiß, seltener gelblich. Im Grase in Wäldern, selten. S. (Fig. 282.) (Scharlach-M.)

L. hysgina (Fries).

Hut niedergedrückt, $5-11 \mathrm{~cm}$ br., oft mit konzentrisch gestellten Tropfen, 5-11 cm br., graugrün od. in der Mitte rötlich, St. $2,5 \mathrm{~cm}$ lg., später hohl, gleichfarbig. L. weiß, bei Verletzung grau. In Lb-u. Ndwäldern, zerstreut. S. H. (Fig. 283.) (Graugrüner M.)

L. blennia (Fries).

(Vgl. auch L. pallida (S. 107), durch ockerfarbene L. ausgezeichnet.)

36. L. weiß.

L. blaß gelbrötlich bis ockerfarben.

38.

37. Hut in der Mitte niedergedrückt, $4-8 \mathrm{~cm}$ br., trocken g]änzend, in der Jugend dunkel blaugrau, später schmutzig fahlgelb od. rötlichbraun, ungezont, Rand eingebogen, häufig. St. hohl, $4-8 \mathrm{~cm} \mathrm{lg.,} \mathrm{blaß.} \mathrm{L.} \mathrm{weiß.} \mathrm{In} \mathrm{Ndwäldern,} \mathrm{zerstreut.} \mathrm{S.} \mathrm{H.}$ (Fig. 284.) (Gawöhnlicher M.)

L. trivialis (Fries).

Hut in der Mitte eingedrückt, $4-8 \mathrm{~cm}$ br., gelblich, gezont, Rand eingerollt, oft verbogen. St. voll, weiß, später gelblich. Im Grase in Wäldern u. Gebüschen, selten. S. H. (Fig. 285.) (Gezonter M.)

L. zonaria (Bulliard).

38. Hut gewölbt, dann in der Mitte eingedrückt, $4-8 \mathrm{~cm}$ br., blaß ledergelb od. blaß fleischrot; ungezont, Rand eingerollt. St. später hohl, 4-6 cm lg., gleichfarbig. L. etwas herablaufend, hell, später ockerfarben, bereift. In lichten Lbwäldern, nicht selten. S. H. (Blasser M.)

L. pallida (Pers.).

Hut genabelt, dann trichterf., bis $11 \mathrm{~cm}$ br., gelblich, schwach gezont. St. später hohl, ca. $3 \mathrm{~cm} \mathrm{lg.,} \mathrm{oft} \mathrm{etwas} \mathrm{grubig,} \mathrm{blaß.}$ L. bla $\beta$, gegabelt. In schattigen Wäldern, selten. S. H. (Geschmackloser M.)

L. insulsa (Fries).

\section{Gattung: Russula Pers. (Täubling).}

Wie Lactaria, aber ohne Milch. Schleim fehlend. L. dick, schief, zerbrechlich, mit scharfer Schneide, weiß od. weißlich (wenigstens zu Anfang). Sporenpulver weiß. Hutrand meist ganz dünn, häutig. Die scharf schmeckenden Arten sind giftig od. verdächtig.

1. Hutoberfläche weiß.

Hutoberfläche grün, olivengrün.

Hutoberfläche gelb, bräunlich, dunkelbraun bis schwarz. 9.

Hutoberfläche rot, rötlich, purpurrot, violett.

2. Hut glockig, dann ausgebreitet, bis $8 \mathrm{~cm}$ br., trocken, rauh, dann rissig, weiß, später etwas lederfarben, Fleisch vor dem Rand verschwindend, Rand gerade, glatt, stumpf. St. voll, bis $4 \mathrm{~cm}$ 
dick, weiß. L. frei, z. T. gegabelt. Eßbar. Geschmack mild. In Buchenwäldern, zerstreut. S. (Fig. 286.) (Milchweißer T.)

R. lactea (Pers.).

Hut in der Mitte eingedrückt, $8-14 \mathrm{~cm}$ br., glatt, weiß, bis zum Rand fleischig, Rand eingerollt, ungestreift. St. voll, 2 bis $6 \mathrm{~cm}$ lg., weiß. L. herablaufend, ungleich lg. Eßbar. Geschmack mild. Besonders in Ndwäldern, zerstreut. S. H. (Wohlschmeckender T.)

3. Scharf schmeckend.

R. deliciosa (Vaillant).

Mild schmeckend.

4. Hut gewölbt u. gebuckelt, dann niedergedrückt u. trichterf., $5-8 \mathrm{~cm}$ br., glatt, seidig schimmernd, lebhaft grün bis umbrabraun, auch braunweißlich, Rand glatt, scharf. St. dick, glatt, wei $\beta, 3-6 \mathrm{~cm}$ hoch. L. angewachsen, herablaufend, gegabelt. Geschmack zuerst mild, dann scharf. In schattigen Wäldern, nicht selten. S. H. (Gegabelter T.) R. bifida (Bulliard).

Hut mit klebriger Oberhaut. L. angeheftet od. frei. (Siehe S. 110.)

R. consobrina Fries.

5. Rand stets häutig, dünn, gestreift od. gefurcht.

Rand ebenso, aber ungestreift, glatt.

6. L. ungleich lang.

Hut flach gewölbt, oft niedergedrückt, $4-7 \mathrm{~cm}$ breit, spangrün oder gelbgrün, in der Mitte fast olivengrün, mit glatter, abziehbarer, feucht klebriger Haut, Rand häutig gestreift. St. voll, $5-6 \mathrm{~cm}$ hoch, weiß. L. locker angeheftet, weiß, fast alle von gleicher Länge, nur wenige kürzere. In Wäldern, zerstreut. S. H. (Fig. 287.) (Spangrüner T.) $\quad$ R. aeruginea Fries.

7. Hut flach gewölbt, dann niedergedrückt, $4-8 \mathrm{~cm}$ br., trocken, glatt, olivengrün, graugrün od. ins Bräunliche übergehend, Rand zuerst eingebogen, fein gestreift. St. voll, $4-8 \mathrm{~cm}$ hoch, weiß. L. dicht, durchgehende u. kürzere gegabelte unregelmäßig gemischt, fast frei. Besonders in Lbwäldern, zerstreut. S. H. (Graugrüner T.)

R. livida (Pers.).

Hut gewölbt, dann flach u. niedergedrückt, klebrig, hell violett od. purpurolivgrün, mit abblassender, oft bräunlicher Mitte u. bläulichem, gestreiftem Rande. St. voll, $6-8 \mathrm{~cm} \mathrm{lg.,} \mathrm{weiß.}$ L. hinten abgerundet, durehgehende, kürzere u. gegabelte unregelmäßig gemischt. In Wäldern, nicht häufig. S. H. (Fig. 288.) (Blaugelber T.)

R. eyanoxantha (Schaeffer).

8. Hut kuglig, dann flach gewölbt, $8-12 \mathrm{~cm}$ br., trocken, spangrün bis gelbgrünlich, flockig od. felderig warzig, Rand scharf, ungestreift. St. voll, 6-8 cm lg., weiß. L. ungleich lg., z. T. gabelig. Eßbar. In lichten Wäldern, Grasplätzen, häufig. S. H. (Fig. 289.) (Grünling.)

R. virescens (Schaeffer).

Hut gewölbt, dann verflacht $u$. niedergedrückt, $6-10 \mathrm{~cm}$ br., schwach filzig od. kleinschuppig, anfangs schmutzig purpurrot, bald olivenfarben od. kaffeebraun. Rand scharf, glatt. St. voll, 
blaßrötlich. L. angeheftet, durchgehende, kürzere u. gegabelte gemischt, gelblich. Eßbar. In Ndwäldern besonders der Vorberge, zerstreut. S. H. (Fig. 290.) (Olivengrüner T.)

R. olivacea (Schaeffer).

9. Geschmack mild.

Geschmack scharf.

10.

13.

10. Anfangs braun, im Alter schwarz werdend.

11.

Nicht schwarz werdend.

12.

11. Hut flach gewölbt, dann niedergedrückt, $8-16 \mathrm{~cm}$ br., graubraun, dann schwärzlich, Fleisch schwärzlich, bis zum Rand gehend, Rand anfangs eingebogen, glatt. St. voll, dick, gleichfarbig. L. angewachsen, etwas herablaufend, wei $\beta$, dann grau, verschieden lg. In Wäldern, häufig. S. H. (Fig. 291.) (Brand-T.)

R. adusta (Pers.).

Hut niedergedrückt-genabelt, sehr festfleischig, fast holzig werdend, 10-14 cm br., olivenbraun, dann schwärzlich, Fleisch bis zum Rand gehend, Rand umgebogen, glatt. St. 7-10 em lg., voll, gleichfarbig. L. abgerundet, weiß, dann grau, ungleich lg., dick. In Wäldern, häufig. S. H. (Fig. 292.) (Schwärzlicher T.)

\section{R. nigricans (Bull.).}

12. Hut rötlich, bald namentlich in der Mitte gelb werdend, L. angeheftet. (Siehe S. 111).

R. depallens (Pers.).

Hut rötlich, dann blaß od. schmutzig gelb verblassend. L. angewachsen. (Siehe S. 111.)

R. sardonia Fries.

Hut schwach filzig od. kleinschuppig, purpurrot, olivenfarbig od. kaffeebraun. (Siehe S. 109.) R. olivacea (Schaeffer).

13. Rand gestreift od. gefurcht.

14.

Rand glatt. Hut gewöhnlich umbrabraun od. grün, seltener hellbraun. (Siehe S. 108.)

14. L. fast alle gleich $\mathrm{lg}$.

R. bifida (Bull.).

L. in der Länge wechselnd.

15. Hut flachgewölbt, oft niedergedrückt, $5-7 \mathrm{~cm}$ br., gelb, verblassend, Fleisch vor dem Rand aufhörend, Rand später streifig. St. 2-4 cm lg., weiß, später grau, netzartig gerunzelt. L. hinten abgerundet, weißlich, fast alle gleichlg. In lichten Wäldern, auf Grasplätzen, häufig. S. H. (Fig. 293.) (Ockergelber T.)

R. ochroleuca (Pers.).

Hut flach gewölbt, meist niedergedrückt, $4-8 \mathrm{~cm}$ br., mattbraun, in der Mitte dunkler, Fleisch unter der Oberhaut gelblich u. nicht bis zum Rand gehend, Rand höckrig-furchig. St. weiß, gestreift. L. nach hinten verschmälert, frei, gleichlg. In lichten Wäldern im Moos u. Gras, nicht häufig. S. H. (Fig. 294.) (Kammartiger T.)

R. pectinata (Bulliard).

16. St. blaß gefärbt, weiß, grau, gelblich.

17.

St. purpurviolett, L. Tropfen ausschwitzend. (Siehe S. 110.)

R. Queletii Fries. 
17. Oberhaut durchaus trocken, nicht klebrig.

Hut später flachgewölbt, $8-15 \mathrm{~cm}$ br., anfangs klebrig, gelbbraun, od. schmutzig-ockerfarben, Rand dünn, höckrig-furchig. St. später hohl, 6-12 cm lg., weiß. L. von verschiedener Länge, weißlich, später bei Verletzungen oft bräunlich werdend. Geruch (namentlich jung) scharf. In Wäldern, Gebüschen, nicht selten.
S. H. (Fig. 295.) (Stink-T.)
R. foetens Pers.

18. Hut flachgewölbt, $4-8 \mathrm{~cm}$ br., stroh- bis ockergelb, Fleisch strohgelb, Rand häutig, gestreift. St. später hohl, glatt, gleichfarbig. L.'angewachsen, ungleich lg., strohgelb werdend. Besonders in Buchenwäldern, zerstreut. S. H. (Fig. 296.) (Gallen-T.)

R. fellea Fries.

Hut glockig, dann ausgebreitet $u$. schwach vertieft, $5-9 \mathrm{~cm}$ br., in der Mitte umbrabraun od. aschgrau-bräunlich, selten hellbräun'ich, Rand heller, stark u. breit gerippt. St. hohl werdend, $2-5 \mathrm{~cm}$ lg., wei $\beta$, etwas grubig. L. angeheftet, wei $\beta$, mit etwas ockergelber Schneide, ungleich lg. Besonders in Ndwäldern, unter Gebüsch, in den Vorbergen, nicht häufig. S. H. (Fig. 297.) (Verwandter T.)

R. consobrina Fries.

19. Geschmack scharf.

Geschmack mild.

20. Rand gestreift, Oberhaut klebrig, abziehbar.

Rand glatt, Oberhaut trocken (wenn nur undeutlich gestreift, dann Hut klebrig bei Queletii).

21. Hut flach, wenig eingedrückt, $3-6 \mathrm{~cm}$ br., Oberhaut feucht, etwas klebrig, abziehbar, purpurrot od. kirschrot (auch mehr blaßrot od. wei $ß$ ), in der Mitte stets anders (bräunlichgrün, violett) gefärbt, Rand häutig, höckrig-furchig. St. später hohl, weiß, selten mit rötlichem Anflug, 2-5 cm lg., L. angeheftet, gleichlg. Geruch nicht so widerlich wie bei folg. Art. Giftig. Auf feuchten Wiesen, an Waldrändern, häufig. S. H. (Fig. 298.) ( (Zerbrechlicher T.)

R. fragilis (Pers.).

Hut flach, 5-10 cm br., Oberhaut feucht klebrig, abziehbar, glänzend kirsch- od. zinnoberrot, oft verblassend mit gelblichen od. helleren Flecken, Rand gefurcht. St. $6-8 \mathrm{~cm} \mathrm{lg.,} \mathrm{schwammig,}$ weiß od. rötlich. L. frei, grauweiß. Geruch widerlich. Giftig. Auf Wiesen, in Wäldern, häufig. S. H. (Fig. 299.) (Speiteufel.)

R. emetica (Schaeffer).

22. Oberfläche gleichmäßig zinnober- od. blutrot, höchstens am Rande etwas abblassend, trocken.

Hut gebuckelt, dann flach gewölbt, seltener etwas trichterf., $3-5 \mathrm{~cm}$ br., klebrig, in der Mitte gelbbräunlich, nach dem Rande hin kirschrötlich-violett, Rand nicht od. wenig gestreift. St. voll, kirschrötlich-violett, $3-4 \mathrm{~cm}$ hoch. L. verschmälert angewachsen, meist mit Tropfen bedeckt. In lichten Ndwäldern, an sandigen Wegen, selten. S. (Fig. 300.) (Quélets T.)

R. Queletii Fries. 
23. Hut gewölbt, dann flach od. niedergedrückt, $5-8 \mathrm{~cm}$ br., trocken, glänzend zinnoberrot, Rand glatt. St. voll, weiß, unten rot. L. meist gleichlg., mit wenigen kürzeren untermischt, stumpf angewachsen, bisweilen mit roter Schneide. Giftig. In Wäldern, nicht selten. S. H. (Fig. 301.) (Roter T.) R. rubra (DC.).

Hut gewölbt u. in der Mitte gebuckelt, dann niedergedrückt, trichterf., $6-8 \mathrm{~cm}$ br., anfangs etwas feucht, nicht klebrig, dann trocken, blutrot, nach dem Rande abblassend, Rand glatt, dünn. St. voll, fein gestreift, rötlich od. weißlich. L. herablaufend, z. T. gegabelt. In Wäldern im Grase, zerstreut. S. H. (Fig. 302.) (Blutroter T.)

R. sanguinea (Bulliard).

24. Rand gestreift.

Rand glatt, ungestreift.

25. Hut flach gewölbt, festfleischig, feinaderig-runzlig, klebrig, zuerst fleischrötlich, dann etwas dunkler u. in der Mitte rot-od. ockerbräunlich, Rand dünn, gestreift. St. voll, starr, weiß, netzig runzelig. L. angewachsen, dicht, von verschiedener Länge. Eßbar. Besonders in Lbwäldern, häufig. S. (Speise-T.)

R. vesea Fries.

Hut hell violett od. purpurolivengrün, mit bräunlicher Mitte u. bläulichem Rande. (Siehe S. 108.)

26. Hutoberfläche seidenfädig od. kleinschuppig.

R. cyanoxantha (Schaeffer).

Hutoberfläche ganz glatt.

27. Hut gewölbt, dann niedergedrückt, bis $8 \mathrm{~cm}$ br., rosa od. blutrot mit weißlicher Mitte, später verblassend, schwach seidenfädig od. rissig-schuppig, Rand glatt, stumpf. St. voll, $8 \mathrm{~cm} \mathrm{lg.,} \mathrm{glatt,}$ weiß od. rosenrot. L. dick, durchlaufende mit gegabelten gemischt. In Wäldern, zerstreut. S. (Fig. 303.) (Zierlicher T.)

R. lepida Fries.

Hut schwach seidenhaarig u. kleinschuppig, zuerst schmutzig purpurrot, dann olivenfarbig od. braun-olivenfarbig. (Siehe S.109.)

R. olivacea (Schaeffer).

28. Hut rot od. rötlich, von der Mitte her gelblich od, weißlich verblassend.

Hut gleichmäßig rot, nicht verblassend.

30 .

29. Hut bis $8 \mathrm{~cm}$ br., klebrig, dann trocken, rötlich, bald aber von der Mitte aus gelblich od. ockerbräunlich, Rand glatt, verbogen. St. fest, hellbräunlich. L. angeheftet, meist gegabelt. In Wäldern, Heiden, nicht häufig. S. H. (Fig, 304.) (Verblassender T.)

R. depallens (Pers.).

Hut flach gewölbt, dann niedergedrückt, $5-8 \mathrm{~cm}$ br., klebrig, rötlich bla $B$ od. schmutzig gelb verbleichend. St. voll, $3-6 \mathrm{~cm} \mathrm{lg.,}$ weiß od. rötlich. L. angewachsen, sehr dicht, etwas gabelig, bla $\beta$ gelblich. In Ndwäldern, selten. S. H. (Fig. 305.) (Sardinischer T.)

R. sardonia Fries. 
30. Hut flach, dann niedergedrückt, $8-12 \mathrm{~cm}$ br., trocken, blutrot od. dunkelpurpurrot, Rand stumpf, glatt. St. voll, 3-4 cm lg., in der Mitte bauchig, meist blutrot, furchig. L. etwas herablaufend durchlaufende mit kürzeren u. gegabelten gemischt. Im Grase in Wäldern, nicht selten. S. (Fig. 306.) (Linnés T.)

\section{R. Linnaei Fries.}

Hut gewölbt, dann flach, 6-11 em br., klebrig, dann trocken, rosenrot, mit weißen, wie Tropfen aussehenden Flecken, Rand scharf, glatt. St. voll, weißlich od. rötlich, $6 \mathrm{~cm} \mathrm{lg}$. L. angewachsen, teilweise gegabelt. In Ndwäldern, nicht häufig. S. (Rosenfarbiger T.)

R. rosacea (Bulliard).

3. Gattung: Russulina Schroeter (Täubling).

Wie Russula, aber das Sporenpulver heller od. dunkler ockergelb. Sporenmembran hell ockerfarbig.

1. L. anfangs wei $\$$, dann gelblich werdend. Sporenpulver hell ockergelb.

L. von Anfang an gelb, dann ockerbraun. Sporenpulver dunkler. Geschmack mild.

2. Rand glatt, höchstens erst im Alter gestreift.

Rand gestreift u. höckerig von Anfang an, Geschmack mild.

3. Geschmack mild.

eschmack mild. farbig, bald ausbleichend, in der Mitte weißlich od. gelblich, am Rande fast häutig. St, später hohl, weiß. L. angewachsen, ungleich lg. Scharf schmeckend. In Lbwäldern, selten. S. (Fig. 307.) (Schläfrigmachender T.)

R. veternosa Fries.

4. Hutoberseite nicht grün.

Hut kuglig, dann flach gewölbt, niedergedrückt, $8-11 \mathrm{~cm}$ br., oliven- od. graugrün, in der Mitte etwas dunkler od. gelblich, Rand dünn. St. voll, weiß. L. angewachsen, wenige gegabelt. In Lbwäldern, Gebüschen, zerstreut. S. H. (Grauer T.)

R. grisea (Pers.).

5. Hut kuglig, dann ausgebreitet u. niedergedrückt, bis $9 \mathrm{~cm}$ br., rötlichgelb, später gelblich, verblassend, Fleisch weiß, grauwerdend, Rand glatt, nur im Alter etwas streifig. St. bis $10 \mathrm{~cm}$ hoch, weiß, runzelig streifig, innen grauwerdend. L. gabelig angeheftet. In Wäldern, zerstreut. S. H. (Fig. 308.) (Verfärbter T.)

\section{R. decolorans Fries.}

Hut gewölbt, dann flach ausgebreitet, niedergedrückt, 6 bis $10 \mathrm{~cm}$ br., trübpurpurn, matt, in der Mitte dunkler, später verblassend u. gelblich werdend.' Rand dick, glatt. St. $5-7 \mathrm{~cm} \mathrm{lg.,}$ weiß od. rötlich. L. angeheftet, z. T. gegabelt. In Ndwäldern, nicht selten. S. H. (Fig. 309.) (Dunkelroter T.)

R. xerampelina (Schaeffer).

6. S. glatt, weiß od. seltener gelblich weiß.

Hut flach gewölbt, $6-8 \mathrm{~cm}$ br., glänzend, klebrig, zitronengelb, 
Lactarieae.
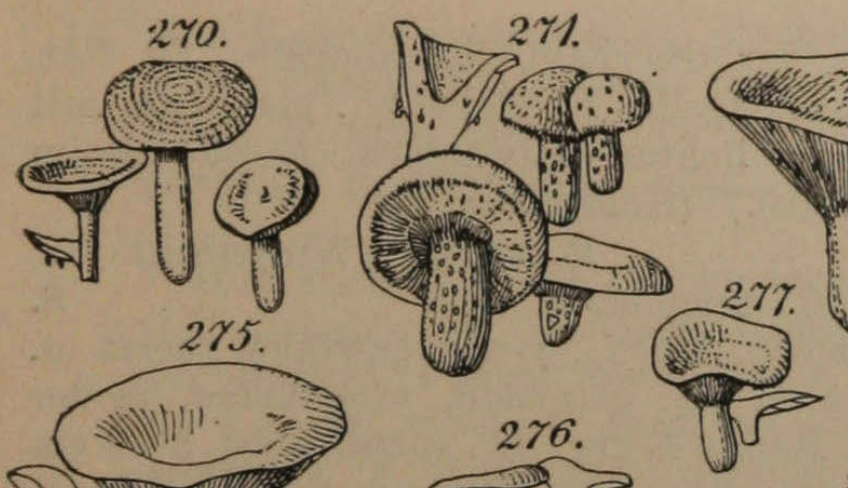

272

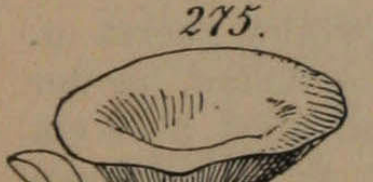

res

1. 10

1. U 281

281.

276.

278.

8.

274.
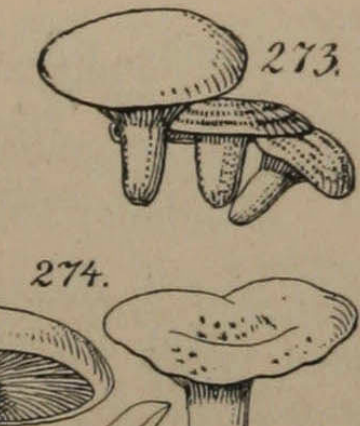

तोiाणnल

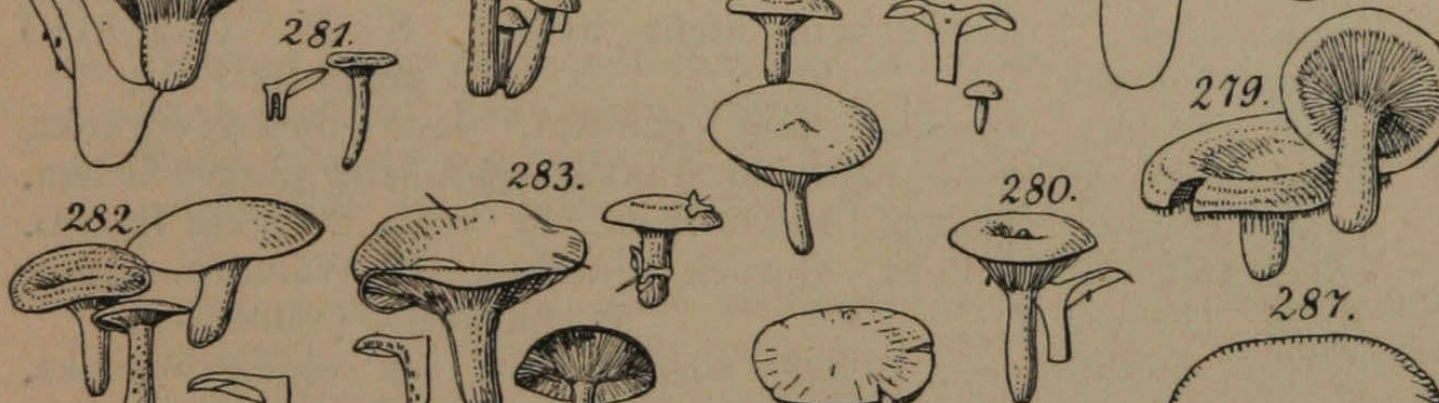

13 (4)
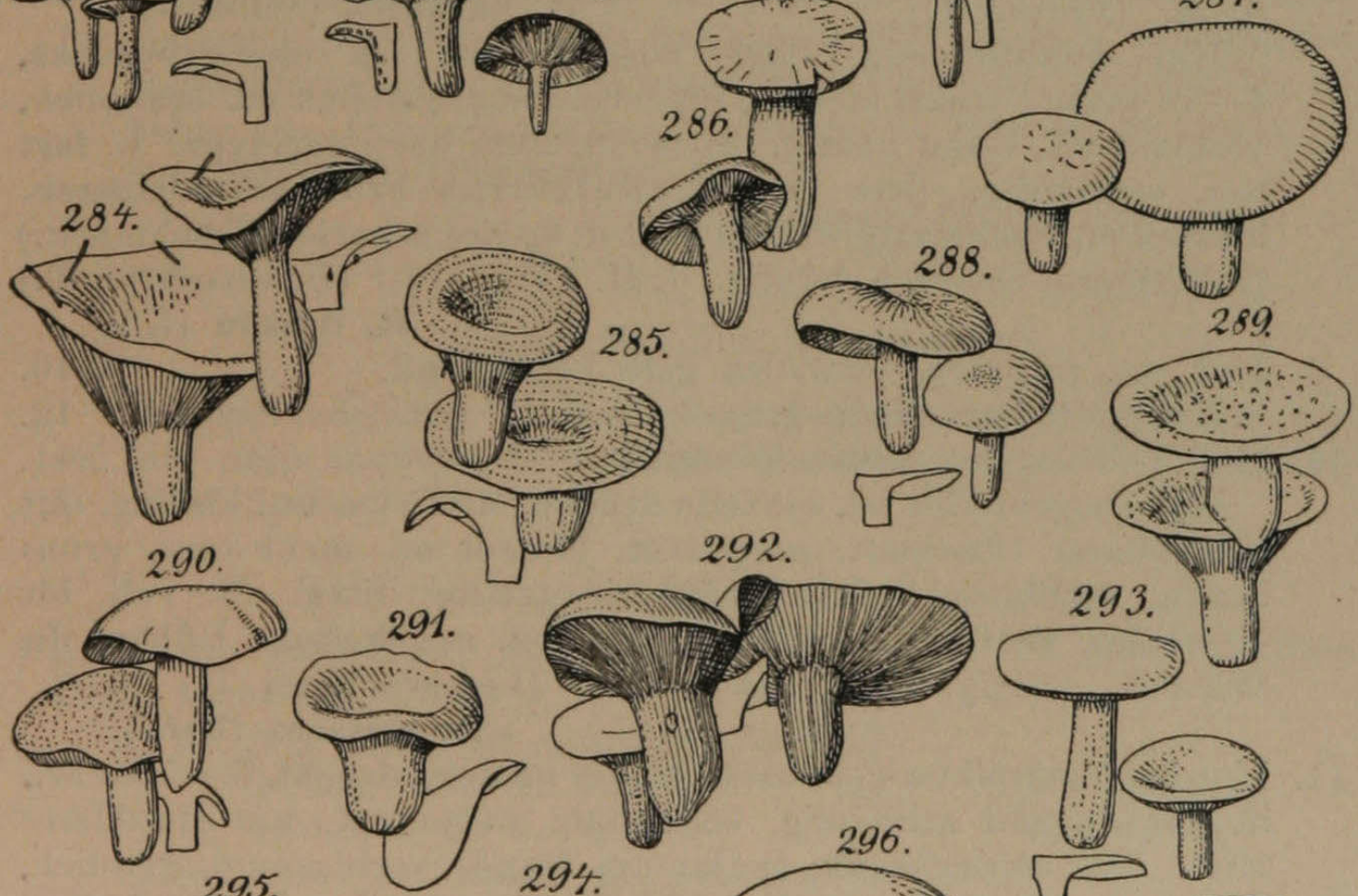
285.

292.
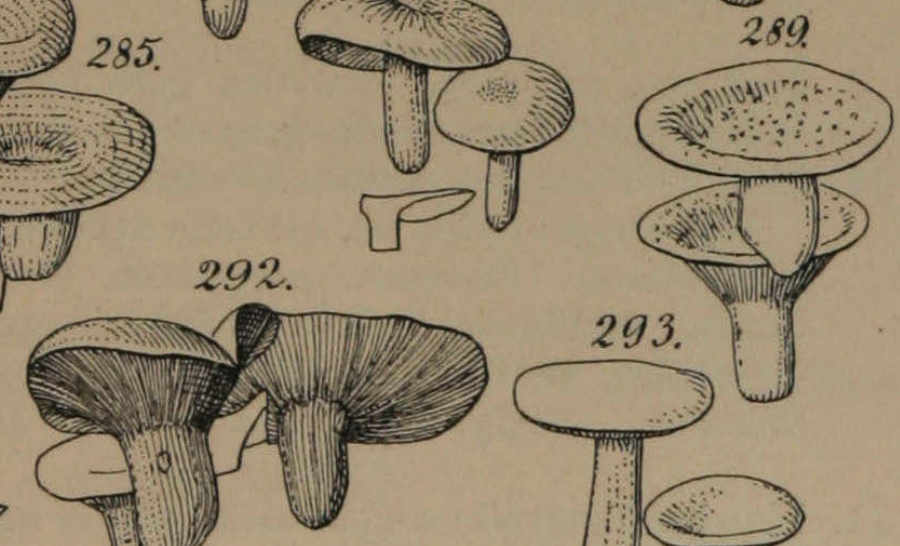

294.
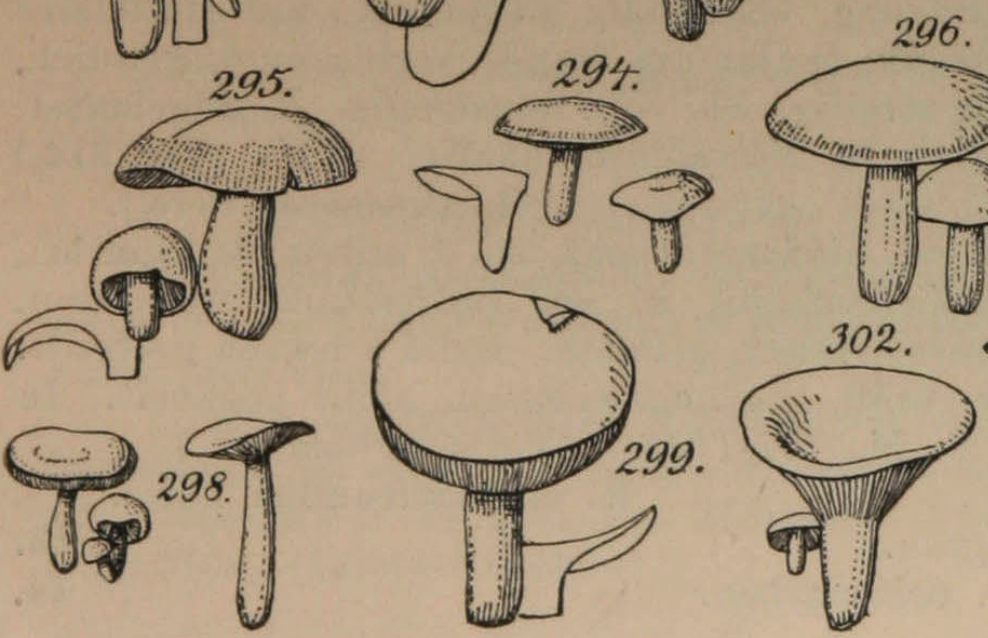

Lindau, Kryptogamenflora. I. 2. Aufl. 
orange, rot, Fleisch unter der Oberhaut zitronengelb. St. fest, bis $8 \mathrm{~cm} \mathrm{lg.,} \mathrm{weiß} \mathrm{od.} \mathrm{zitronengelb.} \mathrm{L.} \mathrm{gleich} \mathrm{lg.,} \mathrm{glänzend,} \mathrm{mit}$ zitronengelber Schneide. In lichten Ndwäldern, besonders im Gebirge, selten. S. (Fig. 310.) (Goldgelber T.)

\section{R. aurata (Withering).}

7. Hut \pm fleischig, L. frei od. angeheftet.

Hut fleischlos, fast häutig, flach, wenig gewölbt zuerst $u$. später wenig vertieft, $4-6 \mathrm{~cm}$ br., glänzend, violettblau, in der Mitte mehr bräunlich, am Rande heller. St. später hohl, $3-4 \mathrm{~cm}$ lg., etwas ockergelb. L. angewachsen, dicht. Auf sumpfigen Waldstellen, Erlenbrüchen, nicht häufig. S. H. (Fig. 311.) (Jungfräulicher T.)

R. puellaris Fries.

8. Hut ziemlich fleischig, flach gewölbt, dann niedergedrückt, $2-5 \mathrm{~cm}$ br., glänzend, heller od. dunkler schmutzig-purpurfarben, später gelblich werdend, Rand dünn. St. weiß, 2-4 cm lg., L. angeheftet, dünn, dicht. Geruch widerlich. In Wäldern, selten. S. H. (Purpur-T.)

R. purpurea (Schaeffer).

Hut dünnfleischig, flach ausgebreitet, oft niedergedrückt, 4-12 cm br., frisch klebrig, rot, violett od. gelblich od. bräunlich, verblassend, Rand häutig. St. weiß, nach oben verjüngt. L. fast frei, weitläufig. (Die Variet. adulterina Fries hat kleineren, blassen od. schmutzig weißen Hut u. später scharfen Geschmack.) In Wäldern, Gebüsch, häufig. S. H. (Fig. 312.) (Unversehrter T.)

R. integra (L.).

9. Hut rot, purpurn, bisweilen gelb abblassend.

Hut gelb, bräunlich, grau.

10.

12.

10. Hut $4-8 \mathrm{~cm}$ br., seltener breiter.

11.

Hut ausgebreitet od. niedergedrückt, bis $15 \mathrm{~cm}$ br., klebrig, mit abziehbarer Oberhaut, purpurrot, blutrot od. mehr rosa, grünbraun, verblassend, Rand höckerig-streifig, dünn. St. voll, bis $12 \mathrm{~cm}$ lg., weiß od. rötlich. L. frei od. angeheftet. Eßbar. In Wäldern, häufig. S. H. (Fig. 313.) (Lederfarbener T.)

R. alutacea (Pers.).

11. Hut flach gewölbtu. gebuckelt, später niedergedrückt, $3-5 \mathrm{~cm}$ br., in der Jugend schleimig, schmutzig purpurrot, mit dunklerer Mitte, fast olivenbraun, später am Rande verblassend, gelblich, Rand dünn, furchig-streifig. St. voll, feinstreifig. L. angeheftet. Geruch unangenehm. In Ndwäldern, häufig. S. H. (Fig. 314.) (Widerlicher T.)

R. nauseosa (Pers.).

Hut ausgebreitet od. niedergedrückt, bis 5 , selten bis $8 \mathrm{~cm}$ br., klebrig, sehr verschiedenfarbig u. am Individuum wechselnd, rosa, blutrot, purpurn, violett, gelblich. Rand schwach gestreift. St. hohl, gestreift, weiß. L. angewachsen, nicht gegabelt. In Wäldern, häufig. S. H. (Fig. 315.) (Veränderlicher T.)

R. chamaeleontina Fries.

12. Fleisch weiß od. grau. 13. Fleisch gelb od. ockerfarben. 
13. Hut flach niedergedrückt, geschweift, braun, grau od. gelblich, matt, Fleisch weiß, dann grau werdend, Rand glatt. St. blaßweißlich, braunstreifig. L. angeheftet, gedrängt. Geruch unangenehm. In Ndwäldern, selten. S. H. (Fig. 316.) (Graugelber T.)

R. ravida (Bulliard).

Hut flach gewölbt od. niedergedrückt, $3-6 \mathrm{~cm}$ br., klebrig, mit abziehbarer Oberhaut, lebhaft gelb, in der Mitte dunkler, verblassend, Fleisch weiß, Rand häutig, glatt. St. später hohl, $3-4 \mathrm{~cm}$ lg., weiß. L. ganz frei, dicht, dottergelb. In Lbwäldern, zerstreut. S. (Fig. 317.) (Gelber T.)

R. lutea (Hudson).

14. Hut nur in der Mitte gelb-fleischig, sonst fast häutig, $[2-4 \mathrm{~cm}$ br., flach gewölbt, dann ausgebreitet, gelb, dann etwas verblassend, Rand höckrig gestreift. St. $2-3 \mathrm{~cm}$ lg., weiß. L. frei, gleichlg., safrangelb. In Wäldern, selten. S. H. (Dottergelber T.)

R. vitellina (Pers.).

Hut flach gewölbt, dann niedergedrückt, $5-8 \mathrm{~cm}$ br., klebrig, glänzend, ockergelb mit dunkler Mitte, Fleisch ockerfarben, Rand dünn, gefurcht. St. gestreift, $3-4 \mathrm{~cm} \mathrm{lg.,} \mathrm{gleichfarbig} \mathrm{od.}$ heller. L. frei, ockergelb. In Misch- u. Ndwäldern, zerstreut. S. (Fig. 318.) (Ockergelber T.)

R. ochracea (Alb. et Schwein.).

\section{Unterfamilie: Marasmieae.}

Fk. zäh lederartig od. fast holzig, vertrocknend u. beim Anfeuchten die ursprüngliche Gestalt wieder annehmend, sehr dauerhaft. L. zähe. Sporenpulver weiß.

\section{Bestimmungsschlüssel der Gattungen.}

A. L. mit gespaltener Schneide.

1. Schizophyllum.

B. L. nicht gespalten.

a) St. mit dem Hut zusammenfließend.

I. Schneide der L. stumpf.

II. Schneide der L. scharf.

2. Xerotus.

3. Lentinus.

b) St. vom Hut scharf abgesetzt, ebenso von den $\mathrm{L}$.

\section{Marasmius.}

\section{Gattung: Schizophyllum Fries (Spaltlamelle).}

Hut lederartig, ungestielt. L. lederartig, verschieden lg., bei der Reife von der Schneide aus sich in zwei Platten spaltend, die sich nach außen umrollen.

Einzige Art oben filzig, weiß, später zottig, grau. L. vom Anheftungspunkt ausstrahlend, grau, dann violett braun. Gesellig auf Lb., namentlich an gefällten Stämmen, häufig. Das ganze Jahr. (Fig. 319.) (Erlenschwamm.)

S. alneum (L.). 
2. Gattung: Xerotus Fries (Trockenschwamm).

Hut häutig-lederig, dauerhaft, in den St. übergehend. L. lederartig, br. faltenf. dichotom, mit ganzer, stumpfer Schneide.

Einzige Art mit flach trichterf., graubraunem, etwas gezontem, feucht gestreiftem Hut. St. voll, braun, weißfilzig. L. sehr entfernt stehend, herablaufend, z. T. gegabelt, grauweißlich. Auf nackter Erde, selten. S. H. (Fig. 320.) (Verbildeter T.) X, degener (Schaeffer).

\section{Gattung: Lentinus Fries (Korkschwamm).}

Fk. zähe, beim Eintrocknen erhärtend. St. in den Hut übergehend, fehlend od. seitenständig od. exzentrisch. L. lederartig zähe. Sporenpulver weiß.

1. L. mit glatter ganzrandiger Schneide (Unterg. Panus Fries). 2.

L. mit gesägter od. zerschlitzt gezähnter Schneide (Unterg. Eulentinus Schroet.).

2. Hut ohne od. mit seitlichem St.

Hut exzentrisch gestielt.

3. Hut umgewendet, dünn, zuerst becherf., dann ausgebreitet, halbiert, ca. $1 / 2 \mathrm{~cm}$ br., am Grunde mit weißlichen Fasern angeheftet, bereift. L. blaßviolett, netzaderig. An Nd, nicht häufig. S. H. (Blaßvioletter K.) L. violaceofulvus (Batsch).

Hut zäh, trocken holzig, nieren- od. halbkreisf., $1-3 \mathrm{~cm}$ br., glatt, später kleiig-schuppig, ockerfarben, verblassend, Fleisch ockerfarben, Rand eingerollt, dann geschweift. St. seitenständig, bis $1 \mathrm{~cm}$ lg., glatt. L. netzadrig verbunden, dicht, ockerfarben. Geschmack erst herb, dann brennend. Herdenweise auf Lbstümpfen, häufig. Fast das ganze Jahr. (Fig. 321.) (Herber K.) L. stipticus (Bulliard).

4. Hutoberfläche glatt od. kleinschuppig (mindestens im Alter.) 5.

Hut unregelmäßig, einseitig, flach trichter- od. halbkreisf., zähfleischig, später fast holzig, $5-8 \mathrm{~cm}$ br., glatt, kahl, hell fleischfarben, dann hellbraun, Fleisch weiß, Rand eingerollt, dann scharf, flach. St. $2-3 \mathrm{~cm}$ lg., grau violett od. hell rötlichbraun, filzig. L. herablaufend, fleischfarben, dann ledergelb. An Birkenstümpfen, besonders in den Vorbergen, zerstreut. S. H. (Fleischfarbener K.) L. carneotomentosus (Batsch).

5. Hutoberfläche kleinschuppig, wenigstens im Alter.

Hüte rasenf., zählederig, \pm fächerf., niedergedrückt, buchtig, blaßrötlich, lederfarbig, von büscheligen Haaren \pm rauh, Rand oft eingerollt. St. sehr kurz, behaart. L. herablaufend, blaß holzfarben. An Stämmen von Lb. u. Nd. nicht häufig. S. H. (Rauher K.)

L. rudis Fries.

6. Hut schief becherf., fast lederig, scherbenfarbig, verblassend, kleinschuppig, Rand eingerollt. St. sehr kurz, glatt. L. herablaufend, blaßgelb, nach hinten verbunden. An Kiefernstämmen, nicht häufig. S. H. (Fig. 322.) (Becher-K.)

L. eyathiformis (Schaeffer). 
Marasmieae.
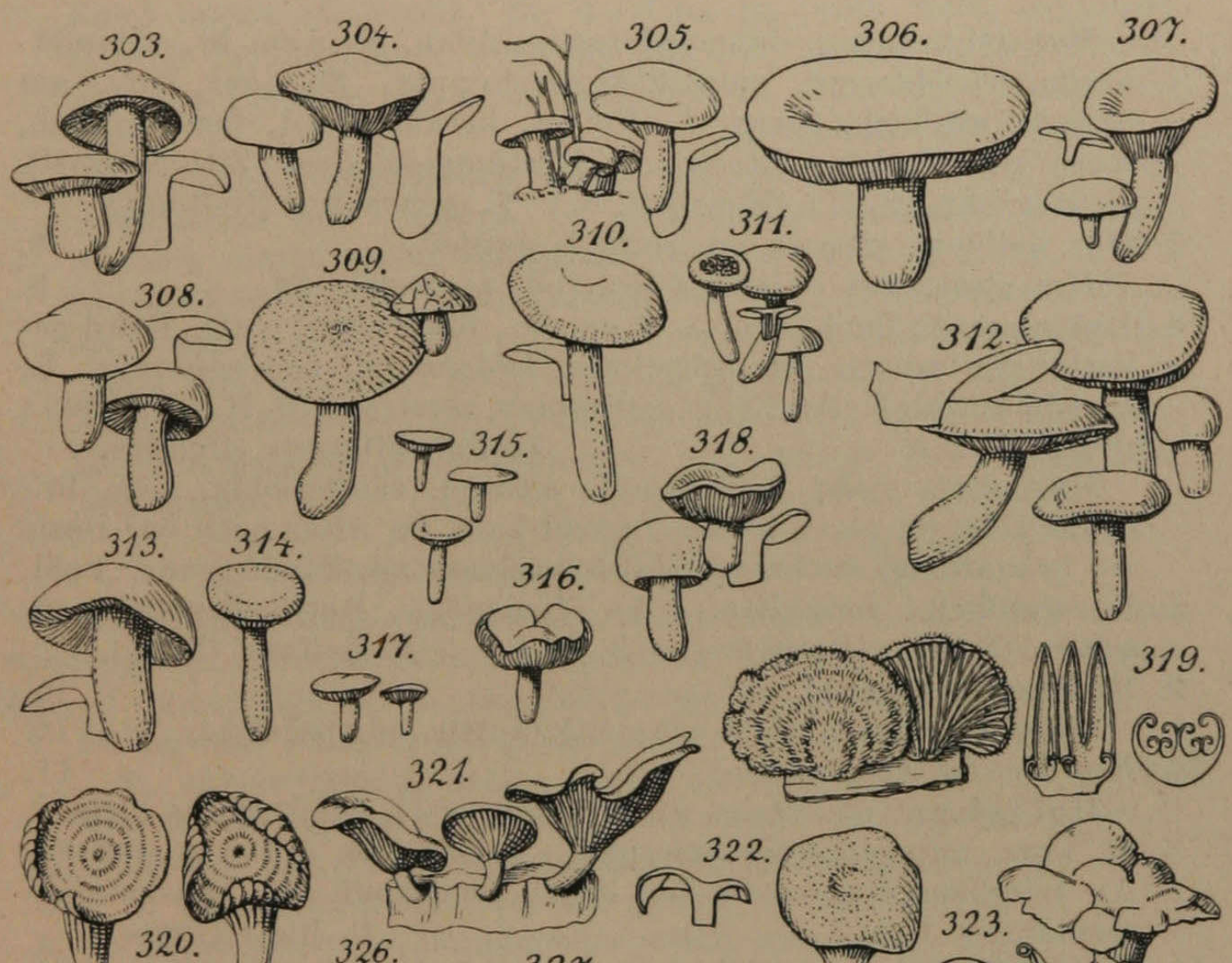

4. A. A 319 .

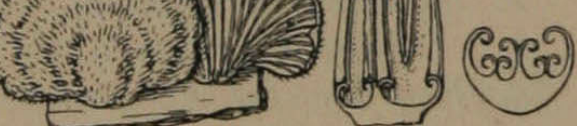

II 320

$\int 326$.

324. (1) $32 \%$ $\sqrt{325 .}$
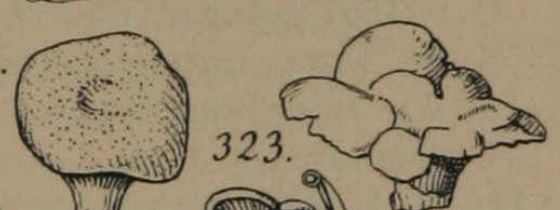

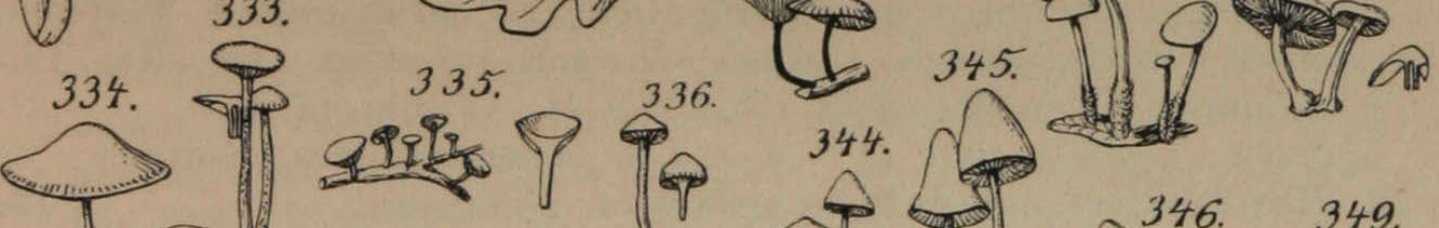
$P$ था 340 . 346.92 Pी

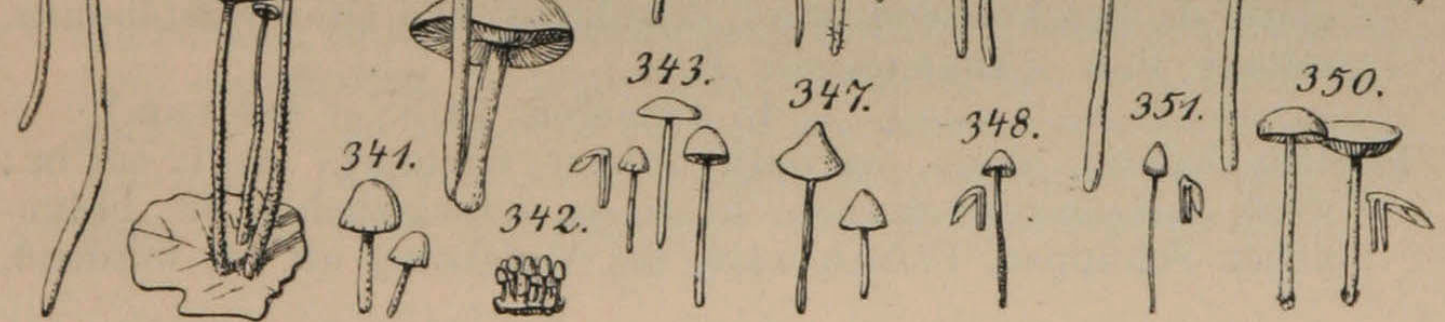


Hut zähfleischig, dann lederartig, dünn, $4-8 \mathrm{~cm}$ br., zimmetbraun, verblassend, zuletzt kleinschuppig. St. sehr kurz, am Grunde weißlich, filzig. L. linienf. herablaufend, fleischrötlich, dann ockerfarben. Rasig an Lbstämmen (bes. Zitterpappel), nicht selten. S. H. (Muschelf. K.) L. conchatus (Bulliard).

7. Hut halbiert, sitzend od. seitlich gestielt.

Hut ganz, mit exzentrischem od. zentralem st.

8. Hut nierenf., flach, zäh, $5-8 \mathrm{~cm}$ br., blaßbraun, glatt, Rand gekerbt gewimpert. St. sehr kurz, fehlend od. seitenständig. L. zerschlitzt, blaß. An Tannenstümpfen, zerstreut. S. H. (Fig. 323.) (Fächerf. K.)

L. flabelliformis (Bolton).

Hut ohrf., meist dachziegelf., sitzend, zähfleischig, $7 \mathrm{~cm}$ br., etwas gelappt, glatt, in der Jugend kahl, im Alter nach der Basis zu braunfilzig, rotbraun, dann verblassend, Rand ganz, kahl. L. weißlich, zerschlitzt. An faulenden Rotbuchenstämmen, selten. S. H. (Bärhaariger K.) L. ursinus (Fries).

9. Hutoberfläche kahl.

10.

Hutoberfläche dunkel schuppig, zottig od. pulverig. 12.

10. Hut rot od. rostfarben.

11.

Hut gelappt od. kraus, zähfleischig, weiß, kahl, etwas klebrig. St. kurz, unregelmäßig, schuppig. L. gezähnt, entfernt stehend. An Lärchenstümpfen in den Alpen, zerstreut. S. (Zusammengespannter K.)

L. jugis (Fries).

11. Hut zähfleischig, gewölbt, dann trichterf., unregelmäßig, glatt, kahl, bla $\beta$, dann braun werdend. St. verlängert, holzig, glatt, L. bla $\beta$ gelblich, gekerbt, zerschlitzt. An bearbeitetem Holz, besonders in Kellern, Zwischenböden, nicht häufig. Gewöhnlich im Dunkeln geweihartig verzweigt mit scharfen bräunlichen Spitzen. Das ganze Jahr. (Fig. 324.) (Strauchiger K.)

\section{L. suffrutescens (Brotero).}

Hut zähfleischig, schlaff, sehr unregelmäßig, trichterf., halbiert u. dütenf., gerollt, $4-8 \mathrm{~cm}$ br. u. hoch, hell gelblich od. schmutzig rötlich, warzig, Rand dünn, wellig. St. $2-6 \mathrm{~cm} \mathrm{lg.,} \mathrm{gefurcht,}$ rötlich, nach unten meist bräunlich. L. herablaufend, weißlich, dann rötlich, gesägt. Geruch schwach anisartig. An alten Lbstämmen u. -ästen, nicht selten. S. H. (Füllhornf. K.)

L. cornucopioides (Bolton).

12. Hutoberseite mit dunkler gefärbten Schuppen.

Hut zähfleischig, gewölbt, dann flach u. zuletzt trichterf., $2-4 \mathrm{~cm}$ br., grubig-runzlig, zuerst blebrig, dann pulverig, schmutzig gelblichweiß od. bräunlich. St. hohl, blaß bräunlich, glatt. L. herablaufend, weiß, zerschlitzt. An alten Ndstämmen, selten. F. S. (Anhängender K.)

L. adhaerens (Alb. et Schwein.).

13. Hut lederig, dünn, vertieft, zuletzt trichterf., $4-12 \mathrm{~cm} \mathrm{br.,}$ wei $\beta$, mit eingewachsenen, haarigen, schwärzlichen od. bräunlichen Schuppen, Fleisch weiß, bei Verletzung oft rot werdend, 
Rand zuerst eingerollt. St. $4-8 \mathrm{~cm} \mathrm{lg.,} \mathrm{voll,} \mathrm{weiß,} \mathrm{schuppig.}$ L. weit herablaufend, weiß od. gelblich, gesägt od. zerschlitzt. An alten Lbstümpfen, nicht selten. S. H. (Fig. 325.) (Gefleckter K.) L. tigrinus (Bulliard).

Hut dick, zähfleischig, dann holzig-lederig, $8-15 \mathrm{~cm}$ br., ockerfarben od. weißlich, in sich dunkel färbende Schuppen reißend, Rand zuerst eingerollt. St. $2-10 \mathrm{~cm} \mathrm{lg.,} \mathrm{voll,} \mathrm{außen}$ filzig 'schuppig. L. herablaufend, weiß od. gelblich, zerschlitzt. An dunklen Orten ist der Hut oft nicht regelmäßig, sondern der ganze Pilz verzweigt sich, wird oft geweihartig u. bis $50 \mathrm{~cm} \mathrm{lg}$. An Kiefernstümpfen im Walde, an bearbeitetem $\mathrm{Holz}$ auf Holzhöfen in Bergwerken, Kellern usw., nicht selten. S. H. (Fig. 326.) (Schuppiger K.)

L. squamosus (Schaeffer).

\section{Gattung: Marasmius Fries (Schwindpilz).}

Fk. meist häutig, zäh, trocken, nicht faulend u. beim Befeuchten wieder auflebend. Hutfleisch von anderer Konsistenz wie der knorpelige od. hornartige St. L. zäh, lederartig, mit ganzer Schneide.

1. St. absolut kahl, meist glänzend.

St. sammethaarig, zottig, filzig, häufig nur bloß oben od. am Grunde, od. aber mehlig bestäubt od. mit abwischbaren Flocken. 9.

2. L. hinten am St. zu einem Ring verwachsen.

L. voneinander frei, am St. \pm angewachsen.

3. St. borstenf., zähe, mindestens unten schwarz.

Hut glockenf., stumpf, faltig-gefurcht, weiß. St. röhrig, glänzend, weißlich od. rötlich-violett, mit knollenf. verdickter, dunklerer Basis. L. dick, weiß. An modernden Stengeln, Ästen, selien. S. H. (Halsband-S.)

M. torquatus Fries.

4. Hut halbkuglig, dann flach gewölbt, in der Mitte eingedrückt, $3-6 \mathrm{~mm}$ br., kahl, hellrotgelblich, oft in der Mitte dunkler. St. haarf., zäh, ganz, schwarzbraun, höchstens an der Spitze blaß. L. 6-8, weiß. Zwischen Gras, zerstreut. S. (Fig. 327.) (Gras-S.)

M. graminum (Libert).

Hut gewölbt, in der Mitte höckrig, dann eingedrückt, strahlig faltig, 5-15 mm br., weißlich, in der Mitte bräunlich. St. borstenf. $3-6 \mathrm{~cm} \mathrm{lg.,} \mathrm{röhrig,} \mathrm{glatt,} \mathrm{glänzend,} \mathrm{unten} \mathrm{schwarz,} \mathrm{nach} \mathrm{oben}$ braun, an der Spitze weiß. L. 12-16, weiß. Myzel pferdehaarartige, schwarze Stränge bildend. An abgefallenen Zweigen, Lb. usw., häufig. S. H. (Fig. 328.) (Rädchenpilz.)

\section{M. rotula (Scopoli).}

5. St. rot od. braun.

Hut fast halbkuglig, dann flach gewölbt, $0,5-1 \mathrm{~cm}$ br., gestreift od. runzlig, rötlichbraun, seltener weißlich. St. zäh, ca. $4 \mathrm{~cm} \mathrm{lg.,}$ hohl, schwärzlich. L. ungleich lg., angewachsen, dem Hut gleichgefärbt. Myzel in Jg., schwarzen, pferdehaarähnlichen Strängen. Auf faulen Blättern, Ästen, Nadeln usw., häufig. Fast das ganze Jahr. (Fig. 329.) (Schildf. S.) M. androsaceus (L.). 
6. Geruchlos.

Hut flach gewölbt, dann ausgebreitet, $1-2 \mathrm{~cm}$ br., glatt, trocken runzlig, weißlich, fleischfarben od. bräunlich. St. röhrig, glänzend, 2-4 cm lg., dunkel rotbraun, nach oben heller. L. angewachsen, weiß. Eßbar. Stark nach Knoblauch riechend. Auf lichten Waldstellen, Heideplätzen, selten an Stümpfen, häufig. S. H. (Fig. 330.) (Mousseron, Lauchpilz.)

\section{M. alliatus (Schaeffer).}

7. Hutoberfläche nicht gestreift, sondern runzlig.

Hut gewölbt, dann ausgebreitet u. genabelt, kahl, gestreift. St. röhrig, hornartig, glänzend, rot, an der Spitze weiß. L. etwas herablaufend, einfach u. anastomosierend, weiß. Auf Blättern u. Nd., selten. S. (Fig. 331.) (Splachnumartiger S.)

M. splachnoides (Hornem.).

8. Hut flach gewölbt, dann ausgebreitet, $1-1,5 \mathrm{~cm}$ br., trocken runzlig, weißlich od. bräunlich. St. hornartig, glatt, hohl, bis $4 \mathrm{~cm}$ lg., rotbraun. L. ausgerandet, angeheftet, weiß. Auf Ästchen u. Wurzeln im Grase, nicht häufig. S. (Schönfüßiger S.)

M. calopus (Pers.).

Hut schwach gewölbt, bald ausgebreitet, $1-1,5 \mathrm{~cm}$ br., runzligfaltig, zuerst hellrötlich, später weißlich mit bräunlicher Mitte. St. $2,5 \mathrm{~cm}$ lg., voll, kastanienbraun, nach oben verdickt u. weißlich. L. 10-12 längere, wenige kürzere, fast herablaufend, weiß. Zwischen Gras u. Moos an Stämmen, nicht häufig. S. H. (Vaillants S.)

M. Vaillantii (Pers.).

9. Rand des Hutes in der Jugend am St. anliegend, gerade. 10.

Rand des Hutes in der Jugend nach innen umgerollt. 14.

10. St. fadenf. schlaff.

St. steif aufrecht.

11. L. von mittlerer Breite, nie faltenf.

Hut gewölbt, dann flach ausgebreitet, 7-11 mm br., kahl, weißlich. St. fadenf., zähe, $3-4 \mathrm{~cm}$ lg., oben weiß, unten kastanienbraun, sehr fein sammethaarig. L. wenige, verschieden lg., dem St. angewachsen, sehr schmal, häufig nur faltenf., weiß. Auf trockenen Blättern u. Blattstielen, häufig. H. (Fig. 332.) (Blattbewohnender S.)

M. squamula (Batsch).

12. Hut gewölbt, in der Mitte schwach papillenf., weiß, kahl, gefurcht u. gefaltet. St. fädig, flockig, später kahl, rötlich, am Grunde meist rotbraun. L. breit angewachsen, sehr entfernt stehend, netzf. verbunden, weißlich. An Blättern, Stielen usw., zerstreut. S. (Zucker-S.) M. saccharinus (Batsch).

Hut flach gewölbt, dann ausgebreitet, $8-15 \mathrm{~mm}$ br., runzlig, am Rande nicht gestreift, kahl, weißlich od. hellbräunlich. St. $3-4 \mathrm{~cm}$ lg., fädig, schwärzlich, nach oben heller, mit sammetartigen, abstehenden, kurzen Härchen besetzt. L. verschieden lg., 
angewachsen, weißlich. Unangenehm riechend. Auf Nd. zerstreut. Fast das ganze Jahr. (Durchbohrender S.)

M. perforans (Hoffm.).

13. Hut glockig, stumpf, im Alter verflacht u. streifig-furchig, ca. $1,3 \mathrm{~cm}$ br., ockergelb. St. zäh, starr, flockig, braun, nach oben blasser u. mehlig, bis $5 \mathrm{~cm} \mathrm{lg.} \mathrm{L.} \mathrm{zahnartig} \mathrm{angewachsen,} \mathrm{gelb,}$ netzig verbunden. Geruchlos. Zwischen Gras in Ndwäldern, selten. S. H. (Fig. 333.) (Holziger S.)

M. cauticinalis (Swartz).

Hut dünnfleischig, glockig, 2-4 cm br., glatt od. unregelmäßig furchig, hellbräunlich, trocken abblassend. Stiel $8-10 \mathrm{~cm} \mathrm{lg.,}$ schwarz, fein sammethaarig, mit nacktem, wurzelndem Grunde. L. frei, bräunlich, dann weißlich. Geruch stark zwiebelartig u. deshalb für Tunken. Zwischen Lb. u. Zweigen in Wäldern, häufig. S. H. (Fig. 334.) (Lauch-S.) M. alliaceus (Jacquin).

14. St. durchgehend knorpelig, nicht faserig.

St. faserig, nur außen mit knorpeliger Rinde.

15. St. verkürzt, nicht wurzelnd, meist voll. L. angewachsen bzw. herablaufend.

St. wurzelnd, stets hohl. L. sich ablösend, frei.

16. St. weiß od. weißlich nach oben hin.

St. kastanienbraun.

18.

17. Hut dünnfleischig, zäh, gewölbt, dann ausgebreitet u. niedergedrückt, gerunzelt, 5-10 mm br., weißlich mit rötlicher Mitte, meist am Rand gestreift. St. $1-2 \mathrm{~cm} \mathrm{lg.,} \mathrm{voll,} \mathrm{weißlich,} \mathrm{nach}$ unten rötlich, kleiig-schuppig. L. angewachsen, weiß. In großen Herden auf abgestorbenen Zweigen, häufig. S. H. (Fig. 335.) (Zweigbewohnender S.)

M. ramealis (Bulliard).

Hut durchscheinend, gewölbt, dann flach und niedergedrückt, furchig-runzlig, $6-8 \mathrm{~mm}$ br., weiß. St. ca. $1 \mathrm{~cm} \mathrm{lg.,} \mathrm{voll,} \mathrm{weißlich,}$ unten rötlichbraun, fein bereift, am Grunde flockig. L. angeheftet, weiß. Wie vor., seltener. S. (Weißer S.)

M. candidus (Bolton).

18. Hut stumpf, flach gewölbt, dann scheibig, zäh, $6-8 \mathrm{~mm}$ br., schwach bereift, hellgelblich mit dunklerer Mitte, Rand gestreift, St. 1-2 cm lg., voll, bla $\beta$, nach unten kastanienbraun, schwach mehlig. L. angewachsen, blaß. An abgefallenen Ästen, zerstreut. S. H. (Fig. 336.) (Verwandter S.)

M. amadelphus (Bulliard).

Hut gewölbt, dann ausgebreitet u. genabelt, ca. $1 \mathrm{~cm}$ br., streifig-furchig, durchsichtig, gelbbraun od. rötlich, trocken verblassend. St. hohl, sammethaarig-bereift, kastanienbraun, $2,5 \mathrm{~cm} \mathrm{lg.,} \mathrm{an} \mathrm{der} \mathrm{Basis} \mathrm{flockig.} \mathrm{L.} \mathrm{angeheftet,} \mathrm{rötlichgelblich.}$ Geruch unangenehm. An faulenden Ästen, selten. S. (Fig. 337.) (Stinkender S.)

M. foetidus (Sowerby).

19. St. in der ganzen Länge bereift, sammetartig.

St. oben kahl, nach unten wollig. 
20. Hut glockig, dann halbkuglig, in der Mitte stumpf bucklig, $1,5-2,5 \mathrm{~cm}$ br., gelbbraun od. fast kastanienbraun, verblassend, zuerst flaumig. St. 4-6 cm lg., trocken gedreht u. stark gestreift, glänzend, sehr fein behaart, rotbraun, unten dunkler, oben heller. L. weiß, mit bräunlichen Haaren bedeckt, frei. Zwischen Lb., nicht selten. S. (Rotstieliger S.) M. erythropus (Pers.).

Hut flach gewölbt, dann ausgebreitet, $2-2,5 \mathrm{~cm}$ br., kahl, ockerfarben, verblassend, trocken runzlig. St. starr, $6-12 \mathrm{~cm} \mathrm{lg.,}$ hellrötlichbraun mit einem feinen, weißlichen, filzigen Überzug bedeckt. L. angeheftet, dann frei, gelblichweiß. In dichten Büscheln auf altem Lb. im Walde, nicht selten. S. (Kleienstieliger S.)

I. achyropus (Pers.).

21. Hut hellfarbig, weißlich, rötlich, gelblich.

Hut ziemlich fleischig, flach gewölbt, schwach genabelt, 1 bis $2,5 \mathrm{~cm}$ br., schwarzpurpurn, später verblassend. St. schwarzpurpurn, 2-8 cm lg., kahl, am Grunde rostrot-striegelig. L. später frei, rötlich. Rasig od, einzeln (dann länger) im Buchenlb., selten. S. (Fig. 338.) (Braunpurpurner S.)

\section{M. fuscopurpureus (Pers.).}

22. Hut flach gewölbt, glänzend, $1-3 \mathrm{~cm}$ br., hellrötlichbraun, dann weißlich, Rand gefurcht. St. $5-8 \mathrm{~cm}$ lg., oben kahl u. blaß, unten rötlich mit weißem zottigen Überzug. L. blaß, später frei. Geruchlos. Im Lb., selten. S. (Häutiger S.)

M. terginus Fries.

Hut halbkuglig, dann flach, $1,5-2,5 \mathrm{~cm}$ br., runzlig, weißlich, in der Mitte oft dunkler. St. $5-8 \mathrm{~cm}$ lg., oben blaß, kahl, unten rötlichbraun, schwach filzig. L. später frei, gelblichweiß. Geruch stark laugenartig. Zwischen Lb., zerstreut. S. H. (Fig. 339.) (Knoblauch-S.)

M. prasiosmus (Fries).

23. Grund des St. nackt.

Grund des St. wollig od. striegelig behaart.

24. Hut fleischig-zähe, kegelf., dann gebuckelt u. ausgebreitet, $9-25 \mathrm{~mm}$ br., kahl, glänzend, braunschwarz bis rußgrau, verblassend. St. voll, $4 \mathrm{~cm} \mathrm{lg.,} \mathrm{nach} \mathrm{oben} \mathrm{verjüngt,} \mathrm{flockig,} \mathrm{weißlich.}$ L. bogig angeheftet, dick, weißlich bis blaßrötlich. Im Moose in Wäldern, namentlich der Gebirge, zerstreut. S. (Pyramiden-S.)

M. pyramidalis (Scopoli).

Hut dünnfleischig, zähe, zuerst kegelf., dann flach, meist in der Mitte stumpfhöckerig, 3-6 cm br., ledergelb bis hellbräunlich verblassend, Rand später gestreift. St. voll, $4-8 \mathrm{~cm} \mathrm{lg.,} \mathrm{gleich-}$ farbig, fein weißzottig, am Grunde nackt. L. frei, heller als der Hut. Speise- u. Suppenpilz. Geruch nelkenartig. Auf Grasplätzen, Triften, Heiden usw., häufig. F. S. H. (Fig. 340.) (Krösling, Herbstmousseron.) M. caryophylleus (Schaeffer).

25. St. nackt, höchstens oben u. unten flaumig od. rothaarig. 26.

Hut flach gewölbt, stumpf, $2-6 \mathrm{~cm}$ br., blaß gelbrötlich, dann ledergelb, Rand gestreift. St. voll, zottig berindet, am 
Grunde striegelig behaart od. wollig (gestiefelt!), gelb, später rötlich, unten gelb od. weiß, 5-8 cm lg., L. angeheftet, dann frei, gelblich od. rötlich. Zwischen altem Lb., nicht selten. H. (Wahrscheinlich ist M. urens (Bulliard) nur eine Form, die ähnlich, nur etwas höher ist und brennenden Geschmack besitzt.) (Gestiefelter S.)

M. peronatus (Bolton).

26. Hut flach gewölbt, $2-3 \mathrm{~cm}$ br., gestreift, schmutzig gelb, trocken blaß. St. später hohl, beidendig verdickt, $8 \mathrm{~cm} \mathrm{lg.,} \mathrm{braunrot,}$ oben heller, flaumig. L. frei, gelb, später verblassend. Nach Knoblauch schwach riechend. Zwischen abgefallenem Lb., zerstreut. S. H. (Zwiebel-S.)

M. porreus Fries.

Hut ziemlich fleischig, zähe, gewölbt-bucklig, dann flach niedergedrückt, $2-4 \mathrm{~cm}$ br., blaßweißlich, glatt. St. kahl, später mit Ausnahme der Basis hohl, am Grunde wie abgebissen, rothaarig. L. angeheftet, weißlich. An Wegen im Grase, selten. S. H. (Fenchel-S.)

M. foeniculaceus Fries.

\section{Unterfamilie: Agariceae.}

Fk. fleischig, seltener häutig, faulend. L. häutig, weich, meist nicht zerbrechlich, leicht spaltbar, weder zerfließend noch milchend, Sporen verschieden gefärbt.

1. Bestimmungsschlüssel der Gattungen nach der Sporenfarbe ${ }^{1}$ ).

A. Sporenpulver tiefschwarz, höchstens mit violettem Schimmer. Membran der Sporen schwarz. 1. Gruppe: Atrosporae.

a) Kein Schleier vorhanden. 1. Coprinarius.

b) Hut mit dem St. anfänglich durch einen

Schleier verbunden.

I. Schleier bald vergehend, Reste höchstens am Hutrand zurückbleibend.

2. Chalymotta.

II. Schleier am St. als Ring zurückbleibend. 3. Anellaria.

B. Sporenpulver dunkelviolettbraun. Membran der Sporen violettod. dunkelbraun. 2. Gruppe: Amaurosporae.

a) Kein Schleier vorhanden.

4. Pratella.

b) Hut mit dem St. anfänglich durch einen

Schleier verbunden.

I. Schleier bald vergehend, nicht als Ring zurückbleibend.

1. Schleier seidenfädig, schnell verschwindend.

\section{Psilocybe.}

1) Ich gebe zwei Bestimmungsschlüssel, wie es Hennings auch getan hat. Der eine nimmt die Sporenfarbe als Haupteinteilungsprinzip und verwertet dann die Hüllenbildung, der zweite dagegen wendet das umgekehrte Prinzip an. 
2. Schleier häutig-flockig, am Hutrande hängend, Hut immer fleischig.

6. Hypholoma.

II. Schleier am St. als Ring zurückbleibend.

7. Psalliota.

C. Sporenpulver rotbraun, gelbbraun, ockergelb. Membran der Sporen trübbraun, gelbbraun, gelb. Inhalt farblos. 3. Gruppe: Phaeosporae.

a) Schleier fehlend.

\section{Derminus.}

b) Schleier vorhanden (einfach od. doppelt).

I. Hülle zart seidenfädig.

1. Sporenpulver u. Sporenmembran trübbraun. Schneide der L. mit charakteristischen Cystiden besetzt.

\section{Inocybe.}

2. Sporenpulver u. Sporenmembran rostod. zimmetbraun. Schneide der L. ohne Cystiden, wenige Arten mit Cystiden.

10. Cortinarius.

II. Hülle häutig od. häutig-flockig.

1. Nur die innere Hülle (Velum partiale) vorhanden, Rest am Hutrand od. als String zurückbleibend.

a) Hülle dünnhäutig, zart, bald verschwindend. Ring fehlt.

11. Naucoria.

$\beta)$ Hülle dickhäutig od. flockig. Mit Ring.

12. Pholiota.

2. Innere u. äußere Hülle (Velum partiale $u$. universale) vorhanden, als Ring $u$. als Schneide u. Flocke auf der Hutoberfläche bleibend.

13. Rozites.

D. Sporenpulver rostrot od. fleischrot. Membran der Sporen hyalin od. hellbräunlich, Inhalt rotbraun. 4. Gruppe: Rhodosporae.

a) Schleier fehlend.

14. Hyporhodius.

b) Nur äußere Hülle (Velum universale) vorhanden.

15. Volvaria.

E. Sporenpulver weiß. Membran u. Inhalt der Sporen farblos. 5. Gruppe: Leucosporae.

a) Schleier fehlend.

16. Agaricus.

b) Irgendeine Hülle vorhanden.

I. Äußere Hülle fehlt, innere vorhanden.

1. Schleier fein seidenfädig, Ring fehlend. 17. Cortinellus.

2. Schleier häutig od. flockig, Ring vorhanden.

a) Sporen dünnwandig. L. herablaufend od. ausgerandet.

18. Armillaria.

$\beta$ ) Sporen dickwandig, L. nicht so, sondern frei od. angeheftet.

19. Lepiota. 
II. Äußere Hülle vorhanden als Scheide an der Stbasis u. als Fetzen auf der Hutoberfläche.

1. Innere Hülle fehlt. Ring fehlt.

2. Innere Hülle vorhanden. Ring vorhanden.

20. Amanitopsis.

21. Amanita.

2. Bestimmungsschlüssel nach der Hüllenbildung.

A. Hut ohne jede merkliche Hülle.
a) Sporen schwarz.
1. Coprinarius.
b) Sporen dunkelviolettbraun.
c) Sporen braun.
4. Pratella.
d) Sporen rötlich.
8. Derminus.
e) Sporen weiß.
14. Hyporhodius.
16. Agaricus.

B. Velum partiale als Schleier (Cortina) ausgebildet, kein Ring am St.
a) Sporen schwarz.
b) Sporen dunkelviolettbraun.
2. Chalymotta.
I. Schleier seidenfädig, bald verschwindend.
5. Psilocybe.
II. Schleier häutig od. flockig, am Hutrande. 6. Hypholoma.
c) Sporen braun.
I. Schleier zart, seidenfädig.
1. Sporenpulver trübbraun. Schneide der L. mit Cystiden besetzt.
2. Sporenpulver rost- od. zimmetbraun. Schneide der L. ohne deutliche Cysti- den.

\section{Inocybe.}
II. Schleier zart, dünnhäutig.
d) Sporen weiß.
10. Cortinarius.
11. Naucoria.
17. Cortinellus.

C. Velum universale fehlt. Velum partiale vorhanden u. als Ring am St. zurückbleibend.
a) Sporen schwarz.
3. Anellaria.
b) Sporen dunkelviolettbraun.
7. Psalliota.
c) Sporen braun.
12. Pholiota.
d) Sporen weiß.

I. Sporen dünnwandig. L. herablaufend od. ausgerandet.

II. Sporen dickwandig. L. frei od. angeheftet, nie herablaufend od. ausgerandet.

18. Armillaria.

19. Lepiota.

D. Velum universale vorhanden, als Scheide am Stgrund u. als Fetzen od. Schuppen auf der Hutoberfläche zurückbleibend.

a) Sporen braun. Velum partiale vorhanden. 13. Rozites.

b) Sporen rötlich. Velum partiale fehlt.

d) Sporen weiß.

15. Volvaria.

I. Velum partiale fehlend.

20. Amanitopsis.

II. Velum partiale vorhanden.

21. Amanita. 


\section{Gattung: Coprinarius Fries (Mistling).}

Ganz ohne Schleier. Sporenpulver schwarz.

1. Hut dünn u. gebrechlich. St. gebrechlich, schlaff, dünn, hohl. (Unterg. Psathyrella Fries.)

Hut ziemlich fleischig, nicht gebrechlich. St. steif, zähe, voll, von einer zähen Rinde bedeckt. (Unterg. Panaeolus Fries.) 7.

2. St. schlaff, gebogen, an der Spitze bereift od. kleiig. 3 .

St. steif, starr, kahl.

3. Rand des Hutes ungekerbt.

Hut eichelf., dann halbkuglig, $1-2 \mathrm{~cm}$ br., hellockerfarben od. rötlichbraun, trocken blaß, mit feinen glänzenden Körnchen besetzt, Rand gekerbt, zuerst mit feinen glänzenden Körnchen besetzt. St. $2-3 \mathrm{~cm}$ lg., weißlich, innen weißflockig, oben gestreift u. kleiig punktiert. L. angewachsen, gelb, dann bräunlich, zuletzt schwarz mit weißer Scheide. Auf fettem Boden in Gärten u. Wäldern, nicht häufig. S. (Fig. 341.) (Gekerbter M.)

\section{c. crenatus (Lasch).}

4. Hut ei-, dann glockenf., $1-2 \mathrm{~cm}$ br., schnell vergänglich, welkend, sehr hell ockerfarben, dann grau, zuerst mit weißlichen, kleiigen Flocken besetzt, dann kahl, Rand furchig-streifig. St. $4-5 \mathrm{~cm} \mathrm{lg.,}$ anfangs kleiig, dann glatt, weiß. L. angewachsen, weiß, dann grau u. schwarz. Herdig am Grunde von Stämmen, auf Waldu. Gartenerde, häufig. F. S. H. (Fig. 342.) (Ausgesäter M.)

C. disseminatus (Pers.).

Hut glockig, stumpf, frisch wässerig durchscheinend, fein gestreift, trocken runzelig, $1-2,5 \mathrm{~cm}$ br., feucht blaugrau, trocken weißlich, ins Rötliche spielend, mit glänzenden Körnchen kleiig bestäubt. St. oben staubig-kleinschuppig, weiß. L. angewachsen, grau, dann schwarz. Auf Grasplätzen, an Wegen, nicht selten. S. H. (Fig. 343.) (Ungeteilter M.)

\section{C. atomatus Fries.}

5. St. ganz kahl, auch am Grunde.

Hut kegelf., $2-3 \mathrm{~cm}$ br., wässerig, feucht grau od. graubraun, trocken weißlich od. blaßgelblich, oft rötlich angehaucht, glatt. St. 8-10 cm lg., kahl, glatt, nur am Grunde mit zottigen Haaren. L. br. angewachsen, grau mit rötlicher od. weißlicher Schneide, dann schwarz. In Gärten, auf Äckern, in Hecken, häufig. F. S. H. (Fig. 344.) (Zierlicher M.)

C. gracilis (Pers.).

6. Hut glocken- od. kegelf., stumpf, sehr gebrechlich, $3-6 \mathrm{~cm}$ br., gelbbräunlich od. ockerfarben, dann graubraun, glatt u. kahl. St. $10-16 \mathrm{~cm}$ lg., weiß, glänzend, kahl. L. schmal angeheftet, ca. $2 \mathrm{~cm}$ br., grau, dann schwarz. In Gärten zwischen Gras u. Lb., zerstreut. S. H. (Fig. 345.) (Kegelhütiger M.)

\section{C. conopileus (Fries).}

Hut glockig, stumpf, kahl, rötlich umbrabraun, trocken verblassend, am Rande fein gestreift. St. kahl, weißlich, $2-14 \mathrm{~cm}$ 
lg. L. angewachsen, rußfarbig-schwärzlich. Auf Grasplätzen, selten. S. H. (Fig. 346.) (Schwärzlicher M.)

7. Hut am Rande mit einer dunkleren Zone. C. subatratus (Fries).

Hut am Rande ungezont.

8. St. über $4 \mathrm{~cm} \mathrm{lg}$.

Hut kegelf., zugespitzt, glatt, glänzend, braunrötlich, um den Rand mit einer schwärzlichen Zone, zuerst am Rande gekerbt. St. $2,5 \mathrm{~cm} \mathrm{lg.,} \mathrm{bereift,} \mathrm{weißlich,} \mathrm{nach} \mathrm{unten} \mathrm{braun} \mathrm{u.} \mathrm{verdickt.}$ L. angeheftet, schwarz werdend. Viehweiden, fetten Grasplätzen, Mist, selten. H. (Fig. 347.) (Zugespitzter M.)

\section{C. acuminatus (Fries).}

9. Hut glockenf., dann halbkuglig, stumpf, kahl, glanzlos, $1-2,5 \mathrm{~cm}$ br., graugelb od. gelbbraun, nahe dem Rande mit einer schmalen, dunkelbraunen Zone. St. $4-8 \mathrm{~cm}$ lg., bla $\beta$, oben weiß bereift. L. angewachsen, rauchgrau, dunkler gefleckt. Auf Mist, Grasplätzen, Triften, häufig. S. H. (Fig. 348.) (Echter M.)

C. fimicola (Fries).

Hut halbkuglig, dann flach, bisweilen mit stumpfem Höcker, 1,5-2 cm br., graubraun, frisch am Rande meist mit dunklerer Zone, später trübrötlichbraun, trocken gelbbraun. St. 4-5 cm lg., anfangs rötlich, seidenglänzend, oben feinkleiig. L. schmal angeheftet, blaßrötlich-, später schwarzbraun, mit weißer Schneide. Sporenpulver schwarz mit braunem Schimmer. Zwischen Gras auf Wiesen u. Wegen, nicht selten. F. S. H. (Fig. 349.) (Heu-M.)

c. foenisecii (Pers.).

10. Oberfläche des Hutes in frischem Zustande klebrig.

11.

Hut glockenf., dann flach gewölbt, $2-4 \mathrm{~cm}$ br., rötlich ockerfarben, in der Mitte dunkler, trocken glänzend, mit scharfem, in der Jugend umgebogenem Rand. St. 5-6 cm lg., ockerfarben, schwach seidenhaarig, oben weißflaumig. L. angeheftet, hellgelblich, dann schwarz bestäubt, mit weißer, welliger Schneide. Zwischen Gras u. Moos auf feuchten Wiesen u. Heiden, nicht häufig. S. H. (Fig. 350.) (Heide-M.) C. ericaeus (Pers.).

11. Hut halbkuglig od. glockenf., dann ausgebreitet, $1-2 \mathrm{~cm}$ br., feucht etwas klebrig, kastanienbraun, trocken glänzend, lederbraun. St. 3-4 cm hoch, blaßbräunlich, weißfaserig. L. hinten sehr br., angewachsen, blaßbräunlich, dann schwarz mit weißer Schneide. Zwischen Moos wie vor. F. S. H. (Zweifarbiger M.) C. dichrous (Pers.).

Hut kegelf., mit warzenf. zugespitztem Scheitel, $1-2 \mathrm{~cm}$ br., frisch klebrig, trocken glänzend, gelb od. fast olivenbraun, Oberhaut abziehbar, Rand eingebogen. St. 6-10 $\mathrm{cm} \mathrm{lg.,} \mathrm{hellgrau-}$ braun, schwach faserig. L. angeheftet, gelb, dann schwärzlich. Zwischen Gras an Wegen, auf fetten Wiesen, häufig. S. H. (Fig. 351.) (Lanzenf. M.)

C. semilanceatus (Fries). 


\section{Gattung: Chalymotta Karst. (Glockenmistling.)}

Hut dünnfleischig, zu Anfang mit dem St. durch einen häutigen Schleier verbunden, dessen Reste als filziger Besatz um Rande zurückbleiben. Ring fehlt.

1. Hutoberfläche glatt u. kahl.

Hut kuglig, dann halbkuglig, schwach gebuckelt, mit netzf. verbundenen, erhabenen Rippen besetzt, glanzlos, fleischfarbenledergelb. St. rötlich purpurn, bereift. L. angeheftet, aschgrauschwärzlich. Auf Mist, selten. S. H. (Netzf. G.)

c. retirugis (Fries).

2. Hut glockenf., oft stumpf genabelt, $1,5-2,5 \mathrm{~cm}$ br., glatt u. kahl, trocken glänzend, grau od. bräunlich, am Rande mit häutigem, weißem, gekerbtem Besatz als Schleierrest. St. 6-10 $\mathrm{cm}$ lg., rötlichbraun, mit flockig-pulveriger, weißer Bekleidung, oben gestreift. L. nach hinten verschmälert, angeheftet, grau, gefleckt, dann schwarz, Schneide weiß. Auf Mist, gedüngten Wiesen, in Gärten, häufig. F. S. H. (Fig. 352.) (Gemeiner G.)

\section{C. campanulata (L.).}

Hut halbkuglig, dann flach gewölbt $u$. ausgebreitet, $2-5 \mathrm{~cm}$ br., graubraun, glatt u. kahl, trocken rissig-schuppig, Schleier schnell verschwindend. St. $6-8 \mathrm{~cm}$ hoch, glatt, hellbräunlich, an der Spitze weiß bereift. L. mit breitem Grunde angewachsen, graubraun, fleckig, später schwarz, Schneide weiß. Auf Mist u. fettem Boden von Gärten u. Äckern, häufig. S. H. (Fig. 353.) (Schmetterlingspilz.)

C. papilionacea (Bulliard).

\section{Gattung: Anellaria Karst. (Ringelpilz.)}

Wie vor. Gattung. Der Schleier als häutiger Ring am zähen St. erhalben bleibend. Oberfläche frisch schleimig od. klebrig.

1. Hut nicht gelb.

Hut zuerst kuglig, dann halbkuglig. $1,5-2,5 \mathrm{~cm}$ br., gelb, trocken glänzend. St. $5-8 \mathrm{~cm} \mathrm{lg.,} \mathrm{hohl,} \mathrm{oberhalb} \mathrm{der} \mathrm{Mitte} \mathrm{mit}$ einem häutigen abstehenden Ring, unterhalb desselben gelblich, klebrig, oberhalb blaß. L. angewachsen, sehr breit, hellgelbbraun, dann schwärzlich, Schneide weiß, gerade. Auf Mist u. gedüngtem Boden, häufig. S. H. (Fig. 354.) (Halbkugliger R.)

A. semiglobata (Batsch).

2. Hut glockenf., mit stumpfem Scheitel, meist $2-3 \mathrm{~cm}$ br., tonfarbig-gelblich od. bräunlich, trocken glänzend. St. $5-11 \mathrm{~cm} \mathrm{lg.,}$ oberhalb der Mitte mit häutigem, weißem Ringe, darunter klebrig, trocken meist mit dunklen, glänzenden Gürteln, am Grunde verdickt. L. angeheftet, hellbräunlich, grau gefleckt, dann schwarz, Schneide weiß. Auf Kuhmist auf Viehweiden, häufig. S. H. (Fig. 355.) (Getrennter R.)

A. separata (L.).

Hut kegelf., dann ausgebreitet, schwach gebuckelt, glatt, 2,5 bis $6 \mathrm{~cm}$ br., aschgrau-schwärzlich, trocken bläulich. St. $5-11 \mathrm{~cm}$ 
hoch, blaß, kahl, mit ringartiger Zone in der Mitte. L. angeheftet, bläulichschwärzlich. Auf Mist u. misthaltigem Boden, häufig. S. H. (Fig. 356.) (Fauldünger-R.)

A. fimiputris (Bulliard).

4. Gattung: Pratella Fries (Wiesenpilz).

Schleier fehlend. Sporenmembran dunkelbraun bis schmutzig. violett, glatt.

1. Hut höchstens bis $2 \mathrm{~cm}$ br.

Hut über $6 \mathrm{~cm}$ br.

2. Hut häutig, kegel- od. glockenf., $10-12 \mathrm{~mm}$ br., gestreift, graubraun, in der Mitte rötlich. St. gebogen, weiß, seidenglänzend, $6 \mathrm{~cm} \mathrm{lg.} \mathrm{L.} \mathrm{angeheftet,} \mathrm{purpur-graubraun.} \mathrm{Gewöhnlich} \mathrm{büschelig}$ an Böschungen, Hohlwegen, Waldrändern, zerstreut. S. H. (Blasser W.)

P. pallescens (Schaeff.).

Hut etwas häutig, glockenf., dann ausgebreitet, stumpf, $2 \mathrm{~cm}$ hoch, kahl, runzlig, frisch durchfeuchtet, schwach glänzend, umbrabraun, trocken blaß. St. steif, glatt u. kahl, bla, $6-8 \mathrm{~cm} \mathrm{lg}$. L. angewachsen, blaß umbrabraun. An alten Baumstümpfen (z. B. Eiche), zerstreut. S. (Stumpfer W.) P. obtusata Fries.

3. Hut fleischig, flach gewölbt, stumpf, 6-11 cm br., glatt, kahl, frişch durchfeuchtet, braun, trocken verblassend. St. hohl, knorpelig, 3-11 cm lg, blaß, kahl. L. abgerundet, angeheftet, weißlich, dann rötlichbraun. Rasig an Stümpfen auf der Erde, nicht selten. S. H. (Fig. 357.) (Kastanienbrauner W.) P. spadicea (Schaeff.)

Hut ziemlich häutig, kegel- bis glockenf.. dann ausgebreitet, schwach gebuckelt, kahl, mehr als $6 \mathrm{~cm}$ br., bis zur Mitte gestreift, kastanienbraun, dann graubräunlich. St. fest, nach oben verjüngt, glänzend, weiß, an der Spitze gestreift, $8-9 \mathrm{~cm} \mathrm{lg.} \mathrm{L.} \mathrm{an-}$ geheftet, braun. An u. bei Stämmen, zerstreut. S. H. (Fig. 358.) (Braungrauer W.)

P. spadiceogrisea (Schaeff.).

5. Gattung: Psilocybe Fries (Kahlkopf).

Hutrand mit dem St. durch einen sehr zarten, seidenfädigen Schleier verbunden, der bald verschwindet. Sonst wie vor. Gatt. 1. St. höchstens bis $2,5 \mathrm{~cm} \mathrm{lg}$.

St. weit über $3 \mathrm{~cm} \mathrm{lg}$.

2. Hut dünnfleischig, fast halbkuglig, dann glockenf., $1-2 \mathrm{~cm}$ br., graubraun, dann ockerfarben, zuerst mit faserigen Schüppchen bedeckt, schimmernd, dann kahl, Rand anfangs eingebogen, mit weißen Fasern besetzt. St. 1,5-2,5 cm lg., hohl, hellbräunlich, seidenglänzend, fädig-faserig, oben weißlich, flockig punktiert. L. angeheftet, grau-, dann umbrabraun mit weißerSchneide. Auf Brandstellen in Wäldern, zerstreut. S. H. (Feder-K.)

P. pennata (Fries).

Hut schwarzrot bis purpurbraun. St. $2,5 \mathrm{~cm}$ lg., kahl, bla 3 kastanienbraun. Sonnenform von P. atrorufa (Schaeff.).

3. St. bräunlich.

Hut häutig, glockenf., gewölbt, dann ausgebreitet, $3-4 \mathrm{~cm}$ br., gestreift, in der Jugend faserig, bläulich, trocken weiß. St. 8 bis Lindau, Kryptogamenflora. I. 2. Aufl. 
$11 \mathrm{~cm}$ lg., weiß, faserig-schuppig, sehr zerbrechlich. L. angewachsen, nach hinten sehr br., purpurschwarz. Auf dem Boden in Wäldern, namentlich im Gebirge, zerstreut. S. H. (Fig. 359.) (Faseriger $\mathrm{K}$.)

P. fibrillosa (Pers.).

4. Rand gestreift.

5.

Hut ziemlich fleischig, halbkuglig, dann flach ausgebreitet, in der Mitte stumpf-höckerig, $2-4 \mathrm{~cm}$ br., rotbraun, trocken lederfarben, glatt, Rand bisweilen fädig befranst. St. $4-8 \mathrm{~cm} \mathrm{lg.,}$ hellbräunlich, flockig, dann glatt, an der Spitze bereift. L. br. angewachsen $u$. etwas herablaufend, schmutzig gelb, dann schwarzbraun. Auf Mist u. gedüngten Wiesen, häufig. F. S. H. (Fig. 360.) (Dungliebender K.)

P. coprophila (Bulliard).

5. Hut ziemlich fleischig, halbkuglig, dann ausgebreitet, $1,5-2,5 \mathrm{~cm}$ br., frisch klebrig, rotbraun, trocken lederbraun, Rand gestreift, anfangs mit feinen, weißen Fäden u. Flocken. St. $3-4 \mathrm{~cm} \mathrm{lg.,}$ bräunlich, faserig, hohl. L. br. angewachsen u. herablaufend, gelbbraun, dann violett-schwärzlich, Schneide weiß. Auf Mist, an Wegen zwischen Gras, häufig. F. S. H. (Fig. 361.) (Aufgeblasener K.)

P. bullacea (Bulliard).

Hut ziemlich fleischig, halbkuglig, stumpf, $8-18 \mathrm{~mm}$ br., kahl, schwarzrot od. purpurbraun, trocken verblassend, Rand fein gestreift. St. bis $6 \mathrm{~cm}$ lg., hohl, weiß-faserig. Waldform auf dem Boden, zerstreut. S. H. (Fig. 362.) (Schwarzroter K.)

\section{P. atrorufa (Schaeff.).}

\section{Gattung: Hypholoma Fries (Schleierkopf).}

Hut fleischig, Schleier als häutige, filzige Fetzen am Hutrande zurückbleibend.

1. Hut, Fleisch u. St. weißlich od. bräunlich, nicht gelb. 2.

Hut, Fleisch u. St. gelb, orangegelb.

2. An Lbstämmen, gelegentlich auch auf Erde.

Hut dünnfleischig, ausgebreitet, mit stumpfem Scheitel, 3 bis $5 \mathrm{~cm}$ br., weißlich, grau od. bräunlich, gerunzelt, mit feinen Flocken besetzt, dann kahl, Rand zuerst weißfilzig. St. bis $12 \mathrm{~cm} \mathrm{lg.,} \mathrm{hohl,}$ weiß, faserig. L. angeheftet, grau, dann dunkler gefleckt u. endlich schwarzbraun. Zwischen Gras u. Moos in Ndwäldern, besonders im Gebirge, selten. S. H. (Langbeiniger S.) H. macropus (Pers.).

3. Hut schwach fleischig, glockig, dann ausgebreitet $u$. stumpf gebuckelt, $6 \mathrm{~cm}$ br., anfang von angedrückten Fasern filzig, dann kahl, fahlgelb, zuletzt grauhellbräunlich, trocken gelbbraun, durchscheinend. St. $10 \mathrm{~cm}$ hoch, hohl, faserig-seidig, schmutzig graubräunlich. L. sich ablösend, bräunlich, dann dunkler, schwarz punktiert. An Baumstämmen, selten auf Erde, zerstreut. S. H. (Sammethaariger S.)

H. velutinum (Pers.).

Hut eif., dann halbkuglig ausgebreitet, $4-9 \mathrm{~cm}$ br., durchfeuchtet, hell ockerfarben, später graubraun, trocken weißlich, Rand anfangs weiß faserig-schuppig, dann kahl, glatt. St. 10 bis 
$11 \mathrm{~cm}$ lg., hohl, weiß, glatt. L. angewachsen, hellrötlichbraun, dann dunkel purpurbraun. In dichten Rasen am Grunde von Stümpfen u. lebenden Lbbäumen, häufig. F. S. H. (Fig. 363.) (Gemeiner S.)

H. appendiculatum (Bulliard).

4. Schleierreste am Hutrand gelb od. weiß.

Hut fleischig, flach gewölbt, stumpf, 2,5-8 cm br., kahl, gelblich, am Rand mit purpurroten Schleierresten. St. fast hohl, $5-8 \mathrm{~cm}$ lg., seidenartig geglättet, blaß. L. angewachsen, graubraun, dann purpurn. An Kiefernstämmen, besonders im Gebirge, nicht selten. S. H. (Rauch-S.)

H. eapnoides (Fries).

5. L. beim jungen Hut schwefel- od. strohgelb.

6.

Hut dickfleischig, flach gewölbt, $5-8 \mathrm{~cm}$ br., gelb, in der Mitte rotgelb, glatt, gegen den Rand zuerst mit hellgelben Schuppen, dann kahl, Rand eingebogen. Fleisch hellgelb. St. $8-15 \mathrm{~cm} \mathrm{lg.,}$ voll, gelblich, nach unten braun, meist verdünnt. L. angewachsen, zuerst weißlich od. graugelb, dann olivenbraun. Meist büschelig an od. bei Baumstümpfen, häufig. S. H. (Fig. 364.) (Ziegelroter S.)

H. lateritium (Schaeff.).

6. Hut dünnfleischig, halbkuglig od. glockenf., $2-3 \mathrm{~cm}$ br., gelb od. rötlichgelb, Rand ziemlich dicht weiß seidenhaarig. St. 3 bis $4 \mathrm{~cm}$ lg., mit weißen, seidenartigen Fasern dicht überzogen, voll. L. blaß strohgelb, dann purpurbraun mit heller Schneide. Geschmack bitter. Auf der Erde an Nd. u. Ästen in Ndwäldern, besonders des Gebirges, zerstreut. S. H. (Berandeter S.)

H. marginatum (Pers.).

Hut fleischig, halbkuglig, dann flach, $3-5 \mathrm{~cm}$ br., schwefelgelb, glatt, in der Mitte rötlichgelb, Rand gelbfaserig, Fleisch gelb. St. $5-15 \mathrm{~cm} \mathrm{lg.,} \mathrm{hohl,} \mathrm{gelb,} \mathrm{faserig,} \mathrm{am} \mathrm{Grunde} \mathrm{oft} \mathrm{zottig.}$ L. angewachsen, schwefelgelb, dann grünlich, zuletzt olivenschwärzlich. Verdächtig. In dichten Rasen an Stümpfen, auf dem Boden, in Gewächshäusern, häufig. F. S. H. (Fig. 365.) (Schwefelkopf.)

H. fasciculare (Hudson).

\section{Gattung: Psalliota Fries (Harfenpilz).}

Hut fleischig, Schleier häutig, am St. in Form eines häutigen od. schuppig-häutigen Ringes zurückbleibend.

1. L. hinten nicht od. wenig verschmälert, dem St. angewachsen.

St. in den Hut übergehend. (Unterg. Stropharia Fr.)

2.

L. hinten abgerundet, frei. St. vom Hut scharf gesondert. (Unterg. Eupsalliota Schroet.)

2. Hut trocken od. klebrig.

Hut flach gewölbt, in der Mitte oft stumpf gehöckert, 3-11 cm br., friseh mit dickem, spangrünem Schleim bedeckt, trocken glänzend, nach der Ablösung des Schleimes gelblich. St. 5 bis $10 \mathrm{~cm}$ hoch, hohl, blaugrün, über der Mitte mit einem schuppighäutigen, abstehenden Ring, unterhalb schuppig od. fädig u. 
zuerst schleimig. L. br. angewachsen, purpurbraun. In lichten Wäldern, Gärten usw. auf der Erde, häufig. S. H. (Fig. 366.) (Grünspanpilz.) P. viridula (Schaeff.).

3. L. in der Jugend irgendwie dunkel gefärbt, niemals weiß. 4.

Hut glockenf., dann ausgebreitet, stark gebuckelt, angedrücktfaserig, feucht schwach klebrig, schmutzig gelblich. St. voll, weiß, 5-8 cm hoch, an der Spitze schwach bereift, am Grunde mit gerandeter Knolle, deren freier Saum scheidig den St. umhüllt. L. weiß, dann bräunlich, fast frei, bauchig. Zwischen faulendem Lb., selten. S. H. (Beschuhter H.)

\section{P. calceata (Schaeff.).}

4. St. weiß od. weißlich.

Hut halbkuglig, dann flach gewölbt, $3-6 \mathrm{~cm}$ br., gelb, mit fast orangefarbener Mitte, schwach klebrig, trocken glänzend mit sparsamen dunkleren, angedrückten Schuppen. St. $8-11 \mathrm{~cm}$ lg., voll, gelbbräunlich, oberhalb der Mitte mit häutigem Ring, darüber fein weißflaumig, darunter fädig-schuppig. L, ausgerandet-angeheftet, grünlichgelb, dann purpurbraun. An abgefallenen Zweigen, besonders in Buchenwäldern, häufig. S. H. (Fig. 367.) (Schuppiger H.) $\quad$ P. squamosa (Pers.).

5. Hut halbkuglig, dann flach gewölbt, $3-5 \mathrm{~cm}$ br., feucht schmierig, trocken glänzend, gelb, verblassend. St. $3-5 \mathrm{~cm}$ hoch, weiß, glatt, Ring weiß. L. angeheftet, zuerst bla $\beta$ violett, dann schwarzbraun. Auf gedüngtem Boden der Wiesen, Gärten, Felder, nicht selten. S. H. (Fig. 368.) (Schwarzsporiger H.)

P. melanosperma (Bulliard).

Hut halbkuglig, dann ausgebreitet, bis $4 \mathrm{~cm}$ br., glatt, kahl, gelb od. etwas grünlich. St. über $8 \mathrm{~cm} \mathrm{lg.,} \mathrm{weißlich,} \mathrm{mit} \mathrm{weißem}$ Ring, darunter flockig, etwas klebrig, innen mit gesondertem Mark ausgefüllt. L. br. angewachsen, blaß, dann umbra- od. olivenbraun. Auf Mist in Wäldern, an Wegen usw., häufig. S. H. (Fig. 369.) (Mist-H.) $\quad$ P. stercoraria (Fries).

6. Hut über $6 \mathrm{~cm}$ br., alles gute Speisepilze.

Hut glockig, dann flach gewölbt, mit stumpfem Höcker, 2 bis $3 \mathrm{~cm}$ br., weißlich, in der Mitte gelblich od. hellrötlich, Rand umgebogen, mit Schleierresten. St. $3-4 \mathrm{~cm} \mathrm{lg.,} \mathrm{weiß,} \mathrm{hohl,}$ Ring weiß. L. rosenrot, dann dunkelbraun. Eßbar, aber der Kleinheit wegen nicht lohnend. Zwischen Gebüsch in Lbwäldern, selten. S. (Rotlamelliger H.)

7. St. voll.

P. rusioph ylla (Lasch).

St. hohl.

8. Hutoberfläche weißlich od. etwas grau od. bräunlich, höchstens mit kleinen Schuppen.

Hut kuglig, zuletzt flach, $10-20 \mathrm{~cm}$ br., in der Mitte glatt, braun, im Umfange mit dicken, braunen, faserigen Schuppen, darunter weißlich od. gelblich. St. voll, mit dickem, br., außen gefeldert schuppigem Ringe. L. blaß, dann dunkelbraun, vom 
Agariceae.

133

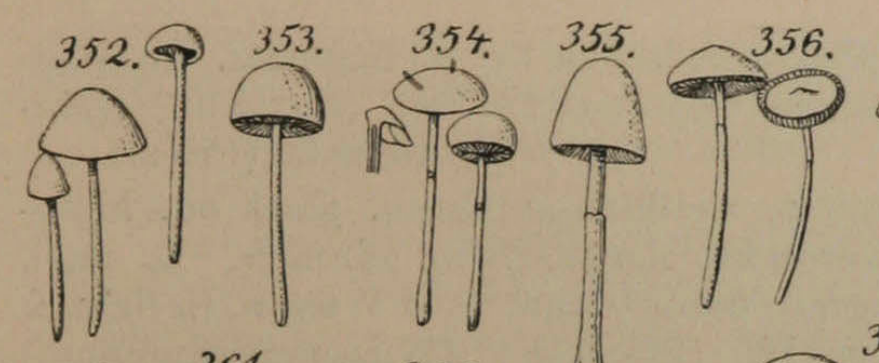
(4) $36 \%$.

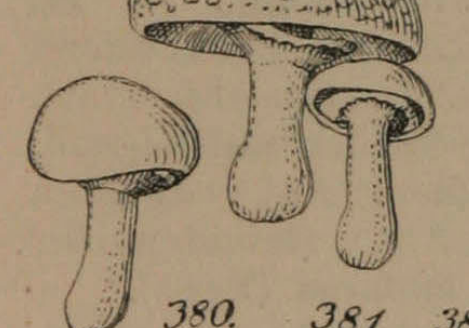

379.

69.

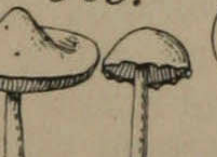

(3)

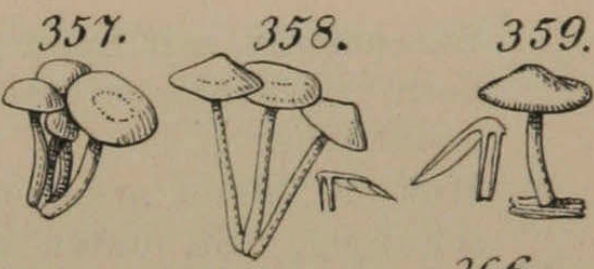

64. $\Rightarrow$

366.
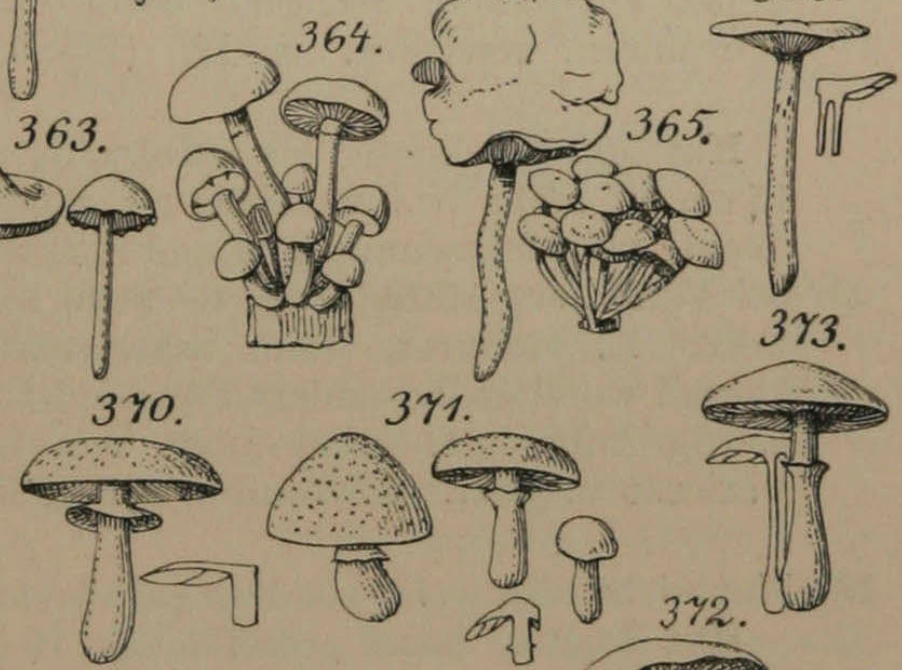

\section{$3 \% 5$.}
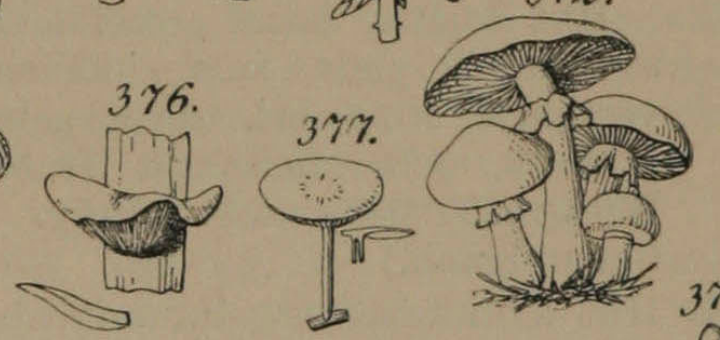

IIN

IU

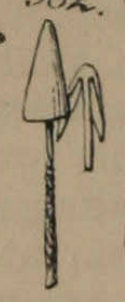

(20)

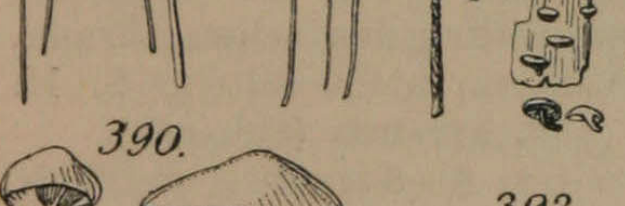

in

386.

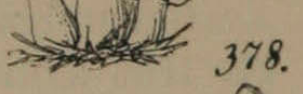

393. 391. 395. 396. 389

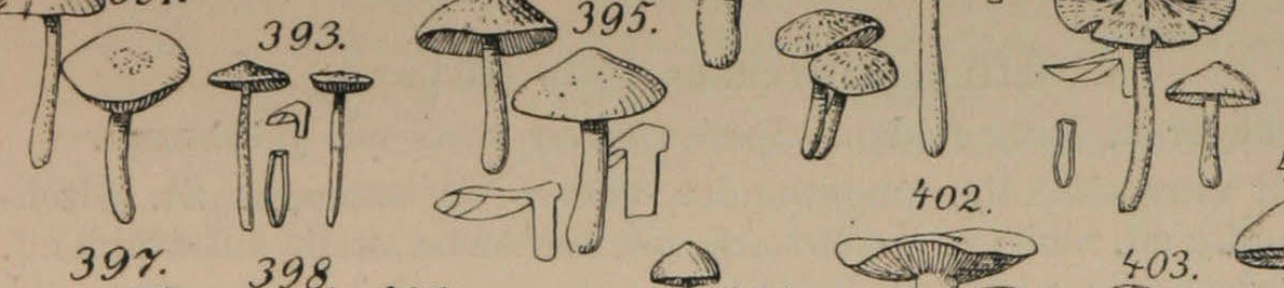

398. 399.400 (301. 
St. entfernt, mit freier Platte zwischen St. u. L.ansatz. In Wäldern, Parkanlagen zwischen Gras, selten. S. (Fig. 370.) (Majestätischer H.)

P. augusta (Fries.)

9. Hut eif., dann ausgebreitet, weißlich-aschgrau, glatt od. kleinschuppig. St. unten verdickt, nackt, Ring einfach. L. nach hinten abgerundet, aschgrau, dann braun. Auf Wiesen, in lichten Lbwäldern, zerstreut. S. H. (Fig. 371.) (Wiesenchampignon.)

\section{P. pratensis (Schaeff.).}

Hut anfangs kuglig bis halbkuglig, dann flach gewölbt, 6 bis $15 \mathrm{~cm} \mathrm{u.} \mathrm{mehr} \mathrm{br.,} \mathrm{weißlich} \mathrm{od.} \mathrm{leicht} \mathrm{bräunlich,} \mathrm{seidenhaarig,}$ flockig od. kleinschuppig, Rand zuerst eingebogen. Fleisch weiß, bei Verletzung rötlich. St. $6-8 \mathrm{~cm} \mathrm{lg.,} \mathrm{weiß,} \mathrm{Ring} \mathrm{dick,} \mathrm{häutig,}$ weiß. L. rosenrot, dann schwarzbraun. An lichten Stellen, überall wo Mist, besonders Pferdemist, liegt, häufig. S. H. Wird häufig kultiviert. (Auf Lohe mit braunschuppigem Hut die Varietät vaporaria Krombh.) (Fig. 372.) (Echter Champignon.)

P. campestris (L.).

10. Hut nicht rein weiß, sondern gelbfleckig od. braunfädig.

Hut kuglig, dann gewölbt, $5-10 \mathrm{~cm}$ br., rein weiß, zuerst seidenartig glatt, später kleinschuppig od. faserig. St. glatt, verjüngt, Ring br., zurückgebogen, dann wieder aufsteigend. L. weiß, später fleischrot bis braunschwärzlich. Auf gedüngten Wiesen, Triften, nicht häufig. S. H. (Fig. 373.) (Kreideweißer Champignon.)

P. eretacea (Fries).

11. Hut zylindrisch-kegelf., mit abgeflachtem Scheitel, dann flach ausgebreitet, $8-15 \mathrm{~cm}$ br., flockig, dann kahl, weiß, bei Berührung gelb, deshalb meist gelbfleckig. Fleisch weiß bleibend. St. $5-14 \mathrm{~cm}$ lg., nach unten verdickt, Ring weiß, aus doppelter Lage bestehend. L. weißlich, dann rötlich bis schwarzbraun. Auf Wiesen, in Gärten, lichten Wäldern, nicht selten. S. H. (Fig. 374.) (Wilder Champignon.) P. arvensis (Schaeff.).

Hut glockig, dann flach ausgebreitet, $6-8 \mathrm{~cm}$ br., weißlich, mit braunen Fäden oder Schuppen besetzt, in der Mitte mit braunem, flachem Höcker. St. 6-10 cm lg., zylindrisch, weiß, Ring dünn. L. rötlich, dann dunkelbraun. In Wäldern, Parkanlagen usw., häufig. S. H. (Fig. 375.) (Waldehampignon.)

P. silvatica (Schaeff.).

\section{Gattung: Derminus Fries (Helmpilz).}

Schleier u. Ring fehlen. Sporenpulver rost- od. gelbbraun.

1. Hut unregelmäßig, umgewendet, fächer- od. zungenf. St. seitenständig od. fehlend. L. fächerf. von der Ansatzstelle ausstrahlend. (Unterg. Crepidotus Fries.)

Hut stets zentral gestielt, regelmäßig.

2. Hüte dachziegelf. übereinander stehend.

Hüte nicht dachziegelf. 
3. Hut fast häutig, $1-3 \mathrm{~cm}$ br., wässerig, ockerfarben, trocken weißlich. St. fehlend. L. weißlich, dann zimmetbraun. Auf faulenden Kiefernstümpfen, selten. S. H. (Treppenf. H.)

D. scalaris (Fries).

Hut ei- od. nierenf., wellig, gallertig-fleischig, $2-8 \mathrm{~cm}$ br., wässerig, gelblich od. gelbbraun, trocken abblassend. St. fehlend od. sehr kurz, seitenständig. L. von Ansatzpunkt ausstrahlend, herablaufend, weißlich, dann zimmetbraun. An alten Baumstümpfen, nicht häufig. F. S. H. (Fig. 376.) (Weicher H.)

D. mollis (Schaeff.).

4. An Ästen, Stengeln, Lb.

Hut ei- od. nierenf., abstehend, 1-4 cm br., dünnfleischig, weich, weiß, seidenhaarig, mit weißem, vergänglichem Filz, später bräunlich, Rand zuerst eingerollt. St. fehlend od. seitenständig. L. bauchig, grau, dann rostbraun. Auf bloßer Erde, meist zwischen Moosen, zerstreut. S. H. (Tröpfelnder H.)

\section{D. depluens (Batsch).}

5. Hut nierenf., abstehend, später umgewendet, fast kreisf., dünnfleischig, $0,5-2 \mathrm{~cm}$ br., weiß, filzig, Rand anfangs eingerollt. St. sehr kurz, dann verschwindend. L. bauchig, weißlich, dann rostbraun. Auf abgestorbenen Kräuterstengeln, Lb., abgefallenen Ästen, nicht selten. F. S. H. (Sitzender H.)

D. sessilis (Bulliard).

Hut nierenf., schlaff, wenig fleischig, $1-1,5 \mathrm{~cm}$ br., flach, glatt, ledergelb, fein zottig. St. seitenständig, nach oben verjüngt, weiß, zottig. L. abgerundet, fast frei, blaß, dann zimmetbraun. An abgefallenen Espenzweigen, selten. S. H. (Gefäß-H.)

D. haustellaris (Fries).

6. Hut fast häutig, zerbrechlich, Rand anfangs gerade. St. zart, zerbrechlich.

Hut meist \pm fleischig, fester, Rand anfangs umgebogen. St. fest, meist faserig.

7. Hut nicht klebrig. (Unterg. Galera Fries.)

Hut klebrig. (Unterg. Pluteolus Fries.)

Hut schwach fleischig, glockenf., dann ausgebreitet, $2-6 \mathrm{~cm}$ br., netzf. durch anastomosierende Adern gezeichnet, durchscheinend violett, am Rande gestreift. St. röhrig, zerbrechlich, weiß. L. bauchig, safran-rostbraun. An alten Rotbuchenstümpfen, zerstreut. S. H. (Fig. 377.) (Netziger H.)

D. reticulatus (Pers.).

8. St. stets ganz kahl.

9.

St. oben od. unten zottig od. filzig. 11.

9. Schneide der L. ganz ungezähnelt.

10.

Hut kegel-glockenf., mit br., scheibenf., glatter, seltener papillenartiger Mitte, 6-11 mm br., am Rande gestreift, fast kastanienbraun. St. $4 \mathrm{~cm} \mathrm{lg.,} \mathrm{glatt,} \mathrm{biegsam,} \mathrm{rostrot.} \mathrm{L.} \mathrm{ange-}$ 
wachsen, zuerst tonfarbig, dann zimmetbraun. Zwischen Moosen u. Gras, selten. S. H. (Fig. 378.) (Gestreifter H.)

D. vittiformis (Fries).

10. Hut glockenf., dann ausgebreitet, stumpf $10-12 \mathrm{~mm}$ br., feucht durchscheinend-gestreift, zimmetbraun, trocken kahl, ledergelb. St. $4 \mathrm{~cm}$ lg., biegsam, kahl. L. angewachsen, zimmetbraun. Zwischen Moosen u. Gras, besonders an Brandstellen im Walde, zerstreut. H. (Fig. 379.) (Gras-H.) D. sparteus (Fries.)

Hut kegelf. od. ellipsoidisch, stumpf, dann glockenf., $1-3 \mathrm{~cm}$ br., frisch durchfeuchtet, ockerbraun, am Rand gestreift, trocken heller, glatt. St. 6-11 cm lg., gleichfarbig, schwach glänzend. L. angewachsen, zimmetbraun. Zwischen Gras auf Schutt, in Gärten, auf Mist, in Wäldern, häufig. F. S. H. (Fig. 380.) (Zarter H.)

D. tener (Schaeff.).

11. L. an der Schneide gezähnelt od. gekerbt.

L. an der Schneide nicht gezähnelt od. gekerbt.

12. Hut wässerig, stumpf kegelf. od. glockig, dann ausgebreitet, $0,5-1,5 \mathrm{~cm}$ br., honiggelb od. gelbbraun, trocken ockerfarbig u. glatt, Rand gestreift. St. $2-8 \mathrm{~cm} \mathrm{lg.,} \mathrm{hohl,} \mathrm{an} \mathrm{der} \mathrm{Spitze}$ leicht honiggelb, glatt, am Grunde der Unterlage angeheftet $u$. weißzottig. L. angeheftet, blaß, dann zimmetbraun. (St. rostrot var. rubiginosus [Pers.].) Zwischen Moos u. Gras auf Wiesen, in Wäldern, häufig bis in die Alpen. S. H. (Fig. 381.) (Moos-H.)

\section{D. hypni (Batsch).}

Hut spitz-kegelf., dann ausgebreitet, genabelt, $1-2 \mathrm{~cm}$ br., olivenfarbig, am Rand durchsichtig-streifig, oft zerschlitzt. St. 6- $11 \mathrm{~cm}$ lg., schmutzig weißbräunlich, am Grunde etwas verdickt, flockig u. mit kurzem, wurzelartigem Fortsatz. L. angeheftet, lange rein weiß, dann braunrot. An feuchten, schattigen Waldplätzen, besonders im Gebirge, nicht häufig. S. H. (Rabenhorsts H.)

D. Rabenhorstii (Fries).

13. Hut kugel-, dann spitz glockenf., $8-16 \mathrm{~mm}$ br., feucht ockerbraun u. gestreift, trocken weißlich od. hellockerfarben, glatt. St. 4-6 cm lg., am Grunde schwach verdickt, an der Spitze weißflockig, braun. L. angewachsen, gelblich zimmetbraun. Herdenweise an alten Kiefernstümpfen u. zwischen Lb. S. H. (Spitzer H.)

D. spiculus (I Lasch).

Hut ellipsoidisch, dann kegelf., stumpf, $2-3,5 \mathrm{~cm}$ br., frisch durchfeuchtet, ockerbraun, am Rande dicht gestreift, trocken runzlig. St. $6-8 \mathrm{~cm}$ lg., ockerbraun, wei $\beta$ bereift, am Grunde verdickt u. weißfilzig, trocken gestreift. L. dunkelrostbraun. Herdenweise zwischen Lb., auf Dünger, auf Wiesen usw., nicht häufig. H. (Fig. 382.) (Ziegelfarbiger H.)

D. lateritius (Fries).

14. Hut \pm fleischig, St. ziemlich fest, mit äußerer fester Rinde. (Unterg. Simocybe Karst.) 
Hut fleischig, St. flêischig, faserig. (Unterg. Hebeloma Fries.)

15. An Stümpfen, auf Rinde vorkommend.

Auf der bloßen Erde, zwischen Moos, Nd., auf Mist. 17.

16. Hut halbkuglig, später in der Mitte niedergedrückt, $0,5-1 \mathrm{~cm}$ br., zimmetbraun, filzig-runzlig. St. $1 \mathrm{~cm} \mathrm{lg.,} \mathrm{gekrümmt,} \mathrm{voll,}$ braun, am Grunde weißfilzig. L. zimmetbraun, Schneide hell. An der Rinde von Bäumen, wie Apfel, Kiefer, gesellig u. fast horizontal abstehend, ziemlich selten. H. W. (Fig. 383.) (Wagerechter $\mathrm{H}$.)

D. horizontalis (Bull.).

Hut halbkuglig mit stumpfem Höcker, $2-3 \mathrm{~cm}$ br., glatt, glänzend, dunkelgelb, stellenweise purpurfleckig. Fleisch gelb. St. $2-3 \mathrm{~cm} \mathrm{lg.,} \mathrm{gelb,} \mathrm{oben} \mathrm{weißlich} \mathrm{bereift.} \mathrm{L.} \mathrm{angeheftet,} \mathrm{gelb-}$ lichgrau, dann rostbraun. An alten Erlstümpfen in feuchten Wäldern, zerstreut. S. H. (Schimmernder H.)

D. micans (Fries).

17. St. im ganzen gelb od. gelblich.

Hut glockenf., dann flach ausgebreitet, $2-4 \mathrm{~cm}$ br., feucht dunkelpurpurbraun mit gelbem Rand, fein bereift, trockèn gelblich. St. schwarzviolett, nach oben rötlich, fein bereift, $3-6 \mathrm{~cm}$ lg., nach oben verdickt. L. locker angeheftet, weißlich, dann gelb od. rötlich. Geruch gurkenartig, bei faulenden Exemplaren nach Heringslake. Zwischen Moos, Nd. in Wäldern u. Waldsümpfen, selten. S. H. (Fig. 384.) (Gurken-H.)

D. cucumis (Pers.).

18. Hut flach gewölbt, stumpf, $1-2,2 \mathrm{~cm}$ br., glatt, kahl, durchfeuchtet, wachsgelb, trocken ockergelb. St. $2-3 \mathrm{~cm} \mathrm{lg.,} \mathrm{kahl,}$ gelb, am Grunde rostbraun. L. angewachsen, zimmetbraun. Im Grase in lichten Ndwäldern, auf Hügeln, selten. S. H. (ZwergH.)

D. pumilus (Pers.).

Hut halbkuglig gewölbt, dann flach, $1,5-4 \mathrm{~cm}$ br., glatt, glänzend, gelblichbräunlich, trocken runzlig. St. $4-6 \mathrm{~cm} \mathrm{lg.,}$ zäh, später hohl, am Grunde verdickt, gelblich. L. angewachsen, ockerfarben, dann kastanienbraun. Geruch u. Geschmack nach frischen Gurken. Auf Mist, gedüngtem Boden in Gärten, Wiesen, an Wegen, häufig. F. S. H. (Fig. 385.) (Halbkugliger H.)

D. semiorbicularis (Bull.).

19. Hutoberfläche kahl.

Hut fleischig, flach ausgebreitet, mit stumpfem Scheitel, 4 bis $7 \mathrm{~cm}$ br., weiß, später gelblich, seidenhaarig-faserig, trocken. St. voll, $2,5-5 \mathrm{~cm} \mathrm{lg.,} \mathrm{weiß,} \mathrm{kahl,} \mathrm{gestreift.} \mathrm{L.} \mathrm{angeheftet,}$ weißlich, später braun bestäubt. Verdächtig. In Ndwäldern, unter Gebüschen, zerstreut. S. H. (Flieder-H.)

D. sambucinus (Fries).

20. Hut flach gewölbt, stumpf, wellig gebogen, $6-8 \mathrm{~cm}$ br., kahl, blaßrot, Rand blasser, Fleisch weiß. St. voll, $2,5 \mathrm{~cm} \mathrm{lg.,} \mathrm{weiß,}$ leicht bereift. L. ausgerandet $u$. frei, weiß, dann fleischfarben 
bis rostbraun. In Lbwäldern, Hecken, nicht selten. S. H. (Abgestutzter $\mathrm{H}$.)

D. truncatus (Schaeff.).

Hut \pm dickfleischig, gewölbt, dann abgeflacht, $4-6 \mathrm{~cm}$ br., schwach klebrig, blaß od. gelblich-lederfarben, in der Mitte meist matt rotbräunlich, Rand anfangs eingebogen. St. $5-8 \mathrm{~cm} \mathrm{lg.,}$ später hohl, flockig-schuppig, weiß, oben weiß punktiert, unten verdickt. L. schwach angeheftet, abgerundet, weißlich, dann wässerig zimmetbraun, Schneide weiß. Meist herdenweise in Wäldern, im Gebüsch, häufig. F. S. H. (Fig. 386.) (Krustenf. H.)

D. crustuliniformis (Bull.).

\section{Gattung: Inocybe Fries (Faserkopf).}

Hut fleischig. Schleier spinnwebfädig. St. fest. L. angeheftet od. frei, an der Schneide, oft auch auf der Fläche mit charakteristischen Cystiden besetzt.

1. Sporen eckig oder sternf., strahlig. (Unterg. Asterosporina Schroet.)

Sporen ellipsoidisch od. eif., glatt. (Unterg. Euinocybe Hennings.)

2. Hutoberfläche stets trocken, faserig od. schuppig.

Hut flach dann in der Mitte niedergedrückt, $1-3 \mathrm{~cm}$ br., frisch etwas klebrig-schleimig, trocken weißlich, seidenglänzend, mit weißen, anliegenden Härchen, am Rande striegelhaarig. Fleisch hellbräunlich. St. $2-3 \mathrm{~cm}$ lg., voll, rötlichbraun, weißfaserig, oben kleinschuppig. L. etwas herablaufend, lehm-, später rostbraun. Zwischen Lb. u. Moos in Wäldern, nicht selten. S. H. (Fig. 387.) (Haariger F.) I. tricholoma (Alb. et Schwein.).

3. Hutoberseite rötlich- od. trübbraun.

Hutoberseite umbrabraun od. grau.

4. Hut halbkuglig od. glockenf., dann flach mit schwach warzenf. Mitte, $0,5-1,5 \mathrm{~cm}$ br., rötlichbraun, anfangs durch dichte, zottig. filzige Fäden fast weißlich, später schuppig, schwach gezont, in der Mitte kahl, braun. St. 1-2 em lg., voll, hellbraunrot, weißflaumig, am Grunde schwach verdickt u. weißzottig. L. leicht angewachsen, dann frei, hellgelblich, dann gelbbraun, Schneide weiß. An Baumstümpfen, auf dem Boden, zwischen Moos in Lbwäldern, zerstreut. S. H. (Fig. 388.) (Räudiger F.)

\section{I. scabella (Fries).}

Hut flach gewölbt, in der Mitte meist stumpfhöckerig, 5-7 cm br., trübbraun, weichfaserig, sparrig-schuppig. St. $4-7 \mathrm{~cm}$ lg., voll, trübbraun, grobfaserig. L. abgerundet-angeheftet, bla $\beta$, dann trübbraun, Schneide wellig. An Stämmen, zwischen Moos, an sumpfigen Stellen in Ndwäldern, zerstreut. S. H. (Zurückgebogener F.)

I. relicina (Fries).

5. Hut halbkuglig, dann ausgebreitet, flachhöckerig, $1-2 \mathrm{~cm}$ br., umbrabraun, dann heller, mit sparrig abstehenden, dann mehr niedergedrückten Schuppen. St. 2-4 cm lg., bräunlich, schwach 
schuppig, oben weiß bereift. L. fast frei, lehm- dann zimmetbraun, Schneide weiß. In Lb.-, besonders Buchenwäldern, nicht selten. S. H. (Fig. 389.) (Wolliger F.) I. lanuginosa (Bull.).

Hut gewölbt, dann ausgebreitet, stumpf, $2-3 \mathrm{~cm}$ br., flockigfaserig, etwas schuppig, durchfeuchtet, umbrabraun, dann grau. St. voll, $2-4 \mathrm{~cm}$ lg., gleichfarbig, flockig-faserig. L. angewachsen. graubräunlich, dann rostfarbig. Auf Sandboden in Ndwäldern, an der Meeresküste, zerstreut. S. H. (Meer-F.)

\section{I. maritima (Fries).}

6. Hutoberfläche glatt, höchstens seidenhaarig, feucht klebrig. 7 .

Hutoberfläche trocken, faserig, später seidenhaarig, rissig od. schuppig.

7. Hut blaßgelb, bräunlich od. weißlich.

Hut glockig, dann ausgebreitet, stumpfhöckerig, ziegelrot. St. voll, $6 \mathrm{~cm}$ lg., weißlich, flockig-schuppig. L. blaßbräunlich, dann zimmetbraun, Schneide weiß. Geruch schwach. In Ndwäldern, selten. S. H. (Fester F.) I. firma (Pers.).

8. Hut rund, seidenhaarig.

Hut dickfleischig, flach gewölbt, bisweilen in der Mitte stumpfhöckerig, 2,5-8 cm br., kahl, weißlich od. ledergelb, Rand zuerst eingebogen. St. 6-12 cm lg., voll, weiß, faserig-chuppig, oben wei $\beta$ punktiert, am Grunde knollig, Schleier deutlich, seidenhaarig. L. weißlich, dann bräunlich bis zimmetbraun, Schneide weiß. Geruch u. Geschmack rettichartig. Giftig. In Wäldern u. Gebüsch, häufig. F. S. H. (Fig. 390.) (Widerlicher F.)

I. fastibilis (Fries).

9. St. von Anfang an od. später hohl.

10.

Hut fleischig, flach kegelf., dann ausgebreitet-nabelf., seidenhaarig, in der Mitte glatt, kastanienbraun, $4-8 \mathrm{~cm}$ br. St. nicht hohl, fiedrig-schuppig, glatt, weinrot, an der Spitze blaß, $5-8 \mathrm{~cm}$ lg., $1-1,5 \mathrm{~cm}$ dick. Fleisch weiß, an der Stielbasis weinrot, von getreideartigem Geruch. L. gedrängt, hinten bauchig angeheftet, fast frei, erst weiß, dann bräunlich bis braun. Sporen fast nierenf., hell goldbraun. Giftig. In Ndwäldern u. Gebüschen, selten. S. H. (Getreide-F.)

I. frumentacea (Bull.).

10. Hut kegelf.-glockig, dann flach, in der Mitte etwas höckerig, 2,5-6 cm br., gelbbraun, am Rande anliegend seidenfaserigschuppig. St. $3-6 \mathrm{~cm}$ lg., später hohl, faserig, gelblichweiß, unten u. innen braun. L. fast frei, weißlich, dann hellbraun, Schneide weiß. Zwischen Gras auf Wiesen u. in Hecken, selten. F. (Fig. 391.) (Fellwechselnder F.) I. versipellis (Fries).

Hut flach gewölbt, dann ausgebreitet, $2-6 \mathrm{~cm}$ br., blaßgelb, in der Mitte dunkler, von klebrigen Papillen punktiert, am Rande seidenhaarig, dann kahl. St. 6-11 cm lg., hohl, blaß, an der Spitze weiß bereift, dann bräunlich. L. bogig angeheftet, blaß, dann kastanienbraun. In Gebirgswäldern, nicht selten. H. (Punktierter F.)

I. punctata (Fries). 
11. Hutoberfläche rissig od. zerschlitzt, Schuppen anliegend, nicht abstehend.

Hut flach gewölbt, stumpfhöckerig, $2-3 \mathrm{~cm}$ br., abstehend, haarig-schuppig, trübbraun, Fleisch gelblichweiß. St. bald hohl, dünn, faserig u. schuppig, an der Spitze oft blaßviolett, kleiig. L. bogig angeheftet, blaß, dann trübbraun. Geschmack schwach süßlich. In Ndwäldern bis ins Gebirge, zerstreut. F. S. (Fig. 392.) (Bittersüßer F.)

I. dulcamara (Alb. et Schwein.).

12. Hutoberfläche nicht rissig, geglättet od. angedrückt schuppig, in der Mitte glatt.

Hutoberfläche rissig od. schuppig od. faserig zerschlitzt. 14.

13. Hut kegelf., dann ausgebreitet, spitzig-höckerig, $2-4 \mathrm{~cm}$ br., seidenglänzend, mit anliegenden seidenartigen Fasern, hellviolett, auch reinweiß od. bräunlich. St. voll, $4-6 \mathrm{~cm} \mathrm{lg.,} \mathrm{gleichfarbig}$ od. weiß, seidenglänzend, an der Spitze weißmehlig. L. angeheftet, weißlich, dann schmutzig lehmfarben, Schneide weiß. Geruch erdartig. Verdächtig, In Wäldern, unter Gebüsch im Grase, häufig. S. H. (Erdblättriger F.) I. geoph ylla (Sow.).

Hut flach gewölbt, schwach gebuckelt, $2,5 \mathrm{~cm}$ br., angedrückt faserig od. schuppig, braun, olivenfarben, verblassend. Fleisch wei $\beta$, stark riechend. St. voll, $6-8 \mathrm{~cm} \lg$., bla $\beta$, kahl, oben schwach bereift. L. frei, gelblichweiß, dann olivenfarbig. An feuchten Stellen in Ndwäldern, zerstreut. S. H. (Fig. 393.) (Lichtfliehender F.)

I. lucifuga (Fries).

14. St. weißlich, weiß, gelblich, nicht braun.

Hut halbkuglig od. kegelf., stumpfhöckerig, dann ausgebreitet, $2-3 \mathrm{~cm}$ br., trüb ockerfarben bis braun, mit dichten, filzigen, erst später etwas abstehenden Schuppen. St. $3-5 \mathrm{~cm} \mathrm{lg.,} \mathrm{voll,}$ braun, innen rötlich. L. angeheftet, weißlich, dann trübbraun, Schneide weiß. Auf Sand in Heiden, an Wegen, in Wäldern, häufig. F. S. H. (Kammartiger F.) I. eristata (Scopoli).

15. St. bei Berührung od. Verletzung sich verfärbend.

St. die Färbung nicht ändernd.

16. Hut fleischig, flach gew ölbt, dann flach ausgebreitet, $2-4 \mathrm{~cm}$ br.,mit eingewachsenen, filzigen Haaren, gelblichweiß, dann gelbbraun, in der Mitte dunkler. St. später hohl, $3,5-5,5 \mathrm{~cm}$ lg., weißlich, seidenfaserig, bei Berührung schmutzig rotbräunlich. L. frei, weißlich, dann rötlich bis hellzimmetbraun. Geruch süßlich, Geschmack schwach salzig. Zwischen Gras u. Moos auf Grasplätzen, selten. S. H. (Fig. 394.) (Bongards F.) I. Bongardi (Weinmann).

Hut kegelf., dann flach ausgebreitet, stumpfhöckerig, $4-7 \mathrm{~cm}$ br., braun, dann blaß ockerfarben, angedrückt faserig-schuppig, Fleisch wei $\beta$, blutrot werdend. St. voll, $5-6 \mathrm{~cm} \mathrm{lg.,} \mathrm{grobfaserig,}$ weiß, bei Verletzung blutrot werdend. L. leicht angeheftet, weißlich, dann trübbraun, Schneide weiß. Geruch obstartig. In sandigen Wäldern, auf Feldern, zerstreut. S. (Fig. 395.) (Birn-F.)

I. piriodora (Pers.). 
17. Hutoberfläche rissig.

Hutoberfläche schuppig od. faserig, nicht rissig.

18. Hut glocken- od. kegelf., $3-6 \mathrm{~cm}$ br., seidenhaarig-faserig, lederbraun, grob faserig, in den Rissen gelblichweiß, Rand scharf, später oft rissig-lappig. St. voll, $2-6 \mathrm{~cm}$ lg., kahl, weißlich od. gelblich, oben weißkleiig, am Grunde knollig. L. frei, hell gelbbraun, dann trübbraun, Schneide weißlich. Geruch laugenartig. Giftig. In Gärten, Gebüsch, an Wegen, häufig. S. H. (Fig. 396.) (Eingerissener F.)

I. rimosa (Bull.).

Hut kegel- od. glockenf., 2,5-3 cm br., grobfaserig, lederbraun, rissig. St. $4-6 \mathrm{~cm}$ lg., dann hohl, weißlich od. gelblich, faserig, an der Spitze weiß bereift. L. frei, wei $\beta$, dann trübbraun, Schneide weiß. Geruchlos. Zwischen Moos in Wäldern, selten. S. H. (Aufgerissener F.)

I. descissa (Fries).

19. Hut kegelf., dann gewölbt, stumpfhöckerig, $4 \mathrm{~cm}$ br., trübbraun, mit angedrückten faserigen Schuppen. St. $4 \mathrm{~cm} \mathrm{lg}$., voll, seidenfaserig, weiß. L. angeheftet, grau-, dann rostbraun. In Wäldern, zerstreut. S. H. (Fig. 397.) (Rauher F.)

I. scabra (Flor. dan.).

Hut flach glockenf., stumpfhöckerig, $2-3 \mathrm{~cm}$ br., ockerfarben, angedrückt-faserig, in der Mitte schwach schuppig. St. voll, $3-5 \mathrm{~cm}$ lg., bla 3 , dann dunkler, faserig, oben fein weißflaumig punktiert. L. angeheftet, schmutzig lehmfarben, dann zimmetbraun, Schneide.weiß. Zwischen Moos in Wäldern, selten. S. H. (Sich häutender F.)

I. deglubens (Fries).

\section{Gattung: Cortinarius Fries (Schleierpilz).}

Hut \pm fleischig. Schleier (Cortina) in der Jugend St. u. Hut verbindend, am Hutrand als Fäden, am St. als ringartige od. schuppige Bekleidung zurückbleibend. L. an der Schneide ohne charakteristische Cystiden. Sporen glatt od. punktiert ${ }^{\mathbf{1}}$ ).

\section{Bestimmungsschlüssel der Untergattungen.}

1. Hut, St., Schleier niemals klebrig-schleimig.

Hut, St., Schleier od. nur der Hut klebrig-schleimig.

2. Hutfleisch durchfeuchtet.

Hutfleisch ganz trocken.

4.

3. Hut dünnfleischig, mit durchscheinender Oberfläche, beim Eintrocknen die Farbe verändernd, kahl od. weißfaserig, St. kahl. Unterg. Hydrocybe Fries.

1) Die Bestimmung der Arten dieser Gattung sowie die Unterscheidung von anderen Gattungen, wie Inocybe, Derminus, Naucoria usw. ist nicht leicht. Frisches, möglichst alle Altersstadien umfassendes Material ist für die sichere Bestimmung hier die Vorbedingung. Man achte hier ganz besonders auf die Schleierverhältnisse, die bei den einzelnen Untergattungen nur geringe, kaum in Worte zu fassende Unterschiede besitzen. 
Hut dünnfleischig, kahl od. weißfaserig, St. unterhalb des seidenfaserigen, weißen Schleiers mit ringf. od. schuppiger $\mathrm{Be}$ kleidung. Unterg. Telamonia Fries.

4. Hut dünnfleischig, zuerst seidig-zottig, später kahl, St. gleichmäßig dick, außen fester. Schleier seidenfädig, seltener als Gürtel den St. umgebend. Unterg. Derm ocybe Fries.

Hut fleischig, schuppig od. faserig, St. dick, fleischig. Schleier einfach, fädig. Unterg. In olom a Fries.

5. Der ganze Pilz in der Jugend von klebrigem Schleim überzogen. Schleier einfach, fädig. Unterg. Myxacium Fries.

Hut fleischig, Oberfläche klebrig-schleimig, St. trocken, derb. Schleier feinfädig. Unterg. Phlegmacium Fries.

\section{Untergattung: Hydrocybe Fries.}

1. Hut dünnfleischig, kegelf., dann ausgebreitet, in der Mitte gebuckelt, Rand gerade, St. dünn, zylindrisch od. nach unten verjüngt.

Hut ziemlich dickfleischig, Rand anfangs umgebogen. St. dick, nach unten breiter.

2. St. weiß.

St. violett od. rötlich.

St. gelblich, ockerfarben bis bräunlich.

3. Hut kegelf., dann gewölbt u. stumpf, $5-7 \mathrm{~cm}$ br., glatt, kahl, tonfarbig. St. knorpelig, steif, wurzelnd, nackt, kahl, weiß, $8 \mathrm{~cm}$ u. länger, nach unten etwas verjüngt. L. angewachsen $u$. etwas herablaufend, dunkel zimmetbraun. In Ndwäldern, besonders im Gebirge, selten. S. H. (Fig. 398.) (Starrer S.)

C. rigens (Pers.).

Hut kegelf., dann ausgebreitet, stumpfhöckerig, $2-3 \mathrm{~cm}$ br., glatt, kahl, feucht gelbbraun, trocken ledergelb, glänzend. St. $2-5 \mathrm{~cm}$ lg., zylindrisch, weiß, später hohl. L. schwach angeheftet, zuerst blaß ockergelb, dann zimmetbraun. In Ndwäldern, besonders in Gebirgen, zerstreut. H. (Weißstieliger S.)

\section{C. leucopodius (Bull.).}

4. Hut kegelf., dann flach gewölbt, glatt, kahl, braunrot, Buckel dunkler. St. $5-8 \mathrm{~cm}$ lg., zylindrisch, später hohl, oberwärts violett, mit faserigem, weißlichem, \pm bläulichem' Schleier. L. locker angeheftet, blaß zimmetbraun. In Wäldern, selten. S. H. (Rötlicher S.)

C. erythrinus Fries.

Hut kegelf., dann ausgebreitet, mit stumpfem Buckel u. um diesen herum eingedrückt, $2-3 \mathrm{~cm}$ br., trübbraun, in der Mitte dunkler, trocken, heller. St. 9-11 cm lg., hohl, zylindrisch, rotbräunlich u. mit feinfädiger, weißer, anliegender Bekleidung, dadurch fast violett erscheinend. L. angewachsen, blaß rotbraun, dann zimmetbraun. Auf Heideplätzen, in Wäldern an feuchten Stellen, zwischen Moos, häufig. S. H. (Fig. 399.) (Trügerischer S.)

C. decipiens (Pers.). 
5. Hutoberfläche od. Rand gestreift.

Hutoberfläche nicht gestreift, glatt.

6. Hut häutig-fleischig, mit spitzem Höcker, 1-2 cm br., gestreift, gelbbraun, trocken hell ockerfarben. St. $6-10 \mathrm{~cm} \mathrm{lg.,} \mathrm{hell} \mathrm{ocker-}$ farben, verblassend, hohl, gebogen, Schleier weiß. L. angewachsen, ockerfarben. In Lb- u. Ndwäldern zwischen Moos, nicht selten. S. H. (Fig. 400.) (Spitzer S.) C. acutus (Pers.).

Hut kegelf. -glockig, zuerst stumpfhöckerig, dann glatt, 2,5 bis $5 \mathrm{~cm}$ br., gelbbraun, trocken ockerfarben, faserig zerschlitzt, Rand gestreift. St. bauchig, $5 \mathrm{~cm} \mathrm{lg.,} \mathrm{blaß} \mathrm{ockerfarben,} \mathrm{ange-}$ drückt faserig. L. angewachsen, zimmetbraun mit weißflockiger Schneide. Widrig riechend. In Ndwäldern, besonders im Gebirge, nicht selten. S. H. (Fig. 401.) (Stumpfer S.)

C. obtusus Fries.

7. Hut häutig-fleischig, kegelf., dann ausgebreitet, $1-2 \mathrm{~cm}$ br., kahl, braun mit schwarzbraunem spitzem Höcker, trocken strohgelb, seidenglänzend. St. zylindrisch, $5-8 \mathrm{~cm}$ lg., grobfaserig, spaltbar, kahl, blaßbräunlich. L. angewachsen, zimmetbraun. In Ndwäldern, nicht selten. S. H. (Gebänderter S.)

\section{C. fasciatus Fries.}

Hut kegelf., dann flachgewölbt mit spitzigem Höcker, $2-3 \mathrm{~cm}$ br., gelbbraun, trocken braun, glänzend, Rand glatt, später oft faserig zerschlitzt. St. $4-8 \mathrm{~cm} \mathrm{lg.,} \mathrm{voll,} \mathrm{blaßgelblich,} \mathrm{Schleier}$ gelblich. L. angewachsen, ockerfarben, dann zimmetbraun. Zwischen Gras u. Moos auf Wiesen u. im Walde, zerstreut. S. H. (Jauchiger S.)

C. saniosus Fries.

8. St. u. Schleier weiß.

St. gelb, rotl violett.

9. L. ausgerandet, höchstens angeheftet.

Hut flach gewölbt, mit breitem, flachem Buckel, $5-11 \mathrm{~cm}$ br., gelblich-zimmetbraun, glatt, glänzend, trocken hell ledergelblich. St. voll, 5-8 cm lg., nach oben verjüngt. L. angewachsen, ockerfarben, dann zimmetbraun. In Wäldern, nicht selten. S. H. (Fig. 402.) (Aprikosenfarbener S.) C. armeniacus (Schaeff.).

10. St. weiß, dann später irgendwie bräunlich werdend.

Hut flach gewölbt, schwach gebuckelt, $3-6 \mathrm{~cm}$ br., gelbbraun, trocken ledergelb, anfangs faserig, später glatt u. kahl. St. 5-8 cm lg., später hohl, weich, blaß, am Grunde verdickt. L. ockerfarben, dann zimmetbraun. In Wäldern, zerstreut. S. H. (Fig. 403.) (Blasser S.)

c. dilutus (Pers.).

11. Hut gewölbt, dann ausgebreitet, in der Mitte flach od. stumpfhöckerig, 3-5 cm br., scherbengelb, braun werdend, Fleisch schwach wässerig, in der Farbe kaum veränderlich. St. fest, voll, bis $7 \mathrm{~cm} \mathrm{lg.,} \mathrm{weißlich,} \mathrm{dann} \mathrm{schmutzig} \mathrm{bräunlich.} \mathrm{L.} \mathrm{trüb-,}$ dann rostbraun. Geruch u. Geschmack unangenehm. In Wäldern, zerstreut. S. H. (Fig. 404.) (Roströtlicher S.)

C. subferrugineus (Batsch). 
Hut halbkuglig, dann ausgebreitet, stumpf, $3-5 \mathrm{~cm}$ br,, geglättet, ockergelb-rostfarbig, Fleisch weiß, fest. St. voll, $4-6 \mathrm{~cm}$ lg., fast knollig, faserig, streifig, Fasern u. Schleier rostfarben werdend. L. rostfarben, dann zimmetbraun. In Lbwäldern, zerstreut. H. (Fig, 405.) (Fester S.) C. firmus Fries,

12. Hut glockig-gewölbt, dann ausgebreitet, stumpf gebuckelt, 3 bis $5 \mathrm{~cm}$ br., dunkelkastanienbraun, mit leicht violettem Schimmer, trocken dunkelbraun, Rand heller, verbogen, Fleisch braunviolett. St. hohl, 6-8 cm lg., braunviolett od. schwach rötlich, faserig, seidenglänzend. L. braunviolett, dann zimmetbraun. In Wäldern, häufig. S. H. (Fig. 406.) (Kastanienbrauner S.) C. castaneus (Bull.).

Hut gewölbt, schwach gebuckelt, kahl, honiggelb. St. hohl, zylindrisch, gelblich, nackt, gestreift, Schleier gelb. L. angewachsen, gelb, dann tonfarben bis zimmetbraun. In trockenen Ndwäldern, namentlich bergiger Gegenden, selten. S. H. (Isabellfarbener S.)

C. isabellinus (Batsch).

\section{Untergattung: Telamonia Fries.}

1. L. schmal, dünn, \pm gedrängt stehend, angewacshen.

L. sehr br., ziemlich dick, \pm entfernt stehend.

2. St. irgendwie braun.

Hut kegelf, dann ausgebreitet, spitz gebuckelt, $1-2 \mathrm{~cm}$ br., violett, dann zimmetbraun, graufaserig, trocken verblassend. St. verbogen, 8-11 $\mathrm{cm} \mathrm{lg.,} \mathrm{oben} \mathrm{violett,} \mathrm{mit} \mathrm{weißer,} \mathrm{ringf.} \mathrm{Be-}$ kleidung. L, dunkel braunviolett, dann zimmetbraun mit weißlicher Schneide. Zwischen Moos in Ndwäldern, zerstreut. S. H. (Fig. 407.) (Gebogenstieliger S.)

c. flexipes (Pers.).

3. Hut braun, St. hohl.

Hut gelb- od: rostbraun, St. voll.

4. Hut kegelf., dann glockenf., stumpf gebuckelt, $2-2,5 \mathrm{~cm}$ br., glatt, glänzend, braun, in der Jugend am Rande mit weißen Fäden. St. ca. $4 \mathrm{~cm}$ lg., später hohl, blaßbraun, mit schuppiger u. anliegend ringf., weißer Bekleidung. L, rostfarben, dann zimmetbraun. Zwischen Gras u. Moos in Gärten, Gebüschen, zerstreut. S. H. (Fig. 408.) (Starrer S.)

C. rigidus (Scopoli).

Hut flachgewölbt, spitz od. stumpf gebuckelt, $2,5-8 \mathrm{~cm}$ br., feucht braun, trocken abblassend, ledergelb, mit dichtstehenden, anfangs aufgerichteten, später angedrückten Fasern bedeckt, Rand anfangs weißfädig. St. $4-8 \mathrm{~cm}$ lg., später hohl, blaßbraun, mit weißflockiger, ringf. Bekleidung. L. lehmbraun, dann zimmetbraun. Zwischen Gras u. Moos in Wäldern u. auf Wiesen, zerstreut. S. H. (Halbbehaarter S. ) C. hemitrichus (Pers.).

5. Hut kegelf., dann flach ausgebreitet, gebuckelt, $2-3 \mathrm{~cm}$ br., feucht glatt, rostbraun, trocken rissig-kleinschuppig, am Rande oft zerschlitzt, ockerfarben. St. voll, $3-4 \mathrm{~cm}$ od. länger, faserig, 
rostbraun, mit ringf., weißэr, bald verschwindender Bekleidung. L. zimmet-, dann rostbraun. In Wäldern u. Gebüsch herdenweise, nicht häufig. S. H. (Fig. 409.) (Eingeschnittener S.) C. incisus (Pers.).

Hut gewölbt, schwach gebuckelt, $2-7 \mathrm{em}$ br., grauseidig, dann kahl, gelblich, zuletzt glatt u. rissig. St. 5-11 em lg., zylindrisch, gelbbraun, am Grunde faserig-streifig od. schuppig, oben nackt. L. blaß zimmetbraun. Gruch widerlich, Geschmack beißend. In Buchenwäldern, zerstreut. S. H. (Fig. 410.) (Schwerfälliger S.)

C. iliopodius (Bull.).

6. St. u. Schleier weißlich.

7.

St. violett, Schleier weißviolett.

St. u. Schleier rötlich od. irgendwie bräunlich.

8.

9.

7. Hut gewölbt, dann ausgebreitet, stumpf, ca. $8 \mathrm{~cm}$ br., von sehr kleinen Schüppchen grau. St. voll, $8-16 \mathrm{~cm} \mathrm{lg.,} \mathrm{faserig,} \mathrm{weißlich,}$ mit zartem Ringe. L. angeheftet, wässerig zimmetbraun. In feuchten Wäldern, selten. H. (Fig. 411.) (Grobstieliger S.)

C. macropus (Pers.).

Hut gewölbt, dann ausgebreitet, 5-14 cm br., kahl, glatt od. am Rande seidenhaarig, scherbengelb, oft dunkler gefleckt. St. voll, ca. $5 \mathrm{~cm}$ lg., unten fast knollig, schwammig-fleischig, schmutzig weißlich, innen hell rostbraun, mit schnell vergänglichem Gürtel. L. angeheftet, gelb-zimmetbraun. In Wäldern u. Heiden, zerstreut. S. H. (Fig. 412.) (Gefranster S.)

C. bivelus Fries.

8. Hut gewölbt, dann ausgebreitet, stumpf, $8 \mathrm{~cm}$ u. breiter, hell scherbenfarbig, mit grauen Schüppchen u. Fasern, später durchlöchert. St. knollig, dann verlängert, zylindrisch, $8-14 \mathrm{~cm} \mathrm{lg.,}$ mit dauerhaftem, weißem Ring u. violettem Schleier. L. purpurnumbrabraun, dann zimmetbraun. Besonders in Buchenwäldern, selten. S. H. (Fig. 413.) (Seharfer S.) C. torvus Fries.

Hut kegelf., dann ausgebreitet, gelblichweiß, Rand strahligstreifig. St. später hohl, zylindrisch, bis $8 \mathrm{~cm} \mathrm{lg}$., weißlih violett, mit gürtelf. Bekleidung. L. angewachsen, gesägt, purpurn, dann zimmetbraun. In Buchenwäldern, selten. S. H. (Vierfarbiger S.)

C. quadricolor (Scopoli).

9. Bekleidung des St. (Schuppen, Ring) einfarbig, gelb od. rot. 10.

Bekleidung des St. andersfarbig.

10. Hut kegelf. ausgebreitet, spitz gebuckelt, $1-3 \mathrm{~cm}$ br., glatt u. kahl, rötlich-zimmetbraun, trocken gelb, rissig eingeschnitten. St. bis $8 \mathrm{~cm}$ lg., gleichfarbig, mit schuppigem, gelbem Ringe. L. angewachsen, gelblich, dann zimmetbraun. In Lb- u. Ndwäldern, bis ins Gebirge, häufig. S. H. (Fig. 414.) (Verwandter S.)

c. gentilis Fries.

Hut glockig, dann ausgebreitet, $5-15 \mathrm{~cm}$ br., glatt, später eingewachsen fädig od. schuppig, zerschlitzt, rötlich-scherbenbraun. St. $8-16 \mathrm{~cm}$ lg., am Grunde schwach knollig, voll, faserig, hell Lindau, Kryptogamenflora. I. 2. Aufl. 
rötlichbraun, mit 1-4 lebhaft zinnoberroten, anliegend faserigen Gürteln. L. angeheftet, ausgerandet, blaß-, dann zimmetbraun, mit welliger Schneide. Zwischen Moos in Nd- u. Lbwäldern, besonders im Gebirge, häufig. S. H. (Beringter S.)

C. armillatus Fries.

11. Hutoberfläche rost- od, rötlich zimmetbraun.

Hut glockenf., dann flach ausgebreitet, stumpf gebuckelt, bis $8 \mathrm{~cm}$ br., feucht umbrabraun, trocken schmutzig ledergelb, gegen den Rand faserig, fast kahl. St. voll, bis $11 \mathrm{~cm} \mathrm{lg.,} \mathrm{nach} \mathrm{oben}$ verjüngt, bräunlich, weißstreifig, mit ringf., hellbräunlicher Bekleidung. L. angewachsen, purpurbraun, dann zimmetbraun. An feuchten Stellen, besonders in Ndwäldern, häufig. S. H. (Fig. 415.) (Brauner S.) C. bruneus (Pers.).

12. Hut kegelig-glockenf., dann ausgebreitet, schwach gebuckelt, 3-4 cm br., rötlich-zimmetbraun, im Alter rissig durchbohrt. St. voll, 2-11 cm lg., nach unten verjüngt, mit weißer, seidenartiger, oben ringf., blasser Bekleidung. L. etwas ausgerandet, rötlich-, später zimmetbraun. In Wäldern, zerstreut. S. H. (Hirschfarbiger S.) C. hinnuleus (Sowerby).

Hut gewölbt, dann ausgebreitet, mit stumpfem, dann verschwindendem Buckel, $2-8 \mathrm{~cm}$ br., rostfarben, in der Mitte oft dunkler, im Alter rissig, Rand anfangs meist eingeknickt. St. voll, 5-12 cm lg., gleichfarben, unten mit glatter, weißer seidenfädiger Bekleidung, die nach oben durch einen rostbraunen Ring begrenzt wird. L. ausgerandet, dunkel-, dann zimmetbraun, In Wäldern, zerstreut. S. H. (Blaßroter S.)

\section{C. helvolus (Bulliard).}

\section{Untergattung: Dermocybe Fries.}

1. St. weiß od, weißlich.

St. irgendwie violett.

St. nicht weiß od. violett gefärbt.

2. Hut über $5 \mathrm{~cm}$ br.

Hut gewölbt, dann ausgebreitet, bisweilen zuerst etwas höckerig, 2-4 cm br., glatt, kahl, weiß, dann gelblich, seidenartig-glänzend. St. später hohl, keulig, 5-6 cm lg., glatt, am Grunde niederliegend. L. angeheftet, hellockerfarben, dann zimmetbraun. Zwischen Moos in Ndwäldern, selten. S. H. (Niederliegender S.)

c. decumbens (Pers.).

3. Hut ganz flach, $8 \mathrm{~cm}$ br., flockig, dann kahl, bräunlich-tonfarben, verblassend. St. voll, $5-8 \mathrm{~cm}$ lg., angedrückt faserig-schuppig. L. ausgerandet, weißlich, dann tonfarben bis blaß rotbraun. In Lbwäldern, selten. S. (Flacher S.) C. tabularis (Bull.).

Hut gewölbt, gebuckelt, dann stumpf, $5-6 \mathrm{~cm}$ br., glatt, kahl, weißlich. St. voll, bauchig, $8 \mathrm{~cm} \mathrm{lg.,} \mathrm{Schleier} \mathrm{faserig.} \mathrm{L.} \mathrm{frei,}$ weißlich, dann hell ockerbräunlich. In Wäldern, zerstreut. H. (Fig. 416.) (Ockergelber S.) c. ochroleucus (Schaeff.). 
4. L. nicht mit einem Zähnchen herablaufend.

Hut stumpf gewölbt, später höckerig, 5-11 cm br., graubraun, rötlich, mit später verschwindenden Fasern bedeckt. St. voll, schlank, 8-14 cm lg., faserig u. schwach schuppig, violett, verblassend. L. mit einem Zähnchen herablaufend, blaupurpurn, dann zimmetbraun. In Wäldern, auf Wiesen, nicht selten. S. H. (Schöngestalteter S.)

C. eumorphus (Pers.).

5. Hut flach gewölbt, stumpf, $8-11 \mathrm{~cm}$ br., ziegelrot, später verfärbt, am Rand grau seidenhaarig, sonst kahl. St. keulig-knollig, $5-8 \mathrm{~cm} \mathrm{lg.,} \mathrm{bla} 3$, an der Spitze violett. L. ausgerandet, purpurn, dann zimmetbraun. In Wäldern, nicht häufig. S. H. (Hunds-S.)

C. caninus Fries.

Hut gewölbt, etwas höckerig, glatt, kahl, blaß olivenfarbig, dann scherbengelb, Rand fast häutig. St. etwas hohl, $8-16 \mathrm{~cm}$ lg., schlank, mit dicker, weißfilziger Knolle, sonst nackt, oft gewunden, an der Spitze gestreift, violett. L. angeheftet, schmutzig, gelb, dann scherbengelb. Zwischen Moos in Ndwäldern, zerstreut. S. H. (Säbelbeiniger S.)

c. valgus Fries.

6. St. rot.

St. gelblich, gelbbraun, hell olivenfarben.

7. Hut gewölbt, stumpf, $2-3 \mathrm{~cm}$ br., blutrot, eingewachsen seidenfädig od. kleinschuppig. St. später hohl, zylindrisch, gleichfarbig, mit rotem Safte. L. dunkelblutrot, später zimmetbraun. In Nd- od. Mischwäldern, nicht allzu häufig. S. H. (Fig. 417.) (Blutroter S.)

C. sanguineus (Wulfen).

Hut flachgewölbt, dann in der Mitte etwas eingedrückt, 4 bis $6 \mathrm{~cm}$ br., lebhaft orange- bis zinnoberrot, glänzend, seidig-flockig, Fleisch rötlich, Rand wellìg verbogen. St. voll, $6-8 \mathrm{~cm} \mathrm{lg.,}$ faserig, gleichfarbig, seidenglänzend, Schleier ebenso gefärbt. L. rotgelb, später zimmetbraun, angewachsen. In Buchenwäldern in kleinen Rasen, zerstreut. S. H. (Fig. 418.) (Zinnoberroter S.) C. cinnabarinus Fries.

8. Geruch- und geschmacklos, jedenfalls nicht scharf.

Hut glockenf., dann flach ausgebreitet, stumpf höckerig, 2 bis $5 \mathrm{~cm}$ br., olivenbraun, dann verblassend, trocken gelbbraun, seidenhaarig-filzig. St. voll, 5-8 cm lg., etwas heller als der Hut, innen gelb, Schleier olivenbraun. L. angewachsen, olivenbraun, später zimmetbraun. Geruch rettichartig, Geschmack scharf. In schattigen Wäldern, zerstreut. S. H. (Fig. 419.) (Rettich-S.)

C. raphanoides (Pers.).

9. Hut flachgewölbt, meist stumpfhöckerig, $2-8 \mathrm{~cm}$ br., gelb od. gelbbraun, eingewachsen seidenhaarig od. kleinschuppig. St. $5-8 \mathrm{~cm}$ lg., grobfaserig, später hohl, gelb. Fleisch u. Schleier gelb. L. angewachsen, gelb, rotgelb od. blutrot, später zimmetbraun. Eßbar. In Wäldern u. Heiden, auf sandigem Boden, zwischen Moos, häufig bis ins Hochgebirge. S. H. (Fig. 420.) (Zimmetschwamm.)

c. cinnamomeus (L.). 
Hut stumpf gebuckelt, zottig-schuppig od. faserig, selten kahl, orangefarben-gelbbraun od. blaß zimmetbraun, Fleisch rötlich. St. voll, streifig-faserig, gelbbraun, Schleier gelbbraun. L. angeheftet, gelb od. gelbbraun, später mehr zimmetbraun. In Wäldern, selten. S. H. (Fig. 421.) (Orleansfarbener S.) C. orellanus Fries.

\section{Untergattung: Inoloma Fries.}

1. Schleier weiß od. violett, L. u. St. entsprechend gefärbt.

Schleier rot, gelb od. braun, L. u. St. entsprechend gefärbt. 5 .

2. Schleier, L. u. St. violett.

Hut gewölbt, flach höckerig, 4-10 cm br., silberglänzend, dann grau, am Rand mit violetten, seidenartigen, bald verschwindenden Haaren. St. knollig, dann gleichmäßig verlängert, bis $10 \mathrm{~cm} \mathrm{lg.,} \mathrm{innen} \mathrm{u.} \mathrm{außen} \mathrm{weiß,} \mathrm{unten} \mathrm{später} \mathrm{schwach} \mathrm{gelblich.}$ L. ausgerandet, blaßbräunlich, dann zimmetbraun, mit gesägter Schneide. Geruch u. Geschmack eigentümlich. In Ndwäldern, nicht häufig. S. H. (Silberglänzender S.) C. argentatus (Pers.).

3. Hutoberfläche hellviolett, dann hell verblassend.

Hut flachgewölbt, dann stumpf gebuckelt, $6-15 \mathrm{~cm}$ br., zottigschuppig, dunkelviolett. St. knollig, 10-12 cm lg., zottig-schuppig, dunkelviolett, trocken fast schwarz. Fleisch violett. L. dunkelviolett, dann zimmetbraun. In Lb-u. Ndwäldern, nicht selten. S. H. (Fig. 422.) (Violetter S.) C. violaceus (L.).

4. Hut dickfleischig, gewölbt, dann ausgebreitet, stumpf gebuckelt, 4-10 cm br., hellviolett, dann weißlich, eingewachsen seidenhaarig. St. zuerst oft kuglig, dann knollig od. keulenf., $5-15 \mathrm{~cm}$ lg., hellviolett, dann weißlich, mit angedrückter, weißlicher, mehrere Gürtel bildender Bekleidung. Fleisch bläulich weiß bis bräunlich. L. angeheftet, violett, dann zimmetbraun, Schneide gesägt. In Wäldern, unter Gebüsch, häufig. S. H. (Fig. 423.) (Weißvioletter S.)

C. alboviolaceus (Pers.).

Hut dickfleischig, gewölbt, stumpf gebuckelt, $4-8 \mathrm{~cm}$ br., hellviolett, dann hellgraubraun, zuerst seidenhaarig, dann rissigschuppig. St. knollig, keulenf., 5-7 cm lg., violett, dann graubraun. Fleisch schmutzig, bräunlich. L. purpurbraun, dann zimmetbraun. In Lbwäldern, selten. S. H. (Violettgrauer S.)

C. violaceocinereus (Pers.).

5. Schleier trübbraun, rostbraun, ähnlich auch der St.

Schleier rot od. gelb, ähnlich der St. (nur bei C. traganus der St. erst violett).

6. Hut über $4 \mathrm{~cm}$ br.

Hut gewölbt, gebuckelt, $2-4 \mathrm{~cm}$ br., rostbraun, von eingewachsenen Schuppen dicht flockig. St. voll, schlank, $5-8 \mathrm{~cm}$ lg., zylindrisch, oben kahl, unten mit angedrückten, rostbraunen Schüppchen. L. angewachsen, dann abgelöst, dunkelbraun mit hellerer Schneide. In Ndwäldern, selten. S. (Pinsel-S.)

C. penicillatus Fries. 
Agariccae.

$405.406 .40 \%$ 408. 409. 410. 414.
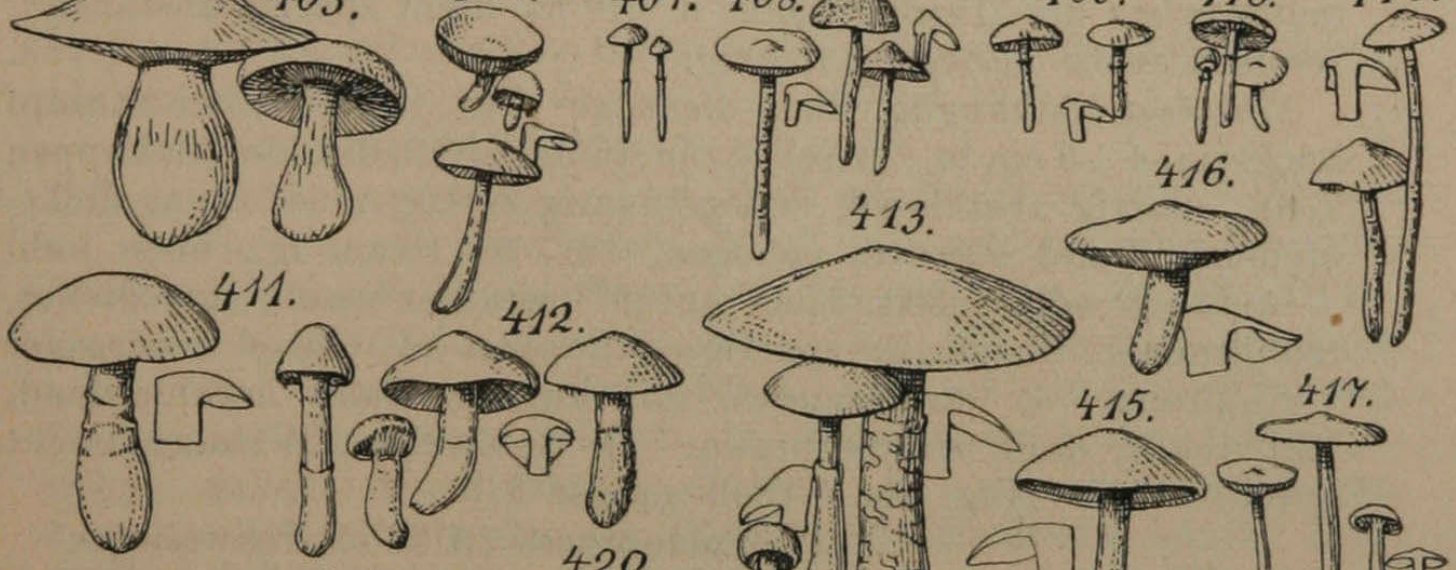

(118.

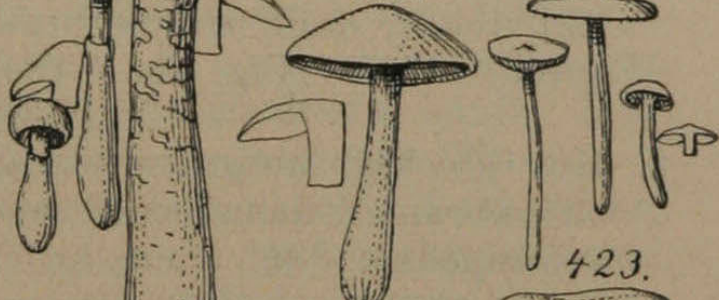

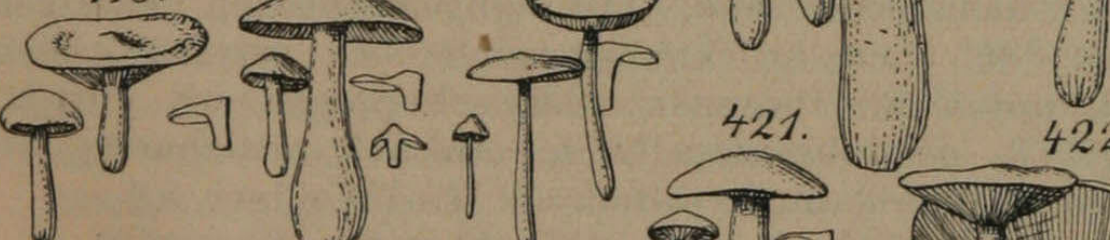

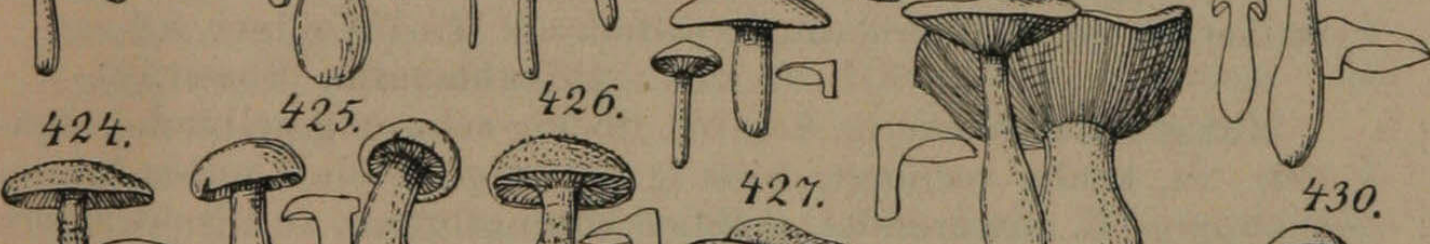

433.434 .436 (i) 431

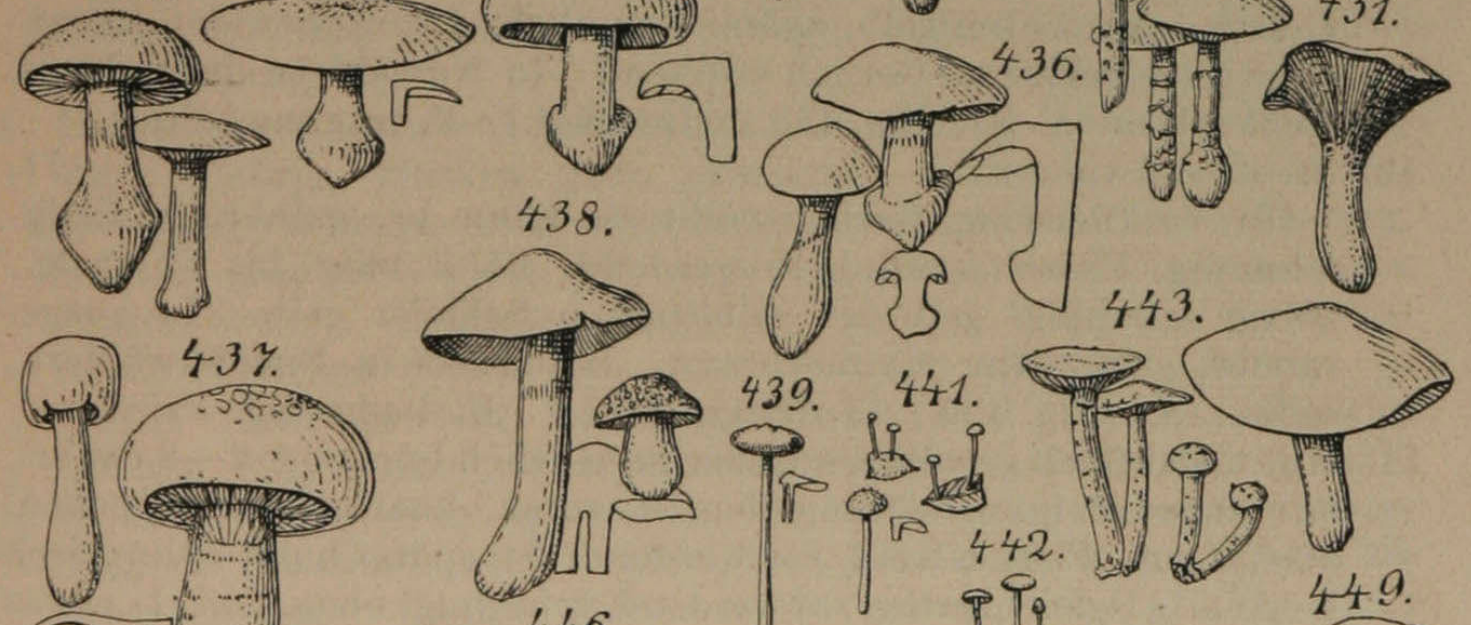

2 (nit)

+46 .

$\underbrace{445 \%}_{444 .}$

1. To

448.
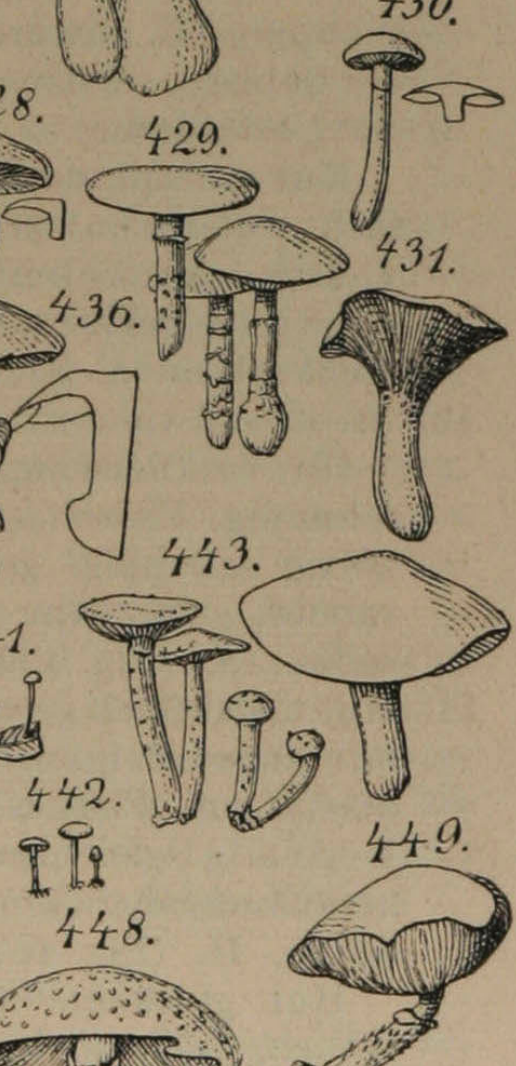

$\checkmark p$ 
7. Schüppchen der Hutoberfläche u. des St. nicht sparrig abstehend, sondern mehr anliegend-flockig.

Hut fast halbkuglig, dann flach gewölbt, in der Mitte stumpf höckerig, 4-8 cm br., hirschbraun, in der Mitte dunkler, Schuppen klein, sparrig abstehend, striegelhaarig-zottig, trübbraun, dichtstehend, Rand abwärts gebogen. St. $5-10 \mathrm{~cm} \mathrm{lg.,} \mathrm{oben} \mathrm{kahl}$ u. weißlich od. violett, nach unten kastanienbraun, mit dicker, trübbrauner, filziger, in sparrige Schuppen od. Gürtel zerrissener Umhüllung. L. ausgerandet, mit kurzem Zahn herablaufend, blaßviolett, dann zimmetbraun. In Gebüschen, Wäldern, nicht selten. S. H. (Fig. 424.) (Schuppiger S.)

C. lepidomyces (Alb. et Schwein.).

8. Hut glockig, ausgebreitet, gebuckelt, $8 \mathrm{~cm}$ br., ledergelb od. olivenbraun, dann rostbraun, mit eingewachsenen haarigen Schüppchen. St. $8 \mathrm{~cm}$ lg., knollig, nach oben verjüngt, oben glatt, blaß, unten mit brauner, filzig-schuppiger, oft gürtelf. Bekleidung. L. olivenbraun-gelblich. Geruch rettichartig (ob immer?). In Wäldern, nicht selten. S. H. (Wolliger S.)

C. sublanatus (Sowerby).

Hut gewölbt, höckerig, $8 \mathrm{~cm}$ br., flockig-schuppig, gelblich-bräunlich. St. keulig verjüngt, $8 \mathrm{~cm}$ lg., oben glatt bla $\mathrm{B}$, unten braunschuppig. L. ausgerandet, gelblich-zimmetbraun. In Mischwäldern der Gebirge, zerstreut. S. H. (Sandiger S.) C. arenatus (Pers.).

9. In Lbwäldern.

Hut stumpf, ca. $8 \mathrm{~cm}$ br., anfangs lilafaserig, dann kahl u. entfärbt, zuletzt außen u.innen gelblich. St. knollig, schwammig, weißviolett, innen safrangelb, später bräunlich. L. ausgerandet, safranockergelb, gekerbt. Geruch stinkend. In Ndwäldern der Gebirge, nicht selten. S. H. (Fig. 425.) (Bocks-S.) C. traganus Fries.

10. St. irgendwie rot.

Hut dickfleischig, flach gewölbt, 6-12 cm br., gelbbraun, filzigschuppig, Fleisch weiß, gelb werdend. St. knollig, bis $12 \mathrm{~cm} \mathrm{lg.,}$ zottig schuppig, gelb bis gelbbraun. Schleier gelb. L. ausgerandet, gelb, dann zimmetbraun. Besonders in Buchenwäldern, selten. S. (Fig. 426.) (Tuffstein-S.) । C. tophaceus Fries.

11. Hut meist flach gewölbt, seltener undeutlich buckelig, $2-8 \mathrm{~cm}$ br., mit angedrückten, safrangelben $u$. roten, haarigen Schüppchen, zuletzt rot. Fleisch wei $\beta$, rot werdend. St. später hohl, zylindrisch 4-8cm lg., gleichfarbig, rotwerdend, schuppig, oben kahl. L. etwas herablaufend, hellbräunlich, dann zimmet-braun. In Lbwäldern, selten. H. (Fig. 427.) (Bolusfarbiger S.) C. bolaris (Pers.).

Hut glockenf., dann gewölbt, flach buckelig, $5-6 \mathrm{~cm}$ br., rötlich, kahl, oft kleinschuppig od. faserig. St. knollig, 5-11 cm lg., weiß, oben kahl, unten mit zinnoberroten Fasern besetzt, rot werdend. L. angeheftet, purpurn, dann rostbraun. In Buchenwäldern, nicht selten. H. (Fig. 428.) (Bulliards S.)

C. Bulliardi (Pers.). 
V. Untergattung: Myxacium Fries.

1. St. mit flockig-schuppiger, anfangs mit Schleim überzogener Hülle, die später anliegende Schuppen od. Gürtel bildet.

St. glatt, trocken firnisartig glänzend.

2. Hut gewölbt, dann ausgebreitet, flach od. breithöckerig, $5-11 \mathrm{~cm}$ br., gelbbraun od. lederbraun, frisch mit schleimigem Überzug, trocken glänzend, Rand dünn, oft längsrunzlig. St. $10-20 \mathrm{~cm}$ lg., voll, zylindrisch, oberhalb des weißen, fädigen Schleiers kahl, weiß od. violett, unterhalb frisch mit schleimigem Überzug, fleischigen Schuppen u. Gürteln, trocken glänzend, mit hellbräunlichen, anliegenden Flocken u. Gürteln. L. angeheftet, hellviolett, dann tonfarben bis rostbraun. Eßbar. In Lbwäldern, häufig. S. H. (Fig. 429.) (Schleimling, Schleimfuß.) C. collinitus (Pers.).

Hut gewölbt, stumpf od. etwas niedergedrückt, $5-8 \mathrm{~cm}$ br., sehr klebrig, kahl od. faserig, gelbbraun od. blaß kastanienbraun. St. $5-8 \mathrm{~cm}$ lg., mit weißer klebriger Haut bedeckt, von ihr oberhalb fast ringf. berandet $u$. mit faserigem, rostrotem Schleier versehen. L, zahnf. herablaufend, sich ablösend, gelb-zimmetbraun, weiß gefranst. Besonders in Ndwäldern, zerstreut. $\mathrm{H}$. (Weichstieliger S.)

3. St. weiß.

C. alutipes (Lasch).

Hut flach gewölbt, ungebuckelt, 2,5-6 cm br., schleimig, trocken glänzend, hellgelb od. gelbbraun. St. $5-7 \mathrm{~cm} \mathrm{lg.,} \mathrm{nach}$ unten bisweilen verdickt, oben hellviolett, unterhalb des fädigen Schleiers weiß, frisch mit hellgelbem Schleim überzogen. L. angewachsen, hellviolett, dann hellrostbraun, Schneide gesägt. Zwischen Moos u. Gras in Wäldełn, selten. S. H. (Fig. 430.) (Bestrichener S.)

C. delibutus Fries.

4. Hut flach od. schwach gebuckelt, $2-6 \mathrm{~cm}$ br., lebhaft gelbbraun, stark klebrig, trocken gelb, glänzend. St. voll, 5-11 cm lg., oft unten verjüngt, weiß, oben kahl, unten frisch farblos-schleimig, trocken glänzend, glatt. L. angewachsen, hellockerfarben, dann zimmetbraun. Zwischen Moos u. Nd, in Wäldern, zerstreut. S. H. (Zittriger S.)

C. vibratilis (Fries).

Hut flach gewölbt od. eingedrückt, $5-10 \mathrm{~cm}$ br., klebrig, trocken oft gefurcht, ledergelb mit dunklerer Mitte, selten weiß. St. keulenf., 4-8 cm lg., weiß, oben weißmehlig, unten schleimig, trocken glänzend. L. herablaufend, weiß, dann tonfarben bis zimmetbraun. In Lbwäldern, nicht selten. S. H. (Fig. 431.) (Glänzender S.)

C. nitidus Fries.

VI. Untergattung: Phlegmacium Fries.

1. Hut dünnfleischig. St. gleichmäßig dick, nicht knollig am Grunde, Schleier zart, zwischen Hutrand u. St. gespannt.

Hut fleischig. St. unten mit einem scharf abgesetzten, meist berandeten Knollen. Schleier anfangs zwischen Hutrand u. Rand des Knollens ausgespannt.

6. 
Hut dickfleischig. St. gleichmäßig dick od. nach unten keulenf. verdickt. Schleier stark entwickelt, in der Jugend zwischen Hutrand u. St. u. ebenso zwischen Hutrand u. Basis des St. ausgespannt, später als seidenfädige Ringbekleidung herabhängend.

2. L. nicht anfangs olivenbraun, sondern purpurn, lila, weißlich. 3.

Hut stumpf u. br. gebuckelt, $8 \mathrm{~cm}$ br., graugelbbraun, glatt, klebrig. St. voll, faserig, blaßbläulich. L. angewachsen, zuerst olivenfarbig, dann zimmetbraun. In etwas feuchten Wäldern. selten. S. (Ähnlicher S.)

3. Schleier weiß.

Schleier rostrot.

4. Hut flach gewölbt, dann ausgebreitet, $3-6 \mathrm{~cm}$ br., glatt, klebrig, hellila, Fleisch weiß. St. hohl, verbogen, $6-10 \mathrm{~cm}$ lg., weißlich. L. ausgerandet, mit einem Zähnchen herablaufend, hellviolett, dann safrangelb bis tonfarben. Zwischen Moos in lichten Lbwäldern, nicht selten. S. H. (Safranvioletter S.)

\section{C. croceocoeruleus (Pers.).}

Hut flach gewölbt, dann flach ausgebreitet, 5-11 cm br., glatt, schleimig, bräunlich ockerfarben, später verblassend, flockig. St. oben weiß, am Grunde bisweilen gelblich, $8 \mathrm{~cm} \mathrm{lg}$., faserig gestreift. L. ausgerandet, weißlich od. hellila, dann lehmfarben bis zimmetbraun. In Wäldern, selten. S. H. (Fig. 432.) (Verfärbter S.)

\section{C. decoloratus Fries.}

5. Hut flach gewölbt, $4-8 \mathrm{~cm}$ br., schwach schleimig, graubläulich, dann braun, Fleisch wei $\beta$, auf Bruch purpurrot. St. $5-10 \mathrm{~cm}$ lg., später hohl, blaß, bet Berührung purpurrot. L. ausgerandet, zuerst purpurviolett, dann bla $\beta$ tonfarben bis zimmetbraun. In Nd- u. Birkenwäldern, selten. S. H. (Purpurstieliger S.)

\section{C. porphyropus (Alb. et Schwein.).}

Hut flach gewölbt, dann flach ausgebreitet, $3-6 \mathrm{~cm}$ br., kahl, schleimig, gelb. St. voll, $6-8 \mathrm{~cm}$ Jg., weiß, nackt. L. angeheftet, purpurn, dann zimmetbraun. In Ndwäldern, nicht häufig. S. H.
(Abfärbender S.)
c. decolorans (Pers.).

6. L. anfangs olivenfarbig, dann zimmetbraun.

L. anfangs irgendwie gelb, dann zimmetbraun.

L. anfang blan, purpurn od. weislich, dann zimetbraun. 19.

7. Nur in Ndwäldern u. auf Heiden.

Hut klebrig, graugelbbraun od. spangrün, später gelblich, schuppig u. flockig, Rand umgebogen, Fleisch weiß. St. voll, verkürzt, blaßgrünlich, Schleier u. Fleisch blaßgrünlich. L. abgerundet, zuerst gelblich-olivenfarben. In Buchenwäldern, selten. H. (Lauchgrüner S.) $\quad$ C. prasinus (Schaeff.).

8. Hut flach gewölbt, dann ausgebreitet, $5-8 \mathrm{~cm}$ br., dunkelgraubraun, dann verblassend, Rand dünn, gestreift. St. $5-10 \mathrm{~cm}$ lg., grünlichbraun, später gelblich, oben zuweilen bläulich. L. an- 
gewachsen, zuerst olivenbraun. In feuchten Ndwäldern, besonders im Gebirge, selten. S. H. (Graubrauner S.)

\section{C. fulvofuligineus (Pers.).}

Hut gewölbt, dann ausgebreitet, bis $11 \mathrm{~cm}$ br., kahl, klebrig, rotbraun, trocken glänzend zimmetbraun. St. voll, 6-8 cm lg., grünlich, später gelblich, oben meist violett, Knollen schwach gerandet. L. ausgerandet, zuerst olivenbraun. In Kiefernwäldern u. auf Heiden, selten. S. H. (Rotgrüner S.)

\section{C. rufoolivaceus (Pers.).}

9. Hutoberfläche nicht in der Mitte rostrot u. am Rande bläulich. 10.

Hut ausgebreitet, $8 \mathrm{~cm}$ br., kahl, klebrig, in der Mitte rostrot, rissig-schuppig, am Rande bläulich. St. voll, fest nackt od. klebrigfaserig, 5-8 cm lg., gelblich, am Grunde mit niedergedrücktem Knollen. L. angewachsen, zuerst schwefelgelb-grünlich. In Ndwäldern, selten. H. (Fig. 433.) (Messingfarbener S.)

\section{C. orichalceus (Batsch).}

10. Hut gelb od. gelbbraun.

Hut flach gewölbt, dann niedergedrückt, $4-8 \mathrm{~cm}$ br., glatt, kahl, schleimig, fast grünlich od. olivenbraun, trocken verbleichend, gelb. Fleisch weiß. St. voll, $5-8 \mathrm{~cm} \mathrm{lg.,} \mathrm{weißlich,}$ glänzend, Grundknollen kreiself. L. schmal angewachsen, anfangs hellgelblich, Schneide ganz. Besonders in Buchenwäldern, nicht selten. S. H. (Fig. 434.) (Kreiself. S.)

C. turbinatus (Bull.).

11. Hut gewölbt, dann flach ausgebreitet, $8 \mathrm{~cm}$ br., glatt, kahl, klebrig, gelbbraun, zuweilen gefleckt, Rand zuerst eingeknickt. Fleisch weiß, gelb werdend. St. voll, faserig, wei $\beta$, gelb werdend. L. angeheftet, dottergelb, dann olivenbraun bis zimmetbraun, Schneide gesägt. In Lbwäldern, zerstreut. S. H. (Schöner S.)

C. elegantior Fries.

Hut flach gewölbt, dann flach, $5-8 \mathrm{~cm}$ br., seidenfaserig, schleimig, trocken glänzend, zuweilen schuppig, goldgelb. St. 4-8 cm lg., wollig-feinfaserig, gelb, Knollen fast scheibenf., Fleisch gelb, bräunlich werdend. L. ausgerandet, zuerst lebhaft gelb. In Lb.- u. Ndwäldern, häufig. S. H. (Fig. 435.) (Glänzender S.)

C. fulgens (Pers.).

12. L. anfangs blau od. purpurn.

Hut gewölbt, dann ausgebreitet, 6-10 $\mathrm{cm}$ br., glatt, klebrig, weißlich, gelblich od. lehmfarben, Rand anfangs dünn, eingebogen. St. voll, $5-11 \mathrm{~cm}$ lg., weißlich od. gelblich, faserig, Knollen schwach gerundet. Fleisch weiß. L. ausgerandet, weißlich, dann lehmfarben bis zimmetbraun, Schneide gesägt. In Wäldern, zerstreut. S. H. (Vielgestaltiger S.)

\section{C. multiformis Fries.}

13. Fleisch weiß, unveränderlich od. gelb werdend.

Fleisch blau, unveränderlich od. gelb werdend. 
14. Hut gewölbt, dann flach ausgebreitet, $6-10 \mathrm{~cm}$ br., glatt, klebrig, in der Jugend oft glänzend blau, später Jehmfarben od. gelbbraun, trocken verblassend, faserig. Fleisch weiß, unveränderlich. St. voll, $8 \mathrm{~cm}$ lg., kahl, blau, weiß werdend. L. angeheftet, blau, dann purpurn, Schneide ganz. In Lbwäldern, nicht häufig. S. H. (Bläulicher S.)

C. coerulescens (Schaeff.).

Hut dünn, scheibig, 5-6 cm br., glatt, schleimig, in der Mitte hellkastanienbraun, am Rande gelblich, trocken glänzend. Fleisch weiß, gelblich werdend. St. voll, $5-6 \mathrm{~cm} \mathrm{lg}$., außen u. innen schwach bläulich, Knollen kegelf., unten spitz. L. leicht angewachsen, zuerst purpurfarben. In dichten Wäldern, besonders im Gebirge, selten. S. H. (Gewölbter S.) C. arquatus Fries.

15. Hut flach ausgebreitet, $8-14 \mathrm{~cm}$ br., klebrig, anfangs kastanienbraun, dann gelblich-olivenbraun, dunkel fleckig, am Rande oft dunkler gezont u, oft geschweift. St. voll, 6-8 cm lg., anfangs bläulich, faserig, Knollen gerandet, später verschwindend. L. ausgerandet, blau, durch Druck purpurn. In Wäldern, besonders im Gebirge, selten. S. H. (Kirschfarbener S.)

C. purpurascens Fries.

Hut flach gewölbt, später ausgebreitet, 5-14 cm br., klebrig, dann faserig od. faserig-schuppig, olivenbraun, dann gelbbraun, in der Nähe des Randes oft mit einer erhöhten, dunkleren Zone, Fleisch bläulich, später gelb. St. voll, anfangs kurz u. knollig, später 8-11 cm lg., gestreift, bläulich, dann gelblich, Knollen gerundet. L. ausgerandet, blau, dann lehmfarben. Im Moos u. Gras in Ndwäldern, Hecken, häufig. S. H. (Fig. 436.) (Blaufüßiger S.)

C. glaucopus (Schaeff.).

16. L. zuerst irgendwie bräunlich od. rötlich, später zimmetbraun. 17.

L. zuerst blau, violett, später zimmetbraun.

17. L. zuerst trübolivenbraun.

L. zuerst hellrotbraun od. gelbbraun.

18. Schneide der L. ganz, höchstens leicht gewellt.

19.

Hut flach gewölbt, flach höekerig, $4-8 \mathrm{~cm}$ br., klebrig, trocken glänzend, trübolivenbraun, in der Mitte oft gelbbraun, oft flockig, Rand meist eingeknickt. St. voll, 5-9 cm lg., weißlich, oben violett, angedrückt seidenfaserig. L. mit stark wellig-gesägter Schneide. In Lbwäldern, selten Ndwäldern, zerstreut. S. H. (Dunkelblauer S.) S. obscurocyaneus (Secretan).

19. Hut gewölbt, dann ausgebreitet, $3-8 \mathrm{~cm}$ br., kahl, glatt, klebrig, dann runzlig, ledergelb, verblassend. St. an der Spitze hohl, etwas gedreht, 5-11 cm lg., blaß, knollig. L. abgerundet angewachsen, gefleckt. Geschmack bitter. In schattigen Ndwäldern, besonders im Gebirge, zerstreut. S. (Gedrehter S.)

C. subtortus (Pers.).

Hut flach gewölkt, dann ausgebreitet, 6-9 cm br., schwach klebrig, zuerst gleichmäßig trübolivenbraun, mit eingewachsenen, strahligen Fasern, später gelblich, mit dunklerer Randzone, 
Rand zuerst eingeknickt, dann gebogen. St. voll, $5-7 \mathrm{~cm} \mathrm{lg.,}$ gelblichbraun, oben meist bräunlichviolett. L. angewachsen, Schneide leicht wellig. In Lbwäldern, zerstreut. S. H. (Fig. 437.) (Eingeknickter S.)

C. infractus (Pers.).

20. Hut ausgebreitet, 8-11 cm br., kahl, kaum klebrig, ledergelb, in der Mitte dunkler. St. voll, $5-8 \mathrm{~cm} \mathrm{lg.,} \mathrm{faserig-streifig,} \mathrm{zuerst}$ knollig, dann gleichdick, blaßweiß, an der Spitze flockig. Schleier als dauerhafter Ring. L. ausgerandet, ungleich herablaufend, hellbräunlich, Schneide fast ganz. An feuchten u. sumpfigen Waldstellen, selten. H. (Fig. 438.) (Breiter S.)

C. latus (Pers.).

Hut halbkuglig, dann flach gewölbt, $3-6 \mathrm{~cm}$ br., klebrig, trocken glänzend, lebhaft dottergelb, in der Mitte dunkler, Rand kurz eingerollt. St. 7-11 cm lg., weiß, oben mit weißem, fädigem Schleier, unterhalb mit lebhaft dottergelbem, stellenweise zerrissenem Überzug bedeckt. L. ausgerandet, angeheftet, hellrotbraun, dann gelbbräunlich, Schneide wellig gesägt. In Ndwäldern, besonders im Gebirge, nicht häufig. S. H. (Gelbstieliger S.) C. vitellinopes (Secretan).

21. St. irgendwie violett.

St. gelb od. weißlich, nie violett.

23.

22. Hut halbkuglig, dann ausgebreitet, flach gebuckelt, $11-16 \mathrm{~cm}$ br., schwach klebrig, angedrückt seidenhaarig, graubläulichviolett, dann gelblich-kastanienbraun. St. voll, kurz knollenf., dann 8-14 cm lg., weißlich, oben violett, durch Druck oft rot werdend. L. buchtig ausgerandet, blauviolett, dann bräunlich. In Lb.- u. Ndwäldern, zerstreut. S. H. (Freigebiger S.)

\section{C. largus (Buxbaum).}

Hut gewölbt, dann scheibig ausgebreitet, $8-18 \mathrm{~cm}$ br., klebrig, rotbraun, mit filzigem, violettem Rande. St. voll, fast knollig, $5-7 \mathrm{~cm}$ lg., violett, später weißlich, anfangs filzig. L. ausgerandet, bläulichviolett, dann lehmfarben. In Ndwäldern, selten. S. H. (Bunter S.)

C. variicolor (Pers.).

23. St. gelblich.

Hut halbkuglig, dann flach scheibenf., über $6 \mathrm{~cm}$ br., glatt, klebrig, rostfarbig-gelbbraun, Rand faserig. St. voll, kegelf., $3-7 \mathrm{~cm}$ lg., weißlich, angedrückt flockig. L. ausgerandet, purpurn, Schneide ganz. In Ndwäldern, nicht häufig. S. H. (Verschiedener S.)

C. varius (Schaeff.).

24. Hut flach gewölbt, 5-8 cm br., glatt, kahl, klebrig, rußfarbigkastanienbraun, Oberhaut abziehbar, Rand später gestreift. St. faserig-streifig, gelblich, mit herabhängenden Schleierfäden. Fleisch weiß, gelb werdend. L. ausgerandet, zuerst blau. In Ndwäldern, selten. S. (Kastanienfarbiger S.)

$$
\text { C. spadiceus (Batsch). }
$$

Hut flach gewölbt, dann ausgebreitet, $4-7 \mathrm{~cm}$ br., kahl, stark schleimig, trocken glänzend, lebhaft gelb, in der Mitte 
gelbbräunlich, Rand zuerst eingerollt, dann gerade. St. voll, 7-9 cm lg., gelblich, faserig, mit mehreren häutig-schuppigen, unterbrochenen Gürteln. L. angewachsen, hellviolett, dann blaßbräunlich, Schneide gesägt, weiß. In Lbwäldern, selten. S. H. (Hellfarbiger S.) $\quad$ c. claricolor Fries.

\section{Gattung: Naucoria Fries (Schnitzelpilz).}

Hut regelmäßig, Rand mit dem St. durch einen fast häutigen Schleier verbunden, der schnell verschwindet. Ring fehlt. Sporen ellipsoidisch od. eif., Membran gelbbraun od. sehr hellgelblich.

1. Hut dünnfleischig, Rand gerade, Schleier zarthäutig. St. zart, gebrechlich. (Unterg. Galerula Karst.) - Hut fast häutig, glockenf., dann ausgebreitet, in der Mitte glatt, bis zur Mitte feinstreifig, 6-20 $\mathrm{mm}$ br., gelblich-ockerfarben, Rand anfangs weißfaserig. St. gelblich, faserig-streifig, $6-11 \mathrm{~cm} \mathrm{lg.,} \mathrm{mit} \mathrm{weißen}$ Fäden bekleidet. L. angeheftet, dann abgelöst, weißlich, dann blaßbräunlich. Auf feuchten Wiesen, Heiden, zwischen Gras u. Moos, nicht häufig. S. H. (Fig. 439.) (Mycenaartiger S.)

\section{N. mycenopsis (Fries).}

Hut dünnfleischig, fast häutig, Rand mit flüchtigem Schleier, St. zähe, dünn. (Unterg. Eunaucoria Schroet.) 2. Hut fleischig, Rand anfangs eingerollt, Schleier häutig-fädig, als Fransen eine Zeit am Rande hängen bleibend. St. faserigfleischig, fest. (Unterg. Flammula Fries.)

2. Hutoberfläche schuppig, haarig, kleiig usw.

Hut flach gewölbt, stumpfhöckerig, $1-2 \mathrm{~cm}$ br., schwach klebrig, fast glänzend, gelbbraun, mit dunklerer Mitte, glatt, kahl, am Rande fein gestreift. Schleier zart, weiß. St. $2-4 \mathrm{~cm}$ lg., hohl, kastanienbraun, weißflockig. L. br. angewachsen, ockerfarben, dann zimmetbraun. Auf faulem Holz, Ästchen, selten Erde in Lbwäldern, Gewächshäusern, nicht selten. F. S. H. (Fig. 440.) (Eingesessener S.)

N. inquilina (Fries).

3. Hut mit kleiigen od. sparrigen Schüppchen besetzt.

Hut gewölbt, in der Mitte warzenf., fast häutig, 2-6 mm br., gelbbraun, trocken ockerfarben, mit feinen, filzigen Härchen besetzt. St. fädig, zähe, ca. $2 \mathrm{~cm} \mathrm{lg.,} \mathrm{rauh,} \mathrm{bräunlich.} \mathrm{L.} \mathrm{leicht}$ angeheftet, bla $\beta$ ockerfarben. An Grashalmen, Stengeln usw., häufig. H. (Grasbewohnender S.) N. graminicola (Nees).

4. L. angeheftet, höchstens angewachsen.

Hut glockig, in der Mitte zuerst gebuckelt, dann abgeflacht u. ausgebreitet, $1-2,5 \mathrm{~cm}$ br., rostbraun, mit konzentrischen, am Rande dichtstehenden, gelblichweißen, haarigen Schüppchen, trocken ledergelb, Fleisch wässerig. St. $2-5 \mathrm{~cm}$ lg., später hohl, rostbraun, unten mit weißen haarigen Schüppchen, die oberhalb der Mitte gürtelf. zusammentreten. L. br. angewachsen, später herablaufend, fast dreieckig, rostbraun, Schneide weiß. In 
Wäldern, an Wegen, auf Triften, an Zweigen od. auf Erde usw., häufig in großen Rasen. F. S. H. (Kleiiger S.)

\section{N. furfuracea (Pers.).}

5. St. über $3 \mathrm{~cm} \mathrm{lg}$.

6.

Hut fast kuglig, dann halbkuglig gewölbt, $1-1,5 \mathrm{~cm}$ br., braun, mit sparrigen büschelhaarigen Schuppen bedeckt. St. $1-1,5 \mathrm{~cm}$ lg., dünn, gekrümmt, braun, behaart. L. angewachsen, ockerfarben. An abgefallonen Zweigen, selten. S. H. '(Wolliger S.)

N. lanata (Sowerby).

6. Hut halbkuglig, dann flach gewölbt, 4-10 $\mathrm{mm}$ br., ockerfarben, trocken fast weißlich, mit sparrigen Schuppen besetzt, schimmernd. St. ockerfarben, mit gleichfarbigen Schüppchen, $3-4 \mathrm{~cm}$ lg. L. angeheftet, hellockergelb. An Lb. u. Fruchthüllen von Buche u. Haselnuß, nicht selten. F. S. (Fig. 441.) (Fruchtliebender S.)

N. carpophila (Fries).

Hut glockig, dann flach gewölbt $\mathrm{u}$. ausgebreitet, $1-2,5 \mathrm{~cm}$ br., zimmetbraun, oft mit dunklerer Mitte, glatt, trocken ockerfarben, fein kleiig-schuppig, Rand gestreift. St. hohl, 4-5 cm lg., ockerbräunlich, unten dunkler, weißfaserig, oben kleiig-schuppig. L. angeheftet, sich ablösend, ockerfarben, Schneide weißlich. In feuchten Wäldern, Gabüschen, an Lb. u. Zweigen, häufig u. gesellig. F.S.H. (Fig. 442.) (Bestreuter S.) N. conspersa (Pers.).

7. Hutoberfläche kahl, nicht kleiig.

Hut kuglig, dann halbkuglig, 1,5-4 cm br., braun, mit dickem, braunem Staube bedeckt, später schuppig, Schleier häutig, am Rande filzig herabhängend $u$. verschwindend. St. hohl, zylindrisch, 3-6 cm lg., oben purpurfarbig, unten dunkelbraun, zuweilen mit filzigem Ringe. L. zuerst lebhaft zinnoberrot, dann rostbraun. Geruch gurkenartig. Zwischen Lb. u. Zweigen in Gärten, auf Lohe, selten. S. H. (Stachliger S.)

N. echinata (Roth).

8. Hutoberfläche mit schleimigem Überzug, trocken glänzend. 9.

Hutoberfläche frisch, kaum klebrig; Geschmack bitter. 12.

9. Zwischen Lb. u. an Stümpfen, nicht auf Brandstellen. 10.

Hut halbkuglig, dann flach gewölbt, 1,5-2,5 cm br., braungelb od. rötlichgelb. Fleisch gelb. St. hohl, gelbbraun, nach oben heller, flockig-schuppig, $1,5-2,5 \mathrm{~cm} \mathrm{lg}$. L. angewachsen, etwas ausgerandet, lehmfarben, dann kastanienbraun, Schneide weiß. Auf Brandstellen in Wäldern zwischen der Holzkohle, häufig. F. S. H. (Fig. 443.) (Kohlen-S.) N. carbonaria (Fries).

10. St. weißlich, Fleisch nicht grünlichgelb.

Hut flach gewölbt, dann ausgebreitet, $4-6 \mathrm{~cm}$ br., gelb, in der Mitte gelb- od. rostbraun. Fleisch grünlichgelb. St. hohl, nach unten verjüngt, 6-11 cm lg., faserig, gelb, dann schmutzigbräunlich. L. angewachsen, gelb, dann rostbraun. In Ndwäldern herdenweise an Wegen, Plätzen, Gräben, zerstreut. H. (Schuppiger S.)

N. squamosa (Fries). 
11. Hut flach gewölbt, dann ausgebreitet u. niedergedrückt in der Mitte, 5-11 cm br., zimmetbraun, mit gelbbrauner, schuppiggefleckter Mitte, Fleisch weiß. St. nach unten schwach verjüngt, 6-11 cm lg., faserig, weißlich, an der Spitze gestreift. L. angewachsen, blaß, dann ockerbraun. An alten Stämmen, zwischen Gras, nicht häufig. S. H. (Fig. 444.) (Schlüpfriger S.)

N. lubrica (Pers.).

Hut flach gewölbt, dann niedergedrückt in der Mitte, $2-8 \mathrm{~cm}$ br., weißlich, seltener bräunlich, anfangs mit feinen, abfallenden Schuppen, dann kahl. Sp. später hohl, zylindrisch, $5-8 \mathrm{~cm} \mathrm{lg.,}$ schuppig, dem Hut gleichfarbig. L. angewachsen, hellockerfarben, dann zimmetbraun, Schneide weiß. Zwischen Lb. in Lbwäldern, nicht häufig. H. (Fig. 445.) (Zäher S.) N. lenta (Pers.).

12. Auf Erde u. an Lb.

Auf Nd.

14.

13. Hut gewölbt, dann ausgebreitet, $5-7 \mathrm{~cm}$ br., blaß scherbengelb od. rotbraun. St. voll, ea. $6 \mathrm{~cm} \mathrm{lg.,} \mathrm{faserig} \mathrm{gestreift,} \mathrm{nach} \mathrm{unten}$ spindelf., gleichgefärbt. Schleier weiß, etwas andauernd. Fleisch gelblich. L. etwas herablaufend, zuerst hellgelblich, dann rostfarben. Auf bloßer Erde u. an faulem Holz, selten. S. H. (Bastard-S.)

N. hybrida (Bull.).

Hut flach gewölbt, dann ausgebreitet, $2-6 \mathrm{~cm}$ br., schwefelod. grünlichgelb, oft in der Mitte rostbraun, frisch feucht, mit feinen, faserigen Schuppen, meist kahl. Fleisch gelb. Schleier weiß. St. später hohl, 6-10 cm lg., schwefelgelb, dann unten rostbraun, faserig. L. angeheftet, hellgelblich, dann rostfarben. An abgestorbenen u. lebenden Stämmen von Lb., meist büschelig, häufig. S. H. (Bitterer S.)

N. amara (Bull.).

14. Hut halbkuglig, dann flach ausgebreitet, $2,5-6 \mathrm{~cm}$ br., goldgelb mit rötlichem Schimmer, am Rande u. in der Mitte mit ziegelroten Flecken, Rand anfangs seidenhaarig. Fleisch gelb, bei Verletzungen schwarz werdend. St. später hohl, gebogen, nach unten verjüngt, $5-11 \mathrm{~cm}$ lg., gleichfarbig dem Hute, faserigschuppig. Schleier weiß. L. blaßgelb, dann rostbraun. An Kiefernstümpfen rasig, nicht häufig. S. H. (Fig. 446.) (Perlschnur-S.)

N. astragalina (Fries).

Hut flach gewölbt, stumpf, 2,5-6 cm br., gelb. St. bald hohl, bis $7 \mathrm{~cm} \mathrm{lg.,} \mathrm{gelb,} \mathrm{später} \mathrm{rostbraun,} \mathrm{faserig.} \mathrm{Schleier} \mathrm{weiß,} \mathrm{bald}$ verschwindend. L. angewachesn, weißlich, dann gelb bis rostbraun. An alten Kiefern- u. Fichtenstümpfen, meist rasig, häufig. S. H. (Fig. 447.) (Gelblicher S.) N. flavida (Schaeff.).

\section{Gattung: Pholiota Fries (Schuppenpilz).}

Hut \pm dickfleischig. Schleier \pm dickhäutig, als abstehender, dickhäutig-schuppiger Ring am St. bleibend. Sporen ellipsoidisch, Membran rost- od. gelblichbraun. 
1. Hutoberfläche kahl.

Hutoberfläche schuppig od. fädig.

2. Rand glatt.

Rand gestreift, Fleisch wässerig.

3. Hutoberfläche weiß, höchstens in der Mitte hellbräunlich. 4.

Hutoberfläche braun, gelbbraun.

4. Hut halbkuglig, dann flach gewölbt, $3-6 \mathrm{~cm}$ br., trocken weiß, in der Mitte zuweilen gelblich od. bräunlich. Fleisch weiß. St. später hohl, zylindrisch, 5-8 cm lg., weiß, flockig, dann kahl, Ring weiß. L. mit Zahn herablaufend, weißlich, dann dunkelbraun, Schneide weiß. Geruch nach frischem Mehl. Geschmack angenehm. Eßbar. Auf Grasplätzen, in Gärten, häufig. F. S. (Weißlicher S.)

P. eandicans (Schaeff.).

Hut halbkuglig, 6-10 em br., in der Jugend schleimig, dann glatt, glänzend, weißlich, in der Mitte meist hellbraun, oft gefleckt. St. voll, bauchig, unten spindelig bewurzelt, 6-12 cm lg., in der Mitte mit weißem Ring, oberhalb kleiig, unterhalb sparrig-schuppig. L. frei, ausgebuchtet, blaßbraun, dann rötlichbraun. Geruch fenchelartig. Am Boden bei altem Lb., besonders Eichen u. Buchen, zerstreut. S. H. (Fig. 448.) (Bewurzelter S.)

P. radicosa (Bull.).

5. Hut flach gewölbt, später felderig-rissig, gelbbraun. St. voll, faserig, oben mehlig, Ring etwas zerschlitzt. L. angewachsen, bauchig, bläulich, dann rostbraun. Geschmack widrig-sülllich, kratzend. In Gärten, auf Lohe, nicht häufig. S. H. (Harter S.) P. dura (Bolton).

Hut gewölbt, dann flach ausgebreitet, stumpfhöckerig, oft in der Mitte niedergedrückt, $5-7 \mathrm{~cm}$ br., zimmetbraun, trocken ockerfarben, Rand dünn, mit verschwindenden Schüppchen, Fleisch wässerig. St. später hohl, 6-10 cm lg., faserig, zimmetbraun, Ring bräunlich, darüber kahl, darunter sparrig-schuppig, an der Basis dunkelbraun. L. herablaufend, hell-, dann rostbraun. Eßbar. An Lbstümpfen rasig, häufig. F. S. H. (Fig. 449.) (Stockschwamm.)

P. mutabilis (Schaeff.).

6. Hut $1-2,5 \mathrm{~cm}$ br.

Hut über $3 \mathrm{~cm}$ br.

7. Hut glockig, dann flach, $1-2,5 \mathrm{~cm}$ br., rostbraun, trocken lederbraun u. glatt. St. hohl, zerbrechlich, $3-6 \mathrm{~cm}$ lg., rostbraun, seidenhaarig, Ring ganzrandig, weiß. L. abgerundet, ockergelb, dann rostbraun, Schneide weiß. Zwischen Gras u. Moos in Wäldern u. Gärten, zerstreut. S. (Schaben-S.)

P. blattaria (Fries).

Hut glockig, dann flach gewölbt, schwach gebuckelt, $2-2,5 \mathrm{~cm}$ br., zimmetbraun, trocken ockerfarben. St. später hohl, $3-4 \mathrm{~cm}$ lg., kahl, dem Hut gleichgefärbt, Ring zart. L. angewachsen, 
dann abgelöst, ockergelb, dann zimmetbraun. An Stümpfen u. Zweigen, oft büschelig, selten. S. H. (Einfarbiger S.)

P. unicolor (Flor. dan.).

8. Hut flach gewölbt, dann in der Mitte niedergedrückt, $3-5 \mathrm{~cm}$ br., feucht schwach klebrig, umbrabraun, in der Mitte dunkler, trocken trübockerfarben u. runzlig. St. zerbrechlich, später hohl, $3-6 \mathrm{~cm}$ lg., leicht hellbraun, später (u. bei Berührung) trübbraun, seidenglänzend, Ring weißlich. L. leicht angeheftet, hell-, dann trübbraun. In Wäldern, Gebüsch auf Erde, zerstreut. S. (Unterweltlicher S.)

P. erebia (Fries).

Hut flach gewölbt, dann ausgebreitet, $3-5 \mathrm{~cm}$ br., feucht, dunkelzimmetbraun, trocken ockerfarben. St. hohl, $3-6 \mathrm{~cm}$ lg., zartbraun, faserig, Ring dünnhäutig, darüber bereift, am Grunde weißfilzig. L. angewachsen, ockerfarben, dann zimmetbraun. An alten Ndstümpfen, selten. S. H. (Fig. 450.) (Berandeter $\mathrm{S}$.)

P. marginata (Batsch).

9. St. weiß od. weißlich.

St. gelb od. seltener bräunlich.

10. Hut halbkuglig, dann ausgebreitet, $3-6 \mathrm{~cm}$ br., weißlich od. gelblich, trocken, mit zerstreuten, angedrückten, br. Schuppen. St. voll, knollig, 4-5 cm lg., faserig weißlich, an der Basis innen gelbbraun. Ring vergänglich. L. abgerundet, angeheftet, blaßbräunlich, dann rostbraun. Geruch scharf. An Birkenstämmen, selten. S. (Abweichender S.)

P. heteroclita (Fries).

Hut halbkuglig, dann flach gewölbt, dickfleischig, 6-10 cm br., weißlich od. gelblich, trocken, mit wollig-flockigen, weißlichen Schuppen, Rand faserig, eingerollt. St. voll, $10 \mathrm{~cm} \mathrm{lg.,}$ meist gekrümmt, weiß, grobschuppig, Ring schuppig-häutig, oberhalb glatt. L. mit Zahn herablaufend, blaß, dann kastanienbraun. An lebenden u. gefällten Pappelstämmen, im Süden häufiger. S. H. (Fig. 451.) (Zerstörender S.)

11. An Nd. od. auf Grasplätzen auf Erde.

$$
\text { P. destruens (Brondeau). }
$$

\section{Auf Lb.}

13.

12. Hut gewölbt, dann flach ausgebreitet, schwach gebuckelt, 4 bis $8 \mathrm{~cm}$ br., trocken, goldgelb od. gelbbraun, mit schwefelgelben, haarigen Schuppen. Sp. später hohl, $8 \mathrm{~cm}$ lg., sparrig-schuppig, gelb, Ring gelb, ganzrandig. L. angeheftet, gelb, dann rostbraun. An alten Ndstümpfen büschelig, nicht häufig. S. H. (Flammen-S.) $\quad$ P. flammula (Alb. et Schwein.).

Hut halbkuglig, dann flach gewölbt, $5-10 \mathrm{~cm} \mathrm{u}$. breiter, goldgelb, in der Mitte etwas dunkler, etwas filzig u. kleinschuppig, Fleisch weiß, gelblich werdend. St. voll, $10-15 \mathrm{~cm} \mathrm{lg.,} \mathrm{fast} \mathrm{zylin-}$ drisch, blaßgelb, Ring abstehend, strahlig gestreift. L. angeheftet, hellgelb, dann zimmetbraun. Auf Heiden u. Grasplätzen meist herdenweise, nicht häufig. S. H. (Fig. 452.) (Gold-S.)

P. aurea (Pers.). 
13. St. höchstens bis $4 \mathrm{~cm} \mathrm{lg}$.

St. über $6 \mathrm{~cm}$, meist sogar über $10 \mathrm{~cm} \mathrm{lg}$.

14. Hut flach gewölbt, stumpf, $2,5-6 \mathrm{~cm}$ br., trocken, angedrücktschuppig, gelbbraun. St. hohl, 2-4 cm lg., knollig, faserig, Ring häutig, vergänglich. L. ausgerandet, gelblich, dann blaßzimmetbraun, klein gesägt. An Lbstrünken hervorbrechend (Birke, Eberesche), selten. S. H. (Höckeriger S.)

\section{P. tuberculosa (Schaeff.).}

Hut halbkuglig, dann flach gewölbt, $4-6 \mathrm{~cm}$ br., lebhaft gelb, in der Mitte meist rötlichbraun, Oberhaut in angedrückte, flockige Schuppen zerrissen. St. gekrümmt, zäh, faserig, $3-4 \mathrm{~cm} \mathrm{lg.,}$ Ring flockig, strahlig. L. angewachsen, gelblich, dann zimmetbraun. An Holz u. Ästchen von Lb. in Gärten, lichten Wäldern, nicht häufig. S. H. (Krummbeiniger S.)

P. curvipes (Alb. et Schwein.).

15. Hut schwach klebrig od. schmierig-schleimig.

Hut stets trocken.

16.

17.

16. Hut halbkuglig, dann flach gewölbt, oft mit flachem Höcker, 6-10 cm br., schwach klebrig, trocken glänzend, goldgelb od. braungelb, mit eingedrückten, faserigen, dunkleren Schuppen. Fleisch gelb. St. voll, 6-9 cm lg., gelb, Ring abstehend, ziemlich dauerhaft, darunter angedrückt-schuppig. L. angeheftet, ausgerandet, hellgelblich, dann oliven- bis rostbraun. An Lbstämmen, häufig. H. (Fig. 453.) (Goldfell-S.)

\section{P. aurivella (Batsch).}

Hut dickfleischig, gewölbt, dann ausgebreitet, $6-20 \mathrm{~cm}$ br., goldgelb, mit schleimigem Überzug, trocken glänzend, mit sparrig. abstehenden, dunkleren, später abfallenden Schuppen. St. voll, $9-18 \mathrm{~cm} \mathrm{lg.,} \mathrm{gelb,} \mathrm{schuppig,} \mathrm{klebrig.} \mathrm{L.} \mathrm{angewachsen,} \mathrm{gelb,}$ dann rostbraun. An frischen od. gefällten Lbstämmen, zerstreut.
S. H. (Fig. 454.) (Fettiger S.)
P. adiposa (Fries).

17. Hut halbkuglig od. glockig, dann flach gewölbt, $6-10 \mathrm{~cm}$ br., trocken, blaßstrohgelb, dicht mit dicken, meist sparrig abstehenden, dunkleren Schuppen besetzt. St. voll, $8-12 \mathrm{~cm} \mathrm{lg.,} \mathrm{gelb,}$ unten rostbraun, Ring schuppig, darunter sparrig-schuppig, darüber glatt, nach dem Grunde meist verjüngt. L. blaßgrünlich-, dann umbrabraun. Geruch unangenehm. Meist rasig auf totem od. lebendem Lb. od. in der Nähe, häufig. S. H. (Fig. 455.) $\begin{array}{ll}\text { (Sparriger S.) } & \text { P. squarrosa (Flor. dan.). }\end{array}$

Hut flach gewölbt, über $11 \mathrm{~cm}$ br., trocken, gelbbraun od, goldgelb, verblassend, mit seidenartigen Fasern u. Schuppen. Fleisch gelb. St. voll, $11 \mathrm{~cm}$ lg., trocken glänzend, Ring kleinschuppig, darüber mehlig. L. angewachsen-herablaufend, gelb, dann rostbraun. An u. bei Eichenstämmen, selten. H. (Ansehnlicher S.)

P. spectabilis (Fries).

Lindau, Kryptogamenflora. I. 2. Aufl. 


\section{Gattung: Rozites Karst (Ziegenpilz).}

Hut fleischig. Schleier (velum partiale) als Ring am St. zurückbleibend, äußere Hülle (velum universale) als Flocken auf der Hutoberfläche u. als Scheide an der Stbasis zurückbleibend.

Einzige Art. Hut glockig od. halbkuglig, dann ausgebreitet, 6-12 cm br., trocken, gelb od. ockerfarben, mit spreuartigen, verschwindenden, weißen, schuppigen Flocken besetzt. St. voll, 6 bis $12 \mathrm{~cm} \mathrm{lg.,} \mathrm{weiß,} \mathrm{Ring} \mathrm{groß,} \mathrm{abstehend,} \mathrm{weiß,} \mathrm{am} \mathrm{Grund} \mathrm{eine} \mathrm{häutige}$ Scheide. L. angewachsen, dann frei, lehmfarben, dann rostbraun. Schneide schwach gesägt. Eßbar. In Lb.- u. Ndwäldern, besonders im Gebirge herdig, zerstreut. S. H. (Fig. 456.) (Runzelschüppling.)

R. caperata (Pers.).

\section{Gattung: Hyporhodius Fries (Glockenpilz).}

Hut \pm fleischig od. seltener häutig. Schleier fehlend. Sporenpulver fleischrot od. rostrot od. rosa. Sporenmembran farblos od. blaßbräunlich, Inhalt durch Öl rötlich gefärbt.

1. Hut ungestielt od. exzentrisch gestielt. (Unterg. Crepidotus Fries.) Vgl. bei Derminus 2 auf S. 134.

Hut zentral gestielt.

2. Sporen eckig od. stachlig.

3.

Sporen kuglig, ellipsoidisch od. eif., nicht eckig od. stachlig. 6.

3. Hut fast häutig od. dünn fleischig. St. dünn, meist knorpelig. 4.

Hut u. St. fleischig. (Unterg. Entoloma Fries.) 19.

4. Hut genabelt, in den St. übergehend. L. herablaufend. (Unterg. Eccilia Fries.)

Hut ungenabelt. L. nicht herablaufend.

- 5. Hut glockenf. mit geradem Rande, anfangs dem St. angedrückt. (Unterg. Nolanea Fries.)

Hut flach gewölbt mit anfangs umgebogenem Rande. (Unterg. Leptonia Fries.)

6. St. in den Hut übergehend. L. herablaufend. (Unterg. Clitopilus Fries.)

St. vom Hute scharf abgesetzt. L. nicht herablaufend. (Unterg. Pluteus Fries.)

7. Hut gewölbt, dann in der Mitte eingedrückt, trichterf., $2-3 \mathrm{~cm}$ br., graubräunlich, seidenglänzend, nach der Mitte schwarzschuppig, Rand gestreift. St. hohl, $4-5 \mathrm{~cm}$ lg., gleichfarbig, oben sehwarzschuppig. L. schwach herablaufend, fleischrot, Schneide schwarz, gezähnelt. In feuchten Lbwäldern, besonders von Erlen, selten. S. (Trauer-G.) H. atrides (Lasch).

Hut halbkuglig, $8-13 \mathrm{~mm}$ br., blaß aschgrau. St. $4 \mathrm{~cm}$ lg., ziemlich zähe, blaß bläulich, mit schwarzen, punktf. Schüppchen, glänzend. L. bogig herablaufend, ziemlich dick, fleischrot-grau od. blaß. Im Gebirge in Buchenwäldern gesellig, selten. S. (Fig. 457.) (Schwarzpunktierter G.) H. atropunctus (Pers.). 
8. Hut schwefel- od. hellgelb.

9. Hut glockig, dann flach gewölbt, oft stumpfhöckerig, 1-2,5 cm br., grüngelblich, wässerig, dann schwefelgelb od. bla $\beta$ strohgelb, feucht, trocken seidenglänzend. Rand gestreift. St. später hohl, $2-4,5 \mathrm{~cm}$ lg., gelblich od. bräunlich, oben heller, zuerst feinflockig. L. angeheftet, dann frei, hellgelblich, später fleischrot. Geruch obstartig. In Gebüschen in Parks, Wäldern, nicht häufig. S. (Fig. 458.) (Gelbsüchtiger G.) H. icterinus (Fries).

Hut glockig, dann flach gewölbt, stumpf, $2-6 \mathrm{~cm}$ br., wässerig, kahl, hellgelblich od. lehmfarben, Rand gestreift od. gekerbt. St. hohl, 6-12 cm lg., glatt, gelblich. L. angeheftet, hellgelblich, dann hellrosa. Zwischen Moos in Ndwäldern, nicht häufig. S. H. (Gelblicher G.)

H. cetratus (Fries).

10. Hut kegel- od. glockenf., spitzhöckerig, $1-3 \mathrm{~cm}$ br., kahl, feucht umbra- od. lederbraun, trocken ockergelb, seidenglänzend, Rand gestreift. St. hohl, 6-9 cm lg., kahl, glänzend, graubraun, an der Spitze wei $\beta$ bestäubt. L. angeheftet, dann abgelöst, grau, dann rot bestäubt. Zwischen Gras u. Moos auf Wiesen, im Gebüsch usw., nicht selten. F. S. (Fig. 459.) (Brustwarzen-G.)

H. mammosus (L.).

Hut kegelf., dann ausgebreitet, $1-4 \mathrm{~cm}$ br., wässerig, feucht bräunlich, trocken graubraun, seidenglänzend, Rand streifig. St. hohl, 6-8 cm lg., gestreift, seidenartig faserig. L. fast frei, grau, dann rot bestäubt. Auf Wiesen u. unter Gabüsch, häufig. S. H. (Fig. 460.) (Wiesen-G.) H. pascuus (Pers.).

11. Hutoberfläche grau- od. gelbbraun, nicht blau. (Vgl. auch placidus S. 164.)

Hutoberfläche blau, violett, schwarzblau.

12.

14.

13.

12. St. nicht gelb.

Hut flach gewölbt, schwach genabelt, ea. $2,5 \mathrm{~cm}$ br., gelbbraun, mit angedrückten, schuppigen, braunen Fasern, fein gestreift. St. fast hohl, $6 \mathrm{~cm} \mathrm{lg.,} \mathrm{gestreift,} \mathrm{kahl,} \mathrm{glänzend,} \mathrm{gelb.} \mathrm{L.} \mathrm{ange-}$ wachsen, gelblich. Besonders im Gabirge im Gebüsch in Wäldern, selten. S. (Schöner G.) H. formosus (Fries).

13. Hut halbkuglig, dann flach ausgebreitet, oft spitz höckerig, $3-5 \mathrm{~cm}$ br., wässerig, rauchbraun, leicht faserig-schuppig od. glatt, in der Mitte fast zottig-schuppig, trocken gelbbraun, seidenglänzend, Rand gestreift. St. hohl, $3-6 \mathrm{~cm} \mathrm{lg.,} \mathrm{grau}$ od. braun, selten bläulich. L. \pm br. angewachsen, hellgraubraun. Zwischen Gras u. Moos auf Wiesen, Triften usw., selten. S. H. (Rauher G.)

Hut halbkuglig, dann glockenf., br. u. stumpf gehöckert, $3-5 \mathrm{~cm}$ br., graubraun, runzlig, schuppig, am Rande faserig, oft zerschlitzt. St. $3-5 \mathrm{~cm} \mathrm{lg.,} \mathrm{bläulich,} \mathrm{anfangs} \mathrm{bereift,} \mathrm{dann}$ flockig-schuppig, oben glatt, nicht punktiert, unten weißfilzig. 
L. angeheftet, grau, dann fleischrot, ganzrandig. Auf Weiden, Wiesen, selten. S. H. (Enten-G.)

14. L. weißlich, später rot bestäubt. H. anatinus (Lasch).

L. graublau, blau od. violett.

15. Hut glockenf., dann verflacht, stumpf, $2,5 \mathrm{~cm}$ br., faserig-schuppig, ungestreift, graủbräunlich od. bläulich, mit dunklerer, zottiger Mitte. St. voll, $4 \mathrm{~cm} \mathrm{lg.,} \mathrm{kahl,} \mathrm{schwarzblau,} \mathrm{an} \mathrm{der} \mathrm{Spitze} \mathrm{weiß}$ bereift u. schwarz punktiert. L. angeheftet, weißlich. Bei alten Buchen, zerstreut. H. (Fig. 461.) (Milder G.)

H. placidus (Fries).

Hut gewölbt, dann ausgebreitet stumpf, zuletzt niedergedrückt, $1-3 \mathrm{~cm}$ br., flockig bis schuppig, mäusegrau od. stahlblau, später graubräunlich od. rußfarben. St. hohl, $2-3 \mathrm{~cm}$ lg., glatt, stahlblauviolett. L. angewachsen, weißlich. Auf Wiesen, Weiden, selten. S. (Glanzfuß-G.)

16. L. an der Schneide nicht gesägt.

H. lampropus (Fries).

Hut halbkuglig, dann ausgebreitet, $1-2 \mathrm{~cm}$ br., in der Mitte niedergedrückt, blauschwarz, dann rauchbraun, trocken fast schwärzlich, schwach schuppig. St. hohl, $2-6 \mathrm{~cm}$ lg., blauschwarz, oben schwarz punktiert. L. angewachsen, graublau, dann rötlich bestäubt, Schneide schwarz, gesägt. Zwischen Moos auf Wiesen u. Triften, zerstreut. S. H. (Sägezähniger G.) H. serrula (Pers.).

17. L. hellblau, höchstens später graublau.

Hut glockenf., dann flach gewölbt, eingedrückt, $2-4 \mathrm{~cm}$ br., meist wässerig, faserig-schuppig, blau, dann violettbräunlich, Fleisch gleichfarbig. St. voll, $3-4 \mathrm{~cm}$ br., innen u. außen violett. L. angeheftet, violett, fleischrot bestäubt. An Stümpfen von Alnus, Corylus usw. in feuchten Wäldern, nicht häufig. S. H. (Schönfarbiger G.)

H. euchrous (Pers.).

18. Hut halbkuglig, dann flach gewölbt, etwas eingedrückt, $2-5 \mathrm{~cm}$ br., blauschwärzlich, dann blauviolett, kleinschuppig, trocken graubraun, Fleisch blauschwarz, wässerig. St. voll, $4-6 \mathrm{~cm} \mathrm{lg.,}$ glatt, violett, blau, trocken bräunlich, nach unten heller $u$. weißfilzig. L. angeheftet, ausgerandet, lebhaft blau, dann graublau. Zwischen Gras u. Moos auf Waldwiesen, zerstreut. S. H. (Fig. 462.) (Stahlblauer G.)

H. chalybaeus (Pers.).

Hut halbkuglig, später niedergedrückt, $2-4 \mathrm{~cm}$ br., lebhaft blauviolett, schuppig, trocken schwarz-runzlig, Rand gestreift. St. hohl, 3-8 cm br., blau, glatt, trocken schwärzlich. L. angewachsen, hellblau. Wie vor., selten. (Blauer G.)

\section{H. lazulinus (Fries).}

19. Hutfleisch wässerig, Hutoberfläche seidig glänzend. 20.

Hutfleisch trocken, Hutoberfläche kahl od. faserig, schuppig usw.

20. Hut glockenf., dann ausgebreitet, stumpf od. mit flachem Höcker, $5-15 \mathrm{~cm}$ br., grau od. hellbräunlich, am Rande fein gestreift, 
trocken ockerfarben u. seidenglänzend. St. hohl, faserig, oft gedreht, 5-15 cm lg., kahl, weiß, seidenglänzend. L. angewachsen, ausgebuchtet bis schwach herablaufend, weißlich, rot bestäubt. Nach frischem Mehl riechend. Im Gebüsch, Wäldern, Gärten, häufig. S. H. (Fig. 463.) (Wässeriger G.)

\section{H. hydrogrammus (Bull.).}

Hut glockig, dann flach, stumpfgehöckert, $10 \mathrm{~cm} \mathrm{u}$. breiter, graubraun, glatt, trocken, dunkler gefleckt u. gestreift, schwach glänzend. St. voll, 7-10 cm br., nach unten verjüngt, außen faserig, blaß, oben schwach bereift. L. abgerundet-angeheftet, sich ablösend, schmutzig-weißlich, dann fleischrot, Schneide gesägt. In Gärten, Lbwäldern, Wiesen, häufig. F. S. (Fig. 464.) (Schildf. G.)

H. elypeatus (L.).

21. Hutoberfläche flockig, filzig, schuppig, faserig.

Hutoberfläche. kahl.

22 .

22. Hut gewölbt, dann flach od. in der Mitte niedergedrückt, $1-2 \mathrm{~cm}$ br., weiß, seidenhaarig, dann kleinschuppig, Rand eingebogen, dann geschweift. St. hohl, faserig, dann kahl, 1,5-3 cm lg., weißlich. L. angewachsen, sich ablösend, weiß, rot bestäubt. Zwischen Gras u. Moos an Wegen, auf Triften usw., nicht selten. S. H. (Fig. 465.) (Seidenhaariger G.)

H. sericellus (Fries).

Hut glockig, dann flach gewölbt, stumpf, 2,5 cm br., grau, etwas lila, flockig-schuppig. St. hohl, bis $8 \mathrm{~cm} \mathrm{lg.,} \mathrm{flockig-faserig,}$ weißlich, dann bläulich. L. angeheftet, dann sich ablösend, weißlich, rot bestäubt. Zwischen Gras u. Moos, besonders im Gebirge, nicht häufig. S. (Graublauer G.)

\section{H. griseocyaneus (Fries).}

23. L. rein weiß, später fleischrot.

L. nicht rein weiß, gelblich od. schmutzig weiß, später fleischrot.

24. Hut flachgewölbt, stumpf gebuckelt, dann ausgebreitet u. um den Buckel herum niedergedrückt, $6-10 \mathrm{~cm}$ br., graubraun od. rötlichgrau, oft gefleckt, trocken verblassend. St. hohl, $6-11 \mathrm{~cm}$ lg., schmutzig weiß, faserig, am Grunde verdickt. L. angeheftet. Nach frischem Mehl riechend. An sumpfigen Waldstellen, selten. S. (Sumpf-G.) H. helodes (Fries).

Hut glockenf., dann ausgebreitet u. gebuckelt, 2,5-6 $\mathrm{cm}$ br., schwach klebrig, weißlich, gelblich od. blaß aschgrau. St. voll, ungleich dick, $8 \mathrm{~cm}$ lg., kahl, weiß, etwas gestreift. L. ausgerandet, frei. Zwischen Moos auf Grasplätzen, nicht häufig. S (Fig. 466.) (Pflaumenartiger G.) H. prunuloides (Fries).

25. Hut gewölbt, dann flach, $8-15 \mathrm{~cm}$ br., glatt, oben der Länge nach faserig, lederbraun-bläulich. St. etwas hohl, aber mit Mark erfüllt, 6-10 cm lg., kahl, weiß, an der Spitze bereift. L. abgerundet, fast frei, blaßfleischfarben. Riecht nach frischem 
Mehl. In lichten Lbwäldern, seltener Ndwäldern, zerstreut. S. (Fig. 467.) (Bleifarbener G.) H. lividus (Bull.).

Hut gewölbt, dann flach u. niedergedrückt, geschweift, $16 \mathrm{~cm}$ br., glatt, kahl, weißgelblich. St. voll, $8-16 \mathrm{~cm} \mathrm{lg.,} \mathrm{weiß,} \mathrm{faserig.}$ L. locker angeheftet, blaß, dann rötlich. Geruch süßlich. In Lbwäldern, zerstreut. S. (Ausgerandeter G.)

H. sinuatus (Fries).

26. L. weit herablaufend.

Hut flach, dann genabelt, $2-6 \mathrm{~cm}$ br., zerbrechlich, flockigkleiig, graubraun, seidenartig, mit gestreiftem, später geschweiftem Rande. St. fast hohl, beidendig verdickt, unten weiß wollig. L. kurz herablaufend, weißlich, dann fleischrot. In feuchten Ndwäldern der Gebirge, nicht häufig. S. (Vogelnest-G.)

H. nidus avis (Secret.).

27. Hut \pm dickfleischig, flachgewölbt, in der Mitte schwach u. stumpf gehöckert, bald niedergedrückt u. trichterf., $4-11 \mathrm{~cm}$ br., weiß od. hellgrau, weich seidenartig, bisweilen etwas fleckig od. dunkler gezont, Rand zuerst eingerollt, dünn. St. voll, 3 bis $6 \mathrm{~cm} \mathrm{lg.,} \mathrm{weißlich,} \mathrm{am} \mathrm{Grunde} \mathrm{meist} \mathrm{zottig.} \mathrm{L.} \mathrm{weißlich,} \mathrm{dann}$ fleischrot. Sporen spindelf. mit 3 tiefen Längsfurchen. Geruch nach frischem Mehl. Eßbar. Auf Wiesen zwischen Moos u. Gras, in Wäldern, häufig. S. H. (Fig. 468.) (Pflaumenpilz, echter Musseron.)

H. prunulus (Scopoli).

Hut dünnfleischig, scheibig, später etwas eingedrückt, feucht wässerig, $2,5-5 \mathrm{~cm}$ br., grau, trocken rein wei $\beta$, seidenglänzend mit eingewachsenen Fäden, Rand zuerst eingerollt, glatt. St. voll, $2,5-6 \mathrm{~cm} \mathrm{lg.,} \mathrm{weißlich,} \mathrm{bei} \mathrm{Berührung} \mathrm{gelblich} \mathrm{werdend,}$ faserig-filzig. L. wei ß, dann hellgelblich bis roströtlich. Geruchlos. Geschmack bitter. Unter Gebüsch in Lbwäldern, nicht häufig. S. H. (Reinlicher G.)

H. mundulus (Lasch).

28. Hutoberfläche nackt u. kahl.

Hutoberfläche pulverig, faserig od. flockig. 31 .

29. Hut nicht zimmetbraun.

Hut glockenf., dann flach ausgebreitet, $2-6 \mathrm{~cm}$ br., zimmetbraun, am Rande gestreift. St. später meist hohl, 4-11 cm lg., glatt, kahl, weißlich. L. frei, wei $\beta$, dann fleischrot. An alten Stümpfen, besonders von Rotbuche, zerstreut. S. (Fig. 469.) (Goldjger G.)

H. chrysophaeus (Schaeff.).

30. Hut glockenf., dann flach ausgebreitet, $3-6 \mathrm{~cm}$ br., gelb, Rand gestreift. St. voll, 6-10 cm lg., weißlich od. gelblich, kahl, g€streift. L. frei, hellgelblich, dann fleischrot. An alten Lbstümpfen, besonders Rotbuche, häufig. S. H. (Fig.470.) (Löwengelber G.)

H. leoninus (Schaeff.).

Hut gewölbt, dann ausgebreitet, $2-6 \mathrm{~cm}$ br., rosenfarbig, schwach glänzend. St. voll, $3-8 \mathrm{~cm}$ br., nach oben verjüngt, wei $\beta$ bereift. L. frei, fleischrot. An alten Lbstümpfen, selten. (Rosafarbener G.)

H. roseoalbus (Fries). 

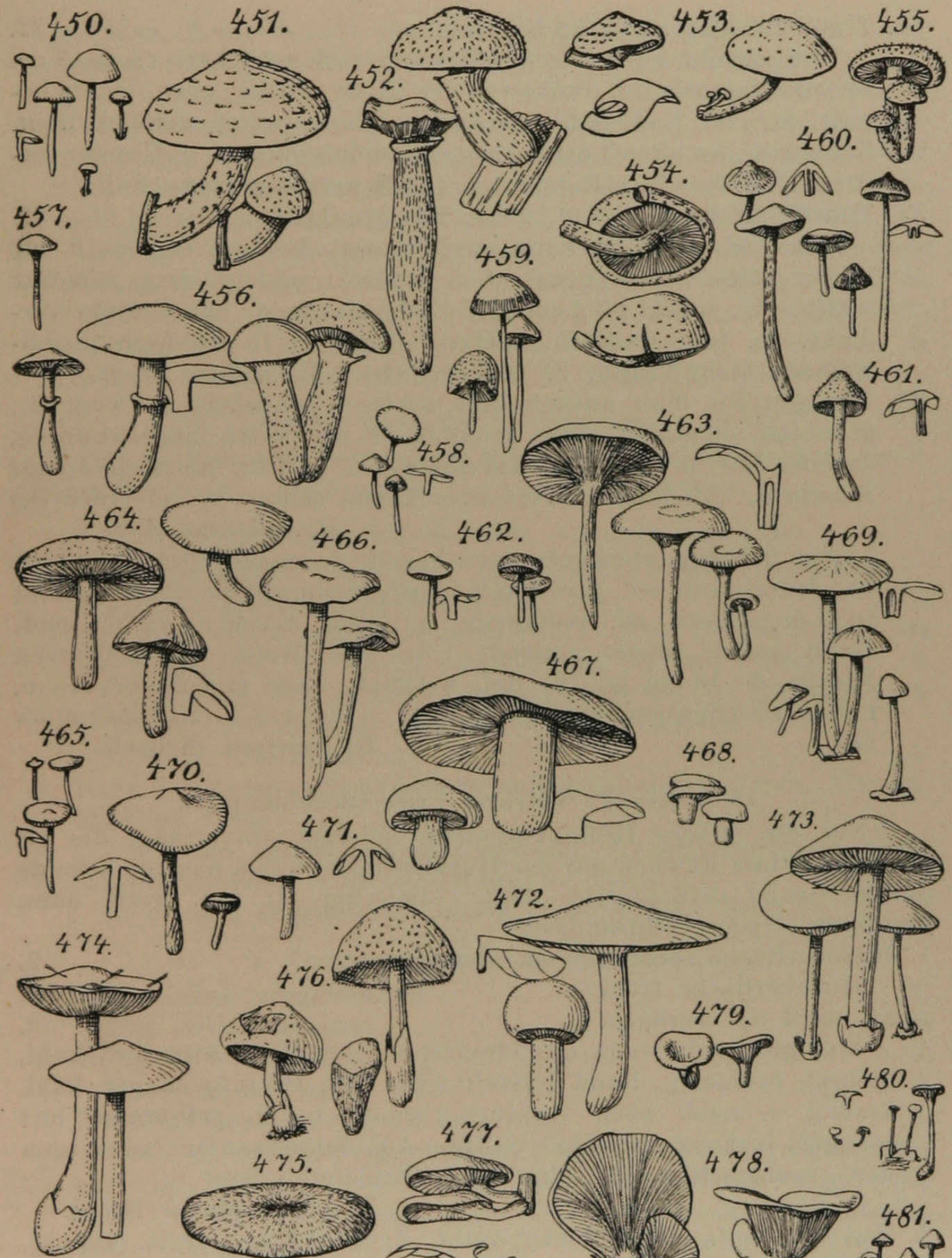

475.

$47 \%$

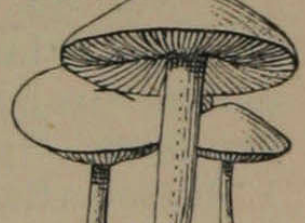

(783.

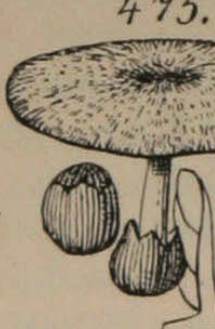

484.
4

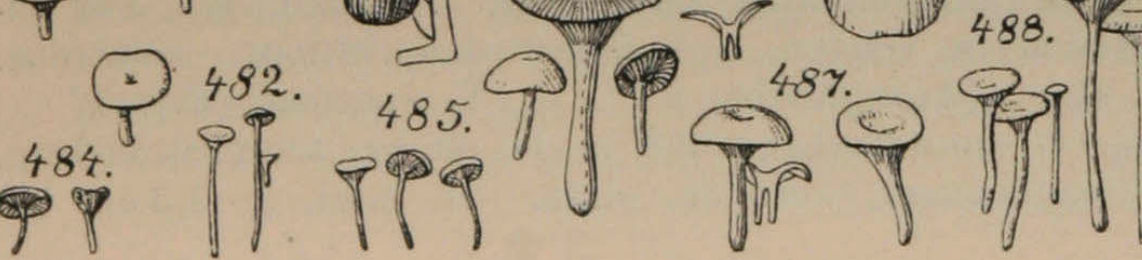

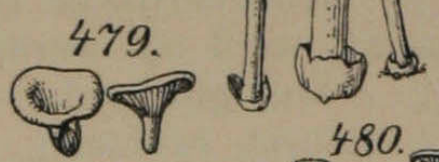

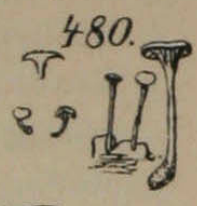

(2)

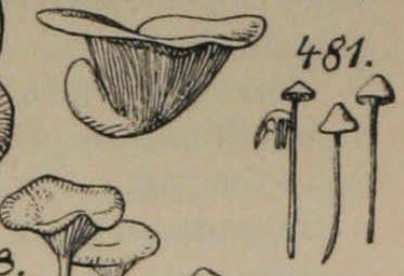

Tip ap 
31. Hutoberfläche nicht umbrabraun.

Hut gewölbt, dann ausgebreitet, schwach gehöckert, ca. $2-3 \mathrm{~cm}$ br., umbrabraun, oft dunkler in der Mitte, runzlig, grau-flockig bereift. St. voll, 3-6 cm lg., weiß od. gelblich. L. frei, weißlich, dann fleischrot. An alten Lbstämmen, besonders Buchen u. Ulmen, zerstreut. S. (Fig. 471.) (Rotsporiger G.) H.pyrrhospermus (Bull.).

32. Hutoberfläche blaugrau, leder- od. graubraun. 33.

Hut flach gewölbt, dann ausgebreitet, $3-6 \mathrm{~cm}$ br., weiß, oft in der Mitte etwas grau od. bräunlich, seidenfaserig, oft fast zottig. St. weiß, 4-6 cm lg., glatt, glänzend, am Grunde verdickt. L. frei, weißlich, später fleischrot. In Gebüsch u. Lbwäldern, nicht häufig. S. (Pelziger G.) H. pellitus (Pers.).

33. Hut gewölbt, dann ausgebreitet, schwach gehöckert, $2-3 \mathrm{~cm}$ br., graublau, bisweilen etwas grünlich, in der Mitte fädig-schuppig, dunkler. St. 4-6 cm lg., bläulichweiß. L. frei, weißlich, später fleischrot. An hohlen Weiden u. Erlen, selten. S. (Weidén-G.)

\section{H. salicinus (Pers.).}

Hut fleischig, glockenf., dann kegelf. u. ausgebreitet, $6-10 \mathrm{~cm}$ br., lederbraun od. graubraun, glatt, dann später die Oberhaut in Längsfasern od. Schuppen zerrissen, trocken verblassend, Rand gerade, meist gestreift. St. voll, weiß, mit schwarzen Fasern, 6-10 cm lg. L. frei, weißlich, dann fleischrot. An u. neben Lbstümpfen, häufig. F. S. H. (Fig. 472.) (Hirschbrauner G.)

H. cervinus (Schaeff.).

\section{Gattung: Volvaria Fries (Scheidenpilz).}

Nur die äußere Hülle vorhanden (Velum universale), die als abfallende, lose Flocken auf der Hutoberfläche u. als hüutige Scheide am St.-Grund zurückbleibt. Hut \pm fleischig. L. frei, weiß, dann fleischrot. Sporen ellipsoidisch.

1. Hutoberfläche schleimig od. klebrig.

Hutoberfläche trocken:

4.

2. St. weiß od. weißlich.

3.

Hut glockenf., dann ausgebreitet u. gebuckelt, $8 \mathrm{~cm}$ br., kahl, klebrig, rußfarbig, Rand gestreift. St. voll, $16 \mathrm{~cm}$ u. länger, kahl, knollig u. nach oben verjüngt, bräunlich od. gelbbraun, mit zottiger, lockerer Scheide. Giftig. Auf Schutthaufen, an Wegen usw., nicht selten. S. (Fig. 473.) (Schleimköpfiger S.)

V. gloiocephala (DC.).

3. Hut glockenf., dann flachgewölbt, $6-10 \mathrm{~cm}$ br., glatt, klebrig, weißlich, in der Mitte graubraun, Rand glatt. St. voll, 10 bis $15 \mathrm{~cm} \mathrm{lg.,} \mathrm{weiß,} \mathrm{anfangs} \mathrm{wollig,} \mathrm{später} \mathrm{glatt,} \mathrm{seidenglänzend,}$ Scheide schlaff, unregelmäßig zerschlitzt. Verdächtig. Auf gedüngtem Boden in Gärten, auf Gemüseäckern usw., zerstreut. F. S. (Fig. 474.) (Ansehnlicher S.)

V. speciosa (Fries).

Hut glockenf., dann flachgewölbt, $1-1,5 \mathrm{~cm}$ br., schwach klebrig, trocken seidenglänzend, weißlich, glatt. St. hohl, $1-3,5 \mathrm{~cm} \mathrm{lg}$., 
weißlich, Scheide weit abstehend, lappig zerschlitzt. Auf Lohbeeten, Gartenerde usw., nicht häufig. S. (Kleiner S.)

V. pusilla (Pers.).

4. Hut glockig, dann ausgebreitet, $4-6 \mathrm{~cm}$ br., weißlich, mit angedrückten, schwarzen Fasern. St. voll, $3-6 \mathrm{~cm} \mathrm{lg.,} \mathrm{glatt,} \mathrm{weiß-}$ lich, Scheide weit, bräunlich. In Mitsbeeten, auf lockerer Erde, nicht selten. S. (Fig. 475.) (Echter S.) V. volvacea (Bull.).

Hut glockenf., dann ausgebreitet, in der Mitte oft mit flachem Höcker, 8-20 cm br., weiß, seidenfaserig od. schuppig. St. voll, $8-16 \mathrm{~cm}$ lg., glatt, weiß, Scheide wollig-häutig, weißlich, zerschlitzt. An lebenden u. gefällten Lbstämmen, zerstreut. S. (Fig. 476.) (Seidenschwamm.) V. bombyeina (Schaeff.).

\section{Gattung: Agaricus L. (Blätterschwamm).}

Hut \pm fleischig, Schleier u. Ring fehlen. Sporenpulver weiß. Sporen kuglig od. \pm ellipsoidisch, glatt od. punktiert.

Bestimmungsschlüssel der Untergattungen.

1- Hut ohne od. mit seitlichem St. Unterg. Pleurotus Fries.

Hut regelmäßig, zentral gestielt.

2. St. dünn, oft knorpelig u. zähe, von anderer Beschaffenheit als das Hutfleisch. Hut meist dünnfleischig od. fast häutig. 3.

St. fleischig, von gleicher Beschaffenheit wie das Hutfleisch. 5.

3. L. am St. herablaufend. Unterg. Omphalia Fries.

L. nicht herablaufend.

4. Rand des Hutes anfangs dem St. anliegend, später gerade. Unterg. Mycena Fries.

Rand des Hutes anfangs eingerollt. Unterg. Collybia Fries.

5. L. herablaufend. Unterg. Clitocybe Fries.

L. buchtig angeheftet. Unterg. Tricholoma Fries.

\section{Untergattung: Pleurotus Fries.}

1. Hut stiellos, umgewendet.

Hut seitlich gestielt.

2. Hutoberfläche weiß.

Hutoberfläche nicht weiß.

3. Hut höchstens bis $1,5 \mathrm{~cm}$ br.

Hut zäh, anfangs umgewendet, dann abstehend, vorgestreckt, ohrf., 3-12 em lg., am Grunde filzig, Rand dünn, umgebogen, kahl. L. weiß. Dachziegelig an Fichtenstämmen, nicht häufig. S. H. (Ausgereckter B.)

A. porrigens Pers.

4. Hut häutig, sehr zart, verkehrt glockenf., dann umgewendet ausgebreitet, 4-10 mm br., glatt, kahl. L. weiß. Auf faulem Holz u. Zweigen, zerstreut. S.H. (Umgewendeter B.)-A. subversus Schum.

Hut dünnfleischig, umgewendet, dann abstehend, 0,5-1,5 $\mathrm{cm}$ br., feinflaumig, trocken. L. weiß, trocken gelblich. An morschen Stämmen, Ästen, Brettern, nicht selten. F. S. H. (Behaarter B.)

A. pubescens Sowerby. 
5. Hut höchstens bis $1 \mathrm{~cm}$ br.

6. Hut sehr zart, fast becherf., bisweilen hängend glockig, meist dachziegelig, 6-9 $\mathrm{mm}$ br., kahl, aschgrau, durchscheinend, gestreift, trocken fast schwarz, runzlig. L. grau, durchscheinend. An faulem Nd., zerstreut. F. S. H. (Streifig-durchsichtiger B.) A. striato-pellucidus Pers.

Hut häutig, becherf., dann flach, ausgebreitet od. mit zurückgeschlagenem Rande, 4-10 $\mathrm{mm}$ br., dunkel aschgrau, weißlich bereift, schwach gestreift, trocken schwärzlich. L. hellgrau. An faulem Lb., zerstreut. S. H. (Angewachsener B.)

7. L. gelblich od. bräunlich.

\section{A. applicatus Batsch.}

Hut fleischig, fast nierenf., $2-5 \mathrm{~cm}$ br., gelb od. fast orangefarben, mit dünnem, gelblichem od. weißlichem Filz überzogen. L. lebhaft orangefarben. Rasig an Ndstümpfen, aber auch an Lb., zerstreut. F. S. H. (Nest-B.)

A. nidulans Pers.

8. Hut fleischig, umgewendet, dann ausgebreitet, abstehend, 2 bis $5 \mathrm{~cm}$ br., blaugrau, rot- od. trübbraun, glatt, klebrig. L. gelblich od. bräunlich. An abgefallenen Birkenzweigen, nicht häufig. H. (Kalter B.)

A. algidus Fries.

Hut fleischig, umgewendet, dann abstehend, $2-5 \mathrm{~cm}$ br., schwarzblau, später schmutzig braun u. verblassend, mit einer knorpelig-gallertigen Substanz überzogen, filzig-zottig. L. weiß, dann gelblich. Rasig an alten Stämmen u. Zweigen von Lb., bes. Pappeln, zerstreut. S. H. (Schwarzblauer B.)

A. atrocoeruleus Fries.

9. L. weiß od. weißlich, nicht mit grauem, gelblichem od. rötlichem Ton.

10.

L. grau od. weißlich mit rötlichem, grauem, gelblichem od. bläulichem Ton.

10. Hutoberfläche weiß (bei lignatilis zuweilen schwarz). 14. Hutoberfläche schwärzlich, grau, braun od, ockerfarben. 13.

11. St. sehr kurz, höchstens bis $1 \mathrm{~cm} \mathrm{lg}$. 11. 12.

Hut fleischig, gewölbt, dann flach od. genabelt, $2-6 \mathrm{~cm}$ br., flockig bereift, dann kahl, weiß, selten schwarz bis aschgrau, Rand weiß. St. später hohl, gewunden, $6 \mathrm{~cm} \mathrm{lg.,} \mathrm{etwas} \mathrm{zottig.}$ L. angewachsen, rein weiß. Geruch nach Mehl. An faulendem Holz rasig. S. H. (Fig. 477.) (Holzliebender B.)

A. lignatilis Fries.

12. Hut fleischig-korkig, polsterf., ziemlich flach, $11-14 \mathrm{~cm}$ br., kahl, schwach runzlig, weiß, in der Mitte fleischrot. St. ca. $1 \mathrm{~cm} \mathrm{lg.,}$ voll. L. herablaufend, weiß. An alten' Stämmen, selten. H. (Polsterf. B.)

A. pulvinatus Pers.

Hut dünnfleischig, zähe, nierenf., $1-2 \mathrm{~cm}$ br., glatt, hellgelblich, später weiß. St. nach oben breiter, zusammengedrückt, weiß, feinschuppig. L. vom St. durch eine Linie getrennt, weiß- 
lich. Geschmack mild. Auf abgefallenen Ndästen, zerstreut. S. H. (Milder B.) A. mitis Pers.

13. Hut fleischig, dick, halbiert, flach gewölbt, hinten meist etwas eingedrückt, 5-15 cm br., grau, braun, dann ockerfarben, glatt, verblassend. St. kurz, filzig-zottig. L. herablaufend, hinten schwach anastomosierend, weiß, dann ockerfarben. Sporenpulver sich violett bis hellbräunlich verfärbend. Eßbar. Meist dachziegelig an Lbstämmen (Weide, Pappel), nicht selten. H. (Weiden-
B.)
A. salignus Pers.

Hut fleischig, fast halbiert, $6-12 \mathrm{~cm}$ br., zuerst schwärzlich, dann aschgrau od. braun, glatt, Rand eingerollt. St. voll, 2 bis $4 \mathrm{~cm}$ lg., weiß, kahl, am Grunde striegelhaarig. L. weiß, herablaufend, hinten anastomosierend. Rasig an Lbstämmen, häufig. S. H. (Fig. 478.) (Austern-B.)

A. ostreatus Jacq.

14. Hut höchstens bis $3 \mathrm{~cm}$ br.

15.

Hut über $5 \mathrm{~cm}$ br.

15. L. grau od. graubraun.

16.

Hut halbkreisf., flach, $1-2,5 \mathrm{~cm}$ br., zerbrechlich, am Rande gestreift, violett, dann fleischfarben. St. am Grunde zottig, sehr kurz. L. scharf abgegrenzt, fleischrot. Auf altem Rotbuchenholz, selten. S. H. (Flacher B.) A. planus Fries.

16. Hut nierenf., in der Mitte niedergedrückt, $0,5-1,5 \mathrm{~cm}$ br., glatt, kahl, graubraun. St. fast zylindrisch, zottig, aufsteigend. L. graubraun, am St. scharf abgegrenzt. Zwischen Moos u. Lb. auf der Erde, meist in Ndwäldern, nicht selten. S. H. (Fig. 479.) (Zittriger B.)

A. tremulus Schaeff.

Hut spatelf., flach od. etwas aufgerichtet, $1-3 \mathrm{~cm}$ br., graubraun, trocken weißlich, seidenhaarig. St. zusammengedrückt, aufrecht, 1-3 cm lg., gleichfarbig, weißzottig. L. herablaufend, grau, später weißlich. An Stümpfen od. auf Erde in Lbwäldern, selten. H. (Blumenblattartiger B.)

A. petaloides Bull.

17. Hut dickfleischig, gewölbt, huff., $5-8 \mathrm{~cm}$ br., gelbbraun, mit verschwindendem, dunkelbraunem Filz, Rand anfangs eingerollt. St. bis $2 \mathrm{~cm} \mathrm{lg.,} \mathrm{gelbbraun,} \mathrm{ebenso} \mathrm{filzig.} \mathrm{L.} \mathrm{abgerundet,} \mathrm{gelb-}$ lichweiß. Dachziegelig an Lbstämmen, zerstreut. S. H. (Später B.)

A. serotinus Schrader.

Hut fleischig, schwach gewölbt, obovat od. nierenf., abstehend, 6-8 cm br., kahl, graubräunlich, dann ledergelb. St. sehr kurz, zylindrisch, zottig. L. herablaufend, weißlich-bläulich. An Lbstämmen, selten. S. (Lungen-B.) A. pulmonarius Fries.

\section{Untergattung: Omphalia Fries.}

1. Hut anfangs glockenf., Rand anfangs gerade, dem St. angedrückt.

Hut von Anfang an ausgebreitet, Rand anfangs umgebogen. 7.

2. Hut u. St. weiß.

Hut u. St. nicht weiß. 
3. L. gleich lg.

Hut halbkuglig, dann in der Mitte niedergedrückt, papillenf., 4-7 mm br., schwach flockig, Rand gefurcht. St. fädig, 6-13 mm lg. L. dünn, abwechselnd halbiert. An faulenden Kräutern u. Stengeln in Sümpfen, zerstreut. S. (Fig. 480.) (Schlanker B.)

A. gracillimus Weinmann.

4. Hut halbkuglig, 1-2 mm br., flockig-flaumig, gefurcht. St. fädig, 6-13 mm lg., hohl, kahl, am Grunde flockig. L. wenige, faltenf., weiß. An abgefallenen Eichen-u. Rotbuchenblättern, rasig, nicht selten. H. (Vielbrüdriger B.) A. polyadelphus Lasch.

Hut halbkuglig, dann ausgebreitet, 5-10 $\mathrm{mm}$ br., Rand gestreift. St. zerbrechlich, $2-3 \mathrm{~cm}$ lg., am Grunde zwiebelf. verdickt. L. wenige, faltenf., weiß. An feucht liegendem Holz, Stümpfen, selten auf Erde in Wäldern, Gärten, zerstreut. S. (Unversehrter B.)

A. integrellus Pers.

5. L. weiß od. weißlich.

6.

Hut glockig, dann in der Mitte niedergedrückt, 6-15 mm br., wässerig, rötlich- od. bräunlichgelb, Rand streifig. St. $2-6 \mathrm{~cm}$ lg., später hohl, gelbbraun, am Grunde gelbbraun-zottig. L. gelb, am Grunde aderig verbunden. An modernden Ndstämmen in feuchten Wäldern, nicht selten, besonders im Gebirge. F. S. H. (Zerbrechlicher B.)

A. fragilis Schaeff.

6. Hut gewölbt, dann niedergedrückt, trichterf., 5-10 $\mathrm{mm}$ br., graubraun, in der Mitte dunkler, Rand gestreift. St. borstig, zerbrechlich, 3-5 cm lg., gleichfarbig, oben oft bläulich. L. weiß, sichelf. Zwischen Gras u. Moos in Gärten u. Wäldern, nicht häufig. S. H. (Fig. 481.) (Borstenstieliger B.) A. setipes Fries.

Hut halbkuglig, dann in der Mitte niedergedrückt u. oft trichterf., 2-13 $\mathrm{mm}$ br., orangefarben, Mitte oft dunkler, Rand streifig. St. borstenf., 2-4 cm lg., gelblich od. bräunlich, oben oft violett. L. sichelf., weißlich. Zwischen Moos u. Gras auf Heiden, Triften usw., häufig. S. H. (Fig. 482.) (Spangen-B.)

7. St. weiß, weißlich od. gelblich.

A. fibula Bull.

St. aschgrau, grau- od. rötlichbraun, schwarz.

8. Hut reinweiß.

Hut gelblich, bräunlich,' bläulich, erst trocken weißlich. 10.

9. Hut häutig-durchscheinend, halbkuglig, ausgebreitet, in der Mitte eingedrückt, $1-1,5 \mathrm{~cm}$ br., Rand gestreift. St. voll, weiß, oft oben gelblich, am Grunde striegelhaarig. L. weiß, weitläufig. An faulem Holz, Baumstümpfen, Grubenhölzern, nicht häufig. S. (Sternf. B.)

A. stellatus Fries.

Hut eingedrückt, trichterf., $1,5-2 \mathrm{~cm}$ br., seidenglänzend, Rand oft verbogen. St. voll, $1-2 \mathrm{~cm} \mathrm{lg.,} \mathrm{weiß,} \mathrm{unten} \mathrm{verdickt}$ u. schwach zottig. L. weiß, sehr schmal. Zwischen Moos auf Triften, Heiden, selten. S. H. (Fig. 483.) (Becheriger B.)

A. seyphoides Fries. 
10. L. br., sehr weitläufig stehend.

11.

Hut genabelt, schlaff, $6 \mathrm{~cm}$ br., wässerig, kahl, bläulich, trocken weißlich, Rand geschweift, etwas wellig. St. hohl, 6-8 cm lg., kahl, weißlich, am Grunde wurzelnd $u$. behaart. L. sehr dicht stehend, weißlich. Zwischen faulenden, feuchtliegenden Rotbuchenblättern, selten. S. (Wässeriger B.)

\section{A. hydrogrammus Fries.}

11. Hut flachgewölbt, in der Mitte eingedrückt, $1-3 \mathrm{~cm}$ br., wässerig, feucht strahlig gestreift, trocken glatt, schwach seidenfaserig, weißlich, gelblich od. hellbräunlich, Rand gekerbt. St. hohl, $1-3 \mathrm{~cm}$ lg., wie der Hut gefärbt, am Grund feinhaarig. L. weißlich. Auf Feldern, Heiden, Triften, Sümpfen, häufig. S. H. (Fig. 484.) (Schirmtragender B.) A. umbellifer L.

Hut häutig, flach gewölbt, in der Mitte eingedrückt, 5-9 mm br., gelblich, ockerfarben, später weißlich. St. voll, $1-3 \mathrm{~cm}$ lg., gelblich, unten meist bräunlich od. schwärzlich, bereift. L. orangefarben, anfangs rosenrot. Auf Triften, in Sümpfen, an Wegen, häufig. S. H. (Fig. 485.) (Dreifarbiger B.)

A. tricolor Alb. et Schwein.

12. St. nicht schwarz.

Hut flach ausgebreitet, dann niedergedrückt, fast trichterf., 6-11 mm br., undeutlich gehöckert, braun, Rand flockig. St. später hohl, ea. $4 \mathrm{~cm}$ lg., schwarz, am Grunde grau bereift. L. bräunlich, entfernt stehend. An faulem Kiefernholz, Zäunen, Pfählen, selten. S. (Schwarzstieliger B.) A. atripes Rabenh.

13. L. weiß od. weißlich.

14.

L. graubraun, rötlich od. gelblich.

15.

14. Hut trichterf., $2-4 \mathrm{~cm}$ br., grau. St. bis $4 \mathrm{~cm} \mathrm{lg.,} \mathrm{wenig} \mathrm{röhrig,}$ aschgrau, kahl. L. etwas entfernt stẹhend, reinweiß. Auf faulem Holz in Wäldern, selten. S. H. (Fig. 486.) (Weißblättriger B.)

\section{A. leucophyllus Fries.}

Hut niedergedrückt, dann trichterf., $3 \mathrm{~cm}$ br., wässerig, feucht grau od. braun, trocken weißlich od. gelblich mit bräunlicher Mitte. St. 2-4 em lg., graubraun, an der Spitze mit weißen Längsfasern. L. dichtstehend, weißlich. Am Grunde alter Stämme, auf feuchtem Boden, selten. S. (Fig. 487.) (Genabelter B.)

A. umbilicatus Schaeff.

15. Hut schwach gewölbt, in der Mitte eingedrückt, 6-11 mm br., wässerig, feucht gestreift, trocken glatt, seidenglänzend, dunkelbraun, später weißlich od. bräunlich. St. später hohl, $2,5 \mathrm{~cm}$ lg., graubraun, kahl. L. ziemlich entfernt stehend, graubraun. Zwischen Moos u. Flechten auf Heiden, Schuttstellen, nicht häufig. F. S. H. (Ländlicher B.)

A. rusticus Fries.

Hut in der Mitte eingedrückt, trichterf., $1-2 \mathrm{~cm}$ br., wässerig, strahlig gestreift, hellrötlichbraun, trocken verblassend, seidenhaarig. St. später hohl, bis $3 \mathrm{~cm}$ lg., gleichgefärbt, glatt. L. etwas entfernt stehend, schmal, rötlich, dann gelblich. An 
Wegen, auf Grasplätzen, häufig. S. H. (Fig. 488.) (Gebecherter B.) A. pyxidatus Bull.

III. Untergattung: Mycena Fries.

1. St. u. L. bei Verletzungen milchend.

Nicht milchend.

2. Saft rot.

Hut zylindrisch, dann glockenf., $1-2 \mathrm{~cm}$ br., grau od. schwärzlich, selten mehr weißlich od. bräunlich, Rand gestreift. St. 5-8 cm lg., gleichfarbig, am Grund weißzottig. Saft milehweiß. Zwischen Moos in Wäldern, häufig. S. H. (Milchender B.)

A. lactescens Schrad.

3. L. weiß od. weißlich.

Hut glockenf., dann flachgewölbt, $0,5-1,5 \mathrm{~cm}$ br., bräunlich od. schmutzig rötlich, gestreift, Rand anfangs blutrot. St. 6 bis $11 \mathrm{~cm} \mathrm{lg.,} \mathrm{blaß} \mathrm{rotbraun,} \mathrm{am} \mathrm{Grunde} \mathrm{zottig.} \mathrm{L.} \mathrm{hellrötlich,}$ Schneide rotbraun. Zwischen Moos in Wäldern, an Stümpfen, häufig. S. H. (Fig. 489.) (Blutender B.)

A. sanguinolentus Alb. et Schwein.

4. Hut kegel-glockenf., dann ausgebreitet, $6-9 \mathrm{~mm}$ br., braunrötlich, gestreift. St. straff, 6-8 cm lg., kahl, am Grunde zottig. L. weißlich. Saft dunkelrot. In Ndwäldern, zerstreut. S. H. (Blutiger B.)

A. cruentus Fries.

Hut glockenf., $1-2,5 \mathrm{~cm}$ br., weißlich, dann rötlich, glatt, Rand gezähnelt. St. hohl, $3-6 \mathrm{~cm} \mathrm{lg.,} \mathrm{rötlich,} \mathrm{weißstaubig.}$ L. mit Zähnchen herablaufend, weißlich. Saft dunkelblutrot. An faulenden Ndstämmen, nicht häufig. S. H. (Fig. 490.) (Blutfuß-B.)

A. haematopus Pers.

5. St. klebrig.

St. trocken.

6. Hut u. St. rein weiß od. zitronengelb.

Hut u. St. nie rein weiß od. zitronengelb.

7. Reinweiß. Hut gewölbt, schwach genabelt, $4-7 \mathrm{~mm}$ br., gefurcht. St. haardünn, über $2,5 \mathrm{~cm}$ lg., kahl, dick schleimig. L. herablaufend. An faulenden Blättern, Stengeln, besonders im Gebirge, zerstreut. S. H. (Fig. 491.) (Betauter B.)

A. roridus Fries.

Hut zylindrisch-glockenf., dann halbkuglig, $4-7 \mathrm{~mm}$ br., zitronengelb, gestreift. St. $2-3 \mathrm{~cm} \mathrm{lg.,} \mathrm{gelb,} \mathrm{am} \mathrm{Grund} \mathrm{zottig,}$ klebrig. L. weiß. Auf abgefallenen Nd. in Ndwäldern, zerstreut. S. H. (Zitronengelber B.)

A. eitrinellus Pers.

8. Hut halbkuglig, dann in der Mitte etwas eingedrückt, $1-2 \mathrm{~cm}$ br., grau od. braun, klebrig, Rand streifig. St. $3-6 \mathrm{~cm} \mathrm{lg.,}$ gleichfarbig, am Grunde zottig, klebrig. L. weiß, etwas herablaufend. Zwischen Moos u. Nd. in Ndwäldern herdig, häufig. S. H. (Fig. 492.) (Gemeiner B.)

A. vulgaris Pers.

Hut glocken- od. kegelf., ausgebreitet, $1-2 \mathrm{~cm}$ br., wei $\beta$, meist mit gelber, bräunlicher od, rötlicher Mitte, auch grau od. 
braun, klebrig, Rand streifig. St. 5-10 cm lg., weiß, unten gelb, klebrig. L. weiß od. hellgrau, mit Zahn herablaufend. Zwischen Moos herdig in Lb- u. Ndwäldern, häufig. S. H. (Fig. 493.) (Flügel-B.)

A. epipterygius Scopoli.

9. L. sich verfärbend od. verblassend.

L. nicht verblassend od. sich verfärbend.

10.

27

10. St. sehr zerbrechlich.

11 .

St. zähe.

15.

11. St. nicht schwarzblau gefärbt.

12.

Hut glockenf., mit stumpfem Buckel, 6-11 mm br., braun, später graubläulich, mit weißem, bald verschwindendem Reif bedeckt, gefurcht. St. 1-6 cm lg., schwarzblau, Basis schwach knollig. L. weißlich. Zwischen Nd., auf Erde, nicht häufig. S. (Schwarzblauer B.)

A. atrocyaneus Batsch.

12. \pm stark alkalinisch riechend.

Geruchlos.

13. Hut glocken- od. stumpf kegelf., dann ausgebreitet, $1-1,5 \mathrm{~cm}$ br., grau od. bräunlich, am Rande heller, feucht durchscheinend, gestreift, trocken grau, glatt, schwach seidenfaserig. St. $4-6 \mathrm{~cm}$ lg., grau od. fast weißlich, am Grunde weißfaserig. L. weißlich, dann grau. Geruch schwach laugenartig. An Wegen, Grasplätzen in Gärten, Wäldern, nicht selten. S. H. (Fig. 494.) (Glatter B.)

A. laevigatus Pers.

Hut ebenso, 1-2 cm br., feucht schwärzlich, grau od. braungrau, am Rand heller, gestreift, trocken heller, glänzend. St. $5-8 \mathrm{~cm}$ br., grau od. bräunlich, glänzend, am Grunde zottig. L. weißlich, später grau, Schneide weiß. Geruch stark laugenartig. An Stämmen, im Gebüsch, Wäldern, häufig. F. S. H. (Fig.'495.) (Alkalischer B.)

A. alcalinus Fries.

14. Hut glockenf., stumpf, $1-3 \mathrm{~cm}$ br., grau od. graubräunlich, feucht durchscheinend. St. 6-12 cm lg., weißlich, fein gestreift, glänzend, am Grunde faserig. L. weißlich. In Waldstümpfen zwischen Moos, selten. S. (Glasheller B.) A. vitreus Fries.

Hut glockenf., dann ausgebreitet, 2,5-3,5 cm br., grau-bräunlich, durchscheinend, trocken zinnfarbig. St. $6-8 \mathrm{~cm} \mathrm{lg.,} \mathrm{kahl,}$ glatt, glänzend, blaß, im Alter zusammengedrückt. L. mit Zähnchen herablaufend, aderig verbunden, graubräunlich-weiß. Zwischen Gras in Wäldern, selten. S. (Zinnfarbiger B.)

\section{A. stanneus Fries.}

15. St. gelb od, braunlila.

16.

St. weiß, grau, bräunlich, graubraun.

16. Hut glocken- od. kegelf., $2-5 \mathrm{~mm}$ br., orangefarben, Rand gestreift. St. borstenf., 4-6 cm lg., gelb, an der Spitze schwach bereift, glänzend, am Grunde wurzelnd. L. weiß, dann gelb, Schneide weiß. Zwischen Lb. u. Ästchen, nicht häufig. F. S. H. (Fig. 496.) (Nd-B.)

A. acicula Schaeff. 
Hut kegelf., 1-1,5 cm br., gestreift, rötlich-violett, am Rande zerschlitzt. St. schlaff, fädig, fein gestreift, braunlila. L. weißlich-grau. Zwischen Torfmoosen in Wäldern, selten. S. H. (Veilchen-B.)

A. janthinus Fries.

17. Hut höchstens bis $2 \mathrm{~cm}$ br., durchweg kleinere Pilze. 18.

Hut über $2 \mathrm{~cm}$ br. bis $4 \mathrm{~cm}$.

24.

18. St. ganz kahl, höchstens am Grunde haarig.

19.

Hut kegel-glockenf., stumpf, $0,5-1,5 \mathrm{~cm}$ br., grau od. blaugrau, gestreift, kahl. St. fädig, $4-9 \mathrm{~cm}$ lg., zartflaumig, am Grunde gedreht wurzelnd, grau od. weißlich. L. frei, grau mit blasser Schneide. An Stümpfen, zwischen Moos, nicht häufig. S. H. (Fig. 497.) (Hüllen-B.)

A. amictus Fries.

19. St. schlaff, zähe.

20.

St. straff, zähe.

22 .

20. L. angewachsen.

21.

Hut glocken- od. kegelf., stumpf, dann ausgebreitet, 0,5 bis $1,5 \mathrm{~cm}$ br., grau, braungrau od. ockerbraun, seltener weißlich, gestreift. St. fädig, $4-8 \mathrm{~cm} \mathrm{lg.,} \mathrm{weißlich} \mathrm{od.} \mathrm{bräunlich,} \mathrm{unten}$ wurzelnd, weißzottig. L. frei, weiß, dann grau werdẹnd. Zwischen Moos u. Lb. in Wäldern, häufig. F. S. H. (Fig. 498.) (Fadenstieliger B.)

A. filipes Bull.

21. Hut glockenf., dann flach gewölbt, $4-7 \mathrm{~mm}$ br., weißlich, später graubraun, gestreift, trocken runzlig, matt. St. fädig, $5-10 \mathrm{~cm}$ lg., wurzelnd, faserig. L. br. angewachsen, weißlich. Zwischen Moos u. Lb. in Wäldern, selten. S. H. (Hiufälliger B.)

\section{A. debilis Fries.}

Hut glockenf., schwach gebuckelt, 1-1,5 cm br., braun, oft bräunlich-grauweißlich, mit bräunlicher Mitte, dann verblassend, gestreift. St. fädig, $2,5 \mathrm{~cm} \mathrm{lg.,} \mathrm{kahl,} \mathrm{fein} \mathrm{gestreift,} \mathrm{glänzend.}$ L. ringf. verbunden u. angewachsen, weißlich od. blaßrötlich. An grasigen Stellen der Wälder, selten. S. H. (Halskragen-B.) A. collariatus Fries.

22. St. nicht in der ganzen Länge weiß.

Hut halbkuglig, dann ausgebreitet, stumpf, $1-2 \mathrm{~cm}$ br., rein weiß, seltener gelb- od. braunfleckig, Rand feinstreifig. St. weiß, 8-14 $\mathrm{cm}$ lg., glatt, kahl, am Grunde striegelhaarig, wurzelartig eingesenkt. L. wei $ß$, zahnf. herablaufend. Rasig an alten Kiefernstümpfen, zerstreut. S. H. (Kappen-B.) A. cucullatus Fries.

23. Hut halbkuglig od. in der Mitte stumpfhöckerig, $1-2 \mathrm{~cm}$ br., grau-, dunkelbraun od. weißlich, in der Mitte braun, glatt, feucht klebrig, Rand gestreift. St. klebrig, $3-8 \mathrm{~cm}$ lg., braun od. an der Spitze weiß od. etwas bläulich, am Grunde weißhaarig, wurzelnd. L. zahnf. etwas herablaufend, weiß, später am Grunde hellgrau od. rötlich, Schneide weiß. Rasig an alten Lbstümpfen, zerstreut. H. (Klingel-B.)

A. tintinabulum Fries.

Hut eif., dann glockenf. u. so bleibend, stumpf, bis $2 \mathrm{~cm}$ br., in der Mitte schwarz, am Rand grau od. weiß, gestreift. St. 
5-10 cm lg., bläulichgrau od. schwärzlich, verblassend, glatt, kahl, am Grunde angeschwollen u. behaart, scharf abgesetzt wurzelnd. Rasig an Ndstämmen, nicht häufig. H. F. (Fig. 499.) (Parabolischer B.)

A. parabolicus Fries.

24. St. ohne Längsstreifen.

Hut stumpf kegelf., selten glockenf. mit stumpfem Höcker, $2-4 \mathrm{~cm}$ br., aschgrau od. bräunlich, Rand runzlig-streifig. St. steif, 6-10 cm lg., grau od. bräunlich, mit dicht stehenden, vertieften Längsstreifen, am Grunde wurzelnd u. striegelhaarig. L. frei od. hakig eingewachsen, weißlich, rötlich od. grau. Rasig an alten Lbstämmen, häufig. S. H. (Fig. 500.) (Längsrilliger B.)

A. polygrammus Bull.

25. L. weiß od. etwas rötlich.

Hut glockig, dann flach gewölbt, $2-3 \mathrm{~cm}$ br., hellgrau od. braun, gestreift. St. $4-6 \mathrm{~cm} \mathrm{lg}$., kahl, graubraun, am Grunde fast kahl, wurzelnd. L. grau, ausgerandet, mit Zähnchen angeheftet, am Grunde faltig verbunden. Rasig an alten Kiefernstämmen, selten. S. (Ausgeschnittener B.)

\section{A. excisus Lasch.}

26. Hut kuglig nickend, mit gezähneltem Rande, dann glockenf., zuletzt in der Mitte niedergedrückt, $2-3 \mathrm{~cm}$ br., braun, Rand gestreift, St. faserig gedreht, an der Spitze unterbrochen gestreift, anfangs nach abwärts gekrümmt, weißlich od. bräunlich, faserig bereift. L. angewachsen, weiß, am Grunde blaugrau. Rasig an alten Stämmen, zerstreut. S. H. (Fig. 501.) (Nickender B.)

A. inclinatus Fries.

Hut stumpf kegel- od. glockenf., dann ausgebreitet u. stumpfhöckerig, über $4 \mathrm{~cm}$ br., grau od, graubraun, selten weißlich, runzlig gestreift. St. fest, 6-10 cm lg., glatt, kahl, glänzend, grau, bräunlich, nach oben heller, spindelf. wurzelnd. L. mit Zahn herablaufend, weiß od. blaß rötlich, am Grunde aderig verbunden: Eßbar. Rasig an Lbstämmen, selten an bearbeitetem Holz od. auf dem Boden, häufig. F. S. H. (Fig. 502.) (Mützenhelmling.)

A. galericulatus Seopoli.

27. L. mit dunklerer gezähnter Schneide, die mit gefärbten Cystiden besetzt ist.

L. mit gleichfarbiger od. hellerer Scheibe.

28.

33.

28. Hut rot.

Hut blaßbraun, grau, schmutzig grau usw. 30.

29. Hut halbkuglig, stumpfhöckerig, $4-5 \mathrm{~mm}$ br., rosenrot, dann verblassend, gestreift. St. $3-5 \mathrm{~cm} \mathrm{lg.,} \mathrm{rosenrot,} \mathrm{unten} \mathrm{weiß-}$ faserig. L. etwas herablaufend, weißlich-od. rosenrot, Schneide dunkler. Zwischen Moos in Ndwäldern, zerstreut. S. H. (Rosenroter B.)

A. rosellus Fries.

Hut glockenf., spitzhöckerig, 0,5-1,5 cm br., scharlachrot, in der Mitte dunkler, Rand gestreift. St. bis $6 \mathrm{~cm} \mathrm{lg.,} \mathrm{gleich-}$ farbig, unten stark weißzottig. L. angewachsen, rötlich mit Lindau, Kryptogamenflora. I. 2. Aufl. 
blutroter Schneide. An Nd., Zapfen, Ästen von Nd., selten. S. H. (Scharlachroter B.) A. coccineus Sowerby.

30. Hut höchstens bis $1,5 \mathrm{~cm}$ br.

Hut halbkuglig, dann flach, $2-6 \mathrm{~cm}$ br., wässerig, schmutzig weißlich od. rötlich, mit anliegenden violetten od. braunvioletten Fasern, Rand gestreift. St. hohl, schmutzig weiß, violettfaserig, $5-8 \mathrm{~cm} \mathrm{lg.} \mathrm{L.} \mathrm{trübviolett,} \mathrm{dann} \mathrm{bräunlich.} \mathrm{Schneide} \mathrm{trüb-}$ violett. Geruch angenehm. Zwischen altem Lb. in Lbwäldern, nicht selten. S. H. (Fig. 503.) (Gezähnelter B.)

\section{A. denticulatus Bolton.}

31. In Ndwäldern.

Hut stumpfkegelf. od. glockenf., $1-1,5 \mathrm{~cm}$ br., schmutzig gelbbraun, in der Mitte oft dunkler, Rand streifig. St. hohl, $5-6 \mathrm{~cm}$ lg., gelbbraun, oben heller, am Grunde weißzottig. L. leicht angeheftet, schmutzig weiß, Schneide braun. In Buchenwäldern, zwischen Gras, in Gärten rasig, zerstreut. S. H. (HaferB.)

A. avenaceus Fries.

32. Hut stumpfkegelf. od. glockenf., dann halbkuglig, oft stumpfhöckerig, 1-1,5 cm br., graublau, graubraun, am Rand gelblich od. fast grünlich, gestreift. St. glatt, $2-6 \mathrm{~cm} \mathrm{lg}$., gelbbraun, am Grunde faserig-flockig. L. angewachsen, weißlich od. gelblich, Schneide lebhaft safranfarben. Zwischen abgefallenen Nd., nicht selten. S. H. (Fig. 504.) (Zierlicher B.) A. elegans Pers.

Hut glockenf., $6-9 \mathrm{~mm}$ br., blaßbraun, dann verschieden gefärbt, außer dem Buckel streifig, bläulich flockig. St. ebenso gefärbt, $4 \mathrm{~cm}$ lg., Grund schwach knollig, filzig. L. locker angeheftet, weißlich, an der Schneide durch dunklere Flöckchen gewimpert. An alten Ndstrünken, selten. H. (Fransiger B.)

A. marginellus Pers.

33. St. am Grunde einer kreisf. Platte aufsitzend od. von striegeligen, stachligen Haaren dicht umgeben.

St. am Grunde ohne Platte, kahl od. nur wenig behaart. 36.

34. Hut weiß, grau od. bräunlich.

Hut glockenf., stumpf, $2-7 \mathrm{~mm}$ br., orange- od. rosenrot, durchscheinend, glatt, am Scheitel schwach kleiig. St. haarf. rötlich, kahl, am Grunde knollig verdickt, mit strahligen, striegligen Haaren. L. angewachsen, rosenrot. Auf faulenden Farnwedeln, besonders im Gebirge, nicht selten. H. (Fig. 505.) (Farnbewohnender B.)

A. pterigenus Fries.

35. Hut glockenf., dann ausgebreitet, $3-5 \mathrm{~mm}$ br., durchscheinend, wei $\beta$, gestreift. St. zerbrechlich, $1-2 \mathrm{~cm}$ lg., weiß, kahl, unten knollig angeschwollen $u$. mit striegligen, abstehenden, weißen Haaren besetzt. L. frei, weiß. An moderndem Lb., Nd., Stengeln, Zweigen, nicht selten. S. H. (Fig. 506.) (Igelfüßiger B.)

A. echinipes Lasch.

Hut glockenf., stumpf, dann flachgewölbt, $4-8 \mathrm{~mm}$ br., weiß, grau od. bräunlich, mit dunklerer Mitte, Rand gestreift. St. 
fädig, 2-6 cm lg., weißlich od. bräunlich, aus einer kreisf., flachkegelf., am Rande gefransten, strahlig streifigen, $2-3 \mathrm{~mm}$ br. Scheibe entspringend. L. frei, weiß. Auf moderndem Lb., Ästen, Stengeln usw., zerstreut. S. H. (Fig. 507.) (Säulenf. B.)

A. stylobates Pers.

36. Hut höchstens bis $5 \mathrm{~mm}$ br., sehr zart. St. fädig.

Hut breiter, wenn nur $5 \mathrm{~mm}$ br., dann lebhaft gefärbt. St. etwas dicker.

40.

37. St. in der ganzen Länge feinflaumig od. fein bereift. 38 .

St. kahl, höchstens am Grunde behaart.

39.

38. Hut gewölbt, etwas genabelt, dann niedergedrückt, $2-5 \mathrm{~mm}$ br., rosa, kahl, glatt. St. $3 \mathrm{~cm}$ lg., haardünn, etwas schlaff, feinflaumig, gelb. L. meist 6, rosa. An Stengeln, St.. Blättern, nicht häufig. S. (Halmiger B.)

A. stipularis Fries.

Hut halbkuglig, gehöckert od. eingedrückt, $2-5 \mathrm{~mm}$ br., rotbraun, grau od. weißlich, gefurcht. St. bis $2 \mathrm{~cm} \mathrm{lg.,} \mathrm{grau} \mathrm{od.}$ bräunlich, durchscheinend, fein bereift. L. hakenf. angewachsen, weißlich. An lebenden Lbstämmen herdig, häufig. Fast das ganze Jahr. (Fig. 508.) (Rindenbewohnender B.)

A. corticola Pers.

39. Hut halbkuglig, dann flach, $1-3 \mathrm{~mm}$ br., weiß, gestreift, trocke $\mathrm{n}$ glatt. St. haarf., $1-2,5 \mathrm{~cm}$ lg., weiß, an der Spitze meist bräunlich. L. zu wenigen, zahnf. angewachsen, weiß. Zwischen abgefallenem Lb. herdig, häufig. H. W. F. (Fig. 509.) (Haarf. B.)

A. ea pillaris Schumacher.

Hut glockenf., schwach eingedrückt, 2-5 mm br., weißlich od. rötlich, schwach bereift, Rand gestreift. St. $2-3 \mathrm{~cm} \mathrm{lg.,}$ weißlich, am Grunde fein behaart. L. weißlich, hakenf. angewachsen. An lebenden Stämmen zwischen Moos u. Flechten, zerstreut. H. W. (Winter-B.)

A. hiemalis Osbeck.

40. St. in der ganzen Länge kahl.

St. kahl, aber am Grunde zottig od. wollig behaart.

41. Hut u. St. gelb od. weiß.

Hut kegel- od. glockenf., 0,5-1 cm br., rosenrot, glatt, kahl. St. fadenf., weiß, 6-9 cm lg., glatt. L. hakig angeheftet, weiß od. rosa. In sumpfigen Wäldern zwischen Moos, zerstreut. S. H. (Fig. 510.) (Adonis-B.)

A. adonis Bull.

42. Hut glockenf., dann ausgebreitet $u . * s c h w a c h$ gehöckert, bis $2 \mathrm{~cm}$ br., glatt, gelb od. weiß. St. $2-5 \mathrm{~cm} \mathrm{lg.,} \mathrm{weiß,} \mathrm{fädig,} \mathrm{durch-}$ scheinend, oben bereift. L. später frei, weiß. Zwischen Moos u. Gras an Wegen, auf Heiden, Triften, nicht häufig. S. H. (Zwerg-B.)

A. pumilus Bull.

Hut kegel- od. glockenf., höckerig, $6-8 \mathrm{~mm}$ br., gelb, trocken glänzend, schwach streifig. St. gelb, glänzend, $3-6 \mathrm{~cm} \mathrm{lg.} \mathrm{L.}$ angewachsen, schwach hakig herablaufend, weiß. Zwischen Moos u. Nd. in Ndwäldern, nicht häufig. S. H. (Fig. 511.) (Gelbweißer B.)

A. luteoalbus Bolton. 
43. Hut bis höchstens $1,5 \mathrm{~cm}$ br.

Hut über $2 \mathrm{~cm}$ br.

44. Hut glockenf., schwach gehöckert, dann ausgebreitet, 0,5 bis $1,5 \mathrm{~cm}$ br., milchweiß, feucht gestreift, trocken glatt. St. fast fädig, ziemlich zähe, $4-8 \mathrm{~cm} \mathrm{lg.,} \mathrm{weiß,} \mathrm{am} \mathrm{Grunde} \mathrm{faserig-zottig.}$ L. weiß, dicht. An abgefallenen Nd. u. Zweigen in Ndwäldern, nicht häufig. F. S. H. (Kleiner B.) A. nanus Bull.

Hut glocken- od. stumpfkegelf., $0,5-1,5 \mathrm{~cm}$ br., weiß od. gelblich, gestreift. St. zart, gebrechlich, bis $6 \mathrm{~cm} \mathrm{lg.,} \mathrm{weiß} \mathrm{od.}$ gelblich, am Grunde weißzottig. L. angewachsen, weiß, etwas entfernt stehend. Herdig zwischen Gras u. Moos in Lbwäldern, an Wegen, auf Grasplätzen usw., nicht selten. S. H. (Fig. 512.) (Gestreifter B.)

A. lineatus Bull.

45. Hut stumpfkegelf. od. glockenf., dann ausgebreitet, $2-3 \mathrm{~cm}$ br., zerbrechlich, weiß, in der Mitte oft rötlich od. bräunlich, oft braunfleckig, am Rande streifig. St. faserig, $4-6 \mathrm{~cm} \mathrm{lg.,}$ fein gestreift, rötlich od. weißlich, am Grunde wollig behaart. L. angewachsen, weiß, am Grunde undeutlich aderig verbunden. Herdig in Lb.- u. Ndwäldern am Boden, nicht häufig. S. H. (Dornfüßiger B.)

A. spinipes Swartz.

Hut wässerig, glockenf., dann ausgebreitet, oft stumpfhöckerig, 2,5-5 cm br., hellrosenrot od. hellviolett, oft weiß od. in der Mitte rotbräunlich, Rand feucht gestreift. St. hohl, oft gedreht, zäh, 6-11 cm lg., am Grunde zottig, gleichgefärbt. L. angewachsen, hinten ausgerandet, gleichgefärbt, am Grunde durch Querfalten verbunden. Geruch rettichartig. Herdig auf altem Lb. in Wäldern, häufig. S. H. (Rosen-B.) A. roseus Bull.

\section{Untergattung: Collybia Fries.}

1. L. aschgrau, Fleisch wässerig.

L. weiß od. anders, nicht aschgrau, gefärbt.

2. L. locker stehend, br.

L. gedrängt stehend, schmal.

3. H. glockenf., fast stumpf, $4 \mathrm{~cm}$ br., rußfarbig, braun gestreift, dann verblassend, rissig, glänzend: St. später hohl, gewunden, 6-11 cm lg., faserig-streifig, an der Spitze flockig bereift, im Alter zusammengedrückt. L. angeheftet. In Ndwäldern, besonders im Gebirge, zerstreut. S. H. (Zerrissener B.)

\section{A. laceratus Scopoli.}

Hut glockenf., bald flach gewölbt, stumpfhöckerig, dann niedergedrückt, $1,5-3(-4,5) \mathrm{cm}$ br., trübgraubraun, matt, trocken schmutziggrau $u$. fast seidenglänzend, feinschuppig od. runzlig. St. hohl, 4-6 cm lg., gleichgefärbt, oben weißkleiig u. faserig. L. gleichgefärbt, trocken fleckig. Zwischen Moos $u$. Gras in Wäldern, auf Grasplätzen, zerstreut. S. H. (Fig. 513.) (Mäusegrauer B.).

A. murinus Batsch.

4. Hut frisch nicht pechschwarz. 
Agariceae.

490. 491. 492. 493. 494. 495. 496.49\%

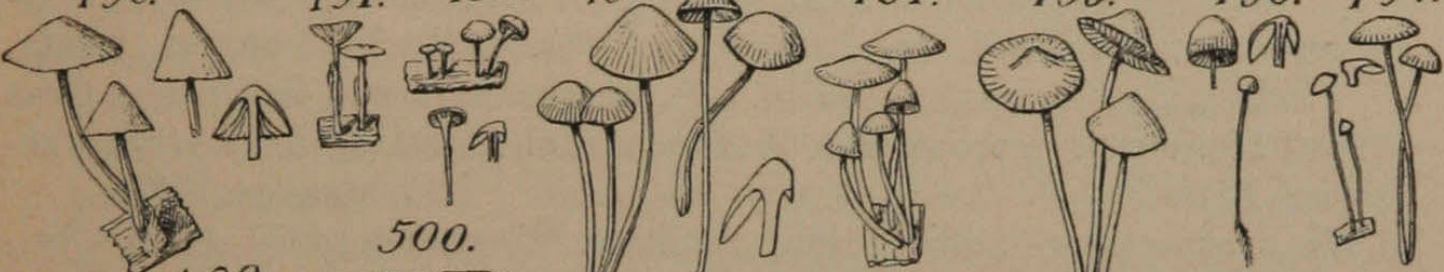
12. 498. 499 . 500 498. 499 . 500.
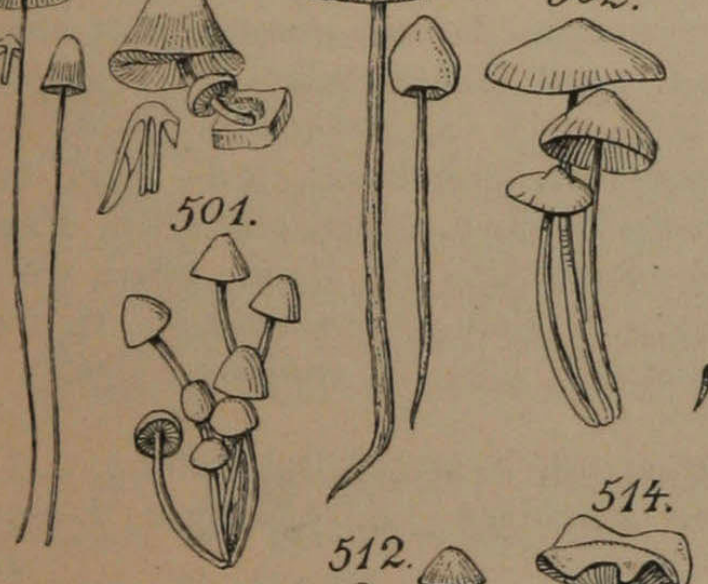

का

504 .

505.

506.

198 W $\int_{a}^{4}\left(\prod_{0}^{9}\right)$

514. (a) 516 
Hut flach gewölbt, dann niedergedrückt, $1-2,5 \mathrm{~cm}$ br., pechschwarz, glänzend, trocken braun. St. voll, $2-3 \mathrm{~cm} \mathrm{lg.,} \mathrm{glatt,}$ kahl, außen $u$. innen braun. L. angewachsen. Zwischen Gras auf Heiden u. in trockenen Wäldern, nicht häufig. S. H. (Schwarzer B.)

A. atratus Fries.

5. Hut stumpf gewölbt, dann flach u. eingedrückt, $1-3 \mathrm{~cm}$ br., graubraun od. etwas schwärzlich, trocken heller, runzlig, Rand eingerollt, streifig. St. graubraun bis schwärzlich, hohl, $2-4 \mathrm{~cm}$ lg., oben weißkleiig, unten weißzottig. L. mit einem Zahn angeheftet od. etwas herablaufend. Auf Brandstellen in Wäldern, selten. S. H. (Angebranntor B.)

A. ambustus Fries.

Hut glockenf., dann ausgebreitet, gebuckelt, 2,5-6 $\mathrm{cm}$ br., bläulich, glanzlos, trocken ledergelblich u. seidenglänzend, Rand gestreift. St. später hohl, $6-8 \mathrm{~cm}$ lg., oft flach, oben weißschuppig, unten weiß-striegelig. L. sich später lösend. In Ndwäldern, selten. S. (Geruchloser B.)

A. inolens Fries.

6. St. glatt u. kahl.

St. glatt, mit kleiiger, flockiger od. haariger Bekleidung. 11.

St. kräftig, mit deutlicher furchiger od. faseriger Längsstreifung.

7. L. br., entfernt stehend.

L. schmal, sehr dicht stohend.

8. Hut sehr flach gewölbt, dann eben, $1-1,5 \mathrm{~cm}$ br., grau od. braun, seltener weißlich, in der Mitte meist dunkler, glatt, trocken, Rand gestreift. St. hohl, 6-10 mm lg., zäh, glatt, glänzend, gelblich od. bräunlich, oben heller, unten in einen langen, zottigen Strang auslaufend, der meist an einem Kiefernzapfen im Boden endet. L. rein weiß. Eßbar. Herdenweise in Kiefernwäldern, nicht selten. F. S. H. (Zäher B.)

A. tenacellus Pers.

Hut sehr flach gewölbt, dann flach ausgebreitet, $1-2 \mathrm{~cm}$ br., glatt, ockergelb od. bräunlich, Mitte dunkler. St. hohl, zähe, $2-3 \mathrm{~cm}$ lg., gelblich od. bräunlich, unten wurzelnd, zähe. L. angeheftet, weißlich. Eßbar. Zwischen Gras u. Moos in trockenen Heiden u. Wäldern, zerstreut. F. S. H. (Krösling.)

A. esculentus Wulfen.

9. Hut über $2 \mathrm{~cm}$ br.

Hut glockenf., 0,8-1 em br., weißlich, mit gelblichem od. bräunlichem Höcker, Rand bisweilen gekerbt. St. fädig, knorpelig, $2-3 \mathrm{~cm}$ lg., kahl, weißlich, am Grunde gelblich od. bräunlich u. wurzelnd. L. weiß. An abgefallenen Ästen, auf Wurzeln, häufig. S. H. (Augenf. B.)

A. ocellatus Fries.

10. Hut flach gewölbt, dann ausgebreitet, stumpfhöckerig, $4-6 \mathrm{~cm}$ br., kahl, wässerig, hellrötlich, in der Mitte bräunlich, trocken weiß, Rand gestreift. St. hohl, $4-10 \mathrm{~cm}$ lg., kahl, rotbraun, am Grunde wurzelnd $u$. filzig. L. weißlich od. schwach rötlich. In feuchten Wäldern herdig, nicht selten. F. S. H. (Fig. 514.) (Gehäufter B.)

A. acervatus Fries. 
Hut flach gewölbt, dann flach, oft etwas eingedrückt, 2,5-6 cm br., etwas wässerig, weißlich bräunlich, oft in der Mitte dunkler, trocken verblassend, glatt. St. hohl, $4-8 \mathrm{~cm} \mathrm{lg.,} \mathrm{weißlich} \mathrm{od.}$ rötlich bräunlich, glatt, am Grunde faserig-wurzelnd. L. frei, weißlich od. gelblich. Zwischen Gras u. Lb. in Lbwäldern, häufig. F. S. H. (Fig. 515.) (Eichenliebender B.)

A. dryophilus Bull.

11. St. einem Sklerotium entspringend.

St. nicht einem Sklerotium entspringend.

12. Hut sehr flach gewölbt, dann flach ausgebreitet, selten stumpfhöckerig, 3-12 mm br., glatt, weißlich od. hellrotbräunlich gefleckt, trocken weiß u. seidenglänzend. St. fädig, schlaff, $2-5 \mathrm{~cm} \mathrm{lg}$. , hohl, weißlich od. hellbräunlich, mit spinnwebiger, unten haariger Bekleidung. L. weißlich. Sklerotium $2-8 \mathrm{~mm}$ lg., braun, dann schwarz, innen weiß, glatt. Auf faulenden, größeren Lpilzen, nicht solten. S. H. (Fig. 516.) (Knolliger B.)

\section{A. tuberosus Bull.}

Hut flach gewölbt, dann flach ausgebreitet, $2-8 \mathrm{~mm}$ br., weiß, oft gelbhöckerig, kahl. St. schlaff, $2-3 \mathrm{~cm} \mathrm{lg}$., weiß, schwach faserig, am Grunde striegelig-zuttig. L. wei ßlich. Sklerotium rundlich-höckerig, $1-3 \mathrm{~mm}$ br., gelblich, innen weiß, glatt. Auf Hutpilzen, zerstreut. S. H. (Fig. 517.) (Kraushaariger B.)

A. cirratus Schumacher.

13. Hut glatt, kahl.

Hut flach gewölbt, dann eben, selten stumpfhöckerig, 2-10 mm br., weißlich mit bräunlichen, oft striegelhaarigen, fasørigen, meist konzentrisch stehenden Schuppen, in der Mitte dunkler. St. zähe, 2-3 cm lg., kastanienbraun, haarig-faserig, der Unterlage fest aufsitzend. L. später frei, weiß. An Stengeln, Graswurzeln auf Grasplätzen, an Wegen, häufig. S. H. (Stengelbewohnender B.)

A. cauticinalis Bull.

14. In Ndwäldern.

Hut flach gewölbt, dann ausgebreitet, $2,5-8 \mathrm{~cm}$ br., glatt kahl, feucht blebrig, honiggelb, in der Mitte kastanienbraun. St. voll, zähe, 6-9 cm lg., kahl, oben gelblich, unten kastanienbraun bis schwärzlich $u$. dicht sammetbraunhaarig. L. angeheftet, gelblich. Meist büschelig am Grunde von Lbstämmen häufig. H. W. F. (Fig. 518.) (Sammetfüßiger B.)

\section{A. velutipes Curtis.}

15. Hut flach gewölbt, dann ausgebreitet, oft höckerig, $0,5-2,5 \mathrm{~cm}$ br., ockerfarben od. bräunlichgelb, in der Mitte dunkler, glatt, kahl. St. feinröhrig, $3-4 \mathrm{~cm} \mathrm{lg}$., gelblich od. rötlichbraun, weißlich-flockig, fasэrig wurzelnd. L. sehr dicht, weißlich od. hellockerfarben. Herdig an Kiefernzapfen in Ndwäldern, zerstreut. S. H. (Fig. 519.) (Zapfenbewohnender B.)

A. conigenus Pers. 
Hut flach gewölbt, dann flach, stumpf, seltener schwach gebuckelt, $2-3 \mathrm{~cm}$ br., wässerig, feucht rötlichbraun, trocken weißlich. St. hohl, etwas flach, oben erweitert, $4-10 \mathrm{~cm} \mathrm{lg.,}$ rotbraun, weißzottig, meist mehrere St. durch filziges Gewebe am Grunde reihenweise verbunden. L. sehr dicht, frei, weißlich. Geruch angenehm. In Ndwäldern, nicht selten. S. H. (Zusammenfließender B.)

A. confluens Pers.

16. St. gleichmäßig weißlich od. grau.

St. unten irgendwie braun, nach oben weißlich od. seltener gleichmäßig irgendwie braun.

19.

17. L. weiß, bei Berührung sich nicht schwärzend.

18.

Hut flach gewölbt, stumpf, 6-11 cm br., glatt, kahl, feucht, bleigrau od. weißlich, trocken isabellfarben od. bleigrau-, rußfarben, Rand abstehend, gestreift. St. voll, faserig, 6-11 cm lg., gestreift, grau, am Grunde verdickt, wie abgebissen. L. entfernt stehend, stumpf angeheftet, mit herablaufenden Zähnchen, weiß, bei Berührung sich schwärzend. In Ndwäldern, selten. S. H. (Fig. 520.) (Wege-B.) A. semitalis Fries.

18. Hut gewölbt, stumpfhöckerig, dann ausgebreitet, $6-11 \mathrm{~cm}$ br., glatt, kahl, weißlich, später rotbraun gefleckt, zuletzt vollständig rötlich, Rand geschweift, schwach filzig. St. $8-12 \mathrm{~cm} \mathrm{lg.,}$ zylindrisch od. in der Mitte bauchig, weißlich, längsgestreift. L. frei, sehr dicht, weiß. Zwischen Moos in feuchten Ndwäldern, zerstreut. S. H. (Gefleckter B.)

A. maculatus Alb. et Schwein.

Hut glockenf., dann ausgebreitet, stumpf, 6-12 cm br., grau od. graubraun, feucht glatt, später faserig, trocken verblassend. St. voll, 8-12 cm lg., weißlich, gestreift, am Grunde wie abgebissen. L. angeheftet, dicht, weiß. Am Grunde alter Stümpfe in feuchten Lbwäldern, zerstreut. S. (Fig. 521.) (Streifiger B.)

A. grammocephalus Bull.

19. L. entfernt voneinander stehend.

Hut flach gewölbt, meist stumpfhöckerig, dann ausgebreitet, $4-8 \mathrm{~cm}$ br., wässerig, feucht hellockerfarben, mit brauner Mitte, oft ganz braunrot, fettglänzend, trocken weißlich, Rand streifig. St. kegelf., 4-8 cm lg., oben weißlich, unten hellbraun od. ganz rotbraun, dicht längsstreifig, selten zottig behaart. L. abgerundet, leicht angeheftet, dicht stehend, weiß. Eßbar. Herdig in Lb.- u. Ndwäldern, häufig. S. H. (Fig. 522.) (Butter-B.) A. butyraceus Bull.

20. St. kahl.

Hut flach gewölbt, stumpfhöckerig, $3-5 \mathrm{~cm}$ br., hellbraun mit dunklerer Mitte, schwach längsrunzlig, dicht braunfilzig-sammetig, Rand scharf, die L. überragend. St. voll, nach unten dicker, $8-12 \mathrm{~cm} \mathrm{lg.,} \mathrm{am} \mathrm{Grunde} \mathrm{schief} \mathrm{wurzelnd,} \mathrm{leder-} \mathrm{od,}$ kastanienbraun, oben etwas heller, gedreht längsstreifig, dicht 
braunfilzig. L. frei, rein weiß. In Lbwäldern, vereinzelt. S. H. (Fig. 523.) (Langstieliger B.)

A. longipes Bull.

21. Hut glockenf. od. halbkuglig, stumpfhöckerig, dann flach gewölbt, 6-10 $\mathrm{cm}$ br., rotbraun, weißlich od. ockerfarben, meist braun gefleckt, glatt, später rissig, Rand geschweift. St. 6-12 cm lg., in der Mitte meist bauchig, unten lg. spindelig auslaufend, hellod. rotbraun, faserig-längsgestreift. L. später frei, weißlich, dann rötlich fleckig, am Grunde aderig verbunden. Am Grunde alter Lbstämme, häufig. S. H. (Spindelstieliger B.) A. fusipes Bull.

Hut glocken- od. stumpfkegelf., dann flach gewölbt, schwach höckerig, 4-6 cm br., reh- od. graubraun, klebrig, mit gewundenen, strahligen Runzeln. St. am Grunde lg. spindelf., 8 bis $12 \mathrm{~cm}$ br., oben weiß, ,unten bräunlich, glatt, kahl, gedreht, längsstreifig. L. zahnf. angeheftet, weiß. Besonders in Lbwäldern, häufig. S. H. (Langschwänziger B.) A. macrourus Scopoli.

\section{Untergattung: Clitocybe Fries.}

1. Hutfleisch wässerig. L. angewachsen, meist wenig herablaufend.

Hutfleisch trocken. Hut trichterf. od. flach. L. von vornherein \pm herablaufend.

2 .Hut dünnfleischig, anfangs gewölbt, dann etwas ausgebreitet u. oft niedergedrückt in der Mitte. L. angewachsen, kaum herablaufend.

Hut dünnfleischig, anfangs niedergedrückt, dann becher- od. trichterf. L. anfangs gerade, später herablaufend.

3. L. graubraun.

L. gelb, rötlich, violett, später von den Sporen weiß bestäubt.

4. Geruchlos.

Hut schwach gewölbt, dann scheibenf. od. niedergedrückt, $2-4 \mathrm{~cm}$ br., feucht durchscheinend, hellgrau-braun, am Rand gestreift, trocken weißlich, glänzend. St. später hohl, $2-4 \mathrm{~cm}$ lg., glatt, kahl, gleichfarbig. L. kurz herablaufend. Geruch fenchelartig. In Lbwäldern zwischen Gras u. Moos, häufig. S. H. (Fig. 524.) (Duftender B.) A. fragrans Sowerby.

5. Hut flach gewölbt, später flach, ea. $4 \mathrm{~cm}$ br., feucht blaugrau, trocken weißlich. Später hohl, 6-7 cm lg., gestreift, gleichfarbig. L. dicht, angewachsen, bisweilen schwach herablaufend. In Ndwäldern, nicht häufig. S. (Pfennig-B.) A. obolus Fries.

Hut flach gewölbt, dann ausgebreitet od. niedergedrückt, 2,5-4 cm br., kahl, feucht grau od. braun, am Rand gestreift, trocken weißlich. St. später hohl, $4-5 \mathrm{~cm} \mathrm{lg}$., oft zusammengedrückt, grau od. braun, oben pulverig bereift. L. dicht, angewachsen, wenig herablaufend. Zwischen Moos in Ndwäldern, häufig. S. H. (Fig. 525.) (Abblassender B.)

A. metachrous Fries. 
6. Hut gewölbt, dann niedergedrückt, $2-6 \mathrm{~cm}$ br., goldgelb, seltener rötlichbraun, mit dunkleren Schüppchen. St. voll, $2-4 \mathrm{~cm} \mathrm{lg.,}$ gelb, gefurcht. L. weitläufig stehend, angewachsen, gelb, am Grunde aderig verbunden. An Ndstümpfen, besonders im Gebirge, nicht häufig. S. H. (Schöner B.) A. bellus Pers.

Hut gewölbt, dann flach, oft eingedrückt, $2-6 \mathrm{~cm}$ br., feucht rötlich, violett od. bräunlich, oft kleinschuppig, trocken verblassend, hellbräunlich, Fleisch rötlich od. violett, Rand eingebogen, dann gerade. St. grobfaserig, voll, $3-8 \mathrm{~cm} \mathrm{lg.,} \mathrm{gleich-}$ farbig. L. weitlänfig, rötlich od. violett, verblassend. Eßbar (Suppenpilz). In Wäldern überall häufig. F. S. H. (Fig. 526.) (Lack-B.) A. laceatus (Scopoli).

7. Rand kaum eingerollt, bald ausgebreitet.

Hut niedergedrückt, dann becherf., $4-8 \mathrm{~cm}$ br., glatt, feucht dunkelumbra- od. graubraun, trocken heller, Rand lange eingerollt. St. voll, 5-10 cm br., gleichfarbig, unten verdickt u. weißzottig. L. weitläufig, schmutzig graubraun, angewachsen, dann herablaufend. Zwischen Gras u. Moos auf Wiesen, an Wegen, Waldrändern usw., häufig. H. (Fig. 527.) (Becher-B.)

\section{A. eyathiformis Bull.}

8. Hut flach, dann trichterf., $3-4 \mathrm{~cm}$ br., glatt, feucht bräunlich, trocken hell ockerfarben od. weißlich. St. später hohl, 4-5 cm lg., gleichfarbig, weißfaserig. L. fast weitläufig, bräunlich, dann hellgrau, herablaufend. Zwischen Moos besonders in Ndwäldern, selten. H. (Verblassender B.)

A. expallens Pers.

Hut flach, dann trichterf., 2-6 cm br., kahl, graubläulich, trocken weißlich, fast seidig u. gezont, Rand gestreift. St. hohl, 6-8 cm lg., kahl, am Grunde weißzottig. L. wenig dicht, angewachsen, dann weit herablaufend, grauweißlich. Zwischen Moosen, besonders in Ndwäldern, sslten. H. (Schwieliger B.)

A. vibecinus Fries.

9. L. weit, aber ungleichmäßig herablaufend, Hut in der Mitte dickfleischig, stumpfhöckerig, dann flach u. etwas niedergedrückt.

L. weit u. gleichmäßig herablaufend od. angewachsøn. 13.

10. Hut graubraun, rußfarben.

Hut 4-6 cm br., glatt, wei $\beta$, feinflockig. St. voll, $4-6 \mathrm{~cm}$ lg., weiß. L. angewachson, sshr dicht, schwach herablaufend. Herdenweise zwischen Lb. in Wäldern, selten. S. H. (Undurchsichtiger B.)

\section{A. opacus Sowerby.}

11. L. ganzrandig.

Hut bis $16 \mathrm{~cm}$ br., kahl od. gestreift, rußfarben, dann bläulich, trocken grau, Rand dünn, nackt, abstehend u. umgebogen. St. fast knorpelig, $16 \mathrm{~cm}$ lg., weiß, kahl, nur oben schwach zottig. L. ziemlich gedrängt, gesägt u. kraus, rußfarben, dann schmutzig weiß. Zwischen Moos in bergigen Ndwäldern, zerstreut. S. (Großer B.)

A. amplus Pers. 
12. Hut $14-16 \mathrm{~cm}$ br., rußfarben, verblassend, in der Mitte bläulich-rötlich. St. $11-16 \mathrm{~cm} \mathrm{lg.,} \mathrm{faserig-streifig,} \mathrm{unten} \mathrm{dick,} \mathrm{blaß,}$ oben kleinschuppig-mehlig. L. angewachsen, grau, dann verblassend. In Lbwäldern, selten. S. (Bleigrauer B.)

\section{A. molybdinus Bull.}

Hut 6-8 $\mathrm{cm}$ br., graubraun, verblassend, schwach seidenhaarig, schuppig, oft glatt, Rand dünn, schwach eingerollt. St. 6-8 cm lg., schmutzig grau od. ockerfarben, schwach gestreift, oben feinflockig. L. mäßig dicht, hell gelblichgrau. Eßbar. In Wäldern meist herdig, häufig. H. (Rauchfarbiger B.)

A. fumosus Pers.

13. Hut in-der Mitte fleischig, nach dem Rand zu verdünnt, dann eingedrückt u. meist trichterf. L. herablaufend.

Hut fast gleichmäßig fleischig, später abgeflacht od. niedergedrückt, ohne Höcker. L. angewachsen od. herablaufend. 22.

14. Hut weiß od. graubraun.

Hut mit gelben, rötlichen, rotbraunen Tönen.

15. Hut flach od. konkav, etwas kreiself., $2,5 \mathrm{~cm}$ br., kahl, weiß St. voll, $2,5 \mathrm{~cm} \mathrm{lg.,} \mathrm{kahl,} \mathrm{nach} \mathrm{unten} \mathrm{verjüngt,} \mathrm{oft} \mathrm{zusammen-}$ gedrückt. L. weitläufig, adrig verbunden. An Wegen, auf Triften, Heiden, nicht häufig. S. H. (Heide-B.)

A. ericetorum Bull.

Hut trichterf., 6-9 $\mathrm{cm}$ br., kahl, graubraun, Rand br. umgeschlagen. St. später hohl, graubraun, gestreift, unten verdickt, L. nicht dicht, aschgrau. Garuch zimmetartig. Zwischen Moos in Ndwäldern, selten. S. H. (Kochtopf-B.)

\section{A. cacabus Fries.}

16. L. weiß u. so bleibend.

L. weißlich, später andersfarbig od. von vornherein nicht weiß.

17. Hut tief trichterf., $2-4 \mathrm{~cm}$ br., bräunlich ledergelb, mit kleinen, dunkleren Schuppen. St. nach oben verjüngt, $5 \mathrm{~cm} \mathrm{lg.,} \mathrm{zähe,}$ L. weitläufig. Grruchlos. In Ndwäldern, selten. S. (Schuppiger B.)

A. squamulosus Pers.

Hut niedergedrückt, dann trichterf., in der Mitte oft mit stumpfem Höcker, $3-8 \mathrm{~cm}$ br., ockerfarben od. hellbräunlichrötlich, bisweilen fast weiß, mit eingewachsenen, seidigen Fasern, Rand dünn, scharf, eingerollt. St. voll, $3-6 \mathrm{~cm} \mathrm{lg.,} \mathrm{gleich-}$ farbig. L. mäßig dicht, sehr weit herablaufend. Geruch schwach zimmetartig. Zwischen Moos u. Gras in Wäldern u. Gebüschen, besonders in den Vorbergen, nicht selten. S. H. (Fig. 528.) (Trichterf. B.)

A. infundibuliformis Schaeff.

18. L. von Anfang hell orange od. hell ockerfarben.

L. weißlich, dann später gelblich od. bräunlich.

19. Hut bald trichterf., $4-6 \mathrm{~cm}$ br., frisch rötlichgelb, fast orange, trocken ledergelb, Rand eingerollt, Fleisch ockerfarben. St. orange, später hohl, $2-5 \mathrm{~cm}$ br., kahl. L. hell orange. Rasig 
in Nd.- u. Mischwäldern, zerstreut. S. H. (Fig. 529.) (Umgedrehter B.)

A. inversus Scopoli.

Hut flach, dann niedergedrückt, $8-10 \mathrm{~cm}$ br., gelbbraun, oft heller gefleckt, Fleisch ockerfarben. St. später hohl, 4-10 cm br., gleichfarbig, kahl. L. sehr dicht, hell ockerfarben. In Ndwäldern, ziemlich häufig. S. H. (Fig. 530.) (Fahlgelber B.)

20. Hutoberfläche kahl. A. gilvus Pers.

Hut niedergedrückt, trichterf., $2,5-5 \mathrm{~cm}$ br., rötlich zimmetbraun od. fast ziegelrot, verblassend, mit kleinen Schüppchen, zerschlitzt, Rand anfangs eingerollt. St. $2-4 \mathrm{~cm} \mathrm{lg.,} \mathrm{oft} \mathrm{etwas}$ zusammengedrückt, rötlichbraun, faserig. L. dicht, reinweiß, später hellgelblich. Geruch nach frischem Mehl. Zwischen Gras u. Moos auf Heiden, Grasplätzen, selten. S. (Roter B.)

A. sinopicus Fries.

21. Hut schlaff, eingedrückt, dann trichterf., $4-8 \mathrm{~cm}$ br., glatt, rostgelb od. rötlich, verblassend, Rand br. umgeschlagen. St. voll, 2-6 cm lg., gleichfarbig, am Grunde zottig. L. weißlich, später gelblich, dicht. Meist rasig in Lbwäldern zwischen Lb., häufig. S. H. (Schlaffer B.)

A. flaccidus Sowerby.

Hut flach trichterf., stumpfhöckerig, bis $11 \mathrm{~cm}$ br., kahl, glatt, weißgelblich od. hellbräunlich. St. voll, bis $16 \mathrm{~cm} \mathrm{lg.,} \mathrm{nach}$ oben verjüngt, weißlich. L. dicht, weiß, später gelblich od. bräunlich. In Wäldern, selten. S. H. (Gekrümmter B.)

\section{A. geotropus Bull.}

22. Hut ganz weiß.

23.

Hut nicht weiß.

28.

23. Hut $2-4 \mathrm{~cm}$ br. St. zylindrisch.

24.

Hut über $6 \mathrm{~cm}$ br.

26.

24. St. hohl.

Hut gewölbt, dann flach ausgebreitet, $2-4 \mathrm{~cm}$ br., glatt, kahl, schwach glänzend, Rand stark geschweift. St. voll, $2,5 \mathrm{~cm} \mathrm{lg}$., weiß, faserig, an der Spitze schwach bereift. L. dicht, weiß, angewachsen. Auf Triften, Heiden, nicht selten. S. H. (Weißlicher B.)

A. dealbatus Sowerby.

25. Hut gewölbt, dann flach, zuletzt etwas niedergedrückt, $2-3 \mathrm{~cm}$ br., mit weißem, seidenartigem Überzuge. St. $2-4 \mathrm{~cm} \mathrm{lg.,}$ weiß, glatt, wachsartig, glänzend. L. dicht, weiß, später herablaufend. Zwischen Lb. in Lbwäldern, häufig. S. H. (Fig. 531.) (Weißer|B.)

A. candicans Pers.

Hut gewölbt, dann flach, $2-3 \mathrm{~cm}$ br., glatt, kahl. St. weiß, kleinschuppig, am Grunde filzig. L. dicht, weiß, schwach herablaufend. In Lbwäldern, selten. S. H. (Schwanenweißer B.)

\section{A. olorinus Fries.}

26. L. unveränderlich weiß.

Hut flachgewölbt, dann niedergedrückt, $6-8 \mathrm{~cm}$ br., weiß, od. selten ledergelb, Rand fädig-silberglänzend, geschweift. St. 
später hohl, $6-8 \mathrm{~cm} \mathrm{lg.,} \mathrm{weiß,} \mathrm{faserig,} \mathrm{am} \mathrm{Grunde} \mathrm{zottig.} \mathrm{L.}$ etwas weitläufig, angewachsen, herablaufend, weiß, dann gelblich. Meist herdig zwischen Lb. in Wäldern, ziemlich häufig. S. H. (Fig. 532.) (Lbliebender B.) A. phyllophilus Pers.

27. Hut flach, dann niedergedrückt, $6-8 \mathrm{~cm}$ br., schlaff, kahl, trocken schwach glänzend. St. weiß, am Grunde filzig, zusammengedrückt, $6-8 \mathrm{~cm}$ lg., L. dicht, wenig herablaufend, weiß. In Ndwäldern, nicht häufig. S. H. (Ndliebender B.)

A. pithyophilus Fries.

Hut ausgebreitet, bisweilen in der Mitte etwas erhöht, $6-8 \mathrm{~cm}$ br., glatt, kahl, trocken runzlig, Rand bisweilen filzig. St. voll, $6-8 \mathrm{~cm}$ lg., unten oft schwach verdickt u. filzig, weiß, faserig. L. später herablaufend, dicht, weiß. Eßbar. Herdig in Wäldern, Gärten, Gebüschen, häufig. S. H. (Bleiweiß-B.)

A. cerussatus Fries.

28. Hut grün od. rötlich.

Hut andersfarbig.

29. Hut flach gewölbt, dann ausgebreitet, niedergedrückt, bisweilen mit stumpfem Höcker, $3-8 \mathrm{~cm}$ br., hell span- od. graugrün, in der Mitte lebhafter, trocken grau, gelb- od. weißlich, kahl, seidenartig gestreift. St. $6-8 \mathrm{~cm}$ lg., weißlich od. grünlich, glatt, am Grunde dicker. L. mäßig dicht, etwas herablaufend, weißlich od. blaßgrünlich, verblassend. Geruch stark nach Fenchel. Eßbar. In Lb.- u. Ndwäldern herdig, häufig. S. H. (Anisschwamm.)

A. odorus Bull.

Hut gewölbt, dann flach u. niedergedrückt, $2,5 \mathrm{~cm} \mathrm{u}$. breiter, kahl, hellrötlich, weißlich bereift, später rinnig, trocken weißlich u. geglättet. St. voll, $2,5 \mathrm{~cm}$ lg., rötlichweiß. L. angewachsen-herablaufend, ziemlich dicht, rötlichweiß. An Wegen, auf Äckern, in Wäldern, selten. S. (Bach-B.)

\section{A. rivulosus Pers.}

30. Hut blaßgelblich od. aschgrau.

Hut verschieden braun gefärbt.

31. Hut weich, flach gewölbt od. niedergedrückt, $3-6 \mathrm{~cm}$ br., uneben, schmutzig gelb, verblassend. St. voll, $2-6 \mathrm{em}$ lg., zähe, kahl. L. angewachsen, herablaufend, ziemlich weitläufig, weißlich. Geruch schwach fenchelartig. Eßbar. In Wäldern, nicht selten. S. H. (Ledergelblicher B.)

A. subalutaceus Batsch.

Hut flach gewölbt, oft stumpfhöckerig, dann ausgebreitet, 6-14 em br., aschgrau, zuerst mit einem grauen, fast schimmelartigen Reif überzogen, dann glatt, kahl, matt. St. voll, 6 bis $10 \mathrm{~cm}$ lg., nach unten verdickt, hellgrau, faserig-streifig. L. dicht, kurz herablaufend, weißlich. Geruch nach frischem Mehl. E Bbar. Herdig zwischen Gras u. Lb. in Wäldern, Gärten, häufig.
S. H. (Fig. 533.) (Nebelgrauer B.)
A. nebularis Batsch.

32. Geschmack nicht bitter. 
später hohl, 6-8 cm lg., weiß, faserig, am Grunde zottig. L. etwas weitläufig, angewachsen, herablaufend, weiß, dann gelblich. Meist herdig zwischen Lb. in Wäldern, ziemlich häufig. S. H. (Fig. 532.) (Lbliebender B.) A. phyllophilus Pers.

27. Hut flach, dann niedergedrückt, $6-8 \mathrm{~cm}$ br., schlaff, kahl, trocken schwach glänzend. St. weiß, am Grunde filzig, zusammengedrückt, 6-8 $\mathrm{cm}$ lg., L. dicht, wenig herablaufend, weiß. In Ndwäldern, nicht häufig. S. H. (Ndliebender B.)

A. pithyophilus Fries.

Hut ausgebreitet, bisweilen in der Mitte etwas erhöht, $6-8 \mathrm{~cm}$ br., glatt, kahl, trocken runzlig, Rand bisweilen filzig. St. voll, $6-8 \mathrm{~cm}$ lg., unten oft schwach verdickt $\mathrm{u}$. filzig, weiß, faserig. L. später herablaufend, dicht, weiß. Eßbar. Herdig in Wäldern, Gärten, Gebüschen, häufig. S. H. (Bleiweiß-B.)

A. cerussatus Fries.

28. Hut grün od. rötlich.

29.

Hut andersfarbig.

30.

29. Hut flach gewölbt, dann ausgebreitet, niedergedrückt, bisweilen mit stumpfem Höcker, $3-8 \mathrm{~cm}$ br., hell span- od. graugrün, in der Mitte lebhafter, trocken grau, gelb- od. weißlich, kahl, seidenartig gestreift. St. 6-8 cm lg., weißlich od. grünlich, glatt, am Grunde dicker. L. mäßig dicht, etwas herablaufend, weißlich od. blaßgrünlich, verblassend. Geruch stark nach Fenchel. Eßbar. In Lb.- u. Ndwäldern herdig, häufig. S. H. (Anisschwamm.)

A. odorus Bull.

Hut gewölbt, dann flach u. niedergedrückt, 2,5 cm u. breiter, kahl, hellrötlich, weißlich bereift, später rinnig, trocken weißlich u. geglättet. St. voll, $2,5 \mathrm{~cm} \mathrm{lg.,} \mathrm{rötlichweiß.} \mathrm{L.} \mathrm{ange-}$ wachsen-herablaufend, ziemlich dicht, rötlichweiß. An Wegen, auf Äckern, in Wäldern, selten. S. (Bach-B.)

\section{A. rivulosus Pers.}

30. Hut blaßgelblich od. aschgrau.

31.

Hut verschieden braun gefärbt.

32.

31. Hut weich, flach gewölbt od. niedergedrückt, $3-6 \mathrm{~cm} \mathrm{br.,}$ uneben, schmutzig gelb, verblassend. St. voll, $2-6 \mathrm{~cm} \mathrm{lg.,}$ zähe, kahl. L. angewachsen, herablaufend, ziemlich weitläufig, weißlich. Geruch schwach fenchelartig. Eßbar. In Wäldern, nicht selten. S. H. (Ledergelblicher B.)

\section{A. subalutaceus Batsch.}

Hut flach gewölbt, oft stumpfhöckerig, dann ausgebreitet, 6-14 cm br., aschgrau, zuerst mit einem grauen, fast schimmelartigen Reif überzogen, dann glatt, kahl, matt. St. voll, 6 bis $10 \mathrm{~cm}$ lg., nach unten verdickt, hellgrau, faserig-streifig. L. dicht, kurz herablaufend, weißlich. Geruch nach frischem Mehl. Eßbar. Herdig zwischen Gras u. Lb. in Wäldern, Gärten, häufig. S. H. (Fig. 533.) (Nebelgrauer B.)

A. nebularis Batseh.

32. Geschmack nicht bitter. 
Hut gewölbt, dann abgeflacht u. niedergedrückt, $4-6 \mathrm{~cm}$ br., in der Mitte rostbraun, am Rande weiß, mit feinen konzentrischen Schüppchen u. Furchen. St. weiß, schwachfilzig, $2-5 \mathrm{~cm} \mathrm{lg.} \mathrm{L.} \mathrm{sehr} \mathrm{dicht,} \mathrm{schwach} \mathrm{herablaufend,} \mathrm{weiß.} \mathrm{In}$ Mischwäldern, selten. S. H. (Bitterer B.) A. amarus Fries.

33. St. bräunlich.

Hut gewölbt, dann flach, oft flachhöckerig, $3-6 \mathrm{~cm}$ br., braun od. graubraun, Rand anfangs eingerollt u. weißlich. St. 4-8 cm lg., nach oben kegelf. in den Hut erweitert, unten stark verdickt, faserig, weißlich od. aschgrau. L. fast weitläufig, weit herablaufend, weiß. Geruch zimmetartig. Eßbar. Zwischen Moos besonders in Ndwäldern, ziemlich häufig. S. H. (Fig. 534.) (Keulenfuß.)

A. clavipes Pers.

34. Hut gewölbt, dann flach, $2-6 \mathrm{~cm}$ br., kahl, glatt, bräunlich, dann ockerfarben verblassend, Rand abstehend. St. voll, ca. $6 \mathrm{~cm}$ lg., nach unten verjüngt, gleich gefärbt, weißkleiig bestäubt. L. dicht, schwach herablaufend, schmutzig hellbräunlich, dann weiß. Auf Triften, Wiesen, besonders im Gebirge, selten. S. H. (Einäugiger B.)

A. luscinus Fries.

Hut flachgewölbt, dann flach ausgebreitet, etwas niedergedrückt, $1-3 \mathrm{~cm}$ br., hellbräunlich, trocken weißlich, glänzend. St. voll, $2-3 \mathrm{~cm}$ lg., bräunlich ockerfarben, weißfaserig, oben oft weißflockig, trocken weißlich. L. br. angewachsen, etwas herablaufend, ziemlich dicht, weißlich, später ockerfarben. Zwischen Gras u. Moos auf Heiden, Triften, an Wegen, nicht selten. S. H. (Kannen-B.)

A. hirneolus Fries.

\section{Untergattung: Tricholoma Fries.}

1. Hut frisch klebrig-schleimig, meist faserig od. schuppig.

Hut frisch nicht klebrig-schleimig, sondern trocken, höchst selten feucht, kahl od. mit seidenhaariger Bekleidung. 12.

2. L. unveränderlich weiß, grau od. gelb.

L. bei Verletzung od. im Alter rot- od. braunfleckig.

3.

3. St. u. L. nicht schwefelgelb.

Hut stark gewölbt mit scharf eingebogenem, welligem Rande, dann ausgebreitet, $5-8 \mathrm{~cm}$ br., gelb od. olivenbraun mit dunklerer Mitte, meist kleinschuppig, Fleisch gelb. St. knollig, dann lggestreckt, 4-6 cm lg., schwefelgelb, feinschuppig. L. dicht, frei, ausgerandet, schwefelgelb. Eßbar. In Ndwäldern, häufig. H. (Fig. 535.) (Grünling, Ritterling, Grünreizker.)

\section{A. equester L.}

4. Hutoberfläche ohne eingewachsene schwarze Fasern.

Hutoberfläche mit feinen eingewachsenen schwarzen $\mathrm{Fa}$ sern.

5. Hut schwach gewölbt, dann ausgebreitet, 5-6 $\mathrm{cm}$ br., reinweiß od. gelblich (besonders in der Mitte) gefleckt, glatt, trocken glänzend. St. voll, $6 \mathrm{~cm}$ lg., weiß, glatt. L. mäßig, dicht, weiß, 
ausgerandet. Eßbar. In Wäldern u. Gebüschen, selten. S. H. (Glänzender B.)

A. resplendens Fries.

Hut gewölbt, dann abgeflacht, geschweift, $6-8 \mathrm{~cm}$ br., trübgelb mit dunklerer Mitte, tigerig gefleckt. St. voll, blasser, kleinschuppig od. faserig. L. ziemlich dicht, weißlich, ausgerandet. Eßbar. In sandigen Ndwäldern, selten. S. H. (Geschminkter B.)

A. fucatus Fries.

6. Hut gewölbt, dann ausgebreitet, schwach höckerig, meist geschweift, 6-12 cm br., grau od. rußbraun, in der Mitte dunkler, mit feinen, eingewachsenen, schwarzen Linien. St. voll, zylindrisch, $6-8 \mathrm{~cm} \mathrm{lg.,} \mathrm{weiß,} \mathrm{gestreift.} \mathrm{L.} \mathrm{später} \mathrm{weitläufig,} \mathrm{abge-}$ rundet $\mathrm{u}$. zahnf. angeheftet, weiß bis grau od. gelblich. Eßbar. In Ndwäldern, nicht selten. S. H. (Fig. 536.) (Grau- od. Schneereizker.)

A. portentosus Fries.

Hut gewölbt, mit stumpfem od. kegelf. Höcker, später ausgebreitet, 7-8 cm br., weißlich grau, gelb od. gelbbraun, von kräftigen, eingewachsenen, schwarzen Fasern gestreift. St. voll, $6-8 \mathrm{~cm}$ lg., bauchig, weiß. L. ziemlich weitläufig, weiß, ausgerandet. Geruch mehlartig. Eßbar. In Ndwäldern, zerstreut. S. H. (Fig. 537.) (Abgesonderter B.)

7. Hut rot od. scherbengelb.

A. sejunctus Sowerby.

Hut rotbraun od. braun.

8. Hut gewölbt, dann niedergedrückt, $5-8 \mathrm{~cm}$ br., fleischrot od. lebhaft karminrot, kleinkörnig, Rand eingerollt. St. voll, 5 bis $6 \mathrm{~cm}$ lg., rosenrot, oben kleinschuppig. L. dicht, weiß, dann rotfleckig. Eßbar. In Wäldern, besonders Süddeutschlands, nicht häufig. S. H. (Fig. 538.) (Rötlicher B.)

A. russula Schaeff.

Hut halbkuglig, dann ausgebreitet, bis $20 \mathrm{~cm}$ br., scherbengelb, kahl, später zerklüftet-schuppig, Rand ungeknickt. St. voll, anfangs knollig, bis $11 \mathrm{~cm}$ dick, oben stark verjüngt, kahl, unten u. innen scherbengelb. L. dicht, abgerundet, später blaß ziegelrot. Eßbar. In Kiefernwäldern, selten. H. (Fig. 539.) (Riesen-B.)

A. colossus Fries.

9. St. kahl od. faserig.

10.

St. ganz od. oberwärts schuppig, wenigstens in der Jugend. 11.

10. Hut flachgewölbt, stumpf, dann ausgebreitet, $6-10 \mathrm{~cm}$ br., rotbraun, glatt, kahl. St. voll, zylindrisch, $4-8 \mathrm{~cm}$ lg., weiß, kahl, seidenartig-geglättet, bei Berührung u. im Alter rotbraun. L. dicht, stark ausgerandet reinwei $\beta$, bei Berührung rotbraun. Eßbar. In Lb.- u. Ndwäldern, zerstreut. S. H. (Brandiger B.)

A. ustalis Fries.

Hut gewölbt, stumpfhöckerig, dann ausgebreitet, $4-10 \mathrm{~cm}$ br., braun, in der Mitte dunkler, faserig-streifig, kleinschuppig, Fleisch gelb. St. später hohl, 5-10 cm lg., faserig, kahl, rötlich od. bräunlich. L. dicht, ausgerandet, mit Zahn herablaufend, 
gelblich, dann rotbraun gefleckt. Geruch nach frischem Mehl. Eßbar. In Lbwäldern, Gebüsch, zwischen Gras, häufig. S. H. (Fig. 540.) (Gelbbrauner B.)

A. flavobrunneus Fries.

11. Hut gewölbt, stumpf, geschweift, $8-10 \mathrm{~cm}$ br., braun od. rotbraun, am Rand heller, fast weiß, körnig od. tropfenf. gefleckt. St. voll, knollig, dann auf $5-8 \mathrm{~cm}$ verlängert, zottig von weißlichen Schuppen, später kahl. L. dicht, ausgerandet, fast frei, weiß, dann rotbraun gefleckt. Geruch nach frischem Mehl. Eßbar. In Ndwäldern, nicht häufig. S. H. (Fig. 541.) (Bodenständiger B.)

A. pessundatus Fries.

Hut kegelf. gewölbt, dann ausgebreitet, $5-8 \mathrm{~cm}$ br., rotbraun, faserig gestreift, in der Mitte körnig-warzig, Rand zuerst eingerollt, feinfilzig, oft furchig-streifig. St. zylindrisch, $4-8 \mathrm{~cm}$ br., weißlich, unten später rotbraun, an der Spitze kleinschuppig. L. dicht, weiß, später rotbraun gefleckt. Eßbar. In Lb.- u. Ndwäldern, Gebüschen, häufig. S. H. (Fig. 542.) (Weißbrauner B.)

A. striatus Schaeff.

12. Fleisch wässerig.

Fleisch trocken, fest.

13. Hut rötlich od. hellviolett.

Hut graubraun bis schwärzlich.

14. Hut glockenf., dann ausgebreitet u. um einen flachen Höcker etwas niedergedrückt, $4-6 \mathrm{~cm}$ br., fleischrötlich od. schmutzig hellviolett, später schmutzig bräunlich, trocken verblassend, Rand wellig, feucht gestreift, Fleisch schmutzig violett, dann bräunlich. St. voll, 4-6 cm lg., faserig gestreift, knollig, gleichgefärbt. L. wenig ausgebuchtet, zahnf. herablaufend, hell rötlichviolett, dann schmutzig bräunlich. Rasig in Gärten, auf Schutthaufen, nicht häufig. H. (Schmutziger B.)

\section{A. sordidus Schum.}

Hut gewölbt, dann verflacht, stumpf, $2-8 \mathrm{~cm}$ br., oben fleischrot, glatt, kahl. St. voll, $6 \mathrm{~cm}$ lg., glatt, kahl, zylindrisch, blaßrötlich, oben weißfleckig. L. zahnf. herablaufend, weiß. Auf Grasplätzen in bergigen Ndwäldern, zerstreut. H. (Pfirsichroter B.)

A. persicinus Fries.

15. St. fast zylindrisch, unten wenig verdickt.

Hut dünn, glockenf., dann ausgebreitet u. schwach gebuckelt, $4 \mathrm{~cm}$ br., schwarzbraun, oft getigert, Rand nackt, gerade, Fleisch weiß, sich schwach bläuend. St. voll, über $6 \mathrm{~cm} \mathrm{lg.,} \mathrm{unten} \mathrm{fast}$ $2 \mathrm{~cm}$, oben $4-5 \mathrm{~mm}$ dick, gekrümmt, faserig-streifig. L. frei, sehr dicht, bläulichweiß. In humosem Waldboden, auch in hohlen Bäumen, selten. H. (Gebogener B.)

A. urbus Fries.

16. St. bräunlich od. schmutzig braun.

Hut anfangs gewölbt, dann ausgebreitet, schwach höckerig, 4-8 cm br., kahl, meist schwärzlich, trocken verblassend. St. zäh, 5-8 cm lg., oft verdickt am Grunde, weißlich, faserig- 
streifig. L. ausgerandet, dicht, weiß. Zwischen Gras u. Moos in Wäldern u. auf Triften, häufig. S. H. (Fig. 543.) (Schwarzweißer B.)

A. melaleucus Pers.

17. Hut gewölbt, höckerig, dann abgeflacht, meist $4-8 \mathrm{~cm}$ br., glatt, graubraun, oft staubig flockig, trocken verblassend. St. voll, $2-6 \mathrm{~cm}$ lg., hellbräuńlich, zottig-flockig. L. zahnf. herablaufend, dicht, hinten wenig ausgerandet, weißlich bis schmutzig bräunlich. Auf fettem Boden in Gärten, auf Feldern, zerstreut. H. (Niedriger B.)

A. humilis Fries.

Hut gewölbt, dann flach, oft flach höckerig, 4-7 $\mathrm{cm}$ br., glatt, braun od. graubraun, trocken hellockerfarbig, Fleisch braun. St. $2-3 \mathrm{~cm}$ lg., dick, am Grunde schwach knollig, voll, schmutzig braun. L. schwach ausgerandet, dicht, weißlich. In Gärten, auf Wiesen, häufig. H. (Kurzfuß-B.)

\section{A. brevipes Bull.}

18. L. sich später irgendwie verfärbend.

L. unverändert bleibend.

19. Hutoberfläche kahl, höchstens am Rand etwas filzig. 20.

Hutoberfläche schwarz schuppig od. in Schuppen od. Flocken zerschlitzt.

20. Hut irgendwie violett.

Hut nicht violett.

21. Hut gewölbt, dann flach ausgebreitet, $5-7 \mathrm{~cm}$ br., matt, braunviolett, dann verblassend, Rand eingebogen kahl. St. zylindrisch. 6-7 cm lg., voll, graublau od. weißlich, schwach bestäubt. L. abgerundet, später etwas herablaufend, dicht, violett, dann bräunlich. In lichten Kiefernwäldern, auf Triften, häufig. H. (Fig. 544.) (Nackter B.)

A. nudus Bull.

Hut gewölbt, dann flach ausgebreitet, $6-16 \mathrm{~cm}$ br., blauviolett, Rand eingerollt, über die L. hinausreichend, schwach filzig, Fleisch blauviolett, später wei $\beta$. St. voll, $6-8 \mathrm{~cm} \mathrm{lg.,}$ blauviolett, später weiß, unten knollig, faserig. L. dicht, frei, blauviolett oder bräunlich. Eßbar. Zwischen Gras u. Lb. in Gärten, Wäldern, häufig. S. H. (Zweifarbiger B.) A. bicolor Pers.

22. Hut gewölbt, dann ausgebreitet, stumpf, 6-12 cm br., hellrötlich, ledergelb od. hellockerfarben, glatt, bisweilen von feinen, eingewachsenen Fasern gestreift, Rand schwach bereift, Fleisch weiß. St. 6-9 cm lg., unten knollig u. wollig, weißlich od. gleichfarbig, faserig. L. dicht, frei, blaßockerfarben. Geruch schwach veilchenartig. Eßbar. In Wäldern, selten. H. (Kreisliebender B.)

A. cyclophilus Lasch.

Hut fast halbkuglig, dann flach gewölbt, 2,5-6 cm br., kahl, oft etwas grubig-furchig, weißlich, oft etwas hellrosa überzogen, im Alter u. bei Verletzung ockerfarben gefleckt, Rand eingerollt, kahl. St. voll, 4-6 cm lg., weißlich, faserig. L. sehr dicht, weißlich, bei Verletzung hell schmutzig bräunlich. Geruch nach Lindau, Kryptogamenflora. I. 2. Aufl. 
frischem Mehl. Eßbar. In Lbwäldern, auf Triften, häufig. F. (Maipilz, Musseron.) A. graveolens Pers.

23. Hut grau, aschgrau, selten bräunlich od. weißlich.

Hut braunrot, gelblich od. ockerfarben.

24. Hut flach gewölbt, schwackhöckerig, starr, 6-11 cm br., aschgrau, von feinen, schwarzen Schüppchen gestreift. St. voll, bis $10 \mathrm{~cm} \mathrm{lg.,} \mathrm{wei} \beta$, gestreift, oben faserig, unten glatt. L. dicht, weißlich, dann grau. Geschmack scharf brennend. In Ndwäldern, Heiden, nicht häufig. H. (Gestreifter B.)

\section{A. virgatus Fries.}

Hut glocken- od. fast kegelf., dann ausgebreitet, höckerig, $5-7 \mathrm{~cm}$ br., grau, seitener weißlich od. bräunlich, mit \pm feinen, haarig-zottigen Schuppen bedeckt. St. zylindrisch, $\overline{3}-8 \mathrm{~cm}$ lg., weißlich, angedrückt-faserig. L. mit Zahn herablaufend, weißlich, später grau, seltener gelblich. Eßbar. In Wäldern, Gebüschen, an Wegrändern, häufig. S. H. (Fig. 545.) (Erd-B.)

A. terreus Schaeff.

25. Hut halbkuglig, dann flach gewölbt, undeutlich höckerig, 5 bis $8 \mathrm{~cm}$ br., braunrot, in der Mitte dunkler, eingewachsen-klein-schuppig, Rand zuerst eingerollt, flockig. St. voll, $7-9 \mathrm{~cm} \mathrm{lg.,} \mathrm{weiß,}$ später unten oft rotbräunlich, oben weiß punktiert. L. mit Zähnchen angeheftet, weiß, dann rotbraun gefleckt. In Ndwäldern, selten. H. (Dachziegeliger B.)

A. imbricatus Fries.

Hut stark gewölbt, dann flach, stumpf, $6-10 \mathrm{~cm}$ br., weißlich mit abziehbarer Haut, faserig-flockig, später rissig-schuppig, gelblich od. ockerfarben, Rand zuerst stark eingerollt, runzlig. St. voll, 7-10 cm lg., weißlich, unten schwach verdickt, wolligschuppig. L. ziemlich dicht, weiß, später gelblich. Geschmack salzig, dann bitter. In Lbwäldern, selten. S. H. (Ungeglättcter B.)

A. impolitus Lasch.

26. L. gelb (vgl. auch noch saponaceus).

27.

L. weiß, weißlich od. rötlich.

27. Hutoberfläche nicht filzig-rotschuppig.

28.

Hut gewölbt, dann flach ausgebreitet, $6-10 \mathrm{~cm}$ br., in der Jugend mit dichtem, purpurrotem Filze, später filzig-rotschuppig auf gelbem Grunde, Fleisch gelb. St. zylindrisch, später hohl, $6-10 \mathrm{~cm} \mathrm{lg.,} \mathrm{gelb,} \mathrm{rötlich-filzig.} \mathrm{L.} \mathrm{dicht,} \mathrm{goldgelb,} \mathrm{Schneide}$ dick, filzig. Meist an alten Stümpfen, selten zwischen Gras, besonders in Ndwäldern, häufig. S. H. (Fig. 546.) (Rötlicher B.)

\section{A. rutilans Schaeff.}

28. Hut flach-gewölbt, stumpf, $2-4 \mathrm{~cm}$ br., glatt, kahl, wachsgelb od. bräunlich, Fleisch weiß. St. voll, $2-4 \mathrm{~cm} \mathrm{lg.,} \mathrm{gelb,} \mathrm{faserig,}$ gestreift, unten oft braun. L. dicht, später sich ablösend, gelb. Geschmack etwas bitter. In Ndwäldern gesellig, nicht selten. S. H. (Wachsgelber B.)

A. cerinus Pers. 
Hut gewölbt, dann flach, 3-6 cm lg., fein seidenhaarig, dann kahl, matt schwefelgelb od. gelbbraun, in der Mitte bisweilen höckerig u. dunkler, Fleisch schwefelgelb. St. voll, zylindrisch, $5-8 \mathrm{~cm}$ lg., schwefelgelb, zart gestreift. L. weitläufig, mit Zahn angeheftet, schwefelgelb. Geruch widerlich. In Lb.- u. Mischwäldern, nicht selten. S. H. (Schwefelgelber B.)

\section{A. sulfureus Bull.}

29. Hutoberfläche rot, rötlich, violett, lila.

Hutoberfläche weiß, weißlich, braun, grau usw.

30. St. rot od. lila.

Hut oft unregelmäßig, höckerig, ca. $5 \mathrm{~cm}$ br., hell fleischfarben, dann verblassend, weißlich, Rand kahl, glatt. St. voll, $5-8 \mathrm{~cm}$ lg., ungleich dick, nach unten verjüngt, oft gedreht, weiß. L. dicht, mit Zahn herablaufend, ausgerandet, weiß. Gəruch nach frischem Mehl. Eßbar. Auf Grasplätzen, zerstreut.
F. (Maipilz.)
A. borealis Fries.

31. Hut flach gewölbt, dann ausgebreitet, $2-3 \mathrm{~cm}$ br., zuerst fein seidenhaarig, dann kahl, fleischrot, Rand eingebogen, zartflockig. St. 2-4 cm lg., fleischrot. L. dicht, ausgerandet, gegen den St. durch eine Linie abgesetzt, weiß. In Gebüsch, an Wegrändern zwischen Gras u. Moos, nicht selten. H. (Fig. 547.) (Fleischroter B.)

A. carneus Bull.

Hut glockenf., dann flach gewölbt, gebuckelt, zuletzt verschieden gestaltet, ea. $6 \mathrm{~cm}$ br., violett, lila, braunrot, verblassend, fast kahl, Rand zuerst flockig. St. voll, $6-8 \mathrm{~cm} \mathrm{lg.,}$ nach oben verjüngt, faserig, purpurn od. lila. L. ausgerandet, mit Zahn herablaufend, weiß, gezähnelt. In lichten Wäldern, zerstreut. S. H. (Fig. 548.) (Violetter B.)

A. jonides Bull.

32. Hutoberfläche glatt u. kahl, höchstens später rissig, nie seidenhaarig od. irgend schuppig.

Hutoberfläche seidenhaarig eingewachsen, körnig, schuppig, schuppig zerspalten.

33. St. nicht in großer Zahl einem Knollen entspringend.

36.

Hut gewölbt, $4-10 \mathrm{~cm}$ br., kahl, glatt, \pm bräunlich, oft fast weißlich, Rand dünn, zuerst eingerollt. St. in großer Zahl aus einem festen Knollen entspringend $u$. oft verwachsen, weißlich, schwach filzig. L. frei, weißlich. Eßbar. In Gärten, Höfen, Kellern, oft unter. dem Pflaster, selten. H. (Zusammengeballter B.)

A. conglobatus Vittadini.

34. Auf der Erde.

Hut fast halbkuglig, dann flach, 7-15 $\mathrm{cm}$ br., kahl, glatt, später felderig rissig, hellockerfarben od. fast weißlich, oft bräunlich gefleckt, Rand anfangs umgebogen. St. meist exzentrisch, voll, 6-8 cm lg., wei $\beta$, filzig. L. dicht, angeheftet, ausgerandet od. abgerundet, weiß. Geruch angenehm. Eßbar. An 
Stämmen lebender Lbhölzer (Ulme, Linde usw.), zerstreut. S. H. (Fig. 549.) (Ulmen-B.) A. ulmarius Bull.

35. Hut gewölbt, dann flach u. niedergedrückt, ca. $8 \mathrm{~cm}$ br., glatt, kahl, rein weiß od. in der Mitte gelblich, Rand umgerollt, später geschweift. St. voll, $6-8 \mathrm{~cm}$ lg., nach oben verjüngt, fast nackt, weiß. L. ausgerandet, weiß. In Lb- u. Mischwäldern, selten. H. (Weißer B.)

A. albus Schaeff.

Hut flach gewölbt, stumpfhöckerig, 4-9 cm br., weiß, oft etwas gelblich, glatt, später rissig, Rand zuerst eingerollt $u$. schwach filzig, oft unregelmäßig verbogen. St. voll, $4-9 \mathrm{~cm}$ lg., weiß, zartflockig od. faserig. L. ausgerandet, mit Zahn angeheftet, dicht, weißlich. Geruch nach frischem Mehl. Eßbar. Auf Grasplätzen, häufig. F. (Fig. 550.) (Maipilz, Hufpilz.)

A. gambosus Fries.

36. Hutoberfläche körnig od. schuppig.

Hut flach gewölbt, schwachhöckerig, $5-8 \mathrm{~cm}$ br., weißlich, in der Mitte hellockerfarben, mit feinen, eingewachsenen Seidenhaaren, Rand etwas eingerollt, seidenglänzend. St. voll, $4-6 \mathrm{~cm}$ lg., unten breiter u. dann etwas spindelf. u. faserig od. flockig, weiß, bei Druck schmutzig gelblich. L. weitläufig, mit Zahn etwas herablaufend, weiß. Geruch in der Jugend mehlartig, später widerlich. In Wäldern, selten. S. H. (Unschöner B.)

A. inamoenus Fries.

37. Hutoberfläche weißlich od. hellgrau, höchstens leicht ins Bräunliche od. Grünliche übergehend.

38.

Hutoberfläche kräftig braun, grau, gelbbraun, oliven: braun.

39.

38. Hut gewölbt, dann abgeflacht, $6-10 \mathrm{~cm}$ br., glatt, dann in kleine Schüppchen zerspalten, weißlich od. hellgrau, ins Bräunliche od. Grünliche übergehend, am Rande meist heller, oft rotfleckig, Fleisch blaßrot werdend. St. voll, 6-8 $\mathrm{cm}$ lg., weißlich, kahl od. mit feinen schwärzlichen Schüppchen, unten meist spindelf. verdünnt. L. weitläufig, hakenf. angeheftet, weißlich, seltener gelblich. Geruch seifenartig. Verdächtig. Besonders in Ndwäldern, häufig. S. H. (Fig. 551.) (Seifenschwamm.)

A. saponaceus Fries.

Hut gewölbt, dann ausgebreitet, oft verbogen, stumpfhöckerig, 8-10 cm br., weiß, seidenglänzend, glatt, später seidenfaserig od. kleinschuppig, oft mit karminroten od. gelblichen Flecken, Rand zuerst fein filzig. St. voll, zylindrisch, 7-9 cm lg., weiß, glänzend, faserig gestreift. L. tief ausgerandet, weiß, Schneide wellig. E Bbar. In Lbwäldern, besonders Birkenw., nicht selten. S. H. (Fig. 552.) (Tauben-B.) A. columbetta Fries.

39. Geruch angenehm, \pm nach frischem Mehl. 40.

Hut gewölbt, dann ausgebreitet, $8-10 \mathrm{~cm}$ br., zimmetbraun od. gelbbraun, flockig, in feine Körnchen od. Schüppchen zerfallend, Rand eingerollt, heller, etwas gefurcht. St. voll, 6 bis 
$10 \mathrm{~cm}$ lg., weiß, flockig. L. dicht, mit Zahn herablaufend, weiß, Schneide wellig. Geruch unangenehm. Geschmack sehr bitter. In lichten Lbwäldern, zerstreut. S. H. (Fig. 553.) (Gatropfter B.) A. guttatus Schaeff.

40. Hutobèrfläche rissig, flockig, nicht körnig.

Hut gewölbt, dann ausgebreitet, höckerig $u$. wellig, $6-8 \mathrm{~cm}$ br., braun od. grau, mit feinen, schwarzen Körnchen dicht besetzt. St. etwas hohl, 2-6 cm lg., glatt, kahl, weiß. L. dicht, weiß. An grasigen Stellen in Ndwäldern, selten. S. H. (Knorpeliger B.)

A. cartilagineus Bull.

41. Hut gewölbt, dann ausgebreitet, oft geschweift od. gelappt, 6-10 cm br., schmutzig gelbbraun od. olivenbraun, glatt, später in eingewachsene, fädige Flocken zerspalten. St. voll, $6-11 \mathrm{~cm}$ lg., ungleich dick, kahl, weiß. L. dicht, ausgerandet, weißlich. Eßbar. In Ndwäldern, nicht häufig. S. H. (Fig. 554.) (Schmutziger B.)

A. luridus Schaeff.

Hut gewölbt, dann flach, endlich niedergedrückt, $1-2,5 \mathrm{~cm}$ br., kahl, bald rissig u. zerklüftet, braun od. bleigrau, Rand wellig, zerschlitzt, umgerollt, zart filzig. St. hohl, $2,5-4 \mathrm{~cm} \mathrm{lg.,}$ unten verjüngt, oben weiß bereift. L. dicht, mit Zahn herablaufend, weiß. An grasigen Stellen, besonders im Gabirge, selten. H. (Keilblättriger B.)

A. cuneifolius Fries.

17. Gattung: Cortinellus Karst. (Schleierschwamm).

Hutrand mit dem St. durch einen fädigen Schleier verbunden, der als vergänglicher, faseriger Ring am St. zurückbleibt. Sporen kuglig bis eif., farblos.

Hut glockenf., dann ausgebreitet, $2-6 \mathrm{~cm}$ br., rotbraun, mit filzigen Schuppen, Rand eingerollt, filzig. St. zylindrisch, $6-10 \mathrm{~cm}$ lg., rotbraun, fasørig u. fädig. L. ziemlich weitläufig, weißlich, dann schmutzig rot gefleckt. Geschmack etwas bitter. In Ndwäldern, besonders im Gabirge, nicht häufig. S. H. (Fig. 555.) (Kuhschwamm.)

C. vaceinus (Pers.).

Hut glockenf., stumpf, geschweift, $6-8 \mathrm{~cm}$ br., aschgrau, dicht faserig, Rand umgerollt, weißwollig. St. voll, 4-6 cm lg., locker faserig, weiß, mit deutlichem Schleier. L. angewachsen, dicht, aschgrau. Zwischen Gras im Gebüsch, selten. H. (Zottiger S.)

C. gausapatus Fries.

\section{Gattung: Armillaria Fries (Armbandpilz).}

Hut fleischig, Hutrand mit dem St. durch einen häutigen Schleier verbunden, der am St. als Ring zurückbleibt. L. herablaufend od. zahnf. angeheftet. Sporen kuglig bis eif., farblos, beim Trocknen zusammenfallend.

1. L. am St. herablaufend.

L. vor dem Ansatz ausgerandet u. zahnf. angeheftet. 
2. St. exzentrisch, L. an der hinteren Seite sehr schwach entwickelt.

St. zentral.

3. Hut weißlich od. hellbraun.

Hut gewölbt, halbkuglig, $8-13 \mathrm{~cm}$ br., rauchgrau, mit angedrückten, haarigen, schwärzlichen Schuppen. St. randständig, meist horizontal, voll, oberhalb des rauchgrauen Ringes glatt, wei $\beta$, unterhalb rauchgrau, schwarzschuppig. L. weiß. An alten Tannenstümpfen, selten. (Lepiotaähnlicher A.)

\section{A. lepiota (Alb. et Schwein.).}

4. Hut fast halbkuglig, $5-8 \mathrm{~cm}$ br., weißlich mit hellbräunlichen, gefelderten Schüppchen. St. fast holzig, $2-4 \mathrm{~cm} \mathrm{lg.,} \mathrm{horizontal}$ od. aufwärts gekrümmt, weißlich, feinschuppig, Ring zerschlitzt, flüchtig. L. weiß, trocken gelblich. An Eichenstämmen u. -pfählen, seltener an anderen Lbhölzern, nicht häufig. H. (Halbierter A.)

A. dimidiata (Schaeff.).

Hut flach gewölbt, 4-10 $(-20) \mathrm{cm}$ br., hellbraun od. fast weißlich, fein filzig, dann flockig-schuppig, Rand stark eingerollt. St. fast randständig, 4-10 cm lg., voll, unten wurzelartig auslaufend, weiß, fasrig gestreift, Ring häutig. flüchtig. L. unten anastomosierend, weiß, trocken gelblich. Geruch fenchel-, dann rettichartig. An alten Pappeln, auch an anderen Laubhölzern, zerstreut. S. H. (Berindeter A.) A. corticata Fries.

5. Hut flach gewölbt, dann ausgebreitet, bisweilen schwach gehöekert, 6-18 cm br., honiggelb, gelbbraun od. mehr rötlich, mit haarigzottigen, gelblichen, bräunlichen oder schwärzlichen Schuppen, Rand eingerollt, dann flach, gestreift. St. voll, $6-20 \mathrm{~cm} \mathrm{lg.,}$ unten etwas verdickt, bla $\beta$, rötlich, bisweilen gelblich od. unten olivenbraun, Ring weiß, flockig-häutig. L. weitläufig, weißlich, dann rötlich od. bräunlich gefleckt, \pm herablaufend. Eßbar. Fk. aus schwarzen, innen weißen, sehr ausgedehnten Rhizomorphen (Rhizomorpha fragilis) entspringend. Dichtrasig an Lb.- u. Ndstümpfen, häufig. S. H. (Fig. 556.) (Hallimasch.)

\section{A. mellea (Vahl).}

Hut flach gewölbt, dann ausgebreitet, schwach höckerig, ea. $6 \mathrm{~cm}$ br., schleimig, weiß, hellumbrabraun od. rötlich-ockerfarben, Rand durchscheinend, bis fast zur Mitte gestreift. St. oben hohl, 6-9 cm lg., Ring zerschlitzt, herabhängend, oberhalb glatt, unterhalb punktiert. L. weiß. Herdig zwischen Gras in Wäldern, selten. S. (Hohler A.) A. subcava (Schumach.).

6. St. am Grunde nicht aus einem scharf abgesetzten Knollen entspringend.

Hut halbkuglig, dann ausgebreitet, $5-8 \mathrm{~cm}$ br., glatt, hellrötlichbraun, graubraun od. ockerfarben, flockig-weißfaserig, dann kahl. St. aus einem berandeten, $2-3 \mathrm{~cm}$ br. Knollen entspringend, voll, 4-6 cm lg., weißlich, faserig, Ring flockig, ver- 
Agariceae.

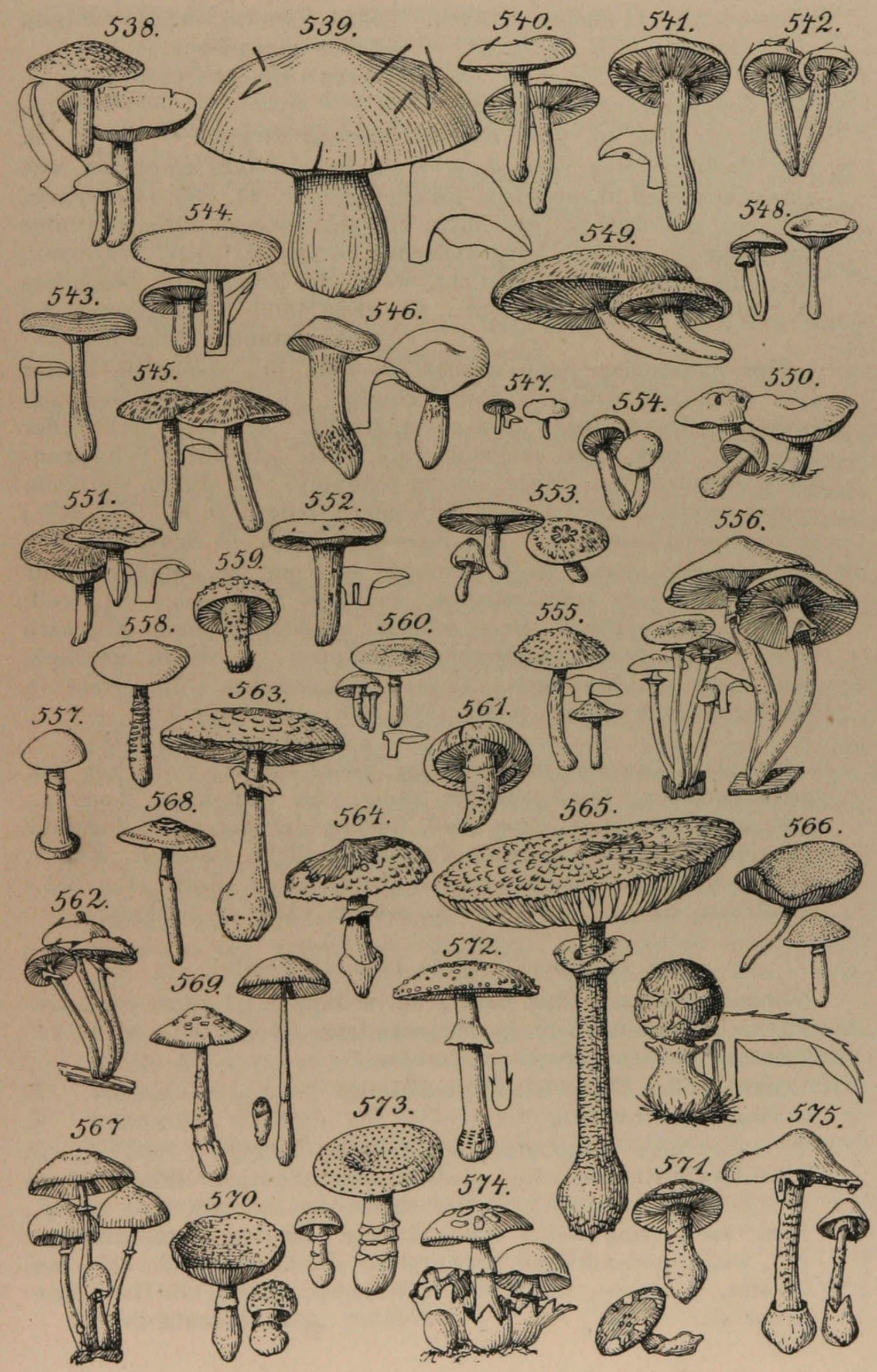


schwindend. L. dicht, weißlich. Eßbar. In Lb.- u. Ndwäldern, nicht häufig. S. H. (Fig. 557.) (Knollentragender A.)

A. bulbigera (Alb. et Schwein.).

7. Hut orangerot od. strohgelb.

8.

Hut weißlich od. gelb, rot- od. kastanienbraun.

9.

8. Hut flach gewölbt, stumpf, $4-8 \mathrm{~cm}$ br., lebhaft orangerot, mit eingewachsenen Schüppchen, Rand eingerollt. St. voll, zylindrisch, 4-6 cm lg., oberhalb der Mitte mit schuppigem Ring, darunter mit filzigen, groben, konzentrischen, orangefarbenen Schuppen, oberhalb weiß. L. mäßig dicht, weiß. In Ndwäldern, besonders in Süddeutschland, zerstreut. H. (Fig. 558.) (Orangeroter A.)

\section{A. aurantia (Schaeff.).}

Hut halbkuglig, dann flacher, $5-7 \mathrm{~cm}$ br., strohgelb, später fast schmutzig grünlich, rissig-schuppig, in der Mitte schwach bestäubt, Rand filzig, anfangs eingerollt. St. voll, nicht über $2,5 \mathrm{~cm}$ lg., nach unten verjüngt, weiß, unter dem durch Schuppenkreis angedeuteten Ringe sparrig-schuppig. L. dicht, weißlich, später gelblich. Im Grase in Ndwäldern, selten. S. H. (Fig. 559.) (Schmutziggrüner A.)

A. luteovirens (Alb. et Schwein.).

9. Hut gewölbt, dann flach, stumpf, $4-6 \mathrm{~cm}$ br., weißlich, mit graubraunen od. schwärzlichen, haarigen Schuppen. St. voll, $5-6 \mathrm{~cm}$ lg., weißlich, Ring schmal, weißlich, flockig, oberhalb kahl, unterhalb mit graubraunen Schuppen. L. dicht, weißlich, dann grau od. bräunlich. Geruch unangenehm. Im Grase in Wäldern, nicht selten. S. H. (Fig. 560.) (Späniger A.)

\section{A. ramentacea (Bull.).}

Hut flach gewölbt, flachhöckerig, 6-12 cm br., gelb-, rot- od. kastanienbraun, Rand weißlich, fädig. St. voll, kaum $3 \mathrm{~cm} \mathrm{lg.,}$ nach unten verjüngt, Ring groß, flockig, darüber weiß, darunter mit rötlichen od. bräunlichen Fasern. L. dicht, weißlich. Eßbar. Herdig in sandigen Kiefernwäldern, nicht selten. S. H. (Fig. 561.) (Kräftiger A.)

A. robusta (Alb. et Schwein.).

\section{Gattung: Lepiota Pers. (Ringpilz).}

Schleier häutig. Ring häutig od. schuppig. L. frei od. angeheftet, nicht herablaufend u. ausgerandet. Sporen eif., nicht zusammenfallend beim Trocknen, farblos.

1. Oberhaut des Hutes klebrig-schleimig.

Oberhaut trocken.

2. St. unter dem Ringe glatt, nicht wollig-flockig.

Hut sehr dünnfleischig, glockenf., dann ausgebreitet, $2-3 \mathrm{~cm}$ br., gelblich od. rötilch, in der Mitte dunkler. St. $3-6 \mathrm{~cm} \mathrm{lg.,}$ hohl, zart, Ring weich wollig-flockig, darüber glatt, darunter mit wollig-seidenartigen, rosenroten, später gelblichen Flocken besetzt. L. dicht, weiß. In Ndwäldern, selten. S. H. (Zärtlicher R.)

L. delicata Fries. 
3. Hut gewölbt, dann ausgebreitet, 3-10 (-16) em br., schwach runzlig, weiß, seltener grau od. bräunlich. St. voll, $4-8 \mathrm{~cm} \mathrm{lg.,}$ am Grunde etwas verdickt, Ring weiß, gestreift, oberhalb weiß, trocken, unterhalb dem Hute gleichfarben. L. sehr weitläufig, weiß. Rasig an altem Lb., bes. Rotbuche, häufig. S. H. (Fig. 562.) (Schleimiger R.)

L. mucida (Schrad.).

Hut ei-glockenf., dann ausgebreitet, etwas gebuckelt, $6-8 \mathrm{~cm}$ br., weiß od. gelblich, kahl, Rand meist gestreift u. wimperig. St. hohl, $8 \mathrm{~cm}$ lg., klebrig, Velum undeutlich. L. dicht, später mehr weitläufig. Auf Heiden, Triften, Waldwiesen, nicht häufig. H. (Bestrichener R.) L. illinita Fries.

4. Ring dick, fest, beweglich. L. frei, aber vom St. durch einen feinen, fast knorpligen Ring getrennt.

Ring nicht beweglich. L. frei od, angewachsen, ohne Ring. 8.

5. St. glatt, nicht schuppig.

Hut eif., dann schirmartig ausgebreitet, stumpfhöckerig, 10 bis $25 \mathrm{~cm}$ br., weißlich od. graubraun, in der Mitte meist dunkler, Oberhaut bald in faserig-zottige, an der Spitze etwas abstehende Schuppen zerreißend. Fleisch u. L. bei Verletzung rosenrot. St. hohl, $10-30 \mathrm{~cm}$ lg., weißlich, angedrückt-braunschuppig, am Grunde knollig, Ring dick, lederartig. L. dicht, weißlich. E Bbar. In dichten Lbwäldern, auf Wiesen, Heideplätzen, häufig. S. H. (Fig. 563.) (Regenschirmpilz.) L. procera (Scopoli).

6. Hut flach, ohne od. mit unbedeutendem Höcker.

Hut eif., dann schirmf. ausgebreitet, mit spitzem, warzenf. Höcker, 4-6 cm br., weißlich od. hellockerfarben, glatt, später kleinkörnig od. schuppig. St. 6-10 cm lg., glatt, weißlich, am Grunde mit zwiebelf. Knollen, Ring dick, ganzrandig. L. weitläufig, weißlich. In Gebüsch, Wäldern, auf Äckern, nicht häufig. S. H. (Gebuckelter R.) $\quad$ L. umbonata (Schumach.).

7. Hut eif., dann ausgebreitet, undeutlich höckerig, etwa $4-13 \mathrm{~cm}$ br., weißlich, in der Mitte oft bräunlich, Oberhaut dünn, besonders am Rande in kleine Schuppen zerfallend. St. hohl, 6-10 cm lg., zylindrisch, weißlich. L. ziemlich dicht, weiß. Auf Äckern, Triften, nicht selten. F. S. H. (Fig. 564.) (Geschundener R.)

L. exeoriata (Schaeff.).

Hut kuglig, dann schirmf. flach, bis $10 \mathrm{~cm}$ br., graubraun, in der Mitte meist lebhaft braun, Oberhaut dünn, in große anliegende Schuppen zerreißend. St. 10-15 cm lg., hohl, glatt, schmutzig, weißlich, am Grunde mit großem Knollen, Ring zerschlitzt am Rande. L. dicht, weiß. In Gärten, Wäldern, zerstreut. S. (Fig. 565.) (Zerrissener R.) L. rhacodes (Vittad.).

8. L. angewachsen od. angeheftet (frei nur bei cinnabarina), Hut körnig od. warzig.

L. frei. Hut kahl, schuppig od. flockig.

9. Hut ockerfarben, rost- od. rotbraun.

Hut rot, seltener weißlich.

12.

10.

11. 
10. Hut eif. od. halbkuglig, dann ausgebreitet, stumpfhöckerig, 2 bis $4 \mathrm{~cm}$ br., ockerfarben, körnig-kleiig, Fleisch gelb. St. zylindrisch, 5-6 cm lg., unterhalb des Ringes kleinschuppig. L. dicht, angewachsen, weiß, dann gelblich. In Wäldern, Heiden, Triften zwischen Moos, nicht selten. S. H. (Unbefleckter R.)

\section{L. amianthina (Scopoli).}

Hut wie bei vor., $2-4 \mathrm{~cm}$ br., rost- od. rotbraun, trocken graubraun, körnig-kleiig, Fleisch weiß. St. zylindrisch, 4-6 cm lg., oberhalb des häutig-schuppigen Ringes kleinschuppig, dem Hute gleichfarben, oberhalb weiß od. schwach violett. L. leicht angeheftet, weiß. Wie vor., nicht selten. S. H. (Fig. 566.) (Körniger R.) L. granulosa (Batsch).

11. Hut wie bei vor., 4-10 cm br., zinnoberrot, körnig-kleiig, Fleisch blaß. St. voll, etwas knollig, unterhalb des häutig-schuppigen Ringes rotschuppig. L. frei, weiß. In Ndwäldern, zerstreut. S. H. (Zinnoberroter R.)

L. cinnabarina Fries.

Hut kegelf. od. halbkuglig, dann ausgebreitet, stumpfhöckerig, $3-6 \mathrm{~cm}$ br., hellfleischrot od. fast weißlich, körnig-schuppig. St. später hohl, 4-7 cm lg., am Grunde wenig verdickt, unterhalb des häutigen Ringes gleichfarbig, kleinschuppig. L. dicht, angeheftet, weiß. Geruch meist unangenehm. Zwischen Moos auf Heiden, in Wäldern, zerstreut. S. H. (Spitzzähniger R.)

L. carcharios (Pers.).

12. Hutoberfläche glatt od. höchstens mehlig, wenn flockig, dann nur ea. $1 \mathrm{~cm}$ br., St. hohl, dünn.

Hutoberfläche seidenhaarig, flockig, schuppig, zottig. 15.

13. St. bei Berührung sich nicht rötend, Hut sehr dünnfleischig. 14.

Hut schwach fleischig, glockenf., dann gewölbt, stumpf od. stumpfbuckelig, sehr zerbrechlich, 1-2 cm br., weiß od. hellfleischrot, am Rand mit dem zerschlitzten Schleier. St. $3-6 \mathrm{~cm}$ lg., seidenartig-faserig, elwas mehlig, weiß, bei Berührung sich rötend. L. dicht, weiß locker angeheftet, dann frei. In Gabüsch u. Wäldern, selten. H. (Halbnackter R.)

\section{L. seminuda (Lasch).}

14. Hut ei- od. glockenf., dann ausgebreitet, spitzhöckerig, $2-3 \mathrm{~cm}$ br., glatt, gelblich od. ockerfarben. St. hohl, $3-4 \mathrm{~cm} \mathrm{lg.,} \mathrm{weiß-}$ lich, rötlich od. hellgelblich, Ring häutig, dauerhaft. L. frei, weiß. Auf Grasplätzen, in Gärten, zerstreut. S. (Mittelgroßer R.)

\section{L. mesomorpha Bull.}

Hut ei- od. glockenf., dann ausgebreitet, stumpfhöckerig, 6 bis $13 \mathrm{~mm}$ br., weißlich od. gelblich, von angedrückten, später etwas abstehenden Flocken überzogen. St. hohl, $1-3 \mathrm{~cm} \lg$., am Grunde schwach verdickt, weißlich, faserig-flockig, mit flockighäutigem, bald verschwindendem Ring. L. dicht, frei, weißlich. In Wäldern, auf Triften, selten. S. (Kleinringiger R.)

L. parvannulata (Lasch). 
15. Hut weiß od. gelblich, ebenso der hohle St.

Hut verschieden braun.

16. Rand glatt, L. vom St. etwas entfernt, abgerundet.

Hut häutig, vergänglich, glockig-kegelf., dann ausgebreitet, $2-8 \mathrm{~cm}$ br., weiß od. gelb, mehlig od. flockig-schuppig, Rand faltig gestreift. St. sehr zerbrechlich, $4-15 \mathrm{~cm} \mathrm{lg.,} \mathrm{unten} \mathrm{zwie-}$ belig verdickt, hellgelblich, flockig, Ring häutig. L. dicht, hinten abgerundet, frei, oben bis zum St. herangehend, weiß od. gelb. In Gewächshäusern, besonders auch auf Lohe, rasig, nicht selten. F. S. (Fig. 567.) (Zwiebelstieliger R.)

17. Oberhaut anfangs glatt, dann schuppig. L. cepistipes (Sowerby).

Hut glockenf., dann flach gewölbt bis ausgebreitet, stumpfhöckerig, bis $6 \mathrm{~cm}$ br., weiß, glatt, dann nach dem Rande hin fein seidenhaarig. St. bis $6 \mathrm{~cm} \mathrm{lg.,} \mathrm{zylindrisch,} \mathrm{weiß,} \mathrm{kahl} \mathrm{werdend,}$ Ring zerschlitzt, vergänglich. L. ziemlich dicht, weiß. Zwischen Gras in Gärten, Parks, zerstreut. F. S. (Hermelin-R.)

\section{L. herminea Fries.}

18. Hut glockenf., dann ausgebreitet, stumpfhöckerig, $2-4 \mathrm{~cm}$ br., weißlich, in der Mitte bräunlich, Oberhaut fast glatt, dann in anliegende od. abstehende, braune Schüppchen zerfallend. St. 4-5 cm lg., zylindrisch, selten unten etwas verdickt, weißlich, oft etwas rötlich, Ring abstehend, meist schnell verschwindend. L. dicht, weiß. Geruch rettichartig. In Gärten, Parks, nicht selten. F. S. (Kamm-R.)

L. eristata (Bolton).

Hut ei- od. glockenf., dann schirmf. ausgebreitet, stumpfhöckerig, $6-8 \mathrm{~cm}$ br., mit anfangs zusammenhängenden, dann konzentrisch zerfallenden, flockigen, \pm bräunlichen Schuppen, weißlich. St. $5-8 \mathrm{~cm} \mathrm{lg.,} \mathrm{Ring} \mathrm{flockig,} \mathrm{meist} \mathrm{schnell} \mathrm{vergäng.}$ lich, oberhalb glatt, unterhalb dichtflockig-schuppig, dem Hut gleichfarbig. L. ziemlich dicht, weiß. In Wäldern unter Gebüsch, nicht selten. S. H. (Fig. 568.) (Schildf. R.)

\section{L. cly peolaria (Bull.).}

19. Fleisch u. L. bei Verletzungen rot werdend.

Fleisch sich nicht verfärbend.

20. Hut glockenf., dann ausgebreitet u. gebuckelt, bis $5 \mathrm{~cm}$ br., bräunlichgrau, in der Mitte dunkler, filzig u. warzig, später von kleinen, bräunlichen Schüppchen scheckig. St. voll, bis $8 \mathrm{~cm}$ lg., spindelf., flockig-schuppig, Ring zerschlitzt, vergänglich. L. weiß. Auf Gerberlohe, nicht häufig. S. (Geperlter R.)

L. meleagris (Sowerby).

Hut glockenf., dann schirmf. ausgebreitet, schwach gebuckelt, 6-8 $\mathrm{cm}$ br., Oberhaut rötlichbraun, in anliegende Schuppen zerreißend. St. hohl, 6-8 cm lg., am Grund schwach knollig, flockig-schuppig, Ring hängend, dauerhaft. L. dicht, weiß. Geruch obstartig. In Lbwäldern, selten. S. (Badhams R.) 
21. Hut stumpf gewölbt, $6-8 \mathrm{~cm} \mathrm{u}$. breiter, gelbbraun, haarig, flockig, kleiig, später mit aufrechten, spitzen, sparrigen Schuppen. St. später hohl, knollig, 6-8 cm u. länger, oberhalb des abstehenden Ringes bereift. In Gärten zwischen Gras, selten. S. (Spitzschuppiger R.)

L. acutesquamosa (Weinm.).

Hut ei- od. glockenf., dann flach gewölbt, schwachhöckerig, $10-15 \mathrm{~cm}$ br., zimmet- bis trüb kastanienbraun, filzig-flockig, in der Mitte mit kegelf., spitzen od. sparrigen Schuppen, am Rand gleichfarbig-zottig. St. hohl, 10-14 cm lg., schwach knollig, Ring breithäutig hängend darunter dicht schuppig, gleichfarbig. L. mäßig dicht, weiß. Geruch unangenehm rettichartig. Auf Grasplätzen, selten. H. (Fries' R.) L. Friesii (Lasch).

\section{Gattung: Amanitopsis Roze (Scheidenpilz.)}

Hut u. St. von einer häutig-fleischigen Hülle (velum universale) umschlossen, die später als Überzug od. filzig-warzige Fetzen auf der Hutoberfläche u. als Scheide am Grunde des St. zurückbleibt. Hut vom St. scharf getrennnt. Ring fehlt. L. frei. Sporen \pm ellipsoidisch, farblos.

Hut glockenf., dann flach ausgebreitet, $6-10 \mathrm{~cm}$ br., seidenglänzend, silbergrau, braun (var. badia Schaeff.), weiß (var. alba Fries) od. orangefarben (var. fulva Schaeff.), zuerst mit \pm großen weißen wolligen Fetzen am Rande furchig gestreift. St. hohl, bis $25 \mathrm{~cm} \mathrm{lg}$., weißlich flockig-schuppig, am Grunde von einer lockeren dickhäutigen Scheide umgeben. L. dicht weiß. In Lb.- u. Ndwäldern, bis ins Gebirge häufig. S. H. (Fig. 569.) (Bleigrauer S.)

\section{A. plumbea Schaeff.}

\section{Gattung: Amanita Pers. (Manschettenpilz).}

Velum universale wie bei vor. Gatt., außerdem noch ein. Velum partiale vorhanden, das als häutiger, hängender Ring am St. zurückbleibt. Sporen wenig ellipsoidisch, farblos. L. weiß, frei, selten angeheftet. Verdächtig od. giftig.

1. Der am St. zurückbleibende Teil der allgemeinen Hülle vollständig mit dem St. verwachsen, meist nur durch eine schwache Linie angedeutet $u$. in Flocken, Schuppen, Warzen zerfallend. 2.

Hülle am St.-Grund als deutliche Scheide zurückbleibend, die lose mit dem knollenf. Grund verwachsen u. oben scharf berandet ist, aber nicht frei über den Rand hervorragt.

Hülle mit dem St.-Grund \pm verwachsen, oben frei u. den St. scheidenf. umgebend.

2. Hutoberfläche mit Warzen als Rest der Hülle bedeckt.

Hut flachgewölbt, stumpf, $8-14 \mathrm{~cm}$ br., kahl, glatt, zuerst klebrig, weiß, in der Mitte braun, Rand glatt. St. später oben hohl, weiß, faserig, 8-14 cm lg., oben gestreift, wurzelartig am 
Grunde, Ring groß, Scheide undeutlieh, versehwindende Floeken bildend. In Buchenwäldern, selten. S. H. (Persoons M.)

A. Persoonii (Fries).

3. Fleisch bei Verletzung od. unter der Oberhaut sich verfärbend. 4 . Fleisch unverändert weiß.

4. Hut kuglig, dann flachgewölbt, $6 \mathrm{~cm}$ br., oliven- od. graubraun, mit schmutzigweißen Warzen dicht besetzt, Rand glatt, Fleisch unter der Oberhaut braun werdend. St. später hohl, $6-8 \mathrm{~cm}$ lg. Knollen am Grund schuppig, Ring abstehend. Zwischen Moos in lichten Wäldern, ziemlich selten. S. H. (Rauher M.)

A. aspera (Fries).

Hut kuglig, dann ausgebreitet, $8-14 \mathrm{~cm}$ br., schmutzig rötlich od. braunrötlich, verblassend, mit ungleichen, oft konzentrischen Warzen, Fleiseh bei Verletzung rot werdend. St. voll, 6-11 cm lg., weiß, dann rötlich, kleinschuppig, Knollen meist unten zugespitzt, mit ringf. Schuppen u. Warzen umgeben, Ring hängend. L. später rötlich, strichf. am St. herablaufend. Verdächtig. In Wäldern, Gebüsch, häufig. S. H. (Fig. 570.) (Grauer Fliegenschwamm).

A. pustulata (Schaeff.).

5. Hut kuglig, dann flach gewölbt, $8 \mathrm{~cm}$ br. umbra- od. graubraun, Warzen sehr klein, grau, fast mehlig, Rand glatt. St. voll, $8 \mathrm{~cm}$ lg., weiß, schuppig, Knollen kuglig, von oben niedergedrückt, schuppig. L. strichf. herablaufend, angeheftet. In Lbwäldern, ziemlich häufig. S. H. (Fig. 571.) (Zäher M.)

\section{A. spissa (Fries).}

Hut kuglig, dann flach gewölbt, 6-10 $\mathrm{cm}$ br., umbrabraun, kupferrot od. lederbraun, Warzen spitz, ungleich, Rand meist gestreift. St. voll, bis $10 \mathrm{~cm} \mathrm{lg.,} \mathrm{schuppig-ringartig,} \mathrm{Knollen}$ nicht berandet, Ring hängend, braun werdend. L. strichf. herablaufend, bei Verletzungen sich bräunend. In Ndwäldern, selten. S. H. (Rauchgrauer M.) A. capnosa (Letellier).

6. Hut gelb, scharlachrot od. orangefarben.

Hut schmutzig rötlich od. irgendwie braun.

8.

7. Hut fast kuglig, dann flach ausgebreitet, $6-10 \mathrm{~cm}$ br., glänzend gelb, mit mehligen, leicht ablösbaren Warzen, Rand gestreift. St. später hohl, 8-12 cm lg., weiß, unterhalb des hängenden Ringes schwach schuppig, Knollen gerandet, schuppig, zylindrisch. In Ndwäldern, nicht häufig. S. (Hoher M.)

\section{A. excelsa (Fries).}

Hut kuglig, dann flach gewölbt, endlich fast scheibig, $8-20 \mathrm{~cm}$ br., lebhaft scharlachrot od. orangefarben, oft verblassend, feucht klebrig, Warzen wei ß od. gelblich, dick, fast regelmäßig, abfallend, Rand gestreift, Fleisch unter der Oberhaut orangefarben. St. später hohl, 6-25 cm lg., weiß, Knollen kuglig od. eif., ringf. berandet, schuppig, Ring weiß, hängend, oben gestreift. L. 
am St. streifig herablaufend. Giftig. In Wäldern, Gebüschen, häufig. S. H. (Fig. 572.) (Fliegenpilz, Fliegenschwamm.)

A. muscaria (L.).

8. Hut kuglig, dann flach ausgebreitet, 10-12 cm br., schmutzig rötlich od. bräunlich, mit flockigen, unregelmäßigen, leicht ablösbaren Fetzen od. flachen Warzen, Rand glatt, weißlich. St. voll, bis $16 \mathrm{~cm} \mathrm{lg.,} \mathrm{weiß,} \mathrm{nach} \mathrm{unten} \mathrm{dachziegelig-schuppig,}$ Knollen unten zugespitzt, wurzelf., berandet, Ring zerschlitzt. In Wäldern, selten. S. H. (Vereinzelter M.)

\section{A. solitaria (Bull.).}

Hut kuglig, dann flach gewölbt, zuletzt flach, $6-8 \mathrm{~cm}$ br., umbra-, leder- od. graubraun, Warzen klein, weiß, ziemlich regelmäßig, Rand gestreift. St. später hohl, 6-8 $\mathrm{cm} \mathrm{lg.,} \mathrm{weiß,} \mathrm{Ring}$ schief, Knollen fast kuglig, von einer berandeten, angewachsenen, aber abziehbaren Hülle umgeben. Sehr giftig. In Lb. u. Ndwäldern, häufig. S. H. (Fig. 573.) (Umbrabrauner M.)

A. umbrina (Pers.).

9. L. weiß, Rand des Hutes deutlich gestreift.

10.

Hut halbkuglig, dann ausgebreitet $u$. verflacht, meist $8-16 \mathrm{~cm}$ br., orangefarben, selten gelb, rot, kupferrot, Warzen dick, weiß, Rand gestreift, Fleisch gelblich. St. etwas bauchig, nach obcn verjüngt, $10-16 \mathrm{~cm} \mathrm{lg}$., innen wollig-markig, Ring schlaff, Volva weit, sackf. L. gelb. Guter Speisepilz. In Wäldern, Heiden, auf Triften, häufig, aber nur im südl. Alpengebiet. S. H. (Fig. 574.) (Kaiserling, Kaiserschwamm.) A. caesarea (Scopoli).

10. Ring häutig, ganz, ebenso die Volva.

Hut kegelf., dann ausgebreitet, spitz, 6-11 $\mathrm{cm}$ br., weiß, klebrig, glänzend, Rand schwach lappig u. geschweift. St. voll, schuppig, unten knollig, Ring u. dicke Volva flockig zerreißend, locker. L. mit flockiger Schneide. Giftig. In feuchten Wäldern, selten. S. (Fig. 575.) (Giftiger M.)

A. virosa (Fries).

11. Hutoberfläche glatt, nicht seidenglänzend.

Hut glockenf. od. halbkuglig, dann fast kegelf. od. flach gewölbt, $6-8 \mathrm{~cm}$ br., weiß (var. albida Schroet.), weiß u. in der Mitte grau od. schwärzlich (var. grisea Schroet.), schwefelgelb (var. citrina Pers.), schmutziggelbgrün $u$. in der Mitte oft olivenbraun (var. viridis Pers.), schwach seidenglänzend, feucht etwas klebrig, oft mit Fetzen der Hülle bedeckt. St. später oben hohl, 8-10 cm lg., oben verjüngt, weiß, Knollen meist kuglig u. auf dem Scheitel mit weißer häutiger Scheide, Ring weiß od. gelblich gestreift. Sehr giftig. In Lbwäldern, seltener Ndwäldern, häufig. S. H. (Fig. 576.) (Knollenblätterschwamm, Gichtschwamm.)

A. bulbosa (Bull.).

12. Hut glockenf., dann ausgebreitet, 5-10 $\mathrm{cm}$ br., trüb-od. purpurbraun, mit filzigen Resten der Hülle od. kahl. St. später hohl, weiß, Ring dünn, hängend, bräunlich, Knollen kaum vortretend, 
locker bescheidet. Eßbar. In feuchten Ndwäldern, namentlich im Gebirge, nicht häufig. S. H. (Fig. 577.) (Porphyrwulstpilz.)

A. porpyhria (Alb. et Schwein.).

Hut gewölbt, dann flach, ca. $8 \mathrm{~cm}$ br., trocken, weißlich, seltener strohgelb, zitronengelb, grünlich, meist mit schuppigen Fetzen bedeckt, seltener nackt. St. später hohl, $8-10 \mathrm{~cm}$ lg., Knollen fast kuglig, Ring hängend, häutig. L. angeheftet. Giftig. In Wäldern u. Gebüschen, zerstreut. S. H. (Fig. 578.) (Strohgelber M.) A. straminea (Scopoli).

\section{Familie: Phallaceae.}

Myzel strangf. Fk. aus einem Rezeptakulum, das sich bei der Reife stark streckt, u. aus einem fertilen, gekammerten Geflecht (Gleba) bestehend, deren Wände mit dem Basidienlager ausgekleidet sind; beide zuerst von einer Hülle (Volva) umschlossen u. von eif. Gestalt. Volva durch das sich streckende Rezeptakulum am Scheitel zerreißend, Gleba bei der Reife zerfließend.

\section{Bestimmungsschlüssel der Gattungen.}

A. Gleba nicht als besonderer Hut abgesetzt.

1. Mutinus.

B. Gleba auf einem besonderen, glockenf. Hut sitzend.

2. Ithyphallus.

1. Gattung: Mutinus Fries (Hundsmorehel).

Rezeptakulum röhrig, unten vollständig gekammert, oben mit sehr dickwandigen Kammern, die nach innen offen sind.

Einzige Art mit hasel- bis fast walnußgroßen Eiern. Rezeptakulum gestreckt bis $15 \mathrm{~cm}$ lg., weiß, an der Spitze rot. Gleba olivengrün, ca. $1,5 \mathrm{~cm} \mathrm{lg.} \mathrm{u.} 1 \mathrm{~cm}$ dick. Geruchlos. Am Grunde von Lbstümpfen, im Moos u. Humus, sehr zerstreut. S. H. (Fig. 579.)

M. caninus (Hudson).

\section{Gattung: Ithyphallus Fries (Gichtmorchel).}

Rezeptakulum röhrig, mit gekammerter Wandung, am Seheitel ein glockenf. Hut befestigt, der die Gleba oberflächlich trägt.

Einzige Art mit tauben- bis hühnereigroßen Eiern. Rezeptakulum weiß, gestreckt bis $30 \mathrm{~cm}$ lg., mit etwa $3 \mathrm{~cm} \mathrm{lg.} \mathrm{Hut.} \mathrm{Gleba}$ olivengrün, abtropfend u. leere Kammern hinterlassend. Aasartig stark riechend. In schattigen Lbwäldern zwischen Lb., oft truppweise, nicht selten, aber unbeständig. F. S., seltener H. (Fig. 580.) (Teufelsei.)

I. impudicus (L.). 


\section{Familie: Hysterangiaceae.}

Fk. unterirdisch, knollig, innen aus Kammern bestehend, die vom Hymenium ausgekleidet sind, $u$. deren Wandungen von einem sterilen Gewebe (Columella) entspringen. Peridie fest.

\section{Bestimmungsschlüssel der Gattungen.}

A. Fk. im erwachsenen Zustande ohne Peridie. Sporen mit Längsrippe.

\section{Gautieria.}

B. Fk. im erwachsenen Zustande mit Peridie. Sporen glatt.

2. Hysterangium.

1. Gattung: Gautieria Vittadini (Gautiere).

Fk. knollig, vom Myzel entspringend. Peridie fehlend, so daß die labyrinthisch runzlige Glebaoberfläche frei liegt. Sporen apfelsinenkernartig, mit br. Rippen.

Fk. 2-3 cm Durchm., weißlich, dann bräunlich-gelb, ebenso innen. Gänge etwa $1 \mathrm{~mm}$ weit, labyrinthf., frei nach außen mündend. Sporen hell rostbraun. Geruch zwiebelartig. In Lbwäldern unter Lb. in der Erde, zerstreut. F. (Fig. 581, Habitus u. Längsschn.) (Riechende G.)

G. graveolens Vittad.

Fk. etwa walnußgroß, rötlichbraun, auch innen. Glebakammern viel größer. Sporen bräunlich. Wie vor., besonders in Eichenwäldern. (Fig. 582, Längsschn.) (Morchelähnliche G.)

\section{G. morchelliformis Vittad.}

2. Gattung: Hysterangium Vittadini (Rettichtrüffel).

Fk. knollig, vom Myzel entspringend. Peridie dickhäutig, leicht von der Gleba ablösbar. Sporen eif., spindelf., glatt, gelblich.

Einzige Art bis $3 \mathrm{~cm}$ Durchm. Peridie weiß, dann gelblich. Gleba später schmutzig graugrün od. olivenbraun. Nach Rettich riechend. In lichten Lbwäldern dicht unter der Bodenoberfläche, selten. F. (Fig. 583, Längsschn.) H. clathroides Vittad.

\section{Familie: Hymenogastraceae.}

Fk. unterirdisch, Columella fehlend, Kammern deshalb gleichmäßig das ganze Innere durchziehend. Peridie vorhanden, sich in die Kammern direkt fortsetzend $u$. deshalb nicht abtrennbar.

\section{Bestimmungsschlüssel der Gattungen.}

A. Fk. ohne jede wurzelartigen Myzelstränge.

a) Sporen ellipsoidisch od. spindelf.

1. Hymenogaster.

b) Sporen kuglig, stachlig.

I. Sporen farblos.

II. Sporen gelb od. braun.

2. Hydnangium.

3. Oeta viania.

B. Fk. mit wurzelf. Myzelsträngen.

4. Rhizopogon. 
1. Gattung: Hymenogaster Vittadini (Brauntrüffel).

Fk. fast kuglig, Peridie dünn, feinfaserig. Gänge fein, gewunden. Sporen \pm rostbraun.

Fk. 0,5-1,5 cm Durehm., Peridie weiß, dann gelblich u. bräun. lich. Gleba später rostbräunlich. Sporen rostbraun, glatt od. feinwarzig. Geruch schwach knoblauchartig. In Blumentöpfen, besonders auf australischen Arten, nicht selten. S. H. (Klotzsch' B.)

H. Klotzsehii Tulasne.

Fk. 1-2,5 cm Durchm., Peridie weißlich, dann gelblich. Gleba schmutzig hellviolett, später braun bis schwarzbraun. Sporen kastanienbraun, mit unregelmäßigen Leisten od. Warzen. Fast geruchlos. In Lbwäldern, selten. S. H. (Schöner B.)

H. decorus Tulasne.

\section{Gattung: Hydnangium Wallroth (Rottrüffel).}

Fk. etwa kuglig, Peridie sehr zart. Gleba mit labyrinthf. Gängen. Sporen etwa kuglig, farblos, stachlig.

Einzige Art, 1-2 cm Durchm., Peridie weiß. Gleba fleischod. hellrosenrot. Geruchlos. In Gewächshäusern in Gartenerde, auf Töpfen von australischen Holzgewächsen, nicht selten. H. W (Fig. 584, Längsschn.)

H. carneum Wallr.

3. Gattung: Octaviania Vittad. (Oktavianie).

Fk. fast kuglig, Peridie häutig od. flockig, abziehbar. Gleba mit steriler Basis. Sporen kuglig, breitstachlig, gelbbraun.

Einzige Art 1-2,5 cm Durchm., Peridie weiß, dann braun bis schwärzlich. Gleba weiß, dann schwarz. Garuch käseartig. In Lbwäldern, besonders von Eichen, unter Lb., selten. S. (Fig. 585, Längsschn.)

o. asterospora Vittad.

\section{Gattung: Rhizopogon Fries (Wurzeltrüffel).}

Fk. unregelmäßig knollig, am Grunde u. auch sonst mit wurzelartigen Myzelsträngen. Peridie häutig, nicht von der Gleba scharf gesondert, Gleba mit feinen Gängen, zerfließend. Sporen eif.-spindelf., glatt, hellgelblich.

Fk. oft gehäuft u. dann abgeplattet, $2-6 \mathrm{~cm}$ br., mit vielen bräunlichen Myzelsträngen. Peridie weiß, dann gelblich bis olivenbraun. Gleba weiß, dann schmutzig olivengrau. Geruch knoblauchartig. In sandigen Wäldern, auf Heiden, zerstreut. S. H. (Fig. 586.) (Gelbbräunliche W.)

R. virens (Alb. et Schwein.).

Fk. $1-5 \mathrm{~cm}$ Durchm., am Grunde mit dickem Myzelstrang, sonst mit wenigen Fasern, Peridie zuletzt gelblich od. olivenbraun. Gleba gelbbraun od. schmutzig olivengrün, zerfließend. Geruch schwach knoblauchartig. Im Sande an Wegen, Abstichen, zerstreut. S. H. (Rötliche W.)

R. aestivus (Wulf.).

Lindau, Kryptogamenflora. I. 2. Aufl. 


\section{Familie: Lycoperdaceae.}

Fk. oberirdisch, aus einer vielkammerigen Gleba bestehend $u$. von einer Peridie umgeben, die aus einer äußeren, sich \pm ablösenden Hülle u. aus einer inneren Hülle besteht (Exo- u. Endoperidie). Gleba bei der Reife pulverig zerfallend, zwischen den Sporen Capillitiumfasern vorhanden.

\section{Bestimmungsschlüssel der Gattungen.}

A. Exoperidie einschichtig, zellig, bei der Reife meist unregelmäßig zerfallend, nicht sternf. aufspringend.

a) Unterer Teil der Gleba steril $u$. als schwammiges Gewebe bleibend.

1. Lyeoperdon.

b) Gleba bis unten hin pulverig zerfallend.

I. Capillitiumfasern \pm gleichmäßig dick, ohne Stammstück. Sporen bei der Reife ungestielt.

\section{Globaria.}

II. Capillitiumfasern mit deutlichem Stammstück u. zugespitzten Ästen. Sporen bei der Reife gestielt.

\section{Bovista.}

B. Exoperidie aus einer zelligen u. faserigen, später verquellenden Schicht bestehend, sternf. aufreißend u. am Grunde mit der Endoperidie verbunden bleibend.

\section{Geaster.}

\section{Gattung: Lycoperdon Tournef. (Staubpilz).}

Fk. \pm kuglig, am Grunde stielf. zusammengezogen u. unfruchtbar Exoperidie in Platten, Warzen od. Stacheln zerfallend. CapillitiumJasern meist reich verzweigt, Enden zugespitzt. Sporen kuglig. 1. Endoperidie unregelmäßig zerfallend, Sporen ungestielt, feinwarzig.

Endoperidie am Scheitel mit einem regelmäßig begrenzten Loch sich öffnend.

2. Fk. keulenf., $10-20 \mathrm{~cm}$ lg., oberer sporentragender Teil fast kuglig, 5-10 cm Durchm., unten stielf., 3-6 cm br. Exoperidie weißlich od. ockerfarben, kleiig od. körnig-warzig, Endoperidie im ganzen oberen Teil zerfallend. Capillitium u. Sporen dunkel oliven- od. umbrabraun. In Lbwäldern u. Gabüschen, zerstreut.
S. H. (Fig. 587.) (Schlauchf. S.)
L. uteriforme Bull.

Fk. zylindrisch-sackf., oben verbreitert, $8-16 \mathrm{~cm} \mathrm{lg.,} 5-10 \mathrm{~cm}$ br., am Scheitel flach. Exoperidie felderig-schuppig, unten feinkörnig, weiß, dann ockerfarben. Endoperidie vollständig zerfallend, daher ein dickgestielter Becher übrig bleibend. Capillitium u. Sporen olivenbraun. Auf Wiesen u. Triften, nicht selten. S. H. (Fig. 588.) (Hasenbovist.)

L. caelatum Bull. 
Lycoperdaceae.
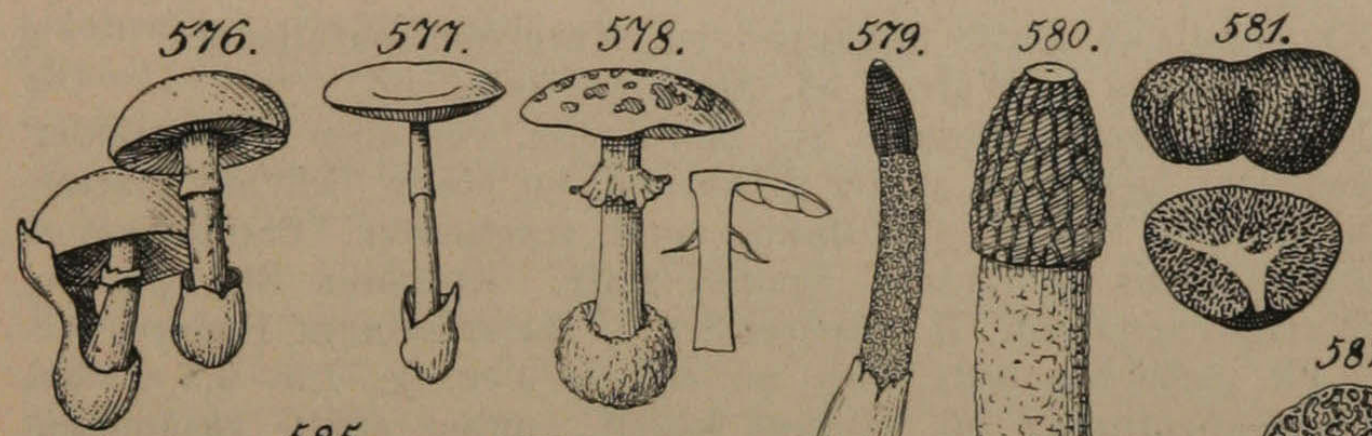

582
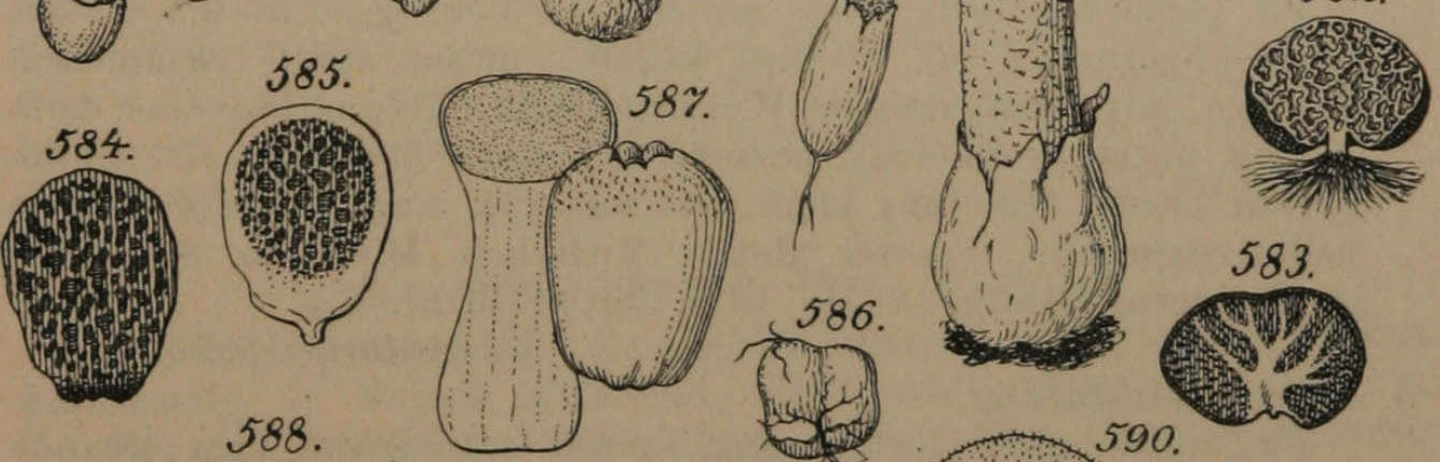

583.
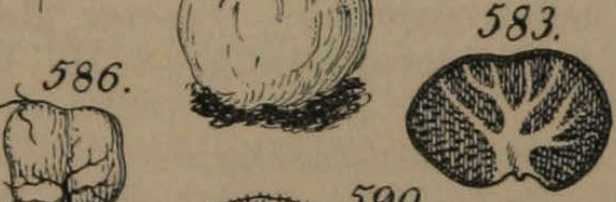

588.
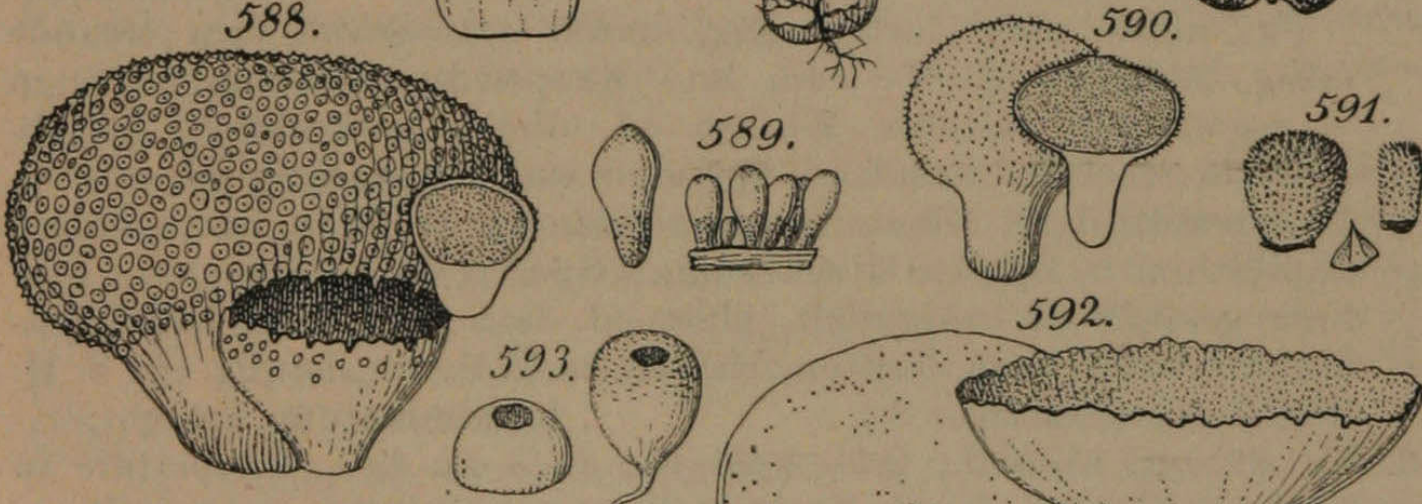

592.
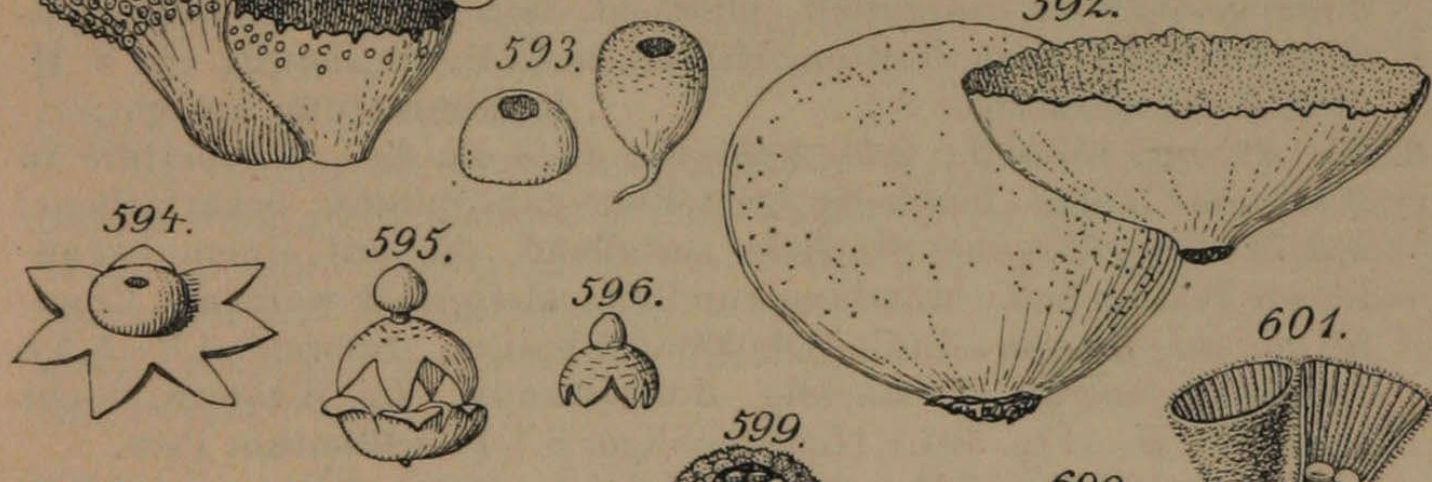

$\overbrace{-\infty}^{597}(1))^{2}$
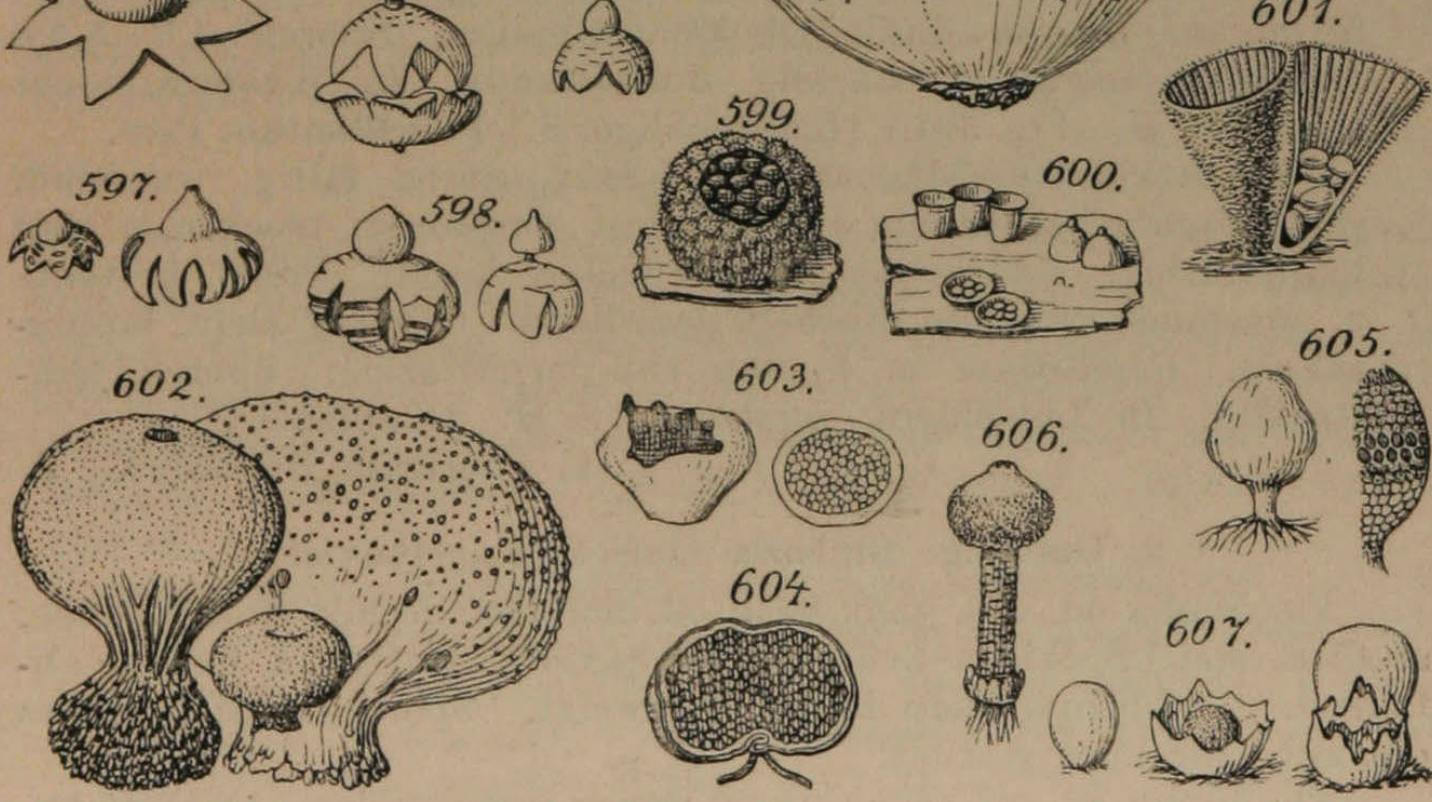

605.

1.:
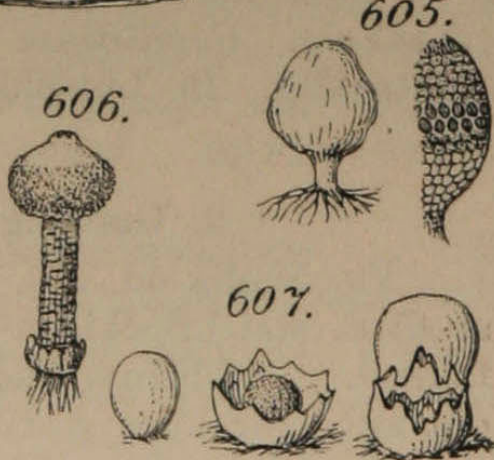
3. Exoperidie in glatte Schuppen od. Körnchen zerfallend.

Exoperidie in Warzen od. Stacheln zerfallend.

4. Fk. mit kurzem, dünnem St., fast kuglig, von oben etwas niedergedrückt, gelbweiß, später gelbbraun, im obern Teil mit glatten, braunroten Schuppen, Öffnung rund, regelmäßig. Capillitium u. sterile Basis gelbbraun. Sporen glatt. An alten Stümpfen u. Wurzeln zerstreut. H. (Später S.) L. serotinum Bonord.

Fk. meist büschelig, birn- od. eif., $2-4 \mathrm{~cm} \mathrm{lg.,} 1,5-2,5 \mathrm{~cm}$ br., oben abgerundet od. stumpf kegelf., unten stielf. zusammengezogen, mit strangartigem Wurzelgeflecht. Exoperidie oben feinkörnig, unten grobkörnig, ockerfarben, dann dunkelbraun. Endoperidie braun, Mündung klein, fast warzenf. Capillitium u. Sporen hellolivenbraun. Sporen glatt. Zwischen Moos an Stümpfen in Wäldern, häufig. S. H. (Fig. 589.) (Birnf. S.)

5. Sporen feinstachlig.

L. piriforme Schaeff.

Fk. meist oben fast kuglig, unten zylindrisch, am Grunde faltig, $2-5 \mathrm{~cm} \mathrm{lg.,} 2-3 \mathrm{~cm}$ br. Exoperidie fleischig, weiß, in 士 regelmäßig gestellte Warzen od. dicke, gebrechliche u. abfallende Stacheln zerfallend, später braun, feinstachlig od. warzig. Endoperidie derb, Mündung scheitelständig, rundlich, fast warzenf. Capillitium u. Sporen olivenbraun. Sporen 3-4 $\mu$ Durchm., sehr kurz gestielt od. ungestielt, glatt od. fein punktiert, hellolivenbraun. Auf Wiesen, Triften, Heiden, in Wäldern, häufig. F. S. H. (Fig. 590.) (Warziger S.)

L. gemmatum Batsch.

6. Fk. ei- od. kreiself., $2,5-4 \mathrm{~cm} \mathrm{lg.,} 2-3 \mathrm{~cm} \mathrm{br.} \mathrm{Exoperidie} \mathrm{in}$ $2-4 \mathrm{~mm}$ lange, büschelig gestellte, gekrümmte, ockerfarbene, später dunkelbraune Stacheln zerfallend, die auf einem bräunlichen Filz stehen. Mündung rundlich, klein, fast warzenf., Capillitium u. Sporen dunkelschokoladenbraun. Sporen $4,5-5,5 \mu$ Durchm., ungestielt, stachlig, dunkelbraun. In Wäldern, nicht selten. S. H. (Fig. 591.) (Igelstachliger S.) L. echinatum Pers.

Fk. verkehrt-kegelf., niedergedrückt, unten faltig, wurzelnd, graufleischfarben, dann dunkler, fast purpurrot, trocken u. reif kupferfarbig. Exoperidie in sehr kleine, kegelf., kreisf. gestellte u. zusammenneigende Stacheln zerfallend. Öffnung klein, lappigzähnig. Capillitium u. Sporen ruß-purpurfarbig. Sporen feinstachlig. In Lbwäldern, zerstreut. S. H. (Kupfer-S.)

L. cupricum Bonorden.

\section{Gattung: Globaria Quélet (Kugelbovist).}

Fk. kuglig od. eif., ganz fertil od. am Grunde mit einer flachen, sterilen, weichflockigen Scheibe. Exoperidie häutig, in Fetzen abfallend. Capillitiumfasern mäßig verzweigt. Sporen kuglig, stiellos od. nur sehr kurz gestielt.

Fk. kuglig od. eif., nach unten etwas verschmälert, $1-2 \mathrm{~cm} \mathrm{lg.,}$ u. br. Exoperidie kleiig-flockig, oben bisweilen gefeldert, weiß, dann 
gelbbraun. Endoperidie dünn, zähe, gelbbraun, am Scheitel mit kleiner, rundlicher Öffnung. Innen lebhaft gelblich-olivenbraun, am Grunde mit dünner, unfruchtbarer Schicht. Sporen 3-4 $\mu$ Durchm., stiellos, glatt, gelbbraun. Auf Heiden, an Waldrändern, nicht selten. S. H. (Kleiiger K.)

G. furfuracea Schaeff.

Fk. fast kuglig od. eif., meist $15-30 \mathrm{~cm}$ br., oft viel größer. Exoperidie weiß, weich, sehr zerbrechlich, fast glatt, später ockerfarben. Endoperidie dünn, oben unregelmäßig zerfallend. Innen gelblich-olivenbraun, am Grunde mit flacher, steriler Schicht. Sporen 4-5 $\mu$ Durchm., kurz gestielt, gelbbraun, glatt od. fein punktiert. In Gärten, auf Äckern, im Gebüsch, sehr zerstreut. F. S. H. (Fig. 592.) (Riesenbovist.)

G. bovista (L.).

\section{Gattung: Bovista Pers. (Bovist).}

Fk. kuglig, ungestielt. Exoperidie fleischig, glatt, später trocken papierartig, in Fetzen abfallend, Endoperidie dünn u. zähe, am Scheitel sich öffnend. Unfruchtbare Basis fehlt. Capillitiumfasern mit kurzem, dickem Stammstück, fast sternf. verzweigt. Sporen kuglig, lggestielt.

Fk. kuglig, 1,5-2 cm Druchm. Exoperidie weiß, glatt, dann gefeldert u. abfallend, am Grunde meist papierartig bleibend. Endoperidie zähe, blaugrau, Mündung scheitelständig, klein, rund. Innen dunkelbraun. Sporen 4-5 $\mu$ Durchm., glatt, braun, Stielchen $9-15 \mu$ lg. Auf Wiesen, in lichten Wäldern, Heiden, nicht selten. S. H. (Fig. 593.) (Bleigrauer B.)

B. plumbea Pers.

Fk. kuglig od. etwas niedergedrückt, $3-5 \mathrm{~cm}$ Durchm. Exoperidie wei $ß$, glatt, fetzig abfallend. Endoperidie gelb-, dann schwarzbraun, pergamentartig glänzend, glatt, Öffnung rundlich, gezähnt. Innen purpur- bis umbrabraun. Sporen $5 \mu$ Durchm., purpurbraun, glatt, gestielt. Auf Wiesen, Heiden, Feldern, zerstreut. S. H. (Schwärzlicher B.)

B. nigrescens Pers.

\section{Gattung: Geaster Micheli (Erdstern).}

Fk. kuglig od. eif., Peridien am Grunde fest verbunden, durch gallertige Mittelschicht getrennt, anfangs geschlossen. Exoperidie papier- od. lederartig, vom Scheitel her sternf. aufspringend u. in sich zurückschlagende spitze Lappen zerteilt. Endoperidie papierartig, glatt, sitzend od. gestielt, am Scheitel mit kleiner, \pm regelmäßiger Öffnung aufbrechend. Capillitium fädig, netzf. Sporen kuglig, sitzend.

1. Endoperidie mit deutlicher, kegelf. begrenzter Mündung.

2.

Fk. zuerst kuglig, 1,5-2,5 cm Durchm. Exoperidie sehr dick, in $7-10$ od. mehr spitze, bis zum Grunde reichende Lappen zerreißend, außen grau, innen schmutzig braun, rissig, flach ausgebreitet. Endoperidie kuglig, 1-2 cm Durchm., sitzend, grau od. braun, am Scheitel mit unregelmäßig gezähnter, flacher, kleiner 
Öffnung aufreißend. Capillitium netzf., mit den Sporen umbrabraun. Sporen kuglig, 8-11 $\mu$ Durchm., kastanienbraun, warzig. Zwischen Moos in sandigen Ndwäldern, zerstreut. S. H. (Fig. 594.) (Sternf. E.)

2. Mündung gewimpert, glatt, \pm scharf abgesetzt.

Mündung kammf. gefurcht, scharf abgesetzt.

3. Lappen der Exoperidie trocken nur nach unten umgeschlagen. 4.

Exoperidie in 2 Schichten zerspalten, die untere flach dem Boden aufliegend, die äußere sich emporwölbend u. auf die 4 Lappenspitzen sich stützend. Endoperidie auf kurzem, zylindrischem, weißem St., von ihm durch eine scharfe Kante getrennt, eif., 8-12 cm br., grau od. bräunlich, mit durch eine scharfe Kante begrenzter, faseriger, hellgelblicher, fast scheibenf. Mündung, die sich kegelf. emporwölbt u. am Scheitel mit gefaserter Öffnung aufbricht. Capillitium unverzweigt, mit den Sporen umbrabraun. Sporen $4-5 \mu$ Durchm., dunkelbraun, warzig punktiert. Zwischen Nd. in Ndwäldern, zerstreut. S. H. (Fig. 595.) (Gekrönter E.) G. coronatus (Schaeff.).

4. Mündung faserig-wimperig, nicht scharf gezähnt.

Exoperidie dick, fast lederartig, bis zur Hälfte in 5-6 Lappen geteilt, dann zurückgerollt, innen rotbraun, glatt. Endoperidie sitzend, kuglig od. br. eif., glatt, blaßbraun, mit gezähnelter, scharf begrenzter Mündung. Sporen $3-4,5 \mu$ Durehm., dunkelbraun, punktiert. In Ndwäldern, selten. S. H. (Fig. 596.) (Rötlicher E.)

G. rufescens Pers.

5. Fk. zuerst kuglig-eif., 1,5-2 cm br., Exoperidie zuletzt papierartig, nach außen gerollt $u$. bis zur Mitte in 6-15, oft ungleiche Lappen zerteilt, innen hellbraun, außen weißlich. Endoperidie kuglig od. etwas zugespitzt, $1-1,5 \mathrm{~cm}$ br., ockerfarben od. hellbraun, glatt, am Scheitel mit etwas vorstehender, seidenfaseriger, meist scharf abgesetzter Mündung. Capillitium unverzweigt, mit den Sporen lehmbraun. Sporen 3-4 $\mu$ Durchm., gelbbraun, feinpunktiert. In Lb.- u. Ndwäldern, zerstreut. S. H. (Gewimperter E.)

G. fimbriatus Fries.

Exoperidie bis zur Mitte in 5-10 Lappen zerteilt, nach unten gebogen od. ausgebreitet (bis $15 \mathrm{~cm}$ br.), dickfleischig, innen rotbraun, rissig, außen weißlich od. ockerfarben. Endoperidie kuglig od. eif., papierartig, braun, glatt, am Scheitel mit undeutlich begrenzter, kleiner, faserig-wimperiger Öffnung. Capillitium u. Sporen umbrabraun. Sporen 4-5 $\mu$ Durchm., dunkelbraun, grob punktiert. In Wäldern, Gebüsch, zerstreut. S. H. (Gesäumter E.)

G. limbatus Fries.

6. Endoperidie deutlich gestielt.

Exoperidie häutig-lederig, in 6-8 Lappen zerspalten, zuletzt eingerollt, ausgebreitet, bis $4 \mathrm{~cm}$ br., innen braun od. rötlichbraun, außen weißlich. Endoperidie kuglig od. ellipsoidisch, sitzend od. sehr kurz gestielt, graubraun od. braun, glatt, Mün- 
dung kegelf., tief gefurcht, nicht als besondere Scheibe abgesetzt. Capillitium u. Sporen braun. Sporen $5 \mu$ Durchm., braun, grob punktiert. In Wäldern, Heiden, zerstreut. S. H. (Fig. 597.) (Gestreifter E.)

G. striatus DC.

7. St. am Grunde ohne Scheide.

Exoperidie häutig, bis zur Mitte in 6-8 Lappen geteilt, umgeschlagen, ausgebreitet bis $4 \mathrm{~cm}$ br., außen weißlich, innen bräunlich. Endoperidie birnf., $1-1,5 \mathrm{~cm}$ br., grau od. graubraun, gestielt, unten abgeplattet, scharf berandet, mit einem scheidenf., häutigen Ringe, darüber gefaltet, Mündung kegelf., scharf abgesetzt, kammartig gefaltet, bräunlich. St. zylindrisch, graubraun, am Grunde mit Scheide. Sporen u. Capillitium umbrabraun. Sporen 5-6 $\mu$ Durchm. In Wäldern u. Gebüsch, zerstreut. S. H. (Kelch-E.)

G. caliculatus Fuck.

8. Exoperidie dickhäutig, bis zur Mitte in 6-10 Lappen zerreißend, zurückgewölbt, ausgebreitet bis $8 \mathrm{~cm}$ br., außen schmutzig weißlich, innen grau od. bräunlich. Endoperidie kuglig od. fast birnf., dunkelbraun, Mündung kreisf., abgegrenzt, scheibig, in eine laneg zylindrische Röhre übergehend, kammartig gefaltet, St. 3-4 mm lg., bräunlich. Capillitium unverzweigt. Sporen 4-6 $\mu$ Durchm., braun, grob punktiert. Zwischen Nd. in Ndwäldern, selten. S. H. (Bryants E.) G. Bryantii Berkeley.

Exoperidie bis über die Mitte in 5-8 Lappen gespalten, umgebogen, ausgebreitet bis $4 \mathrm{~cm}$ br., innen glatt, braun. Endoperidie rhomboidisch im Längsschnitt, unten abgesetzt in einen Halsteil u. dann in den ziemlich langen, zylindrischen od. etwas zusammengedrückten St. übergehend, bleigrau-bräunlich, Mündung kreisf. gerandet, lg. kegelf., tief furchig-faltig. Capillitium u. Sporen braun. Sporen 5-6 $\mu$ Durchm., grob warzig. In trockenen Ndwäldern, sehr selten. S. H. (Fig. 598.) (Schmidels E.) G. Sehmidelii Vittad.

\section{Familie: Nidulariaceae.}

Fk. anfangs kuglig od. keulig. Peridie geschlossen, später aufspringend u. becher- od. schüsself. gestaltet, lederig, im Innern mit mehreren linsenf., gesonderten, meist durch einen Strang am Peridium befestigten Kammern (Sporangiolen) versehen. Hymenium die Innenfläche der Sporangiolen überziehend. Sporen ellipsoidisch, farblos, glatt.

Bestimmungsschlüssel der Gattungen.

A. Sporangiolen frei, nicht mit Ștrang befestigt. 1. Nidularia.

B. Sporangiolen durch Strang an der Peridie befestigt.

a) Peridie dick, filzig-häutig, am Scheitel mit kreisf. abgegrenztem, gleichartigem, schwindendem Deckel. Schleier fehlt.

2. Crucibulum. 
b) Peridie aus mehreren verschiedenartigen Lagen zusammengesetzt, am Scheitel mit zentraler Öffnung aufspringend, eine Zeitlang noch von einem Schleier geschlossen.

\section{Cyathus.}

1. Gattung: Nidularia Bull. (Nestpilz).

Fk. kuglig, Peridie dünn filzig, oben unregelmäßig od. mit kreisf. Decke, aufspringend, zuletzt schüsself. Sporangiolen zahlreich, in Schleim eingebettet, dann frei.

1. Peridie fast deckelartig sich öffnend, nicht unregelmäßig zerreißend.

Fk. kuglig, 2-4 mm br., einzeln od. zusammenfließend. Peridie dünn, feinfilzig, weißlich, durch die Sporangialen höckerig, unregelmäßig zerfallend. Sporangiolen zahlreich, $0,7 \mathrm{~mm}$ br., scheibig, beiderseits genabelt, glatt, glänzend, gelbbraun. Auf feuchten Zweigen, besonders von Nd. in Wäldern, selten. F. (Nackter N.) N. denudata Sprengel.

2. Fk. rasig dicht, oft fast zusammenfließend, kuglig, dann niedergedrückt, $6-7 \mathrm{~mm}$ br., $3-5 \mathrm{~mm}$ hoch. Peridie zottig-filzig, schmutzig weißlich od. gelblichgrau, mit fast regelmäßigem kreisf. Deckel aufspringend. Sporangiolen zahlreich, scheibig, weiß, dann glänzend kastanienbraun, $1-2 \mathrm{~mm}$ br. Sporen $8-10 \mu$ lg., $6 \mu$ br. Auf der Erde, Holzsplittern, Zweigen, selten. S. H. (Fig. 599.) (Zusammenfließender N.) N. confluens Fries et Nordheim.

Fk. meist einzeln, kuglig, etwas niedergedrückt, $4-6 \mathrm{~mm}$ br., am Grunde meist mit wurzelf. Fäden. Peridie filzig-zottig, höckerig, schmutzig grau, scharf umschrieben aufreißend. Sporangiolen scheibig, ca. $2 \mathrm{~mm}$ br., glänzend braun. An abgefallenen Ästen, Nd., auf Erde in Wäldern, selten. S. H. (Gefüllter N.)

\section{N. farcta (Roth).}

\section{Gattung: Crucibulum Tul. (Becherpilz).}

Fk. kuglig, dann etwas zylindrisch. Peridie lederig-filzig, am Scheitel mit scharf abgesetztem, kreisf. Deckel, später nach Zerfall des Deckels topff., an der Mündung ungesäumt. Sporangiolen linsenf., mit Strang befestigt.

Einzige Art mit geselligen, 5-8 mm lg., $5-7 \mathrm{~mm}$ br. Fk., die meist einem dicken, gelbbraunen Filz aufsitzen. Peridie ockerfarben. Sporangiolen 1,5-2 mm Durchm., weißlich od. hellockerfarben. Auf Zweigen, Holzstücken, Pfählen, Balken, Stengeln usw., häufig. S. H. (Fig. 600.) (Gemeiner B.) C. vulgare Tul.

3. Gattung: Cyathus Haller (Trommelpilz).

Fk. zylindrisch, dann kreiself. Peridie lederig, mehrschichtig, oben sich öffnend, zuerst mit einer dünnen, weißlichen Haut überspannt, dann becherf. mit scharfer, deutlicher Berandung. Sporangiolen linsenf., mit Strang befestigt. 
Fk. meist gesellig, anfangs eif., dann kreiself., $10-14 \mathrm{~mm}$ lg., 6-10 $\mathrm{mm}$ br. Peridie lederig, außen filzig, dann glatt, blaß ockerfarben od. grau, innen glatt, glänzend, bleigrau od. bräunlich, Mündung zuletzt wellig zurückgebogen. Sporangiolen $2-3 \mathrm{~mm}$ br., glänzend grau. Auf faulendem Holz, Brettern, auf Erde usw. in Gärten, Feldern, häufig. S. H. (Topff. T.) C. olla (Batsch).

Fk. gesellig, eif., dann kreiself., $10-16 \mathrm{~mm}$ hoch, $8-10 \mathrm{~mm}$ br. Peridie rost- bis umbrabraun, zottig-filzig, innen glänzend bleigrau, gestreift, Mündung später scharf kreisf. mit aufrechten zottigen Haaren. Sporangiolen weißlich, ca. $2 \mathrm{~mm}$ br. Wie vor. (Fig. 601.) (Gestreifter T:)

C. striatus (Hudson).

\section{Familie: Sclerodermataceae.}

Fk. kuglig, mit sterilem, stielf. Grund. Peridie dick, einfach. Gleba gekammert. Zwischenschichten reif erhärtend, faserig-schollig zerfallend, als Gerüst od. Hülle ausdauernd. Basidialhyphen büschelig verzweigt $u$. das ganze Innere gleichmäßig füllend. Capillitium fehlt.

\section{Bestimmungsschlüssel der Gattungen.}

A. Bei der Reife im Innern keine bestimmte Kammerung mehr zeigend, alles von Sporenstaub u. Gewebefetzen erfüllt.

a) Sporen vor der Reife mit dichter Hyphenhülle, Fk. oberirdisch.

1. Scleroderma.

b) Sporen ohne solche Hülle, Fk. unterirdisch. 2. Pompholyx.

B. Bei der Reife im Innern noch deutliche, rundliche Kammern erkennbar.

a) Peridie fleischig, von der Gleba nicht scharf abgesetzt, Fk. unterirdisch.

3. Melanogaster.

b) Peridie häutig, scharf abgesetzt von der Gleba, Fk. oberirdisch.

4. Pisolithus.

1. Gattung: Scleroderma Pers. (Kartoffelbovist).

Peridie dick, lederig, korkig, weiß, dann schwarz. Gleba kleinkammerig, Zwischengewebe in Fasern zerfallend. Basidien viersporig, Sporen kuglig, schwarzbraun, warzig-stachlig.

1. Sporenmasse bei der Reife grau bis graubraun, mit gelben Flocken od. Fasern durchsetzt, Fk. stielf. am Grunde.

Fk. knollenf., meist 3-6 em br., sitzend, am Grunde mit Myzelsträngen. Peridie $2-3 \mathrm{~mm}$ dick, schmutzig lederbraun, oben rissig aufspringend. Sporenmasse erst weiß, dann grau, zuletzt schwarz, mit graubraunen Flocken vermischt. Verdächtig. Auf Triften, in lichten Wäldern, häufig. S. H. (Fig. 602.) (Falsche Trüffel.)

S. vulgare Hornemann. 
2. Fk. $3-5 \mathrm{~cm}$ br., am Grunde zylindrisch verschmälert, oft geteilt u. in weiße Myzelstränge auslaufend. Peridie häutig-lederig, bräunlich gefeldert od. körnig, oben lochf. od. unregelmäßig aufreißend. Sporenmasse zuletzt grau, mit gelblichen Flocken. In Wäldern, Gebüsch, zerstreut. S. H. (Fig. 603.) (Bräunlicher K.)

S. bovista Fries.

Fk. $3-8 \mathrm{~cm}$ br., am Grunde stielf. verschmälert u. in Myzelstränge übergehend. Peridie fast holzig, dick, bräunlich-gelblich, unten blasser, schuppig-gefeldert, am Scheitel weit aufbrechend, zuletzt becherf. Sporenmasse graubraun, mit gelben Fasern. Giftig. Auf sandigem Boden in Wäldern, zerstreut. S. H. (Hartbovist, Kartoffelbovist.) S. verrucosum (Bull.).

\section{Gattung: Pompholyx Corda (Weiße Trüffel).}

Fk. knollig, unterirdisch, sonst ähnlich wie vor. Sporen nicht von Hyphengeflecht eingeschlossen.

Einzige Art weiß, dann braun, innen schwarz-violett. In humöser Erde der Wälder, nur in Böhmen. Eßbar. P. sapidum Corda.

\section{Gattung: Melanogaster Corda (Schwarzknolle).}

Fk. kuglig, höckerig, unterirdisch, oberflächlich oft mit Myzelsträngen. Peridie festfleischig, in die Gleba allmählich übergehend. Gleba mit rundlichen Kammern, Zwischengewebe fest, ein Gerüst bildend. Sporen dunkelbraun.

Fk. 2-4 cm br., oliven- dann dunkel lederbraun. Peridie weich, fein wollig faserig, fast glatt, trocken runzlig. Kammern ungleich groß. Sporen fast zitronenf., $13-16 \mu \mathrm{lg}$., $7-8 \mu \mathrm{br}$. Geruch schwach zwiebelartig. In Wäldern u. Gebüsch, $2-6 \mathrm{~cm}$ unter der Oberfläche, am Grunde alter Stämme, zerstreut. S. H. (Zweifelhafte S.)

M. ambiguus (Vittad.).

Fk. höckerig, 3-6 cm br., ockerfarben od. gelblich, dann gelbbraun, mit wenigen Myzelsträngen. Peridie weich, filzig. Kammern klein. Sporen ellipsoidisch, 6-10 $\mu$ lg., 3-5 $\mu$ br. Geruch juchtenartig. Wie vor. S. (Fig. 604 Längsschn.) (Bunte S.)

M. variegatus (Vittad.).

\section{Gattung: Pisolithus Alb. et Schwein. (Erbsenstreuling).}

Fk. kuglig, knollig, keulig, am Grunde gestielt. Peridie im oberen Teil sehr dünn, brüchig. Gleba mit zahlreichen, rundlichen Kammern, bei der Reife in eckige, linsenartige Körperchen zerfallend, die von einer festen Hülle umschlossen u. mit Sporen gefüllt sind. Sporen kuglig, braun, warzig.

Fk. kurz gestielt, 3-6 cm lg. u. br., St. 1-2 cm br., eingesenkt u. in Stränge übergehend. Peridie steif, dünn, rost-, gelb- od. rotbraun, oben zerfallend. Innenmasse weiß od. gelblich, dann braun, hart u. eine große Zahl linsenf., eckiger Körperchen bildend. Auf 
Sand od. Kies in Wäldern, Heiden, zerstreut. S. H. (Fig. 605 Hab. u. Längsschn.) (Sand-E.) P. arenarius Alb. et Schwein.

Fk. keulig, oben abgerundet, gestielt, $1-10 \mathrm{~cm} \mathrm{lg.,} 2-10 \mathrm{~cm}$ br., St. $2-7 \mathrm{~cm}$ br., unten grubig u. dick wurzelartig verzweigt. Peridie ockerfarben, dann braun. Inneres in ungleich große, gelbe, dann braune Körper zerfallend. In Wäldern, auf Sandplätzen, nicht selten. S. H. (Dickfüßiger E.)

P. crassipes (DC.).

\section{Familie: Tulostomaceae.}

Fk. kuglig, mit langem, scharf abgesetztem, sich bei der Reife streckendem St. Gleba ungekammert, von dem büschelig verzweigten Basidialgewebe glıichmäßig erfüllt. Capillitium haarf. Basidien mit 4 Sterigmen. Sporen kuglig, bräunlich.

Einzige Gattung: Tulostoma Pers. (Stielbovist).

Peridie doppalt. Exoperidie häutig abfallend, Endoperidie am Scheitəl mit Öffnung. Capillitium netzf., mit der Peridie verwachsen.

Fr. kuglig, haselnußgroß, St. $3-6 \mathrm{~cm} \mathrm{lg.,} \mathrm{hohl,} \mathrm{bräunlich} \mathrm{od.}$ gelblich. Exoperidie schuppig abfallend. Endoperidie dünn, zäh, weißlich od. ockerfarben, Mündung warzen- od. röhrenf. ausgezogen, Öffnung kreisf., scharf umgrenzt. Capillitium u. Sporen lehmfarben. Zwischen kurzem Gras u. Moos auf Dämmen, trockenen Wiesen u. Heiden, zerstreut. Fast das ganze Jahr. (Fig. 606.) (Zitzenf. S.)

T. mammosum (Micheli).

Fk. ebenso, abər Mündung gewimpert. Aủf Sandboden wie vor., zerstreut. (Gewimperter S.)

T. fimbriatum Fries.

\section{Familie: Sphaerobolaceae.}

Fk. in der Jugend kuglig od. eif., geschlossen, mit fleischighäutiger Hülle, im Innern mit einer kugelf. sporenführenden Masse. Peridie mehrschichtig, äußere Schicht sternf. aufreißend, mittlere verquellend $u$. die innere hervorstoßend, wodurch die sporenführende Kugel abgeschleudert wird.

Einzige Gattung: Sphaerobolus Tode (Kugelschneller).

Charaktere der Familie.

Fk. kuglig, 1,5-2 mm Durchm., orangegelb, weißflockig, mit 5-8 spitzen Lappon sternf. zerreißend. Innere Schicht der Peridie weiß, halbkuglig nach außen gewölbt, mit den Spitzen der äußeren Schicht aufsitzend. Sporenkugel bräunlich. Auf faulem Holz, Stengeln in Wäldern, Gärten, nicht selten. S. H. (Fig. 607.)

S. carpobolus (L.). 


\section{Verzeichnis der Gattungen, Arten und Abbildungen des systematischen Teiles.}

Die in Klammern stehenden Ziffern geben die Nummer der Figur an. Die Figuren sind zum größten Teil dem Werke von Costantin et Dufour, Nouvelle Flore des Champignons, entnommen, andere nach Brefeld, Cooke, Michael gezeichnet, wenige nach Herbarmaterial. Die Namen mit dem = Zeichen geben die gebräuchlichsten Synonyme.

abietina (Clavariella) (67) 34 .

- (Hymen.) 19.

- (Lenz.) (166) 75 .

abietinus (Dacryom.) (11) 5 .

- (Polyst.) (147) 69.

acanthoides (Polyp.) (129) 63.

acerinus (Aleurod.) 17.

acervatus (Ag.) (514) 182.

acheruntius (Pax.) 88.

achyropus (Mar.) 122.

acicula (Ag.) (496) 175.

acris (Lact.) = pudibunda (Lact.)

104.

acuminatus (Coprinar.) (347) 127.

acutesquamosa (Lep.) 204.

acutus (Cort.) (400) 143.

adhaerens (Lent.) 118.

adiposa (Phol.) (454) 161.

adonis (Ag.) (510) 179.

adusta (Russ.) (291) 109.

adustus (Polyp.) (115) 58.

aegerita (Kneiff.) 13.

aereus (Bol.) (183) 79.

aeruginea (Russ.) (287) 108.

aeruginosa $(\mathrm{Ag})=$. viridula

(Psall.) 132.

aestivus (Rhiz.) 209.

Agaricus 169.

agathosmum (Lim.) (241) 96 .

Albertinii (Ag.) = lepiota (Arm.)

198.

albida (Exidia) 3.

- (Lenz.) 75.

albidus (Polyst.) 69.

albobrunneus (Ag.) = striatus

(Ag.) 192.

alboviolaceus (Cort.) (423) 148.

alboviolescens (Cyph.) (43) 24.

album (Microst.) 7. albus (Ag.) 196.

- (Ceriom.) 83.

- (Polyp.) 60.

alcalinus (Ag.) (495) 175.

Aleurodiscus 16.

algidus (Ag.) 170.

alliaceus (Mar.) (334) 121.

alliatus (Mar.) (330) 120.

alligatus (Polyp.) 63.

alneum (Schizoph.) (319) 115.

alnicola (Ag.) = amara (Nauc.)

158.

alutacea (Grandin.) 37.

- (Russulin.) (313) 114.

alutaceum (Cortic.) 11.

- (Hydn.) (78) 40.

alutaceus (Polyp.) 58.

alutarius (Tylop.) 77 .

alutipes (Cort.) 151.

amadelphus (Mar.) (336) 121.

Amanita 204.

Amanitopsis 204.

amara (Nauc.) 158.

amarus (Ag.) 190.

Amaurodon 43.

ambiguus (Melan.) 218.

ambustus (Ag.) 182.

amethystina (Clav.) (64) 33.

amianthina (Lep.) 202.

amictus (Ag.) (497) 176.

amorphus (Aleurod.) (28) 17.

- (Polyp.) (120) 60.

amplus (Ag.) 186.

anatinus (Hyporh.) 164.

andromedae (Exob.) 7.

androsaceus (Mar.) (329) 119.

Anellaria 128.

anfractus (Cort.) = obscurocyaneus (Cort.) 154. 
annosus (Fom.) (104) 53. anomala (Solen.) (40) 24. anomalus (Ag.) = eumorphus (Cort.) 147.

anthocephala (Theleph.) (35) 22 . anthochroum (Cortic.) 12. apiculata (Clavariella) 34 . appendiculatum (Hyph.) (363) 13. appendiculatus (Bol.) (187) 80 . applanatus (Fom.) (107) 54 . applicatus (Ag.) 170. arcularius (Polyp.) (140) 67. ardenia (Clav.) (60) 32. arenarius (Pis.) (605) 219. arenatus (Cort.) 150. argentatus (Cort.) 148. argillacea (Clav.) 32. argutum (Hydn.) 39. arida (Conioph.) 9. armeniacus (Cort.) (402) 143. Armillaria 197. armillatus (Cort.) 146. arquatus (Cort.) 154. Arrhenia 84. arvensis (Psall.) (374) 134. aspera (Aman.) 205. asprellus (Bol.) 78 .

- (Hyporh.) 163. asterospora (Octav.) (585) 209. astragalina (Nauc.) (446) 158. aterrimum (Rad.) 38. atomatus (Coprinar.) (343) 126. atramentarius (Copr.) (217) 90. atratus (Ag.) 182.

atrides (Hyporh.) 162.

atripes (Ag.) 173.

atrocoeruleus (Ag.) 170.

atrocyaneus (Ag.) 175.

atropunctus (Hyporh.) (457) 162. atrorufa (Psil.) (362) 129, 130. atrotomentosus (Pax.) 88. augusta (Psall.) (370) 134. aurantia (Arm.) (558) 200. aurantiaca (Lact.) (280) 106. - (Phleb.) 45.

aurantiacus (Ag.) = caesarea (Aman.) 206.

- (Cal.) 43.

- (Canth.) (208) 87. aurantius (Aleurod.) 17. aurata (Russulin.) (310) 114. aurea (Clavariella) (70) 35. aurea (Phol.) (452) 160.

aureus (Mer.) 49.

auricula judae (Auricul.) (1) 1.

Auricularia 1.

auriscalpium (Arrh.) 84.

- (Hydn.) (82) 41.

aurivella (Phol.) (453) 161.

avenaceus (Ag.) 178.

azonites (Lact.) (261) 102.

Badhami (Lep.) 203.

badius (Bol.) (195) 82 .

barba jovis (Odont.) (73) 38 .

bellus (Ag.) 186.

benzoinus (Polyp.) 61.

betulina (Lenz.) (167) 75 .

betulinus (Polyp.) (119) 59.

bicolor (Ag.) 193.

biennis (Polyp.) (144) 68.

bifida (Russ.) 108.

bivelus (Cort.) (412) 145 .

blattaria (Phol.) 159.

blennia (Lact.) (283) 107.

bolaris (Cort.) (427) 150 .

Bolbitius 89.

Boletus 77.

bombycina (Volv.) (476) 169.

bombycinum (Cortic.) 11.

Bongardi (Inoc.) (394) 140.

borealis (Ag.) 195.

- (Polyp.) (117) 59.

botrytes (Clav.) (63) 33 .

Boucheanus (Polyp.) 66.

bovinus (Bol.) (196) 82 .

Bovista 213.

bovista (Glob.) (592) 213.

- (Scler.) (603) 218.

brevipes (Ag.) 193.

brumale (Tul.) $=$ mammosum (Tul.) 219.

brumalis (Polyp.) (141) 67.

bruneus (Cort.) (415) 146.

Bryantii (Geast.) 215.

bryophilus (Lept.) (203) 86 .

bulbigera (Arm.) (557) 200.

bulbosa (Aman.) (576) 206.

- (Clav.) 32.

bullacea (Psil.) (361) 130.

Bulliardi (Cort.) (428) 150 .

butyraceus (Ag.) (522) 184 .

byssoidea (Kneiff.) 13. 
cacabus (Ag.) 187.

caelatum (Lyc.) (588) 210.

caesarea (Aman.) (574) 206.

caesius (Polyp.) 61.

calceata (Psall.) 132.

Caldesiella 43.

caliculatus (Geast.) 215.

callosa (Poria) 51.

CaIocera 6.

Calodon 43.

calopus (Bol.) (188) 80 .

- (Mer.) 120.

calva (Mucron.) 37.

campanella (Ag.) = fragilis (Ag.) 172.

campanulata (Chal.) (352) 128.

campestris (Psall.) (372) 134.

camphorata (Lact.) 103.

candicans (Ag.) (531) 188.

- (Phol.) 159.

candida (Solen.) 23.

candidus (Mar.) 121.

caninus (Cort.) 147.

- (Mut.) (579) 207.

Cantharellus 86.

caperata (Roz.) (456) 162.

capillaris (Ag.) (509) 179.

capnoides (Hyph.) 131.

capnosa (Aman.) 205.

caprinus (Hygr.) (259) 100.

capula (Cyph.) (41) 24.

carbonaria (Nauc.) (443) 157.

carbonarius (Canth.) (210) 87.

carcharios (Lep.) 202.

carneoalbus (Irp.) 46.

carneotomentosus (Lent.) 116.

carneum (Hydnang.) (584) 209.

carneus (Ag.) (547) 195.

carpobolus (Spaer.) (607) 219.

carpophila (Nauc.) (441) 157.

cartilagineus (Ag.) 197.

caryophyllea (Teleph.) (38) 22.

caryophylleus (Mar.) (340) 122.

cascus (Ag.) = macropus (Hyph.) 130.

castaneus (Cort.) (406) 144.

- (Fom.) 53.

- (Suill.) (173) 76.

caudicinus (Polyp.) (132) 64 . cauticinalis (Ag.) 183.

- (Mar.) (333) 121.

cavipes (Bol.) (186) 80 . centrifugum (Cortic.) 10.

cepistipes (Lep.) (567) 203.

ceraceus (Hygr.) (253) 98.

cerasi (Crateroc.) (9) 4.

cerebella (Conioph.) (22) 9 .

cerinus (Ag.) 194.

Ceriomyces 83.

cerussatus (Ag.) 189.

cervinus (Hyporh.) (472) 168.

cetratus (Hyporh.) 163.

chalybaea (Toment.) 9.

chalybaeum (Cortic.) 12.

chalybaeus (Hyporh.) (462) 164.

Chalymotta 128.

chamaeleontina (Russulin.) (315)

114.

chioneus (Polyp.) (124) 61.

chlorophanus (Hygr.) (249) 98.

chrysenteron (Bol.) (194) 82.

chrysocomus (Dacryom.) 5.

chrysodon (Lim.) (236) 95.

chrysophaeus (Hyporh.) (469)166.

ehrysorrhea (Lact.) 104.

ciliatus (Polyp.) 66.

cinerea (Clavul.) (51) 29.

- (Daed.) 74.

- (Kneiff.) 14.

cinereoviolaceus (Cort.) $=$ vio-

laceocinereus (Cort.) 148.

cinnabarina (Daed.) 74.

- (Lep.) 202.

cinnabarinus (Cort.) (418) 147.

- (Polyst.) (150) 70.

cinnamomea (Hymen.) 20.

cinnamomeus (Cort.) (420) 147.

cibarius (Canth.) (207) 86.

circinatus (Polyst.) 70.

cirratus (Ag.) (517) 183.

cirrhatum (Hydn.) (79) 41.

citrina (Aman.) = bulbosa(Aman.)

206.

citrinellus (Ag.) 174.

claricolor (Cort.) 156.

clathroides (Hyster.) (583) 208.

Clavaria 30.

Clavariella 34.

clavatus (Crater.) (46) 26.

clavipes (Ag.) (534) 190.

clavularis (Theleph.) 22.

Clavulina 29.

cliduchus (Cort.) $=$ vitellinopes

(Cort.) 155. 
clypeatus (Hyporh.) (464) 165. clypeolaria (Lep.) (568) 203. coccineus (Ag.) 178.

- (Hygr.)=miniatus(Hygr.)99. cochleatus (Lent.) = cornucopioides (Lent.) 118.

coerulescens (Cort.) 154.

coeruleum (Cortic.) 12.

collariatus (Ag.) 176.

collinitus (Cort.) (429) 151.

colossus (Ag.) (539) 191.

columbetta (Ag.) (552) 196.

comatus (Copr.) = porcellanus

(Copr.) 90.

comedens (Vuillem.) (23) 10.

commune (Schizoph.) = alneum

(Schizoph.) 115.

compactus (Cal.) 44.

complanata (Typh.) 28.

conchatus (Fom.) 55.

- (Lent.) 118.

condensata (Clavariella) (69) 35 . confluens (Ag.) 184.

- (Cortic.) (25) 10.

- (Nid.) (599) 216.

- (Polyp.) (134) 64.

- (Sistot.) (91) 46.

confragosa (Daed.) (164) 74.

conglobatus (Ag.) 195.

congregatus (Copr.) (220) 91.

conicus (Hygr.) (247) 98.

conigenus (Ag.) (519) 183.

Coniophora 9.

connatus (Fom.) (105) 53.

conocephalus (Bolb.) (214) 89.

conopileus (Coprinar.) (345) 126. consobrina (Russ.) (297) 110. conspersa (Nauc.) (442) 157.

- (Odont.) 37.

contigua (Poria) 50.

controversa (Lact.) = sanguina-

lis (Lact.) 106.

Coprinarius 126.

Coprinus 89.

coprophila (Psil.) (360) 130.

coralloides (Clavul.) (55) 30 .

- (Hydn.) (81) 41.

- (Theleph.) (37) 22.

corium (Mer.) 49.

cornea (Caloc.) (15) 6.

cornucopioides (Crater.) (44) 25.

- (Lent.) 118. coronatum (Cortic.) 11

coronatus (Geast.) (595) 214.

corti_alis (Kneiff.) (27) 16.

corticata (Arm.) 198.

Corticium 10.

corticola (Ag.) (508) 179.

- (Poria) 51.

Cortinarius 141.

Cortinellus 197.

cossum (Lim.) 95.

crassipes (Pis.) 219.

Craterellus 25.

Craterocolla 4.

cremea (Kneiff.) 13.

crenatus (Coprinar.) (341) 126.

cretacea (Psall.) (373) 134.

crispum (Ster.) 18.

crispus (Crater.) (45) 26.

- (Polyp.) 58.

cristata (Clavul.) (54) 30.

- (Inoc.) 140.

- (Lep.) 203.

- (Theleph.) (32) 21.

cristatus (Polyp.) (130) 64 .

crocea (Clavariella) 35.

croceocoeruleus (Cort.) 152.

croceum (Cortic.) 11.

croceus (Ag.) = cinnamomeus

(Cort.) 147.

- (Polyp.) (126) 62.

Crubiculum 216.

cruenta (Cytid.) 16.

cruentus (Ag.) 174.

crustosa (Odont.) 37.

crustuliniformis (Derm.) (386)

138.

cucullatus (Ag.) 176.

cucumis (Derm.) (384) 137.

culmigena (Typh.) 29.

cuneifolius (Ag.) 197.

cupricum (Lyc.) 212.

cupularis (Arrh.) (201) 84.

curvipes (Phol.) 161.

cuticularis (Polyp.) (127) 62.

cyanescens (Suill.) (172) 76.

cyanoxantha (Russ.) (288) 108.

cyathiforme (Hydn.) 41.

cyathiformis (Ag). (527) 186.

- (Lent.) (322) 116.

cyathula (Lact.) 102.

Cyathus 216.

cyclophilus (Ag.) 193. 
Cyphella 24.

Cytidia 16.

Dacryomitra 6.

Dacryomyces 5 .

Daedalea 73.

dealbatus (Ag.) 188.

debilis (Ag.) 176.

decipiens (Cort.) (399) 142.

decolorans (Cort.) 152.

- (Russulin.) (308) 112.

decoloratus (Cort.) (432) 152 .

decorus (Hymen.) 209.

decumbens (Cort.) 146.

degener (Xerot.) (320) 116.

deglubens (Inoc.) 141.

delibutus (Cort.) (430) 151.

delicata (Lep.) 200.

deliciosa (Lact.) (260) 102.

- (Russ.) 108.

deliquescens (Dacryom.) 5.

denticulatus (Ag.) (503) 178.

denudata (Nid.) 216.

depallens (Russ.) (304) 111.

depluens (Derm.) 135.

Derminus 134.

descissa (Inoc.) 141.

destructor (Polyp.) 60.

destruens (Phol.) (451) 160.

diaphanum (Hydn.) 40.

dichrous (Coprinar.) 127.

- (Polyp.) (121) 60.

digitalis (Copr.) (221) 91.

- (Cyph.) (42) 24.

dilutus (Cort.) (403) 143.

dimidiata (Arm.) 198.

disciformis (Aleurod.) 17.

discoideum (Lim.) (239) 96.

dispersus (Ag.) = marginatum (Hyph.) 131.

disseminatus (Coprinar.) (342) 126.

Ditiola 5 .

domesticus (Copr.) (223) 91.

dryadeus (Polyp.) = pseudoigniarius (Bull.) 62.

dryinus (Ag.) = dimidiata (Arm.) 198.

dryophilus (Ag.) (515) 183.

dulcamara (Inoc.) (392) 140.

dura (Phol.) 159.

eburneum (Lim.) (238) 95. echinata (Nauc.) 157.

echinatum (Lyc.) (591) 212.

echinipes (Ag.) (506) 178.

edulis (Bol.) (184) 80.

elegans (Ag.) (504) 178.

- (Bol.) 83.

- (Polyp.) 65.

elegantior (Cort.) 153.

emetica (Russ.) (299) 110.

encephala (Tremella) (4) 2.

ephemeroides (Copr.) (216) 90.

ephemerus (Copr.) 92.

epiphyllus (Mar.) = squamula (Mar.) 120.

epipterygius (Ag.) (493) 175.

equester (Ag.) (535) 190.

erebia (Phol.) 160.

ericaeus (Coprinar.) (350) 127.

ericeus (Hygr.) 99.

ericetorum (Ag.) 187.

erinaceus (Ag.) = lanatus (Nauc.)

157.

- (Hydn.) (80) 41.

erubescens (Hygr.) $=$ rubescens

(Limac.) 95.

- (Polyp.) 62.

erythrinus (Cort.) 142.

erythropus (Mar.) 122.

- (Typh.) (48) 28.

esculentus (Ag.) 182.

euchrous (Hyporh.) 164.

eumorphus (Cort.) 147.

euphorbiae (Typh.) 29.

europaeus (Favol.) (169) 75.

excelsa (Aman.) 205.

excisus (Ag.) 177.

excoriata (Lep.) (564) 201.

Exidia 3.

Exobasidium 7.

expellens (Ag.) 186.

faginea (Cyph.) 25.

- (Trog.) (202) 86.

falcata (Cilav.) (56) 30 .

farcta (Nid.) 216.

farinaceum (Hydn.) 40.

fasciatus (Cort.) 143.

fasciculare (Hyph.) (365) 131.

fascicularis (Mucron.) (72) 37 .

fasciculata (Solen.) (39) 23.

fastibilis (Inoc.) (390) 139.

fastidiosa (Theleph.) 22. 
fastigiata (Clav.) 34.

Favolus 75 .

fellea (Russ.) (296) 110.

felleus (Tylop.) (174) 77 .

Femsjoniana (Guep.) (13) 5.

ferruginea (Cald.) 43.

- (Toment.) (21) 9.

ferruginosa (Poria) (97) 50.

fibrillosa (Psil.) (359) 130.

fibula (Ag.) (482) 172.

ficoides (Hygr.) 100.

filipes (Ag.) (498) 176.

fimbriata (Odont.) 38.

fimbriatum (Poroth.) (170) 76.

- (Tul.) 219.

fimbriatus (Geast.) 214.

fimetarius (Copr.) (230) 93.

fimicola (Coprinar.) (348) 127.

- (Ag.) = eoprophila (Psiloc.) 130.

fimiputris (Anell.) (356) 129.

firma (Inoc.) 139.

firmus (Cort.) (405) 144.

Fistulina 76.

flabelliformis (Lent.) (323) 118.

flaccida (Clavariella) 35.

flaccidus (Ag.) 188.

flammans (Hygr.) 99.

flammeus (Ag.) = flammula (Phol.) 160.

flammula (Phol.) 160.

flava (Clav.) (65) 33.

flavescens (Cortic.) 11.

flavida (Nauc.) (447) 158.

flavidus (Bolb.) 89.

- (Bol.) (198) 83.

flavoalbus (Ag.) = pumilus (Ag.) 179.

flavobruneus (Ag.) (540) 192.

flavus (Bol.) (185) 80.

flexipes (Cort.) (407) 144.

flexuosa (Lact.) 105.

flocculenta (Cytid.) 16.

foeniculaceus (Mar.) 123.

foenisecii (Coprinar.) (349) 127.

foetens (Russ.) (295) 110.

foetidus (Mar.) (337) 121.

foliacea (Uloc.) 4.

fomentarius (Fom.) (109) 55.

Fomes 52.

formosa (Clavariella) (68) 35 .

formosus (Hyporh.) 163. fornicatus (Geast.) = coronatus (Geast.) 214.

fragile (Hydn.) (85) 42.

fragilis (Ag.) 127.

- (Clav.) (61) 32.

- (Polyp.) 60.

- (Russ.) (298) 110.

fragrans (Ag.) (524) 185.

- (Bol.) 81.

fraxineus (Fom.) 53.

Friesii (Lep.) 204.

frondosus (Polyp.) (133) 64.

frumentacea (Inoc.) 139.

frustulosum (Ster.) 19.

fucatus (Ag.) 191.

fugax (Mer.) 48.

fulgens (Cort.) (435) 153.

fuligineoalbum (Hydn.) 43.

fuligineus (Bol.) 78 .

- (Polyp.) 66.

fuliginosa (Lact.) = azonites (Lact.) 102.

fulvidus (Suill.) 76 .

fulvofuligineus (Cort.) 153.

fulvus (Fom.) 55.

fumosus (Ag.) 187.

- (Polyp.) 58.

furcata (Caloc.) 6 .

furfuracea (Glob.) 213.

- (Nauc.) 157.

fusca (Toment.) 9.

fuscescens (Copr.) 90.

fuscidulus (Polyp.) 66.

fuscoalbum (Lim.) 96.

fuscoatrum (Hydn.) 40.

fuscopurpureus (Mar.) (338) 122.

fuscoviolaceus (Irp.) (90) 46 .

fusipes (Ag.) 185.

galericulatus (Ag.) (502) 177 .

galopus (Ag.) = lactescens (Ag.) 174.

gambosus (Ag.) (550) 196.

gausapatum (Ster.) 19.

gausapatus (Cortinell.) 197.

Gautieria 208.

Geaster 213.

gelatinosa (Exidia) 3.

gelatinosus (Tremell.) (10) 4 .

gemmatum (Lye.) (590) 212.

genistae (Tremella) 3.

gentilis (Cort.) (414) 145. 
geophylla (Inoc.) 140.

geotropus (Ag.) 188.

gibba (Cyph.) 24.

gibbosa (Tram.) (161) 73 .

gigantea (Kneiff.) (26) 13.

giganteus (Polyp.) 63.

gilva (Typh.) 27.

gilvus (Ag.) (530) 188.

glandulosa (Exidia) (6) 3.

glaucopus (Cort.) (436) 154 .

glaucum (Leptogl.) (205) 86.

Globaria 212.

gloiocephala (Volv.) (473) 168.

Gloeopeniophora 12.

glossoides (Dacryomitra) (14) 6 .

glutinosus (Gromph.) (233) 94.

glyciosma (Lact.) (278) 106.

Goldbachii (Cyph.) 25.

Gomphidius 93 .

gracilis (Coprinar.) (344) 126.

- (Gomph.) 94.

gracillimus (Ag.) (480) 172 .

graminicola (Nauc.) 156.

graminum (Mar.) (327) 119.

grammocephalus (Ag.) (521) 184.

Grandinia 37.

granulatus (Bol.) (197) 82 .

granulosa (Lep.) (566) 202.

graveolens (Ag.) 194.

- (Gaut.) (581) 208.

- (Hydn.) (83) 42.

grisea (Clavariella) 34 .

- (Russulin.) 112.

griseocyaneus (Hyporh.) 165.

griseopallida (Cyph.) 24.

Guepinia 5.

guttatus (Ag.) (553) 197.

gyrans (Typh.) (50) 29.

gyroflexus (Ag.) = pallescens

(Prat.) 129.

haematopus (Ag.) (490) 174.

haustellaris (Derm.) 135.

helodes (Hyporh.) 165.

helva (Lact.) (277) 106.

helveolus (Polyp.) 61.

helveticum (Cortic.) 11.

helvolus (Cort.) 146.

hemitrichus (Cort.) 144.

hepatica (Fist.) (171) 76.

herminea (Lep.) 203.

heteroclita (Phol.) (450) 160. heteromorpha (Lenz.) 75 .

hiemalis (Ag.) 179.

himantoides (Mer.) (93) 49.

hinnuleus (Cort.) 146.

hirneolus (Ag.) 190.

hirsutum (Ster.) (30) 18.

hirsutus (Polyst.) 69.

hispidus (Polyp.) (128) 63.

horizontalis (Derm.) (383) 137.

humilis (Ag.) 193.

hybrida (Nauc.) 158.

hybridus (Cal.) 44.

Hydnangium 209.

hydnoideum (Rad.) 38.

Hydnum 39.

hydrogrammus (Ag.) 173.

- (Hyporh.) (463) 165.

hydrolips (Canth.) 87.

hygrometricus (Geast.) = stellatus (Geast.) 214.

Hygrophorus 97.

Hymenochaete 19.

Hymenogaster 209.

Hypholoma 130.

hypni (Derm.) (381) 136.

hypnorum (Ag.) = hypni (Derm.) 136.

hypothejus (Hygr.) $=$ vitellum (Limac.) 96.

Hyporhodius 162.

hysgina (Lact.) (282) 107.

Hysterangium 208.

jänthinus (Ag.) 176.

icterinus (Hyporh.) (458) 163.

jecorina (Lact.) (281) 106 .

igniarius (Fom.) (110) 55.

illinita (Lep.) 201.

iliopodius (Cort.) (410) 145.

imberbis (Polyp.) (112) 56.

imbricatus (Ag.) 194.

- (Polyp.) (131) 64.

- (Sare.) (87) 44.

impolitus (Ag.) 194.

- (Bol.) (190) 81.

impudicus (Ityph.) (580) 207.

inaequalis (Clav.) (62) 33.

- (Pistill.) 27.

inamoenus (Ag.) 196.

incarnata (Gloeopen.) 12.

- (Poria) (96) 50.

- (Tulas.) (20) 7. 
incisus (Cort.) (409) 145.

inclinatus (Ag.) (501) 177.

incrustans (Sebac.) (3) 2.

infractus (Cort.) (437) 155.

infundibuliformis (Ag.) (528) 187. - (Canth.) (211) 87.

Inocybe 138.

inolens (Ag.) 182.

inquilina (Nauc.) (440) 156.

insulsa (Lact.) 107.

integra (Russulin.) (312) 114.

integrellus (Ag.) 172.

intybacea (Theleph.) (33) 21.

intybaceus (Polyp.) 64.

inversus (Ag.) (529) 188.

involutus (Pax.) (213) 88.

jonides (Ag.) (548) 195.

irinus (Ag.) = cyclophyllus (Ag.) 193.

Irpex 45.

irrigatus (Hygr.) (257) 99.

isabellina (Toment.) 9.

isabellinus (Cort.) 144.

Ithyphallus 207.

jugis (Lent.) 118.

juglandis (Microst.) (19) 7 .

juncea (Clav.) (59) 32.

Klotzschii (Hymen.) 209.

- (Melan.)= ambiguus (Melan.) 218.

Kmetii (Rad.) 39.

Kneiffia 13.

Kunzei (Clavul.) (53) 30.

laccatus (Ag.) (526) 186.

laceratus (Ag.) 180.

lacerus (Ag.) $=$ eristata (Inoc.) 140.

laciniata (Teleph.) 21.

lacrimans (Mer.) (92) 48.

Lactaria 100.

lactea (Russ.) (286) 108.

lactescens (Ag.) 174.

lacteum (Cortic.) (24) 10.

lacteus (Ag.) = nanus (Ag.) 180 .

- (Irp.) 46.

- (Polyp.) (123) 61.

laetus (Hygr.) (252) 98.

laeve (Cortic.) 12.

laevigata (Kneiff.) 14.

laevigatum (Hydn.) 42. laevigatus (Ag.) (494) 175.

laevis (Kneiff.) 14.

lagopus (Copr.) (229) 93.

lampropus (Hyporh.) 164.

lanata (Nauc.) 157.

lanuginosa (Inoc.) (389) 139.

largus (Cort.) 155.

Laschii (Typh.) 28.

lateritium (Hyph.) (364) 131.

lateritius (Derm.) (382) 136.

latissima (Daed.) 73.

latus (Cort.) (438) 155.

lazulinus (Hyporh.) 164.

lenta (Nauc.) (445) 158.

Lentinus 116.

Lenzites 74.

leoninus (Hyporh.) (470) 166.

lepida (Russ.) (303) 111.

lepideus (Lent.) = squamosus (Lent.) 119.

- (Polyp.) 66.

lepidomyces (Cort.) (424) 150.

Lepiota 200.

lepiota (Arm.) 198.

lepista (Pax.) 88.

leptocephalus (Polyp.) (139) 66.

Leptoglossum 86.

Leptotus 86.

leucomelas (Polyp.) (145) 68.

leucophyllus (Ag.) (486) 173.

leucopodius (Cort.) 142.

leucopus (Ag.) = leucopodius (Cort.) 142 .

lignatilis (Ag.) (477) 170.

lignyota (Lact.) (264) 103.

ligula (Clav.) (58) 32.

limacinum (Lim.) (244) 97.

Limacium 94.

limbatus (Geast.) 214.

lineatus (Ag.) (512) 180.

Linnaei (Russ.) (306) 112.

livida (Russ.) 108.

lividus (Bol.) (178) 78.

- (Hyporh.) (467) 166.

lobatus (Lept.) (203) 86.

- (Polyp.) 63.

longipes (Ag.) (523) 185.

lubrica (Nauc.) (444) 158.

lucidus (Fom.) (103) 52.

lucifuga (Inoc.) (393) 140.

lupinus (Bol.) 79.

lurida (Lact.) 104. 
luridus (Ag.) (554) 197.

- (Bol.) (182) 79.

luscinus (Ag.) 190.

lutea (Russulin.) (317) 115.

luteoalbus (Ag.) (511) 179.

luteolum (Hydn.) 41.

luteolus (Rhiz.) = virens (Rhiz.) 209.

luteovirens (Arm.) (559) 200.

lutescens (Crater.) 26.

- (Tremella) 2.

luteus (Bol.) (199) 83.

lycoperdoides (Nyct.) (235) 94.

Lycoperdon 210.

macropus (Cort.) (411) 145.

- (Hyph.) 130.

macrourus (Ag.) 185.

maculatus (Ag.) 184.

maculiformis (Gloeopen.) 12.

mammosum (Tul.) (606) 219.

mammosus (Hyporh.) (459) 163.

mappa (Ag.) = straminea (Aman.) 207.

Marasmius 119.

marginata (Phol.) (450) 160.

marginatum (Hyph.) 131.

marginatus (Fom.) 54.

marginellus (Ag.) 178.

maritima (Inoc.) 139.

mastoideus (Ag.) = umbonata

(Lep.) 201.

medulla panis (Poria) (98) 51.

melaleucum (Hydn.) 42.

melaleucus (Ag.) (543) 193.

Melanogaster 218.

melanopus (Polyp.) (138) 66.

melanosperma (Psall.) (368) 132.

meleagris (Lep.) 203.

mellea (Arm.) (556) 198.

membranaceum (Rad.) (75) 38.

Merulius 48.

mesenterica (Tremella) (5) 2.

mesomorpha (Lep.) 202.

metachrous (Ag.) (525) 185.

metatus (Ag.) = laevigatus (Ag.) 175.

micaceus (Copr.) (225) 92.

micans (Derm.) 137.

- (Pistill.) (47) 27.

- (Poria) 50.

Microstroma 7. miniatus (Hygr.) (254) 99. - (Hygr.) = flammans (Hygr.) 99.

mitis (Ag.) 171.

mitissima (Lact.) (266) 103.

molariforme (Rad.) 38.

molle (Cortic.) 11.

mollis (Derm.) (376) 135.

- (Polyp.) 60.

- (Tram.) 72.

mollusca (Poria) 52.

molluscus (Mer.) 49.

molybdinus (Ag.) 187.

montanus (Ag.) = atrorufa (Psil.)

129. 130 .

morchelliformis (Gaut.) (582) 208. mucida (Clav.) 30.

- (Lep.) (562) 201.

- (Poria) 51.

mucidum (Cortic.) 10.

- (Hydn.) 40.

Mucronella 37.

mucronellus (Hygr.) 99.

multiformis (Cort.) 153.

mundulus (Hyporh.) 166.

murinus (Ag.) (513) 180.

muscaria (Aman.) (572) 206.

muscicola (Cyph.) 25.

- (Typh.) 29.

muscigena (Cyph.) 25.

muscigenum (Leptogl.) (206) 86. muscoides (Clav.) 33.

mutabilis (Phol.) (449) 159.

Mutinus 207.

mycenopsis (Nauc.) (439) 156.

nanus (Ag.) 180.

- (Ag.) = pyrrhospermus

(Hyporh.) 168.

narcoticus (Copr.) 92.

Naucoria 156.

nauseosa (Russulin.) (314) 114.

nebularis (Ag.) (533) 189.

necator (Lact.) 106.

Neesii (Fom.) 53.

nemorosus (Hygr.) (256) 99.

nidulans (Ag.) 170.

- (Polyp.) 62.

Nidularia 216.

nidus avis (Hyporh.) 166.

nigrescens (Bov.) 213.

nigricans (Russ.) (292) 109. 
nigrum (Hydn.) 41.

nitida (Poria) (95) 50.

nitidum (Lim.) (240) 96.

nitidus (Cort.) (431) 151.

$-(\mathrm{Ag})=$. purpurea (Russulin.) 114.

nitratus (Hygr.) (246) 97.

niveum (Hydn.) 40.

niveus (Ag.) = sessilis (Derm.)

135.

- (Copr.) (227) 93.

- (Hygr.) (255) 99.

nuda (Kneiff.) 14.

nudus (Ag.) (544) 193.

Nyctalis 94 .

obducens (Poria) 51.

obliquus (Fom.) (106) 54.

- (Xyl.) (89) 45.

obolus (Ag.) 185.

obrusseus (Hygr.) (250) 98.

obscurocyaneus (Cort.) 154.

obtusata (Prat.) 129.

obtusus (Cort.) (401) 143.

ocellatus (Ag.) 182.

ochracea (Russulin.) (318) 115.

- (Solen.) 23.

ochraceum (Cortic.) 11.

- (Hydn.) 40.

ochroleuca (Russ.) (293) 109.

ochroleucus (Cort.) (416) 146.

Octaviania 209.

Odontia 37.

odora (Tram.) (160) 73.

odorata (Tram.) (158) 72.

odoratum (Ster.) 19.

odorus (Ag.) 189.

officinalis (Polyp.) (118) 59.

olivacea (Russ.) (290) 109.

olivaceoalbum (Lim.) 97.

olivaceus (Bol.) 81.

olla (Cyath.) 217.

olorinus (Ag.) 188.

opacus (Ag.) 186.

orbiculare (Rad.) (74) 38.

oreades (Mar.) = caryophylleus

(Mar.) 122.

orellanus (Cort.) (421) 148.

orichalceus (Cort.) (433) 153.

ostreatus (Ag.) (478) 171.

ovata (Typh.) 29.

ovatus (Copr.) 90. ovinus (Hygr.) (258) 100.

- (Polyp.) (143) 67.

pachypus (Bol.) (189) 81. pallescens (Polyp.) 56.

- (Prat.) 129.

pallida (Lact.) 107.

- (Theleph.) 23.

palmata (Caloc.) (16) 6 .

- (Clavariella) 35.

palmata (Teleph.) (36) 22.

panaeolus (Pax.) 88.

pantherinus (Ag.) = umbrina

(Aman.) 206.

panuoides (Pax.) 88.

papilionacea (Chal.) (353) 128.

papillatus (Copr.) 91.

papillosa (Grandin.) 37.

parabolicus (Ag.) (499) 177.

paradoxus (Xyl.) 45.

parasitica (Nyct.) (234) 94.

parasiticus (Bol.) (191) 81 .

pargamena (Lact.) 105.

parvannulata (Lep.) 202.

pascuus (Hyporh.) (460) 163.

Paxillus 87.

pectinata (Russ.) (294) 109.

pedunculatum (Lyc.) = mammosum (Tul.) 219.

pediades (Ag.) = semiorbicularis (Derm.) 137.

pelianthinus (Ag.) = denticulatus (Ag.) 178.

Pelletieri (Pax.) 88. pellicula (Toment.) 9.

pellitus (Hyporh.) 168.

penarium (Lim.) (237) 95.

pendulus (Irp.) 45.

penicillata (Theleph.) 21.

penicillatus (Cort.) 148.

pennata (Psil.) 129.

perennis (Polyst.) (155) 72.

perforans (Mar.) 121.

peronatus (Mar.) 123.

perpusillus (Ag.) = subversus

(Ag.) 169 .

persicinus (Ag.) 192.

personatus (Ag.) = bicolor (Ag.) 193.

Persoonii (Aman.) 205.

pes capare (Polyp.) (142) 67.

pessundatus (Ag.) (541) 192. 
petaloides (Ag.) 171.

Petersii (Pilacre) (2) 1.

peziza (Guep.) 6.

phacorrhiza (Typh.) 28.

phalloides(Ag.)=bulbosa (Aman.) 206.

Phlebia 44.

pholideus (Cort.) $=$ lepidomyces (Cort.) 150.

Pholiota 158.

phyllophilus (Ag.) (532) 189.

picipes (Polyp.) (136) 65.

pictus (Polyst.) 72.

Pilacre 1.

pinastri (Hydn.) (77) 40.

pini (Ster.) 18.

- (Tram.) (157) 72.

pinicola (Fom.) 54.

piperata (Lact.) (272) 105.

piperatus (Bol.) (180) 79 .

piriforme (Lyc.) (589) 212.

piriodora (Inoc.) (395) 140.

pisocarpium (Polysacc.) = arenarius (Pisol.) 219.

Pisolithus 218.

Pistillaria 27.

pistillaris (Clav.) (57) 32 .

pithyophilus (Ag.) 189.

placidus (Bol.) 78.

- (Hyporh.) (461) 164.

planus (Ag.) 171.

platyphyllus (Ag.) = grammocephalus (Ag.) 184.

plicatilis (Copr.) (224) 92.

plumbea (Amanitops.) (569) 204.

- (Bov.) (593) 213.

- (Lact.) (274) 105.

polyadelphus (Ag.) 172.

polygonius (Aleurod.) 17.

polygrammus (Ag.) (500) 177.

polymorphus (Polyst.) 69.

Polyporus 56.

Polystictus 68 .

Pompholyx 218.

populinus (Fom.) 53.

porcellanus (Copr.) (219) 90.

Poria 49.

poriiformis (Solen.) 23.

Porothelium 75.

porphyria (Aman.) (577) 207.

porphyropus (Cort.) 152.

porreus (Mar.) 123. porrigens (Ag.) 169.

portentosus (Ag.) (536) 191.

praecox (Ag.) = candicans (Phol.)

188.

prasinus (Cort.) 152.

prasiosmus (Mar.) (339) 122.

Pratella 129.

pratensis (Psall.) (371) 134.

procera (Lep.) (563) 201.

prunuloides (Hyporh.) (466) 165.

prunulus (Hyporh.) (468) 166.

Psalliota 131.

pseudoigniarius (Polyp.) (125) 62.

Psilocybe 129.

psittacinus (Hygr.) (248) 98.

pterigenus (Ag.) (505) 178.

pubera (Kneiff.) 14.

pubescens (Ag.) 169.

- (Polyp.) (116) 58.

pudibunda (Lact.) 104.

pudorinum (Hydn). 40.

- (Lim.) 95.

puellaris (Russulin.) (311) 114.

pulmonarius (Ag.) 171.

pulvinatus (Ag.) 170.

pumilus (Ag.) 179.

- (Derm.) 137.

punctata (Inoc.) 139.

punicea (Toment.) 9.

puniceus (Hygr.) (251) 98.

purpurascens (Cort.) 154.

- (Lim.) 96.

purpurea (Russulin.) 114.

purpureum (Ster.) (29) 18.

purus $(\mathrm{Ag})=$. roseus (Ag.) 180 . pusilla (Pistill.) 27.

- (Volv.) 168.

pusillum (Lyc.) $=$ furfuracea

(Glob.) 213.

pustulata (Aman.) (570) 205.

pustulatum (Lim.) (242) 96.

pyramidalis (Mar.) 122.

pyrogala (Lact.) (273) 105.

pyrrhospermus(Hyporh.)(471)168. pyxidata (Clav.) 33 .

pyxidatus (Ag.) (488) 174.

quadricolor (Cort.) 145.

Queletii (Russ.) (300) 110.

quercina (Daed.) (163) 74.

quercinum (Cort.) $=$ corticalis

(Kneiff.) 16. 
quercinum (Rad.) (76) 38. quercinus (Polyp.) 59. quieta (Lact.) (262) 102. quisquiliaris (Typh.) 29.

Rabenhorstii (Derm.) 136. radians (Copr.) (222) 91. radiata (Teleph.) 23. radiatus (Copr.) (226) 92. - (Polyst.) (152) 70. radicans (Bol.) 82.

radicata (Ditiola) (12) 5 . radicatus (Ag.) = macrourus (Ag.) 185.

radicosa (Phol.) (448) 159.

radula (Poria) (101) 52.

Radulum 38.

ramealis (Mar.) (335) 121. ramentacea (Arm.) (560) 200. ramosa (Sparass.) (71) 36. raphanoides (Cort.) (419) 147. ravida (Russulin.) (316) 115. regius (Bol.) 80 .

relicina (Inoc.) 138. repanda (Exidia) 3.

repandum (Hydn.) (84) 42. resima (Lact.) 104. resinosus (Polyp.) 61. resplendens (Ag.) 191. reticulata (Poria) (99) 52. reticulatus (Derm.) (377) 135. retirugis (Chal.) 128. retirugus (Lept.) (204) 86. rhacodes (Lep.) (565) 201. Rhizopogon 209. rhododendri (Exob.) 7. rhodopolius (Ag.) = hydrogrammus (Hyporh.) 165. ribis (Fom.) (111) 56. rigens (Cort.) (398) 142. rigidus (Cort.) (408) 144. rimosa (Inoc.) (396) 141. rivulosus (Ag.) 189. robusta (Arm.) (561) 200. roridus (Ag.) (491) 174. rosacea (Russ.) 112. rosellus (Ag.) 177. roseoalbus (Hyporh.) 166. roseum (Cortic.) 12. roseus (Ag.) 180.

- (Fom.) 54.

- (Gomph.) (232) 94.
Rostkovii (Polyp.) 65. rotula (Mar.) (328) 119.

Rozites 162.

rubescens (Ag.) = pustulata (Aman.) 205.

- (Bol.) 78.

- (Ceriom.) 84.

- (Lim.) 95.

- (Rhiz.) $=$ acstivus (Rhiz.) 209.

- (Tram.) 73.

rubiginosa (Hymen.) (31) 20. rubra (Russ.) (301) 11. rudis. (Lent.) 116. rufa (Lact.) (276) 105.

- (Poria.) 50.

rufus (Bol.) 77.

rufescens (Geast.) (596) 214.

- (Polyp.) 68.

rufoolivaceus (Cort.) 153.

rufus (Mer.) 49.

rugosa (Clavul.) (52) 29.

rugosum (Ster.) 19.

rusiophylla (Psall.) 132.

Russula 107.

russula (Ag.) (538) 191.

Russulina 112.

rusticus (Ag.) 173.

rutilans (Ag.) (546) 194.

- (Polyp.) 62.

saccharina (Uloc.) (8) 4. saccharinus (Mar.) 120. salicinus (Fom.) 55.

- (Hyporh.) 168. salignus (Ag.) 171.

- (Polyp.) (114) 58.

sambuci (Cortic.) 11. sambucinus (Derm.) 137. sanguinalis (Lact.) 106. sanguinea (Kneiff.) 16. - (Russ.) (302) 111. sanguineus (Cort.) (417) 147. sanguinolenta (Poria) 50. sanguinolentum (Ster.) 18. sanguinolentus (Ag.) (489) 174. saniosus (Cort.) 143. sapidum (Pomph.) 218. saponaceus (Ag.) (551) 196. Sarcodon 44. sarcoides (Cytid.) 16. sardonia (Russ.) (305) 111. 
satanas (Bol.) (181) 79.

scabella (Inoc.) (388) 138.

scaber (Bol.) (175) 77.

scabra (Inoc.) (397) 141.

scalaris (Derm.) 135.

seaurus (Cort.) = fulvofuligineus (Cort.) 153.

Schiedermayri (Hydn.) 41.

Schizophyllum 115 .

Schmiedelii (Greast.) (598) 215.

Schroeteri (Cort.) 91.

Schweinitzii (Polyp.) = sistotremoides (Polyp.) 67.

Scleroderma 217.

sclerotioides (Typh.) 28.

scorodonius (Mar.) = alliatus (Mar.) 120.

scrobiculata (Lact.) (271) 104. scyphoides (Ag.) (483) 172.

Sebacina 2.

sejunctus (Ag.) (537) 191.

semiglobata (Anell.) (354) 128.

semilanceatus (Coprinar.) (351)

127.

seminuda (Lep.) 202.

semiorbicularis (Derm.) (385) 137.

semitalis (Ag.) (520) 184.

separata (Anell.) (355) 128.

sepiaria (Lenz.) (165) 74.

septicus (Ag.) = pubescens (Ag.) 169.

serialis (Kneiff.) 14.

- (Tram.) (159) 73.

sericellus (Hyporh.) (465) 165.

seriflua (Lact.) 103.

serotinum (Lyc.) 212.

serotinus (Ag.) 171.

serpens (Mer.) 49.

- (Tram.) (156) 72.

serrula (Hyporh.) 164.

serrulatus $(\mathrm{Ag})=.\operatorname{serrula}(\mathrm{Hy}-$ porh.) 164.

sessilis (Derm.) 135.

setigera (Kneiff.) 14.

setipes (Ag.) (481) 172.

silvatica (Psall.) (375) 134.

sinopicus (Ag.) 188.

sinuatus (Hyporh.) 166.

sinuosa (Poria) 52.

Sistotrema 46.

sistotrema (Bol.) (177) 78.

sistotremoides (Polyp.) 67.
Solenia 23.

solitaria (Aman.) 206.

sordidus (Ag.) 192.

spadicea (Prat.) (357) 129.

spadiceogrisea (Prat.) (358) 129.

spadiceum (Ster.) 18.

spadiceus (Bol.) (192) 81.

- (Cort.) 155.

spadiceus (Hygr.) (245) 97.

Sparassis 35.

sparteus (Derm.) (379) 136.

spatulatus (Xyl.) 45.

speciosa (Volv.) (474) 168.

spectabilis (Phol.) 161.

Sphaerobolus 219.

spiculus (Derm.) 136.

spinipes (Ag.) 180.

spissa (Aman.) (571) 205.

splachnoides (Mar.) (331) 120.

spumeus (Polyp.) 60.

squalidus (Hygr.) 97.

squamosa (Nauc.) 157.

- (Psall.) (367) 132.

squamosus (Lent.) (326) 119.

- (Polyp.) (137) 65.

squamula (Mar.) (332) 120.

squamulosus (Ag.) 187.

squarrosa (Phol.) (455) 161.

stanneus (Ag.) 175.

stellatus (Ag.) 172.

- (Geast.) (594) 214.

- (Sphaer.) $=$ carpobolus

(Sphaer.) 219.

stercoraria (Psall.) (369) 132. stercorarius (Copr.) (228) 93. stereoides (Polyst.) (148) 69.

Stereum 17.

sterquilinus (Copr.) (218) 90 . stillatus (Dacryom.) = abietinus

(Dacryom.) 5. stipatus (Ag.) = spadicea (Prat.) 120.

stipitata (Solen.) 24.

stipitarius (Ag.) $=$ cauticinalis

(Ag.) 183.

stipticus (Lent.) (321) 116.

- (Polyp.) (113) 58.

stipularis (Ag.) 179.

straminea (Aman.) (578) 207.

striatopellucidus (Ag.) 170.

striatulus (Ag.) = striatopelluci-

dus (Ag.) 170. 
striatus (Ag.) (542) 192.

- (Cyath.) (601) 217.

- (Geast.) (597) 215.

stricta (Clavariella) (66) 34.

strobilaceus (Strobil.) (200) 83.

strobilinus (Ag.) = coccineus

(Ag.) 178.

Strobilomyces 83 .

stylobates (Ag.) (507) 179.

suaveolens (Cal.) (86) 43.

- (Tram.) 73.

subalutaceus (Ag.) 189.

subatratus (Coprinar.) (346) 127.

subcava (Arm.) 198.

subcostatum (Ster.) 19.

subdulcis (Lact.) (265) 103.

subferrugineus (Cort.) (404) 143.

sublanatus (Cort.) 150.

sublateritius (Ag.) = lateritium (Hyph.) 131.

subsimilis (Cort.) 152.

subsquamosus (Polyp.) (146) 68.

- (Sarc.) (88) 44.

subtile (Hydn.) 39.

- (Poroth.) 76.

subtilis (Clav.) 33.

subtomentosus (Bol.) (193) 82 .

subtortus (Cort.) 154.

subversus (Ag.) 169.

suecica (Clavariella) 35.

suffrutescens (Lent.) (324) 118.

Suillus 76.

sulfureus (Ag.) 195.

tabacina (Hymen.) 20.

tabularis (Cort.) 146.

tenacellus (Ag.) 182.

tener (Derm.) (380) 136.

tephroleucum (Lim.) (243) 96.

terginus (Mar.) 122.

terrestris (Poria) 51.

- (Theleph.) (34) 21.

terreus (Ag.) (545) 194.

testaceus (Polyp.) 60.

Thelephora 20.

thiogala (Lact.) (270) 104.

tigrinus (Lent.) (325) 119.

tintinabulum (Ag.) 176.

titubans (Bolb.) (215) 89.

Todei (Typh). 27.

Tomentella 8 .

tomentosus (Polyst.) (154) 70. tophaceus (Cort.) (426) 150.

torminosa (Lact.) (279) 106.

torquatus (Mar.) 119.

torulosus (Panus) = carneotomentosus (Lent.) 116.

torvus (Cort.) (413) 145.

trabea (Lenz.) 74.

trabeus (Polyp.) (122) 61.

traganus (Cort.) (425) 150.

Trametes 72 .

Tremella 2.

Tremellodon 4.

tremellosus (Mer.) (94) 49.

tremulus (Ag.) (479) 171.

tricholoma (Inoc.) (387) 138.

tricolor (Ag.) (485) 173.

- (Lenz.) 75 .

triqueter (Polyst.) (153) 70.

trivialis (Lact.) (284) 107.

Trogia 84.

truncata (Exidia) (7) 3.

truncatus (Derm.) 138.

truncorum (Copr.) 92.

tuberculosa (Phol.) 161.

tuberosus (Ag.) (516) 183.

tubiformis (Canth.) (212) 87.

Tulasnella 7 .

Tulostoma 219.

turbinatus (Cort.) (434) 153.

turpis(Lent. $)=$ necator(Pers. $) 106$.

Tylopilus 76 .

Typhula 27.

ulmarius (Ag.) (549) 196.

- (Fom.) 54.

Ulocolla 3.

umbellatus (Polyp.) (135) 65 .

umbellifer (Ag.) (484) 173.

umbilicatus (Ag.) (487) 173 .

umbonata (Lep.) 201.

umbonatus (Canth.) (209) 87.

umbrina (Aman.) (573) 206.

- (Lact.) (268) 103.

undatus (Polyst.) 68.

undulata (Teleph.) 23.

unicolor (Daed.) (162) 73.

- (Phol.) 160.

urbus (Ag.) 192.

urens (Mar.) = peronatus (Mar.)

123.

ursinus (Lent.) 118.

ustalis (Ag.) 191. 
uteriforme (Lyc.) (587) 210. uvida (Lact.) (267) 103.

vaccinii (Exob.) (18) 7. vaccinus (Cortinell.) (555) 197. vaginatus (Ag.) = plumbea (Amanitops.) 204.

Vaillantii (Mar.) 120.

- (Poria.) 52.

validus (Ag.) = capnosa (Aman.) 205.

valgus (Cort.) 147.

vaporaria (Poria) (102) 52.

variabilis (Ag.) = sessilis (Derm.) 135.

- (Typh.) (49) 28.

variegata (Lenz.) (168) 75.

variegatus (Bol.) (179) 79 .

- (Melan.) (604) 218.

variicolor (Cort.) 155.

varius (Cort.) 155.

- (Polyp.) 65.

vegetus (Fom.) (108) 54.

vellerea (Lact.) (275) 105.

velutina (Kneiff.) 14.

velutinum (Hyph.) 130.

velutinus (Polyst.) 69.

velutipes (Ag.) (518) 183.

vernalis (Ag.) = bulbosa (Aman.) 206.

vernus $(\mathrm{Ag})=.\operatorname{virosa}(\mathrm{Aman})$.206 . verrucosum (Scler.) 218.

versicolor (Polyst.) (149) 69.

versipelle (Hydn.) 42.

versipelis (Bol.) = rufus(Bol.)77.

- (Inoc.) (391) 139.

vesca (Russ.) 111.

veternosa (Russulin.) (307) 112.

vibecinus (Ag.) 186.

vibratilis (Cort.) 151.

vieta (Lact.) (269) 104.

villosa (Cyph.) 25.

violacea (Poria) 50.

violaceocinereus (Cort.) 148.

violaceofulvus (Lent.) 116.

violaceus (Cort.) (422) 148. violascens (Hydn.) 42.

- (Lact.) 102.

virens (Rhiz.) (586) 209.

virescens (Russ.) (289) 108.

- (Tremella) 3.

- (Typh.) 28.

virgatus (Ag.) 194.

virgineus (Hygr.) $=$ ericeus

(Hygr.) 99.

viridis (Aman.) = bulbosa(Aman.) 206.

- (Amaur.) 43.

viridula (Psall.) (366) 132.

virosa (Aman.) (575) 206.

viscidus (Bol.) (176) 77 .

- (Gomph.) (231) 94.

viscosa (Caloc.) (17) 6.

vitellina (Russulin.) 115.

vitellinus (Bolb.) 89.

vitellinopes (Cort.) 155.

vitellum (Lim.) 96.

vitrea (Poria) 51.

vitreus (Ag.) 175.

vittiformis (Derm.) (378) 136.

volema (Lact.) (263) 102.

volvacea (Volv.) (475) 169.

Volvaria 168.

Vuilleminia 9.

vulgare (Cruc.) (600) 216.

- (Scler.) (602) 217.

vulgaris (Ag.) (492) 174.

- (Poria) (100) 52.

vulpinus (Polyst.) (151) 70 .

Weinmanni (Polyp.) 59.

xerampelina (Russulin.) (309) 112.

Xerotus 116.

Xylodon 45.

zephirus (Ag.) $=$ spinipes (Ag.) 180.

zonaria (Lact.) (285) 107.

zonatus (Cal.) 44.

- (Polyst.) 70. 
Verlag von Julius Springer in Berlin W9.

\section{Kryptogamenflora für Anfänger.}

Eine Einführung in das Studium der blütenlosen Gewächse für Studierende und Liebhaber.

Herausgegeben von

Prof. Dr. Gustav Lindau

Privatdozent der Botanik an der Univers. zu Berlin, Kustos am Kgl. Botan. Museum zu Dahlem.

\section{Zweiter Band: \\ Die mikroskopischen Pilze. \\ Von Prof. Dr. Gustar Lindau.}

Mit 558 Figuren im Text. Preis M. 8,-; in Leinwand gebunden M. 8,80.

Dritter Band:

\section{Die Flechten.}

Von Prof. Dr. Gustav Lindau.

Mit 306 Figuren im Text. Preis M. 8,-; in Leinwand gebunden M. 8,80.

Vierter Band, Teil I und II:

Die Algen.

Von Prof. Dr. Gustav Lindau.

Erste Abteilung; Mit 489 Figuren. Preis M. 7,-; in Leinwand geb. M. 7,80. Zweite Abteilung: Mit 437 Figuren. Preis M. 6,60; in Leinwand geb. M. 7,40.

\section{Vierter Band, Teil III: \\ Die Meeresalgen.}

Von Prof. Dr. Robert Pilger.

Dritte Abteilung: Mit 183 Figuren. Preis M. 5,60.

Fünfter Band:

Die Laubmoose.

Von Dr. Wilhelm Lorch.

Mit 265 Figuren im Text. Preis M. 7,-; in Leinwand gebunden M. 7,80.

Sechster Band:

Die Torf- und Lebermoose.

Von Dr. Wilhelm Lorch.

Mit 296 Figuren im Text.

\section{Die Farnpflanzen (Pteridophyta).}

Von Guido Brause, Oberstleutnant a. D.

Mit 73 Figuren im Text. Preis M. 8,40; in Leinwand gebunden M. 9,20.

Zu beziehen durch jede Buchhandlung. 
Verlag von Julius Springer in Berlin W9.

\section{Arzneipflanzen-Merkblätter des Kaiserlichen Gesundheitsamts}

bearbeitet in Gemeinschaft mit dem Arzneipflanzen-Ausschuß der Deutschen Pharmazeutischen Gesellschaft Berlin-Dahlem.

1. AllgemeineSammelregeln. 18. Rainfarn.

2. Bärentraubenblätter.

3. Herbstzeitlosensamen.

19. Eisenhut (Akonit) -Knollen.

4. Bitterkleeblätter.

5. Arnikablüten.

6. Huflattichblätter.

7. Kamillen.

8. Löwenzahn.

9. Wildes Stiefmütterchen.

10. Kalmusw urzel.

11. Schatgarbe.

12. Ehrenpreis.

13. Stechapfelblätter.

14. Tausendgüldenkraut.

20. Malvenblüten u. -blätter.

21. Wermutkraut.

22. Tollkirschenblätter.

23. Fingerhutblätter.

24. Bilsenkrautblätter.

25. Wacholderbeeren.

26. Bibernellwurzel.

27. Schachtelhalm.

28. Isländisches Moos.

29. Steinkleekraut.

15. Quendel.

16. Hauhechelwurzel.

17. Wollblumen.

30. Bärlappsporen.

31. Katzenpfötchenblüten.

32. Blätter und Blüten zur Teebereitung.

Preis jedes dieser 32 Merkblätter 10 Pf., zuzüglich Porto und Verpackung 15 Pf. Von 20 Exempl. eines Merkblattes an je 6 Pf., von 100 Exempl. eines Merkblattes an je 4 Pf., zuzüglich Porto. Ferner: Buchausgabe aller 32 Merkblätter auf besserem Papier in festem Umschlag M. 1,80.

\section{Pilz-Merkblatt.}

Mit 1 Tafel in farbiger Ausführung. Preis 20 Pf. (einschl. Porto u. Verpackung 25 Pf.). 10 Expl. M. 2,-; 50 Expl. M. 7,50; 100 Expl. M. 12,50; 1000 Expl. M. 115,- zuzüglich Porto. Das Porto beträgt für 1-3 Expl. 5 Pf., 8 Expl. 10 Pf., 18 Expl. 20 Pf., 40 Expl. 30 Pf., 200 Expl. 60 Pf.

\section{Arzneipflanzenkultur und Kräuterhandel.}

Rationelle Züchtung, Behandlung und Verwertung der in Deutschland zu ziehenden Arznei- und Gewürzpflanzen.

Eine Anleitung für Apotheker, Landwirte und Gärtner von Th. Meyer, Apotheker in Colditz.

Zweite Auflage. Mit 21 Textabbildungen. In Leinwand geb. M. 5,40.

Zu beziehen durch jede Buchhandlung. 
Verlag von Julius Springer in Berlin W9.

\section{Einführung in die Mikroskopie.}

Von Prof. Dr. P. Mayer in Jena.

Mit 28 Textfiguren In Leinwand gebunden M. 4,80.

\section{Das Mikroskop und seine Anwendung.}

Handbuch der praktischen Mikroskopie und Anleitung zu mikroskopischen

Untersuchungen. Von Dr. Hermann Hager.

Nach dessem Tode vollständig umgearbeitet und in Gemeinschaft mit Fachgenossen neu herausgegeben von Dr. Carl Mez, Professor der Botanik an

der Universität und Direktor des botan. Gartens zu Königsberg. Elfte, umgearbeitete Auflage.

Mit 471 in den Text gedruckten Figuren. In Leinwand gebunden M. 10,-

\section{Pflanzenkrankheiten}

durch kryptogame Parasiten verursacht.

Eine Einführung in das Studium der parasit. Pilze, Schleimpilze, Spaltpilze u. Algen. Zugleich eine Anleit. zur Bekämpf. d. Krankheiten der Kulturpflanzen.

Von Dr. Carl Freiherr v. Teubeuf

Privatdozent an der Universität München.

Mit 306 in den Text gedruckten Abbild. M. 16,-; in Leinw. geb. M. 17,20.

\section{Beispiele zur mikroskopischen Untersuchung von Pflanzenkrankheiten. Von Dr. Otto Appel}

Regierungsrat, Mitglied der kaiserlich biologischen Anstalt für Land- und Forstwirtschaft. $\mathrm{Z}$ weite, vermehrte und verbesserte Auflage. Mit 63 Textfiguren. M. 1.60.

\section{Die Reizbewegungen der Pflanzen.}

\section{Von Dr. Ernst G. Pringsheim}

Privatdozent an der Universität Halle.

Mit 96 Abbildungen. M. 12,-; in Leinwand gebunden M. 13,20.

\section{Die Variabilität niederer Organismen.}

Eine deszendenztheoretische Studie. Von Dr. Hans Pringsheim.

M. 7,-; in Leinwand gebunden M. 8,- .

Pflanzenphysiologie.

Von Prof. Dr. W. Palladin.

Bearbeitet auf Grund der 6. russischen Auflage.

Mit 180 Textfiguren. M. 8,-; in Leinwand gebunden M. 9,--

\section{Die Naturwissenschaften.}

Wochenschrift für die Fortschritte der Naturwissenschaft, der Medizin und der Technik. Begründet von Dr. A. Berliner und Dr. C. Thesing. Hrsgeg. von Dr. Arnold Berliner u. Prof. Dr. August Pütter. Erscheint in wöchentlichen Heften.

Preis für den Jahrg. M. 24,—; für das Vierteljahr M. 6,一; Einzelheft M. —,60.

Zu beziehen durch jede Buchhandlung. 
Verlag von Julius Springer in Berlin W 9.

Soeben erschien:

Die Grundlagen unserer Ernährung

unter besonderer Berücksichtigung der Jetztzeit. Von Emil Abderhalden

o. ö. Professor der Physiologie an der Universität zu Halle a. d. S.

Mit 2 Textfiguren. M. 2,80 .

Synthese derZellbausteinein Pflanze undTier.

Lösung des Problems der künstlichen Darstellung der Nahrungsstoffe.

Von Prof. Dr. Emil Abderhalden

Direktor des Physiologischen Instituts der Universität zu Halle a. d. S.

M. 3,60; in Leinwand gebunden M. 4,40.

\section{Neuere Anschaumgen über den Bau und den Stoffwechsel der Zelle. \\ Von Emil Abderhalden \\ o. ö. Professor der Physiologie an der Universität Halle a. d. S.}

Vortrag, gehalten auf der 94. Jahresversammlung der Schweizerischen

Naturforschenden Gesellschaft in Solothurn 2. August 1911.

Zweite Auflage. M. 1,- .

\section{Umwelt und Innenwelt der Tiere.}

\section{Von J. von Uexküll}

Dr. med. hon. c.

M. 7,-; in Leinwand gebunden M. 8,- .

\section{Instinkt und Erfahrung.}

Von Professor C. Lloyd Morgan

Autorisierte Úbersetz. von Dr. R. Thesing. M. 6,-; in Leinw. geb. M. 6,80.

Biologie des Menschen.

Aus den wissenschaftlichen Ergebnissen der Medizin für weitere Kreise dargestellt. Bearbeitet von Dr. Leo Heß, Prof. Dr. Heinrich Joseph, Dr. AlbertMüller, Dr.KarlRudinger, Dr.PaulSaxl, Dr.Max Schacherl. Herausgegeben von Dr. Paul Saxl und Dr. Karl Rudinger.

Mit 62 Textfiguren. M. 8,-; in Leinwand gebunden M. 9,40.

\section{Gesundheitsbüchlein.}

Gemeinfaßliche Anleitung zur Gesundheitspflege. Bearbeitet im Kaiserlichen Gesundheitsamte. Mit Abbildungen im Texte und drei farbigen Tafeln. Sechzehnte Ausgabe. Kartoniert Einzelpreis M. 1,-. Bei Bezug von 20 Exemplaren an Einzelpreis M. -,80.

Zu beziehendurch jede Buchhandlung. 